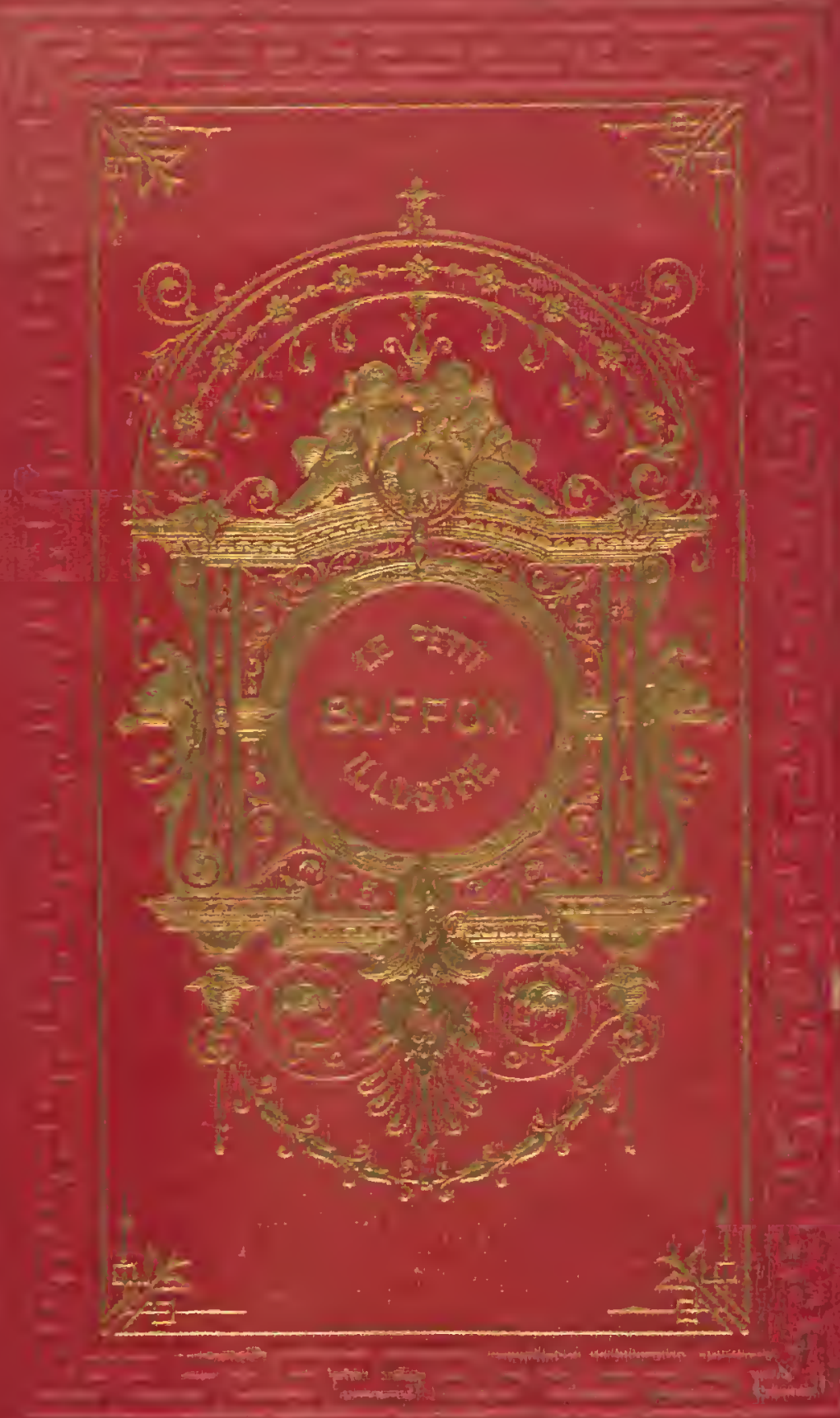




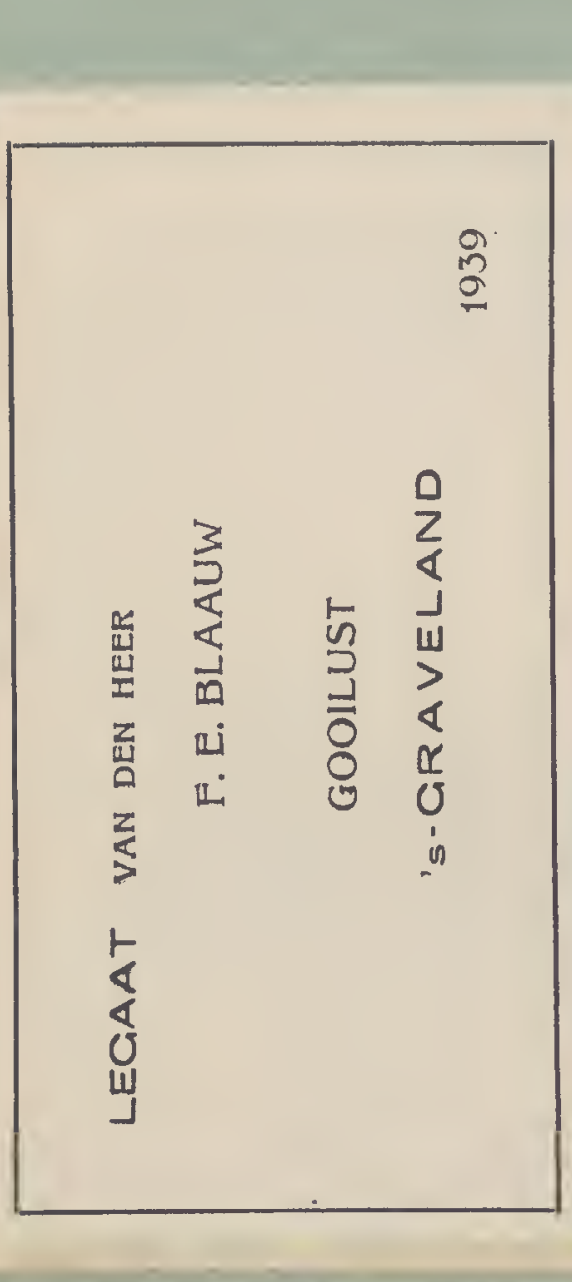

N"NM"

BIBL I OTHEEK

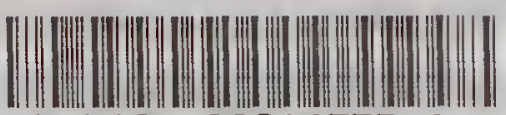

77496000417731 
$\frac{(\text { PDBtacesu }}{n}$ 



\section{LE PETIT}

\section{BUFFON}




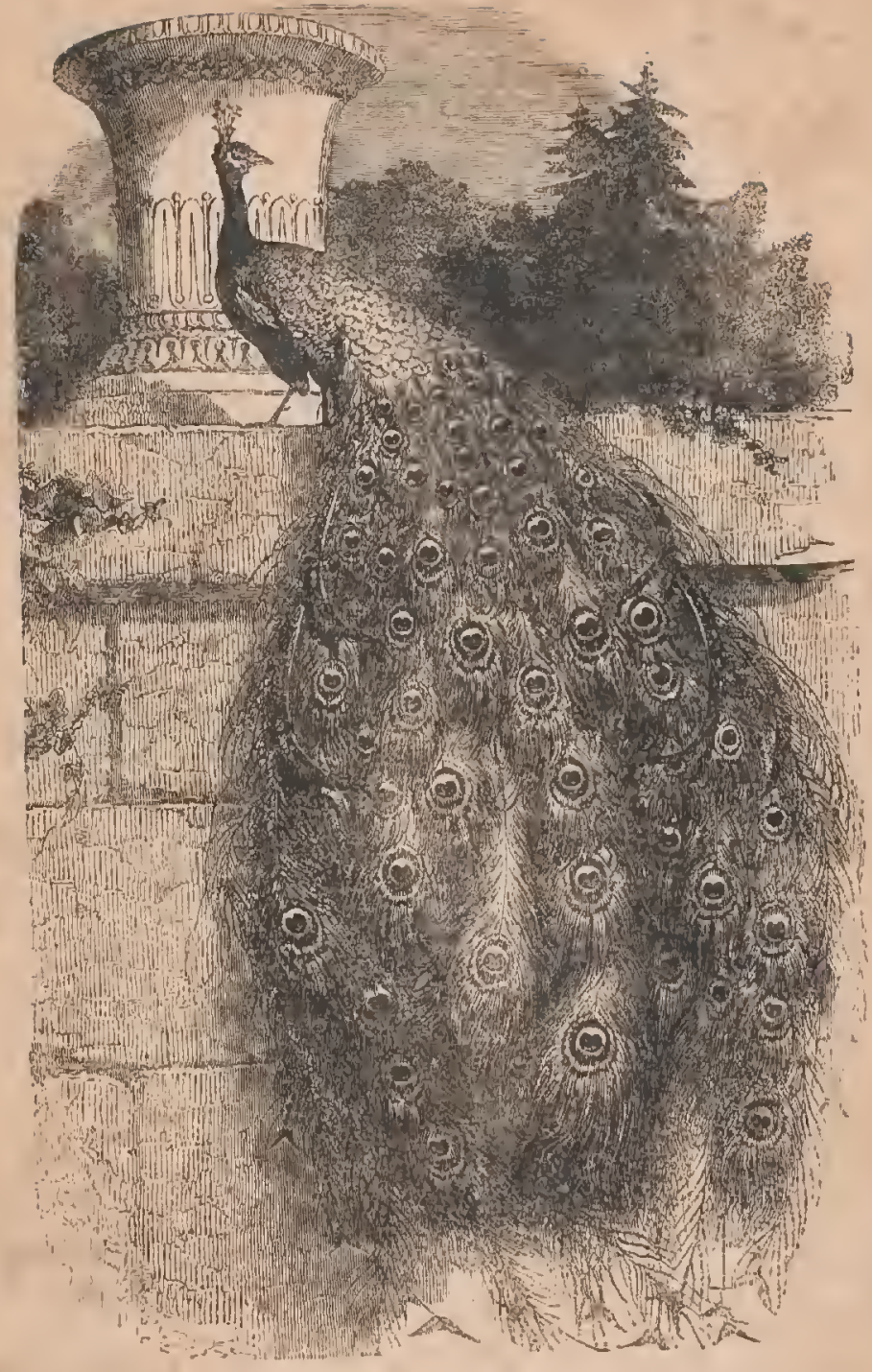




\section{LE PETIT}
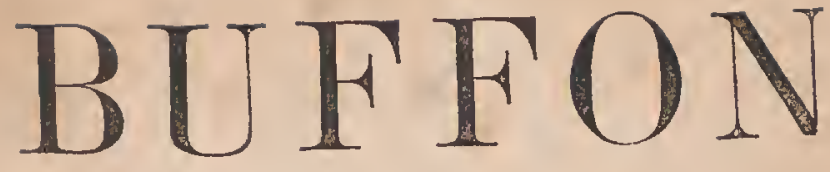

\section{ILLUSTRE}

\section{IISTOIRE ET DESCRIPTION DES ANIMAUX}

EXtraIte DES EUVRES

DE BUFFON ET DE LACÉPÈDE

NOMBREUSES VIGNETTES

GRAVÉES PAR IAES MEILLEURS ARTISTES D'Après LES DEssins DE fregman, massieu, etc.

- - sano-.....

\section{PARIS}

GARNIER FRÈRES, LIBRAIRES-ÉDITEURS 6, RUE DES SAINTS-YĖRES, ET PALALS-ROYAL, 215 
Clichy. - Imp. Paul Dupont, rue du Bac-d'Asnières, 12 


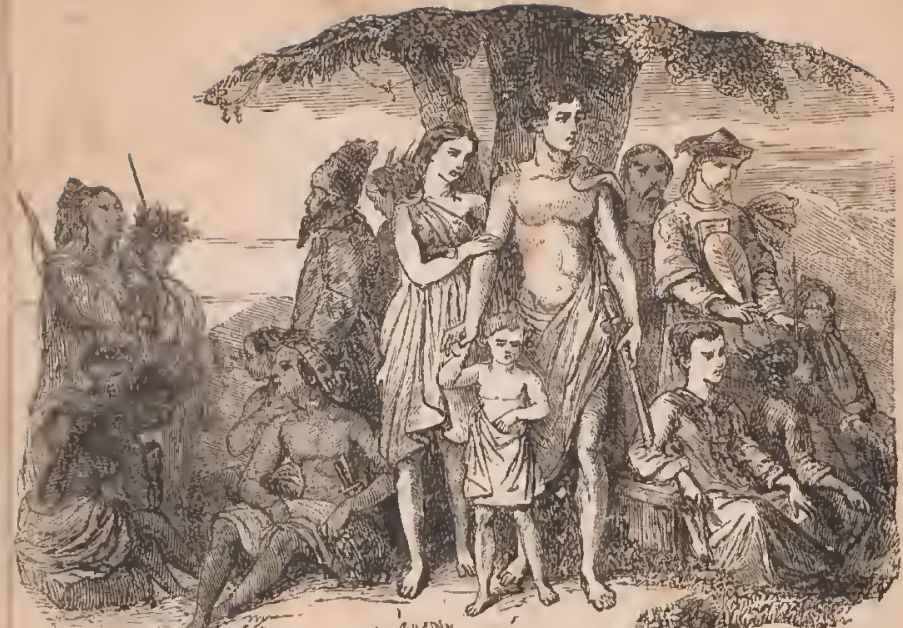

$-=-20$ -

4

\section{L'HOMME.}

SA SUPÉRIORITÉ SUR LES ANIMAUX.

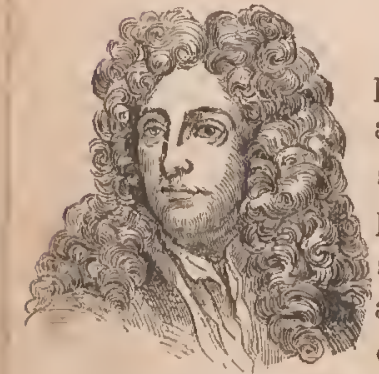

Le plus stupide des hommes suffit pour conduire le plus spirituel des animaux; il le commande et le fait servir à ses usages, et c'est moins par force et par adresse que par supćriorité de nature, et parce qu'il a un projet raisonué, un ordre d'actions et une suite de moyens par lesfrucls il contraint l'animal it lui obcir' ; car nous ne 
voyons pas que les animaux qui sont plus forts et plus adroits commandent aux auties et les fassent servir à leur usage: les plus forts mangent les plus faibles, inais eelte aetion ne supj ose qu'un besoin, un appétit, qualités fort différentes de celle qui pout produire une suite d'aclions dirigées ver's le même but. Si les animaux étaient doués de eette fieultó, n’en verrions-nous pas quelquesuns prendre l'ompire sur les autres et les obliger à leur chercher la nourriture, ì les veiller, à les garder, à les soulager lorsqu'ils sont malades ou blessćs? Or il n'y a parmi tous les animaux aucune remarue de subordination, aueune apparence que quelqu'un d'entre eux connaisse ou sente la supériorité de sa nature sur eelle des autres; par eonséquent on doit penser qu'ils sont en effet tous de mêne nature, et en même teinps on doit eonelure que celle de l'homme est non-seulement fort au-dessus de celle de l'animal, mais qu'elle est aussi tout ù fuit différente.

L'hormme rend par un signe extérieur ee qui se passe au-dedans de lui; il communique sa pensée par la parole: ec signe est commun à toute l'espèee humainc. L'homme sauvage parle comme l'homme policé, et tous dcux parlent naturellement, et parkent pour se faire entendre; aueun des animaux n'a ce signe de la pensće: ee n'est pas, comme on le croit communément, faute d'organes. La languc du singe a paru aux anatomistes aussi parfaite que eclle de l'homme; le singe parlerait done, s’il pensait; si l'ordre de ses pensćes avait quelııc chose de eommun avee les nôtres, il parlerait notre lingue, et en supposant qu“il n'eùt que des pensées do singe, il parlerait aux autres singes; mais on ne les a 
jamais vus s'entretenir' ou diseourir ensomble; ils n'ont done pas la pensée, mème au plus petit degrí.

Il est si vrai que ee 11'est pas faute d'organes que les animaux ne parlent pas, qu'on en eonnait de plusieurs espèces auxquels on apprend à prononeer des mots et même à répéter des phrases assez longues, et peut-être y en aurait.il un grand nombre d'autres auxquels on pourrait, si l'on voulait s'en donner la peine, faire artieuler quelques sons; mais jamais on est parvenu à leur faire naitre l'idée que ees mots expriment; ils semblent ne les répéter, même ne les artieuler, que eomme un éeho ou une maeline artifieielle les répéterait ou les artieulerait : ee ne sont pas les puissanees méeaniques ou les organes matériels, mais e'est la puissance intelleetuelle, e'est la pensée qui leur manque.

S'ils étaient doués de la puissanee de réfléehir, ils seraient eapables de quelque espèee de progrès, ils acquerraient plus d'industrie; les eastors d'aujourd'hui bàtiraiont avee plus d'art et de solidité que ne bâtissaient les premiers eastors, l'abeille perfeetionnerait eneore tous les jour's la eellule qu'elle habite.

D'où peut venir eette uniformité dans tous les ouvrages des animaux? yourquoi ehaque espèee ne fait-elle jamais quo la même ehose, de la même façon, et pourquoi ehaque individu ne la lait-il mieux ni plus mal qu'un autre individu? S'ils avaient la moindre étineelle de la lumière qui nous éelaire, on trouverait au moins de la variété si l'on ne voyait pas de la perfection dans leurs ouvrages.

Pourquoi mettons-nous au-eontraire tant de diversité et de variété dims nos produetions et dans nos ouvrages? C'est paree que notre àme est à nous, qu'elle est indépen- 
dante de colle d'un autro, que nous n'avons rien de comınun avec notre espèce que la malièrc de notre corps, ct que ce n'est en effet que par les dernièr'cs de nos facultés que nous ressemblons aux animaux.

En voilà plus qu'il n'en faut pour nous dómontrer l'excollence de notre nature ct la distance inmense que la bonté du Créateur a mise entre l'homme et la bête. L'homme est un être raisonnable, l'animal ost un être sans raison; el comme il n'y a point d'êtros intemédiairos entre l'ètre raisomnable et l'ètre sans raison, il est évident que l'homme est d'une nalure entièrement différente de colle de l'animal, qui ne lui ressemble que par l'extéricur, et que le juger par cutte ressemblanco matćrielle, e'est se laisser tromper par l'apparence et fermer volontairoment les yeux à la lumic̀re qui doit nous la faire distingruer de la l’éalilé.

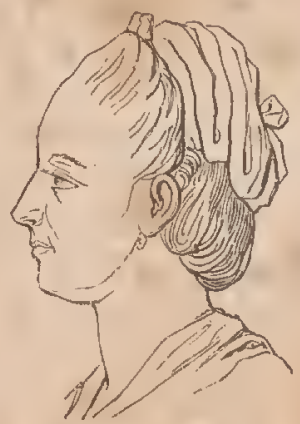




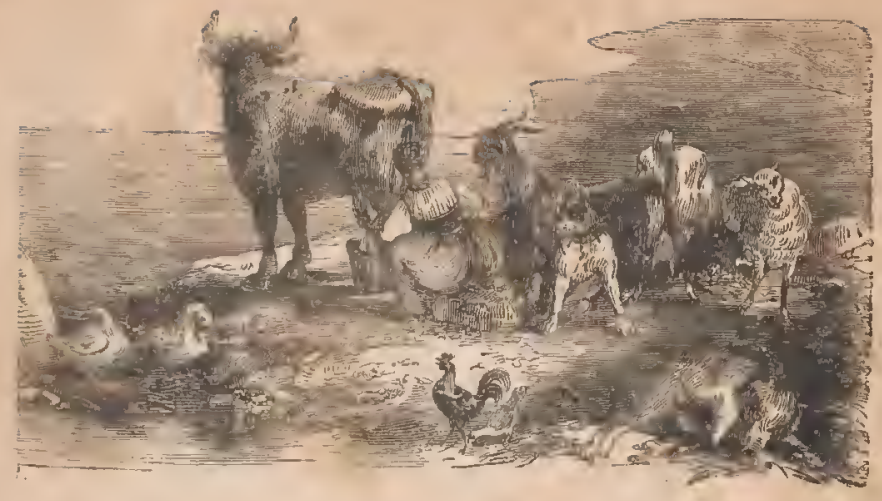

\section{QUADRUPẼDES.}

\section{ANINAUUX DOMESTIQUES.}

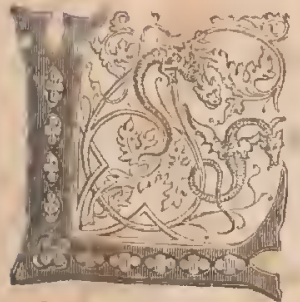

'Honse force les animaux à lui obéir et les fait servir à son ısage : son empire sur eux est un empire légilime qu'aucune révolution ne peut détruire ; c'est l'empire de l'esprit sur la matic̀re, c'est non-seulement un drort de nature, un pouvoir fordé sur des lois inaltérables, mais c'est encore un don de Dicu, par lequel l'hornme peut reconnaître à tout instant l'excellence de son être. Car ce n'est pas parce qu'il est le plus parfait, le plus fort ou le plus adroit des animanx qu'il leur connmande: s'il n'élait que le prenicr du même ordre, les 
scconds se réuniraient par lui disputer l'empire; mais c'est par la supériorité de naturc que l'homme règne et commande : il pense, ct dès lors il est maitre des êtres qui ne pensent point.

I Il est maîtro des corps bruts, qui ne peuvent opposer à sa volonté qu'une lourde résistance ou qu'une inflexible dureté, que sa main sait toujours surmonter et vainere en les faisant agir les uns contre les autres; il cst maitre des végétaux que, par son industrie, il peut angmenter, diminuer, rcnouveler, dénaturer, détruire ou multiplier à l'infini ; il est maître des animaux, parce que non-sculement il a comme eux du mouvenient et du sentiment, mais qu'il a de plus la lumière de la pensée, qu’il connaît les fins ot les inoyens, qu'il sait diriger' ses actions, concerter ses opérations, mesurer sos mouvements, vaincre la force par l'esprit, et la vitesse par l'emploi du temps.

Cependant, parmi les animnux, les uns paraissent plus ou moins familiers, plus ou moins sauvages, plus ou moins doux, plus ou moins féroces. Que l'on compare la docilité et la soumission du chien avec la fierté et la férocité du tigre : l'un paraît être l'ami de l'homme, et l'autre son ennemi; son empire sur les animaux n'est done pas absolu.

Mais le rayon divin dont l'homme est animé l'ennoblit et l'élòve au-dessus de tous los êtres matériels; cetto substance spirituelle, loin d'être sujette à la matière, a le droit de la faire obéir, et quoiqu'elle ne puisse pas commander ì la nature entière, olle domine sur les êtrcs parliculicrs. Dicu, source unique de toute lumière et de toute intelligence, régit l'univers et les ospèces entiòres 
avee une puissanee infinie: l'homme qui n'a qu'un rayon de cette intelligence, n'a de même qu'une puissance limitée à de petites portions de matière, et n'est maître quo des individus.

C'est done par les talents de l'esprit, et non par la folee et par les antres qualités de la matiòre, que l'homme a su subjuguer les animaux.

Lorsque avec le temps l'espèce humaine s'est étendue, multipliée, répandue, et qu'à la faveur des arts et de la soeiété l'homme a pu marcher en foree pour eonquérir l'univers, il a fait reculer peu à peu les hêtes féroees, il a purgé la terre de ees animaux gigantesques dont nous trouvons eneore les ossements énormes, il a détruit ou réduit à un petit nombre d'individus les espèees roraces et nuisibles, il a opposć les animaux aux animaux; et subjuguant les uns par adresse, domptant les autres par la foree, ou les écartant par lo nombre et les attaquant tous par des moyens raisonnés, il est parvenu à se mettre en sûreté et à établir un empire qui n'est borné que par des lieux inaecssibles, les solitudes r'eeulées, les sables brûlants, les montagnes glacées, les cavernes obscures, qui servent de retraites au petit nombre d'espèces d'animaux indomptables.

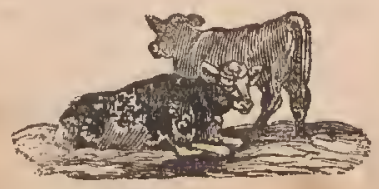




\section{LE CHEVAL.}

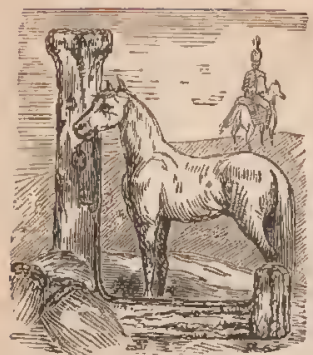

A plus noble conquête que l'hommo ait jarnais faite est celle de ce fier ct fougueux animal qui partage avec lu les fatigues de la guerre ct la gloire des combats : aussi intrépide que son maître, le clieval voit le péril ct l'affronte, il se fait au bruit des armes, il l'aime, il le clierche et s'anime de la même ardeur. Il partage aussi ses plaisirs : à la chassc, aux tournois, à la course, il brille, il ćtineelle; mais docile autant que courageux, il ne se laisse point cmporter à son feu, il sait réprimer ses mouvements. Non-senlement il fléehit sous la main de colui qui le frnide, mais il somble consulter ses désirs, cl obćissant toujours aux improssions cu'il en reçoit, il se préeipite, se modère ou s'arrête, ct n'agit que pour' y satisfaire. C'est une créature çui renonee à son êtro pour n'exister que par la volonté d'un autro, qui sait même la prévenir, qui par la promptitude et la prócision do ses mouvenents l'exprime et l'exécute, qui sent aulant qu'on le désire, et ne rend qu'autant qu'on veut; qui, se livrant sans réserve, ne se refuse à rien, sert de toutes ses forees, s'excède, ot même meurt pour mieux obéir.

Les ehevaux sont naturellement doux et très-disposés à se familiariser avec l'homme et à s'attacher à lui : aussi u'arrive-t-il jantis qu'aucun d'eux quitte nos maisons 


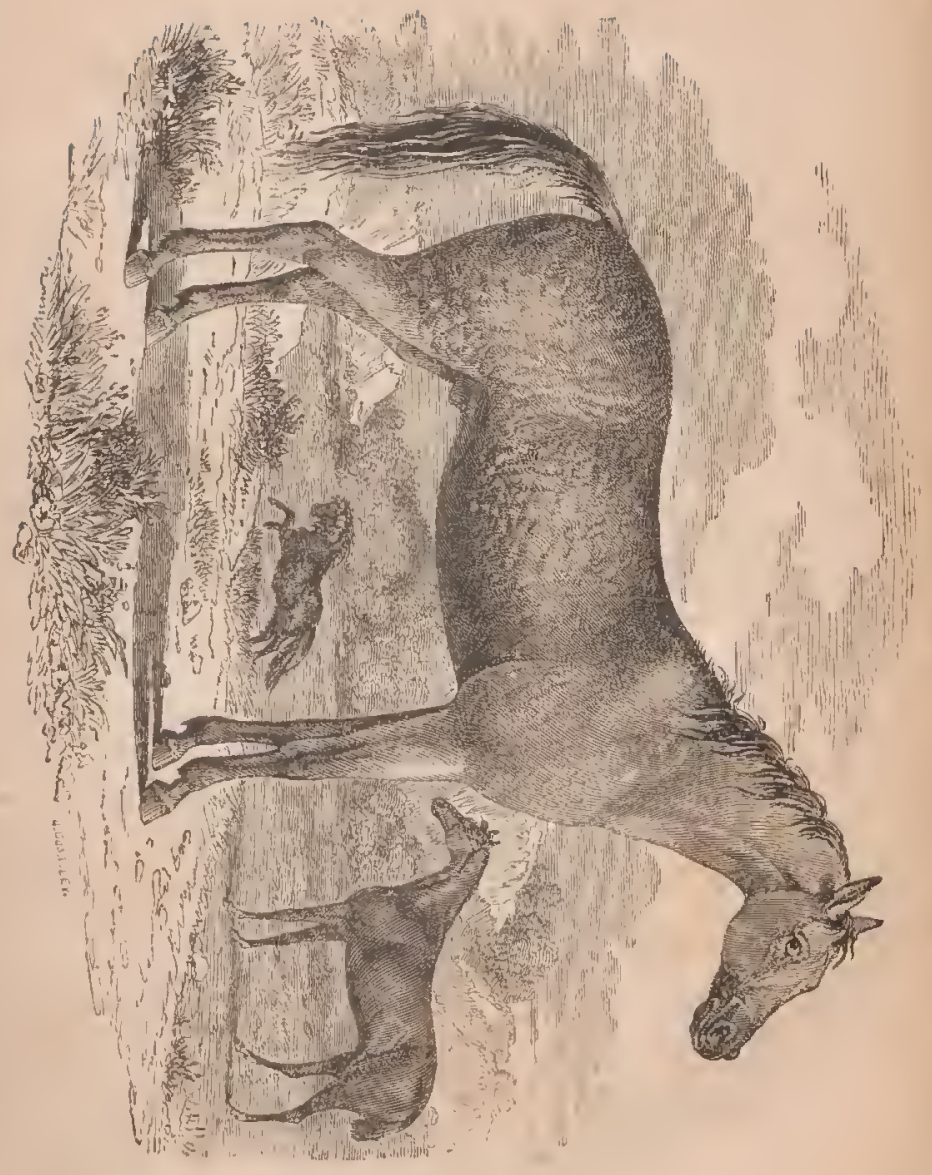



pour se relirel dans les forêts ou dans les déserts; ils marquent an contraire leaucoup d'empressement pour revenir an gite, où cependant ils ne trouvent qu'unc nourriture grrossière, toujours la même, ot ordinairement mesurée sur l'économie beaucoup plus que sur leur appétit; mais la douccur de l'hahitude lour tient licu de ce 'qu'ils perdent d'filleurs. Après avoir été excédós de fatigue, le lieu du rejos est un lieu de délices; ils le sentont de loin, ils savent le reconnaître au milieu des plus grandes villes, el scmllent préférer en tout l'esclavage à la liberté; ils se font même une sceonde nature des hrbiludes auxquelles on les a forećs ou soumis, puisqu'on a vu des chevaux abandonnés dans les bois hennir eontinuellement pour se faire entendre, accourir à la voix des lıommes, et on même temps maigrir ot rlépórir en peu de temps, quoiqu'ils eussent abondamment ile quoi varier leur nourtiture et satisfairc leur appétit.

Le clıcval cst de tous les animaux celıi qui, avec une grande taille, a le plus de proportion et d'ćléganee dans les partice de son corps. Le grand allongement des mîclıoires est la principalc cause de la diflóronce entre la tête des quadrupèdes et celle de l'homıne; c'est aussi le caractère le plus ignoble de tous. Ciependant, quoique les mâchoires du cheval soient fort allongóes, il n'a pas, counme l'ìne, un air d'imbécilité, on de stupidité comme le bocuf; la régularité des proportions de sa tête luı donne au contraire un air de légèreté çui est bien souteuu par la beauté de son cncolure. Le cheval semble voulöir se mettre all-dessus de son élat de quadrupède en élevant sa têto; dans cette noble attitude il regarde l'homme face à lace : ses yeux sont vifs ct bien ouxerts, 
ses orcillea sont bien faitos et d'une juste grandeur, sans être courtes comme celles du taureau, ou trop longues comme celles de l'âne; sa crinière necompagne bien sa tête, orne son con, et lui donne un air de force et de fierté ; sa queue trainante et toulfue couvre et termine avantageusement l'extrémité de son colps. Bien différente de la courte queue du cerf, de l'éléphant, etc., et de la queuc nue de l'àne, du chaneau, du rhinocéros, etc., la queue du cheval est fornće par des crins ćpais et longs qui somblent sortir de la croupe, parce que le tronçon dont il sortent est fort court; il ne peut relever sa queuc comme lo lion, mais elle lui sied mieux quoique abaisscé : et comme il peut la mouvoir de côté, il s'en sert utilement pour chasser les mouclies qui l'incommodent; car quoilyue sa peau soit très-ferme, et qu'elle soil girnie partout d'un poil ćpais et serré, elle cst cependant très-sensible.

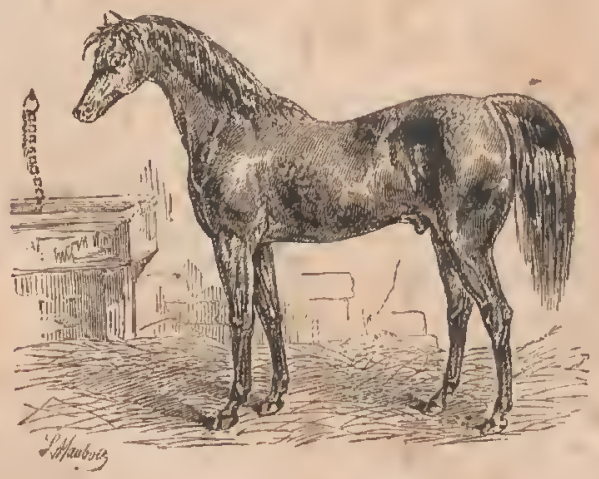




\section{LE MULET.}

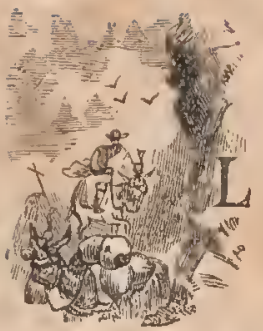

E mulet supporle mienx la fatigue et la faim que le cheval; il est moins délicat sul le choix des alimenls et moins maladif; il a le pied plus sûr et porte mieux los fardeaux; aussi l'emploie-t-on de préférence dans les jay's montagneux. 11 est diffieile de faire quitter au mulet la route qu'il veut suivre, et plus diffieile encore de le faire marcher dans la compagnie des chevaux, pour lesquels il a une aversion extrême. La ićsistance qu'il oppose s'accroît d'ordinaire sous les coups qu'il reçoit, et se change en une colère terıible; alors il se précipite sur l'imprudent qui a voulu le contraindre, et malheur à celui-ci! car en pareil cas, ainsi que le dit un proverbe provencal : $I l$ n'y a pas de mulet qui no lue son conduclon:.

L'Espagne, le Portugal, l'Italie et le midi de la France élèvent beaucoup de mulcts qui sont très-utiles, grâce à leuı vigueur et à la sûreté de leur marche, pour gravir les sentiers les plus escarpés à traver's les montagnes. Quoique le mulet aime les pays chauds, il s'lıabitue aisément aux climats froids. Il vit, comme l'ine, environ trente ans, et n'est utile qu'à quatre oul ciny ans.

Il y a deux sortes de mulets : les uns, issus de l'àne et de la jument, sont les grands inulets; les autres, issus du cheval et de l'ànesse, sont les petits, qui diffirent beaucoup des premiers, et sont bien moins estimés. 


\section{L'A E.}

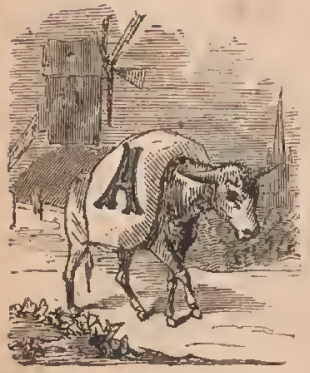

considéner cet animal, même avec des yeux altentifs et dans un assez grand détail, il paraît n'être qu'un clıeval dégénéré : mais il ne laisse pas de différer matéricllement du cheval par la petilosse de la taille, la grosscur de la tête, la longueır des oreilles, la dureté de la peau, la nudité de la queue, la forme de la croupe; par la voix, l'appétit, la manière de boire, ete.

L'âne est donc un âne et n'est point un cheval dógénéré; il a, comme tous les autres animaux, sa famille, son espèce et son rang; son sanğ est pur, et quoicquo sa noblesse soit moins illustro, elle est tout aussi bonne, tout aussi ancienne que celle du cheval; pourcjuoi done tant de mépris pour cet animal si bon, si patient, si sobre, si utile? Les homunes mépriseraient-ils juspue duns los animaux ceux qui les servent tıop bien et à tiop peu de frais ? On donne au cheval de l'ćducation, on le soiğne, on l'instruit, on l'exerce, tandis que l'îne, abandonné à la grossièreté du dernier des valets, ou c̀ ia malice des enfants, Jien loin d'acquérir, ne peut que perdre par son éducation; et s'il n'rvait pas un grand fonds de bonnes qualités, il les perdrait, en effet, jar la manière dont on le traite : il est le jouct, le plastron des rustres qui le conduisent le bâton à la main, qui le frappent, le surchargent, l'excèdent, sans précaution, 


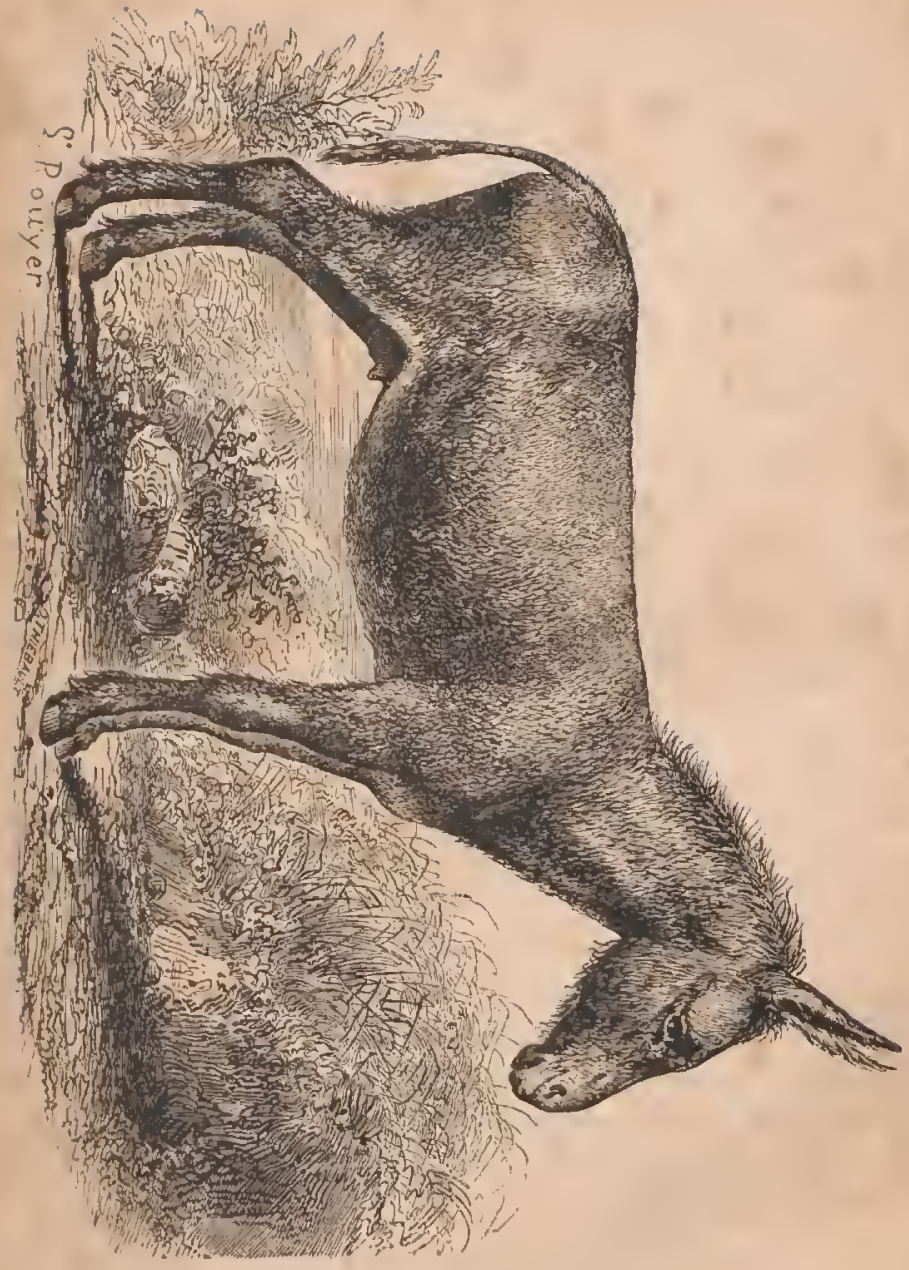




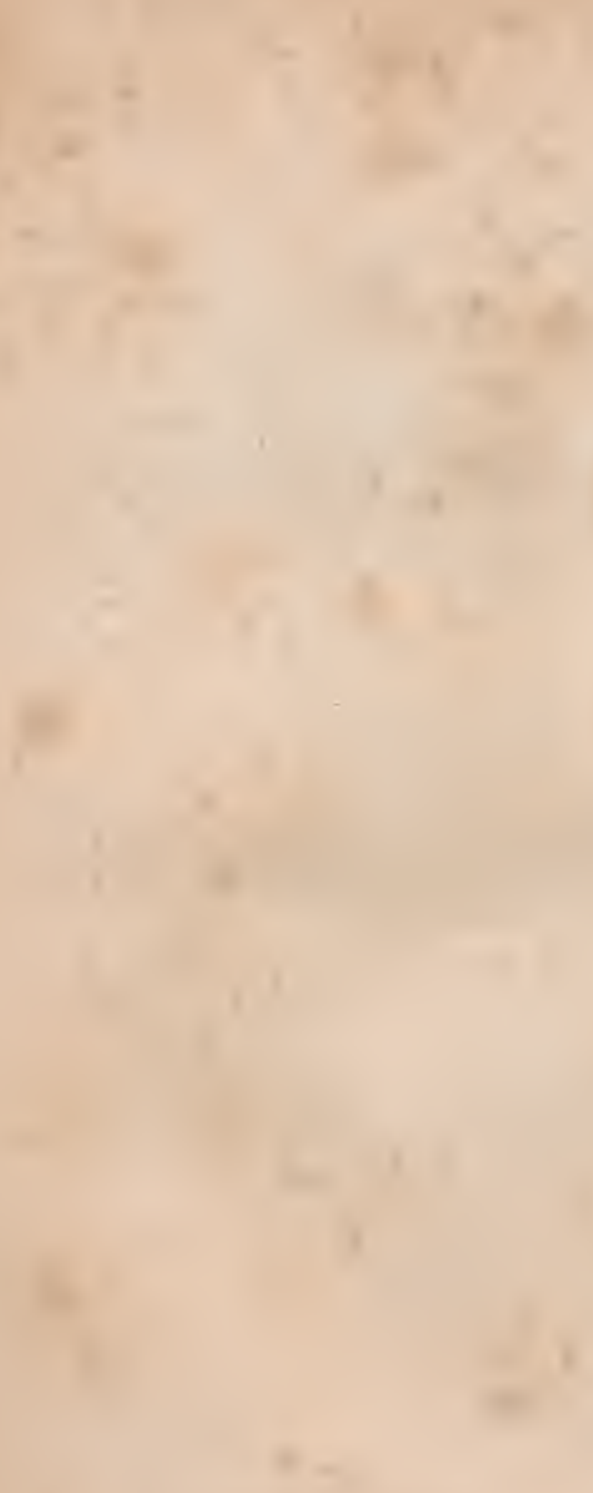


sans mćnageinents; on ne fail pas attention que l'ânu serait par lui-même, et pour nous, lc premier, lo plus beau, lo micux fait, le plus distingué dos animaux, si dans lo monde il n'y avait point de eheval ; il est le second au lieu d'être le premicr, et par cola scul il somble n'ètre plus rien.

Il est de son naturcl aussi humble, aussi patient, aussi trinquille que lc elieval est ficr, ardent, impétueux; il souffre avee eonstance, et peut-être avee eourage, les châtiments ot los eoups; il cst sobre et sur la quantité ot sur" la qualité de la nourriture: il se eonlente des herbes les plus dures, les plus désagréables, que le elicval ct les aulres animaux lui laisscnt et dédaignent; il est fort délieat sur l'eau, il ne veut boire que de la plus elair'c el aux luisseaux qui lui sont connus; il boit aussi sobrement qu'il mange, et n'enfonce point du toul son $11 e z$ dans l'eau par la penl que lui fait, dil-on, l'ombre de ses oreilles. Comme l'on ne prend pas la pcine de l'étriller, il sc roule souvent sur le gazon, sur les chardons, sur la fougère, et sans se soucier bcaucoup de ce 'qu'on lui fait porter"; il se eouehe pour se r'ouler toutcs los fois (pu'il le peut, et semble par là reproelıer à son maître le peu de soin qu'on prend de hri ; car il ne sc rautre pas comme le eheval dans la fange el dans l'cau, il eraint mêne de so mouiller les pieds, et se détourro pour éviter la bouc; aussi a-t-il la jambe plus sèche et plus nctte quo le ehcral; il est susceptible d'éducation, el l'on en a vu d'assez bien dressés pour faire curiosilć de speetacle.

Dans la premicirc jeunessc, il est gai, et même assez joli : il a de la légìreté el de la gentillosse; mais il la 
perd bientôl, soit par l'âge, soit par les mauvais trailements, et il devient lent, indocile et têtu; il a pour sa progénilure le plus fort altacliement. Pline nous assure que lorsqu’on sépare la mère de son petit, elle passe ì traver's les flammes pour aller le rejoindre; il s'attache aussi à son maître, quoiqu'il on soit ordinairemont maltraité; il le sent de loin et le distingue de tous les autres hommes; il reconnaît aussi les lieux qu'il a coutunc d'habiter, les chemins qu'il a fréquentés ; il ales yeux bons, l'odornt admirable, l'oreille excellente, ce qui a encore contribué à le faire mettre au nombre des animaux timides, qui ont tous, à ce qu'on prétend, l'ouïe très-fire et les oreilles longues. Lorsqu'on le surcharge, il le marque en inclinant la tête et baissant les orcilles; lorsqu'on le tourmente trop, il ouvre la bouche et retire les lèvres d'une manière très-désagréable, ce qui lui clonne l'air moqueur' et dérisoire; si on lui couvre les yeux, il reste immobile : et lor'squ'il est conché sur lc côlé, si on lui place la tête de manière que l'oeil soit appuyé sur la terre, et qu'on couvie l'autre oil avec unc pier'e ou un morceau debois, il restera dans cetle siluation sans fairo un mouvement et sans se secouer pour se relever: il marche, il trotte et il galope comme le cheval, mais tous ses mouvements sontpetits et beaucoup plus lents; quoiqu'il puisse d'abord couril avec assez de vitesse, il ne pent fournir qu'une petite carrièrc pendant un petit espace de temps; et, quelque allure qu'il prenne, si on le presse, il est bientôt rendu.

Le cheval hennit, l'âne brait, ee qui se fail par un grand cri très-long, très-désagréable. L'ânesse a la voix plus claire et plus perçante. 
L'âne, qui eomme le choval cst trois ou quatre ans à croitre, vit aussi comme lui vingt-cinq ou trente ans.

Comme la peau de l'îne est très-duro et très-élastique, on l'omploic utiloment à différents usages : on en fait des eribles, des tambours et de très-bons souliers; on en fait du gros parchemin pour les tablettes de poche, que l'on enduit d'une couche légère de plâtre; c'est aussi avee le cuir de l'âne que les Orientaux font le sagri, que nous appelons chagrin. Il y a apparence que les os, comme la peau de cet animal, sont aussi plus durs que Ics os des autres animaux, puisque les anciens en faisaient des flûtes, et qu'ils les trouvaient plus sonnants que tous les autres os.

L'âne est peut-être de tous les animaux celui qui, relativement à son volume, peut porter los plus grands poids; et eommc il ne coûte prosque ricn à nourrir, et qu'il ne demande, pour ainsi dire, aucun soin, il cst d'une grande utilité ì la campagne, au moulin, etc. Il peut aussi servir de monture; toutes sos allures sont douces, et il bronche moins que le chcval; on le met souvent à la charrue dans les pays où le terrain est léger.

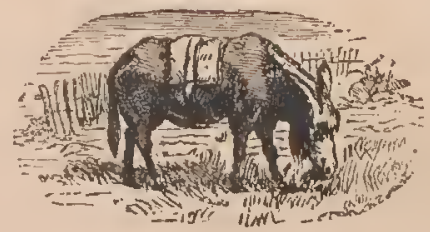




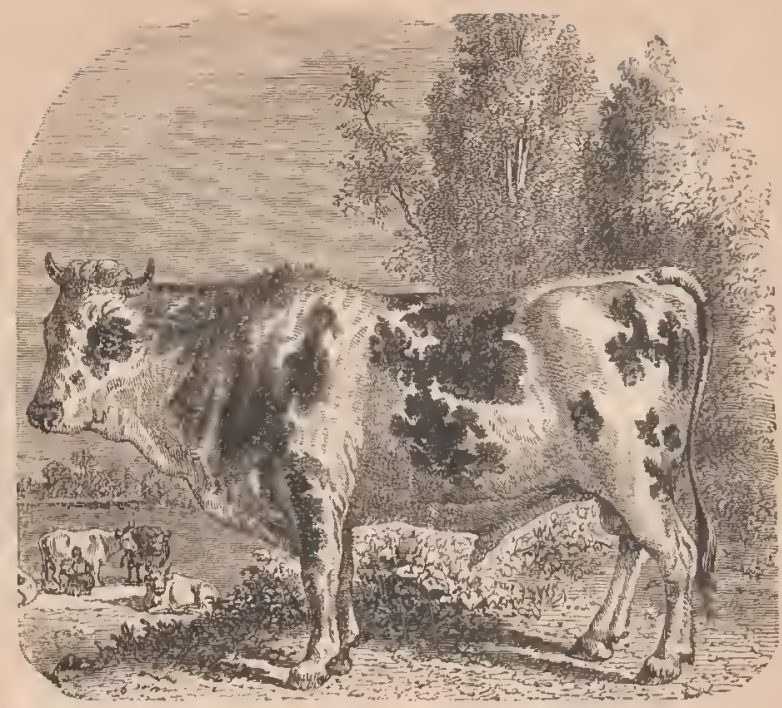

\section{LE B OEUF.}

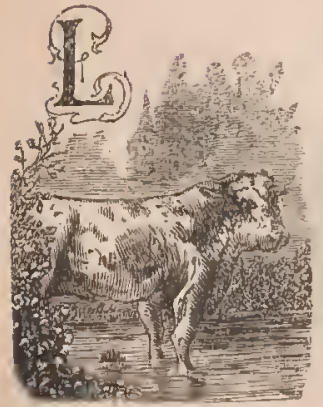

E bouf, le mouton of les autres animax qui paissent l'herbe, nonseulement sont les meilleurs, les plus utiles, les plus prócieux pour l'lomme, puisqu'ils le nourrissent, mais sont encore cerx qui consomment et dćpeusent le moins; le boeul surtout est à cet égard l'animal par l'excellence, car il rend à la terre tout autaut qu'il on tire, ot nnême anéliore te 
fonds sur louuclil vit; il engraisse son pâturagge, au licu que le cheval et la plupart des animaux auaigrissent en peu d'années les meilleures prairies.

Le bouf ne conviont pas autant quo le cheval, l'âne, le chameau, ctc., pour porter des fardeaux, la forme de son dos et de ses reins le démontre; inais la grosseur de son cou el la largeur de sos épaules indiquent assez qu'il est propre à tirer cl à porter le joug : c'est aussi de cetle manièrc qu'il tire le plus avantageusement. Il semble avoir été fait exprès pour la cliarruc: la masse de son corps, la lenteur de ses mouvementis, le peu de liauteur de ses jambes, toul, jusqu'à sa tranquillité et sa palicuce dans le travail, semble concourir d̀ le rendre propre à la culture des champs, et plus capable qu'aucun autre de vaincre la résistance constante et toujour's nouvelle que la terre oppose à ses efforts.

Dans les espèces d'animaux dont l'homme a fait dos troupeaux et où la multiplication est l'objet principal, la femelle est plus nécessaire, plus utile que le mâle; le produit de la vache cst un bicn qui croît et qui se renouvolls à chaque instant; la chair du veau esl une nourribure aussi abondante que saine et délicale, le lait est l'aliment des enfants, le beurre l'assaisonnement de la plupart de nos mets, le fromage la nourriture la plus ordinaire des habitants de la canpragne.

On peut aussi faire sorvir la vache à la charrue, et 'quoiqu'elle ne soit pas aussi forte que lo boeuf, elle ne laisse pas de le remplaccr souvent; mais lor'squ'on veut l'employer à cet usage, il faut avoir' attenlion de l'assortir, autant qu'on le jeut, avee un bouf de sa taille et de sa force, ou atvee rule aulle vache, afin de conscrver l'éra- 
lité dı trait et de maintenir le soc en équilibre entre cos doux puissances.

Le cheval mange nuit et jour, lentement, mais presque continuelloment; le boul au contraire mange vitc et prend en assez pcu de temps toute la nour'riture qu'il lui faut, apròs quoi il cesse de manger et se couche pour ruminer. Cette différence vient de la différente conformation de l'estomac de ces animaux : le bœuf, dont les deux premicrs estomacs ne forment qu'un mème sac d'une trèsgrande eapacité, pout sans inconvénient prendre à la fois beaucoup d'herbe ot le remplir en peu de temps pour ruminer ensuite et digérer à loisir'; le cheval, qui n'a qu'un pelit estomac, ne peut y recevoir qu'une pelite quantité d'herbe et le romplir successivement à mosure qu'elle s'affaisse et qu'olle passe dans los intestins, où se fait principalement la décomposition de la nourriture.

La grande chaleur incommode ces animaux pout-être plus encore que le grand froid; il faut pendant l'été los mener au travail dès la pointe du jour, les ramener à l'étable ou les laisser dans les bois pâtur'er à l'ombre pendant la grande ehalcur', et ne les remettre à l'ouvrage qu'à trois ou quatro heures du soir; au printenips, en hiver et en automne, on pourra les faire travailler sans interruption depuis huit ou neuf heuros du matin jusqu'i cinq ou six heures du soir. Ils no domandent pas autant de soin quo les ehevaux; cependant, si l'on vout les entretenir sains et vigoureux, on ne peut gucre se disponser de les étriller tous les jour's, de les laver, do lcur graisser la corne des pieds, eic. ; il faut aussi les faire boir au moins deux fois par jour; ils aiment l'eau notte et fraicho, au licu que le cheval l'aino trouble ch tiede. 
La nourriture et le soin sont à peu près les mômes et pour la vache et pour le bœuf; cependant la vache à lait exige des attentions particulières, tant pour la bien choisir que pour la bien conduire: on dit que les vaches noires sont celles qui donnent le meilleur lait, et que les blanches sont celles qui en donnent le plus; mais de quelque poil que soit la vache à lait, il faut qu'elle soit en bonne chair, qu'elle ait l'œil vif, la démarche léģòre, qu'elle soit jeune, et que son lait soit, s'il se peut, abondant et de bonne qualité. On la traira deux fois par jour en été ct une fois seulement en hiver'; et si l'on veut augmenter la quantité du lait, iln'y aura qu'à la nourrir avee des aliments plus succulents que l'lierbe.

En Irlande, on Angleter're, on Hollande, en Suisse et dans le Nord, on sale et on fume la chair du boouf en grande quantité, soit pour l'usage de la marine, soit pour l'avantage du commerce; il sort aussi de ces pays uns grande quantité de cuirs: la peau du bœuf et même celle du veau sẹrvent, commo l'on sail, à une infinilé d'usages; là graisse est aussi une matiòre utile, on la môle avec le sıif du mouton; le fumier du bouf est le meilleur engrais pour les terres sèches el légères; la eorne de eet animal est le premier vaisscau dans lequel on ait bu, le premier instrument dans lequel on ait soufflé pour augmenter le son, le première matière transparente que l'on ait employée pour faire des vitres, des lanternes, el que l'on ait ramollie, travaillée, moulée pour faire des boîtes, des reignes et mille autres ouvrages. 


\section{LA BREBIS.}

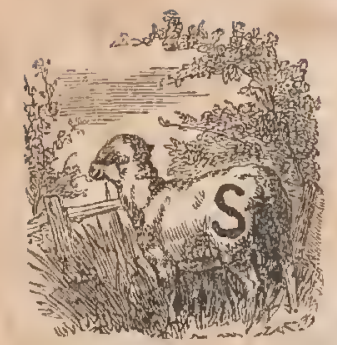

I l'on fait attention à la faiblesso et à la stupidité de la brebis, si l'on considère en même temps que eet animal sans défense ne peut même trouver son salut dans la fuite, qu'il a pour ennemis tous les animaux earnassiers qui semblent le ehereher de préférenee et le dévorer par goùt, que d'ailleur's eette espèee produit peu, que ehaque individu ne vit que peu de temps, ete., on serait tenté d'imaginer que, dès les emmmencernents, la brebis a été eonfiée à la garde de l'homme, qu'elle a eu besoin de sa proteetion pour subsister.

Il paraît done que ee n'est que parnotre seeours et par nos soins que eette espèee a duré, dure, et pourra durer cneore; il paraît qu'elle ne subsisterait pas par ellemême. La brehis est absolument sans ressouree et sans défense ; le bélier n'a que de faibles arnes, son eourage n'est qu'une pétulanee inutile poui lui-même et ineommode pour les autres; les moutons sont eneore plus timides que les brebis : e'est par erainte qu'ils se rassentblent si souvent en troupeaux; le moindre bruit extraordinaire suffit pour qu'ils se préeipitent et se serrent les uns contre les autres, et eette erainte est aeeoinpagnée de la plus graude stupidité, ear il ne savent pas fuil le danger. Ils semblent même ne pas sentir l'ineounmodité de leur situation; ils restent où ils se trouvent, à la pluie, 
à la nege, ils y deineurent opiniâtrément, ot pour les obliger à changer de lieu el.à prendre uno route, il lour faut un chef qu'on instruit à marchor le premier, et dont ils suivont tous les mouvements pas à pas: ce chof derncurerait lui-même avec le reste du troupeau, sans

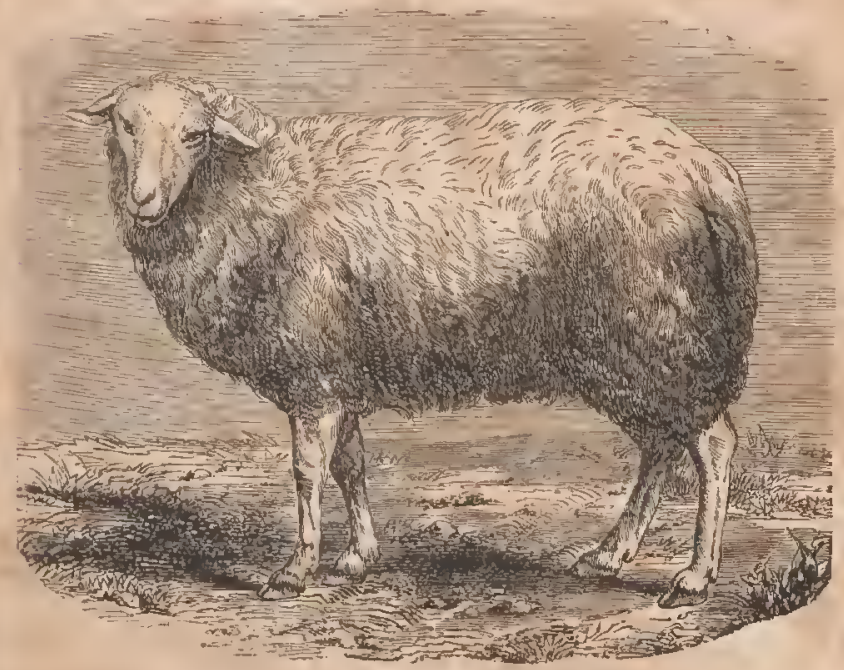

Inouvement, dans la même place, s'il n'était chassé par lo herger ou excilé par le chien commis à leur gardo, loque? sait, en effet, veiller à leur sûreté, les défondre, les diriger, les séparer, los rassembler et leur communiquor les mouvernents qui leur manquent.

La brebis no sait ni fuir, ni s'approcher; quelque besoin qu'cllo ait de secours, ello ne vient point à l'hornme 
aussi volontier's que la elıèvie, ol, ee qui dans les animaux parait être le dernier degré de la timidıté ou do l'insensibilité, elle se laisse enlevel" son agneau sans le défendre, sans s'irriter, sans résister et sans marquer sa douleur par un eri différent du bêlement ordinaire.

Mais eet aninal, si clétif en lui-mêmo, si dépourvu de sentiment, si dénué de qualités intẻricures, est pour l'lomme l'animal le plus précieux, eelui dont l'utilité est la plus immédiate et la plus ètendue : seul il peut suffire aux besoins de première néeessité ; il fournit tout à la fois de quoi se nourrir el se vêtir, salls eompter les avantages parliculiers que l'on sail tirer du suif, du lait, de la peau, et même des boỹaux, des os et du fumier de eet animal, auquel il semble que la nalure n'ait, pour ainsi dire, rien aecordé en propre, rien donné que pour le rendre ù l'homme.

Ces animaux, dont le naturel est si simple, sont aussi d'un tempérament très-faible; ils ne peuvent marchor longtemps, les voyagres los afl'aiblissent et les exténuent; dès qu'ils eoureut, ils palpitent ct sout bientòt essoufflés; la grande chaleur, l'ardeur du soleil les incommodent autant que l'hunidité, le froid et la neige: ils sont sujets à grand nombre de maladies, dont la plupart sont contagieuses; la surabondanee de la graisse les fail quelquefois nourir, et toujours elle empêche los brebis de produire; elles mettent bas difficilement, el demandent plus de soin qu'aueun des autres animaux domestiques.

Tous les ans on fait la tonte de la iaine des moutons, des brebis el des agneaux : dans les pays chauls, où l'un ne eraint pas de mettre l'animal tout à fail nu, l'on ne coupe pas la laine, mais on l'alriache, et on lait souvent 
deux récoltes par an; cn France et dans les climats plus froids, on se contente de la couper une fois par an avee le. grands ciseaux, et on laisse aux montons me partie de leur Loison, afin de les garantir de l'intempérie du elimat. C'est au mois de mai que se fait eette opératioug après les avoir bien lavés, afin de rendre la laine auss: nette qu'elle peut l'être : au mois d'avril il fait encore trop froid, et si l'on attendait les mois de juin et de juillet, la laine ne croîtrait pas assez pendant le reste de l'été pour les garantir du froid pendant l'hiver. La laine des moutons est ordinairement plus abondante et meilleure que eelle des brebis. On préfère la laine blanche à la grise, ù la brune, à la noire, paree que à la teinture elle peut prendie toutes sortes de couleurs : pour la qualité, la laine lisse vaut mieux que la laine crépue; on prétend même que les moutons dont la laine est trop frisée ne se portent pas anssi bien que les autres. On peut encore tirer' des moutons un avantage eonsidérable en les faisant parquer, c'est-ù-dire en les laissant séjourner sur les terres qu'on veut améliorer : il faut pour cela enelore le terrain et y renfermer lo troupeau toutes les nuits pendant l'été: le fumior et la chaleur du corps de ces animaux ranimeront en pou de temps les terres épuiséos, ou froides et infertiles; eent moutons amélioreront, en un été, luit arpents de terre pour six ans.

Le goûl de la chair du mouton, la finesse de la laine, la quantilé du suif, et même la grandeur et la grosseur du corps de ces animanx, varient beaucoup suivant les différents pays. Les animaux à longue et large queue, qui sont communs en Afrifue of en Asie, et auxquels les voyageurs ont domné le noun de moutons de Barlaric, pa- 
rasssent être d'une espèce différente de nos moutons, aussi bien que la vigogne et le lama d'Alrique.

Comme la laine blanche est plus estimée que la noire, on détruit presque partout avec soin les agneaux noirs ou tachés; cependant il y a des endroits où presque toutes les brebis sont noires, et partout on voit souvent naître d'un bélier blanc et d'une brebis blanche des agneaux noirs. 


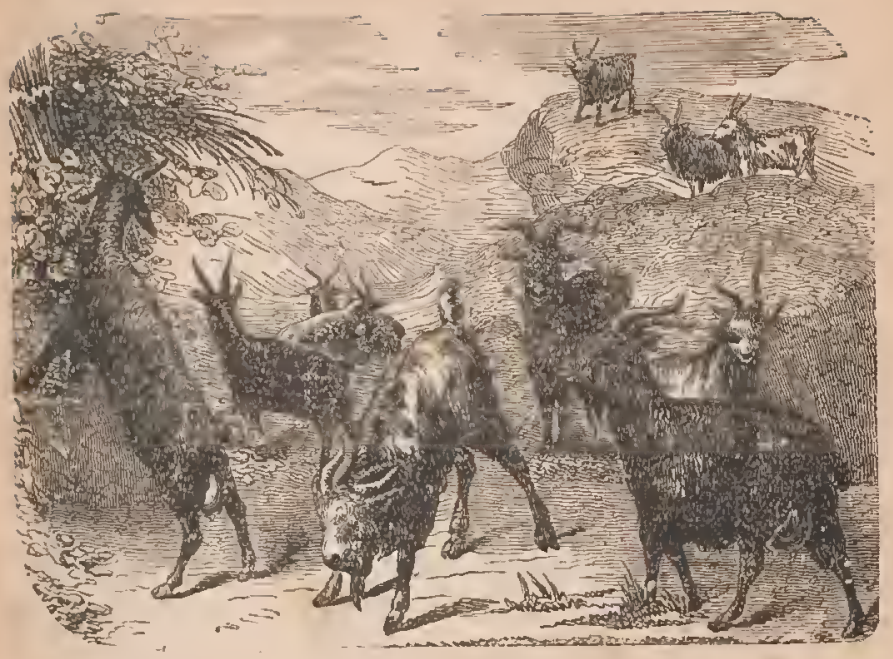

\section{LA CHEVRE.}

a l'espèce de la Jrobis venait à nous manquer, collo do la chève " pourrail y supplier. La chèvre $\perp$ fournit du lait comme la brebis,

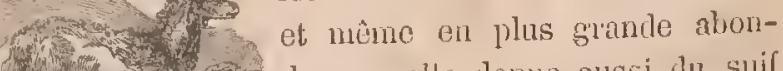
- 1 rance; clle donne aussi du suil

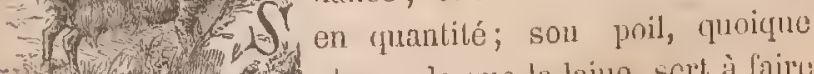

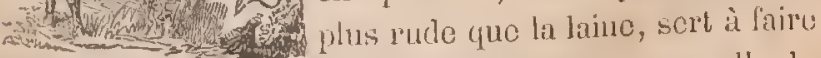
do très-bonnes etollos; sa peau vaut micux que celle du monton; la chail du chovreau aproche assez de colle cle landrucan, ctc. 
La chìvre est une espèce distincte, el peut-être encore plus éloignèe de celle de la brebis que l'espèce de l'îne ne l'est de celle du cheval.

La chèvre a de sa nature plus de sentiment et de ressource que la brebis; elle vient à l'homme volonticrs, elle se familiarise aisément, elle est scusible aux caresses et capable d'attachement; elle est aussi plus forte, plus légère, plus agile et moins timide que la brehis; elle ost vive, capricieuse et vagabonde. Ce n'est qu'avec peine qu'on la conduit et qu'on peut la róduire en troupran: elle aime à s'écarter dans les solitudes, à grimper sur les lieux escarpés, à se placer, et même à dormir sur la pointe des rochers et sur le bord des préeipiees, elle produit de très-bonne heule; elle est robuste, aisée à nourrir • presque toutes les herbes lui sont bonnes, et il y en a peu qui l'incommodent; elle ne craint pas, comme la brebis, la trop grande chalcur; elle dort au solcil, et s'expose volontiers à ses rayons les plus vifs sans être incommodée, et sans que cette ardeur lui canse ni étourdissements, ni vertiges; elle ne s'effraye point des orages, ne s'impatiente pas à la pluie, mais elle paraît être sensible à la rigueur du froid. L'ineonstanee de son natturel se maryue par l'irrégularité de ses actions; clle marche, elie s'arrête, elle eourt, elle hondit, elle saute, s'approche, s'éloigne, se montre, se cache ou fuit, comme par eaprice et saus autre eause déterminante que celle de la vivaeité bizarre de son sentiment intérieur.

On a des preuves que ces animaux sont naturellement amis de l'homme, et que daus les lieux inhabilés ils ne deviement poiat sauvages.

Lorsqu'on conduit les ehèvres avee les molitons, elles 
ne restent pas à leur suite, elles précèdent torjours le troupean ; il vaut mieux les mener séparément paitre sur les collines. Elles aiment les lieux élevés et les montagnes, même les plus escarpées; elles trouvent autant de nourriture qu'il leur en faut, dans les bruyc̀res, dans les friches, dins les terrains incultes et dans les terres sté. riles. Il faut les éloigner des endroits cultivés, les empêclicr d'entrer dans les blés, dans les vignes, dans les bois; elles font un grrand dégât dans les taillis: les arbres dont elles broulent avec avidité les jeunes pousses et les écorces tendres périssent presque tous. Elles craignent les lieux liumides, les prairics marécageuses, les pâturages gras : on en élève rarement dans les pays de plaines; elles s'y portent mal, et leur cliair est de mauvaise qualité. Dans la plupart des climats cliauds, l'on nourrit des chèves en grankle quantité, et on ne leur donne point d'útable : en France, elles périraient si on ne les mettait pas à l'abri pendant l'hiver. On peut se dispenser de leur ilonner de la litiòre en été, mais il leur en faut pendant l'hiver; el conme toute lumidité les incommode leaucoup, on ne les laisse pas coucher sur leur fumier, et on leur donne souvent de la litière fraîche. On les fait sortir de grand matin pour les mener aux chanps ; l'herbe chargée de rosée, (qui n'est pas bonne pour les moutons, fait gr'and bien aux chèvres. Comme elles sont indociles et vagaljondes, un lomme, quelque robuste et quelque agilo qu'il soit, n’en peut guère conduire que cinquante.

Ces animaux, qui ne coûtent prosque rien à nourrir, no laissent pas de fairc un produit assez consilérable; un en vend la cliair, le suif, le poil et la peau. Leur liat 
est plus sain et meilleur que eelui de la brebis; il est d'usage dans la médecine, il se eaille aisément, et l'on cn fait de très-bons fromages.

\section{LE COCHON, LE COCHON DE SIAII ET LE SANGLIER.}

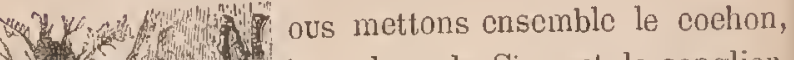

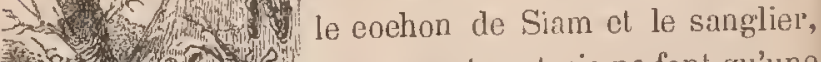

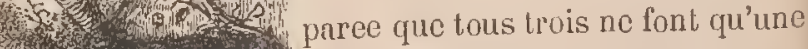

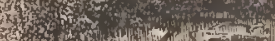
paree quc tous trois nc tont qu'une seule et même espice; l'un est l'animal sauvage, les deux autres sont l'animal domestique.

De tous los quadrupèdes, le coclıon parait être l'animal le plus brut : les imperfections de la forme semblent influer sur le naturel; toutes ses habiludes sont grossières, tous scs goûts sont immondes, toulc:s ses sensations se réduisent à une gourmandisc brutalc, qui lui fait dévorer indistinetement tout ce qui se présente, et même sa progénilure au moment qu'elle vient de naître. Sit voraeité dépend apparemment du besoin continuel qu'il a de romplir la grande eapaeité de son estomae; ct la grossièreté lo ses appétits, de l'hébétation du sens clu goût el du toucher. La rudesse du poil, la dureté de la peau, l'épaisseu' de la graisse, rendent ees animaux peu sensibles aur 


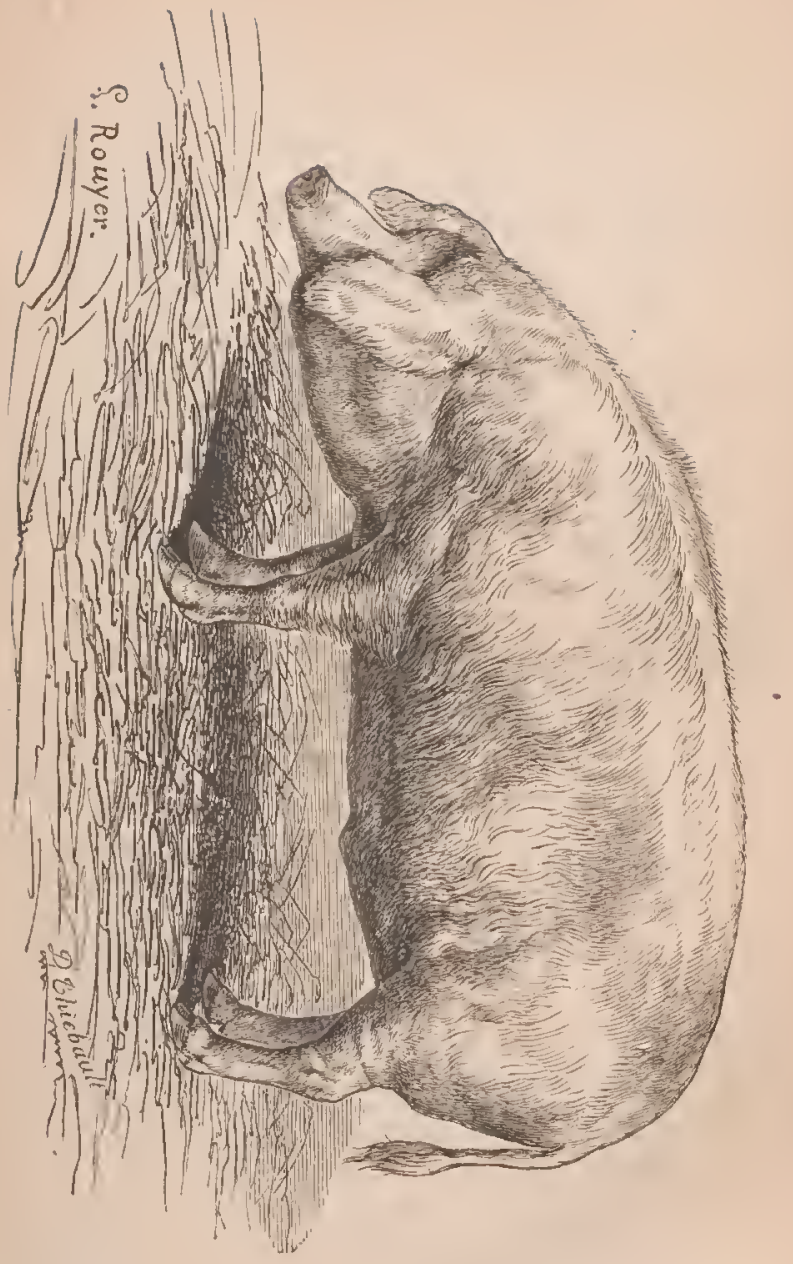



coups: l'on a vu des souris se loger sur lour dos et leur manger le lard et la peau sans qu'ils parussent le sentir. lis ont donc le touclier for't obtus, et le goût aussi grossier que lo toucher : les autres sens sont bons.

Cette imperfection dans le sens du goût et du toucher est encore augrmentée par une maladie qui les rend ladres, c'est-à-dire presque absolument insensibles, et de laquelle il faut peut-être moins chercher la première origine dans la texture de la claair ou de la peau de cet animal que dans sa malpropreté naturelle, et dans la corruption qui doit résulter des nourritures infectes dont il so remplit quelquefois; car le sanglier, qui n'a point do parcilles ordures à dévorer, et qui vit ordinairement de grain, do fruits, de glands et de racines, n'est point sujet à cette maladie, non plus que le jeune cochon pendant qu'il tette: on ne la prévient même qu'en tenant le cochon domestique dans une étable propre et en lui donnant abondamment des nourlitures saines. Sa chair deviendra même excellente au goût, et le lard ferme et cassant, si on le tient, pendant quinze jours ou trois semaines avant de le tuer, dans une étable pavée et toujour's propre, sans litière, en ne lui donnant alor's pour toute nourriture que du grain de froment pur et sec, et ne le laissant boire que très-peu.

Liu manière ordinaire de les engraisser est de leur donner abondamment de l'orge, du gland, des choux, des légunnes cuits et beancoup d'eau mêlé de son : en deux mois ils sont gras, le lard est abondant et épais.

On n'altend pas, comme pour le reste du bétail, que le cochon soit âgé pour l'engraisser : plus il vieillit, plus cela est dilficile et moins sa chair est bonne. 
La durée do la vie du sanglier peut s'étendre jusqu'à vingt-oinq ou trente ans. Aristote dit vingt ans peur les cochons en général. La première portée de la truı n'est pas nombrouse, les petils sont faibles ct môme imparfaits lorsqu'elle n'a pas un an. La laie, qui ressomble à tous autres ćgards à la truic, ne porto qu'une fois l'an appa-

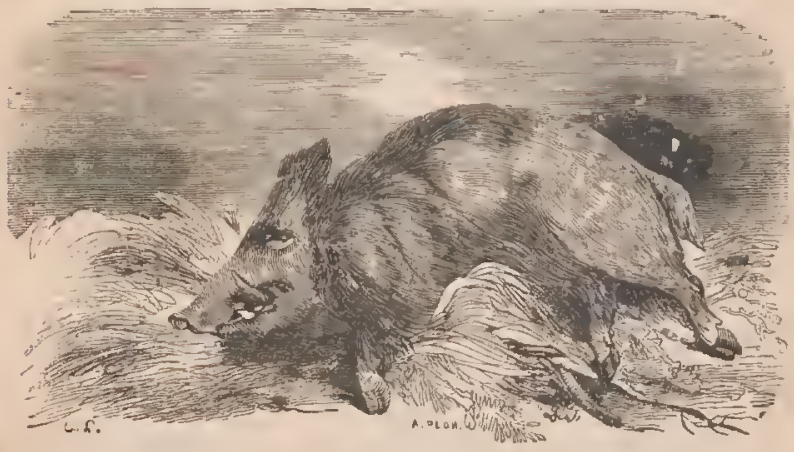

remment par la disctte de nourriture et par la nécessité où elle se trouve d'allaiter et de nourrir pendant longtomps tous les petits qu'ello a produits; au lieu qu'on ne souff'c pas que la truio domestiquo nourrisse tous ses pelits pendant plus de quinze jour's ou trois semaines : on ne lui en laisse alors que huit ou noul à nourrir; on vend les autres; à quinze jours ils sont bons à manger.

Ces animatux aiment beaucoup los vers de torre et certainos racines, comme celles de la carotte sauvage : c'est jour trouver ces vers et pour couper ces racines qu'ils fouillent la terre avec lour Joutoir. Le sanglier dont la 
hure est plus longue et plus forte que celle du cochon, fouille plus profondóment; il fouille aussi presque loujours en ligne droite dans le même sillon, au lieu que le cochon fouille çà et là, et plus légèrement. Comme il fait beaucoup de dégât, il faut l'éloigner des ter'ains cultivés, et ne le mener que dans les bois et sur les terres qu'on laisse reposer.

Quoique ees animaux soient forts gourmands, ils n'attaquent ni ne dévorent pas, comme les loups, les auties animaux; cependant ils mangent quel (juefois de la chair corrompue: on a vu des sangliers manger de la chair de cheval, et nous avons trouvé dans leur estomac de la peau de chevreuil et des pattes d'oiseaux; mais c'est pcut-être plutòt nécessité qu'instinct. Cependant on no peut nier qu'ils ne soient avides de sang el de chair sanguinolente ct fraichc, puisque les cochons mangent leur's petits, et même des enfants au berceau : dès qu'ils trouvent quelque chose de succulent, d'lrumide, de gras ou d'onctucux, ils le lèchent et finissent bientôt par l'avaler. Leur gourmandise est, comme on le voit, aussi grossière (1ı:e leur naturel est hrutal ; ils n'ont aucun sentiment bien dislinct; les petits reconnaissent à peine leur Inère, ou du moins sont fort sujets à se méprendre et à teter la premic̀re truie qui leur laisse saisir ses mamelles.

On chasse le sanglier à force ouverte avec des chiens, ou bien on le tue par surprise pendant la nuit au elair de la lune: comme il ne fuil que lentement, qu'il laisse une odeur très-forte, qu'il se défend contre les chiens er classer avec les bons chiens courants destinés pour le cerf et le chovicuil. Il ne faut attaquer rue les plus 
vicux sangrliel's; on les connaît aisémcut aux traces : un jeune sanglier de trois ans est difficile à forcer, parce qu'il court très-loin sans s'arrêter', au lieu qu'un sanglier' plus âgé ne fuit pas loin, sc laissc chasser de près, n'a pas grand'peur des cliens et s'arrête souvent pour leur faire tête. Il n'y a que la liurc qui soit bonne dans un vicux sanglier, au licu que toute la chair du mareassin, et celle du jeune sanglier qui n'a pas encore un an, est délicatc ct même assez line.

Pour peu qu'on ait halité la campagne, on n'ignore pas les profits qu'on tire du cochon; sa chail' se vend à peu près autant que celle du bocuf, le lard se vend au double, et même au triple ; le sang, les boy aux, les viscères, les pieds, la langue, se préparent ot se mangent. Le fumier du cochon est plus froid que colui des autres animaux; $\mathrm{ct}$ l'on ne doit s'en servir que pour les terres trop chaudes et trop sèches. La graisse des intestins et de l'épiploon, qui est differrente du lard, fait le saindoux et le vieux oing. La peau a scs usages ; on en fait des cribles, comme l'on fait aussi des vergettcs, des brosses, des pinecaux avec les soics. La chair dc cet animal prond mieux le sel, le salpêtre, ct se consorve salée plus longtomps qu'aucune autre.

Ces animaux n'affectent point de elimat particulier; seulement il parail que daus les pays froids le sanglier, en devenant auimal clomestique, a plus dégénéré qu dans les pays chauds : un degré de température de plus suffit pour changer leur couleur ; les cochons sont communément blanes dans nos provinees septentrionales de France et même en Vivarais, tandis que dans la provinco du Dauphiné, qui est tı̀̀s-voisine, ils sont tous noir's; 
ceux de Languedoc, de Provence, d'Espagne, d'Italie, des Indes, de la Chine et de l'Amérique, sont aussi de la même coulcur.

\section{LE CHIEN.}

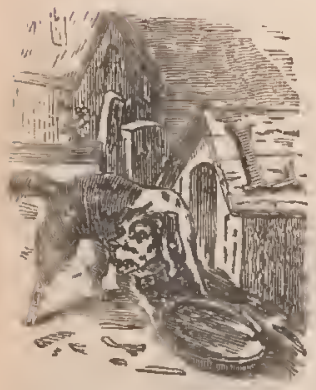

a chien, indépendamment de la beauté de sa forme, de la vivacité, de la force, de la légrèreté, a par excellence toutes les qualités intérieures qui peuvent lui attirer les regards de l'homme. Un naturel ardent, colère, même féroce et sanguinaire, rend le chien sauvage redoutable à tous les animaux, et cède dans le chien domestique aux sentiments les plus doux, au plaisir de s'attacher et au désir de plaire. Il vient en rampant mottre rux pieds de son maître son courage, sa force, ses talents; il attend ses ordres pour en faire usage, il le consulte, il l'interroge, il le supplie: un coup d'œil suffit, il entend les signes de sa volonté. Sans avoir, comme l'homme, la lumière de la nensée, il a toute la ehaleur du sentiment; il a de plus que lui la fidélité, la constance dans ses affections: nulle ambition, nul intérêt, nul désir de vengeance, nulle crainte que celle de déplaire; il est tout zèle, tout ardeur et tout obéissance. Plus sensible au souvenir des bienfaits 'qu'à celui des outrages, il ne se 
rebute pas par les mauvais traitements, il les subit, les oublie, ou ne s'en souvient que pour s'attacler davantinge; loin de s'irriter ou de fuir, il s'expose de lui-même à de nouvelles épreuves, il lèche cette main, instrument. de douleur, qui vient de le frapper, il ne lui oppose que li plinite, et la désarme enlin par la patience et la soumission.

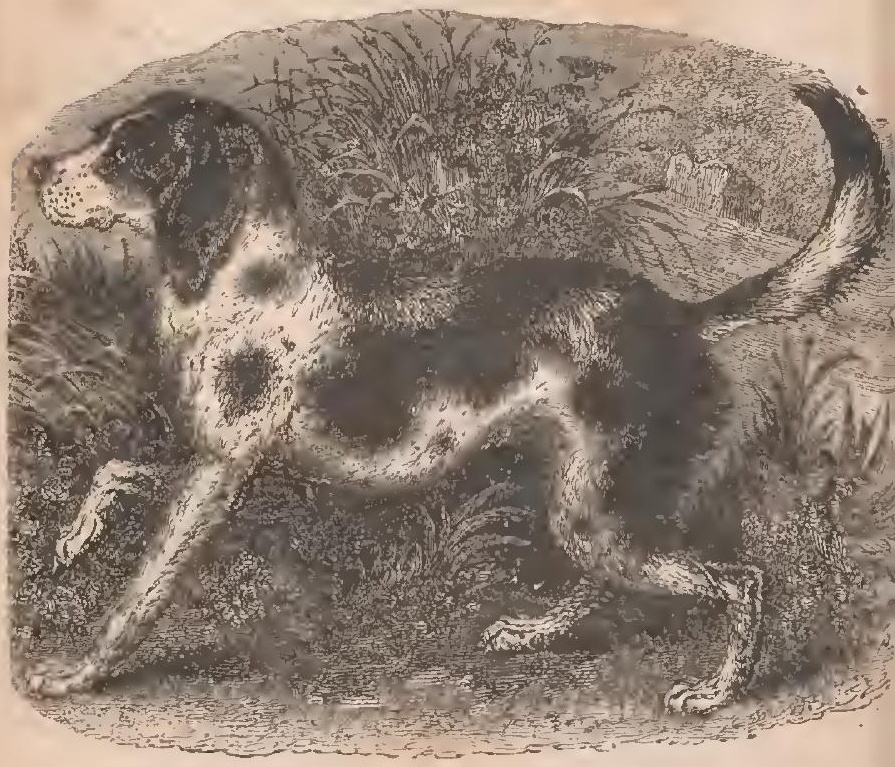

Plus docile que l'homme, plus souple qu'aucun des animaux, non-seulement le ehien s'instruit en peu de temps, mais miême il se eonforme aux mouvements, aux manicios, à toutes les habitudes de cuux yui lui com- 
mandent; il prend le ton de la maison qu'il habite; comme les autres domestiques, il est dédaigneux chez les grands et rustre à la campagne : toujours empressé pour son maître et prévenant pour ses seuls amis, il ne fait aucune attention aux gens indifférents, et se cléclare contre ceux qui par état ne sont filits que pour inportuner; il les connaît aux vêtements, à la voix, à leurs gestes, et les empêehe d'approcher. Lorsqu'on luia confié pendant la nuit la garde de la maison, il devient plus fier, et quelquefois féroce; il veille, il fait la ronde; il sent de loin les étrangers, et pour peu qu'ils s'arrêtent ou tentent de franchir les barrières, il s'élance, s'oppose, et par des aboiements réitérés, des efforts et des cris de colère, il donne l'alarme, avertit et eombat: aussi fulieux contre les hommes de proie que contre les animaux carnassiers, il sc précipite sur eux, les blesse, les dichire, leur ôte ce qu'ils s'efforçaient d'enlever; mais content d'avoir vaincu il se repose sur les dépouilles, n'y touche pas, même pour satisfaire son appélit, et donne cn même temps des excmples de courage, de tempéranec ct de fidélité.

On sentira de quelle importance cette espèce est dans l'ordre de la nature, en supposant un instant qu'elle r'eût jamais existé. Comment l'homme aurait-il pu, sans le seeours du chien, conquérir, dompter, réduire en csclavage les autres animaux? Comment pourrit-il encore aujourd'hui découvrir, clısser, détruire Ies bètes Sauvages et nuisibles? Pour se mettre en sûreté, et pour sc rendre maître de l'univers vivant, il a fallu commencer par se fairc un parti parni les animaux, se concilier avec donceur et par caresses ceux qui se sont trouvés 
capables de s'attacher et d'obćir, afin de les opposcr aux autres: le premicr art de l'homme a donc été l'éducation du chicn, et le fruit de cet ar't la conquête et la possession paisible de la terre.

Lc chien, fidèle à l'homme, conservera toujours une portion de l'empirc, un degré de supériorité sur les autres animaux; il leur commando, il régne lui-même à la têto d'un troupeau, il s'y fait micux entendre que la voix du berger; la sûreté, l'ortro et la discipline sont les fruits de sa vigilance et de son activité; c'est un peuple qui lui est soumis, qu’il conduit, qu'il protćge, et contre lccuel il n'enploic jamais la force que pour $\mathrm{y}$ maintenir la paix.

Iais c'est surtout à la guerro, c'est contro les animaux cnnemis ou indépendants qu'éclate son courag'c, ct que son inlelligence se déploie tout entic̀re : les talents naturels se réunissent ici aux qualités acquises. Dès que le bruit des armes se fait cntendre, dès que le son du cor ou la voix du cliasscur a donnć le sigrual d'une guerre prochaine, brillant d'une ardeur nouvelle, le chien marque sa joic par les plus vifs transports, il annonce par ses mouvements et par ses cris l'impatience de conbattre ct le désir de vaincre ; marchant ensuite en silence, il clrerelıe à reconnaître le pays, à découvrir, à surprendre l'ennemi dans son fort; il recherche ses traecs, il les suit pas à pas, et par des accents différents indique le temps, la distance, l'espèec et même l'âğe de colui qu'il poursuit.

Lc clien, par cette supériorité que donncnt l'exereico et l'éducation, par ectte finesse du sentiment qui n'appartient qu'à lui, ne perd pas l'objet de sa poursuite ; il 
démêle les points eommuns, défie les nœuds du fil tortueux qui seul peut y eonduire; il voit de l'odorat tous les détours du labyrintlie, toules les fausses routes où f'on a voulu l'égarer; et, loin d'abandonner l'ennemi pour un indifférent, après avoir triomphé de la ruse, il s'indigne, il redouble l'ardeur, arrive enfin, l'altaque, ct, le mettant à mort, étanehe dans le sang sa soil et sa haine.

L'on peut dire que le chien est le seul animal dont la fidélité soit à l'épreuve; lo seul qui eonnaisse toujours son maître et les amis de la maison; le seul qui, lorsqu'il arrive un ineonnu, s'en apercoive; le seul qui ne se eonfie point à lıi-même; le scul qui, lorsqu'il a perdu son mâtre et qu'il ne peut le retrouver, l'appelle par ses gémissements; le seul qui, dans 111 vorage long qu'il n'aurait fait qu'une fois, se souvienne du ehemin et retrouve la route; le seul enfin dont les talents naturels soient évidents et l'édueation toujour's heureuse.

Ce qui est difficile à saisir dans ectle nombreuse var riélé de races différentes, e'est le earaetère de la raeo primitive, de la raee originaire, de la race mère de toutes les autres raees.

La plus ou moins grande perfeetion des sens, qui no fait pas dans l'homme une qualité éminente, ni même remarquable, fait dans les animaux tout leur mérite, et produit, eomine eause, lous les talents dont leur nature peut être suseeptible. Je n'entreprendrai pas de faire iei l'énumération de toutes les qualités d'un chien de chasse: on sait assez combien l'excellence de l'odorat, jointe à l'édueation, lui donne d'avantage et de supériorité sur les autres animanx. 
La durćc de la vic est dans le chien, comme dans les autres animaux, proportionnelle au temps de l'accroissement; il est environ deux ans à croître, il vit aussi sept fois deux ans. L'on peut conrıître son âge par les dents, qui pendant la jounesse sont blanches, tranchantes et pointues, et qui, à mesurc qu'il vicillit, deviennent noires, mousses ct inégales : on le connaît aussi par le poil, car il blanchit sur le museau, sur le front et autour des yeux.

Ces animaux, qui de lcur naturel sont très-vigilants, très-actifs, et qui sont faits pour le plus grand mouvement, deviennent dans nos maisons, par la surcharge de la nourriture, si pesants et si paressenx qu'ils passent toute lcur vie t̀ ronfler, dormir et manger. Cc sommeil, presque continuel, est accompagnnć de rêves, et c'est peut-être unc douce manière d'cxistor : ils sont naturellcment voraces ou gourmands, et cependant ils peuvent se passer de nourriturc pendant longtemps.

Le chien de berger est la souche de la race : ce chien, transporté dans les climats rigoureux du Nord, s'est cnlaidi et rapetissé chez los Lapons, et paraît s'être maintonu et même perfectionné en Islande, en Russie, en Sibérie, dont lo climat ost un pou moins rigoureux, et où les peuples sont un peu plus civilisés. Cos changements sont arrivés par la seulc influcnce de ces climats, qui n'a pas produit une grande altération dans la forme; car tous ces chicns ont les orcillos droites, le poil épais ot long, l'air sauvage, et ils n'aboicnt pas aussi fréquemmont ni de la même manière que ccux qui, dans les climats plus favorables, se sont perfectionnés davantagc. Lc chien d'Islande et lo seul qui n'ail pas les oreilles 
entièrement droites, elles sont un pou pliées par leur extrémité : aussi l'Islande est, de tous ces pays du Nord, l'un des plus ancionnement habités par des hommes à demi civilisés.

Le mêmo chien de berger, transporté dans des climats tempérés et chez des peuplos ontic̀rement policós, commo cn Anglolerre, en France, on Allemagne, aura perdu son air sauvago, ses or'cilles droites, son poil rude, épais et lon§, ct sora devenu doğue, chicn cournnt et mâtin, par lin scule influcnce de ces climats. Le mâtin et lo dogne ont cncore les oreilles on partie droites; ellos ne soit qu'ì demi pendantes, et ils ressemblent asscz, par leurs moeurs et par lenr naturel sangninaire, au chien ducpuol ils tirent leur origine. Le ehicn courant est colui des trois qui s'en élnigne le plus ; les oreillos longucs, entiiroment pondantes, la doucour, la docilité, et, si on peut le dire, la timidité de ec chion, sont autant de prouves do la grrande dégénćration, ou, si l'on veul, de la grandu perfection qu'a produite uno longue domesticilé, jointe à une éducation soigonée ct suivic.

Le chien conrant, le brapue et lo basset ne font qu'une seule et même race de clicens ; car l'on a romarqué que dans la même portéc il se trouve assez souvent des chiens couranis, des braques et des bassets.

Le chien courant, transpoltó en Fispagno et en Barbarie, où prosque tous les animaux ont le poil fin, long ct fourni, sera devenu épagnoul et barlbet; le grand et petit épagnnoul, qui no diffèrent quo par la laille, transportés on Angleterre, ont changé de couleur du blanc au noir, et sont devenus, par l'influence du climat, grand et petit gredins, auxquels on doit joindro le pyrame, qui 
n'est qu'un gredin noir comme les autres, mais marquó de feu au quatre pattes, aux yeux et au muscau.

Le mâtin, transporté au Nord, est dovenu grand danois, et, transporté au Midi, est devenu lévrier : les g̊rands líviers viennent du Levant, ceux de taille nnédioere, d'Italie; el ees lévriers d'Ilalie, transportés en Angleterre, sont devenu levrons, e'est-à-dire lévriers encore plus pelits.

Le grand danois, transporté en Irlande, en Ukraine, en Tartarie, en Épire, en Albanie, est devenu ehien d'Irlande et c'est le plus grand de tous les eliens.

Le doģue, transporté d'Angleterre en Danemark, est devenu petit danois; et ec même petit danois, transporté dans les climats chaurls, est devenu ehien trre.

Le lévrier et le mâtin ont produrt le lévıicr mélis, que l'on appelle aussi lévrier' à poil de loup; ee métis a le museau moins elfilé que le franelévrier, qui est très-raro en Franee.

Le grand danois et le grand épagneul ont produit ensemble le ehien de Calahre, qui est un beau chien ì longs poils touffus, et plus grand par la taille que les plus gros mâtins.

L'ćpagneul et le petit danois produisent le ehien-lion, qui est maintenant fort rare.

Les chiens à longs poils fins ot frisés, que l'on appolle bouffes et qui sont de la taille des plus gr'ands barbets, viennent du grand épagneul et du barbet.

Le petit barbet vient du petil épagneul et du barbct.

Le dogue produit avee le mâtin un chien métis que l'on appelle dogue de forte race, qui est beaucoup plus gros que le vrai dogue, ou dogue d'Angleterr'e, et qui tient plus du dogue que du mâtin. 
Le doguin vient du dogue d'Angleterre et du petit danois.

Tous ees elliens sont des métis simples, et viennent du mélange de deux raees pures; mais il y a encore d'autres ehiens qu'on pourrait appeler doubles métis, paree qu'ils viennent du mélange d'une race pure et d'une raee déjà mêlée.

Le roquet est un double métis qui vient du doguin et du petit danois.

Le ehien d'Alieante est aussi un double métis, qui vient du doguin et du petit épagneul.

Le ehien de Malte, ou biehon, est encore un double métis, qui vient du petit épagneul et du petit barbet.

Enfin il y a des chiens qu'on pourrait appeler triples - métis, parce qu'ils viennent du mélange de deux raees déjà mêlées toutes deux; tel est le chien artois, islois ou quatre-vingt, qui vient du doguin et du roquet; tels sont eneore les chiens que l'on appelle vulgairement ehiens des rues, qui ressemblent à tous les ehiens en général sans ressembler à aueun en particulier, paree qu'ils proviennent du mélange de raees déjà plusieurs fois mêlées. 


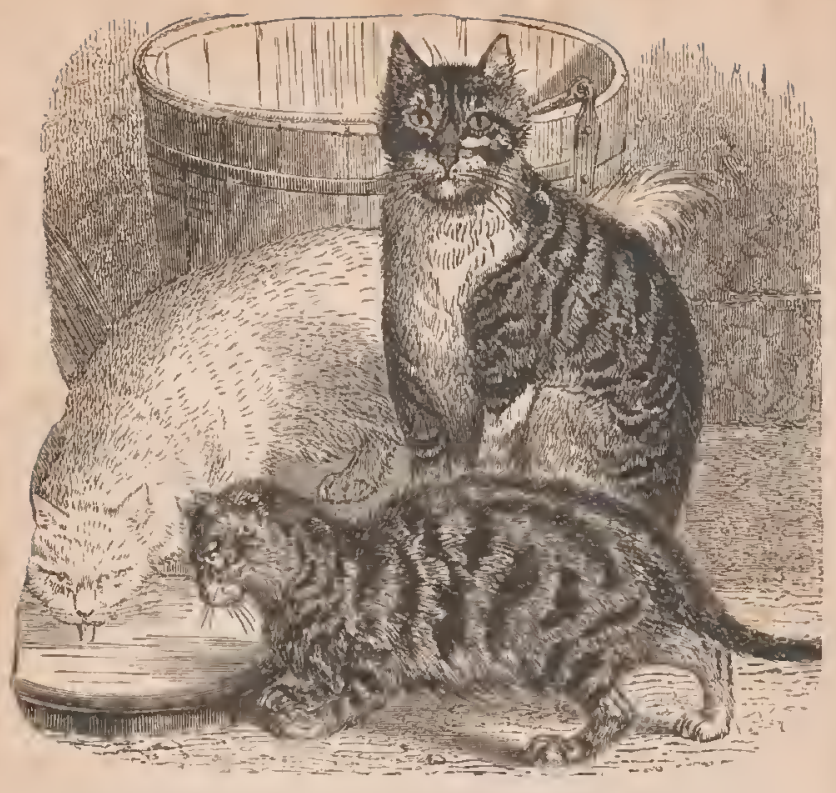

LE CHAT.

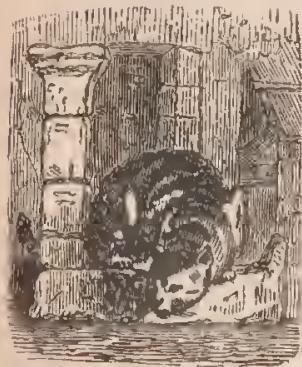

E chat, bien différent de cet animal fillèle, dont tous les sentiments se rapportent ì la personne de son maître, paraît ne sentir quo pour soi.

Il est joli, léger, adroit et propre; il aime ses aises, il cherche les meubles les plus mollets pour s'y reposer et s'ébattre. Les chattes portent cinquante ou cin- 
quante-six jours; clles ne produisent pas en aussi grand nombre que les ehiennes; les portées ordinaires sont de quatre, de eing̣ ou de six. Comme les mâles sont sujets à dévorcr leur progéniture, les femelles se cachent pour mettre bas, et lorsqu elles eraignent qu'on ne déeouve ou qu'on n'enlève leur's petits, elles les transportent dans des trous ou dans d'autres lieux ignorés ou inaccessibles; et, après les avoir allaités pendant quelques semaines, clles leur apportent des souris, de petits oiseaux, et les accoutument de bonne heure à manger de la chair : mais, par une bizarrerie diffieile à eomprendre, ees mêmes mires, si soigneuses et si tendres, deviennent quelquefois cruelles, dénaturées, et dévorent anssi leurs petils qui leur étaient si ehers.

Les jeunes ehats sont gais, vifs, jolis, ct seraient aussi très-propres à amuser les enfants, si les coups de palto n'élaient pas à eraindre; mais leur badinage, quoique toujours agréable et lćger, n'est jamais innoeent, et bientôt il se tourne en maliee habituelle; et comme ils ne peuvent exercer ces talents avec quelque avantage que sur les plus petits animaux, ils se mettent à l'affût près d'une cage, ils épient les oiseaux, les souris, les rats, et deviennent d'eux-mêmes, et sans y être dressés, plus labiles à la chasse que les ehiens les mieux instruits. incapables d'une óducation suivie. On raeontenéanmoins que les moines grees de l'île de Chypre avaient dressé

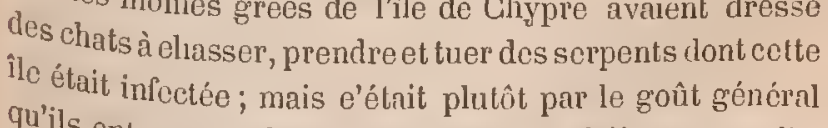
qu'ils ont pour la destruction que par obéissanee qu'ils
elıassaient; ear il sc plaisent à épier, attaquer et détruire 
assez indiffércmment tous les animaux faibles, comme les oiseaux, les jeunes lapins, les levrauts, les rats, les souris. les mulots, les chauves-souris, les taupes, les crapauds, les grenouilles, les lézards et les serpents. Ils n'ont aucune docilité, ils manquent aussi de la finesse de l'odorat, cqui, dans le chien, sont deux qualités éminentes.

La cause physique la plus immédiate du penchant qu'ils ont à épier et surprendre les autres animaux vient de l'avantage que leur donne la conformation particulière de leurs yeux. La pupille, dans l'homme, commc dans la plupart des animaux, est eapable d'un certain degré de contraction et de dilatation; elle s'clargit un peu lor'sque la lumière manque, et se rétrécit lorsqu'elle devient trop vive. Dans l'wil du chat et des oiseaux de nuit, cettc contraction et eette dilatation sont si considerables que la pupille, qui dans l'obscurité est ronde et larıre, devient au grand jour longue et étroite comme une lignc, et dès lors ces animaux voient mieux la nuit que le jour, comme on le remarque dans les chouettes, les hiboux, etc.

Les chats prennent moins d'attachement pour les personnes que pour les maisons. Ils craiguent l'eau, le froid ct les mauvaises odeur's: ils aiment à se tenir au soleil, ils cherchent à se gîter dans les lieux les plus chauds, derrière les cheminées ou dans les fours; ils aiment aussi les parfums, ct se laissent volontiers prendre et caresser par les personnes qui en portent : l'odcur de cette plante que l'on appelle l'herbe aur" chatsles remuc si fortcment et si délicieusement, (qu'ils en paraissent transportés de plaisil’.

A quinze ou dit-huit mois, ces animaux ont pris lout lcur accroisscment; leur vie ne s'étend guèrc au delù do 
neuf ou dix ans; ils sont cependant très-durs, très-vivaces, et ont plus de nerf et de ressort que d'autres animaux qui vivent plus longtemps.

Les chats ne peuvent mâcher que lentement et difficilement: leurs dents sont si courtes et si mal posćes qu'elle ne leur servent qu'à déchircr et non pas à broyer les aliments: aussicherchent-ils de préférenceles viandes les plus tendres ; ils aiment le poisson et le mangent cuit ou cru; ils boivent fréquemment; leur sommeil est léger, et ils dorment moins qu'ils ne font semblant de dormir ; ils marclient légèrement, presque toujours en silence et sans faire aucun bruit. Comme ils sont propres, et que leur robe est toujours sèche et lustrée, leur poil s'élcctrise aisément, et l'oul en voit sortir des étincelles dans l'obscurité lorsqu'on les frotte avec la main: leurs yeux brillent aussi dans les ténçbres, à peu près comme les diamants, qui rélléchissent au delıo's pendant la nuit la lumière clont ils se sont, pour ainsi dire, inbibés pendant le jour.

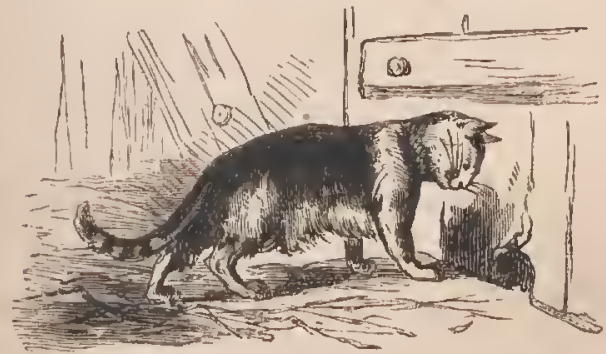




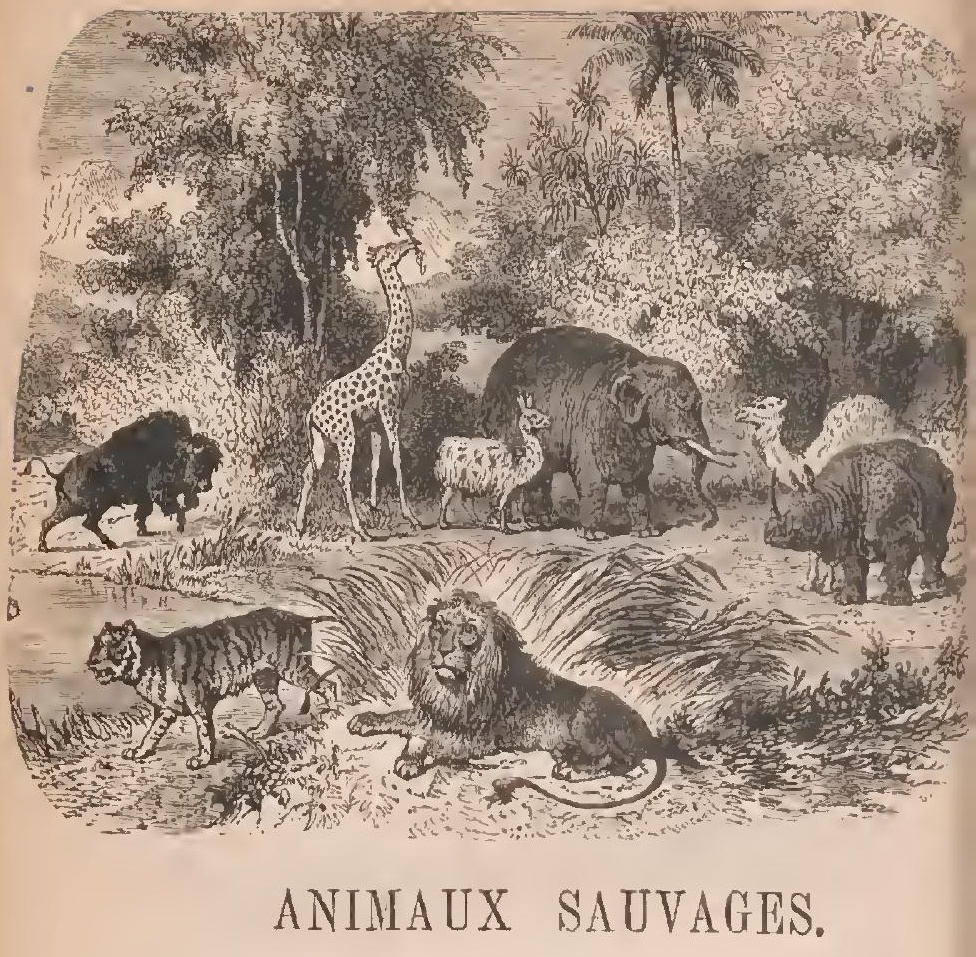

QUADRUMANES.

LE SINGE.

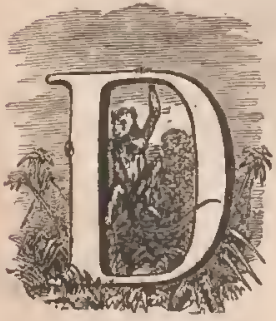

E dix-sept espèces auxijuelles on pent réduire tous les animaux appelós singes dans l'ancien conlinent, et de douze ou treize auxquelles on a transféré ee nom dans le nouveau, aucune n'est la même. 
SINGES DE L'ANCIEN CONTINENT

\section{L'ORANG-OUTAN PONGO}

De tous les singes, c'est eelui qui ressemble le plus ì l'lomme; il dort sur les arbres, et se construit une liutte, un abri contre le soleil et la pluie; il vit de fruits et ne mange point de ehair. Quand les Nègres font du feu dans les bois, les pongos viennent s'asseoir autour et se ehauf$f_{\mathrm{er}}$, mais ils n'ont pas assez d'esprit pour entretenir le feu en y mettant du bois; ils vont de compagnie, et tuent quelquefois des Nègres dans les lieux éeartés. On ne peut les prendre vivants, paree qu'ils sont si forts que dix hommes ne suffirnient pas pour en dompter un seul, on ne peut done attraper que les petils tout jeunes: la mère les porte marehant debout, et ils se tiennent attaehés à son eorps avee les mains et les genoux. Il y a deux espèces de ces singes très-ressemblants à l'homme, le pongo qui est aussi grand et plus gros qu'un homme, et le jocko qui est beaucoup plus petit. Un pongo enleva un jour un petit Nègre qui passa un an entier dans la société de ces animaux; à son retour, il raeonta que les pongos ne lui avaient aueun mal.

Ils ont l'instinet de s'asseoir à table eomme les hommes; ils mangent de tout sans distinction; ils se servent du eouteau, de la euiller et de la fourchette pour couper et prendre ee qu'on leur sert sur l'assiette; ils loivent du vin et d'autres liqueurs.

On apprivoise les pongos; on leur apprend à mareher sur les pieds de derrière et à se servir des pieds de de- 
vant, qui sont à peu près comme des mains, pour fairo certains ouvrağes et même ceux du ménagge, comme rincer les verres, donner à boire, tourner la broche, etc.

: Quand les pongos ne trouvent plus de fruits sur les montagnes, ils vont au bord de la mor où ils attrapent les crabes, des huîtres ot autros choses somblables. II $y^{\prime}$ a une espèce d'huîtres qu'on appelle taclovo, qui pèsent plusieurs lives et qui sont souvent ouvertes sur le I’ivage; or le singe craignant que, quand il veut les manger, elles ne lui attrapent la patte en se reformant, jette dans la coquille une pierre qui l'empẻche de se fermer, et ensuite il mange l'huître sans crainte.

Ce qui distingue le jocko du pongo, c’est que le pongo marche presque toujours debout sur ses deux pieds de derrière, tandis que le jocko ne prend cette attitude que rarement et lorsqu'il veut monter sur un arbre.

\section{LE PITHÈQUE}

Los pithèques ont les pieds, les mains, et, s'il faut ainsi dire, le visage de l'homme, avec beaucoup d'esprit ct de malice; ils vivent d'horbes, de blé et de toutes sortes de fruits qu'ils vont en troupes dérober dans les jardins ou dans les champs ; mais, avant qu'ils sortent de leur fort, il y en a un qui monte sur une éminence d'où il découvre tonte la campagne, ct quand il ne voit paraittre personne, il fait signe aux autres par un cri pour les faire sortir, et ne bouge pas de là tant qu'ils sont dehors; mais sitôt qu'il voit venir quelqu'un, il jette de grands cris, ef, sautant d'arbre en arbre, tous se sauvent dans les montagnes. C'est une chose admirable que de 
les voir fuir, car les femelles portent sur leur dos quatre ou cinq petits, et ne laissent pas, nalgré cela, de fuire des grands sauts, de branche en lranche; il s'en prend quantité par diverses inventions, quoiqu'ils soient trèsfins : quand ils deviennent farouches, ils moldent ; mais pour peu qu'on les flatte, il s'apprivoisent aisément; ceux qui sont apprivoisés font des choses ineroyables, imitant l'homme dans tout ce qu'ils voicnt. Le pithèque marche Sur ses deux pieds; il a environ une coudée, c'est-à-dirc tout au plus un pied et demi de hauteur.

\section{LE GIBBON}

Le gilbbon se tient toujour's debout, lor's même qu'il marche à quatre pieds, parce que ces bras sont aussi lungs que son corps et ses jamhes. Lc caractère qui le ristingue évidemment des autres singes, e'est la prodlgieuse grandeur de ses bras qui sont aussi longs que le $c_{01} p s$ et les jaunbes pris ensemble. Ce singe est d'un naturel tranquille et de mœurs assez douces; il se nourrit les fruits ct d'amandes; il craint beaucoup le froid et l'humidité ; il est originaire des Indes orientales.

\section{LÉ MAGOT}

Cet animal est de tous les singes, c'est-à-dire de tous ceux qui n'ont point de queue, celui qui s'accommode Ic mieux de la tcmpérature de notre climat. Il peut avoir deux pieds et demi ou trois pieds de hauteur, lorsqu'il est debout sur ses jambes de derrière ; la fcmelle est plus petite que le mâle. L'espèce du magot est assez générale- 
ment réprindue dans tous les climals chauds de l'ancicn continent, el on le trouve également en Tartarie, on Arabie, en Éthiopie, an Malabar, en Barbarie, on Mauritanie et jusque dans les teries du eap de Bonne-Espćrance.

\section{LE PAPION OU BABOUIN PROPREMENT DIT}

Les balouins, qui ne ressemblent plus à l'homme que par les mains, et qui ont une queue, des ongles aigus, do gros muscaux, ont l'air de bêtes féroces, et le sont en effet. Ils ne produisont pas dans les pays tempérés; la femelle ne fait ordinairement, qu'un petit qu'elle porte entre ses bras. Quoique méchants et fóroces, les balouins ne sont pas du nombre des animaux carnassiers; ils sc nourrissent prineipalement de fruits, de racines et do ģrains; ils se réunissent et s'entendent pour piller les jardins; ils se jettent les fruits de main en main et pardessus les murs, et font de grand dégâts dans toutes les terres cultivéos.

Le mandrille, autre espèce de babouin, ost d'une laideur désagréable ct dégoûtantc. On lo trouvo à la Côled'Or et dans los autres provinecs méridionalos de l'Afrique; après l'orang-outang, c'est le plus grand de tous les singes et de tous les hahouins. Le mandrille marche toujours sur les deux pieds, il pleure et il gémit commo les hommes.

L'ouanderou et lo lowando, autre varićté des babouins, lorsqu'ils ne sont pas domptés, sont si méchants qu'on est obligẻ de les tenir dans une cage de fer, où souvent 
ils s'agitont avee furcur; mais lorsqu'on les prend jounes, on les apprivoise aisément, et ils paraissent mêrne plus suseeptibles d'édueation que les autres babouins. Dans leur état de liberté, ils sont extrêmement sauvages ot se tiennent dans les bois.

Le maimou, autre babouin, quoique très-vif et plein de feu, n'a rien de la pétulanee des babouins; il est doux, traitable et même earessant, on le trouve à Sumatra; il souffre avee peine le froid de notrc elimat.

\section{LES GUENONS}

De toutos les guenons ou singos à longue queue, lo ma cargue est colui qui approche lo plus des babouins; il est d'une laideur hideuse. L'aigrelle, autre guenon, ainsi appelé parec qu'il a sur lo sommet de la tête un ópi ou tigrette de poil, a, eomme le macaque, les mou's douces et estassez docile; mais, indépendamment d'une odeur de fourmi ou de faux muse qué ces deux singes répandent aulour d'eux, il sont si malpropres et si affreux lors'?'il $l_{S}$ font la grimace, qu'on ne peut les regarder sans horreur et dégoût.

Le malbrouck etle bonnet chinois, variétés des guenons, derrobent les fruits et surtout les cannes à sucre; l'un d'eux fait sentinelle sur un arbre, pendant que les autres se elıargent du bulin; s'il apercoit quclqu'un, il crie houp, loup, houp, d'une voix elaire et distincte; au moInent de l'avis, tous jettent les eannes qu'ils tenaient dans la main gauche, et s'enfuient en courant à trois pieds. Ces animaux ne s'apprivoisent qu'ì demi, il faut toujours les tenir à la chaine; ils ne produiscnt pas dans leur état 
de servitude, même dans leur' pays ; il faut qu'ils soient en liberté dans leur bois. Ils eueillent les noix de eoeos, ot savent fort bien en tirer la liqueur pour la boire, et lo noyau pour le manger.

La mone est la plus eommunos des guenons; e'cst avec le magot l'espèee qui s'aecommode le mieux de la température de notre climat. Les guenons sont d'un naturel bcaueoup plus doux que les babouins, et d'un earactèrc moins triste queles singes ; clles sont vives et sans féro* cité; la mone, en particulier, est suseeptible d'élucation, et même d'un ecrtain attachement pour ceux qui la soignent.

Le eallitriche ou singe vert se trouve au Sénégal aussi bien qu'en Mauritanie et aux îles du Cap-Vert.

Le mouslae est d'assez petite taillc, et c'cst le plus joli de tous les singes à longue queue.

La guenon qu'on appelle talapoin est de petite taille et d'une assez jolie figure.

Le doue est le dernier des animaux que nous avons appelés singes, babouins et guzenons: sans ĉtre préeisćmont d'aucun de ces trois genres, il participe de tous.

SINEES DU NOUVEAU CONTINENT

\section{LES SAPAJOUS ET LES SAGOUINS}

Nous connaissons huit sapajous (qu'on peut réduire à einq espèces : l'ouarine ou gouariba du Bl'ésil ; le coaita ; le sajou ou sapajou proprement dit; le saï, appelé le plettrour; et le saimiri, qu'on appelle vulgairenent le singe 
aurore ou sapajou orangé; c'est le plus petit et lo plus joli des sapajous.

Nous connaissons de même six espèces de sagouins: le premier et le plus grand de tous est lo saki, nonmé singe à quene de renard; le second est le tamarin; le! troisième est l'ouistiti; le quatrième est le marikina ou petil lion; le cinquième est le pinche, ct le sixième est le mico, lo plus joli de tous.

L'ouarine, mâle et femelle, sont sauvages ct méoliants; on ne pcut les apprivoiscr ni même les dompter; ils mordent cruellement; sans ĉtre du nombre des animaux carnassiers et féroces, ils ne laissent pas d'inspirer de la crainte, tant par leur voix effroyable que par leur air climpudence. Ces animaux produisent ordinairement deux potits; la mère en portc un sous le bras et l'autre sur le dos.

Le coaïta est, apròs l'ouarine, le plus grand des sapajous; par son naturel doux et docile, il diffère bcaucoup de l'ouarine, qui est indomptable et farouche : ces sapajous sont intelligents et trìs-adroits; ils vont de compagnic, s'avertissent, s'aident et se secourent. Ils ont l'adresse de easser' l'écaille des huitres pour les manger, et il est certain qu'ils se suspendent plusicurs les uns au bout des autres, soil pour traverser un ruisseau, soil lour' s'ćlancer d'un arbre ì un autro. lls ne produisent O'dinairement (qu'un ou deux petits, qu'ils portent toujours sur le dos; ils mangent du poisson, des vers et des inscotes, mais les fruits sont leur nourriture la plus ordinairc.

I.e sajou est très-vif, très-agile et très-plaisant par son adresse et par sa légèreté; la température de notre 
climat lui convient assez; il y subsiste sans peine et pendant quelques années, pourvu qu'on le tienne dans une chambre à feu pendant l'hiver; ils peuvent même produire, mais ehaque portée n'est iei que d'un petit, au lieu que dans leur elimat ils en ont souvent deux. Au reste, les sajous sont fantasques dans leurs goùts et dans leurs affeetions: ils paraissent avoir une forte inelination pour de certaines personnes, et une grande aversion pour d'autres, et cela eonstamment.

Les saïs ne produisent qu'un ou deux petits; ils sont doux, dociles et si crantifs que leur eri ordinaire, qui ressemble à celui du rat, devient un gémissement dès qu'on les menaee. Dans ee pays-ei, ils mangent des liannetons et des limaçons de préférenee à tous les autres aliments qu'on peut leur présenter; mais au Brésil, dans leur pays natal, ils vivent prineipalement do graines et de fruits sauvages qu'ils cueillent sur les arbres, où ils demeurent, et d'où ils ne deseendent que rarement à Lerr'c.

Le saïniri est assez commun à la Guyane; par la gentillesse de ses mouvements, par sa pelite laille, par la eouleur brillante de sa robe, par la grandeur et le feu de ses yeux, par son petit visage arrondi, il a loujours eu la préfél'ence sur les autres sapajous, et c'est, en cffet, le plus joli, le plus mignon de tous : mais il est aussi le plus délicat el le plus diffieile à transpoiter et à eonserver.

Le sali, lorsqu'il est adulte, a environ dix-sept pouees de longueur, au lieu que le plus grand des einq autres sagouins n'en a que neuf ou dix. Le saki est aise à reeonnaître et à distinguer de tous les autres sigouins, de tous les sapajous et de toutes les guenons. 
Le tamarin est beaucoup plus petit que le saki, et en diffère par plusieurs earaclères, princijalement par la queue qui n'est couverte que de poils courts, au lieu que celle du saki est garnic de poils très-longs. Le tamarin est remarqquable aussi par ses larges oreilles et ses pieds jaunes; e'est un joli anmimal, très-vif, aisé ì illu'ivoiser,

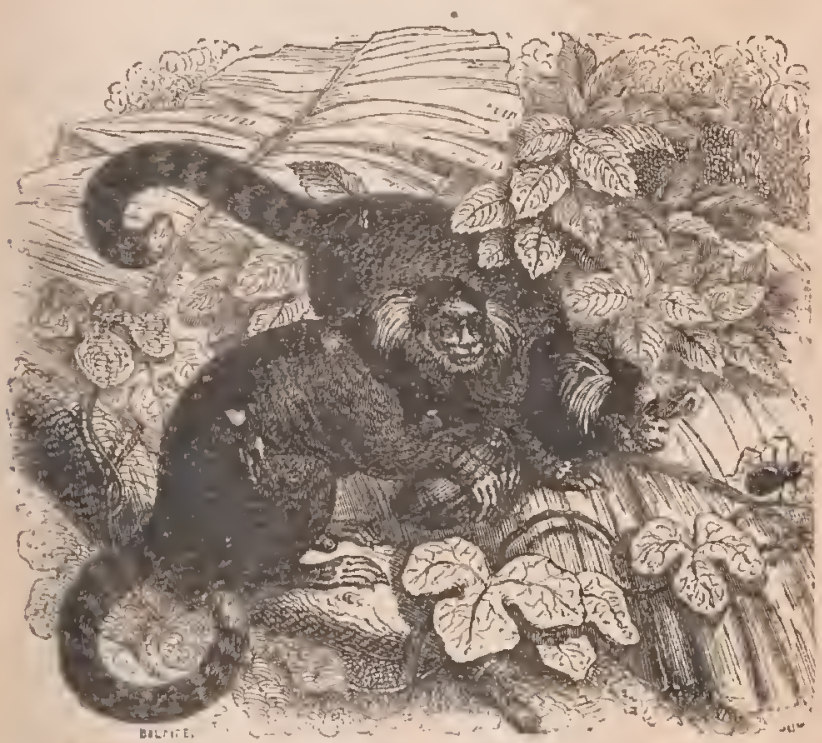

Inais si délicat qu'il ne peut résister longtemps à l'intempérie de notre climat.

L'ouistiti est encore plus petit que le tamarin; il n'a pas un demi-pied de longueur, le cor'ps et la têle compris, et sa queue a plus d'un pied de long. Le plus gros ne lıèse guère que six onces, et le plus jetit quatre onees et 
demie; l'ouistili se nourrit de biscuits, de fruits, de légumes, d'insectes. Ses petits sont d'abord forls laids; quand ils sont develus un peu grands, ils se cramponnent fortement sur le dos ou sur les épaules de leur mère, el, quand elle est lasse de les porter, elle s'en débarrasse en sc frottant contre la muraille; lorsqu'elle les a écartés, le mâle en prend soin sur-le-champ, et les laisse grimper sur son dos pour soulager la femelle.

Le marikina a les mêmes manières, la même vivacité et les mêmes inclinations que les autres sagouins, el il paraît être d'un tempérament un peu plus roluste, car il y en a ur qui a vécu cinq ou six ans à Paris, avec la seule attention qu'on a cue de le grarder pendant l'hiver dans une chambre, où tous les jours ou allumait du feu.

Le pinche, quoique fort petit, l'est cependant moins que l'ouistili; c'est encore un joli animal et d'une figure très-singulière; sa voix est douce el ressemble plus au chant d'un petit oiseau qu'au cri l'un animal; il est trèsrélicat, et ce n'est qu'avec de grandes pléeautions qu’on peut le transporter d'Amérique en Europe.

Le mico esı d'une espèce très-différente et vraisembliblement beaucoup plus rare que le tamarin, puisque longlemps il a été tout ì fait inconnu, quoiqu'il soil très-remarquable par le rouge vif qui anime sa face et par Ia beauté de son poil ; il marelie à yuatre pieds, et il u'a environ que sept ou liuit pouces de longucur en tout.

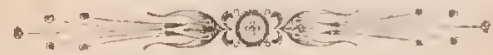




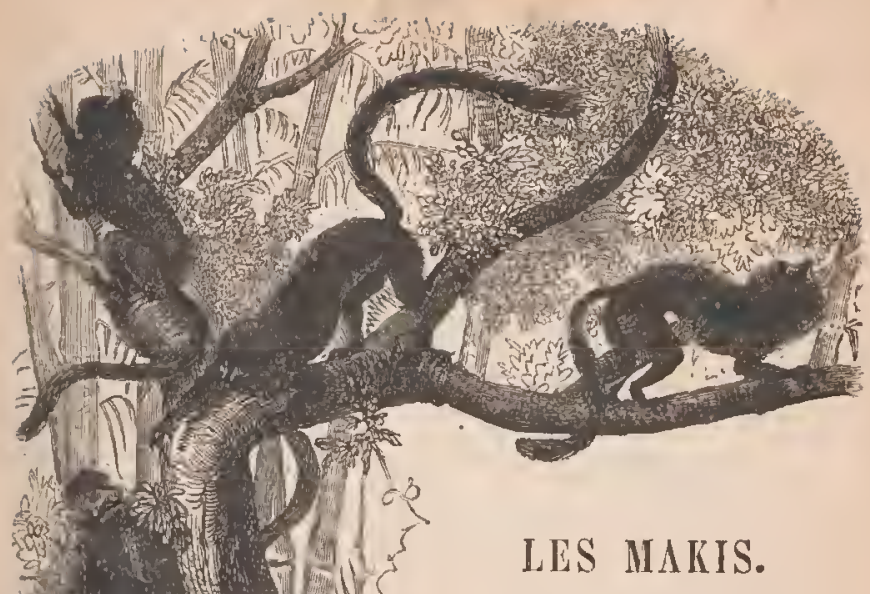

y nom de maki a été donné à plusieurs espòces d'animaux différentes ; nous ne pouvons done l'employer que comme un terme génćrique, sous lequel nous comprendons trois animaux qui se ressemblent assez pour être du môme genre, mais qui difR.i.

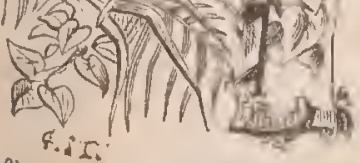
fèrent a constituer des espéces évidemment différentes. Ces trois animaux ont tous une longue queue, et les pieds conforInés comme les singes; mais leur museau est allongé comme celui d'une fouine. Le premier de ces animaux est le mocock ou mococo, que l'on connaît vulgairement sous le nom de maki à queue annclée. Le second est le mongous, appelé vulgairement maki brun. Le troisième est le vari, appelé par quelques-uns maki-pie. Ces trois 
animaux sont tous originaires de Madagascar, ou on les trouve en grand nombre.

Le mococo est un joli animal, d'une physionomie fine, d'une figure élégante et sveltc, d'un beau poil toujour's propre et lustré ; il est remarquable par la grrandeur de ses yeux, par la hauteur de ses jambes de derrière qui sont beaueoup plus longues que eclles de derant, et par sa belle et grande quene qui est tonjours relevée, toujours en mouvement, et sur larpuelle on compte jusqu'i trente anncaux alternativement noirs et blancs, tous bien distincts et bien séparés les uns des antres: il a les moeurs douces, et quoiqu'il ressemble en beaucoup de choses aux singes, il n'en a ni la malice ni le naturel. Dans son état de liberté il vit en sociélé, et on le trouve à Madagascar par troupes de trente ou quarante; dans celui de captivité il n'est incommorle que par le mouvement prodigieux qu'il se donne. Quoique très-vif et trèséveillé, il n'est ni méchant ni sauvage; il s'apprivoise assez pour qu'on puisse le laisser aller ct venir sans craindre qu'il s'enfuie; sa démarche est oblique comme celle de tous les animaux qui ont quatre mains au lieu de quatre pieds; il saute de meilleure grâce et plus légèrement (qu'il ne marche; il est assez silencieux et ne fait entendre sa voix que par un cri court et aigu, qu'il laisse, pour ainsi dire, éclıapper lorsqu'on le surprend ou qu'on l'irrite. Il dort assis, le muscau incliné ct appuyé sur sa poitrine; il n'a pas le corps plus gr'os qu'un chat.

Le mongous est plus petit que lo mococo; il y a dans l'espèce du mongous plusieurs variétés.

Le vari est plus grand, plus fort et plus sanvage que lo 
mococo; il est même d'une méchancelé farouche dons son état de liborté. Les voyageurs disent que ces animaux sont furicux comme des tigres, et qu'ils font un tcl bruit dans les bois que, s'il y on a deux, il somble qu'il y on ait un cent, ct qu'ils sont très-difficiles à apprivoiser. En effet, la voix du vari tient un pcu du rugissement du lion, et elle est effrayantc lorsqu'on l'entend pour la premic̀re fois.

Les mococos, les mongous ot les varis sont du même pays et paraissent être confinés à Madagascar; ils tiennent des singes par los habitudes essentielles, car, quoiqu'ils mangent quelquefois de la chair et qu'ils so plaiscnt aussi à épier les oiscaux, ils sont copendant moins carnassiors que frugivores, ot ils préfòrent, mêmo dans l'état do domesticité, los fruits, les racines et lo pain à la chair cuite ou crue.

\section{LE LORIS.}

Lo loris est un petit animal qui se trouve à Ceylan, et qui est très-remarquable par l'élégance do sa figure ot la Singularilé de sa conformation: il est peut-être de tous les animaux cclui qui a le corps lc plus long relativement à sa grosseur. Certains loris no sont pas plus gros que le poing, et ils sont d'une espèce différento des singes ordinaires; ils ont le front plal, les yeux ronds et grands, jauncs et clairs comme coux de certains chats : leur museau cst fort pointu, et le dodans des oreilles ost jaune; ils n'ont point de queue. 


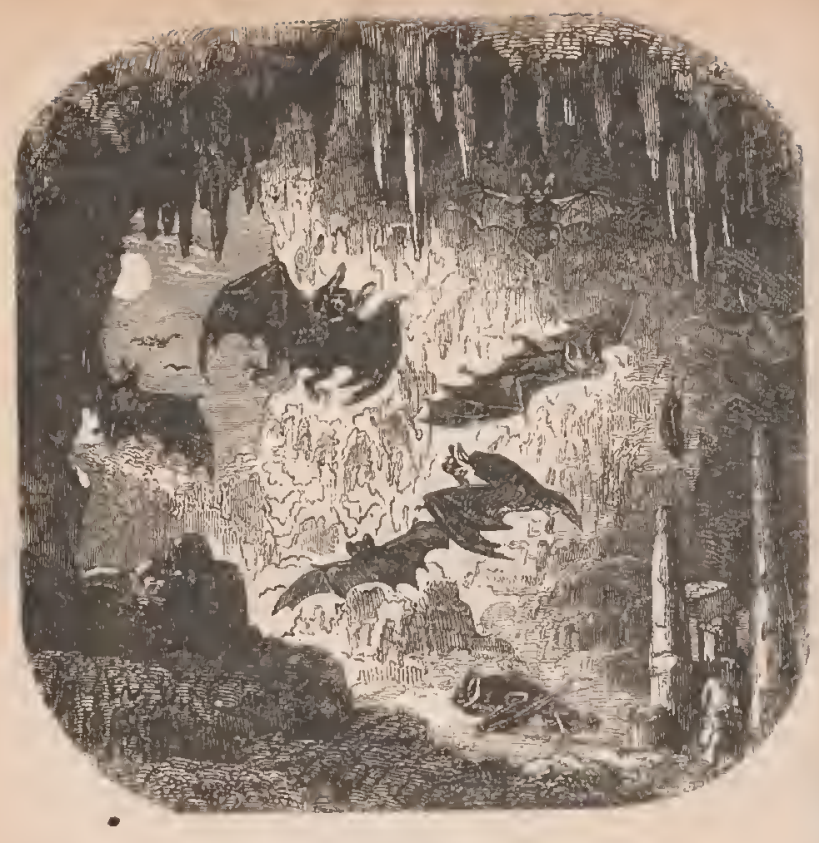

CARNASSIERS.

CHIROPTEेRES.

\section{I.A CHAUVE-SOURIS.}

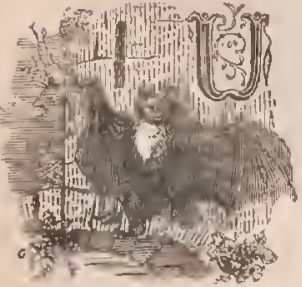

N animal qui, commo la chaurcsouris, est à demi quadrupède, à demi volatile, et qui n'est en toul ni l'un ni l'autre, est, pour ainsi dire, un être monstre, en ce que, réunissant les attributs de deux gemres si différents, il ne res" 
semble à aucun des molèles que nous offrent los grandes classes de la nature. Il n'est qu'imparfaitement quadrupède, et il est encore plus imparfaitement oiscau. Aussi les chauves-souris cherchent à se cacher, fuient la lumière, n'habitent que les lieux ténébreux, n'en sortent que la nuit, y rontrent au point du jour pour demeurer eollées contre les murs. Leur mouvement dans l'air est moins un vol qu'une espèce de voltigement incertain qu'elles semblent n'exécuter que par effort et d'une manière gauche; olles s'élèvent de terre avee peino, elles ne volent jamais à une grande lıauteur, elles ne peuvent qu'imparfaitement préeipiter, ralentir, ou même diriger leur vol; elles ne laissent pas de saisir en passant les moucherons, les cousins, et surtout les papillons phalènes qui ne volent que la nuit; elles les avalent, pour ainsi dire, tout entiers.

Les ehauves-souris sont de vrais quadrupèdes; elles n'ont rien do commun que le vol avec les oiseaux; elles en diffèrent par tout le reste de la eonformation, tant extérieure qu'intérieure; elles produisent, comme les quadrupèdes, leurs petits vivants; enfin elles ont, comme eux, des dents et des mamelles: l'on assuro qu'elles ne portent rue deux petits, qu'elles les allaitcnt et les transpoltent même en volant. C'est en été qu'elles mottent has, eir clies sont ongourdies pendant l'hiver : les unes se rccouvrent de leurs ailes comme d'un inanteau, s'accrochent à la voûto de leur souterrain par les picds de derrière, et demourent ainsi suspendues; les autres se collent eontre les murs ou se reeèlent dans des trous; clles sont toujours en nombre pour se défendre du froid. toutes passent l'liver sans bouger, sans manger, ne se 
réveillent qu'au printemps, et se recèlent de nouveau vers la fin de l'izutomne. Flles supportent plus aisément la diète que le froid, elles peuvent passer plusieurs jours sans manger, et ecpendant elles sont du nombre des animaux earnassiers ; ear, lorsqu'elles peuvent entrer dans un oflice, elles s'attachent aux quartiers le lard qui $y$ sont suspendus, et elles mangent aussi de la viande crue ou cuite, fraîche ou corrompue.

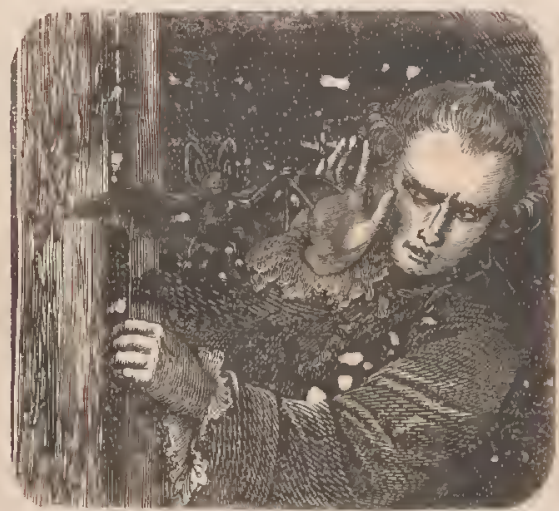




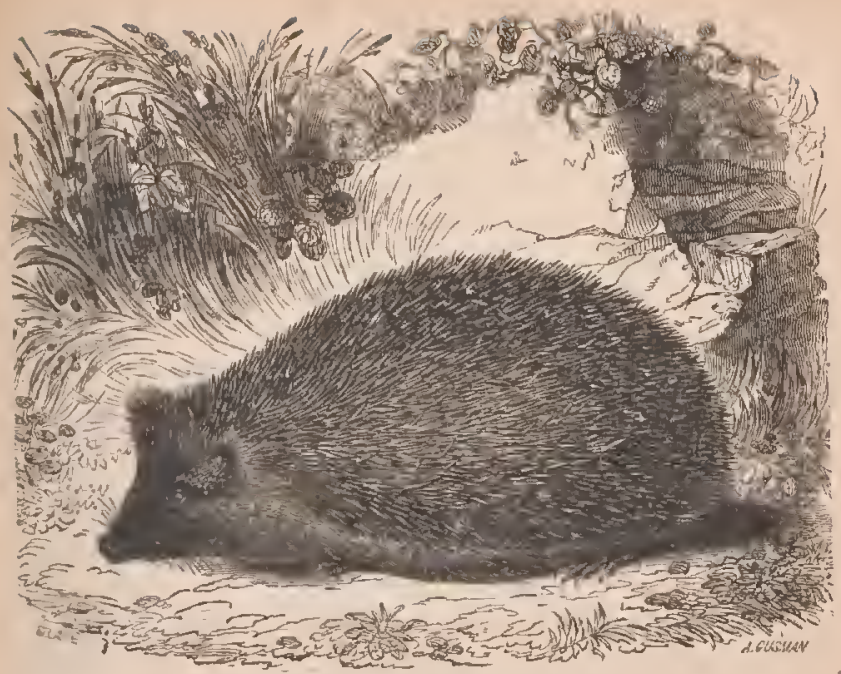

INSEGTIVORES.

\section{LE HERISSON.}

Le renard sail beaucoup de choses, le hérisson n'en sait qu'une grande, disaient proverbialement les anciens. Il sait se défendre sans combattre, et blesser sans attaquer : n'ayant que peu de lorce et nuile agilité pour fuir, il a reçu de la nature une armure épineuse, avec la facilitó de se serrer en boule et de présenter de tous côtés des armes défensives, poignantes et qui rebutent ses ennernis; plus ils le tourmentent, plus il se hérisse et se resserre. Aussi la plupart des chiens se contentent de l'aboyer et ne se soucient pas de le saisil' : cependant il 
y en a quelques-uns qui trouvent moyen, comme le renard, d'en venir à bout on se picpuant les pieds et se meltant la gucule en sang; mais il ne eraint ni la fouine, thi la marte, ni le putois, ni le furet, ui la bolctte, ni les oiseaux de proie. La femelle et le mâlo sont également couverts d'épines depuis la tête jusqu'à lạ queuc, et il n'y a que le dessous du corps qui soit garni de poils; ils produisent au commencement de l'été. On m'a souvenl apporté la mère et les petils an mois do juin: il en a ordinairement trois ou cuatre, et quelquefois cinq; ils sont blanes dans ec premier temps, et l'on voit seulemenl sur lcur peau la naissance des épines. Ils vivent de fruits tombés; ils fouillent la terre avee le nez à une petitc profondeur; ils mangent les hannetons, les scarabécs, les grillons, les vers et quelques racines; ils sont aus très-avides de viande, et la mangent cuite on nrue. A lin campagne, on les trouve fréquemment dans les bois, souls les trones des vieux arbres, et aussi dans les ferices do rochers, et surlout dans les monceaux de picrres qu'or amasse dans les champs of dans les vignes. Quoiqu'il y en ait un grand nombre dans nos forêts, nons n'en avon' janais vu sur les arbres; ils se tiennent toujour's au pied dans un ereux ou sur la mousse. IIs ne bougent pas tant qu'il est jour, mais ils courent, ou plutôt ils marehent pendant toute la nuit : ils approchent rarement des habitations, ils préfèrent les lieux élevés et sees, quoiqu'ils se trouvent aussi quelquefois dans les prés. On les pren li à la main: ils ne fuient pas, ils ne se défendent ni de pieds ni des dents ; mais ils se mettent en boule dès qu' ort les touehe, ef pour les faire étendre il faut les plonger dans l'eau. Ils dorment pendant l'liver'. Ils ne mangen" 
pas beaucoup, et peuvent se passer assez longtemps de noulyiture. Ils ont le sang froid à peu près eomme tous les autres animaux qui dorment en hiver. Leur chair n'est pas bonne à manger, et leur peau, clont on ne fait inaintenant aueun usage, servait autrefois de vergette et de frottoir pour serancer le chanvre.

\section{LA IIUSARAIGNE.}

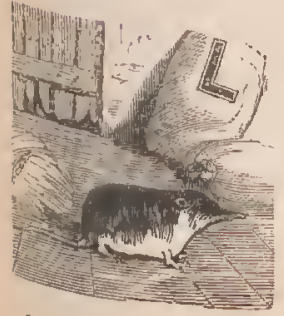

A musaraigne semble faire une nuanee dans l'ordre des petits animaux, et remplir l'intervalle qui se trouve entre le rat et la taupe, qui, se ressemblant par lcur petitesse, diffèrent beaueoup par la forme, et sont en tout d'espèees trc̀s-éloi= gnées. La musaraignc, plus petite eneore que la souris, ressemble à la taupe par le museau, ayant le nez beaueoup plus allongé que les màchoires; par les yeux qui, quoique un peu plus gros que eeux de la taupe, Sont eaehés de même et sont beaueoup plus petits quẻ ccux de la souris ; par le nombre des doigts, dont elle a einc ì tous les pieds; par la queue, par les jambes, surtout celles de derrières qu'elle a plus eourtes que la souris; par les oreilles, ct enfin par les dents. Ce trèspetit animal a une odeur forte qui lui est particulière, et qui répugne aux ehals; ils ehassent, ils tuent la musaraigne, mais ils ne la mangent pas comme la souris. Cet 
animal habite assoz communémont, surtout pendant l'hiver, dans les greniers à foin, dans les écuries, dans les granges, dans les cours à funier ; il mange du grain, des inseetes et des chairs pourries: on le trouve aussi fréquenment à la campragne, dans lés bois où il vit de graines; et il se eache sous la mousse, sous les feuilles, sous les trones d'arbres, et quelquefois dans les trous abandonnés par les taupos, ou dans d'autres trous plus petits qu'ils se pratiquent lui-même en fouillant avec les ongles et le museau. La musiraigne produit en grand nombre, autant, dit-on, que la souris, quoique moins fréqueminent. Elle a le cri beaucoup plus aigu que lasouris, mais elle n'est pas aussi agile à beaucoup près : on la prend aisément, paree qu'cllo voit et court mal. La couleur ordinaire do la musaraigne est d'un fr'un môlé de r'oux, mais il y en a aussi de cenlrées, de prespuo noires, et toutes sont plus au moins blinchàtres sous le ventre. Eilles sont très-eommunes dans toute l'Europe.

\section{LA IIUSARAIGNE D'EAU.}

Ge qu'on peut assurer' au sujet de la musaraigne d'eau, c'est qu'on la prend à la source des fontaines, au lever et au eoucher du soleil ; que dans le jour elle reste cachée dans des fontes de roehers ou dans des trous sous terre, le long des petits ruisseaux; qu'elle met bas au printemp's, et qu'ordinairement elle produit neuf jotits. 

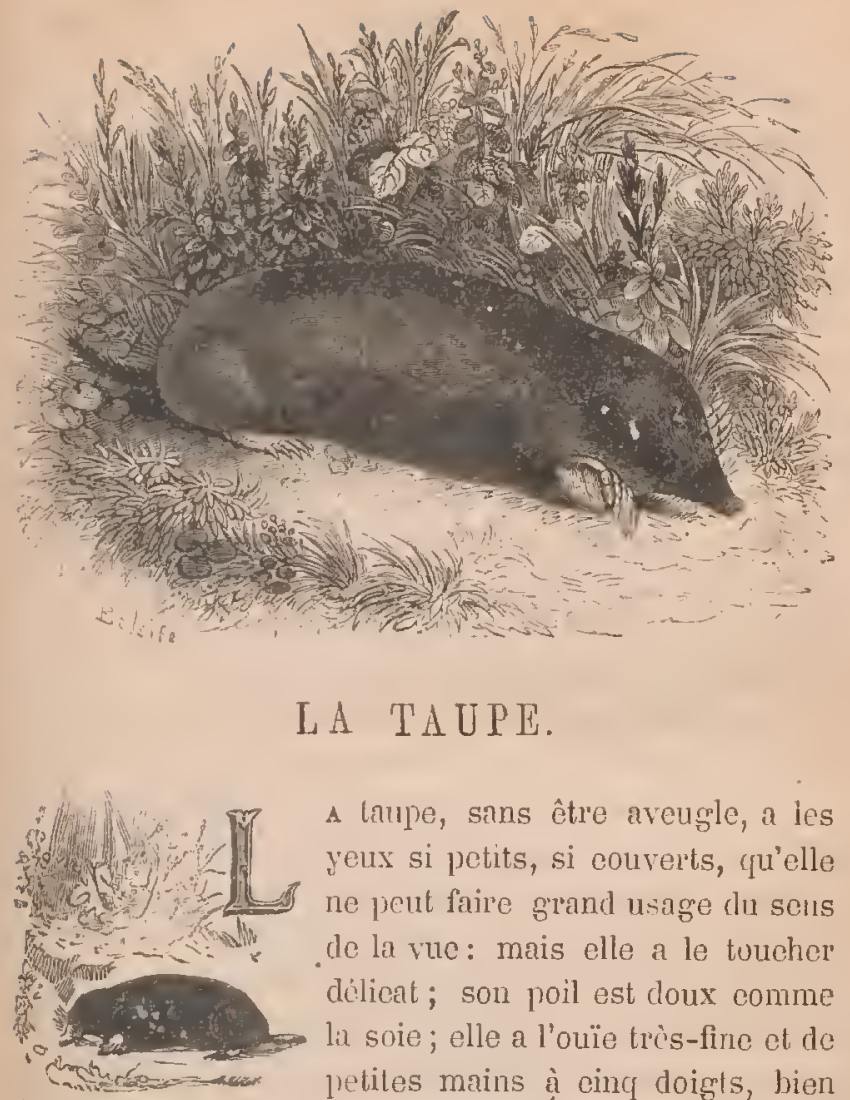

A laupe, sans être aveuğle, a les yeux si petits, si couverts, qu'elle ne peut faire grand usage du seis de la vuc: mais elle a le tuucher délicat; son poil est doux comme lil soie; elle a l'oüe tròs-fine ot de petites mains à einq doights, bien rlifférentes de l'extrémité des pierls des autres animaux, ct presque semblables aux mains de l'homme; beaueoup de force pour le volume de son eorps, le euir forme, un embonpoint couslant, les douces habitudes du repos et de la solitude, l'urt de se mettre en sûreté, de se faire en un instant un asile, un domicile, la facilité de l'étendre, ot d'y trouver, sans en sortir, une abondante subsistance. 
Elle ferme l'entrée de sil retraite, n'en sort presque jamais qu'elle n'y soit forcée par l'abondance des pluies d'été, lorsque l'eau la remplit ou lorsque le pied du jardinicr en affaisse le dôme; elle se pratique une voùte en rond dans les prairies, et assez ordinairement un boyau long duns les jardins, jarce qu'il y a jlus de facilité à diviser et à soulever une torre neuble et cultivće qu'un gazon fer'me el tissu de racinos; elle ne demeure ni dans la fange ni dans les terrains durs, trop compactes ou trop pierreux; il hi faut une terre douce, fournic de lacincs esculentes, et surtout bien peuplée d'insectes et de ver's, dont elle fuit sa principale nourriture.

Comine les taupes ne soltent que rarement de leul' domicile souter'ain, elles ont peu d'cnnemis, et échap' jent aisément aux animaux carnassicrs : leur plus grand lléau est le débordement des riviòres; on les voit, dans les inondations, fuir en nombre à liı nage, et faire tous leurs efforts pour gagner les terres plus élevées; mais la plupart périssent aussi bien que leul's petils qui restent dans les trous ; elles ne les portent pas longtemps; ear on trouve déjà beaucoup de petits au mois cle mai ; il y en a ordinailement quatre ou cinq dans chaque portío, et il est assez aisé de distinguer, parmi les mottes qu'elle élèvent, eelles sous lesquelles elles mettent bas: ces mottes sont faites avee beaucoup d'ari, et sont ordinairement plus grosses et plus élevées que les auties.

Le domicile où clles font leur's petils mériterait n1le description particulic̀re. 11 'st fait avee unc intelligence singulière ; elles commencent par pousser, par élever la terre et former une voûte assez élevéc; clles laissent des eloisons, dos espucous de pilicr's de distance en distance i 
elles pressent et battent la terre, la inêlent avee des raeines et des lierbes, et la rendent si dure et si solide par dessous, que l'cau ne peut pénétrer la voûte à cause dc sa convexité et de sa solidité; elles élèvent ensuite un tertre par-dessous, au sommet duquel elles apportent de l'herbe et des feuilles pour faire un lit à leur's petits ; dans eette situation, ils se trouvent au-dessus du niveau du terrain, et par conséquent à l'abri des inondations ordinaires, et en même temps à couvert de la pluie par la voûte qui reeouvre le tertre sur lequel ils reposent. Ce tertre est pereé tout autour de plusieurs trous en pente, qui deseendent plus bas ot s'étendent de tous eôtés, comme aulant de routes souterraines par où la mère taupe peut sortir et aller ehelcher la subsistance néeessaiı'e à ses petits; ees sentiers souter'rains sont fermes et battus, s'étendent à douze ou quinze pas, et partent tous du domieile comme des rayons d'un eentre. On y tronve, aussi bien que sous la voûte, des débris d'oignons de colehique, qui sont apparemment la première nourriture qu'elle donne à ses petits.

La taupe ne se trouve guère que dans les pays eultivés; il n'y en a point dans les déserts arides ni dans les elinats froids, où la terre est gelée pendant la plus grande partie de l'année.

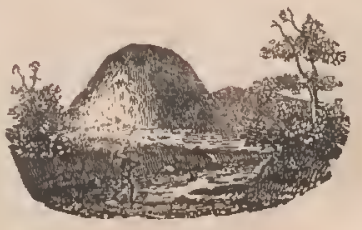




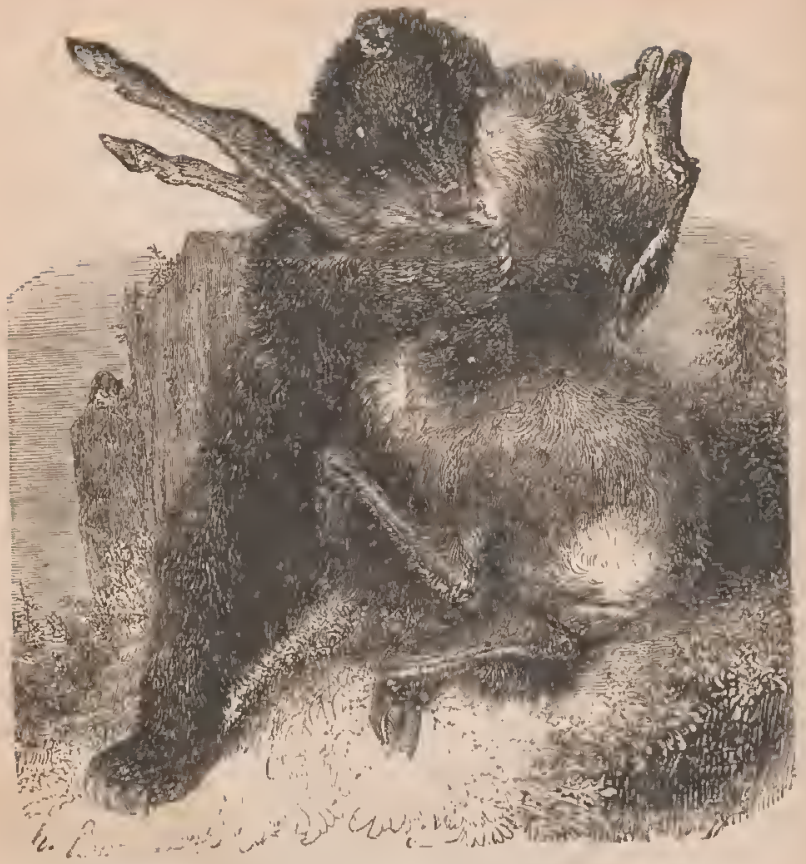

CARNIVORES PLANTIGRADES.

\section{L'OURS.}

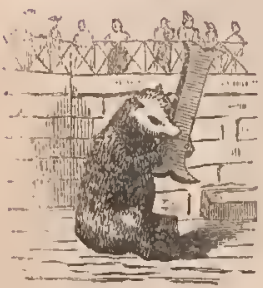

I. n'est pas rare de trouver dans les Alpes i'ours brun; on y lrouve moins souvent l'ours noir, que l'on rencontre en grand nombre dims les forêts des pays septentrionaux do l'Europe et de l'Amèrique. Le brull est féroce et carnassier, le noir n'est 
que farouche, et refuse eonslamment de manger de la chair.

L'our's est non-seulement sauvage, mais solitaire; il fuit par instinct loutc société, il s'éloigne des lieux où les hommes ont aeeès, il ne se trouve à son aise que dans les endroils qui apparticnnent encore à la vicille nature. Une caverne untique dans des rocher's inaccessibles, une grotte formée par le tomps clans le trone d'un vicux arbre, au milieu d'unc ćpaisse forèt, lui servent do domicile; il s'y retire scul, y passe unc partie de l'hiver sans provisions, saus en sortir pendant plusieurs semaines. Cependant il n'est point engourdi ni privé de scntinent, mais eomme il est naturellement gras, et qu'il l'est excessivement sur' la fin de l'automne, temps auquel il sc reecle, eette abondanee de graisse lıi fuit supporter l'abstincnce, et il ne sol't de sa biugge que lor'squ'il se sent aflumé.

La mère a le plus grand soin de scs petits; elle lcur prépare un lit de mousse et d'hel'bes dans le fond de sa eaverne, et les allaite jusqu'ù ce qu'ils puissent sortir' avec clle : elle met bas en liver, et ses petits commencent à la suivre au printemps. Le mâle ct la fomelle n'lialitent point ensemble; ils ont cliacun leur retraite séparée, et mêne fort éloigrnéc. Lorsqu"ils ne peuvent trouver une grotte pour se giter, ils cassent et ramassent du bois pour se faire une loge qu'ils recouvrent d'herbes et do fcuilles au point de la rendre impićnétrable à l'eau.

La voix de l'ours est un grondcment, un gros murmure, souvent mêlé d'un fr'ćnissement de dents qu'il fait surtout entendre lorsqu'on l'irrite; il est très-susceptible de colìre, ct sa colc̀re tient toujours de la fureur 
et souvent du caprice : quoiqu'il paraisse doux pour son maître, et même ohéissant lor'squ'il est apprivoisé, il faut toujours s'en dćfier, le triter avec crrconspection, et surtout ne le pas frapper au bout du nez. On lui apprent à se tenir debout, à gesticuler, à danser ; il semble même écouter le son des instruments el suivre grossièrement la mesure; mais pour lui donner cette espèce d'éducation, il faut le prendre jeune, et le contraindre pendant toute sa vie. L'ours qui a de l'âge ne s'apprivoisc ni ne se contraint plus; il est naturellement intrépide, ou tout au moins indifférent au danger. L'ours sauvage ne se détourne pas de son chemin, ne fuil pas à l'aspect de l'homme; cependant on prétend que par un coup de sifflet on le surprend, on l'étonne au point qu'il s'arrête et se lève sur les pieds de clerı.ic̀re. C'est le temps qu'il faut prendre pour le tirer, et tîcher de le tuer; car s'il n'est que blessé, il vient en furie se jeler sur le tireur, et, l'embrassant des pattes de dovant, il l'étoufferait, s'il n'étail secouru.

La peau de l'ours est de toutes les fourrures grossières celle qui a le plus de prix, et la quantité d'huile que l'on tire d'un seul ours est fort considérable.

La quantité de graisse dont l'ours est chargé le rend très-léger à la nage, aussi traver'se-t-il sans fatigue des flcuves et dos lacs.

L'ours a les sens de la vue, de l'ouie et du toucher très-bons, quoiqu'il ait l'œil très-pctit relativement au volume de son corps, les oreilles courtes, la peau épaisse et le poil fort touffu : il a l'odorat excellent, et peut-être plus exquis qu'aucun autre animal. Il a jambes et les bras charnus comme l'homme, l'os du talon court et fol'- 
mant une partie de la plante du pied, cinq orteils opposés au talon dans les pieds de derrière, les os du carpe. égaux dans les pieds de devant; mais le pouce n'est pas séparé, et le plus gros doigrt est en dehor's de cette espèce de main, au lieu que dans celle de l'homme il est cn derlans : ses doights sont gros, courts et serrés l'un contre l'aulle, aux mains comme aux pieds; les ongles sont noirs, et d'une substance homogène fort dure. 11 frappe avec ses poings comme l'homme avec les siens; mais ces ressemblances grossières avec l'homme ne rendent l'ours que plus difforme, el ne lui donnent aucune supériorité sur les autres animaux.

\section{L'OURS BLANC.}

L'ours hlanc se trouve surlout dans les mers du Nord. Il vil de poissons, il ne quitte pas les rivages de la mer, et souvent même il habite en pleine eau sur les glaçons flottants. Mais, lorsqu'il trouve quelque proie sur terre, il ne se donne pas la peine d'aller chasser en mer ; il dévore les rennes et les autres animaux qu'il peut saisir ; il attaque même les hommes et ne manque jamais de déterrer les cadavres.

On a lieu de penser que ces ours dle mer sont d'une espèce plus féroce et plus vorace que l'espèce ordinaire de l'ours. Ils ne peuvent nager que pendant peu de temps; ils ne sont done point amphibies.

Tous les outs ont naturellement beancoup de graisse, 
et ccux-ei, qui ne vivent que d'animaux ehargés d'huile, en ont plus que les autres ; elle cst aussi à pou près semblable à eclle de la baleine. La ehair de ees ours n'est, dit-on, pas mauvaise à manger, et leur peau fournit une fourrure très-claaude et très-durable.

\section{LE BLAIREAU.}

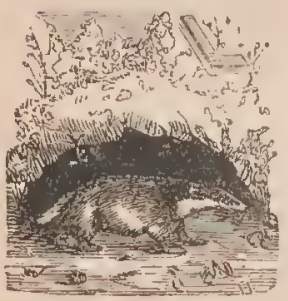

E blaireau est un animal paresscux, défiant, solitaire, qui se retire daus les lieux les plus écartés, dans les bois les plus sombres, ct s'y crouse une demeure souterrainc; il semble fuir la soeieté, même la lumière, et passe les trois quarts de sa vie dans ee séjour ténébreux, dont il ne sort que pour eherelıel sa subsistance. Comme il a le corps allongé, les jambes courtos, les ongles, surtont ceux des pieds de devant, Irès-lonģs et trc̀s-fermes, il a plus de facilité qu'un autre pour ouvirir la terre, y fouiller, y pénćtrer, et jeter derric̀re lui les déblais de son exearation, qu'il rend tortueuse, oblique, et qu'il pousse quelquefois fort loin. Le blaireau, forcé par le l'enard à changer de manoir, ne ehange pas de pays; il ne va cu'à quelque distance travailler sur nouveaux frais à se pratiquer ul autre gîte, dont il ne sort que la nuit, dont il ne s'éearte guère, et où il revient dès qu'il sent quelque danger. Il n'a que ee moyen de se mettre en sùreté, ear il no peut 


\section{ANIMAUX SAUTARES.}

échapper par la fuile; il a les jambes trop eourtes pour pouvoir lien courir. Les chiens l'atteignent promptement, lorsqu'ils le surprennent à quelrue distanee de son trou: eependant il est rare qu'ils l'arrêtent tout à fait et qu'ils en vierment à bout, à moins qu'on ne les aide. Le blaireau a le poil trìs-épais, les jambes, la mâchoire et les dents très-fortes, nussi bien que les ongles; il se sert de toute sa foree, de toute sa résistanee ct de toutes ses armes en se couehant sur le dos, et il fait aux ehiens de profondes blessures. 11 a d'ailleurs la vie très-dure; il eombat longtemps, se défend eourageusement et jusqu'à la dernière extrémité.

Les jeunes s'apprivoisent aisément, jouent avee les petits ehiens, et suivent comme eux la personne qu'ils eonnaissent et qui leur donne ì manger ; mais ceux que l'on prend vieux demeurent toujour's sauvages : ils ne sont ni malfaisants ni gourmands comme le renard et le loup, et cependant is sont animaux carnassiers; ils mangent de tout ce qu'on lenr offre, de in ehair, des œufs, du fromage, du beurre, du pain, du poisson, des fruils, des noix, des graines, des raeines, ele., et ils préfèrent la viande erue à tout le reste. lls dorment la nuitentière et lus trois quarts du jour, saus eependant être sujets à l'ellgourdissement pendant l'hiver, eormme les marmottes ou les loirs. Ce sommeil frécquent fuit qu'ils sont toujour's gras, quoiqu'ils ne mangent pus beaueoup ; et c'est par la nnême raison qu'ils supportent aisément la dic̀le, et qu'ils restent souvent dans leur terrier trois ou quatre jour's sans en sortir, surtout dans les temps de neige.

Ils tiennent leur domieile propre. Lorsque la femelle est prête ì mettre bas, elle coupe l'licrbe, en fail une 
espèce de fagot qu'elle traine entre ses jambes jusqu'an fond du terrier, où elle fait un lit commode pour elle et ses petits. C'est en été qu'elle met bas, et la portée est ordinairement de trois ou de quatre. Lorsqu'ils sont un peu grands, elle leur apporte à manger; elle ne sort que la nuit, va plus au loin que dans les autres temps; elle déterre les nids de guêpes, en emporte le miel, perce les rabouillères des lapins, prend les jeunes lapereaux, saisit aussi les mulots, les lézards, les serpents, les sauterelles, les ouf́s des oiseaux, et porte tout à ses petits, qu'elle fait sortir souvent sur le bord du terrier, soitpour les allaiter, soit pour leur donner ì manger.

Ces animaux sont naturollement frileux; ceux qu'on élève dans la maison ne veulent pas quitter le coin du feu, et souvent s'en approchent de si près qu'ils se brùlent les pieds, et ne guérissent pas aisément. Le blaileau a torjours le poil gras et malpropre. Sa chair n'est pas absolument mauvaise à manger, et l'on fait de sa peau des foururues grossières, des collicrs pour les chiens, des couvertures pour les chevaux, etc.

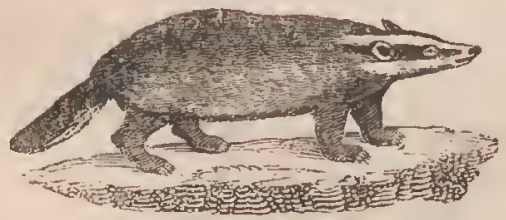




\section{LA MARTE.}

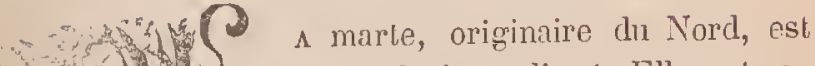
naturelle à ce climat. Elle est, au eontraire, en pelit nombre dans les climats tempérés, el ne se trouve point dans les pays chauds: elle est aussi lare en France que la fouine y est commune. Il n'y en a point du tout en Angleterre, parce qu'il n'y a pas de bois. Ellc fuit éggaloment les pays habités et los licur découverts; elle demeure au fond des forêts, no se cache point dans les rochers, mais parcourt les bois et grimpe au-dessus des arbres; elle vit de chasse et détruit une quantité prodigieuse d'oiseaux, dont elle cherche les nids pour en sucer les outs; elle prend les écureuils, les mulots, les lérots, etc., elle mange aussi du miel comme la fouine et le putois. Or ne la trouve pas en pleine campagne, dans les prairies, dans les champs, dans les vignes. alle ne s'approche jamais des habitations, et elle diffire encore de la fouine par li manière dont elle se fait chasser. Dès que la fouine se sent pour'suivre par un chien, clle se soustrait en gagnant promptement soll grenier ou son trou: la inarte, su contraire, se fait suivre assez longtemps 
par les chiens, avant de grimper sur un arbre; elle ne se donne pas la paine de monter jusqu'au-clessus des branches, elle se tient sur la tiģe, et de là les regarde passel. La trace que la marto laisso sur la neige parait être celle d'une granido bête, parce qu'clle ne va qu'en sautant et qu'elle marrque toujours de deux pieds à la fois ; elle est un peu jlus grosse quo la fouine, ct cependant elle a la tèto plus courte; elle a les junnles plus longues, et court par conséquent plus aisément; olle a la gorge jaune, au lieu que la fouine l'a blanche; son poil est aussi bien plus fin, bier plus fourni ot moins sujet à tomber ; elle ne própare pas, comme la fouine, un lit à ses petits : néanmoins elle les loge encore plus commodément. Les éeureuils font, comme l'on sait, des nids au-dessus des arbres avec autant d'art que les oiseaux; lorsque la marte est prête à meltre bas, elle grimpe au nid de l'écureuil, l'en chasse, en élargit l'ouvorture, s'en empare et y fuit ses petits; ello se sel't aussi des anciens nids de duos et les buses, et des trous des vieux arbres, dont olle dériche les pies-de-bois et los autres oisenux. Ello met bas au printemps: la portée n'est que de doux ou trois ; les petits naissent les yeux-fermés, et cependant grandissent en peu de temps; elle leur apjortc bientôt des oiseaux, des oufs, et les mòne ensuite d̀ la clısse avec elle.

Les martos sont aussi communes dans le nord de l'Amérique que dans le nord de l'Europe ct de l'Asie: on en apportc beaueoup du Canada; il y en a dans toutel'étendue des terres septentrionales do l'Anérique jusqu'à la baie d'Hudson, et en Asie, jusqu'an nord du royaume de Tonquin et de l’empire de la Chine. 


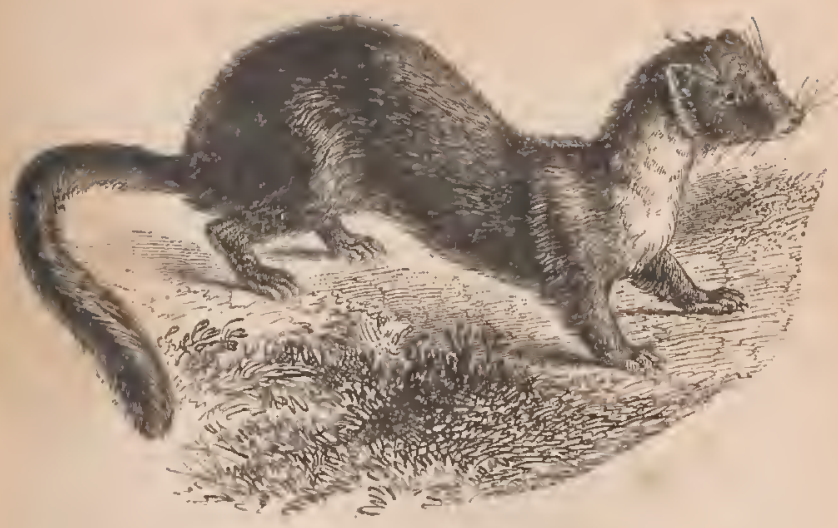

\section{A FOUINE.}

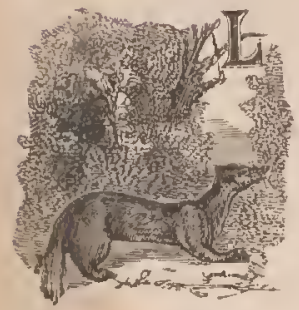

A plupart desnaturalistes ont écrit que la foune el la marto ćtaient des aninatx de la môme espèee. Mais la fouine differe de la marte par le naturel et par le tempérament, puisque celle-ci fuit les lieux découvel's, liabite au fond des bois, demeure sur les arbres, ne se trouve en grand nombre que duns les clinats froirls, au lieu que la fouine s'appi’ollu des labjutatious, s'établit même dans les vieux bâliments, dans les greniersà foin, dans les trous de murailles; Yu'enfin l'espèce en est généralement répandue en grand nombre daus tous les pays tompérés, et mème dans les climats cliauds, et qu'elle ne so trouve pas dans les pays Ulu Nord.

I $а$ fouine a la physionomic très-fine, l'wil vif, le saut 
ligor, les membres souples, le corps flexible, tous les mouvoments tris-prestes; elle saute et boudit plutôt qu'clle ne marche; elle grimpe aisément contre les murailles qui ne sont pas bien enduites, entre dans les eolombiers, les poulailler's, ctc., mango les coufs, les pigeons, les poules, etc., en tue quelquefois un grand nombre et les porte ì ses petits; elle prend aussi les souris, les rats, les taupes, les oiseaux dans leurs nids.

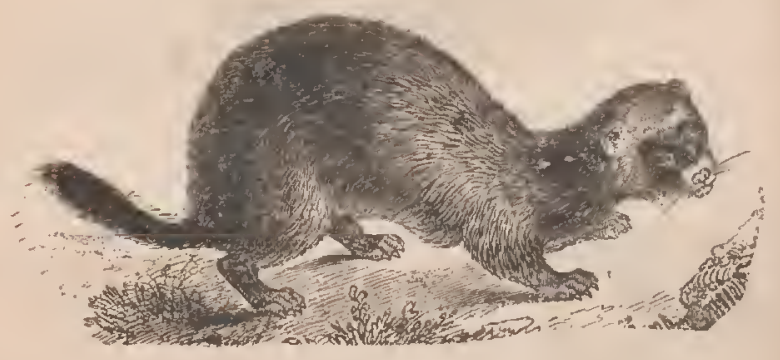

LE PUTOIS.

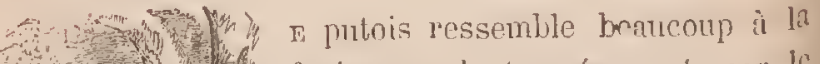

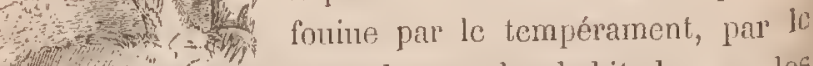

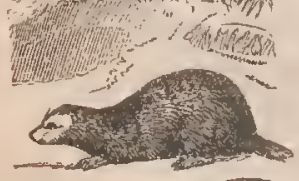
naturel, par les habitudes ou les mocurs, et aussi par la forme dil corps. Comme elle, il s'approche des labilations, monte sur lestoits, s'établit dans les greniers à foin, dans les granges et dans le lieux peu fréquentés, d'où il ue sort quela nuit pour cher" cher sa proie. Il se glisse dans les basses-cours, monte 
aux volir res, anx colombicrs, où, sans faire nutant de bruit que la fouine, il fait plus de dégàt ; il coupo ou ćcrase la lête à loutes les volailles, et cnsuite il les transporte une à une et en fait magasin; si, comme il arrive souvent, il no peut les emporter entières, parce que lo trou par où il est entré se trouve trop étroit, il leur mango la cervelle et emporte les têtos. Il ost alassi fort avide de miel; il attaque les ruches en hiver et force les abeilles à les abandonner.

A la ville il vit do proic, et de chisse à la oampagne ; il s'étallit, pour passer l'été, dans les terriors de lapins, dans les fentes de rochere, dans des trones d'nrbres reux, d'où il no sort gुuc̀ro que la nuit pour se répandre dans les champs, dans les bois; il oherche les nids des perdrix, des alonettes et des cailles; il frrimpo sur les arbres pour prendre ceux des antres oiseaux; il épie los rals, les taupes, les mulots, et fait une guerre continuclle altx lapins, qui ne peuvent lui échapper', parec cu'il entre aisément dans leurs trous: une seule famille de putois Suffit pour détruire une garenne. Ce serait le moyen le plus simple pour diminuer le nombre des lapins dans les endroits où ils deviennent trop abondants.

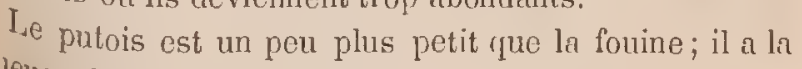
queue plus courte, le museau plus pointu, le poil plus épais et plus noir"; il a du lylano sur le front, aussi bien Yu'aux côtés du nez et autour de la gueule. Il en diffèro Elcore par la voix: ln fouine a le cri aigu et assez ćclntant; le putois a le cri plus obscur ; il ont tous deux, alssi bien que la marte et l'écureuil, un grognement d'un ion grave et colèro, qu'ils répètent souvent lorsqu'on les l'ode; enfin le putois ne ressemble point à la fouine par l'odenr, qui, loin d'ètre ag'réable, est au contraire si fí-- 
tide qu'on l'a d'abord distiugnué et dénommé par là. C'est surtout lorsqu’il est ćchauffé, irrité, qu'il exhale et répnnd au loin une odcur insupportable: Les chiens ne veulent point manger dc sa cliair, el sa peau mène, quoique bonte, est à vil prix, parce qu'elle ne perd jamais entièrement son odeur naturelle.

Le putois parait être un animal des pays tempérés: on n'en troure que peu ou point dans les pays du Norl, et ils sont plus rares que la fouine daus les climats núpidionaux.

\section{LE FURET.}

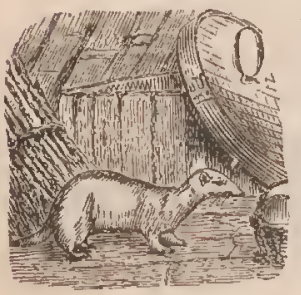

tELQUES auteurs ont douté si li furet et le putois étaient des anjnaux d'espèces différentes. Mais il ne se mêlent point ensemble, et diffèrent d'ailleurs par' un grand nombrc de caractères essentiels. Le furet a le corps plus allongé el plü mince, la tête plus étroite, le museau plus pointu qut le putois; il n'a pas lo mêne inslinct pour trouvel subsistance; il faut en avoir soin, le nourrir à la maison. du moins dans ces climats; il ne va pas s'établir il tit campagine ni dans les bois; et ceux que l'on perd da $1^{15}$ les trous de lapins, et qui ne revicnnent pas, ne se sol ${ }^{1}$ jamais multipliés dans les champs ni dans les bois; ilo périssent apparemment pendant l'hiver: le furet vari aussi par la couleur du poil comme ies autres animas 
domostiques, ot il est aussi commun dans les pays chaurls, que lo putois y est rare.

Cot animal.est naturellement ennemi mortel du lapin: lorşu'on présente un lapin, même mort, à un jeune furet qui n'en a jamais vu, il se jette dessus et le mort avec fureur; s'il est vivant, il le prend par le cou, par le nez, et lui suce le sang; lorsqu'on le lìche dans les trous des lapins, on le musèle, afin qu'il ne les tue pas daus le fond ru terrier, ot qu'il los obligge seulement à sortir et à se jeter dans le filet dont on couvre l'entrée. Si on laisse aller lo furet sans mus elière, on court risque de le perdre, parce qu'après avoir sucé le sang du lapin il s'ondort, et la fumée qu'on fait dans le terrier n'est pas toujours un Moven sûr pour le ramener, parce que souvent il y a plusieur's issues, et qu'un terricr communique à d'autres, clans lesquels le furct s'engage à mesure que la fumée le gagne. Lcs enfants se servent aussi du furet pour dénicher des oiseaux; il entre aisément dans los trous des arbres et des muraillos, et il les apporte au dehors.

Le furet, quoique facile à apprivoiser et même assez. docile, ne laisse pas d'être fort colère; il a une mauvaise odeur en tout temps, qui devient bien plus forte lorsqu'il s'échauffe ou qu'on l'irrite; il a les ycux vifs, le regard enflammé, tous les mouvements tris-souples, et il est en même temps si vigoureux, qu'il vient aisément à bout d'un lapin qui est au moins quatre fois plus gros que lui.

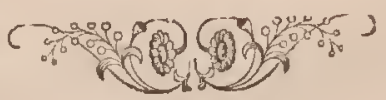




\section{I $\Lambda$ BELETTE.}

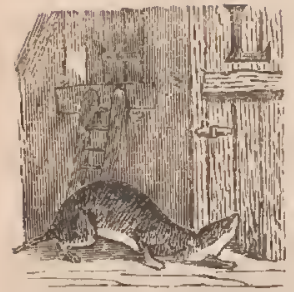

A belette ordinaire est aussi commune dans les pays tempérés et chauds qu'elle est rare dans les climats froids.

Lorsqu'une belettc peut entrer dans un poulaillor, olle n'attaque pas les coqs ou les vieilles poules; elle choisit les pouleltes, les petits poussins, les tuc par une seule blessure qu'elle leur fait à la tête, et ensuite les emporte tous les uns après les autres; elle casse aussi les œufs et les suce avec une incroyable avidité. En hiver, elle demeute ordinairement dans les greniers, dans les granges; souvent même elle y reste au printemps pour y faire ses petits dans le foin ou la paille; pendant tout ce temps, elle fait la guerre, avec encore plus de succès que le chat, aux rats et aux somris, parce qu'ils ne peuvent lui ćchapper et qu'elle entre après eux dans leurs trous; elle grimpe aux colombiers, prend les pigeons, les moineaux, etc. En été, ello va à quolque distance des maisons, surtout dans les lieux bas autour des moulins, le long des ruissenux, des rivic̀res, se cache dans les buissons pour abtraper des oiseaux, et souvent s'établit dans le creux d'un vieux saule pour y faire ses petits; elle leur prépare un lit avec de l'herbe, de la paille, des feuilles, des ćtoupes ; elle met bas au printemps ; l’s portées sont quelquefois de trois, et ordinairement de quatre ou do 
cinq; les petits naissent les yeux fermés, anssi bien que ceux du putois, de la marte, de la fouine, etc., mais on peu de temps ils prennent assez d'accroissement et de force pour suivre leur mère à la chasse, elle attaque les couleuvres, les rats d'eau, les tampes, les mulots, etc., parcourt les prairies, dévore les cailles et leurs œufs. Elle ne marche jamais d'un pas égal, elle ne va qu'en bondissant par petits sauts inégaux et précipités, et lorsqu'elle veut monter sur un arbre, elle fait un bond par lequel elle s'élève tout d'un coup à plusieurs pieds dc hatuteur; elle bondit même lorsqu'elle veut attraper un oiseau.

Ces animaux ont, aussi bien que le putois et le furet, l'odeur si forte qu'on ne peut les garder dans une chambre habitée; ils sentent plus mauvais en été qu'en hiver, et lorsqu'on les poursuit ou qu'on les irrite, ils infectent de loin. Ils marchent toujours en silence, ne donnent Jamais de voix qu'on ne les frappe; ils ont un cri aigro et enroué qui exprime bien le ton de la colère.

\section{L'HERMINE OU LE ROSELET.}

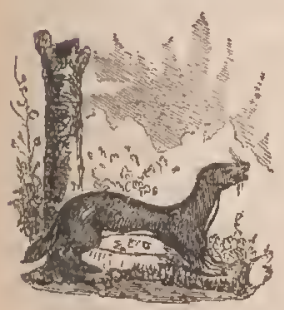

A belette à queue noire s'appelle hermine ou roselet : hermine lorsqu'elle est blanche, rosclet lor'squ'elle est rousse ou jaunâtre.

La peau de cet animal est précieuse: tout le monic connait les fonrures d'hermine; elles sont bien 
plus belles et d'un blanc plus mat que celles du lapin blanc; mais elles jaunissent avec lo temps, et même les hermincs de cc climat ont toujours une lćgère teinte jaune.

Les hermines sont très-communes dans tout le Nord, surtout en Russie, en Norwćge, en Laponie : elles y sont, comme ailleurs, rousses en été et blanches en hiver ; elles se nourrissent de pelits-gुris et d'une espèce de rat qui est très-abondantc cn Norivége et en Laponie; les hermines sont rares dans les pays tempérés, et ne se trouvent point dans les pays chauds.

\section{IA ZIBELINE.}

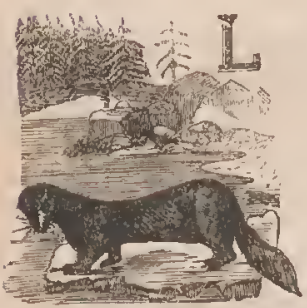

es zibclines habitent lc bord des fleuves, les lieux ombragés et les bois les plus épais; elles sautent très-agrilement d'arbre en arbre, et craignent fort le soleil, qui change, dit-on, cn très-peu do prétend qu'clles se cachent et qu'elles sont engourdies pendant l'hiver'; cependant c'est dans ce temps qu'ol' les chasse et qu'on les chcrclie de préférence, parce qư leur fourrurc est alor's bien plus belle et bien meilleur qu'en ćté; elle vivent de rats, de poisson, de graine de pin et de fruits sauvages; on les trouve principa" lement en Sibérie; il n'y en a que peu dans les forêts do 


\section{ANIMAUX SAUVAGIS.}

la Grandc-Russie, et encore moins en Lalnonic. Les zibelines les plus noires sont celles qui sont les plus estimées.

La chasse des zibelines se fait par des criminels confinés en Sibérie, ou jar les soldats cu'on y envoie exprès, et qui y demeurent ordinairement plusieur's annćes; les uns el les autros sont ojligés de fournir une certaine quantité de fourrures à laquelle ils sont taxés; il ne tir'ent qu'à balle seule pour gàter le moins qu'ili est possiblo la peau de ces animaux, el quelcucfois au lieu d'urmes ì feu ils se servent d'arbalètes et de très-petites flèchos.

\section{LE PEKAN ET LE VISON.}

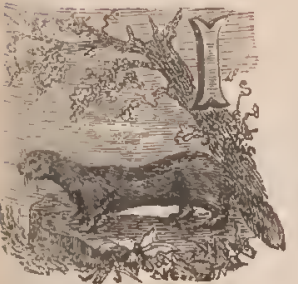

L y a longtemps que le nom rle pokan était en usage dans le commerce de la pelleteric du Canada, sans que l'on on connût mieux l'animal auquel il appartient en propre. Il en est du vison comme pekan : nous ignorons l'origine de ces deux nouns; nous savons seulement qu'ils appartiennent à deux animaux de l'Amérique septentrionale.

Le pekan ressemble à la marle, et le vison à la fouine. Ils ont la même forne de corps, les mêmes proportions, les mêmes longueurs de queuc, la même qualité de poil, le mòne nombre de dents et d'ongles, le mêne irstinct, 
les mêmes habitudes naturelles ; seulementils ont le poil plus brun, plus lustré et plus soyeux.

\section{LA LOUTRE.}

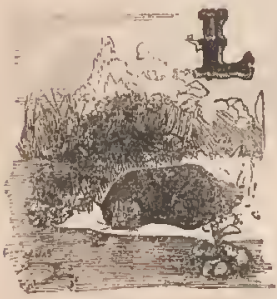

A loutrc est un animal vorace, plus avide de poisson que de ehair, qui ne quitte gucire le bord des rivières ou des laes, el qui dépeuple quelquefois les étangs; elle a plus de fieilité qu'un autre pour nager, plus mûme que le castor, car il n'a des membranes qu'aux pied's de derrière, et il a les doigts séparés dans les pieds de devant, tandis que la loutre a des membranes à tous les pieds; elle nage presque aussi vite qu'clle marche; elle no va point à la mer, comne lo castor, mais elle pareourt les eaux douees et remonte ou deseend les rivières à des distanees eonsidérables: souvent elle aage entre deux eaux et y demeure assez longtemps; elle vient ensuite à la surfaee, atin de resjirer.

A parler exaetement, elle n'est point animal amphibie, c'est-à-dire animal qui peut vivr'e également et dans l'air' et dans l'eau; elle n'est pas conformée pour demeurer' dans ee dernier élément, et elle a besoin de respirer à jeu près comme tous les autres animaux terrestres: si même il arrive yu'elle s'engage dans une nasse à la pout" stite d'un poisson, on la trouve noyćc, et l'on voit qu'elle 
n'a pas eu le temins d'en couper tous les osiers pour en sortir. Elle a les dents eomme la fouine, mais plus grosses ct plus fortes relativement au volume de son eorps. Faute de proisson, d'écrevisses, de grenouilles, de rats d'eau, ou d'autie nourriture, elle coupe les jeunes rameaux et mange l'écoree des arbres aquatiques; elle mange aussi de l'herbe nouvelle au jrintemps; elle ne craint pas plus le froid que l'lumidité; elle met bas au mois de mars; les portées sont de trois ou quatre. Ordinairement les jounes animaux sont jolis; les jeunes loutres sont plus laides que les vieilles. La tête mal faite, les oreilles placées bas, des yeux trop petils et couverts, l'air obseur, les mouvements gauches, toute la figure ignoble, informe, un eri qui paraît inachinal, et qu'elle répètent à tout moncut, sembloraient annoncer un animal stupidc; cependiant la loutre devient industrieuse avee l'àge, au moins assez pour faire la guerre avee graud avantage ax poissons, qui pour l'instinct et le sentiment sont trèsinférieurs aux autres animaux.

La loutre est, de son naturel, saurage et eruelle ; quand clle pent entrer dans un vivier, elle y fait ce que le jutois lait dans un poulaillor' elle tuo beaucoup plus de poissons yu'elle ne peut en manger', et ensuite elle en emportc un dans sa gueule.

Lẻ poil do loutre ne mue guère; sa penu d'hiver est ceprendant plus brune el se vent plus eher que celle d'ćté; elle fait une très-bonne fourrure. Sa elıair se manģe en maigle et a, en effet, un mauvais goùt de poisson, ou plulòt de marais. Sa retraile est infectée de la matvaise

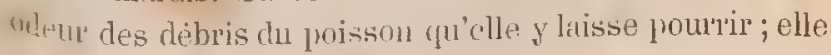
sent elle-môme assez nauvais: les chiens les chassent 
volontiers et l'attcignent aisément, lor'squ'cllo ost éloignć de son gîte et de l'eau ; mais quand ils la saisissent, elle se défend, les mord cruellement, et quelquefois avod tant de force et d'acharnement qu'clle leur brise les os des jambes, et qu'il faut la tuer pour la faile démordre. Le castor ecpendant, qui n'est pas un animal hien fort, chisse la loutre et ne lui permet pas d'habiter sur les bords qu'il fréquente.

Cette ospèce, sans être en très-grrand nombre, est généralement répandue en Europe, depuis la Suède jusqu'à Naples, et so r'etrouve dans l'Amérique septentrionale.

\section{LE LOUP.}

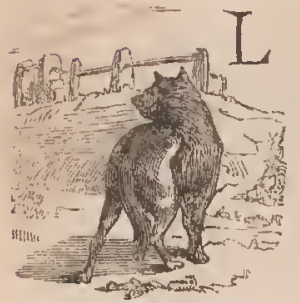

E loup est naturellement grossier et poltron, mais il devient ingénieux par besoin, ot hardi par nćcessilé; pressć par la famine, il brave le dlanger, il vient attaquer les animatix qui sont sous la garde de l'homme, ceux surtout qu'il peut emporter aisćment, comme les agneaux, les petits chiens, les chevrcaux; et lorsque colte maraude lui réussit, il levicnt souvent à la charge, jusqu'à ce qu'ayant été blessé ou chnssé et maltraité pal' les hommes et les chiens, il se recèle pendant le jour dans son fort, n'en sort que la nuit, parcourt la campague, ròde autour des habitations, ravit les animaux abando: ${ }^{*}$ 
nés, vient allaquer les bergories, et creuse la terre sous les porles, entre furieux, met tout ì mort avant de choisir el d'emporler sa proie. Lorsque ces courses ne lui frorluisent rien, il retourne au fond des bois, se met en quête, cherche, suit à là piste, chasse, poursuit les ınimaux sturages dans l'espérance qu'un autre loup pour'ra les atriter, los saisir dans lenr fuite, et qu'ils on parta-

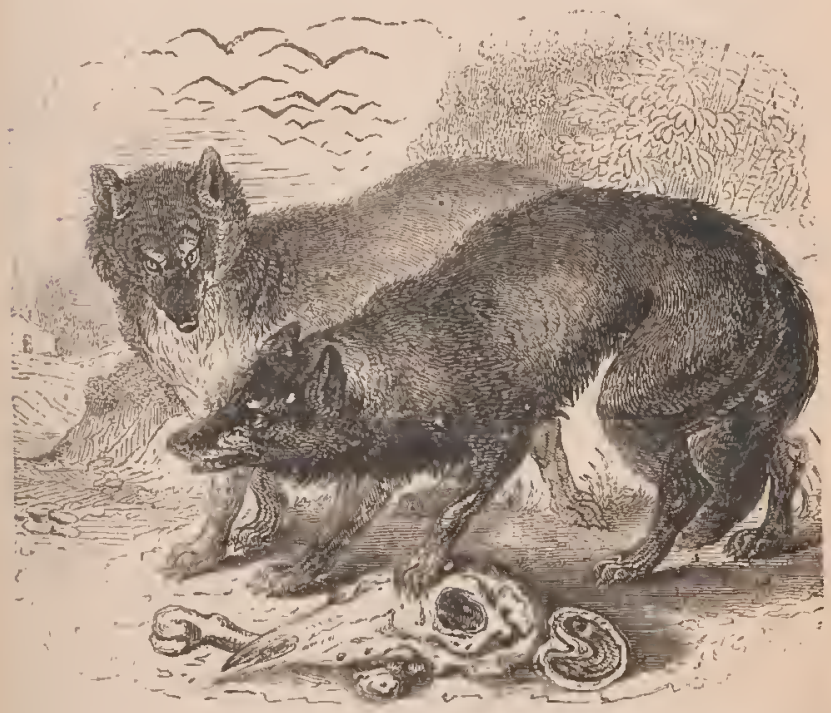

Gerout la dépouille. Enfin, lor'sque le besoin est cxtrếme, il s'expose à tout, attaque les femmes et les enfants, mêmo se jette quelquefois sur les hommes.

Le loup, tant à l'extérieur qu'à l'intérieur, ressemble si for' au chicn, qu'il paraît modelć sur la môme forme; 
eependant il n'offre tout au plus que le rever's de l'empreinte, etne présente les mêmes earaetères que sous une faee entièrement opposée : si la forme est semblable, ce qui en r'ésulte est bien eontraire; le naturel est si différent que, non-seulement ils sont ineompatibles, mais antipathiques par nature, ennemis par instinet. Si le loup est le plus fort', il déehire, il dévore sa proie; le ehien au contraire, plus généreux, se eontente de la vieloire; il l'abandonne pour servir de pâlure aux eorbeaux, et mème aux autres loups; ear ils s'entre-dévorent, et lorsqu'un loup est grièvenent blessé, les áutres le suivent au sang, et s'altroupent pour l'achever.

Le elien, même sauvage, n'est pas d'un naturel farouehe; il s'apprivoise aisément, s'altaehe el demeure fidèle à son maître. Le loup, pris jeune, se prive, mais ne s'attache point; la nature est plus forte que l'údueation; il reprend avee l'âge son earactère füroee, et relourne, dès qu'il le peut, à son état sauvagge. Les ehiens, mêmu les plus grossiers, elierchent la compagnie des autres animaux; ils sont naturellement portès à les suivr'c, à les aecompagner, ct e'est par instinct seul el non par édueation cju'ils savent eonduire et grarder les troupeaux. Le loup est, au contraire, l'ennemi de toule soeiété, il ne fait pas mème eompagnie à eeux de son espèce; lorsqu'on les voit plusieurs ensemble, ce n'est point une soeiété de paix, c'est un altroupenent de guer.e, qui se fait à grand bruit, avee des liurlements affreux, et qui dénote ul projet d'attaquer quelque gros unimal eomme un cerl", un bocuf, ou de se dófaire de quel ¿̨ue redoul le mâtir. Dès que leur expédition militairo est eonsommée, ils st' séprarcul et relournent en silence à leur solitude. 
Il n'y a pas de races intermédiaires entre lo chicn et lo loup; ils sont d'un naturel tout opposé, d'un tempérament différent.

Lor'sque les louves sont prêtes à mettre bns, elles cherchent au fond du bois un fort, un endroit Jjien fourré an milieu duquel ellcs aplanissent un cspace assez considéralule en coupant, en arrachant les épines avec les dents ; elles y apportent ensuite une grande quantitć de mousse, et préparent un lit commode pour leurs petits. Elles cn font ordinairement cinq ou six, quelquefois sept, huit et même neuf, et jamais moins de trois; ils naisscnt les yeux fermés comme les chiens; la mère les allaite pondant quelques semaines et leur apprend bientôt à manger de la chair qu'elle leur prépare en la mîchant. Quel(que temps après elle leur apporte des mulots, des levrauts, des perIrix, des volailles vivantes; les louveteaux commencent lar jouer avec elles et finissent par les étrangler ; la louve ensuitc les déplume, los écorche, les déchure et en donnc une part à chacun. lls nc sortent du fort où ils ont pris naissance qu'au bout de six scmaines ou deux mois; ils suivent alors leur mère qui les mène boire dans quelque trone d'arbre ou quelque mare voisine; elle les ramène iu gite on les oblige à se recéler ailleur's, lor'squ'clle craint quelque danger. Ils la suivent ainsi pendant plusieurs mois. Quand on les attaque elle les défond de toutes ses forces, et mêne avec fureur, quoique dans los autres temps elle soit, comme toutes los femelles, plus timide que lc mâle.

Ces animaux, qui sont deux ou trois ans à croître, vivent quinze ou vingtans. Les loups blanchissent dans la vieillesse; ilś ont alors tontes los dents usées. Ils dorment lors- 
qu'ils sont massasićs ou latigućs, mais plus le jour que la nuit, et toujour's d'un sommeil légel ; ils boirent fréquenment, et dans les temps de sécheresse, lorsqu'il n'y a point d'eau dans les ornières ou dans les vieux trones d'arlures, ils viennent plus d'une fois par joul' aux mares et aux rnisseaux. Quoique très-voraces ils supportent aisément la diète; ils peuvent passer quatre ou cinq jours sans manger, pourvu qu'ils ne manquent pas d'enu.

Le loup a beaucoup de foree, surtout dans les partics antérieures du corps, dans les museles du cou et de li mâchoire. Il porte avee sa gueule un mouton sans le laj:ser toueher à terre, et court en même temps plus vite que les hergers; en sorte qu'il n'y a que les ehiens qui puissent l'alteindre et lui faire làcher prise. Il mord erticllement, et toujours avee d'autant plus d'acharnement qu'on lui résiste moins; car il prend des précautions avec les animaux qui peuvent se défendre. Il eraint pour lui et ne se bat que par nécessité, et jamais par un mouvement de courage: lorsqu'on le tire et que lit balle lui casso quelque membre, il crie, et cependant lorsqu'on l'achève à coups de bâton il ne se plaint pas eomme le ehien ; il est plus dur, moins sensible, plus robuste; il marche, court, rôde des jour's entier's et des nuits; il est infatignble, et c'est peut-être de tous les animaux le plus diffeilo à for'cer à la eourse. Le ehien est doux et courageux; le loup, quoique fóroce, est timide. Lorsqu'il tornbe dans un piége; il est si fort et si longtemps épouvanté qu'ou peut ou le tuer sans qu'il se défende, ou le pr'endre vivant sal.s qu'il résiste; on peut lui mettre un collier, l'enchâner', le museler, le conduire ensuite jartout où l'on veut salıs qu'il ose donner le moinul'e signe de colère ou mène de 
méconlentement. Le loup a les sens tris-bons, l'wil, l'oreille et surtout l'odorat; il sent sourent de plus loin qu'il ne voit; l'odem du carnage l'uttire de plus d'une lieue; il sent aussi de loin les animiux vivants, il les chasse móne assez longtemps en les suivant aux porties. Lorsqu'il reut surtir hu bois, janais al ne manque do prendre le vent; il s'arrèto sur la lisière, évente de tous côtés, at recoit ainsi les émanations des corjs morts ou vivants que le vent lui apporte de loin. Il prófère la chair vivante it la chair ınortc, et cependant il dévore les voiries les julus infoctos; il aime la chlair lumaine, et, peut-ôtre, s'il était lo plus fort, n'en mnangerait-il pas d'autre. On a vu des loups suivre do loin les armées, arriver en nombre ì des champs de Lataille où l'on n'avait enterré que négligermmont les corps, les découvrir, les dévorer avcc une insatiable avidité; et ces rrêmes loups, accoutumés à la chair liumaine, se jeter ensuite sur les hommos, attaquer le lerger plutòt quo lo troupeau, dévorer des fommes, emporter des enfunts, ctc. L'on a appelé ces mauvais loups loups-garous, c'est-à-dire loups dont il faut se garrer.

On est done obligé cluclquofois d'armer tout un pays pour se defiare des loups.

Dans les campagnes, on fuit des battues à for'ce d'loonmes et de mâtins, on tend des piéges, on présente des appàts, on fuit des fosses, on l'épand des boulettes ompoisonnées; tout cola n'ompèche pas que ces animuux ne soient toujours en mème nombre, surtout dans les pays où il y a beaucoup de bois.

La couleur et le poil de cos aninnaux changent suivant les différents climats, et varient.quelquefois dans le même pays. On trouve en France et en Allemagne, outre les 
lnups ordinaires, quelques loups ì pril plıss épais et tirant sur le jaune. Ces loups, plus sauvages et moins nuisiblos que les autres, n'approchent jannais ni des maisons ni des troupeaux, el ne vivent que de chasse et non pas de rapine. 'Dans les jays du Nord, on en trouve de tout blanes et de tout noirs; ces derniers sont plus grands et plus forts que les autres. L'espèce commune est très-généralement répandue. En Orient, et surtout en Perse, on fait servir les loups à des spectacles pour le peuple ; on les cxerce le jeunesse à li danse, on plutôt à une espèce de lutte contre un grand nombro d'hommes. On achète jusqu'i rinq cents ńcus mn loup bien dressé à la danse. Ce fait prouve au moins qu'c̀ forec de temps et de contrainte ces animaux sont susecptibles de (quelque espèce d'éducation. Tant qu'ils sont jeunes, c'est-ì-dire dans la première et la seconde annéc, ils sont assez dociles; ils sont même caressants; et, s'ils sont bien nourris, ils ne se jettent ni sur la volaille, ni sur les autres animaux; mais à dixluit mois ou deux ans ils reviennent à leur naturcl; on est forcé de les enchâner pour les empêcher de s'enfuir et de faire du mal.

Il n'y a rien de bon dans cet animal que sa peau; on en fait des fourrures grossières, qui sont chaudes et durables. Sa chair est si mauvaise qu'elle répugne à tous les animaux, et il n'y a que le loup qui mange volontiers dı loup. Il exhale une odcur infecte par la gueule. Enfin, désagréable en tout, la mine basse, l'aspect snuvage, li voix effrayante, l'odeur insupportable, le naturel pervers, les mœurs f́ćroces, il est odieux, nuisible de son vivant, inutile après sa mort. 


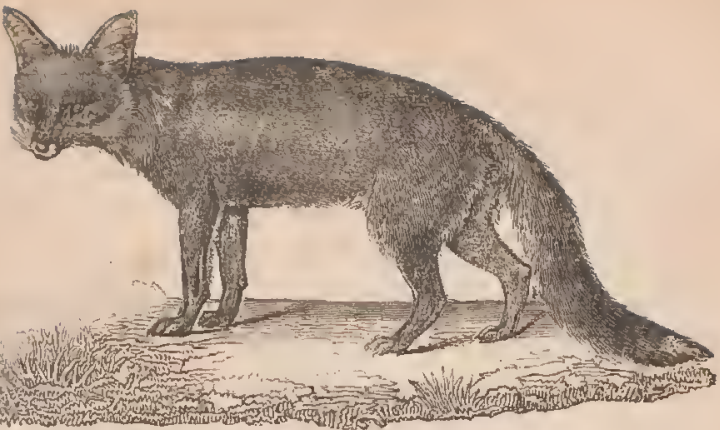

\section{LE RENARD.}

I.e renard est fameux par ses ruses, et mérite en partie sa réputation; ce que le loup ne fait que par la force, il le fait par adresse, et rćussit plus souvent.

Fin autant que circonspect, ingénieux et prudent, même jusqu'à la patience, il varie sa conduite, il a des moyens de réserve qu'il sait n'employer qu'à propos. Il veille de près à sa conscrvation; quoique aussi infatiEable, et même plus léger que le loup, il ne se fie pas entièrement à la vitesse de sa course; il sait se mettre en sûreté en se pratiquant un asile oùil se retire dans les dangers pressants, où il s'établit, où il élève ses petits . il n'est point animal vagabond, mais animal domicilié.

Le renard tourne tout à son profit ; il se loge au bord des bois, à portée des hameaux; il écoute le champ des coqs et le cri des volailles; ll les savoure de loin; il prend habilement son temps, cache son dessein et sa marche, 
se glisse, se traine, arrive, et fait rarement des tentatives inutiles. S'il peut franehir les elôtures, ou passer par-dessous, il ne perd pas un instant; il ravage lit basse-cour, ily met tout à mort, se retire ensuite lestement en emportant sa proie, qu'il eache sous la mousse, ou porte à son terrier ; il revient quelques moments après en chercher une autre, qu'il cmporte et cache de mène, mais dans un autre endroit, ensuite une troisicme, une quatric̀me, elc., jusqu't̀ ce que le jour ou le nouvement dans la maison l'avertisse qu'il fuut se retirer et ne plus revenir. Il fait la mème manouvre dans les pipées et dans les boqueteaux où l'on prend les grives et les béeasses au laect; il devanee le piqueur, va de très-grand matin, et souvent plus d'une fois par jour, visiter les lacets, les gluaux, emporte successivement les oisenux qui se sont empêtı'és, les dépose tous en différents endroits, surtout au bor des ehemins, dans les ornicres, sous de la mousse, sols un genièvre, les y laisse quelquefois deux ou trois jour's, et sait parfaitement les I'etrouver au bosoin. 11 chasse les jeunes levrauts en plaine, saisit quelquefois les lièvres at gîte, ne les manque jamais lor'squ'ils sont blessés, déterre les lapereaux dans les garennes, découvre les nids de perdrix, de eailles, prend la nıère sur les œufs, et détruit une quantité prodigieuse de gibier.

Pour délruire les renards, il est plus commode de tendre des piéges, où l'on met de la cliair pour appàt, ull pigeon, une volaille vivante, ete. Le renard est aussi vorace que carnassier; il mange de loutavee une égale avidité, des œufs, du lait, du fronagee, des fruits, et sul'tout des raisins: lorsque les levrauls et les perdrix lıi. manquent, il se rabat sur les rats, lesinulols, les ser'pents, 
les lézards, les erapauds, ete., il en clétruit un grand nombre: e'est là le seul bien qu'il proeure. Il est trèsavide de rniel; il attaque les abeilles sauva geses, les guêpes, les frelons, qui d'abord tiiehent de le mettre en fuite, en le perçant de mille eoups d'aiguillon ; il se retire, en effel, mais e'est en se roulant pour les éeraser, il revient si souvent à la charge qu'il les oblige à abandonner le guêjier; alors il le déterre et en mange et le niel et la cire. Il prend aussi les hérissons, les roulc avee ses pieds, et les foree ù s'étendre. Enfin il mange du poisscn, des éerevisses, des hannetons, des sautcrelles, ete.

Le renard a les sens aussi bons que le loup, le sentiment plus fin, et l'organe de la voix plus souple et plus perfait.

Son glapissement est une espèce d'aboiement qui se fait par des sons scmblubles et très-précipités. C'est ordinail'einent à la fin du glapissenent qu'il donne un eoup de voix jlus fort, plus élevé, et semblable au eri du paon. En hiver, surtout pendant la neige et la gelće, il ne eesse de donner de la voix, et il est uu eontraire presque nuet en étć. C'est dins eette saison que son poil tombe et se renouvelle; l'on fait peu de eas de la peau des jeunes renards, ou des renards pris en été. La ehair du renar'd est moins mauvaise que eelle du loup; les ehiens et même les lommes en mangent ell automme, surtout lorsqu'il s'est nourri et engraissé de raisins, el sa peau d'hiver fait le bonnes fourrures. Il a le sommeil profond, on l'approche aisément sans l'éveiller: lorsqu'il dort, il se met en rond cornme les ehiens ; inais lor's (u'il ne fait que se r'eposer, il étend los jambes de derricire ot demeure étendu sur le ventre c'est dans eetle posture qu'il épic les oiseaux 
lo long des haies. Ils ont pour lui une si grande antipathie que, dès qu'ils l'aperçoivent, ils font un petit cri d'avertissement : les geais, les merles surtout, le conduisent du haut des arbres, répètent souvent le petit cri d'avis, et lo suivent quelquefois à plus de deux ou trois cents pas.

\section{LE CIIACAL OU ADIVE.}

Quoique l'espèce dı loup soit fort voisine de celle dı chien, celle du chacal ne laisse pas de trouver place entre les deux. Le chacal ou adive est bête entre loup et chien; avec la férocité du loup, il a, en effet, un peu de la familiarité du chien; sa voix est un hurlement mêlé d'aboiement et de gémissements; il est plus criard que le chien, plı̄ vorace que le loup; il ne va jamais senl, mais toujours par troupes de vingt, trente ou quarante; ils se rassemblent chaque jour pour faire la guerre et la chasse; ils vivent de petits animaux, ot se font redouter des plus puissants par le nombre. Ils attaquent toute espèce de hétail ou de volailles prosque à la vue des hommes; ils entrent inso. lemment et sans marquer de crainte dans les bergeries, les étables, les écuries, et lorsqu'ils n'y trouvent pas autre chose, ils dévorent le cuir, des han'nais, des botles, dos soulier's, etemportent des lanières qu'ils n'ont pas le temps d'avaler. Faute de proie vivante, ils déterrent les cadavres des animanx et des hommes; on est obligé de batlip la terre sur les sépultures, el l'y mếler de grosses épines 
pour les empêcher de la grıatter el fouir, car une épaisseur de quelques pieds de terre ne sulfit pas pour les rehuter ; ils travaillent plusieur's ensemble, ils accompagrnent de cris lugubres cette exhumation, et lorsqu'ils sont une fois accoutumés aux cadavres humains, ils ne cessent de courir les cimetières, de suivre les arınées, do

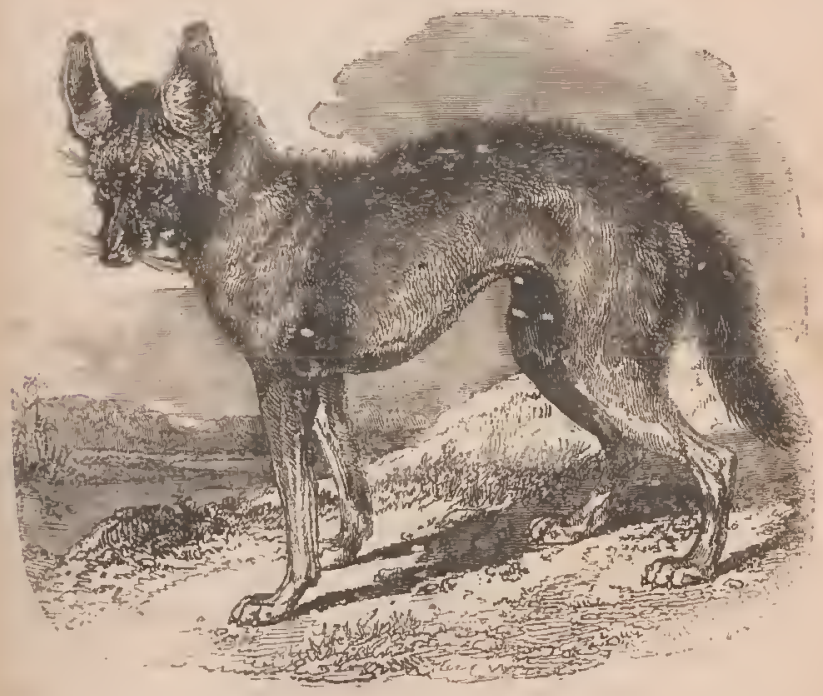

S'attacher aux caravilles: ce sont les corbeaux des quildrupèdes ; la chair la plus infecte ne les dégoùte pas ; lour appétil esi si constant, si véliément, que le cuir le plus sec est encore savoureux, et que toute peitu, toute graisse lur est également borme. Tous les voyageur's se plaignent des cris, des vols et des excès du chacul, yui r'ćunit l'im- 
pudence du clien à la bassesse du loup, et qui, participant de la nature des deux, semble n'être qu'un odieux composé de toulos les mauvaises qualités de l'un et do l'autre.

\section{LA GIVETTE RT LE ZIBET.}

Il y a un auimal qu'on appelle lia genetle, qui est taché de même, qui a la tôte à peu près de là mône forme et qui porte, comne la civette, un sac dans loquel se filtre une lumeur odolunte. Mais la grenetle est plus petite que nos civettes; elle a les jambes beaucoup plus courtes et lo col'ps bien mince; son parfum est très-faible et de peu de durée : au contraire, le parfuin des civettes est trísfort ; celui du zilset est d'une violence extrême et plus vif encore que celui do la civette. Ces liqueurs odorantes sont une limeur épaisse, d'une consistance scmblable à celle des pommades, et dont lo parfum, quoique très-lort, est agrćable au sortir même du corps de l'animal. Il ne fiaut pas confondre cette matiòre des civettes avec le inuse, qui est une humeur' sanguinolente qu'on tire d'un animal tout different de la civette ou du zibet; cet animal, qui produit le musc, est une esprèce de chevreuil sans bois, oll de ehèvre sans cornes, qui n'a rien de commun avec les civeltes que de fournir comme elles un parfum violent.

Les civettes (c'est-à-dire la civette et le zibet) sont des animaux dos climats les plus cliauds de l'ancien continent, qui n'ont pu passer par le Nord pour allor dans le nou- 


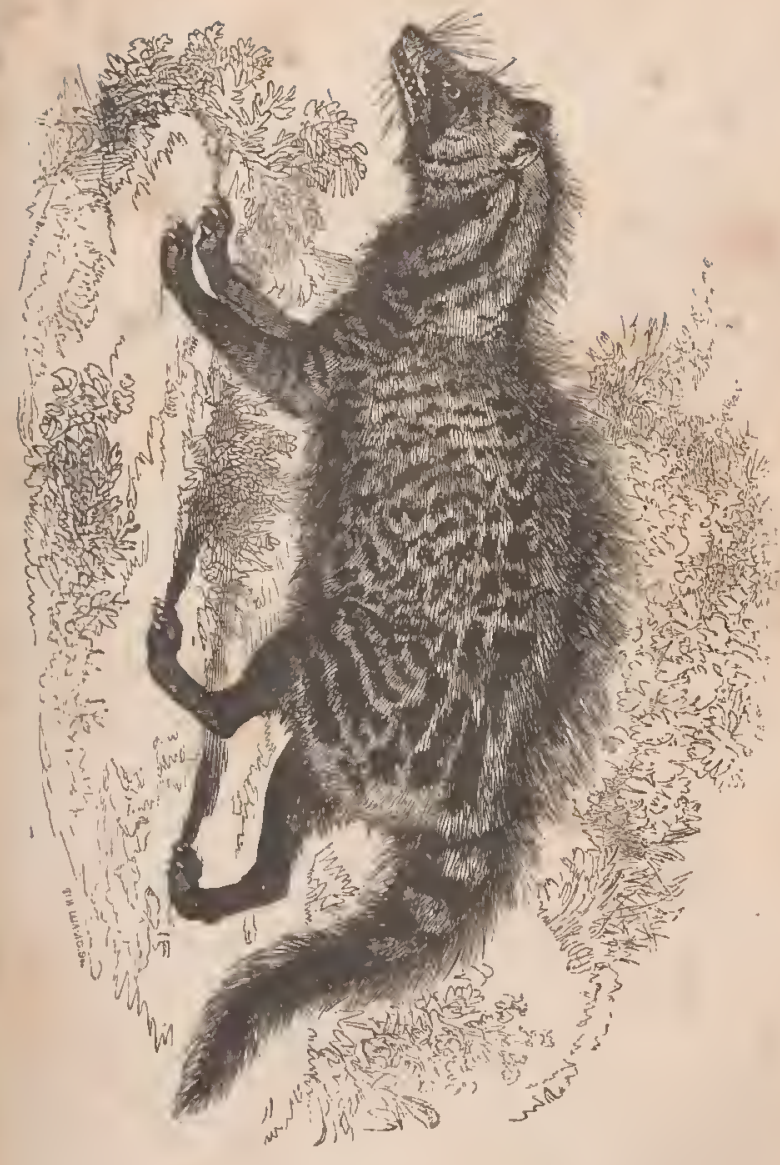



veau, ct dans le fait il n'y a jamais eu en Amérique d'autres civetles que celles qui y ont été transportées des îles Philippines et des côtes de l'Afrique; mais, quoique oriGinaires et natives des climats les plus chauds de l'Afrique et de l'Asie, elle peuvent cependant vivre dans les Dàss tempérés et même froids, pourvu qu'on les défende âee soin des injures de l'air et qu'on leur donne des aliments sucoulents et choisis; on cn nourrit un assez grand Iombre en Ilollande, où l'on fait commerce de leur parflun. La civelte faite à Amstcrdam est préférée par nos Cornmereants à celle qui vient du Levant ou des Indes, Tui est ordinairement moins pure; eelle qu'on tire de Guinée serait la meilleure de toutes, si les Nògres, ainsi "Yue les Indiens et les Levantins, ne la falsifiaient en y Inêlant des sues végétaux, comme du ladanum, du storax et d'autres drogues balsamiques et odoriférantes. Pour 'echeillir' ce parfum, ils mettent l'animal dans une cage étroite où il ne peut se tourner; ils ouvrent la cage par le bout, tirent l'animal par la queue, le contraignent à demeurcr dans celte situation en mettant un bâton à travers les barreaux de la cage, au moyen duquel ils lui fônent les jambes de derrière ; ensuite ils font cntrer une Velite cuiller dans le sac qui contient le parfum, ils raclent ${ }^{a} \mathrm{vec}_{\mathrm{e}}$ soin toutes les parois intérieures de ce sac, etmetlent la matic̀re qu'ils en retirent dans un vase qu'ils coubent avec soin. Cette opération se répète deux ou trois fois par semaine: la quantité de l'humeur odorante dé-

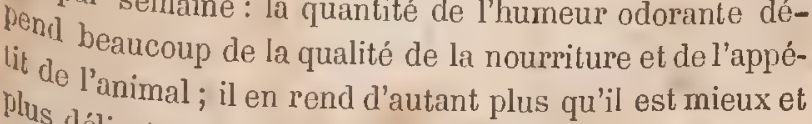
olus animal; il en rend drautant plus qu'il est mieux et délicatement nourri.

Le parfum de ces animaux est si fort, qu'il se commu- 
nique à toutes les parties de leur corps : le poil en est imbu, et la peau pénétrée au point que l'odeur s'en conserve longtemps après leur mort, et que de leur vivant l'on ne peut en soutenir la violenee, surtout si l'on est enfermé dans le même lieu.

Les civettes sont naturellement farouches, et même un peu fóroees; eependant on los apprivoise aisément, au moins 'assez pour les approcher et les maniel' sans grand danger : elles ont les dents fortes et tranchantes, mais leurs ongles sont faibles et émoussés ; elles sont agiles et même légères, quoique leur eorps soit assez. épais; elles sautent comme les ehats, et peuvent aussi courir eomme les ehiens; elles vivent de chasse, sulprennent et poursuivent les petits animaux, les oiseaux; elles cherchent, eomme les renards, à entrer dans les basses-eours pour emporter leurs volailles; leurs youx brillent la nuit, et il est à eroire qu'elles voient dans l'obseurité.

\section{LA GENETTE.}

La genette ost un plus petit animal que les eivettes; elle a le eorps allongé, les jambes courtes, le museall pointu, la tête effilée, le poil doux ct mollet, d'un gri ris $^{\text {s }}$ eendré, brillant êt marqué de taches noires, rondes et séparées sur les eôtés du corps, mais qui se réunissent de si près sur la partic du dos qu'elles paraissent former des bandes noires eontinues qui s'étendent tout le lon 10 ? du eorps; elle a aussi sur le eou et le long de l'épine dil 
dos unc espèce de crinière ou de poil plus long, qui forme une hande noire et continue depuis la tête jusqu'ì la queue, laquelle est aussi longue que le eorps, et marquée de sept ou huit anneaux alternativement noirs et blanes sur toute sa longueur; les taches noires du cou sont en forme de bandes, et l'on voit au-dessous de chaque oeil une marque blanche très-apparente. La genette a sous la queue, et dans le même endroit que les civettes, une Ouverture ou sac dans lequel se filtre une espèce de parfunr, mais faible et dont l'odeur ne se conserve pas : elle est un peu plus grande que la fouine, qui lui ressemble beaucoup par la forme du corps aussi bien que par le naturel et par les habitudes; seulement il parait 'qu'on apprrivoise la genette plus aisément. Le nom de genclle ne vient point des langues anciennes, et n'est probablement qu'un nom nouveau pris de quelque lieu Plañić de genêt, qui, comme l'on sait, est fort commun en Espagne. Les naturalistes prétendent que la genette n'habite que dans les endrorts humides et le long des ruisscaux, et qu'on ne la trouve ni sur les montagnes ni dans les terres arides. L'espèce n'en est pas nombreuse, du moins elle n'est pas fort rópandue; il n'y en a point en France ni dans aucune autre province de l'Europe, à l'exception de l'Espagne et de la Turquie. Il lui faut done un climat chaud pour subsister et sc multiplier; néanmoins il ne paraît pas qu'elle se trouve dans les pays les plus ehauds de l'Afrique et des Indes.

La peau de cet animal fait une fourrure légère et très. jolie : les manchons de grenette ont été fort à la mode et se vendaient fort cher. 


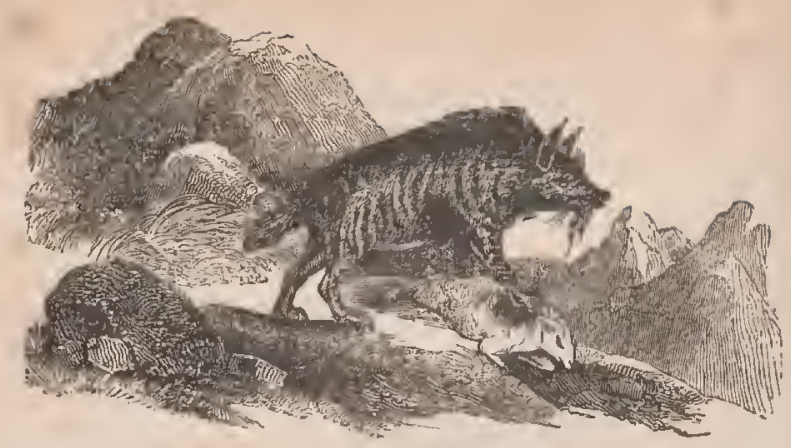

\section{L'IIYÉNE.}

Cet animal sauvage et solitaire demeure dans lea cavcrnes des montrignes, dans les fentes des rocher's ou dans des tanières qu'il se creuse lui-même sous terre: il est d'un naturel féroce, ct, quoique pris tout petit, il ne s'apprivoise pas; il vit de proic commc le loup, mais il cst plus fort et parait plus hardi. Il attaque quelquefois les lommes, il se jette sur le bétail, suit de près les troupeaux et souvent rompt dans la nuit les portes des ćtables et les clôtures des bergeries : ses yeux brillent dans l'obscurité, et l'on prétend qu'il voit mieux la nuil que le jour. Si l'on en croit tous les naturalistes, son $\mathrm{cl}^{\mathrm{i}}$ ressemblc aux sanglots d'un homme qui vomirait avec effort, ou plutôt au mugissement du veau.

L'hyène se dćfend du lion, ne craint pas la panthère, - attaque l'once, laquelle ne peut lui résister. Lorsque la proie lui manque, elle creuse la terre avec les pieds et en tire par lambeaux les cadavres des animaux et des hommes que, dans le pays qu'elle habite, on enter'⿳0 



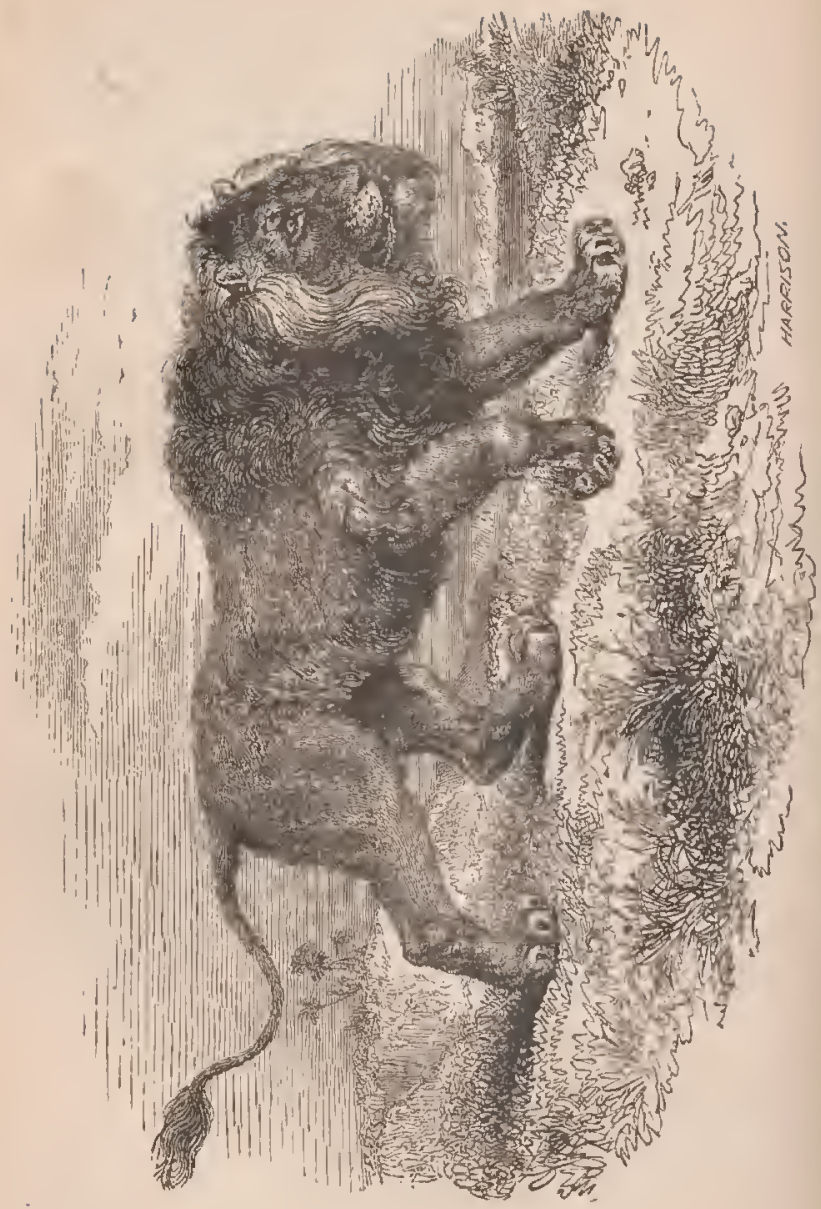


également dans les champs. On la trouve dans presque tous les climats chauds de l'Afrique et de l'Asie.

Il y a peu d'animaux sur lesquels on ait fait autant d'histoires absurdes que sur celui-ci. On a dit qu'il savait imiter la voix humaine, retenir le nom des bergers, les appeler, les charmer, les arrêter, les rendre immobiles; faire en même temps courir les bergères et leur faire oublier leur troupeau, etc.

\section{LE LION.}

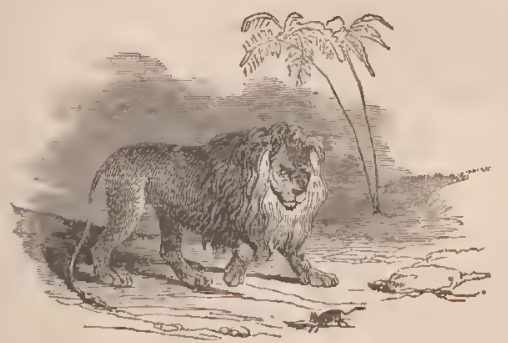

L'extérieur du lion ne dément point ses grandes qualités intérieures; il a la figure imposante, le regard assuré, la démarche fière, la voix terrible. Sa taille n'est point excessive comme celle de l'éléphant ou du rhinocéros; elle n'est ni lour'de comme celle de l'hippopotame ou du boeuf, ni trop ramassée comme celle de l'hyène ou de l'ours, ni trop allongée ni déformée par des inégalités comme celle du chameau; mais elle est, au contraire, si bien prise et si bien proportionnée que le corps du lion paraît être le modèle de la force jointe à l'agilité. Aussi solide que nerveux, n'étant chargé ni de chair ni de graisse, et no contenani ricn de surabondant, il est tout 
nerf et muscle. Celte grande force musculaire sc marque au dehors par les sauts et les bonds prodigieux que le lion fait aisément, par le mouvement brusque de sa queue qui est assez fort pour terrasser un homme, par la facilité avec lacjuclle il fait mouvoir la peau de sa faco et surtout colle de son front, ce qui ajoute beaucoup à la physionomic ou plutôt à l'expression de la fureur, ct enfin par la faculté qu'il a de remuer sa crinière, laquclle non-sculement se hérisse, nais se meut et s'agsite en tous sens, lorsqu'il est en colère.

La liome mot bas au printemps et ne produit qu'une fois tous les ans : ce qui indique encore qu'elle est occujée pendant plusieur's mois à soignner et allaiter ses petits, et que par consćcfuent le temps de lcur premier accroisscment, pendant lequel ils ont besoin des secour's de la mère, est au moins de quclques mois.

Dans ces animaux, toutes les passions, même les plus douces, sont excessives, et l'amour maternol est extrême. La lionne, naturellement moins forte, moins courageuse ct plus tranquille que le lion, devient terrible dès qu'elle a des petits; elle se montre alors avec encorc plus de lıardiesse que le lion, elle ne connaît point lo danger, elle se jette indifféremment sur les hommes et sur les animaux qu'elle rencontre, elle les met à mort, se charge ensuite de sa proie, la porte et la partage à ses lionceaux, auxquels elle apprend de bonne heurc à sucer le sang' et à déchirer la chair. D'ol'dinairc elle met bas dans des lieux très-écartés et de difficile accès, et lorsqu'elle craint d'être découverte, ellc cache ses traces en retournant plusieurs fois sur ses pas, ou bien elle les efface avec sa queue; quelqucfois mêne. lorsquo 
l'inquiétude est grande, elle transporte ailleurs ses pelits, et quand on veut les lui enlever, elle devient furieuse et les défend jusqu'à la dernière extrémité.

On eroit que le lion n'a pas l'odorat aussi parfait ni les yeux aussi bons que la plupart des autres animaux de proie : on a remarqué que la grande lumière du soleil paraît l'ineommoder, qu'il marehe rarement dans le milieu du jour, que e'est pendant la nuit qu'il fait toutes ses eour'ses, que, quand il voit des feux allumés autour des troupeaux, il n'en approehe guère, ete. On a observé qu'il n'évente pas de loin l'odeur des autres animaux, qu'il ne les ehasse qu'à vue et non pas en les suivant à la jiste, eomme font les ehiens et les loups, dont l'odorat est plus tin. On a même donné le nom de guide ou de pourvoyeur du lion à une espèce de lynx auquel on supjose la vue perçante et l'odorat exquis, et on prétend que ee lynx aecompagne ou précède toujours le lion pour lui indiquer sa proie.

Le lion, lor'squ'il a faim, attaque de faec tous les animaux qui se présentent; mais eomme il ost tròs-redouté, et que tous cherchent à éviter sa reneontre, il est souvent obligé de se eaeher et de les attendre au passage; il se tapit sur le ventre dans un endroit fourré, d'où il s'élanee avee tant de foree qu'il les saisit souvent du premier bond. Dans les déserts et les forêts, sa nourriture la plus ordinaire sont les gazelles et les singes, quoiqu'il ne prenne eeux-ci que lorsqu'ils sont à terre, car il ne grimpe pas sur les arbres eomme le tigre ou le puma; il mange beaucoup à la fois et se remplit pour deux ou trois jour's; il a les dents si fortes qu'il brise aisément les os et il les avale avee la chair. On prétend 
qu'il supporte longtemps la faim; comme son tempérament est excessivcment chaud, il supporte moins patiemment la soif, et boit toutes les fois qu'il peut trouver de l'eau; il prend l'eau en lapant comme un chien, mais au lieu que la langue du chien se courbe en dessus pour laper, celle du lion se courbe en dessous, ce qui fait qu'il est longtemps à boire et qu'il perd beaucoup d'eau. Il lui faut environ quinze livres de chair crue chaque jour; il préfère la chair des animaux vivants, de ceux surtout qu'il vient d'égorgere'; quoique d'ordinaire il se nourrisse de chair fraiche, son haleine est très-forte.

Le rugissement du lion est si fort que, quand il se fait entendre par éehos, la nuit dans les déserts, il ressemble au bruit du tonnerre; ce rugissement est sa voix ordinaire, car quand il est en colìe il a un autre cri, qui est court et réitéré subitement, au lieu que le rugissement est un cri prolongé, une espèce de grondement d'un ton grave, mêlé d'un frémissement plus aiğu : il rugit cinq ou six fois parjour, ot plus souvent lor'squ'il doit tomber de la pluie. Lc cri qu'il fait lorsqu'il ost en colère est encore plus terrible que le rugissement: alors il se bat les flancs de sa queue, il en bat la terre, il agite sa crinière, fait mouvoir la peau do sa face, remue ses gros sourcils, montro des dents menaçantes, et tire une langue armée de pointes si dures, qu'ellc suffit seule pour éeorcher la peau et entamer la chair sans le secours des dents ni des ongles, qui sont, après les dents, ses armes les plus cruelles. Il est beaucoup plus fort par la tête, les mâchoires et les jambes de devant, que par les parties postérieures du corps; il voit la nuit, comne les chats; il ne dort pas longtemps, et s'éveille aisément; 
mais c'est mal à propos que l'on a prétendu qu'il dormait les yeux ouverts.

La démarche ordinaire du lion est fière, grave et lente, quoique toujours ol,lique; sa eourse ne se fait pas par des mouvements égaux, mais par sauts et par bonds, et ses mouvements sont si brusques qu'il ne peut s'arrêter à l'instant et qu'il passe presque toujour's son but. Lorsqu'il saute sur sa proie, il fait un bond de douze ou quinze pieds, tombe dessus, la saisit avee les pattes de devant, la déchire avee les ongles et ensuite la dévore avee les dents. Tant qu'il est jeuno et qu'il a de la légèreté, il vit du produit de sa ehasse, et quitte rarement ses déserts et ses forêts où il trouve assez d'animaux sauvages poul' subsister aisément; mais lorsqu'il devient vieux, pesant et moins propre à l'exereiee cle la cliasse, il s'approehe des lieux fréquentés et devient plus dangereux pour l'homme et pour les animaux domestiques : soulement on a remarqué que lorsqu'il voit des hommes et des animaux ensemble, e'est toujour's sur' les animaux qu'il se jette et jamais sur les hommes, à moins qu'ils ne le frappent, ear alors il reeonnait à merveille eolui qui vient de l'offenser, et il quitte sa proie pour' se venger. On prétend qu'il préfère la ehair du ehameau à eelle de tous les autres animaux; il aime aussi beaneoup eclle des jeunes éléphants; ils ne peuvent lui résister lorsque leurs défenses n'ont pas eneore poussé et il en vient aisément

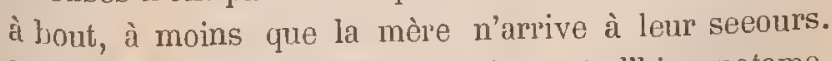
L'éléphant, le rhinoeéros, le tigre et l'hippopotame, sont les seuls animaux qui puissont résister au lion. Sa peau, quoique d'un tissu ferme et serı'é, ne résiste point à la balle ni même au javelot; néanmoins on ne le 
tue presque jamais d'un seul coup : on le prend souvent par adresse, comme nous prenons les loups, en le faisant tombel' dans une fosse profonde qu'on recouvre avec des matières Iégères, au-dessus desquelles on attache un animal vivant. Le lion devient doux dès qu'il esł pris, et, si l'on profite des premiers moments de sa surprise ou de sa honte, on peut l'attacher, le museler et le conduire oì l'on veut.

La chair du lion est d'un goût désagréable et fort; copendant les Nègres et les Indiens ne la trouvent pas mauvaise et en mangent souvent: la peau, qui faisait autrefois la tunique des héros, sert à ces peuples de manteau et de lit; ils en gardent aussi la graisse, qui est d'une quaiitá fort pénétrante, et qui mòme est de quelque usage dans notre médecine.

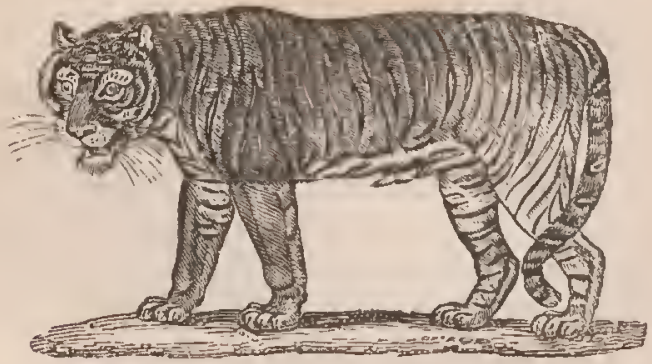

LE TISRE.

Dans la classe des animaux carnassiers, le lion est le premier, le tigre est le second; comme le premier, mème dans un mauvais genre, est toujour's le plus graind et sou- 
vent le moilleur, le second est ordinairement le plus méchant de tous. Le tigre est bassement féroce, cruel sans juslice, c'est-à-dire sans nócessité. Aussi est-il plus à craindre que le lion : celui-ci oublic souvent qu'il est lo roi, c'est-ì-dire le plus fort de tous les animaux. Le tigre au contraire, quoique rassasié de chair, semble toujour's être altécé de sang; sa fureur n'a d'autres intervalles que ceux du temps qu'il faut pour dresser des embûches; il saisit et déchire une nouvelle jroie avec la mème raģc qu'il vient d'exereer, et non pas d'assouvil, en dévol'unt la première; il désole le pays qu'il labite, il ne craint ni l'aspect ni les armes do l'honmo; ilégorge, il dévaste les troupeaux d'animaux domestiques, met i mort toutes les bêtes sauvages, attargue los petits éléphauts, les jeunes rhinocóros, et quelquefois même ose braver le lion.

Le tigre, trop long de corps, trop bas sur ses jambes, la tête nue, les yeux hagnarits, la languc couleur de sang, toujours hors de la gueule, n'a que les caractères de la basse méchanceté et de l'insatiable cruauté; il n'a pour tout instinct qu'une rage constante, une fureur avengle qui ne connait, qui no distingue rien, et qui lui fait souvent dóvorer ses propres enfants et déchirer leur mère lorsqu'elle veut les défendre.

Comme le sanğ ne fait que l'altérer, il a souvent besoin d'eau pour tempérer l'ardeur qui lc consume; et d'ailleur's il attend près dos eaux les animaux qui y arrivent, et que la clialeur du elimat contraint d'y venir plusieurs fois chaque jour : e'est là qu'il choisit sa proie, ou plutôt qu'il multiplie ses massacres; car' souvent il abandonne les animaux qu'il vient de mettre ì mort pour en égorger d'autres; il semble qu'il cherche à goôtter de leur sang, 
ll le savoure, il s'en enivi'e, et lor'squ'il leur' fend et déchire le eorps, e'est pour y plonger la tête et pour sueer à longs traits le sang dont il vient d'ouvrir la souree, qui tarit presque toujours avant que sa soif ne s'éteigne.

Cependant quand il a mis à mort quel(ques gros animaux eomme un eheval, un buffle, il ne les éventre pas sur'la plaee, s'il craint d'y être inquiété; pour les dépeecr à son aise il les emporte dans les bois, en les traînant avee tant de légèreté, que la vitesse de sa eourse paraît à peine ralentie par la masse énorme qu'il entraîne. Ceei seul suffirait pour faire juger de sa foree; mais pour en donner une idée plus juste, arrêtons-nous un instant sul les dimensions et les proportions du eorps de eet animal terrible. Quelques voyageurs l'ont comparé pour la grartdeur, à un eheval, d'autres à un buffle, d'autres ont seulement dit qu'il était beaueoup plus grand que le lion.

Le tigre est peut-être le seul de tous les animaux dont on ne puisse fléehir le naturel: ni la foree, ni la contrainte, ni la violence ne peuvent le dompter. Il s'irrito des bons eomme des mauvais traitements; la douee habitude, qui peut tout, ne peut rien sur cette nature de fer'; le temps, loin de l'amollir en tempérant les humeur's féroees, ne fait qu'aigrir le fiel de sa rage; il déchire la main qui le nourrit comme eelle qui le frappe; il rugit à la vue de tout être vivant; ehaque ohjet lui parait une notvelle proie qu'il dévore d'avance de ses regards avides, qu'il menaee par des frémissements affreux mêlés d'un grincement de dents, et vers lequel il s'élanee souvent malgré les chaînes et les grilles qui brisent sa fureur sans pouvoir la ealmer.

L'espèee du tigre a toujours été plus rare et beaucoup 
moins répandue que celle du lion; cependant la tigresse produit, comme la lionne, quatre ou cinq petits. Elle est furieuse on tout temps, mais sa rage devient extrême lorsqu'on les lui ravit; elle brave tous les périls, elle suit les ravisseurs qui, se trouvant pressés, sont obligés de lui relâcher un de ses petits; elle s'arrête, le saisit, l'emporte pour le mettre à l'abri, revient quelques instants après et les poursuit jusqu'aux portes des villes ou jusqu'à leurs vaisseaux : et, lorsqu'elle a perdu tout espoir de recouvrer sa perte, des cris forcenés et lugubres, des hurlements affieux, expriment sa douleur cruelle et font encore frémir ceux qui les entendent de loin.

Le tigre fait mouvoir la peau de sa face, grince des dents, frémit, rugit comme fait le lion ; mais son rugissement est différent.

La peau de ces animaux est assez estiméc, surlout en Chine; en Europe, ces peaux, quoique rares, ne sont pas d'un grand prix. On fait beaucoụ plus de cas de celles du léopard de Guinée et du Sénégal, que nos fourreurs appelent tigre.

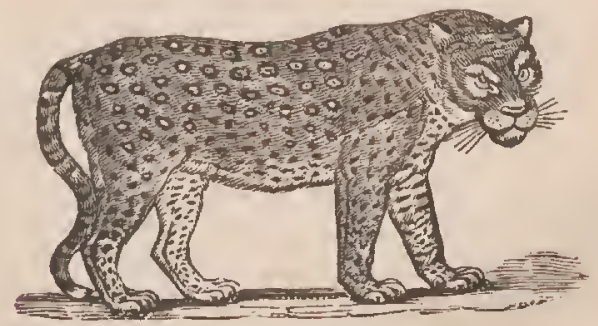




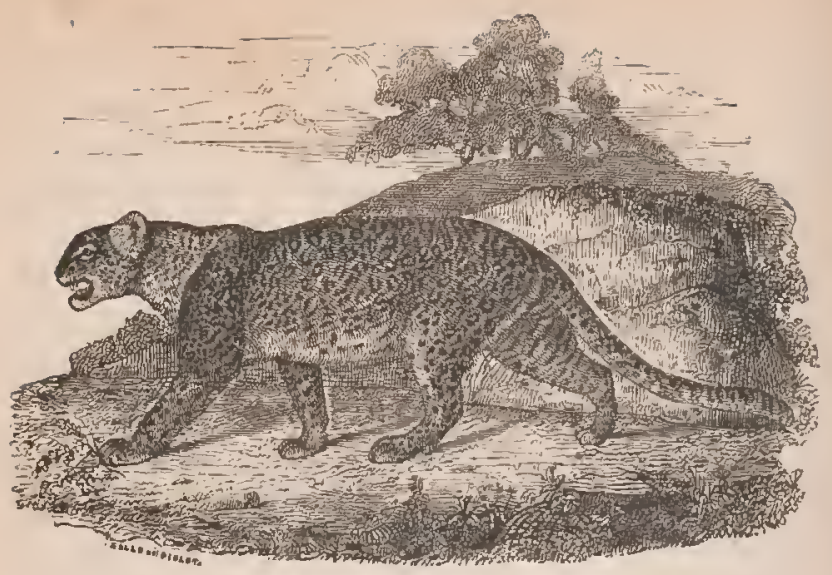

\section{LA PANTHËRE, L’ONCE ET LE LEOPARD.}

Il se trouve eneore, en Asie et en Afriçue, trois autres espèees d'animaux de ee genre, toulos trois différentes du tigre et toutes différentes entre elles : la panthère, l'once et le léopard.

La panthère a l'air féroce, l'œil inquiet, le regard eruel, les mouvements brusques et le eri scmblable ì eelui d'un dogue en colère; elle a même la voix plus forte et plus rauque que le ehien irrité; elle a la langue rudo et trèsrouge, les dents fortes et pointues, les ongles aigus et durs, la peau belle, d'un fauve plus ou moins foneć, semée de taches noircs arrondies en anneaux, ou réunies en forme de roses, le poil eourt, la queue marquée de grandes taches noires au-dessus et d'anneaux noirs et blanes vers l'extrémité. La panthère est de la taille et de la tournure d'un dogue de forte raee, mais moins haute de jambes. 
L'onee s'appritoise aisément, on le dresse à la ehasse pt on s'en sert à eet usage en Perse et dans plusieurs autres provinces de l'Asie; il y a des onees assez petits rour qu'un eavalier puisse les porter en eroupe; ils sont assez doux pour se laisser manicr et earesser avee la main. La panthère parait être d'une nalure phus fière et moin flexible; on la dompte plutôt qu'on ne l'apprivoise; jamais elle ne perd en entier son carnetère féroee, et, lor'squ'on veut s'en servir pour la ehasse, il faut beaucoup de soins pour la dresser, et eneore plus de préeautions pour la eonduire et l'exereer. On la mène sur une elıarrette enfermée dans une eage, dlont on lui ouvre la porte lorsque le gibier paraît; elle s'ćlance ver's la bête, l'atteint ordinairement en trois ou quatre sauts, la terrasso et l'étrangle : mais, si elle manque son coup, elle devient furieuse et se jetto ruclquefois sur son maître, qui d'ordinaire prévient ee danger en portant avee lui des morceaux de viande ou des animaux vivants, eomine des agneaux, des ehevreaux, dont on lui en jette un pour ealmer sa fureur.

L'espèee de l'onee paraît plus nombreuse et plus répandue que eelle de la panthc̀re: on la trouve trèscommunément en Barbarie, en Arabie et dans toutes los parties méridionales de l'Asie, à l'exeeption peut-être de l'Égypte; elle s'est même étendue jusqu'ì la Chine.

Cie qui fait qu'on se sert de l'onee pour la ehasse dans les elimats ehauds de l'Asie, e'est que les eliens y sont très-rares; il n'y a, pour ainsi dire, que eeux qu'on $\mathrm{y}$ transporte, et eneore perdent-ils en peu de temps leur voix et leur instinet; d'ailleur's, ni la panthère, ni l'onee, ni le léopard, ne peuvent souffrir les chiens; ils semblent 
les ehereher et les attaquer de préférence sur toutes les autres bêtes.

Le léopard a les mêmes mours et le même naturel que la panthère; et je ne vois nulle part qu'on l'ait apprivoisé eomme l'onee, ni que les nègres du Sénégal ct de Guinée, où il est très-eommun, s'en soient jamais selris pour la ehasse. Communément, il est plus grand (que l'onee et plus petit que la panthère; il a la queue plus courte que l'onee, quoiqu'elle soit longue de deux pieds ou deux pieds preds et demi.

La panthère, l'onee et le léopard n'habitent que l'Afrique et les elimats les plus ehauds de l'Asie; ils ne se sont jamais répandus dans les pays du Nord, ni même dans les régions tempérées. Ces animaux, en général, se plaisent dans les forêts touftues, et fréquentent souvent les bords des fleuves et les environs des habitations isolées, où ils eherehent à surprendre les animaux domestiques et les bêtes sauvages qui viennent cherelier les eaux. Ils se jettent rarement sur les hommes, quand môme ils seraient provoqués; ils grimpent aisément sur les arbres, où ils suivent les ehats sauvages et les animaux, qui ne peuvent leur éehapper. Leurs peaux sont toutes préeieuses et font de très-belles fourrures; lit plus belle et la plus ehère est eolle du léopard; une seule de ces peaux eoûte huit ou dix louis lorsque le fauve ${ }^{11}$ fest vif et brillant, et que les taehes en sont bien noircs et bien terminées.

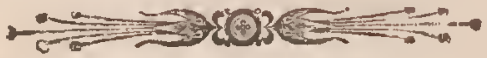





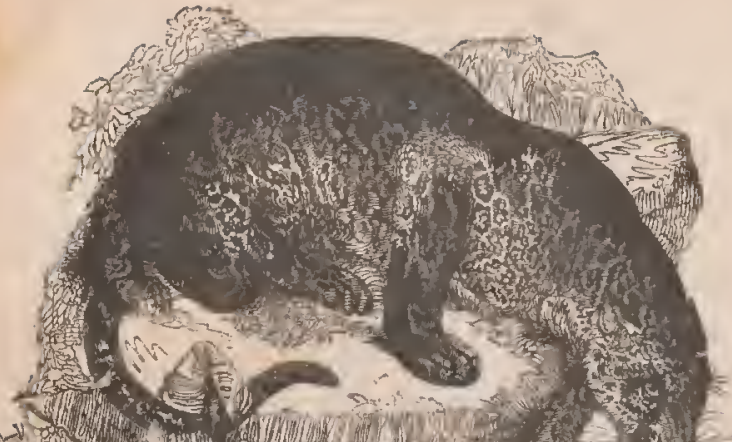

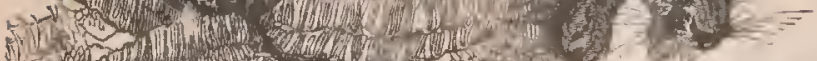

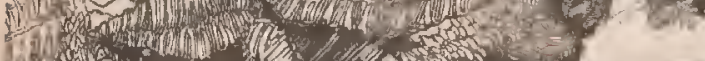

10.

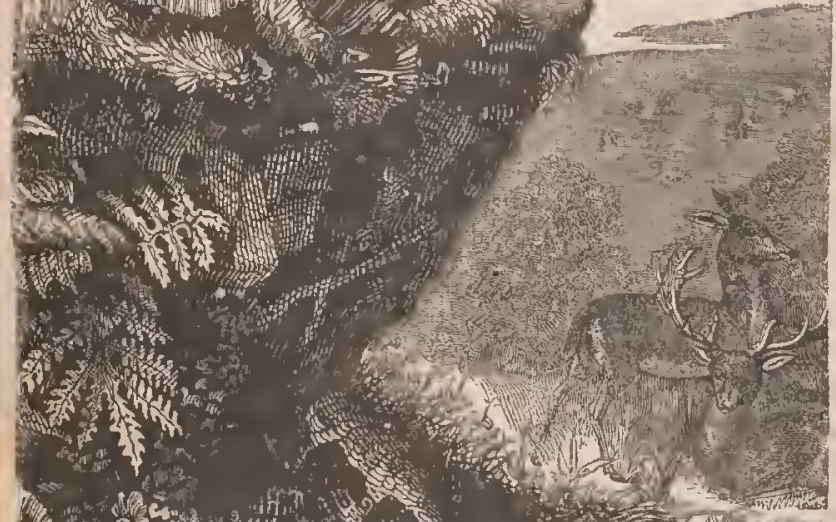

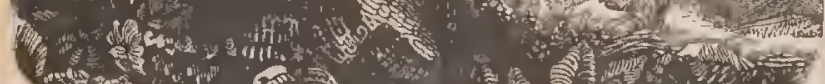

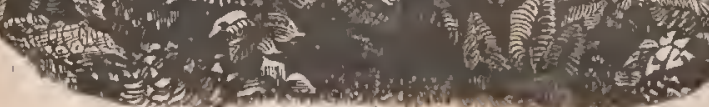




\section{LE JAGUAR.}

Le jaguar ressemble à l'onee par la grandeur du eorps, par la forme de la plupart des taehes dont sa robo est semée, et même par le naturel; il est moins fier et moins féroee que le lćopard et la panthère. Il a le fond du poil d'un beau fauve eomme le léopard, et non pas gris comme l'onee; il a la queue plus eourte que l'un et l'autre, le poil plus long que la panthère et plus eourt que l'once. Le jaguar vit de proie eomme le tigre; mais il ne faut pour le faire fuir que lui présenter un tisen allurnć, et inême lorsqu'il est repu, il perd tout eourage et toute vivacité, un tison seul suffit pour lui donner la chasse; il se ressent en tout de l'influence du climat du nouveau monde; il n’est liger, agile, alerte, que quand la faim le presse.

Le jaguar se trouve au Brésil et dans toutes les eontrées méridionales de l'Amérique; il est cependant plus rare à Cayenne que le couguar, qu'on a appelé tigre rouge; et le jaguar est maintenant moins commun au Brésil, qui paraît être son pays natal, qu'il ne l'était autrofois : 011 at mis sa tête à prix; on en a beaucoup détruit, et il s'est reliré loin des eôtes dans la profondcur des terıes.

\section{LE LYNX OU LOUP-CERVIER.}

Le lynx, dont les anciens on dit que la vuc était assez perçante ṇour pónćtrer les corps opaques, est un ani- 
mal fabuleux aussi bien que toutes les proprićtés qu'on lui attribue. Ce lynx imaginaire n'a d'autre rapport avec le vrai lynx que celui du nom.

Le vrai lynx ne voit point à travers les murailles, mais il est vrai qu'il a les yeux brillants, le regard doux, l'air

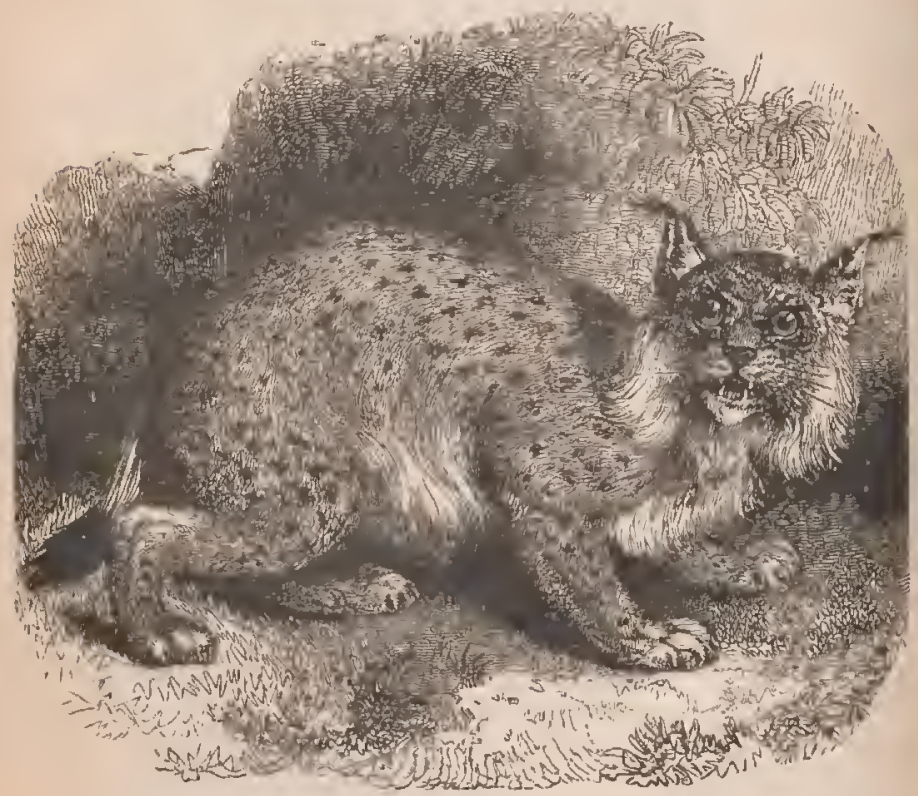

agréable ct gai. Il n'a rien du loup qu'une espèce de hurlement, qui, se faisant entendre de loin, a dû tromper les chasscur's ot leur faire croire qu'ils entendaient un loup. Cela seul a peut-être suffi pour lui faire donner le nom do loup, auquel, pour lo distinguer du vrai loup, les chasscurs auront ajouté l'épithète de cervier, parce qu'il atta- 
que les cerfs, ou plutôt parce que sa peau est variée de taches à peu près comme celle des jeunes cerfs. Le lynx est moins gros que le loup et plus bas sur ses jambes; il est communément de la grandeur d'un renard. Il ne court pas de suite comme le loup, il marche et saute comme le chat; il vit de chasse et poursuit son gibier jusqu'à la cime des arbres; les chats sauvages, les martres, les hermines, les écurcuils ne peuvent lui échapper; il saisit aussi les oiseaux; il attend les cerfs, les chevreuils, les lièvres au passage et s'élance dessus; il les prend à la gorge, ct, lorsqu'il s'est rendu maître de sa victime, il en suce le sang et lui ouvrc la tête pour manger la cervelle, après quoi souvent il l'abandonne pour en chercher une autre : rarement il retourne à sa première proie, et e'est ce qui a fait dire que, de tous les animaux, le lynx était celui qui avait le moins de mémoire. Son poil chạnge de couleur suivant les climats et la saison; les fourruros d'hiver sont plus belles, meilleures et plus fournies que celles de l'été; sa chair, comme collo de tous les animaux de proie, n'est pas bonne à manger.

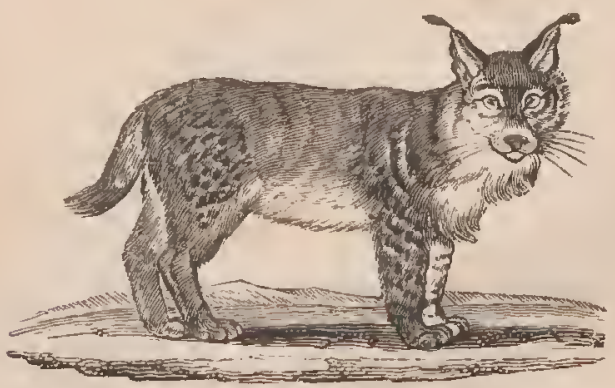




\section{LE LAMANTIN.}

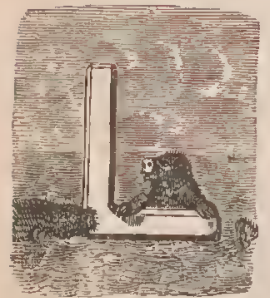

E lamantin est gros comme un bœuf et tout rond comme un tonneau; il a une pctite tête et peu de queue; sa peau est rude et épaisse comme celle d'un éléphant; il y en a de si gros, qu'on en tire plus de six cenls livres de viande très-bonne à manger ; sa graissc est aussi douce que lc beur're. Cet animal se plaît dans les rivières proche de leur embouchure à la mer, pour y brouter l'herbe qui croît le long de rivages; il y a de certains endruits, à dix ou douze lieues de Caycnne, où l'on en trouve en si grand nombre que l'on peut dans un jour en remplir une longue barque, pourvu qu'on ait des gens qui se servent bien du harpon. Le lamantin se nourrit d'une petite herbe qui croît dans la mer; il la broute comme le bouf fait de celle des prés, et après s'être rempli de cette pâture, il cherche les rivières et les eaux douces, où il s'abreuve deux fois par jour; après avoir bien bu et bien mangé, il s'endort le mufte à demi hors de l'eau, ce qui le fait remarquer do loin ; la femcllc fait cleux petits qui la suivent partout ; et, si on prend la mère, on est assuré d'avoir les petits.

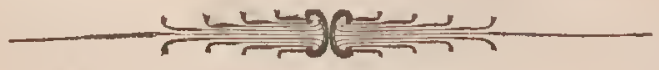




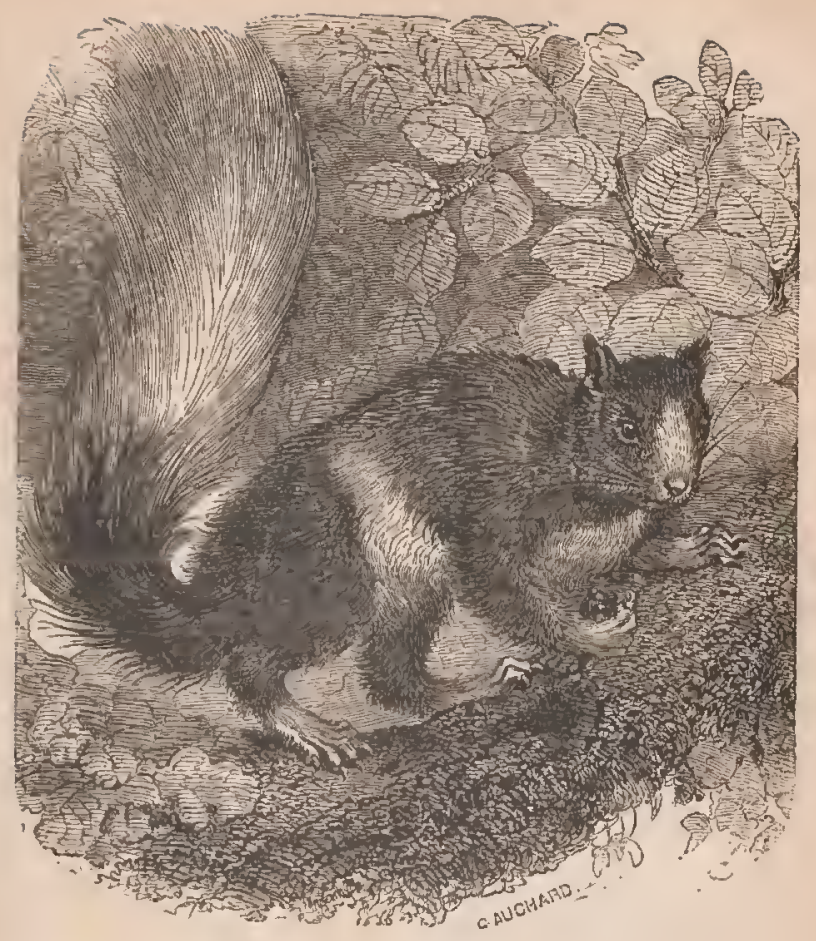

\section{LES RONGEURS.}

\section{L'ÉCUREUIL.}

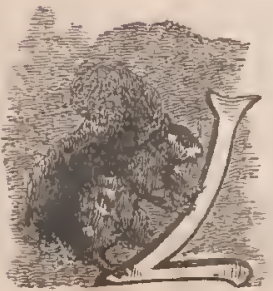

'Écuneur est un joli petit animal qui n'est qu'à demi sauvage, et qui, par' sa grentillesse, pur sa docilité, par l'innocence mêmo de ses mour's, mériterit d'être épargné. Il n'estni carnassier' ni nuisible, quoiqu'il suisisse 
quelquefois des oiseaux; sa nourriture ordinaire sont des fruits, des amandes, des noisettes, de la faîne et du ğland; il est propre, leste, vif, très-alerte, très-éveillé, très-industrieux; il a les yeux pleins de feu, la physionomie fine, le corps nerveux, les membres très-dispos : sa jolie figure est encore rehaussée, parée par une belle queue en forme de panache, qu'il relève jusque dessus sa tête, et sous laquelle il se met à l'ombre; il est, pour ainsi dire, moins quadrupède que les autres; il se tient ordinairement assis, presque debout, et se sert de ses pieds de devant comme d'une main, pour porter à sa bouche. Au lieu de se cacher sous terre, il est toujours en l'air ; il approche des oiseaux par sa légèreté; il demeure comme eux sur la cime des arbres, parcourt les forêts en sautant de l'un à l'autre, y fait aussi son nid, cueille les graines, boit la rosée, et ne descend à terre que quand les arbres sont agités par la violence des vents. On ne le trouve pas dans les champs, dans les lieux découverts, dans les pays de plaine; il n'approche jamais des habitations, il ne reste point dans les taillis, mais dans los bois de hauteur, sur les vieux arbres des plus belles futaies. Il craint l'eau plus encore que la terre. Il ne s'engourdit pas comme le loir pendant l'hiver ; il ost on tout temps très-éveillé, et pour peu que l'on touche au pied de l'arbre sur lequel il repose, il sort de sa petite bauge, fuit sur un autre arbre, ou se cache à l'abri d'une branche. Il ramasse des noisettes pendant l'été, en remplit les troncs, les fentes d'un vieux arbre, et a recours en hiver à sa provision; il les cherche aussi sous la neige, qu'il détourne en grattant. Il a la voix éclatante, et plus perçante encore que celle de la fouine; il a de plus un murmure à bouche fermée, un petit grognement 
de mécontentement qu'il fait entendre toutes les fois qu'on l'irrite. Il est trop léger pour marcher, il va ordinairement par petits sauts et quelquefois par bonds; il a les ongles si pointus et les mouvements si prompts, qu'il grimpe en un instant sur un hêtre dont l'écorce est for't lisse.

On entend les écureuils, pendant les belles nuits d'été, crier en courant sur les arbres les uns après les autros; ils semblent craindre l'ardeur du soleil, ils demeurent pendant le jour à l'abri dans leur domicile, dont ils sortent le soir pour s'excrcer, joucr et manger ; ce domicilc est propre, chaud et impénélrable à la pluie; c'est ordinairement sur l'enfourchurc d'un arbre qu'ils l'ćtablissent; ils commencent par y transporter des bûchettes qu'ils mêlent, qu'ils entrelacent avec de la mousse; ils la scrrent ensuite, il la foulent, et donnont assez de capacité et de solidité à lour ouvrago pour y être à l'aise ct en sûreté avec lours petits. Ils produisent ordinairement trois ou quatre petits, et mettent bas au mois de mai ou au commencement de juin; ils muent au sortir de l'hiver; le poil nouveau est plus roux que colui qui tombe. Ils se peignont, il se polissent avec les mains et los dents; ils sont propres, ils n'ont aucune mauvaise odeur' leur chair est assez bonne à manger. Le poil de la quoue sert à faire des pinccaux; mais leur peau no fait pas uno bonne fourrure.

Il y a beaucoup d'esjèces voisines de celle de l'écureuil, et peu de variélés dans l'espòce même; ils s'en trouve quelques-uns de cendrés; tous les autres sont roux. 


\section{LE PETIT-GRIS.}

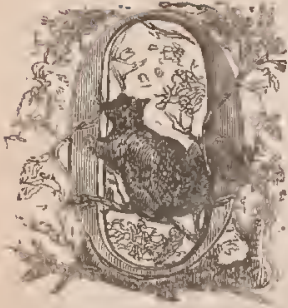

s trouve dans les parties septentrionales de l'un et de l'autre eontinent l'animal que nous donnons ici sous le nom de pelit-gris ; il ressemble bcaucoup à l'écureuil, et n'en diffère à l'extérieur que par les caractères suivants: il est plus grand quc l'écurcuil; il n'a pas le poil roux, mais d'un gris plus ou moins foncé; les oreillos sont déruées de ces long's poils qui surmontent l'extrćmité de celles de l'écureuil.

On a peu de faits sur l'histoire des petils-gris : l'écureuil gris ou noirâtre d'Amérique se tient ordinairement sur les arbres et particulièrement sur les pins; il sc nourrit de fruits et de graines et on fait provision pour l'hiver, il les dópose dans le creux d'un arbre où il se retire luimôme pour passer la mauvaise saison, il y fait aussi ses petits, etc. Ces habitudes du petit-gris sont encore différ'entes de celles de l'écureuil, lequel se construit un nid au-dessus des arbres, eomme font les oiseaux. Cet éclrcuil noirâtre est-il le même que l'écureuil gris de Virginie, et tous deux sont-ils les mêmes que le petil-gritis du nord de l'Europe, c'est une chose qui paraît être trèsvraisemblable, parce quc cos trois animaux sont à peu près de la même grandcur, de la même couleur et du même climat froid, qu'ils sont précisćment de la mêne forme, et qu'on emploic égalcment leurs peaux dans les fourrures qu'on appelle petil-gris. 

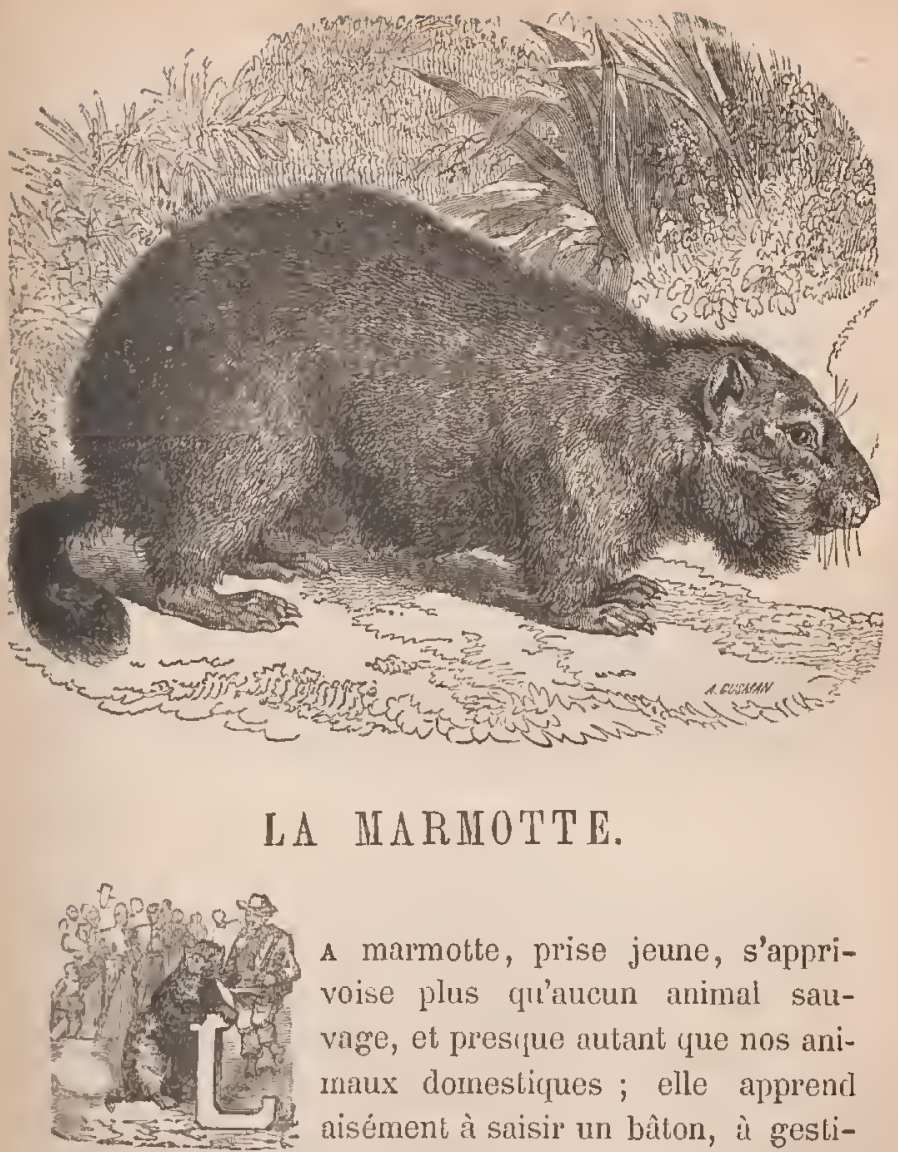

A marmotte, prise jeune, s'apprivoise plus qu'aucun animal sauvage, et presifue autant que nos animaux domestiques; elle apprend aisément à saisir un bàton, à gesticuler, t̀ danser, à obéir en tout ì la voix de son maîlre. Elle est, comme le chat, antipathirue avec le chien. Quoiqu'elle ne soit pas tout à fait aussi grande qu'un lièvre, elle joint beaucoup de force à beaucoup de souplesse. Ceprendant elle n'altaque que les chiens, et ne fait de mal à personne à moins qu'on ne l'irrite. Si l'on n'y 
prend pas garde, elle ronge les meubles, les étoffes ot perce même le bois lorsqu'elle est renfermée. Elle se tient souvent assise, et marche aisément sur ses pieds de derrière; elle porte à sa gueule ce qu'elle saisit avec ceus de devant, et mange debout comme l'écureuil ; elle court assez vitc en montant, mais assez lentement en plaine; elle grimpe sur les arbres, elle monte entre dcux parois de rochers, entre deux murailles voisines, et c'est des marmottes, dit-on, que les Savoyards ont appris à grimper pour ramoner les cheminées. Elles mangent de tout ce qu'on leur donne, mais elles sont plus avides de lait et de beurre que de tout autre aliment. Quoique moins enclines que le chat à dérober, elles cherchent à entret dans les endroits où l'on renferme le lait, et elles le boivent en grande quantité en marmottant, c'est-à-dire en faisant comme le cliat une espèce de murmure de contentement.

La marmotte tient un peu de l'ours et un peu du rat pour la forme du corps. Elle a le nez, les lèvres et la forme de la tête comne le lièvre, le poil et les ongles du blaireau, les dents du castor, la moustache du chat, les youx du loir, les pieds de l'ours, la queue courte et les oreilles tronquées. Elle a la voix et le murmure d'un petit chien, lorsqu'elle joue ou quand on la caresse ; mais lor'squ'on l'irrite ou qu'on l'effraye, elle fait entendre un sifflet si perçant et si aigu, qu'il blesse le tympan. Elle aime la propreté, mais elle a, comme le rat, surtout en été, une odeur forte qui la rend très-đésagréable; en automne, elle est très-grasse : elle serait assez bonne à manger, si elle n'avait pas toujours un peu d'odeur, qu'on ne peut masquer que par des assaisonnements très-forts. 
Cet animal, qui se plaît dans la région de la neige et des glaces, qu'on ne trouve que sur les plus hautés montagnes, est eependant sujet plus qu'un autre à s'engourdir' par le froid. C'est ordinairement à la fin de septembre ou au commeneement d'octobrc qu'il se reeèle dans sa retraite pour n'en sortir qu'au commeneement d'avril. Les marmottes demeurent ensemble et elles travaillent en commun à leur habitation; elles y passent les trois quarts de leur vie, elles s'y retirent pendant l'orage, pendant la pluie ou dès qu'il y a quelque danger ; elles n'en sortent même que dans les plus beaux jour's, et ne s'en éloignent guère; l'une fait le guet, assise sur une roche élevée, tandis que les autres s'amusent à jouer sur le gazon, ou s'oeeupent à le eouper pour en faire du foin; et lorsque eelle qui fait sentinelle apercoit un homme, un aigle, un chien, ete., olle avertit les autres par un coup de sifflet, et ne rentre elle-même que la dernière.

Elles ne font pas de provisions pour l'hiver, il semble qu'elles devinent qu'elles seraient inutiles; mais lor'squ'elles sentent les premières approehes de la saison qui doit les engourdir, elles travaillent à fermer les deux portes de leur domieile, et elles le font avee tant de soin et de solidité, qu'il est plus aisé d'ouvrir la terre partout ailleurs que dans l'endroit qu'clles ont muré. Lorsqu'on dćcouvre leur retraite, on les trouve resserrées en boule tt fourrées dans le foin; on les emporte tout engourdics, on peut inême les tuer sans qu'elles paraissent le sentir ; on ehoisit les plus grasses pour les manger, et les plus jeunes pour les apprivoiser. Une chaleur graduéc les ranime eomme les loirs, et celles qu'on nourrit à la maison, en les tenant dans les lieux chauds, ne s'engourdis- 
sent pas, et sont même aussi vives que dans les autres temps.

Ces animnux ne produisent qu'une fois l'an; les portées ordinaires ne sont que 'Le trois ou quatre petits; levl' aeeroissement est prompt, et la durée de leur vie n'est (que de neuf ou dix ans; nussi l'espèee n'en est ni nombreuse, ni bien rópandue.

\section{LE RAT.}

L'on a eompris et eonfondu, sous le nom ghénérigita de rat, piusieurs espèces de jetits animaux; nous ne doll" nerons ee nom qu'au rat eommun qui est noirâtre et qq1i habile dans les maisons ; eliaeune des autres espèees a all? sa dénomination partieulière, paree que, ne se mêlarl point ensemble, ehaeune est différente de toutes les autre ${ }^{5}$. Le rat est assez eonnu par l'ineommodité qu'il nous eause' i] habile ordinairement les greniers où l'on entasse 10 grain, où l'on serre les fruits, et de là deseend et se répand dans la maison. Il est earnassier, et même omnivore: it semble seulement préférer les ehoses dures aux plus ten" dres; il ronge la laine, les étoffes, les meubles, perice ${ }^{1 e^{\prime}}$ bois, fait des trous dans les murs, se loge dans l'épais' seur des planehers, dans les vides de la eharpente ou de la boiserie, il en sort pour chereher sa subsistance, et souvent il y transporte tout ee qu'il peut traîner ; il y fait même quelquefois magasin, surtout lorsqu'il a des petits. Il produit plusieurs fois par an, presque toujours en été ; 


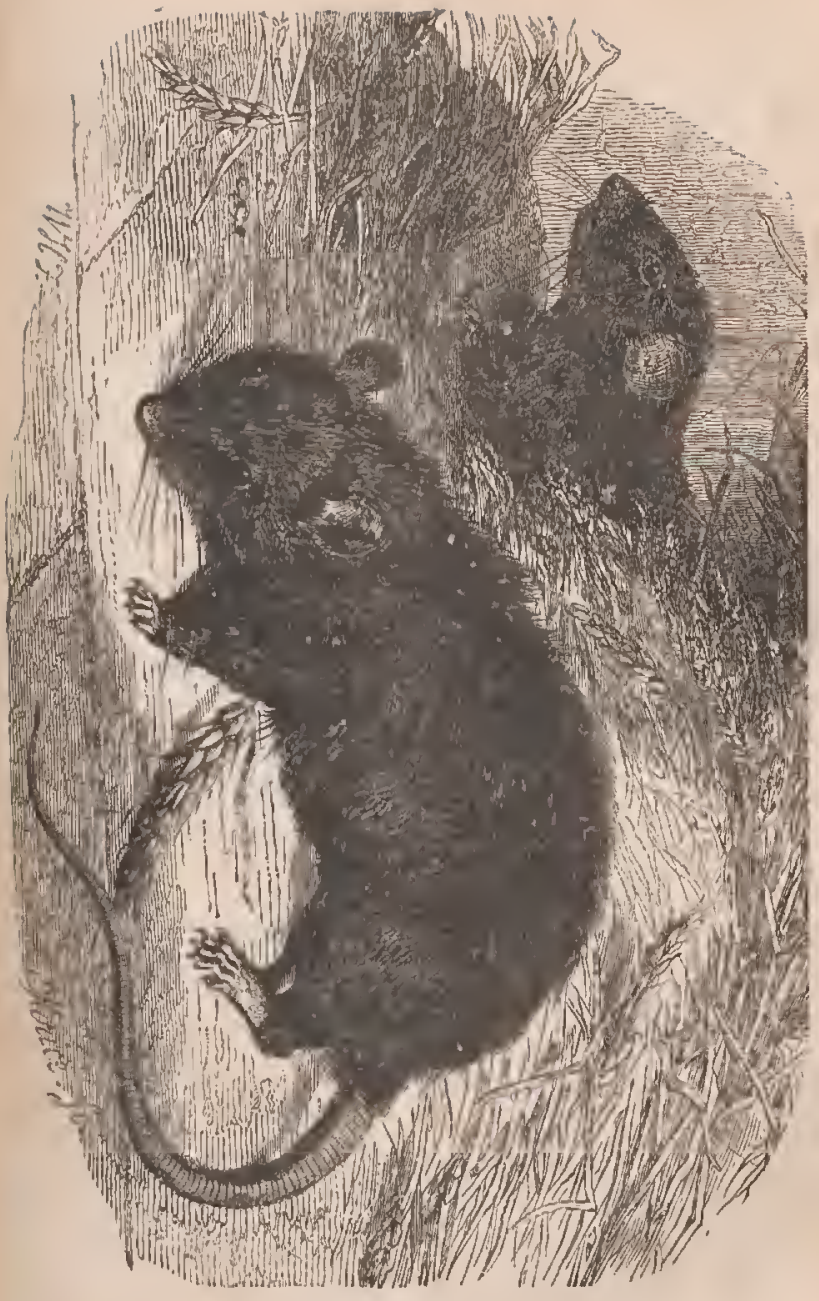



les portées ordinaires sont de cinq ou six. Il cherche les lieux chauds ot se niche en hivor auprès des cheminées ou dans le foin, dans la paille. Malgré les chats, le poison, les piéges, les appâts, ccs animaux pullulent si fort qu'ils Causent souvent de grands dommages ; c'est surtout dans les vieilles maisons à la campagne, où l'on garde du blé dans les greniers, et où lc voisinage des granges et des Inagasins à foin facilite leur retraite et leur multiplication, qu'ils sont en si grand nombre qu'on serait obligú de démeubler, de déserter, s'ils ne se détruisaiont euxnêmes; mais nous avons vu par expérience qu'ils se tuent, qu'ils se mangent entre eux pour peu que la faim les plesse; en sorte que, quand il y a disctic à causc du trop grand nombre, les plus forts se jottent sur les plus faibles, leur ouvrent la tête et mangent la cervelle, et ensuite lo roste du cadavre; le lendemain la guerre recommence, ct dure ainsi jusqu'à la destruction du plus grand nombre; e'est par cette raison qu'il arrive ordinairement, qu'après avoir été infesté de ces animaux pendant un temps, ils semblent souvent disparaitre tout ì coup quel"quefois pour longtemps.

Los rats crient quand ils se battent; ils préparent un lit à lcurs petits ct lour apportent bientôt à manger; lor'squ'ils commencent ì sortir de leur trou, la mère les veille, les défend, et se bat même contre les cliats pour les sauvor. Un gros rat est plus méchant et presque aussi fort y'un joune cliat; ilales dents de devant longues et fortes; le chat mord mal, et conme il ne se sert guère que de ses griffes, il faut qu'il soit non-sculcment vigoureux, mais agtuerri. La belette, quoique plus petite, est un cmnemi llus dangereux, et yue le rat redoute darantage. 
On trouve des variétés dans cette espèce comme dans toutes celles qui sont très-nombreuses en individus; outre les rats ordinaires, qui sont noirûtres, il y en a do bruns, de presque noirs, d'autres d'un gris plus blanc ou plus roux, et d'autres tout à fait blanes.

\section{LA SOURIS.}

La souris, beaucoup plus petite que le rat, est aussi plus nombreuse, plus commune et plus générulement répandue; elle a le môme instinct, Ie même tempórament, 10 nême naturel, et n'en diffère guòre que par la faiblessc et par les habitudes qui l'accompagnent. Timide par nature, familière par nécessité, la peur ou le besoin font tous ses mouvements; elle ne sort de son trou que pour chercher à vivre; elle ne s'en écarte guère, y y'entre à la première alerte, ne va jas, comme le rat, de maisons en maisons, à moins qu'elle n'y soit for'cée, fait aussi beaucoup moins de dégût, a les mours plus douces ct s'apprivoise jusqu'à un certain point, mais sans s'attachel" comment aimer, en effet, ceux qui nous dressent des enbûolıes? Plus faible, elle a plus d'emnemis, auxquols elle ne peut ćchapper que par son agilité. Les chouettes, tous les oiseaux de nuit, les cliats, les fouines, les belettes, les rats mêne lui font la gruerı'e; on l'attire: on la leurre aisément par des appâts, on la détruit par milliers; elle ne subsiste cnfin une par son inmense fécondité.

On en a vu qui avaient mis bas dans des souricières; 
elles produisent dans toutes les saisons ct plusicur's fois par an ; les portées ordinaires sont do einq ou six petils ; en moins de quinze jours ils premnent assez de foree pour se disperser et aller ehereher à vivre : ainsi la durée de la vie de ees petits animaux est fort courte, puisque leur aecroissement est si prompt; et cela augmente encore l'idée qu'on doit avoir de leur prodigieuse multiplication. Aristote dit qu'ayant mis ane souris pleine dans un vase à serrer du grain, il s'y trouva peu de temps après eent vingt souris toutes issues de la même mòre. Ces petits animaux ne sont point laids, ils ont l'air vif et mème asscz fin. Toutes les souris sont blanchâtres sous le ventre, etil y on a de blanehes sur tout le corps; il y en a aussi do plus ou moins brunes et de plus ou moins noires. L'espèce est génćralement répandue en Europe, en Asie, en Afrique; mais un prétend qu'il n'y en avait point en Amérique, et que eelles qui y sont acluellement en grand nombre viennent originairement de notre eontinent: ce qu'il y a de vrai, e'est qu'il parait que ee petit animal suit l'homme et fuit les pays inhabités par l'appótit naturel qu'il a pour' le pain, le fromage, le lard, l'luile, le beurre et les autres aliments que l'homune préjure pour lui-même.

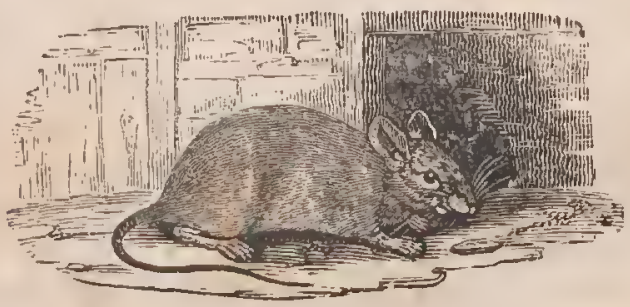




\section{LE MULOT.}

Le mulot est plus petil que le rat et plus gros que la souris; il n'labite jamais les maisons et ne se trouve que dans les ehamps et dans les bois; il est remarquable par les yeux qu'il a gros et proéminents, et il diffère eneore dn rat et de la souris par la coulcur du poil qui est blanehâtre sous le ventre et d'un roux brun sur le dos: il est très-généralement et très-abondamment répandu, surtout dans les terres élevées.

On le trouve en girande quantité dans les bois et dans les ehamps qui en sont voisins. Il se retire dans les trous qu'il trouve tout faits, ou qu'il se pratique sous des buissons ou des trones d'arbres; il y amasse une quantitó prodigieuse de glands, de noisetles ou de faines; on en trouve quelquefois jusqu'è un boisseau dans un seul trou, et cette provision, au lieu d'ètre proporlionnée à ses besoins, ne l'est qu'ù la capaeilé du lieu; ees trous sollt ordinairement de plus d'un pied sous terre, et souvent partagés en deux loges, l'une où il habite avee ses petits, et l'autre où il fait son magasin. On a souvent éprouvé le dommage eonsidérable que ees animaux eausent aux plantations; ils emportentles glands nouvellement semés, ils suivent le sillon traeé par la eharrue, déterrent ehaque gland l'un après l'autre et n'en laissent pas un: eela arrive surtout dans les années où le gland n'est pas fort abondant; eomine ils n'en trouvent pas assez dans les bois, ils viennent le eherehor dans les terres semées, ne le mangent pas sur lo lieu, mais l'einjorterit dirıs le tub" 
trou, où ils l'entasscnt ct le laissent souvent sécher et pourrir. Eux seuls font plus de tort à un semis de bois que tous les oiseaux ct tous les autres animaux ensemble.

Le mulot est très-généralement répandu dans toute l'Europe; ou le trouve en Suède ; il est très-commun en France, en Italie, en Suisse; il l'est aussi en Allemagne et en Angleterro. Il a pour ennemis les loups, les renards, les martes, les oiseaux de proie et lui-môme.

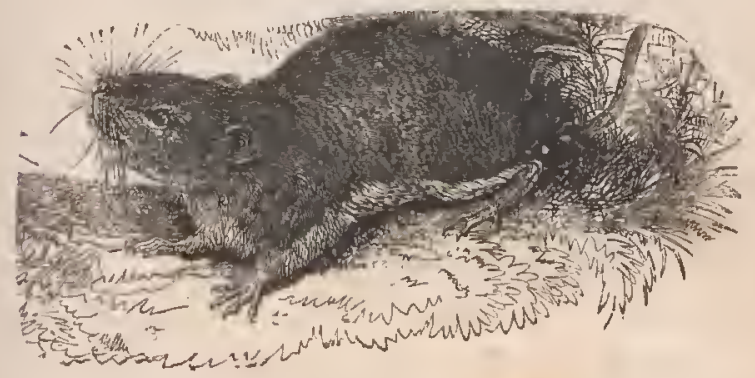

\section{LE CAMPAGNOL.}

Le campagnol est encore plus commun, plus généralement répandu que le mulot; celui-ci ne se trouve guère que dans les terres élevées; le campagnol so trouve par'tout, dans les bois, dans les champs, dans les prés, et même dans les jardins; il est remarquable par la grosseur de sa tête, ot aussi par sa queue courtc el tronquéc, qui n'a guère qu'un pouce de long; il se pratique des trous en terre où il amasse du grain, des noisettes et du gland; cepenilant il parait qu'il préfùrc lc blé à toutes les 
autres nourritures. Dans le mois de juillet, lorsque les blés sont mûrs, les campagnols arrivent de tous eôtéș et font souvent de grands dommages en eoupant les tiges du blé pour' en manger l'éri ; ils semblent suivre les moissonneurs, ils profitent de tous les grains tombés et des épis oubliés; lor'squ'ils ont tout glané, ils vont dans les terres nouvellement semées, et détruisent d'avanee la ríeolte de l'annéc suivante. En automne et en hiver, la plupart se retirent dans les bois où ils trouvent de la faine, des noisettes el du gland. Dans certaines années, ils paraissent en si grand nombre qu'ils détruiraient tout, s'ils subsistaient longtemps : mais ils se ditruisent euxmêmes et se mangent dans les temps de disette; ils scl'vent d'ailleurs de pâture aux mulots, et de gibier ordinaire au renard, au ehat sauvage, à la marte et aux belettes.

Les eampagnols ressemblent plus au rat d'ean qu'ì aueun animal; ils ne se nourrissent pas de poisson et ne se jottent point à l'eau; ils vivent de gland dans les bois, de llé dans les ehamps, et dans les prés de racines tubereuleuses, eomme eelle du chiendent. Leurs trous ressemblent à eeux des mulots, et sont souvent divisés en deux loges, mais ils sont moins spaeieux et beaueoup moins enfoneés sous terre : ees petits animaux y habitent quelquefois plusieurs ensemble. Lorsque les femelles sont prêtes à mettre bas, elles y portent des herbes pour faire jun lit à leurs petits : elles produisent au printemps ot en 'été; les portées ordinaires sont de einq ou six, et quelquefois de sept ou huit. 


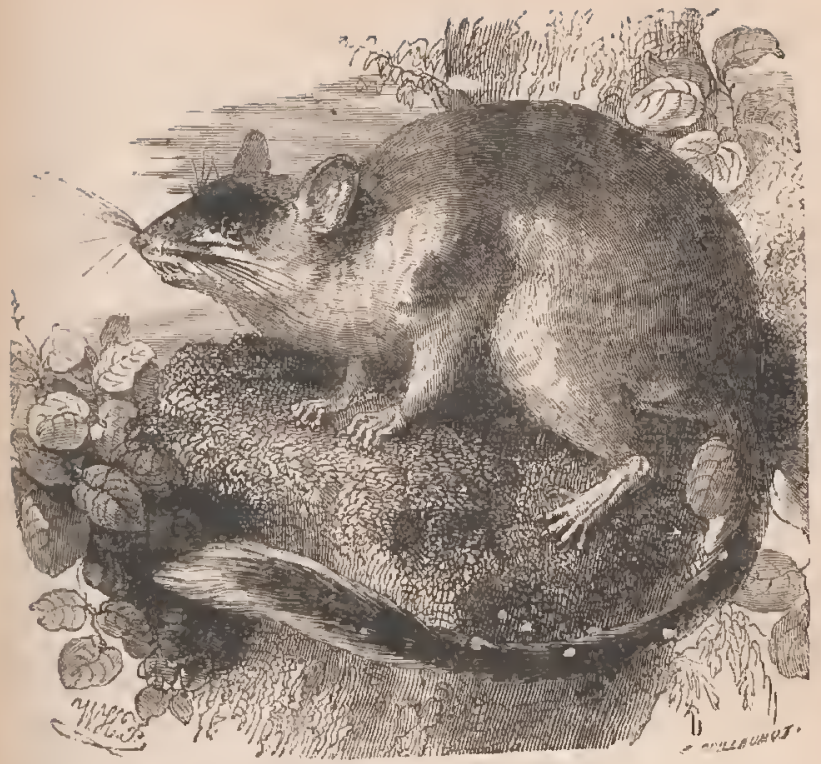

\section{LE LOIR.}

On connait trois espèces do loirs, qui, comme la marmotte, dorment pendant l'hiver : le loir, le lérot et le muscardin; le loir est le plus gros des trois, le muscardin est le plus petit. Le loir est à peu près de la grandeur de l'écurenil; il a, comme lui, la queue couverte de longss poils; le lórot n'est pas si ggros que le rat, il a la queuc couverte de poils très-courts, avec un bouquet de poils longos à l'cxtrćmité; lo muscardin n'est pas plus gros que la souris, il a la queue couverte de poils plus longs que le lérot, mais plus courts que le loir, aveo un 
gros bouquet do longss poils à l'cxtrémité. Le lérot diffùre des deux autres par les martues noires qu'il a près des yeux, ct le muscardin par la coulcur blonde de son poil sur le dos. Tous trois sont blanes ou blanchâtres sous la gorge et le ventre; mais le lérot est d'un assez beau blanc, le loir n'est que blanchâtre, et le muscardin est plutôt jaunâtre que blanc dans toutes les parties inférieures.

- C'est improprement que l'on dit que ces animaux dorment pondant l'hiver : leur état n'est point celui d'un sommeil naturel, c'cst une torpeur, un engourdissemont des membres et des sens, et cet engourdissement est produit par le refroidissement du sang. Ces animaux ont si peu de chaleur intérieure, qu'elle n'excède guère celle de la température de l'air.

Leur engourdissement dure autant que la cause quilc produit, et cesse avec lo froid; quelques degrís de chalour au-dessus de dix ou onze suffisent pour ranimer ces animaux, et, si on les tient pendant l'hiver dans un lieu lien chaud, ils ne s'engourdissent point du tout; ils vont et viennent, ils mangent et dorment seulement de temps en temps, comme tous les autres animaux.

Le loir ressemble assez à l'écureuil par los habitudes naturelles; il habite comme lui les forêts, il grimpe sur los arbres, saute de branche en branche, moins légèroment à la vérité que l'ècureuil, qui a les jamlies plus longues, le ventre bien moins gros, et qui est aussi maigre que le loir est gras : ccpendant ils vivent tous dcur des mêmes aliments; de la faine, des noisettes, de la châtaigne, d'autres fruits sauvages, font leur nourrituro ordinaire. Le loil mange aussi de petits oiseaux qu'il 
prend dans les nids; il ne fait point de hauge au-dessus des arbres commo l'éoureuil, mais il se fait un lit do mousse dans le trone de ecux qui sont creux; il se gîte aussi dans les fentes des roehers élevés, et toujours dans dos licux soes; il eraint l'humidité, boit peu et descend rarement à terre; il diffòre oneore de l'ceureuil en co que eelui-ei s'apprivoise, et que l'autre demeure toujours sauvage. Les loirs font leurs petits en été, les portées sont ordinairement de quatre ou do eing; ils eroissent vite, et l'on assure qu'ils ne vivent que six ans. Ces petits animaux sont courageux, et défendent leur vie jusqu'ì la dernière exluémité; ils ont los dents de devant trìslongues et très-fortes, aussi mordent-ils violemment; ils ne craignent ni la belette ni les petits oisfaux de proic, ils échappont au renard, (jui ne peut les suivre an-dessus des arbres; lours plus grands cnnemis sont les elıats sauvages ot les martes.

Il faut aux loirs un elimat tempéré et un pays couvert de bois; on en trouve en Espagne, en France, en Grice, en Italie, en Allenagne, en Suisse, où ils hribitent dans les forêts ol sur les collines.

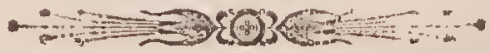




\section{LE RAT D'EAU.}

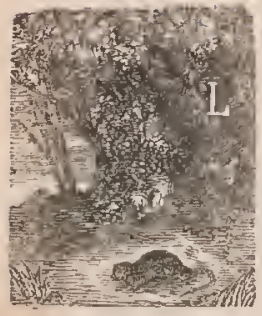

E rat d'eau est un petit animal de la grosseur d'un rat, mais qui, par le naturel et par les habitudes, ressemble beaucoup plus à la loutre qu'au rat; comme elle il ne fréquente que les eaux douees, et on le trouve communément sur les bol'ls des rivières, des ruisseaux, des étangss; comme ellc, il ne vit guère que de poissons: les goujons, les mouteilles, les vérons, les ablettes, le frai de la carpe, du broehet, du barbeau, sont sa nourriture ordinaire; il mange aussi des grenouilles, des inseetes d'eau, et quelquefois des raeines et des herbes; il a tous les doigts des pieds séparés, et cependant il nage faeilement, sc tient sous l'eau longtemps, et rapporte sa proie pour la manger à terre, sur l'herbe ou dans son trou; les pêeheurs l'y surprennent quelquefois en eherehant des éerevisses, il leur mord les doigts, et eherehe à se sauver en se jotant dans l'eau. Il a la tête plus courte, le museau plus gros, le poil plus hérissé, et la queue beaueoup moins longue que le rat. Il fuit, comme la loutre, les grands fleuves ou plutôt les rivières trop fréquentées. Les cliens lo ehassent avee une espèce de fureur. On ne le trouve jamais dans les maisons, dans les granges; il ne quitte pas le bord des eaux, ne s'en éloigne pas même autant que la loutre. Le rat d'eau ne va point dans les terres élevées; il est fort rare dans les hautes montagnes, dans 
les plaines arides, mais très-nombreux dans tous les vallons humides et marécageux. Lcs femelles mettent bas au mois d'avril; les portées ordinaires sont de six ou scpt. Pcut-être cos animaux produisent-ils plusieurs fois par an, mais on ne le sait pas au juste; leur chair n'est pas absolument mauvaise, les paysans la mangent.les jomrs maigres comme celle de la loutre. On les trouve jartout en Europe, excepté dans le climat trop rigoureux du pôle.

\section{LE CASTOR.}

Lc casto: est le seul parmi les quadruncides (fri ait li queuc plate, ovale et couverte d'écailles, de lacquelle il se sert comme d'un gouvernail pour se diriger clans l'eau; le seul qui ait des nageoires aux pieds de derric̀re, et en même temps les doigts séjarés dans ceux du dcvant, qu'il emploie comme des mains pour porter it sa Jouche; lc seul qui, resscmlılant aux animaux ter'restros par les parties antérieures de son corıs, parnisse en mêrne temps lenir des aninaux aquatiques par les parties postérieures. Mais ces singularités seraient plutôt des défauts que des perfections, si l'animal ne savait tirer de cette conformation, qui nous parait bizarre, des avantages uniques, et qui le rendent supéricur à tous les autres.

Lcs castors coinmencent par s'assembler au mois de juin ou de juillet pour se róunir en société; ils arrivent en nombre et do plusieur's côlés, et forment bientôt unc 
troupe de deux ou trois cents: le lieu du rendez-vous est ordinairement le licu de l'établissement, et e'est toujours au bord des eaux. Si ce sont des eaux plates, et qui se soutiennent à la même hauteur eomme dans un lac, ils se dispensent d'y construire une digue; mais dans les eaux courantes, et qui sont sujettes à hausser ou baisser, comme sur les ruisseaux, les rivières, ils établissent une chaussée, et par cette retenue ils forment une espèce d'étang ou de pièce d'eau, qui se soutient toujours à la même hauteur : la chaussće traverse la rivic̀re comme une ćcluse, ct va d'un bord à l'autre; elle a souvent quatrevingts ou cent pieds de longueur sur dix ou douze pieds d'épaisseur à sa base. Cette construction jaraît énorme pour des animaux de eette taille, et suppose, ell effet, un travail immense; mais la solidité avec laquelle l'ouvrage est construit étonne encore plus que sa grandeur. L'endroit de la rivière où ils établissent eette digue est ordinairement peu profond; s'il se trouve sur le bord un gros arbre qui puisse tomber dans l'enu, ils commencent par l'ahattre pour en faire la pièce prineipale de leur construction : cet arbre est souvent plus gros que le corps d'un homme: ils le scient, ils le rongent au pied, et sans autre instrument que leurs quatre dents incisives ils le coupent en assez peu de temps, et le font tomber du côtó qu'il leur plaît, e'est-ì-dire en travers sur la rivière; ensuite ils coupent les branches de la cime de cet arbire tombé pour le mettro de niveau et le faire porter partout également. Ces opérations se font en eommun ; plusieurs castors rongent ensemble le pied del'arbre pour l'abattre, plusieur's aussi vont ensemble pour en couper' les branehes lorsqu'il est abattu; d'autros pareourent en 
même temps les bords de la rivière ct coupent de moindres arbres, les uns gros comme la jambe, les autrcs comme In euisse; ils les dépc̀cent et les scient à une certaine lrauleur pour en faire des pieux; ils amènent ces pièces de bois d'abord par terre jusqu'au bord de la rivière, et cnsuite par eau jusqu'au lieu de leur construc-

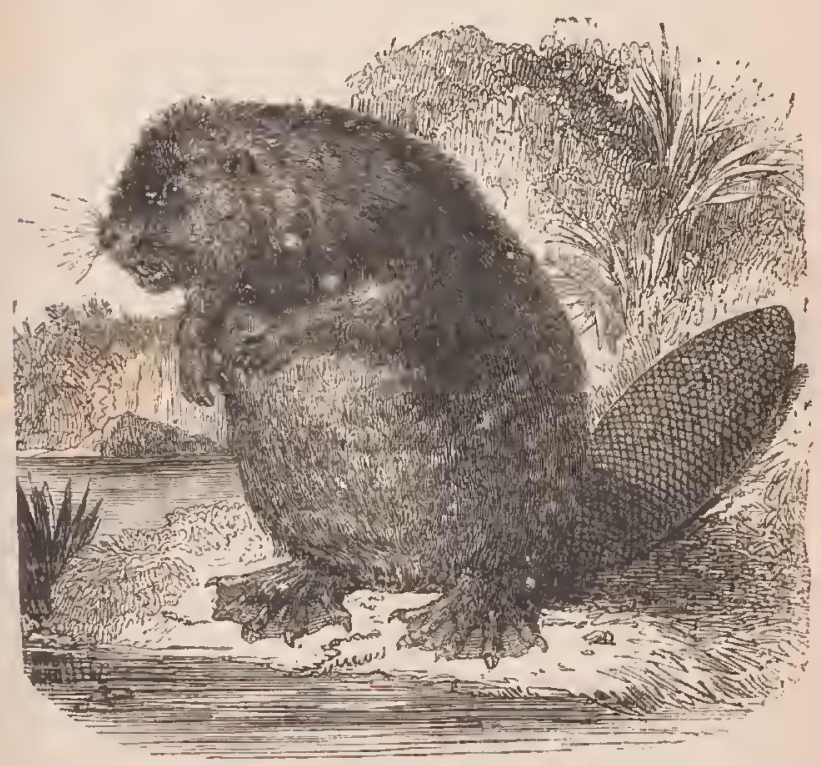

Lion; ils en font une espèce de pilotis scrré,qu'ils enfoncont encore en entrelaçant des branches cntre les picux. A mesure que les uns plantent ainsi leurs pieux, les autres vont chercher de la terre qu'ils gâchent avcc leurs pieds ct battent aveoleur queue; ils la portent dans leur gueule et avec les pieds de devant, et ils en transportent en si grande quantité, qu'ils en remplissent 
tous les intervalles de leur pilotis. Ce pilolis ost composí de plusicurs rangs de picux, tous égaux en liauleur, et tous plantés les uns contre les autres; il s'étend d'un bord à l'autre de la rivière, il est lompli ot maconué partout : les pieux sont plantés verticalement du còté de la chute de l'eau; tout l'ouvrage est au continire on talns du côté qui en soutient la charge, cn sorte que la chaus sée, qui a dix ou douze pieds de largenr à sa basc, so ríduit à deux ou trois picds d'épaisteur au sommet; ello a done non-seulement toute l'étendue, toute la solidité nécessaire, mais encore la forme la plus convenable pour retenir l'eau, l'empêcher de passcr, cn soutenir le poids et en rompre les efforts. Au liaut dle la chaussće, e'cst-ìdire dans la partie où elle a le moins d'ópaisseur, ils pratiquent doux ou trois ouvertures en pente, qui sont autant de décharges de superficie qu'ils élar'gissent ou rétréeissent selon que la rivic̀re vient à hausser ou baisser ; et lorsque par des inondations trop grandes ou trop subites il se fait quelques bròches à leur digue, ils savent los réparer", ot travaillent de nouvcau dès que les caux sont baissécs.

Ils travaillont assis, et, outre l'avantrge de cotle situation commode, ils ont le plaisir de ronger continuellc. ment de l'écorce et du hois dont le goût leur est fort agréable, car ils préfèrent l'écorce fraîche et le bois tendre à la plupart des aliments ordinaires; ils en font ample provision pour se nourrir pendant l'liver; ils n'aiment pas le bois sec. C'est dans l'enu et près de lour's habitations qu'ils établissent leur mngasin; chaque cabane a le sien proportionnó au nombre de ses habitanl,s, qui tous $\mathrm{y}$ ont un droit commun et ne vont jamais piller 
leurs voisins. Ils ne souffrent pas que des ćtranger's viennent s'établir dans leur's enceintes. Les plus petites cabanes contiennent deux, quatre, six, et les plus grandes dix-huit, vingt, et même, dit-on, jusqu'à trente castor's, presque toujours en nombre pair, autant de femelles que de mâles; ainsi, en comptant même au rabais, on peut dire que leur sociétć est souvent composée de cent cinquante ou doux cents ouviers associćs, qui tous ont travaillé d'abord ell corps pour élever le grand ouvragoc public, et ensuite par compagnies pour édifier des habitations particulières. Quelque nombreuse que soit celle socićté, la paix s'y maintient sans altération; le travail commun a resserré leur union; les commodités qu'ils se sont procurées, l'abondance des vivres qu'ils amassent et consomment ensemble, servent à l'entretenir ; des goûts simples, de l'aversion pour' la chair et le sang, lcur ôtent jusqu'à l'idée de rapine et de guerı’e: ils jouissent de tous les biens que l'homme ne fait que désirer. Amis entre eux, s'ils ont quelques ennemis au dehors, ils savent les éviter ; ils s'avertissent en frappant avec leur 'queue sur l'eau un coup qui letentit au loin dans tontes les voûles des habitations; chacun prend son parti, ou de plonger dans le lac ou de se recéler dans leurs murs qui ne craignent que le feu du ciel ou le fer de l'homme, et qu'aucun animal n'ose entreprendre d'ouvir ou ronverser.

C'est au commencement de l'été que les castors sc rassemblent ; ils emploient les mois de juillet et d'août à construire leur digue et leur's cabanes; ils font leur provision d'écorce et de bois dans le mois de septembre, ensuite ils jonissent do lcur's travaux, ils goûtent les 
douceurs domestiques; e'est lo temps du repos. Se connaissant, prévenus l'un pour l'autre par l'habitude, par les plaisirs et les poines d'un travail conmun, chaquo couple ne se forme point au hasard, mais s'unit par clıoix et s'assortit par goût: ils passent ensemble l'automne et l'hiver; contents l'un de l'autre, ils ne se quittent guère; à l'aise dans leur domicile, ils en rapportent des écorces fraîches qu'ils préfèrent à celles qui sont sc̀ches ou trop imbibées d'eau. Les femelles portent, dit-on, quatı'c mois; elles mettent bas sur la fin de l'hiver, et prodıisent ordinairement deux ou trois petits; les mâles les quiltent à peu près dans ce temps, ils vont à la campagne jouir des douceurs et des fruits du printemps; ils reviennent de temps on temps à la eabane, mais ils n'y sćjournent plus : les mères y demeurent oceupées à allıiter, à soigner, à élever leurs petits, qui sont on état de les suivre au bout de quelques somaines; elles vont à leur tour se promener, se rétablir à l'air, manger du poisson, des écrevisses, des écorces nourelles, et passent ainsi l'été sur' les eaux, dans les bois. Ils ne se rassemllent qu'en automne, à moins que les inondations n'aient renversé lour digue ou détruit leurs cabanes, oar alors ils se réunissent de honne heure pour en réparel les brèches.

Outre los eastors qui sont en société, on reneontre prartout, dans lo mêrne climat, des castor's solitaires, lesquels rejetés, dit-on, de la société pour lours défauts, ne participent à aucun de ses avantages, n'ont nimaison, ni magasin, et demeurent, commo le blaireau, dans un boyau sous terre : on a mêne appelé ces castors solitinires castors terriers. 
Les castors hahitent de préférence sur les bords des lacs, des rivières et des autres enux douces; cependant il s'en trouve au bord de la mer, mais c'est principalement sur les mers septentrionales, et surtout dans les golfes méditerranés qui recoivent de grands fleuvos, ct dont les eaux sont peu salées. Ils sont ennemis de la loutre; ils la ehassent, et ne lui permettent pas de paraitre sur les eaux qu'ils fréquentent. La fourrure du castor est encore plus belle et plus fournic que colle de la loutre. Mais indépendamment de la fourrure, qui est ee que le castor fournit de plus précieux, il donne encorc unc matière dont on a fait un grrand usago en médecine. Les sauvages tirent dit-on, de la queue dn castor', une luile dont ils se servent comme do topique pour différents manx. La cliair du castor, cuoique grasse et délicate, a loujour's un goût amer assez désagréable.

Lc eastor se scrt de ses pieds de devant comme de mains, avec une adresse au moins égale à celle de l'écureuil; les doigts en sont lien séparés, bien divisćs, an lieu que coux des pierls de derrière sont réunis entre eux par une forle membrane; ils lui servent de nageoires, et s'ćlargissent comme ceux de l'oie, dont le castor a nussi en partie la démarche sur la terre. Il nago beauconp mieux cu'il ne court: comme il a les jambes de devant lion plus courtes que celles de derrière, il marehe tonjours la tête baissće et le dos arqué. 11 a les sens trèshons, l'odorat très-fin, et même susceptible ; il parnât qu'il ne peut supporter ni la malpropreté, ni los mauvaises odour's.

La durćc do sa ric ne pcut ètre bion longue, ct c'est trop sans doute que de l'étendre à quinze ou vingt ans. 


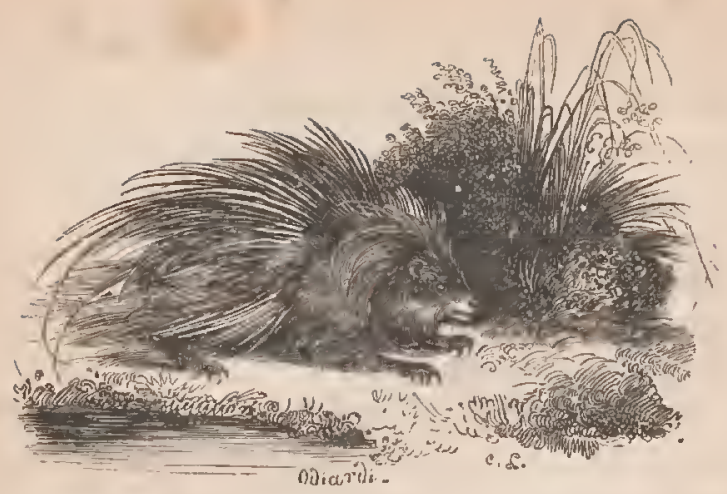

\section{E PORC-EPIC.}

Le pore-épie, quoique originaire des climats les plus chauds de l'Afrique et des Indes, pent vivie et se multiplier dans les pays.moins claauds.

On dit que le porc-épic, comme l'ours, se cache pendant l'hiver et met bas au bout de trente jours. Dans l'état de domesticité, il n'est ni féroce ni farouche, il n'est que jaloux de sa liberté; à l'aide de ses dents do devant, qui sont fortes et tranehantes comme celles du castor, il coupe le hois et perce aisément la porte de sa loge. On le nourrit aisément avec de la mie de pain, du fromage et des fruits ; dans l'état de liberté il vit de racines et de graines sauvages ; quand il peut entrer dans un jardin, il y fait un grand dégât et mange les légumes avec avidité ; il devient gras comme la plupart des autres animaux, vers la fin de l'été, et sa chair, quoique un peu fade, n'est pas mauvaise à manger. 


\section{LF LIEVRE.}

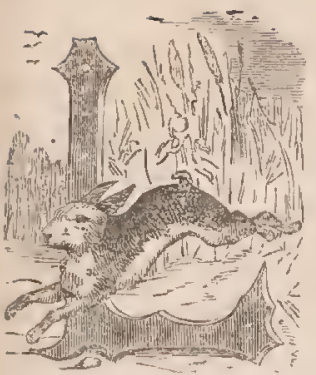

'Estìce du lièvre et clu lapın ont pour nous lo double avantage du nombre et de l'utilité : les lièvres sont universellement et très-abondamment répandus dans tous les elimats de la terre; les lapins, quoique originaires de elimats partienlicrs, multiplient si prodigieusement presque dans tous les licux où l'on veut los transporter, qu'il n'est plus possible de les détruire, et qu'il faut même employer beaueoup d'art pour en diminuer la quantité, quelquefois ineommode.

Dans les cantons eonservés pour le plaisir de la ehassc, on tue quelquefois quatre ou einq cents lièvres dans une seule battue. Ces animaux multiplient beaucoup ; les femelles ne portent que trente ou trente et un jours; elles produisent trois ou quatre petits.

Les petits ont les yeux ouverts en naissant; la mòre les allaite pendant vingt jours, apròs quoi ils s'en séparent et trouvent eux-mêmes leur nourriture ; ils ne s'écartent pas beaucoup les uns des autres, ni du lieu où ils sont nés; eependant ils vivent solitairement, et se forment chacun un gite à une petite distance, comme dc soixante à quatre-vingts pas; ainsi lorsqu'on trouve un joune levraut dans un endroit, on est presque sûr d'en liouver eneore un ou deux antres aux environs. Ils 
paissent pendant la nuit plutôt que pendant le jour ; ils se nourrissent d'herbes, de racines, de feuilles, de fruils, de graines, et préfèrent les plantes dont la sévo cst laiteuse; ils rongent même l'écorce des arbres pendant l'hiver, et il n'y a guère que l'aulne et le tilleul auxqucls ils ne touchent pas. Lorsqu'on en élève, on les nourrit avec de la laitue et des légumes; mais la ehair de ces lièvres nourris est tonjours dc mauvais goût.

Ils dorment ou se reposent au gîte pendant le jour, et ne vivent, pour ainsi dirc, que la nuit : c'est pendant la nuit qu'ils se promènent et qu'ils mangent; on les voit au clair de la lune jouer ensemble, sauter et courir les uns après les autres; mais le moindre monvement, le bruit d'unc feuille (qui tombc, suffit pour les troubler; ils fuient, et fuient chacun d'un côté différent.

Les lièvres dorment beaucoup, et dorment les yeux ouverts ${ }^{1}$; ils n'ont pas de cils aux paupières ${ }^{2}$, ct ils paraissent avoir les yeux mauvais; ils ont, comme par dédommagement, l'ouïe très-fine et l'oreille d'une gorandeur démesurće, relativement à celle de leur corps; ils remucnt ces longucs oreilles avec uno extrême facilitć; ils s'en servent comme de gouvernail pour se diriger dans leur cour'se, qui est si rapide, qu'ils devancent aisément tous les aulres animaux. Comme ils ont les jambes de devant beaucoup plus courtes que celles de derrière, il leur est beaucoup plus commode de courir en montant qu'en descendant; aussi, lorsqu'ils sont poursuivis,

1. Le liivre dort les youx fermés. (Note de M. Flourens.)

2. Le lièvre a des cils aux paupières. (Id.) 
commencent-ils toujours par sagner la montagne; lcur mouvement dans leur coul'se est une cspèce de galop, une suite de sauts très-prestcs et très-pressés, ils mar'client sans faire aucun bruit, parce qu'ils ont les pieds couverts et garnis de poils, même par-dessous; cc sont aussi peut-êtrc les seuls animaux qui aient des poils au dedans de la bouche ${ }^{\prime}$.

Les lièvres ne vivent que scpt ou huit ans au plus, et la duréc de la vie est, commedans les autros animaux, proportionnelle au temps de l'enticr développement du corps; ils prennent presque tout leur accroissement cu un an, et vivent cnviron sept fois un an. Ils passent leur vic dans la solitude et dans le silence, et l'on n'entend leur voix que quand on les saisit avec force, qu'on les tourmente et qu'on les blesse : ce n'est point un cri aigrc, mais une voix assez forte, dont lc son est presque semblable à cclui de la voix humaine. Ils ne sont pas aussi snuvages que leurs habitudes et leur's mour's paraissent l'indiquer; ils sont doux et susceptibles d'unc espèce d'éducation; on les apprivoisc aisément, ils deviennent même caressants, mais ils ne s'attachent jamais assez pour pouvoir devenir animaux domestiques; car ccux même qui ont été pris tout petits et ćlevés dans la maison, dès qu'ils en trouvent l'occasion, se mettent en liberté et s'enfuient à la campagne. Comme ils ont l'oreille bonne, qu'ils s'asscyent volontiers sur' lcurs pattes de derrière, et qu'ils se servent de celles de devant eomme de bras, on en a vu qu'on avait dressés à battre du tambour, à gesticulcr en cadence, ctc.

1. Toules les espìces du genro lièvre ont des poils au dedans de la bouche (Nole de M. Flourens.) 
Lin génćral, le lièvre ne manque pas d'inslinct pour sa propre eonservation, ni do sagaeité pour éehapper à ses ennemis ; il se forme un gîte, il ehoisit en hiver les licux exposés au midi, et en été il se loge au nord; il se cache, pour' n'ètre pas vu, entre des mottes qui sont de la couleur de son poil.

La nature du terroir influe sur ees animaux eommo sur tous les autres; les lièvres de montagne sont plus grands et plus gros que les lièvres de plaine; ils sont aussi de eouleur différente; ceux de montagne sont plus bruns sur le eorps et ont plus de blane sous le eou que ceux de plaine, qui sont presque rouges. Dans les hautes montagnes et dans les pays du Nord, ils deviennent blanes pendant l'hiver et reprennent en été leur couleur ordinaire; il n'y en a que quelques-uns, et ee sont peutêtre les plus vieux, qui restent toujour's blanes, ear tous le deviennent plus ou moins en vieillissant.

La ehasse du lièvre est l'amusement et souvent la seule oeeupation des gens oisifs de la campagne : eomme ello se fait sans appareil et sans dépense, et qu'elle est même ulile, elle convient à tout le monde; on va le matin et le soir au eoin du bois attendre le lièvre ì sa rentrée ou à sa sortie; on le eherehe pendant le jour dans les enlroits où il so gite. Lorsqu'il y a de la fraicheur' dans l'air par un soleil brillant, et que le lièvre vient de se gîtel' après avoir eouru, la vapeur de son corps forme une petite fumée que les chassours aperçoivcnt de fort loin, surtout si leurs yeux sont excrcés à cette espèee d'observation. Il se laisse ordinairement ayproelier de for't près, surtout si l'on ne fait pas semblant de le regarder', et si, au licu d'aller directernent à lui, on tourne obliçue- 
ment pour l'approcher. Il eraint les ehiens plus que les lommes, et lorsqu'il sent ou qu'il entend un elien, il part de plus loin : quniqu'il coure plus vite que les ehiens, eomme il ne fait pas une route droite, qu'il tourne et retourne autour de l'endroil où il a été laneé, les lévriers, qui le ehassent ì vue plutôt qu'à l'odorat, lui coupent le ehemin, le saisissent et le tuent. Il se tient volontiers en été dans les champs, en automne dans les vignes, et en hiver dans les buissons et dans les bois, et l'on peut en tout temps, sans le tirer, le forcer à la course avec des ehiens courants; on peut aussi le faire lrendre par des oiseaux de proie. Les ducs, les buses, les aigles, les renards, les loups, les lommes, lui font ordinairement la guerre : il a tant d'ennemis qu'il me leur éehappe que jar hasard, et il est bien rare qu'ils le laissent jouir du petit nombre de jours que la nature lui a eomptés.

\section{LE LAPIN.}

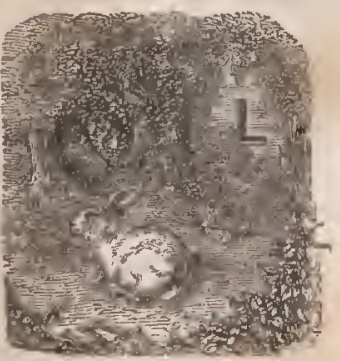

E lièvre et le lapin, quoique fort scmblables tant à l'extérieur qu'à l'intérieur, ne se mêlant point eusemble, font deux espèees dislinctes et séparées.

La fécondité du lapin est encore plus grande que eclle du lièvre; el sans ajouter foi à ce que dit un naturaliste, que d'une seule pairc qui fut mise dans une île il s'en trouva six mille au bout d'un an, il est sûr que 
ces animaux multiplient si prodigicusement dans les pays qui leur convicnnent, que la terre ne peut fournir à leur subsistance. Ils détruisent les herbes, les racines, les grains, les fruits, les légumes, et même los arbrisseaux ct les arlures; ct si l'on n'avait pas contre eux lo sccours des furels ct des chiens, ils feraient descrter les habitants de ces campagnes. Non-sculement le lapin produit plus fréfuemment et en plus grand nombre que le lic̀vre, nais il a aussi beaucoup plus de ressources pour échapper à ses ennernis: il se soustrait aisément aux yeux de l'loume; les trous qu'il se creuse dans la terre, où il se retire pendant lo jour et où il mel ses

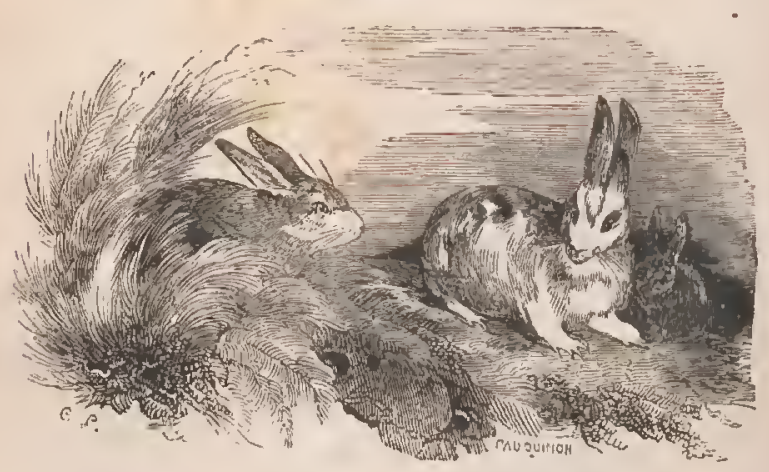

petits, lo meltent ì l'abri du loup, du renard et de l'oiseau de proie; il y habite avec sa famille en pleine sécurité; il y élève et nourrit ses petits jusqu'à l'âge d'environ deux mois, et il ne les fail sortir de leur retraite pour les amener au clehors que quand ils sont tout ćlevés; il leur évite par lì tous les inconvénients du bas âre, jendant leyucl, au contraire, les lièvres périssent 
en plus grand nombre et soufrent plus que dans tout le l'este de la vie.

1 Cela seul suffit pour prouver que le lapin est supérieur' au lièvre par la sagacité : tous deux sont conformés de même, et pourraient également se creuser des retraites; tous deux sont égalenent timides à l'excès, mais l'un, Whs imbécile, se eontente de se formcr un gîte à la surface de la terre, où il demneure eontinuellement exposé, tandis que l'autre, par un instinct plus réfléchi, sc donne la peine de fouiller la terre el de s'y pratiquer un asile. Les lapins clapiers, ou domestiques, varient pour les coulcurs, oomme tous les autres animaux domestiques; le blane, le noir et le gris sont ccpendant les seules qui ontrent iei dans le jeu de la nature: les lapins noirs sont les plus rares; mais il y en a bcaucoup de tout blanes, beaucoup de tout gris, et beaucoup de mêlós. Tous les lapins sauvages sout gris, et, parmi les lapins domestiques, c'est cncore la eouleur dominante, ear dans toutes les portées il se trouve toujours des lapins grris, et môme en plus grand nombre.

Les femelles portent trentc ou trente et un jours, ct Iroduisent quatre, cing ou six, ct quelquefois sept et huit petils.

Quelques jours avant de mettre bas, elles se creusent un nouveau terrier, non pas en ligne droite, mais en zigzag, au fond duquel elles pratiquent une excavation, uprès quoi elles s'arrachent sous le ventre une assez gr'ande quantité de poils, dont elles font une espèce de lit lour reccoir leurs petits. Pendant les deux promiers jours, elles nc les quiltent pas ; clles ne sortent que lor'sque le lesoin les presse, et reviennent dès qu'elles ont 
pris de la nourriture: dans ce temps elles mangent heatrcoup et fort vite; elles soignent aussi el allaitent leurs petils pendant plus de six semaines. Juscu'alors lo père ne les connaît point, il n'entre pas dans ce terrier qu'i pratiqué la mère; souvent même, (prand elle un sort et qu'elle y laisse ses petits, elle en bouche l'entréc avco de la terre ; mais lorsqu'ils commencent à venir au bord du trou, et à manger du séneçon et d'autres horbos que lil mère leur présente, le père semble les reconnaître ; il les prend entre ses pattes, il leur lustre le poil, il lour lèche les youx, et tous, les uns après les autres, ont également part à ses soins.

Ges animaux vivent huit ou neuf ans : comme ils passent la plus grande partie do leur vie dans les terricrs, où ils sont on repos et tranquilles, ils prennent un pou plus d'embonpoint que los lièvres; leur chair est aussi différonte par la coulcur et par le goût; celle des jeunes lapereaux est très-délicate, mais cello des vieux lapins est toujours sèche et dure. Ils sont oriminairos des climats chauds : les Greas les connaissaient, et il parait qute les seuls endroits de l'Europe où il y on cût anciennement étaient la Grèce et l'Espagne. De là on los a transportés dans des climats plus tempérés, comme en ltalie, en France, en Allemagne où ils so sont naturnlisés ; milis dans les pays plus froids, comme on Suède et dans le resto du Nord, on ne pout les élever tque dans les maisons, ut ils périssent lorsqu'on les abandonne à la canpugne. Ilj aiment, au contraire, le chaud excessif, cal ou en troule dans les contréus les plus méridionales de l'Asic et do l'Afrifue, comme au golfe Persirjuc, à la baic de Gatdanha, en Libye, au Sónégul, en Guinće ; ct on en trouro 


\section{ANIMAUX SAUVAGES.}

aussi dans nos îles de l'Amérique, qui y ont été transporlés de l'Europe et qui ont très-bien réussi.

\section{LT COCHON D'TNDE.}

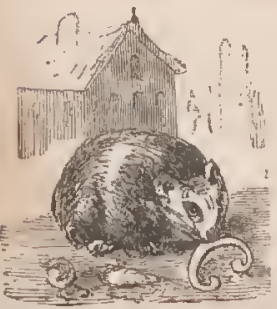

E petit animal, originaire dos climats chauds du Brésil, ne laisse pas de vivre ob de produire dins le climat tompúré, et même dans les payss froils, en lc soignant et le mettant à l'abri de l'intempérie dos sarsons. On ćlève des cochons d'Inde en France, et quoiqu'ils multiplient prodigieusement, ils n'y sont pas en grand nombre, parce que les soins qu'ils demandent ne sont pas compensés par le profit qu'on en tire. I cur poau n'a prosque aucune valeur, et leur chair, quoique mangeable, n'est pas assez bonne pour être recherchóc.

La mòre n'allaite ses petits que pendant douze ou quinze jour's, an plus tard trois semaines après qu'clle a mis bas ; et s'ils s'obstinent à demcurer auprès d'elle, leur pire les maltraite et les true.

Le froid et l'humidité los font mourir, ils se laissent manger par les cliats sans se défendre; les mères mème ne s'irritent pas eontre eux: n'ayant pas le temps de s'attacher à leurs petits, elles ne font aucun effort pour les sauver. Les mâles se soucient cncore moins des petits, ct se liiissent manger eux-mêmes sans résistance. Ils pas- 
sent leur vie à dormir ct manger ; lcur sommcil est court, mais fréquent; ils mangent à toutc heure du jour et de la nuit; ils ne boivent jamais. Ils sc nourrissent de toulcs sortes d'herbes, ot surtout de persil; ils lo prófèrent môme au son, à la farine, au pain; ils aiment aussi beaucoup les ponmes et les autros fruits. Ils mangent prócipitamment, pou à la fois, mais très-souvent. Ils ont un grognement semblable à celui d'un potit cochon de lait, et un cri fort aigu lorsqu'ils ressentent de la doulcur. Ils sont délicats, frilcux, et l'on a de la peine à lcur faire passer l'hiver; il faut les tenil dans un endroit sain, scc ct chaud. Lor'squ'ils sentent le froid, ils se rassemblent ct se scrrent les uns contre les aulres, et il arrive souvent que, saisis par le froid, ils meurent tous ensemble. Ils sont nalurellement doux et privés, ils ne font aucun mal, mais ils sont ćralement incapables do bien, ils ne s'atlaclient point: ils sont doux par tempérament, dociles par faiblesse ct presque insensibles à tout.

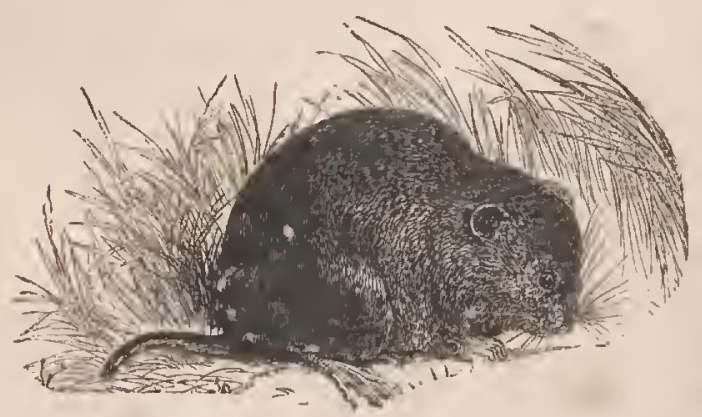




\section{ÉDENTÉS.}

\section{L'UNAU ET L'A I.}

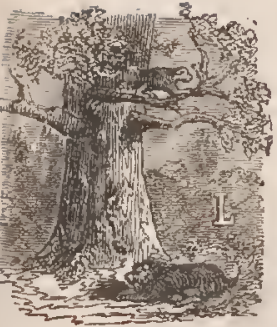

'ov a donnó à ces deux animaux l'épithète de paresseux, à-cause de la lenteur do leurs mouvements et de la difficulté qu'ils ont à marcher. Quoiqu'ils se ressemblent à plusieur's égards, ils diffèrent nćanmoins par des caractères si marqués qu'il n'est plus possible, lorsqu'on les a examinés, de les prendre l'un pour l'autre, ni même de donter qu'ils ne soient de deux espèces très-éloignées. L'unau n'a point de queue, et n'a que deux onglos aux pieds de devant; l'aï porte uno queue courte et trois ongles à tous les piods. L'unau a le museau plus long, le front plus élevé, les oreilles plus apparentes que l'aï; il a aussi le poil tout différent; mais le caractère le plıs distinctif, et en même temps le plus singulier, c'est que l'unau a quarante-huit côtes, tandis que l'aï n'en a que trente. Le commun des animaux ost à tous ces égards très-richcment douć; et les espècos disgraciécs de 1"unau et de l'ai sont peut-être les seulos que la nature ait maltraitées, les seules qui nous offrent l'image do la misère innée.

Voyons-la de plus près; faute de dents, ces pauvres 
animaux ne peuvent ni saisir une proic, ni se nourrir do chair, ni même brouter l'herbe. Réduits à vivre de feuilles et do fruils sauvages, ils consumont du teinps à so traîner au picd d'un arbje, il leur on faut enoore beaucoup poul grimper jusqu'aux branchos; et pendant ce lent et triste exercice qui dure quelquefois plusicur's jours, ils sont obligés de supporter la faim.

A terre, ils sont livrós à tous leur's ennemis : comme leur chair n'est pas absolument manvaise, les hommes of les animaux de proie les chcrolient et les tucnt; il paraît qu'ils multiplient peu, ou du moins que, s'ils produisent fróquemnient, ce n'est qu'on potit nombre; lout concourt done à les détruire, et il est bien diffieile que l'cspòco se maintienne : il est vrai que, quoiqu'ils soient lents, gauchos et presques inhabiles au mouvement, ils sont durs, forts de corlus et vivaces; qu'jls peuvent supporter longtemps la privation do toute nourriture.

\section{LE TAMANOIR, LE TAMANDUA ET LE FOURMILIER.}

Il existe dans l'Amérique méridionale trois espèces d'animaux à long muscau, à gueule étroite et sans aucunes dents, à langue ronde et longue qu'ils insinuent dans les fourmilicipes et qu'ils retirent pour avaler les fourmis dont ils font leur principqle nourriture. Le prenier de cos mangeurs de fourmis est lo Tamanoir. Cet animal agite fréquemment et bruspuenent sa queue lorspüil est 


\section{AXIMILX SIIVAGES.}

irrité, mais il la laisse trainer en marchint, lors fu'il est triucpuille, et il balaye le chemin par oi it passe. Le tamanoir marche lentement, un homine peut aisément l'attcindre à la course; ses pieds paraissent moins fails

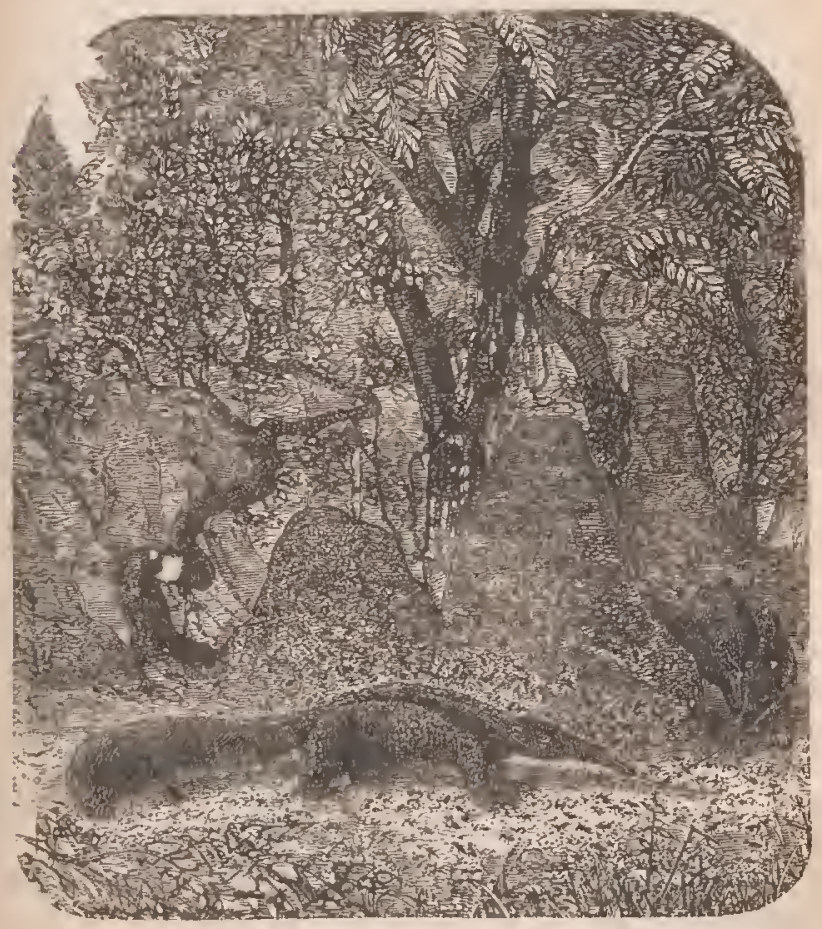

pour marcher que pour grinper et pour saisir des corps arrondis, aussi serre-t-il avec une si grande force une branche ou un bâton qu'il n'est pas possible de les lui arracher.

Lo second do ces animaux est lo Tamandua; il est beau- 
coup plus petit que le tamanoir. Il grimpe et serre aussi bien que lui, et ne marche pas mieux; il ne se couvre pas de sa queue qui ne pourrait lui servir d'abri étant en partie dénuće de poil, lequel d'ailleurs est beaucoup pl1's court que celui de la queue du tamanoir ; lorsqu'il dort, il cache sa tête sous son cou et sous ses jambes de devart. Le troisième de ces animaux est le Fourmilier, bcatcoup plus petit encore que le tamandua. Celui-ci se suspend aux hranches des arbres. Le fourmilier a aussi l? même habitude: dans cette situation ils balancent lent corps, approchent leur museau des trous et des creux d'arbres, ils y insinuent leur lonģue langue et la retirent ensuite brusquement pour avaler les insectes qu'elle a ramassés.

Au restc, ces trols animaux, qui diffèrent si fort par la grandeur et par les proportions du corps, ont néanmoins leaucoup de choses communes, tant pour la conforniation que pour les habitudes naturelles: tous trois se nourlissent de fourmis et plongent aussi leur langue dans 10 miel et dans les autres substances liquides ou visqueuses ; ils ramassent assez promptement les miettes de pain et les petits morceaux de viande hachée; on les apprivoise et on les élève aisćment; ils soutiennent longtemps Ia privation de toute nourriture; ils n'avalent pas toute la liqueur qu'ils prennent en buvant: il en retombe une partie qui passe par les narines; ils dorment ordinairement pendant le jour ct changent de lieu pendant la nuit; ils marchent si mal qu'un homme peut facilement les atteindre à la course dans un licu découvert. Les saulvages niangent leur chair, qui cependant est d'un trùs" mauvais goût. 
On prendrait de loin le tamanoir pour un grand ronard, et c'est par cette raison que quelques voyageur's l'ont appelé renard américain; il est assez fort pour se défendre d'un gros chicn et même d'un jaguar; lorsqu'il en est attaqué, il se bat d'abord debout, et, comme l'ours, il se défend avec les mains, dont les ongles sont meurtrier's; ensuite il se couche sur le dos pour'sc servir des pieds comme des mains, et dans cette situation il est . prosque invincible et combat opiniâtrément jusqu'à la dernière extrémité, ct même, lorsqu'il a mis à mort son ennemi, il ne le làche que très-longtemps après; il résiste plus qu'un autre au combat, parce qu'il est couvcrt d'un griand poil touffu, d'un cuir fort épais, et qu'il a la chair pou sensible ct la vic très-dure.

Le tamanoil, le tamandua et le fourmilier sont des animaux naturcls aux climats les plus chauds de l'Amérique. On ne les trouve point en Canada, ni dans les autres contrées froides du Nouveau-Monde.

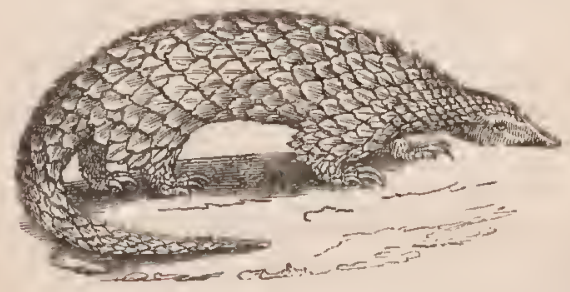




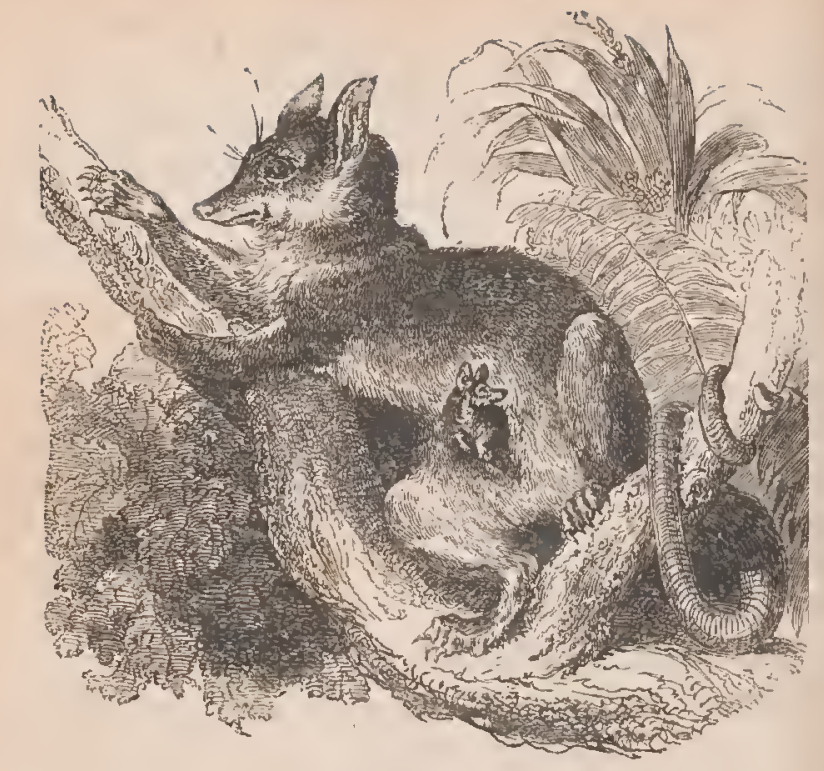

MARSUPIAUX.

\section{LA SARIGUE OU L'OPOSSUII.}

Le sarigñe on l'opossnm est mn animal de l'Amérine qu'il cst aisé de distingner de tous les autres par deux caractires très-singuliers. Le premier de ces caractères est que la fomelle a sous le vontre une ample cavilé dans laquelle elle reçoil el allaite ses petits. Le sccond est que le mâle ê la fomolle ont tous deux le jremier doigt des pichs de derrirre sans onglo el ljen séparé des autres 
doigts, iel qu'est le pouce dans la main de l'homme, tandis quз les quatre autres doigts de ees mêmes pieds de derrière sont plaeés les uns eontre les autres et armés d'ongles erochus, eomme dans les pieds des autres quadirupèdes.

Le sarigue est uniquement originaire des eontrées méridionales du Nouveau-Monde. On le trouve non-seulement au Brésil, à la Guyane, au Mexique, mais aussi à la Floride, en Virginie, et daris les autres régions tempérées de ee continent. Il est partout assez commun, paree qu'il produit souvent et en grand nombre. La plupart des auteirs disent qualre ou einc petits; d'autres, six ou sept.

Les pelits sarigues restent atlachés et eomme collés aux mamelles de la mère pendant le premier âgre et jusqu'à ce qu'ils aient pris assez do for'ce et d'accroissement pour se mouvoir aisément. Ils se laissent alors tomber dans la poehe et sortent ensuite pour se promener et pour ehereher leur subsistanee; ils y entrent souvent pour dormir, pour teter, et aussi pour se eacher lorsqu'ils sont épouvantés : la mère fuit alor's et les emporte tous.

A la seule inspeetion de la forme des pieds de eet animal, il est aisé de juger qu'il marehe mal et qu'il eourt lentement: aussi dit-on qu'un homme peut l'attraper sans même prćcipiter son pas. En revanche, il grimpe sur les arbres avec une extrême faeilité ; il se caele daus le feuillage pour attraper des oiseaux, ou bion il se suspond par la queue, dont l'extrémité est musculeuse et flexible eomme une main, en sorte qu'il peut serrer ot mêrne environner de plus d'un tour les corps qu'il saisit; il reste quelquefois longtemps dans cclle siluation sans mourement, le corps suspendu, la tôte en bas; il ćpie et 
attend le petit gibier au passage; d'autres fois, il se halanee pour sauter d'un arbre à un autre, à peu près comme les singes à queue prenante, auxquels il ressemble aussi par la conformation des pieds. Quoique earnassier et même avide de sang, qu'il se plait à sueer, il mange assez de tout, des repliles, des inseetes, des eannes de sucre, des patates, des raeines, et même des feuilles et des éeorees. On peut le nourrir eomme un animal domestique; il n'est ni féroee, ni farouche, et on l'apprivoise aisément; mais il dégoûte par sa mauvaise odeur, qui est plus forte que eelle du renard, et il déplaît aussi par sa vilaine figure; ear, indépendamment de ses oreilles de ehouette, de sa queue de serpent et de sa gueule fendue jusqu'auprès des yeux, son eorps paraît toujours sale, parce que le poil, qui n'est ni lisse ni frisé, est terne et semble être eouvert de boue. Sa mauvaise odeul réside dans la peau, ear sa ehair n'est pas mauvaise à manger' : c'est même un des animaux que les sauvages ehassent de préférenee et duquel ils se nourrissent le plus volontier's.

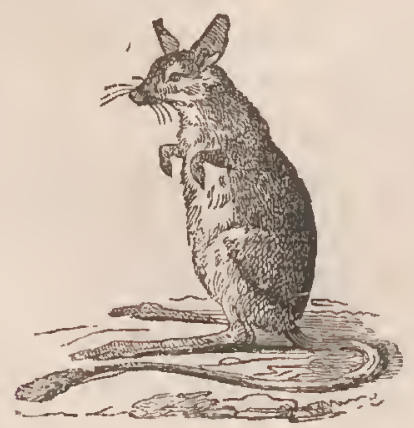


X. 


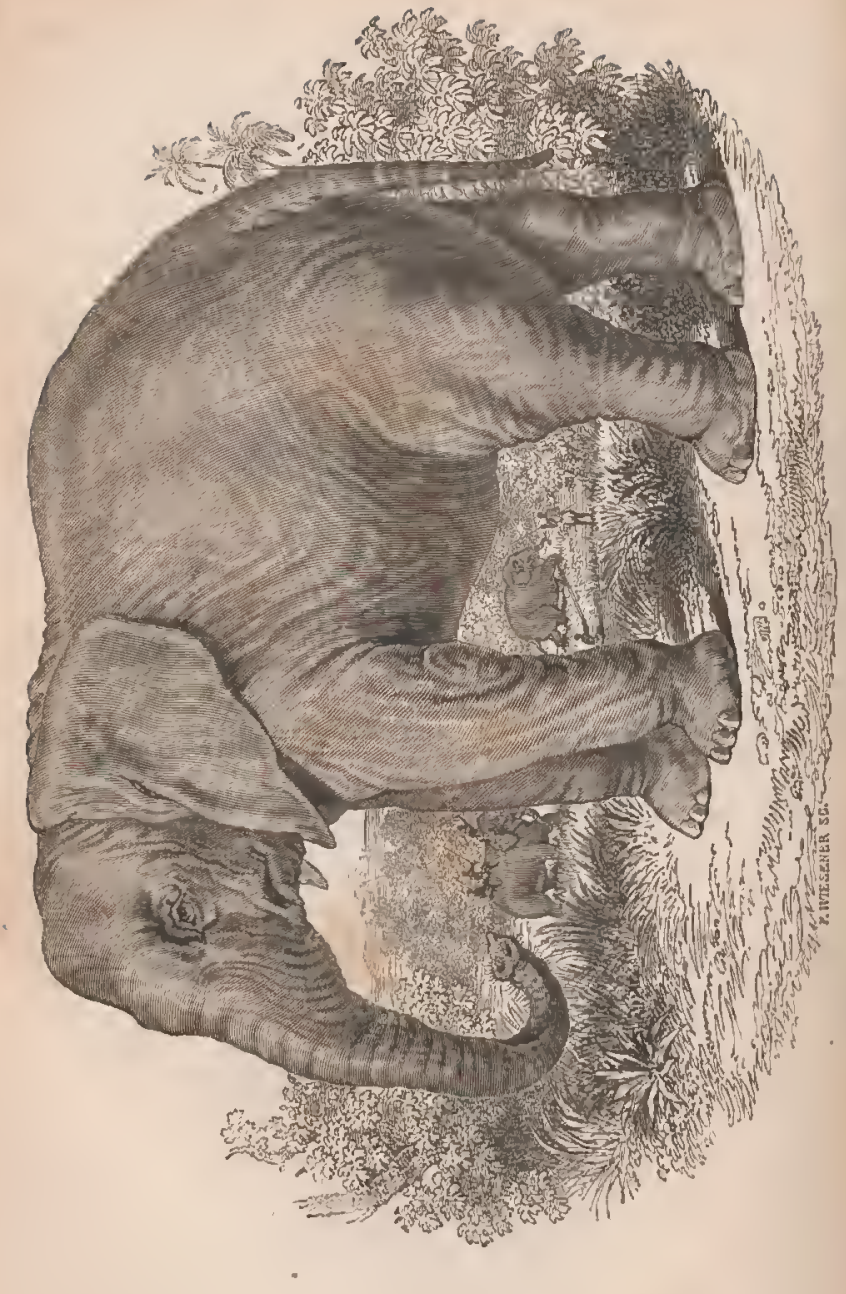




\section{PACHYDERMES.}

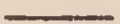 \\ L'ÉLERHANT。}

$\because$

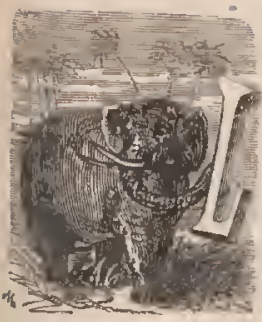

'ÉLÉPHANT est, si nous vonlons ne nous pas compter, l'être le plus considérable de ce monde : il surpasse tous les animaux terrestres en grandeur, et il approche de l'homme par l'intelligence.

Aussi les hommes ont-ils eu dans tous les temps pour ce grand, pour ee premier animal une espèce de vénération. Les anciens le regardaient comme un prodige, un miracle de la nature, ils ont boaucoup exagéré ses facultés naturelles, ils lui ont attribué sans hésiter des qualités intellectuclles et des vertus morales. On respecte à Siam, à Laos, à Pégu, les éléphants blanes comme les mânes vivants des empereurs de l'Inde; ils ont ehacun un palais, une maison composée d'un nombreux domestique, une vaisselle d'or, des mets choisis, des vêtements magnifiques, et sont dispensés de tout travail, de toute obéissance; l'empereur vivant est le seul dovant lequel ils fléchissent les genoux, et ce salut leur est rendu par le monarque.

En écartant les fables de la crédule antiquité, en rejetant aussi les fictions puériles de la superstition toujours 
subsistante, il reste encore assez à l'éléphant, aux yeux mêmes du philosophe, pour qu'il doive le regarder comme un être de la prenic̀re distinction; ìl est digne d'être eonnu, d'être observé.

Dans l'état sauvage, l'éléphant n'est ni sanguinaire, ni féroce; il est d'un naturel doux, et jamais il ne fait abu.s de ses armes ou de sa force; il ne les emploie, il ne les exercè que pour se défendre liui-même ou pour protéger ses semblables. Il a les mœurs sociales, on le voit rarement crrant ou solitaire; il marche ordinairement de compagnie; leplus âgé conduit la troupe, le scconıl d’âge la fait aller et marche le dernier ; les jeunes et les faibles sont au milieu des autres; les mères portent leurs jetils et les tiennent embrassés de leur trompc; ils ne gardent cet ordre que dans les marches périlleuses, lorsqu'ils vont paître sur des terres eultivées ; ils se promènent oul voyagent avec moins de prócaution lans les forcts eb dans les solitudes, sans cependant se séparer absolument ni même s'écarter assez loin pour être hors de portée des secour's et des avertissements. Il serait dangereux de leur faire la moindre injure ; ils vont droit à l'offenseur', ef quoique la masse de leur corps soit très-pesante, leur pas est si grand qu'ils atteignent aisément l'homme le plus léger à la course; ils le percent de leurs défenses, ou, le saisissant avec la trompe, le lancent comme unte pierr'e et achèvent de le tuer en le foulant aux pieds; mais ce n'est que lorsqu'ils sont provoqués qu'ils font ainsi main-basse sur les hommes; ils ne font aucun mal à ceux qui ne les cherclient pas; eependant comme ils sont susceptibles et délicats sur le fait dosinjures, il cst bon d'éviter leur rencontre, et les voyagrcurs qui frci- 
quentent leur pays allument de grands feux la nuit et battent de la caisse pour les cmipecher d'approcher. On prétend que lorsqu'ils ont été une fois attaqués par les homines, ou qu'ils sont toinbés dans quelque embûche, ils no l'oublient jamais el qu'ils cherchent à se venger en toute occasion; comme ils ont l'odorat excellent et pont-être plus parfait qu'aucun des animaux, à cause do la grande étendue de leur nez, l'odeur do l'homine les frappe de très-loin; ils pourraient aisément le suivie à la piste. Ces animaux aiment le bord des fleuves, les profondes vallées, les licux ombragés et les terrains lumides; ils no peuvent se passer d'eau et la troublent avant que de la boire; ils en remplissent souvent lem trompe, soit pour la porter à leur bouche ou seulement pour' se rafraîchir le ncz et s'amuser eu lú répandant à flots ou l'aspergeant à la ronde. Ils ne pelivent supporter le froid et souffront aussi de l'cxoòs de la ehaleur; car, pour éviter la trop grande ardeur du soleil, ils s'enfoncent, autant qu'ils peuvent, dans la profondeur des forêts les plus sombres; ils se mettent aussi assez souvent dans l'eau; le volume énorme de leur corps leur nuit moins qu'il ne leur aide à nager; ils enfoncent moins dans l'eau que les autros animaux, et d'ailleurs la longucur de lour trompe qu'ils redressent en liaut et par laquelle ils respirent, lour ôle toule crainte d'être submergés.

Leurs aliments ordinaires sont des racines, des herbos, des feuilles et du bois tendre; ils mangent aussi des fruits et des grains, mais ils dédaignent la chair et le poisson : lorsque l'un d'entre eux trouve quelque part un pâturage abondant, il apvelle les autres ot les invite 
à venir manger avec lui. Comme il leur faut une grando quantité de fourrage, ils changent souvent de lieu, et lorsqu'ils arrivent à des terres ensemencées, ils y font un dégât prodigieux. Leur corps étant d'un poids énorme, ils écachent et détruisent dix fois plus de plantes avec leur's pieds qu'ils n'en consomment pour leur nourriture, laquelle peut monter à eent cinquante livres d'herbe par jour: n'arrivant jarnais qu'cn nombre, ils dévastent donc une campagne en une heure. Il est difficile de les épouvanter, et ils ne sont guère susceptibles de crainte; la seule cliose qui les surprenne et puisse lcs arrêter sont les feux d'artifice, les pétards qu'on leur lince, et dont l'effet subit et promptement renouvelé lcs saisit et leur fait quelquefois rebrousser olımin. On vicnt très-rarement à bout de les séparer les uns des autres, car, ordinair'cment, ils prennent tous ensemble le même parti d'attaquer, de passer indifféremment ou de fuir.

La femelle porte vingt mois; elle ne produit qu'un petit, lequel au moment de sa naissance a des dents, et est rléjà plus gros qu'un sanglier; cependant les défenses no sont pas cheorc apparentes, elles eommeneent,a percer peu de temps après, et à l'àgo de six mois elles sont de quelques pouces de longueur. L'éléphant à six mois cst déjì plus gros qu'un bœuf, et les défenses continuent de grandir' et de croître jusqu'à l'âge avancé, pourvu que l'animal se porte bien et soit en liberté; ear on n'imagino pas à quel point l'esclavage et les aliments apprêtés détériorent le tempérament et changent les habitudes naturelles de l'éléphant. On vient à bout de le dompter, de le soumettre, de l'instruire, et comme il est plus fort et plus intelligent qu'un autre, il sert plus à propos, plus 
puissamment et plus utilement. Il n'y a aucun éléphant domestique qui n'ait été sauvage arparavant, et la manière de les prendre, de les rlompter, de les soumettre, mérite une attention particulière. Au milieu des forêts et dans un lieu voisin de ceux qu'ils fréquentent, or choisit un espace cqu'on environne d'une forte palissade, les plus gros arbres de la forêt servent de pieux prineipaux contre lesquels on attache les traverses de charpente qui soutiennent les autres pieux : cette palissade est faile à claire-voie, en sorte qu'un liomme peut y passer aisément; on y laisse une autre grandle ouverture par laquelle l'éléphant peut entrer, ct cetle baie est surmontée d'une trappe suspendue, ou bien elle reçoit une barrière qu'on ferme derrière lıi. Pour l'attirer jusque dans celte enccinte, il faut l'aller clercher : on conduit une femolle privée dans la forêt, et lorsqiin'on imagine être à portće de la fairc entendre, son gouverneur l'oblige à faire un cri : le mâle sauvagge y répond à l'instant et se met cn marche pour la joindre; on la fait marcher elle-même en hai faisant de tcinps en temps répéter l'appol; elle arrive la première à l'enceinte, où le mâle, la suivant à la pistc, entre par la mème porte. Dès qu'il se voit enfermé, son ardeur s'évanouit, et, lorsqu'il aper'coit les chasscur's, elle se change en fureur' on lui jette des cordes ì nœuds coulants pour l'aryêter, on lui met dos cntraves aux piods et à la trompe, on amène deux ou trois éléphants privés et conduits par des hommes adroits, on essaye de les attacher avcc l'éléphant sauvage; enfin l'on vicntà bout, par adrosse, par force, par tourment et par carcsse, de le dompter en pen do jour's.

liéléphant, une fois dompté, devient le plus doux, le 
plus obéissant de tous lcs animaux ; il s'attachc à eeluı qui le soigne, il le caresse, lc prévient, et scinble deviner tout co qui peut lui plaire; en pou de temps, il vicnt ì eomprendre les signes et même à entendre l'expression des sons; il distingute le ton impératif, celui de la colc̀re ou de la satisfaction, et il agit en conséquence. Il ne se trompe point à la parole de son maître, il reçoit ses ordres avee attention, les exécute avec prudence, aveo empressement, sans précipitation, car ses mouvcinents sont toujours mesurés, et son earaetère paraît tenir de la gravité de sa masse. On lui apprend aisément à fléchir les genoux pour dommel plus de facilité à ceux qui veulent le monter ; il caresse ses amis avec sa trompe, en salue les gens qu'on lui fait remarquer; il s'en sert pour enlever des furdeaux et aido lui-même à se eharger; il se laisse vêtir et semble prendre plaisir ì se voir eouvert de harnais dorćs ot de housses brillantes. On l'attelle, on l'attache par des traits ì des ehariots, des charrues, des navires, des eabestans : il tire ógalement, continûment et sans se rebuter, pour'vu qu'on ne l'insulte pas par des coups donnés mal à propos, et qu'on ait l'air de lui savoil' şé de la bonne volonté avcc laquelle il emploie sus forces. Celui qui le conduit ordinairement cst monté sul' son cou et se sert d'une verge de fer, dont l'extrémilé fait le croehet, ou qui est armée d'un poinçon avec lequel on le pique sur la tête, à côté des oreilles, pour l'avertir', le détourner ou le presser ; mais souvent la parole suffil, surtout s'il a eu le temps de faire eonnaissance eomplète avec son conducteur et de prendre en lui une entière confiance. Son attachement devient quelquefois si fort, si durable, et son affection si profonde, qu'il refuse ordi- 
nairement de servir sous tout autre, ot qu'on l'a quelruefois vu mourir de regret d'avoir, dans un accès de colère, tué son gouverneur.

L'cs|ièce de l'éléphant ne laisse pas d'être nombreuse, quoiqu'il ne produise qu'une fois et un seul petit tous les deux ou trois ans. Plus la vic des animanx est courte, et plus leur production est nombreuse. Dans l'éléphant, la đurée de la vie compense le petil nombre, et s'il est vrai, comme on l'assure, qu'il vive deux siècles et qu'il prothise jusyu'ì cent vingl ans, claque couple donne quarmute pelits dans cet espace de temps : l'espèce se trouve généralement répandue dans tous les pays méridionaux de l'Afrique et de l'Asie. lls sont fidèles à leur patrie et constants pour leur climat ; car, ruoiqu'ils puissent vivre dans les régions tempérées, il ne paraîl pas yu'ils aient jamais tenté de s'y établir, ni même d'y voyager'; ils étaient jadis inconnus dans nos climatş. Alexantle est le prennier qui ait montré l'éléplunt à l'Europe: il fit jonsser en Grice ceux qu'il avait concuis sur Porus, ef ce furent peut-être les mêmes que Pyrrhus, plusienr's annéus après, employa contre les Romains dans la guerre de Tarente, et avec lesquels Curius vint triomplier it Rome. Amibal ensuite en amena d'Afrique, leur fit passu' la Méditerranée, les Alpes, et les conduisit, pour ainsi -lire, juscu'aux portes de Rome.

ll paraît que le climat de l'Inde méridionale et de l'Afrique orientale est la rraie patric, le pays nalurel cl le séjour le plus convenable à l'élépllant; il y cst bcaucoup plus grand, bcaucoup plus fol't qu'en Guirléc et daus toutes les autres parties de l'Afrique occidentale. L'Indo méridionale et l'Africuc orientale sout done les contries 
dont la terro et le cicl lui conviennent le mienx; et, en effet, il orainl l'excessive chaleur, il n'habite jamais dans les sables brûlants, et il ne se trouve en grand nombro dans les pays des Nègres que le lonor des rivières el non dans les tcrres élevées; au lieu qu'aux Indes, les plus puissants, les plus courag'eux de l'espèce, et dont les armes sont les plus fortos et les plus grandes, s'appelient éléphants de montagnes, et habilent, en effet, les hanteurs où l'air étant plus tempéré, les eaux moins impures, les aliments plus sains, leur nature arrive ì son plein développement et acquiert toute son étendue, toute sa perfection.

La force de cos animaux cst proportionnolle à lcur grandeur : les élépliants des Indes portent aisémont trois ou quatre milliers; les plus pelits, c'est-ì-dire ceux d'Afrique, entòvent librement un poids de deux cents livres avec lcur trompe, et le placent eux-mêmes sur lenrs épaules; ils promnent dans cette trompe une grande quantité d'cau qu'ils rejettent en haut ou à la ronde, à me ou deux toises de distance; ils peuvent porter plus d'un millicr pesant sur leurs défenses; la trompe leur sert ù casser les branclies des arbres, et les défenses à arracher les arbres mêmes. On peut encore juger de lcur force par la vitosse de leur mouvement, comparée a la masse de leur corps ; ils font au pas ordinaire à peu près autant de ehemin qu'un cheval en fait au petit trot, el autant qu'un eheval au galop lorsqu'ils courent, ce qui dans l'état de liberté ne leur' arrive guère que quand ils sont animés de eolère ou poussés par la crainte. Oll inène ordinairement au pas les éléphants domestiques; ils font aisément et sans fatigue quinze ou vingul lieues 
par jour, et quand on veut les presser, ils penvent on filire jusqu'à trentc-cinq ou quarante.

Un éléphant domestique rend peut-ĉtre à son maîtro plus de service que cinq ou six chevaux, mais il lui faut du foin el une nourriture abondante et clooisie. On lui donne ordinairement du riz clu ou cuit, mêlé avec de l'eau, ot on prétend cqu'il faut cent livres de riz par joul' jour qu'il s'entrelienne dans sa pleine vigueur; on lui donne aussi de l'herbe pour le rafraichir, car il est sujet à s'échauffer, et il faut le mener ì l'eau et le laisser baigner deux ou trois fois par jour. Il apprend aisément à se laver lui même; il prend de l'eau dans sa trompe, il la porte à sa bouche pour boire, el ensuite, en retournant sa trompe, il en laisse couler le reste à flots sur toutes les parties de son corps. Pour donner une idée des services qu'il peut rendre, il suffira de dire que tous les tonneaux, sacs, paquets qui se transportent d'un lien à un autre dans les ludes, sont voiturés par des éléphants; (qu'ils peuvent porter des fardeaux sur leurs $\mathrm{col}^{\prime}$ ) $)$, sur lenr cou, sur leurs défenses, el même avec leur gueule, en leur présentant le bout d'une corde qu'ils serrent avec les dents; que, joiguant l'intelligence à la force, ils ne cassent ni n'endomuagent rien de ce qu'on lem confie ; qu'ils font tourner et passer ces paquets du bord des eaux dans un bateau sans les laisscl mouiller, les posant doucement et les arrangeant où l'on veut les placer; que, (quand ils les ont déposés dans l'endıoit qu'on leur montre, ils essayent avec leur trompe s'ils sont bien silués; et que quand c'est un tonnenu qui roule, ils vont d'eux-mêmes cliercher des pierres pour le caler et l'ćlablir solidement, etc. 
Lorsque l'éléphant est bien soigné il vit longtemps, quoique cn captivité, Au r'este, la captivité abrége moins lcur vie que la disconvenance du climat : quelque som qu'on en prenne, l'ćléphant ne vit pas longteinps dans les pays tempérés, et encore moins dans les climats froids. La couleur ordinaire des éléphants est d'un gris cendlé ou noirître; les blancs sont extrêmement rares, et on cite ceux qu'on a vus en différents temps dans quelques endroits des Indes, où il s'en trouve aussi quelques-uns qui sont roux, et ces éléphants blancs et rouges sont très-cstimés.

L'éléphant a les ycux très-petits relativement au volume de son eorps, mais ils sont brillants et spiriluels, et eo qui les distingue de ceux de tous les autres animaux, c'est l'expression pathétique du sentinent et la conduite presque réfléchie de tous leurs mouvements: il les tourne lenlement et avec douceur vers son maitre; il a pour lui le r'cgard de l'amitió, celui de l'attention lorsqu'il parle, le coup d'wil de l'intelligence quand il l'a écouté, celui de la pénétration lorsqu'il veut le prévenir'; il semble réfléchir, délibércr, penser, et ne se déterminel qu'après avoir examiné ot regardé à plusieurs fois et salls prćcipitation, sans passion, les signos auxquels il doit obéir.

Il a l'auie très-bonne, et cet organe est à l'extérieur', comme celui de l'odorat, plus marqué dans l'éléphant que dans aueun autre animal. Ses oreilles sont trèsgrandes, beaucoup plus longues, même à proportion du corps, que celles de l'âne, et aplaties contre la tête comme celles de l'homme; elles sont ordinairement pendantes, mais il les relc̀ve et les remue avee une grande facilité : 
clles lui scrvent à essuyer ses youx, ì les préserver de l'incommodité de ln poussière et des mouehes. Il se délecte au son des instruments et paraît aimer la musique ; il apprend aisćment à marquer la mesure, à se remuer cn cadence, et à joindre à propos quelques accents au bruit des tambour's et au son des trompcttes. Son odorat est exquis, ct il aime avec passion les parfums de toute espèce et surtout les fleurs odorantes; il les choisit, il les cueille une à une, il en fait des bouquets, et, après cn avoir savouré l'odeur, il les porte ì sa bouchc et semble les goûter ; la fleur d'orange est un de ses mets les plus délicieux : il dépouille aveo sa trompe un oranger do toute sa verdure ot en mange les fruits, les flcurs, les feuilles, et jusqu'au jeune hois. Il choisit dans les prairies les plantes odoriférantes, et dans les bois il préfèro les eocotiors, les hananiers, les palmiers, les sagous; et comme ees arbres sont moelleux ot tenclres, il en mango non-seulement les feuilles et les fruits, mais même les branclies, le trone et les racines, car quand il ne peut arracher ces arbres avee sa trompe, il les déracinc avec sos défenses.

A l'égard du sens du toucher, il ne l'a, pour ainsi dire, que dans la trompe, mais il est aussi délicat, aussi distinct dans cette espèee de main que dans celle de l'homme. Cette trompe, composée de membranes, de nerfs et de muscles, est en même temps un membre capable de mouvement et un organe de sentiment. L'animal peut non-seulement la remuer, la fléchir, mais il peut la raecourcir, l'allonger, la courber et la tourner en tous sens. L'extrémité de la trompe est terminée par un rebord qui s'allonge par le dessus en forme de doigt : e'est par le 
moyen de co reborl et de cette espèce de doight que l'éléphant fait tout ce que nous faisons avec les loigts : il ramasse d terre les plus petites pic̀ces de monnaie, il cueille les herbes et les flours en les choisissant unc it une, il dénoue les cordes, ouvrc et forme les portes en tournant les clefs et poussant les verrous; il apprend ì tracer des caractères réguliers avoc un instrument aussi jelit qu'une plume.

La délicatesse du toucher, la finesse de l'odorat, la ficilité du mouvement el la puissance de succion se tronvent done à l'extrómilé du nez de l'óléphant. De tous les instruments dont la nature a si libéralement muni ses prodıctions chéries, la trompe cst peut-être le plus complet et le plus admirable : c'est non-seulement un instrument organique, mais un triple sens, dont les fonctions réunies et combinécs sont en même temps li causc, et produisent les effets de cette intelligence et dc ces fìcultés qui distinguent l'éléphant et l'élèvent audessus de tous les animaux.

Au reste, quoique l'éléphant ait plus de mémoire et plus d'intelligence qu'aucun des animaux, il a cependant le corveau plus petit que la plupart d'entre cux, relativement au volume de son corps. C'est done en vertu de cette combinaison singulic̀re des sens ot de ces facultés uniques de la trompe que cet animal est supérieur aus autres par l'intelligence, malgré l'énormilé de sa masse, malgré la disproportion de sa forme; car l'éléphant cst en même temps un miracle d'intelligonce et un monstre de matière.

Il résulte pour l'animal plusicurs inconvénients de cette conformation bizarre; il pout à peine tourner la 
Lête, il ne peut sc tourner lui-môme, pour rétrograder', qu'en faisant un circuit.

Les oreilles de l'ćléphant sont trìs-longues; il s'en ser't comme d'un éventail, il les fait remuer ot claquer comme il lui plaît; sa quene n'est pas plus longue que l'oreille, of n'a ordinairement que deux pieds et demi ou trois pieds de longueur; elle est assez mcnue, pointue et garnie à l'extrémité d'une houppe de gros poils ou plutôt de filets de corne noirs, luisants et solides.

Le climat, la nourriture et la condition influent heaucoup sur l'aceroissement et la grandeur de l'éléphant; en génúral, ceux qui sont pris jeunes et réduits à cet âgee en captivité n'arrivent jamais aux dimensions entières cle la nature. Ises plus grands éléphants des Indes et des côtes orientales de l'Afrique ont quatorze pieds de haulcur; les plus petits, cqui se trouvent au Sénégal et dans les autres parties de l'Afrique oecidentale, n'ont que dis $0 ! 1$ onze pieds, et tous ceux qu'on a amenés jeunes en Europe ne se sont pas élevćs à cetle hauteur.

Quoique l'éléplant ne se nourrisse ordinairement que d'herbes ot de bois tendre, et qu'il lui faille un prodigieux volume de cette espèce d'aliment pour pouvoir en tirer Ia quantité de molécules organiques nécessaires à la mutrition d'un aussi vaste corps, il n'a cependant pas plusieurs estonacs, comme la plupart des animaux qui se nourrissent de même; il n'a qu'un estomac, il ne rumine pas, il est plutôt conformé comme lo oheval que comme le bocuf ou les autres animaux l'uminants. Quelque grand uque soit l'appétit de l'éléphant, il mange avec modération, et son goût pour la propretć l'emporte sur le sentiinent lu besoin; son adrosse à séparer avec sa trompe 
les bonnes fenilles d'avec les mauvaisns, el, lo soin ru'il a de les bien secouer, pour qu'il n'y reste point d'insectes ni de sable, sont des choses agréables à voir; il aime beaucoup le vin, les liqueurs spiritueuses, l'cau-de-vic, l'arack, etc. On lui fait faire les corvées les plus pénibles et les entreprises les plus fortes, en lui inontrant ul vase rcmpli de ces liqueurs, et en le lui promettant pour' prix de ses travaux; il paraît aimer aussi la funce do tabac, mais elle l'ètourdit et l'enivre; il craint toutes le's mauvaises odeurs, et il a une lorreur si grande pour to cochon, que le seul eri de cet animal l'émcut et le linit fuil.

Nous allons achever de donner une idée du naturel al de l'intclligence de ce singulier animal. Son conducteul' veut-il lui faire faire quelque corvée pénible, il lui explique de cquoi il est question, et lui détaille les raisons qui doivent l'engager à obéir; si l'éléphant marque de la répugnance à ce qu'il exige de lui, le cornac (c'est ainsi qu'on appelle son conductern') promet de lui donner de l'arack ou quelque chose qu'il aime: alors l'animal se prête ì tout ; mais il est dangereux do lui manquer klc parole : plus d'un cornac en a été la victime. Il s'est passéai ce sujct dans le Dekan un trait qui mérite d'ĉtrc rapporté, et qui, tout incroyable qu'il paraît, est cependant exactement virai. Un éléphant venait de se venger de soll cornac en le tuant; sa femme, témoin de ce spectaclc, prit ses deux enfants ot les jeta arx pieds de l'animal, encore tout furieux, en lui clisant: Puisque tu as tué mon mari, ôte-moi aussi la vie, ainsi qu'ù mes enfants. L'ćlćphant s'arrêta tout court, s'adoncit, ot, comne s'il eût été touelı́ de regret, prit avee sa trompe le plus grand 
de ees deux enfants, le mit sur son eou, l'adopta pour' son comae, et n'en voulut point souffrir d'autre.

Si l'éléphant est vindicatif, il n'est pas moins reeonnaissant. Un soldat de Pondichéry, qui avait eoutume do porter à un de ees animaux une eertaine mesure d'araek clıque fois qu'il touchait son prêt, ayant un jour bu plus que de raison, et se voyant poursuivi par la garde, qui le voulait eonduire en prison, se réfugia sous l'éléphant et $s^{\prime} y$ endormit. Ce fut en vain que la garde tenta de l'ar'rcher de cet asile : l'éléphnnt le défendit avee sa trompe. Le lendemain, lo soldat, levenu de son ivresse, flémit $\grave{a}$ son réveil de se trouver eouehé sous un animal d'uno grosseur si énorme. L'éléplıant, qui sans doute s'aperçut de son effroi, le caressa avee sa trompe pour le rassurer, et lui fit entendre qu'il pouvait s'en aller

L'eléphant tombe quelıuefois dans une espèce do folie qui lui ôte sa docilité et le rond nême très-redoutable; on est alor's obligé de le tuer. On se eontente quelquefois de l'attacher avee de grosses ehaines de fer, dans l'espéranee qu'il viendra à résipiscenee. Mais quand il est dims son état naturel, les douleurs les plus áiguës ne peuvent l'engager à faire du mal à qui ne lui en a pas fait. Un éléphant, furieux des blessures qu'il avait reçues à la bataille de Hambourg, courait à travers champs et poussait des eris affreux; un soldat qui, malgré les avertissements de ses eamarades, n'avait pu fuir, peut-être parce qu'il était blessé, se trouva à sa reneontre : l'éléphant craignit de le fouler aux pieds, le prit avec sa trompe, le plaça doueement de côté, et continua sa route. Certain éléphant semblail connaître quand on se moquait de lui, el s'en suuvenir pour s'on venger quand il en trou- 
vait l'ocension. A un homme qui l'avait trompé, en faisant semblant de lui jeter quelque chose dans la gueule, il donna un comp de sa trompe qui le renversa et lui rompit deux ồtes; ensuite de quoi il le foula aux pieds et lui l'ompit une jambe, et s'étant agenouillé, il voulut lui cufoncer ses défenses dans le vontre. Il écrnsa un autre lomme, en le froissant contre unc muraille pour le même sujot. Un peintre lo vouliat dossiner dans une atlitude extraordinaire, qui était de tenir sa trompe levéc et la gueule ouverte; le valct du peintre, pour le faire demeur'er' en cet ćtat, lui jetait des fruits dans ln gueule, et le plus souvent faisait semblant d'en jeter ; il en fut indigné, ot comme s'il ent connu que l'envie que lo peintre avait to le dessiner était la eause de cette importunité, au lien do s'on prenclre au valctil s'adressa au maitre, et lui jela par sa trompe une quantité d'eau dont il gâta le papier' sur lequel le peintre dessinait.

En donnant aux ćléplinnts tout ce qui peut leur plaire, on les rend aussi privés et aussi soumis que le sont los hommes. L'on pout dire qu'il ne leur manque que la parole. Ils sont orgueilleux ot ambitieux, mais ils se sonviennent du bien qu'on leur a fiat et ont de la reconnaissance, jusque-là qu'ils ne inmquent point de baissel la tète pour marquer le respect en passant devant les maisons où ils ont été bien traités. Ils se laissent condnive et eommander par un enfant, maisils veulent ctre loués et chćris. On ne saurait se moquer d'eux ni les injurier qu'ils ne l'entendent, et eeux qui le font doivent prendre garde à eux, car ils seront bien heureux s'ils s'empêchent d'être arrosés de l'eau des trompes de ces animaux ou d'être jetés par terre, le visage contre la poussière. 
Ils saluent en fléchissant les genoux ob on ljaissant la tête, et lorsque leur maîtro veut les monter, ils lui prósentent si adroitoment le pied qu'il s'en peut servir comne d'un dogré. Lorsqu'on a pris un éléphant sauvage ot qu'on lui a lić les picds, lo chasseur l'aborde, le salue, lui fait des excuses de ce qu'il l'a lić, lui proteste que ee n'est pas pour lui faire injure, lui expose que ln plupart du temps il avait faute do nourriture dans son premier ćtat, au lieu que désormais il sera parfaitement bien t'aitć, qu'il lui en fait la promesse. Le chasseur n'a pas plutôt achevé ce discour's obligeant, que l'ćléplıant le suit comme ferail un très-doux agneau.

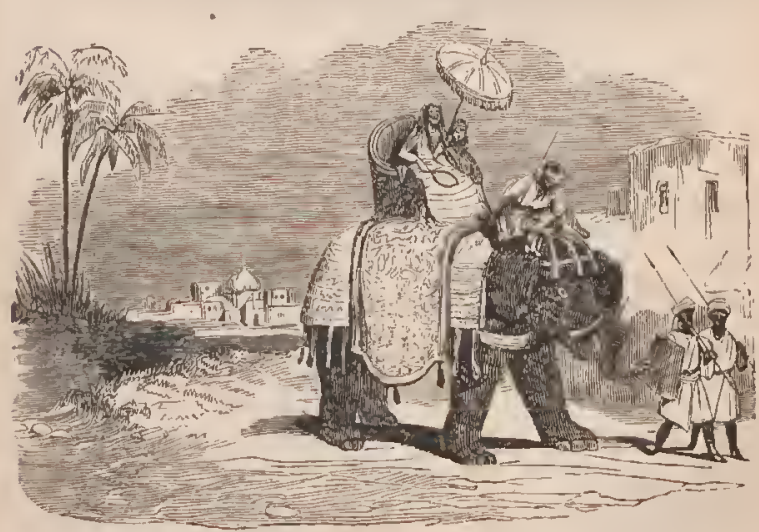




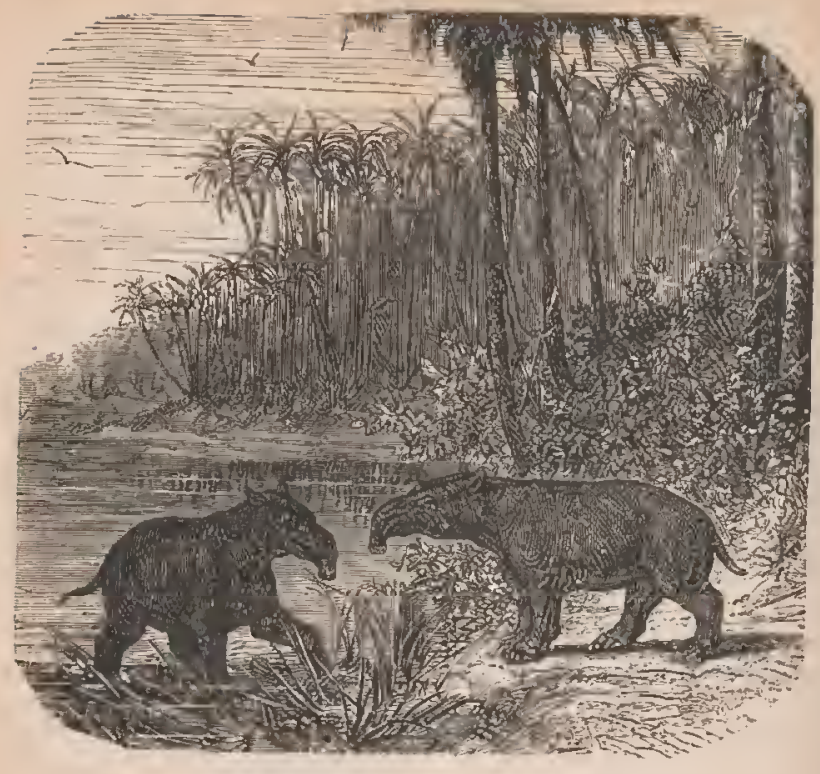

\section{LE TAPIR OU L'ANTA.}

Lo lapir est de la grandeur d'une pelito vache, mais sans cornes ol sans queuc; les jambes courtes, le corps arqué comme eelui d'un cochon, portant une livrée dans sa jeunesse comme le cerf, et ensuite un pelage uniforme d'un brun foncé; la tête grosse et longue avee une espèce do trompe eornme le l'hinocéros, dix dents incisives et dix molaires à chaque mâchoire, caractèro qui le sépare entièroment du genre des bocufs.

Le tapir est un animal triste cl ténébreux, qui ne sort que de nuil, qui ne se plaît que dians les caux, où il habite plus souvent que sur la torre; il vit dans les marais, 
et ne s'éloigne guc̀re du bord des fleuves ou des laes; dìs qu'il est nenaeć, poursuivi ou blessé, il se jette it l'eau, s'y ylonge et y demeure assez de temps pour faire un grand trajet avant de reparaître: ees habitudes, qu'il a eommunes avee l'hippopotame, ont fait eroile à quelques naturalistes qu'il était du même genre, mais il en diffère autant par la nature qu'il en est éloignć par le climat. Quoique habitant des eaux, le tapir ne se nourrit pas de poisson; et quoiqu'il ait la gueule armée de vingt dents incisives et tranelıantes, il n'est pas carnassier; il vil de plantes ct de racines, et ne se sert point de sos armes eontre les autres animaux. Il est d'un naturel doux, timide, et fuit tout comlsat, tout dangel: avec des jambes eourtes et le eorns massif, il ne laisse pas de courir assez vite, et il nage encore mieux qu'il ne eourt. Il marehe ordinairement de cornpagnie et quelquefois en grande troupe; son cuir est d'un tissu très-ferme et si serré que souvent il résiste ì la lualle; sa ehair est fade et grossic̀rc, zependant les Indiens la mangent: on le trouve eommunément au Brésil, au Paraguay, à la Guyane, aux Amazones et dans toute l'étenduc de l'Amérique méridionale, depuis l'extrómité du Chili jusqu'à la Nouvelle-Espagne.

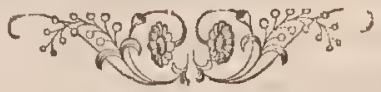




\section{LE RHINOCEROS.}

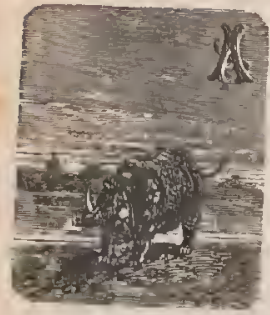

PRÈs l'éléphant, le rhinocéros est le plus puissant des animaux quadrupèdes; il a au moins douze pieds do longueur, depuis l'extrémité du museau jusqu'd̀ l'origine de la queue, six à sept pieds de hrauteur, et la cireonférence du corps à peu près égale à sa longueur. Il approche done de l'éléphant pour le volume et par la masse, et s'il paraît bien plus petit, c'est que ses jambes sont bien plus eourtes à proportion que celles de l'éléphant ; mais il en diffère beaucoup par les facultés naturelles et par l'intelligence: n'ayant l'eçu de la nature que ce qu'elle accorde assez communément à tous les quadrupèdes, privé de toute sensibilité dans la peau, manquant de mains et d'organes distincts pour le sens du toucher, n'ayant, au lieu de trompe, qu'une lèvr'e mobile, dans laquelle consistent tous ses moyens d'adresse. Il n'est guère supérieur aux autres animaux que par la force, la grandeur et l'arme offensive qu'il porte sur le nez, et qui n'appartient qu'à Iui. Cette arme est une corne très-dure, solide dans toute sa longueur, et placée plus avantageusement que les eornes des animaux ruminants : eelles-ci ne munissent que les parties supérieures de la tête et du cou, au lieu que la corne du rhinocéros défend toutes les parties antérieures du museau et préserve d'insulte le mufle, la bouche et la face; en sorte que le tigre attaque plus volontier's l'élépliant, dont il saisit la trompe, 
que le rhinocéros, qu'il ne peut coiffer sans risquer d'ètre éventré; car le corps ct les membres sont recouvorts d'une onveloppe impénétrable, et cet animal ne craint ni la griffe du tigre, ni l'ongle du lion, ni le fer, ni le feu du chasseur'; sa peau cst un cuir noirâtre de la même couleur mais plus épais et plus dur que celui de l'ćléphant. Il n'est pas sensible comme lui ì la piqûro des mouches; il ne peut aussi ni froncer ni contracter sa peau : elle est seulement plissćc par de grosses rides au cou, aux ćpaules et à la croupe pour faciliter le mouvemont de la tête et des jambes, qui sont massives ct terminées par de larges pieds armés de trois grands ongles. Il a la tête plus longue à proportion que l'ćlóphant; mais il a les yeux encore plus petits, il ne les ouvre jamais qu'à demi. La mâchoire supérieure avance sur l'inférieure, et la lèvre du dessus a du mouvcmont el peut s'allonger jusqu'ì six ou sept pouces de longucur. Cettc lòvre, musculeusc et flexible, est une espèee de main ou de trompe tròs-incomplète, mais qui ne laisse pas de saisir avec force et de palper avec adresse. Au lieu de ces longues dents d'ivoire qui forment les défenses de l'éléphant, le rhinocéros a sa puissante corne et deux fortes dents ineisives ì chaque mâchoire; ccs dents incisives sont fort éloignćes l'unc de l'autre dans les inâehoires du rhinocéros; mais indépendamment de ces quatre dents incisives placćes en avant aux quatre coins des mâcloires, il a de phus vingt-quatre dents molaires, six de chaque côté des dcux mâchoires. Ses oreilles se ticnnent toujours droites; elles sont assez semblables pour la forme à celles du cochon, sculcment elles sont moins grandes à proportion du corps : ce sont les seules parties 
sur lesquelles il y ait du poil ou plutôt des soies; l'extrémité de la queue est, comme celle de l'éléphant, garnic d'un bouquet de grosses soies trc̀s-solides et très-dures.

Il est très-certain qu'il existe des rhinocćros qul n'ont qu'une corne sur le nez, et d'autres qui en ont deux; mais il n'est pas égalemont cortain que cettc variété soit constante, toujours dépendante du climat de I'Afrique ou des Indes. Il paraît que les rhinocéros qui 'n'ont qu'une corne l'ont plus grosse et plus longuc que ceux qui en ont deux; c'est avec cette arme, dit-on, que le rhinocćros attaque ct blesse quelquefois mortellement les éléphants de la plus haute taille, lont les janbes élevées permettent au rhinocéros, qui les a bien plus courtes, de lcur jorter des coups de boutoir et de corne sous le ventre, où la peau est la plus sensible et la plus pénétrable; mais aussi lorsqu'il manque son premicr coup, l'éléphant le terrasse et le tue.

La corne du rhinocéros est plus ostimée des Indiens que l'ivoire de l'éléphant, non pas tant à cause de la matière dont cependant ils font plusieurs ouvrages au tour et au ciseau, mais à cause de sa substance même, à laquelle ils accordent plusieurs qualités spéciflques et uroprićtés médicinales; les blanchies, comme les plus rares, sont aussi celles qu'ils estiment et qu'ils recher" chent le plus.

Le rhinocéros, sans être ni féroce, ni carnassier, ni ınême extrêmement farouche, est cependant intraitablc ; il faut même qu'il soit sujet à des accès de fureur que ricn ne peut calmer, car' celui qu'Emmanuel, roi de Por'tugal, envoya au pape en 1513, fit pćr’ir le bâtiment sur lequel on le transportait. Ces animaux sont aussi, conme 
le cochon, très-enclins à se vautrer dans la boue el à se rouler dans la fange: ils aiment les licux humides et marécageux, et ils ne quittent guc̀re les bords des rivières; on en trouve en Asie et en Afrique; mais en génúral, l'espèce en est moins nombreuse et moins répandue que celle de l'éléphant; il ne produit de môme qu'un seul pelit à la fois, et à des distances de temps assez considérables. Dans le premier mois le jeune rhinocéros n'esl guère plus gros qu'un chien de grande taille. Il n'a point en naissant la corne sur le nez.

Sans pouvoir devenir utile comme l'éléphant, le rhinocéros est aussi nuisible par la consommation, et surtout par le prodigieux dégât qu'il fait dans les campagnes; il n'est bon que jrar sa dépouille, sa chair est excellente au goût des Indiens ct des Nègres. Sa pcau fait le cuir le meilleur et le plus dur qu'il y ait au monde, et non-seulement sa corne, mais toutes les autres parties de son corps et même son sang sont estimés comme des antidotes contre le poison ou comme des remèdes à plusieurs maladies.

Le rhinocéros se nourrit d'herbes grossières, de chardons, d'arbrisseatux épineux, et il préfere ces aliments agr'estes à la douce pâture des plus belles prairies; il aine heaucoup les cannes de sucre, et mange aussi de toutes sortes de grains: n'ayant nul goût pour la chair, il n'inquiète pas les petits animanx, il ne craint pas les grands, vit cn paix avec tous et même avec le tigre, qui souvent l'accompagne sans oser l'altaquer. Pline est, je crois, le premicr qui ait parić des combats thu rhinocéros et de l'éléphant: il paraît qu'on les a forcés à sc battre dans les spectacles de Rome, el e'cst probablement de là 
que l'on a pris l'idéc que, quand ils sont en liberté et dans leur état naturel, ils se battaicnt de mênu.

Les rhinocéros ne sc rassemblent pas en troupcs, ni ne marchent en nombre comme les ćléphants; ils sont plus solitaires, plus sauvages, et peut-être plus difficiles à cliasser ct à vaincre. Lls n'altaquent pas les hommes, à moins qu'ils ne soient provoqués; mais alor's ils prennent de la fureur et sont très-redoutables : l'acier de Damas, les sabres du Japon n'entanent pas Icur jeau; les javelots et les lances ne peuvent la percer, elle résiste même aux lualles du mousquet; celles de plomb s'aplatissent sur ce cuir, et les lingots de fer ne le pénètrent pas en cnticr ; les seuls cndroits absolument pénćtrables dans co corps cuirassé sont le ventre, les yeux et le tour des oreilles.

Cet animal a l'oreille bonne et même très-attentive; on assure aussi qu'il a l'odorat excellent; mais on jurétend cqu'il n'a pas l'weil lon, et qu'il ne voit, pour ainsi dire, que devant lui. La petitesse extrême de ses yeux, leur position basse, oblique et cnfoncée, le peu de brillant et de mouvement qu'or y remarque, semblent confirmcr ce fait. Sa voik est assez sourde Iorsqu'il est tranquille; clle r'cssemble en gros au grognement du eoclıo; et, lorsqu'il est en colère, son cri devient aigu et se fuil entendre de fort loin. Il ne vit que de végrétaux; sa eonsommation, quoique considćrable, n'approche pas do celle de l'éléphant, et il paraîl, par lal continuité cl l'épaisseur non interrompuc de sa peau, fu'il jerd aussi beaucoup moins que lui par la transpiration. 


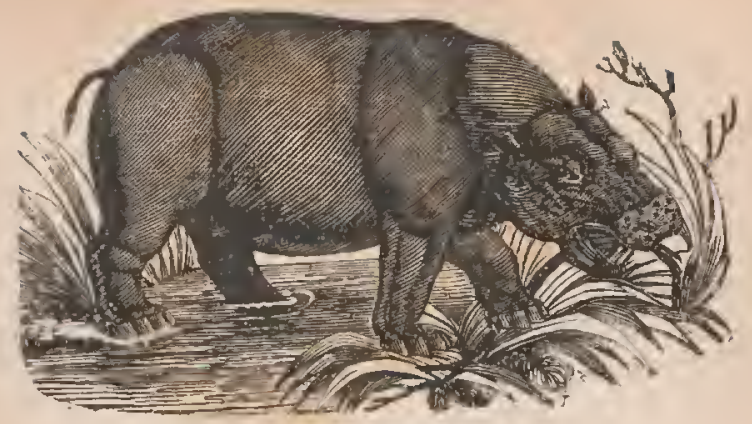

\section{L'HIP P OP OTANE.}

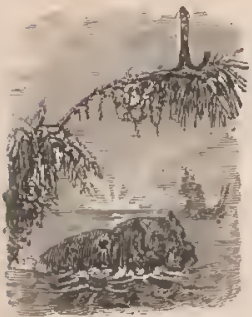

'Hippopotame est un animal dont le corps est plus long et aussi gros que celui du rhinocéros; ses jambes sont beaucoup plus courtes, il a la tête moins longue et plus grosse à proportion du corps; il n'a de cornes ni sur le nez comme le rhinocéros, ni sur la têtecommc les animaux ruminants. Son cri de doulcur tenant autant du hennissement du cheval que du mu* gissement du buffle, il se pourrait que sa voix ordinaire fût semblable au hennissement du cheval, duquel néanmoins il diffère à tous autres égards ; et si cela est, l'on peut prósumer que ce seul rapport de la ressemblance de la voix a suffi pour lui faire donner le nom d'llippopotame, qui veut dire chevalde rivière. Les dents incisives de l'hippopotame, et surtout les dents canines dans la mâchoire inférieur'e sont très-longues, très-fortes et d'une substance si dure qu'elle fail feu contre le fer. Cette matière des dent 
canines de l'hippopotame est si blanche, si nelle et si dure, qu'elle est de benucoup préférnble à l'ivoire pour faire des dents artilicielles et postiches. Les rlents incisives de l'hippopotame, surtout colles de la mâchoil'e inféricure, sont très-longues, cylinclicques et cannclées; les dents canines, qui sont aussi très-longues, sont courbćes, prísmaliques et coupantes. Les deuts molaires sont carrécs ou barlongues, asscz scmblables aux dents mâchelic̀res de l'homme, et si grosses qu'une sculo pèso plus de trois liv'es; les plus grandes incisives et canines ont jusqu'ì douzo et même seize pouces de longueur, et pèsent quelquefois douze ou treize livres chacune.

Avec d'aussi puissantes armes et une force prodigieusc de corps, l'hippopotane pourrait se rendre redoutable à tous les animaux; tnais il est naturellement doux; il est d'aillcur's si pesant et si lent à la cour'se, qu'il ne pourrait attraper aucun des quadrupèdes; il nage plus vite qu'il ne court, il chasse le poisson el en fait sa proie; il se plait dans l'eau, ct y' séjourne aussi longtemps que sur la terre. 11 ne nage aisément que par la grande capacité de son ventre, qui fait que, volume pour volume, il est à peu près d'ın poids égal ì l'eau : d'ailleurs, il se tient longtemps au fond de l'eau, et y marche comme en plein air, et lorsqu'il on sort pour paîlee, il mange des cannes de sucre, des jones, du millet, du riz, des racines; il en consomme et déltuit une grande quantité, et il fait beaucoup de dommagre dans les terres cultivées; mais comme il est plus timide sur terre que dans l'eat, on vient aisément à bout de l'ćcarter'; il a les jambes si courtes, qu'il ne pourrait échapper par la fuite, s'il s'éloignail du bord des eaux; sa ressource, lor'squ'il est en danger, est de se jeter à l'eau, de s'y plongel' 
et de faire un grand trajet avant de reparaître; il fuil ordinairement Ior'squ'on le chasse, mais, si l'on vient à le blesser, il s'irrite, et sc retournant avec fureur, se lance contre les barques, les saisit avec les dents, en enlève souvent des pic̀ces, ct quelquefois les submerge.

Cet animal n'est en grand nombre que dans quelques endroits, et il paraît même que l'espèce en est confinée a des climats particulicrs, ct qu'elle ne se trouve guère que dans les fleuves de l'Afrique.

\section{LE ZEBRE.}

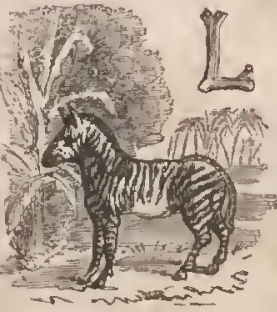

₹ zèbre cst peut-être de tous les animaux quadrupèdes le mieux fait ct le plus élégamment vêtu : il a la figure et les grâces du chcval, la légrèreté du cerl', et la robe rayéo de rubans noir's et blancs, disposés alternativement avec tant de réginlarité et de symétric qu'il semble quc la nature ait enployé la règle et le compas pour la peindre: ecs bandes alternatives de noir et de blane sont d'autant plus singlulières qu'elles sont étroites, parallèles et très-exactement séparćes comme dans une étoffe rayée; que d'ailleur's, elles s'étendent non-seulement sur le corps, mais sur la tête, sur les cuisses et les jambes, et jusque sur les oreilles et la queue; en sorle que de loin cet animal paraît 
eomme s'il était environné partout de bandelettes qu'on aurait pris plaisir et employé beaucoup d'art à disposer régulièrement sur toutes les parties de son eorps. Dans la femolle ces bandes sont alternativement noires et blanehes; dans le mâle elles sont noires et jaunes, mais toujours d'une nuance vive of brillante sur un poil eourt, fin et fourni, dont le lustre augmente eneore la beauté des eouleurs. Le zèbre est, en général, plus petit que le eheval el plus grand que l'âne ; et quoiqu'on l'ait souvent comparé à ces deux animaux, qu'on l'ait même appelé cheval sauvage et âne rayé, il n'est la copic ni de l'un ni de l'autre, et sorait plutôt leur modèle.

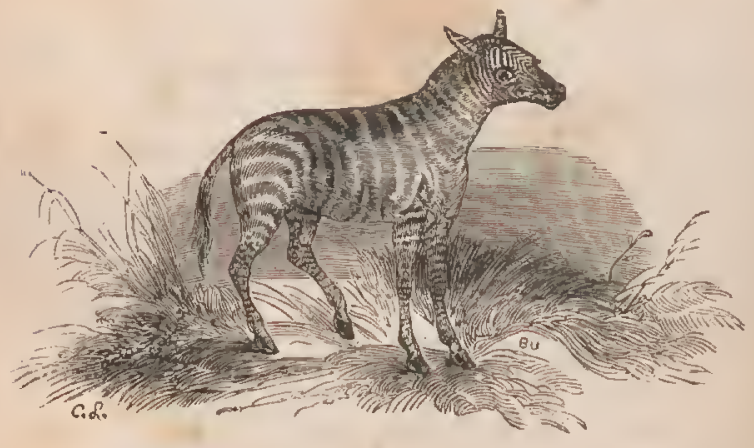


RUM INANTS.

\section{LE CHAMEAU ET LE DROMADAIRE.}

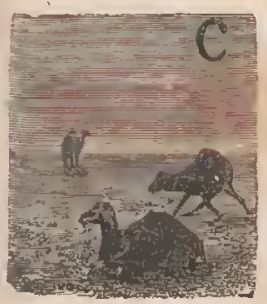

Es deux noms, dromadaire el chameau, ne désignent pas deux espèces différentes, mais indiquent seulement deux races distinetes, et subsistantes de temps immémorial dans l'espèce du chameau: le principal et, pour ainsi dire, l'unique raractèr's sensible par lequel ees deux raees differrent, consiste en ce que le chameau porte deux bosses, et que le dromadaire n'en a qu'une : il est aussi plus petit et moins fort que le chameau; mais tous deux se mêlent, produisent ensemble, et les individus qui proviennent de cette raee eroisée sont ceux qui ont le plus de vigueur et qu'on préfère à tous les autres. II paraît, depuis que l'on a déeouvert les parties de l'Afrique et de l'Asie inconnues aux anciens, que le dromadaire est sans eomparaison plus nombreux et plus généralement répandu que le clrameau : eelui-ei ne se trouve guère que dans le Turkestan et dans quelques autres endroits du Levant; tandis que le dromadaire, plus commun qu'aucune autre bête de somme en Arabie, se trouve de même en grande quantité dans toute la partie septentrionale de l'Afrique, 
ct qu'on le retrouve en Égypte, en Perse, dans la Tartaric méridionale et dans les parties septentrionales de l'Incle.

Le dromadaire occupe done des terres immenses, et le channeau est bornć à un petit terrain; lc premier habite des régions arides et chaudes, le second, un pays moins seo ot jlus tempérć; et l'espèce entìre, tant des uns que des autres, paraît ôtre confinée dans une zone de trois ou quatre ecnts lieues de largeur. Cet animal paraît ĉtre or'iginaire d'Arabie; car non-seulennent c'est le pays où il est en plus grand nombre, mais c'est aussi celui auquel il est le plus conforme : l'Arabie est le pays du monde le plus aride, et oí l'eau est la plus rare; le chameau cst le plus sobre des aninaux, et peut passel plusieurs jours sans boire; le terrain est prespre partout sce et sablonneux; le chamcau a les pieds faits pour marcher dans les sables, et ne peut au contraire se sontenir dans los terrains humides et glissants; l'lerbo et les pâlurages manquant à cotte terro, le bouf y mancjue aussi, et le chanican romplace cette bête de sommo. On a inutilement essayó de multiplier les chameanx en Espagne, on les a Vainement transportés en Anćrique, ils u'ont réussi ni dans l'un ıi, dans l'autre climat, et dans les grandes Indes on n'en trouve grure au delil de Surate et d'Orinus. Les Arabes regartcul le chameau eomine un jresent du ciel, un animal sacrí, sans le secours duquel ils ne pourmient ni sulssisict, ni connmcrcei, ni voyager. Le lait des clıaneaux fait leur nomrviture ordinaire; ils en mangent aussi la chnir, surtout celle des jeuncs, qui est très-bonne ì leur groûl; le poil de ces aninaus, qui est fin of moolleus, et yui so 
renouvelle tous les ans, leur sert à faire los étoffes dont ils se vêtisscnt et se moublent; avoc leurs chancaux, non-seulement ils ne manquent do rien, mais même ils ne craignent rien; ils peuvent mettre en un seul jour cinquante lieues do désert cntre eux et leurs ennemis.

Qu'on se figure un pays sans verdure et sans eau, un soleil Jrûlant, un eiel toujours sec, des plaines sablonneuses, des montagnes eneore plus arides, sur lesyuelles l'wil s'étend et le l'egard se perd sans pouvoir s'arrêter sur aneun objct vivant, une terre morte, ot ponr ainsi dire écoreliée par los vents, laquelle ne présente que des ossements, des eailloux jonchćs, des l'ocher's debout ou renvorsés, un désert entièrement llćcouvert, où le voyagcur n'a jamais respiré sons l'ombrage, où rien ne l'aceompagne, rien ne lui rappelle la nature vivante : solitude absolue, mille fois plus aflirouse que eello des forêts; car lọ rrbres sont encore dos êtres pour l'homme qui se voit scul; plus isolé, plus dénué, plus perdu dans ces lieux vides et sans bormes, il voit partout l'espace comme son tombeau; la lumière du joür, plus triste que l'ombre de la nuit, ne renaît que pour éclairer sa nudité, son inpuissance, et pour lui prósenter l'horreur de sa situation, en reculant à scs yeux les barrières du virle, en étendant autour de lui l'abîme de l'immensité qui le sépare de la terłe habitée; immensité qu'il tontorait en vain de parcourir, ear lis faim, la soif et la chaleur brûlante pressent tous les instants qui lui restent entre le désespoir et la mort.

Cependant l'Arabe, à l'aide dı chameau, a su firanchir et niôme s'approprier ees lagunes de la nalure; elles lni servent d'asile, elles assurent son repos et le main- 
tiennent dans son indépendance. L'Arabe, qui se destine au métier de pirate de terre, s'endurcit do bonne heure à la fatigue des voyages; il s'essaye à se passer du sommeil, à souffrir la faim, la, soif et la ehaleur. En mêmo temps, il instruit ses elımeaux, il les ćlève et les exereo dans eette même vue; peu de jours aprìs leur naissance, il leur plie les jambes sous le ventre, il les eontraint it demeurer à terre et les cliarge, dans celte situation, d'un poids assez fort qu'il les accoutume à porter et qu'il ne leur ôle que pour leur en donner un plus fort. Au lieu de les laisser paitre à toute heure et boire à lcur' soif, il commenee par régler leurs repas, et peu à peu les éloigne à de grandes distanees, en diminuant aussi la quantité de la nourriture. Lorsqu'ils sont un peu forts, il les exeree à la course, il les excite par l'exemple des chevaux et parvient à les rendre aussi lćgers et plus robustes; enfin, dès qu'il est sûr de la foree, de la léğ̀ reté et de la sobriété de ses chameaux, il les charge de ee qui est néeessaire à sa subsistance et à la leur, il part avec eux, arrive sans etre attendu aux confins du cléser't, arrôte les premier's passants, pille les habitations écartées, charge ses elımeaux de son lutin; et s'il est poursuivi, s'il est forcé de précipiter sa retraite, e'est alors qu'il développe tous ses talents et les leurs : monló sur l'un des plus légers, il eonduit la troupe, la fai mareher jour et nuit, presque sans s'arrèter, ni boire ıi manger; il fait aisément trois conts lieues en huit jour', et pendant tout ee temps de fatiguc et de mouvement, il laisse ses ehameaux chargés; il ne leur donne cliaque jour qu'une heure de repos et une pelote de pâtc ; souvent ils eourent neuf ou dix jour's sans trouver de l'eau, 
ils se passent de boire; et lor'sque par hasard il se trouve une mare à quclquc distancc de leur route, ils sentent l'cau de plus d'unc demi-lieuc; la soif qui los presse leur fait doubler le pas, et ils boivent cn une sculc fois pour tout le temps passé et pour autant de temps à venir; car souvent lcurs voyages sont de plusieurs semaines, ct leurs tcmps d'abstinence durent aussi longtemps que leurs voyages.

En Turquie, en Persc, en Arabie, en Égypte, en Barbarie, le transport des marchandises ne se fait que par le moyen des chameaux. Des marchands ct autres passager's se réunisscnt en caravanc pour éviter les insultes et les pirateries des Arabes; ces caravanes sont souvent très-nombrcuses et toujour's composées de plus de chimeaux que d'hommes; chacun de cos chamcaux est chargé selon sa force : il la scnt si bien lui-même, que, quand on lui donne unc charge trop forte, il la refusc el r'este constamment couché jusqu'à ce qu'on l'ait allégée. Ordinairement lcs grands chameaux portent un millier, et même douze cents pesant, les plus petits six à sept cenis. Dans ces voyages de commerce, on ne précipite pas lcur marche; comme li route est souvent do sept ou huit cents lieucs, on règlc leur mouvement et leurs journécs; ils ne vont que le pas et font chaque jour dix à douze lieucs; tous les soirs on lcur ôte leur charge ct on les laissc paitre cn libcrté. Si l'on est en pays vort, dans une bonne prairie, ils prennent en moins d'une licuro tout co qu'il leur faut pour en vivre vingt-quatro, et pour ruminer pendant toute la nuit; mais rarement ils trouvent de ces bons pâturages, et cetto nourriturc délicate ne leur est pas nécessairo; ils semblent même 
préférer aux herbes les plus douces l'absinthe, le char' don, l'ortie, le genêt, l'acacia et les autres végétaux épineux; tant qu'ils trouvent des plantes à brouter, ils se passent très-aisément de boire.

Au reste, eette facilité qu'ils ont dc s'abstenir longtemps de boire n'est pas de pure habitude, e'est plutôt in effet de leur conformation.

Si l'on réfléchit sur les difformités, ou plutôt sur les non-conformités de cet animal avec les autres, on ne pourra douter que sa nature n'ait été eonsidérablement altérée par la contrainte de l'esclavage et par la eontinuité des travaux.

On n'en a jamais fait qu'une bête de somme qu'on né s'est pas même donné la peine d'atteler ni de faire tirer', mais dont on a regardé le corps comme une voiture vivante qu'on pouvait tenir chargée et sur'chargćc mêne pendant le sommeil; car, lorsqlion est pressé, on se dispense quelquefois de leur ôter le poids qui les acoable et sous lequel ils s'affaissent pour dormir, los jambes pliécs et le corps appuyé sur l'estomac; aussi portent-ils . tous les cmpreintes de la servitude et les stiginates de la douleur.

Ces pauvres animaux doivent souffrir beaucoup, cal' ils jettent des cris lamentables, surtout lorsqu'on les surcharge ; cependant, quoique continucllement excédés, ils ont autant de cour que de docilité; au prenier signe îls ploient les genoux et s'acoroupissent jusqu'à terre pour se laisser charg'el dans cette situation, ce qui évite à l'homme la peine d'élever les fardeaux à une grande hauteur; dès qu'ils sont chargés ils se relèvent d'euxmômes sans être aidés ni soutenus; celui qui les con- 
duit, monlé sur l'un d'entre cux, les précède tous ct leur fait prendre le même pas qu'à sa monture. On u'a besoin ni de fouet, ni d'éperon pour les exciter; mais lol'squ'ils commencent à être fatigués, on souticnt leur courage ou plutôt on charme leur cnnui par le chant ou le soll de quelque instrument; leurs conducteurs sc rclayent à chanter, et los'squ'ils veulent prolonger la route et doubler la journée, ils ne leu' donnent qu'une lieure de r'epos, après quoi, reprenant leur chanson, ils les reinettent en marche pour plusieur's heures de plus, et le chant ne finit que quand il faut s'arrêter'; alor's les chameaux s'accroupissent de nouveau et se laissent tomber avec leur cliarge : on leur ôte lo farrleau cul clénouant les cordes et laissant couler les ballots des deux côtés; ils restent ainsi accroupis, couchés sur le ventre et s'endorment au milieu de lour bagage, qu'on rattache le lendemain avec autant de promptitude et de facilité 'qu'on l'avait détaché la veille.

La femelle portc près d'un an, et, comme tous lis autres grands animaux, ne produit qu'un petit; son lail est abondant, épais, et fait une bonno nouriture, mêmo poù les hommes, en le mêlant avee une plus grancle untantité d'eau. On ne fait guère travaillor los lemelles; on les laisse paître un liberté; le prolit que l'on tire du leur produit et de lour lait surpasse peut-être celui 'ju'on tirerait de leur travail. Plus los chameaux sont gras et plus ils sont capables de résister à de longues fatigues. Leurs bosses no paraissent être formées que de la suralondance de la nourriture; car dans de grauds voyitges cì l'on est obligé de l'épargner, ol où ils soulfreit somvent la fain et la soif, ees bosses dinimuent jeu it pen 
et se réduisent au point que la jlaee et l'éminence n'en sont plus marquées que par la hauteur du poil, qui est toujours beaucoup plus long sur ces parties que sur le reste du dos; la maigreur du eorps auginente à mesure yque les bosses diminuent.

Le petit elıameau tette sa mère pendant un an, et lorsqu'on veut le inénager, your le rendre dans la suite plus fort et plus robuste, on le laisse en liberté teter ou laître pendant les premières années, et on ne eommenee à le charger et à le faire travailler qu'à l'àğe de quatre ans. Il vit ordinairement quarante et même einquante ans, et e'est sans fondement que quelques auteur's ont avancé qu'il vivait jusqu'à eent ans.

Le ehameau vaut non-seulement mieux que l'éléphanl, mais peut-être vaut-il autant que le eheval, l'âne et le bouf tous réunis ensemble; il porte seul autant que deux mulets; il mange aussi peu que l'âne, el se nourrit d'herbes aussi grossières; la femelle fournit du lait pendant plus de temps que la vache; la chair des jeunos chameaux est bonne et saine, eornmo eelle du veau; leul' poil est plus beau, plus recherché que la belle laine.

\section{LE LAMA ET LE PAC.}

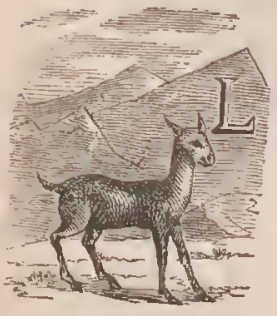

E Pérou est le pays natal, la viais patrie dles lamas : on les eonduil, ì la vérité, dans d'autres provinces, eomme à la Nouvelle-Espagne, mitis e'est plutôt pour la euriosité qu10 pour l'utilité; au lien que dans lonte l’ćtendue du P'óror, clepuis Polosi 
jusqu'à Caracas, ces animaux sont on très-grand nombre; is sont aussi de la plus grande nécessité; ils font seuls toute la richossc des Indiens et contribuent beaucoup à celle des Espaghiols. Leur ehair est bonne à unanger ; leur poil est une laine fine d'un cxcellent usage, et pendant toute leur vie ils servent constamuent à transporter toutes les denrées du pays; leur chirrge ordinaire est de cent einquante livres, et les plus forts en portent jusqu'à deux cent cinquante. lls font des voyages assez longs dans des pays impraticables pour tous los autres animaux; ils marchent assez lentement et ne font que quatre ou cing lieues par jour; leur démarche est grave et ferme, lour jas assuré; ils descentent des ravines précipitées et surnantent des rochers escarpés, où les hommos même ne peuvent les accompagner; ordinairoinent ils marchent yuatre ou cinq jours rle suite, après quoi ils veulent du repos, et prennent d'eux-mêmes un séjour de vingt-quatre ou trente heures avant de se remettre en marche. On les occupe beaucoup au transport des riches matières que l'on tire des mines du Potosi.

Leur accroisscment est assez prompt et leur vie n'est pas bien longue; ils sont en état de produire à trois ans, en pleine vigueur jusqu'c̀ douze, et its commeneent cnsuite à répérir, en sorte qu'à (junze ils sont entièreinent usés. Lerur naturel paraît ĉtre inodelé sur celui dus Américains; its sunt doux et flegmatiques, et font tout avec poids et mesure : lorspu'ils voyagent et qu'ils venlent s'arrêter pour quelques instants, ils plient les genoux avec la plus mrande préran!ion, ot haissent le corps ('n I"'oportion afin d'empêcher leur charge de tomber ou de 
sc déranger, et dès qu'ils entendent le eoup de sifflet de leur condueteur, ils se relèvent avce les mêmes précautions et se remettent en marche. Ils broutent ehemin fassant et partout où ils trouvent de l'herbe, mais jamais ils ne mangent la nuit, quand même ils auraient jeûné pendant le jour; ils emploient ee temps à ruminer; ils dorment appuyés sur la poitrine, les pieds repliés sous le ventre, et ruminent aussi dans cette situation. Lor'squ'on les excède de travail et qu'ils succombent une fois sous le faix, il n'y a nul moyen de les faire r'elever; on les frappe inutilement, ils s'obstinent à demeurer au lieu même où ils sont tombés, et si l'on eonïinue de les inalIraiter, ils se désespèrent ct se tuent, en baltant la torı it droits et à gauelıe avec leur tète. Ils ne se défendent ni des pieds ni des dents, et n'ont pour ainsi dire, d'autres amnes que celles de l'indignation; ils crachent à la face de ceux qui los insultent, et l'on prétend que celte salive qu'ils laneent dans la colère est âcre et mordicante au point de faire lever des anpoules sur la peau.

Les lamas sont hauts d'environ quatre pieds, et leur colps, y compris le cou ct la tête, en a einq ou six de lougucur. Ils ne produisent ordinairement qu'un petit et très-rarement deux. La mère n'a aussi que deux mamellos, ot le petit la suit au moment qu'il est né. La chair des jounes est très-bonne à manger, eelle des vieux est sc̀che et trop dure; cn gónéral, celle des lamas domestiques est bien meilleure yuc celle des sauvages, et leur luinc est aussi plus douce. Leur peau est assez ferme; les ludione on faisaient leur cliaussure, et les Espagnols l'emploient pour faire des harnais.

Ces animaux, si utiles et mème si nécessaires dans le 
pays qu'ils habitent, ne coûtent ni entretien ni noulriture; comme ils ont le picd fourchn, il n'est pas nécessaire de les ferrer ; la laine épaisse dont ils sont converts dispense de les bâter; ils n'ont besoin ni de grain, ni d'avoine, ni de foin; l'herbe verte qu'ils broutent euxmêmes leur suffit, et ils n'en prennent qu'on netite quan-. tité; ils sont encore plus sobres sur la boisson: ils s'abreuvent de leur salive, qui, dons cet animal, est plus abondante que dans aucun autre.

Les pacos ou vigognes sont aux lamas une cspèce succursale; ils sont plus petits et moins propres au service, mais plus utiles par leur dépouille; les pacos que l'on appelle aussi alpaques, et qui sont les vigognes domestiques, sont souvent toutes noires et quelquefois d'un brun mêlé de fauve. Les vigognes ou pacos saurages sont de couleur rose sèclic, et cettc coulcur naturelle est si fixe qu'elle ne s'altère point sous la main de l'ouvrier : on fait de très-beaux gants, de très-bons bas avec cette laine de vigogne; l'on en fait d'excellentes couvertures et des tapis d'un très-grand prix. Cet animal a bcaucoup de choses communes avee le larna, il est du même pays, et comme lui il en est exclusivement, car on ne le trouve nulle part ailleurs que sur les Cordillères; il a aussi le même naturel et à peu près les mêmes mours, le même tempérament.

Les vigognes ressemblent aussi, par la figure, aux lamas, mais elles sont plus petites, leurs jambes sont plus courtes ot leur mufle plus ramassé; elles n'ont point de cornes; elles habitent et paissent dans les endroits les plus élevés des montagnes : la neige et la glace semblent plutôt les récréer que les incommoder"; elles vont en troupes et courcnt très-légèrement; elles sont timides, 
et dès qu'elles apercoivent quelqu'un, elles s'enfuient ^n eluassant leurs petits devant elles. La manière dont on les prend prouve leur extrême timidité, ou leur imbécillitó. Plusieurs hounmes s'assemblent pour les faire fuir et les engrager dans yuelquespassages étroits oùl'on a tendu des eordes à trois ou quatre pieds de haul, le long desquelles on laisse pendre des moreeaux de linge on du drap; les vigognes qui arıivent à ees passages sunt tellement intimidées par le mouvemont de ees lambeaux agités par le vent, qu'elles n'osent passer ar delà, et qu'elles s'attroupent et demeurent en foule, cn sorte qu'il est faeile de les tuer en grand nombre; mais s'il se trouve dans la troupe quelques huanaeus, eomme ils sont plus haut de eorps et moins timides que les vigognes, ils sautent pardessus les corrles, et dis qu'ils ont donné l'exemple, les vigognes sautent de même et éehrappent aux elıasseurs.

\section{F MUSC.}

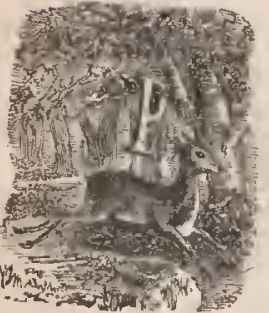

our aehever l'histoirc des ehèvres, des gazellos, des chevrotains ot lles autres animaux de ee geme, qui tous se trouvent dans l'aneien eontinent, il ne nous manque quo eelle do l'animal aussi célèlıre que peu eonnı rluquel on tire le vrai muse. Tous les naliralistos modurues et la plupart des voyagems di: l'Asie en ont fait meution, les uns sous le nom de cerf, de 


\section{ANIMAUX SAUVAGES.}

chevrenil ou de chèvre du musc; les autres l'ont considéré eomme un grand chevrotain; il est de la grandeur d'un petit chevreuil ou d'une gazelle, mais sa tête est sans cornes et sans bois.

Le musc se forme dans une poche ou tumeur qui est près dú nombril de l'animal, et il parait qu'il n'y a que lc mâle qui produse le bon musc.

A l'égard de la matiòre même du musc, son essence est pcut-être aussi peu connue que la nature de l'animal qui le produit ; tous les voyageurs conviennent que cette drogue est toujour's altéréc et mêléc avce du sang ort d'autres drogues par' ceux qui la vendent; les Chinois ell augmentent non-seulement le volume par ce mélange, mais ils cherchent encore à en augmenter le poids en y incorporant du plomb bien trituré; le musc le plus pur et le plus recherché par les Chinois mêmes est celui que l'animal laisse couler sur des pierres ou des trones d'arbres contre lesquels il se frotte lorsque cette matière devient irritante pour lui-incunc.

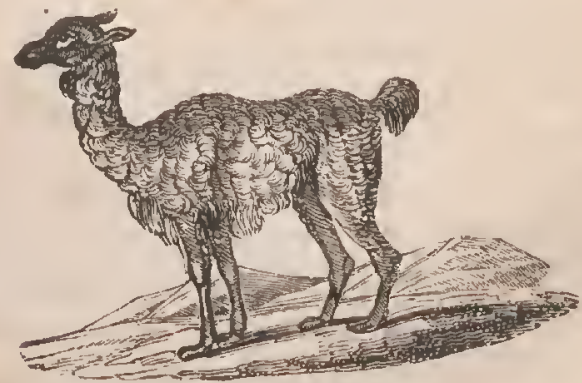




\section{LE CERF.}

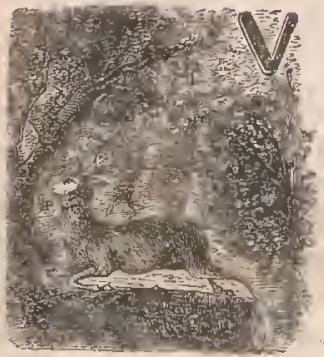

orci l'un de ces anmmaux innocents, doux et tranquilles, qui ne semblentêtre faits que pour embellir, animer la solitude des forêts, et occuper loin de nous les retraites paisibles de ces jardins de la nature. Sa forme élégante et légère, sa taille aussi svelte que bien prise, ses membres flexibles et nerveux, sa tête parée plutôt qu'armée d'un bois vivant, et qui, comine la cime des arbres, tous les ans se renouvelle, sa grandcur, sa légèrelé, sa force, le distinguent assez des autres habitants des bois; et commc il est le plus noble d'enire eux, il ne scrt aussi qu'aux plaisirs des plus nobles des hommes; il a dans tous les temps oceupé le loisir des héros: l'excrcice de la chasse doit succéder aux travaux de la guerı'e, il doit même les précéder.

Dès que les ccrf́s ont mis bas, ils se séparent les uns des autres, et il n'y a plus que les jeunes qui demeurent ensemble; ils ne se tiennent pas dans les forts, mais ils gagnent les beaux pays, les buissons, les taillis clairs, où ils demeurent tout l'ćté pour y rcfaire leur tête ; ct dans cette saison ils marchent la tête basse, crainte de la froisser contre les branclies, car elle est sensible tant qu'elle n'a pas pris son entier accroissement. La tête des plus vieux corfs n'est encorc qu'ù inoitić refaile ver's le 
milieu du moss de mai, et n'est tout à fait allongée et endurcie que ver's la fin de juillet: eelle des plus jeunes cerfs, tombant plus tard, repousse et se refait aussi plus tard ; mais dès qu'elle est entièrement allongée et qu'elle a pris de la solidité, les eerfs la frottent contre les arbres pour la dépouilier de la peau dont elle est revêtue.

! La tête des eerrs va tous les ans en augmentant en grosseur et en hauteur, depuis la seconde année de leur vie jusqu'à la huitième; elle se soutient toujours belle ct à peu près la même pendant toute la vigueur de l'âge; mais, lor'squ'ils deviennent vieux, leur tête déeline aussi.

Il en est de même de la grandeur et de la taille de ees animaux; elle ost fort différente selon les lieux qu'ils habitent: les eerfs de plaines, de vallées ou de collines abondantes en grains, ont le eorps beaucoup plus grand et les jambes plus hautes que les eerfs des montagnes sèches, arides ou pierreuses; eeux-ei ont le eorps bas, eourt et trapu; ils ne peuvent courir aussi vite, mais ils vont plus longtemps que les premiers ; ils sont plus míelıants, leur tête est ordinairement basse et noire, à peu près comme un arbre rabougri, dont l'éeorce est rembrunie, au lieu que la tête des cerfs de plaines est haute ct d'une eouleur elaire et rougeâtre eomme le bois et l'éeorce des arbres qui eroissent en bon terrain. Le cerl' de Corse paraît être le plus petit de tous les corfs de - inontagne ; il n'a guère que la moilié de la hauteur des eerfs ordinaires ; c'est, pour ainsi dire, un basset parıni les cerfs.

I.e cerf paraît avoir l'oil bon, l'odorat exquis et l'oreille excellente. Lorsqu'il veut écouter, il lève la tête, 
dresse les oreilles, et alors il entend de fort loin; lorsqu'il sort dans un petit taillis ou dans quelque autre endıoit à denni découvert, il s'arrête pour regarder' de tous côtés, et cherche ensuite le dessous du vent pour sentir s'il n'y a pas quelqu'un qui puisse l'inquiéter. Il cst d'un naturel asscz simple, et cependant.il est curieux ct rusé : lorsqu'on le siffle ou qu'on l'appelle de loin, il s'arrête tout court et regarde fixement ct avec une espèce d'adniration les voitures, le bétail, les hommes; ct, s'ils u'ont ni armes, ni chions, il continue à marcher d'assurance et passe son chemin fièrement et sans fuir : il paraît aussi écouter avec autant de tranquillité que de plaisir le chalumeau ou le flageolet des berper's, et les veneurs se servent quelquefois de cet artifice pour lorassurer. En génćral, il craint bcaucoup unoins l'homme que les chiens, et ne prend de la défianee et de la ruse qu'ù mesure et qu'autant qu'il aura été inquićté. Il mange lentement, il choisit sa nourriture; ct, lorsqu'il a viaudé, il cherche à so reposer pour rumincr à loisir. Il a la voix d'autant plus forte, plus grosse et plus tremblante qu'il est plus ûgé ; la biche a la voix plus faible et plus courte. Il ne boit guère en hrver, et encore moins au printemps; l'herbe tendre et chargée de r'osée lui suffit ; inais dans les chaleurs et les séelreresses de l'été il va borre aux r'lisseaux, aux mares, aux fontaines. Il nage parfaitement bien: on on a vu traverser de trèsgrandes rivières; on prétend inêrne uqu'attirés par les biches, les cerfs se jettent à la mer et passent d'une île à une autre à des distances de plusicurs lieves; ils sautent encoro plus légèreınent qu'ils ne nagent, car, lor'sun'ils sont poursuivis, ils framchissent aisément uno liaic et 


\section{ANIMAUX SAUVAFES.}

même un palis d'une toise de lanteur. Leur nourriture est différente suivant les différentes saisons. La ehair du faon est bonne à manger', celle de la biche et du dagnet n'est pas absolument mauvaise, mais celle des cerfs a toujours un goût lésagréable et fort. Ce que cet animal fournit de plus utile, e'est son bois et sa peau; on li prépare, et elle fait un euir souple et très-durable; le bois s'emploie par les couteliers, los fourbisseurs, etc. ; et l'on en tire, par la elinic, des esprits alealis volatils, dont la médeeine fait un fréquent usage.

\section{LE DAIN.}

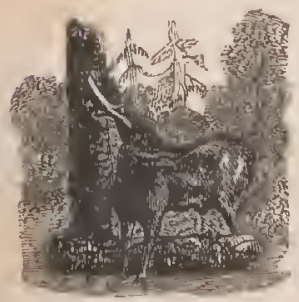

'EsPèce du daim est plus voisine de eelle du eerf́ qu'aucune espèce ne l'est d'une autre; ecpendant ces animaux, qui se ressemblent à tant d'égards, ne vont point ensemble, se fuient, ne se mêlent jamais, et ne forment par conséquent aueune race intermédiaire: il est mêrne rare de trouver des daims dans les pays qui sont peuplés de beaueoup do eerfs, à moins yu'on ne les y ait apportés ; ils paraissent être d'une nalure moins robuste el moins agreste que celle du eerf, ils sont aussi beaueoup moins communs dans les forêts; on les élève dans les pares où ils sont, pour ainsi dire, à demi domestiques. L'Anghleter're est le layss de l'Europe où il y en at to plus, et l'on y fait grand 
cas de cette venaison; les chiens la préfìrent aussi à la chair de tous les autres animaux, et, lorsqu'ils ont une fois mangé du daim, ils ont beaucoup de peine à garder le elrange sur le cerf ou sur le ehevreuil. Il y a des daims aux cnvirons de Paris et dans quelques provinces de France; il y en a en Espagne et en Allemagne; il y en a aussi cn Amćrique, qui peut-être y ont été transportés d'Europe: il scmble que ee soit un animal des clinats tempérés, car il n'y en a point on Russic, et l'on n'en trouve que très-rarement dans les autres pays du Nord.

Comme le daim est un animal moins sauvage, plus délicat, et, pour ainsi dire, plus domestique que le corf, il est aussi sujet à un plus grand nombre de variétés. Ontre les daims communs et les daims blanes, l'on en connait encore plusieu's autres: les daims d'Espagne, par exemple, qui sontpresque aussi grands que des certs, inais qui ont le cou moins gros et la couleur plus obscurc, avee la queue noirâtre, non blanche par-dessous, et plus longue que celle des daims communs; d'aulios qui ont le front comprimé, ajplati entre les yeux, les orcilles et la queue plus longues que le daim commun, et qui sont inarqués d'une tache blanehe sur les ongles des pieds de derrière; d'autres qui sont tachés ou rayjés de blane, de noir et de fanve clair; et d'autres cnfin qui sont enticrement noirs : tous ont le bois plus aplati, plus étendu en largeur que celui du cerf. Ils sont portés ì deméurer ensemble, et restent presque toujours les uns avec les autres. Dans les parcs, lorsqu'ils se trouvent en grand nombre, ils forment ordinairement deux troupes qui sonl bien distinctes, bien séparées, el qui bientôt deviennent ennemics, parce qu'ils veulcnt égalcunent 


\section{ANIMAUX SAUVAGES.}

occuper le même endroit du pare: cliaeune de ces troupes a son chef, qui marche le premier, et c'est le plus fort et lo plus âgú ; les autres suivent, et tous se disposent à combattre pour chasser l'autre troupe du bon pays. Ces combats sont singuliers par la disposition qui parait y régner; ils s'attaquent avec ordre, se battent avec courage, se soutiennent les uns les auties, et ne se eroient pas vaineus par un seul échec, car le combat se renouvelle tous les jours, jusqu'à ce que les plus forts chassent les plus faibles et les relòguent dans le mauvais pays. Ils aiment les terrains élevés et entrecoupés de pelites collines : ils ne s'éloignent pas comme le cerf, lor'squ'on les ehasse ; ils ne font que tourner, et eherchent seulement à se dérober des chiens par la ruse et par le cliange; cependant, lorsçu'ils sont pressés, ćchauffés et ćpuisés, ils se jettent à l'eau comme le cerf, mais ils ne se hasardent pas à la traverser dans une aussi grande étenduc ; ainsi la chasse du daim et celle dı cerf n'ont entre elles alucune différence essentielle. Les connaissances du dain sont, en plus petit, les mêmes que cell's du cerf; les mômes ruses leur sont communes, seulement elles sont plus répétées par le daim: eomme il cst moins entrcprenant, il a plus souvent besoin de s'aeeompagner, de revenir sur ses voies, ete., ee qui rend en général la chasse du daim plus sujette aux ineonvénients que celle du cerf.

Le daim s'apprivoise très-aisćment; il mange de bcaucoup de choses que le cerf refuse : aussi conserve-t-il mieux sa venaison, car il ne paraît pas que l'hiver le plus rude et lo plus long le mairrisse et l'altìre, il est presque dans le niêne ćlat pendant toute l'année; il broute de 
plus près que le cerl', et c'est ce qui fait que le bois coupé par la dent du dain repousse beaucoup plus difficilement que celui qui ne l'a étó que par le corf; les jeunes mangent plus vite et plus avidernent que les vieux; ils ruminent: la daine porte huit mois et quelques jours comme la biche; elle produit de même ordinairement un faon, quelquefois deux, et très-parement trois; enfin ils ressemblent aux cerfs par presque toutes les habitudes naturelles, et la plus grande différence cqu'il y ait entre ces animaux, c'est dans la durée de la vie. Les cerfs vivent trente-cinq ou quarante ans, et les daims ne vivent qu'environ vingt ans: comme ils sont plus petits, il y a apparence que leur accroissement est encore plus prompt que celui du cerf; car dans tous les animaux la durée de la vie est proportionnelle à celle de l'accroissement, à compter depuis la naissance jusqu'au développernent presque entier du colps de l'animal.

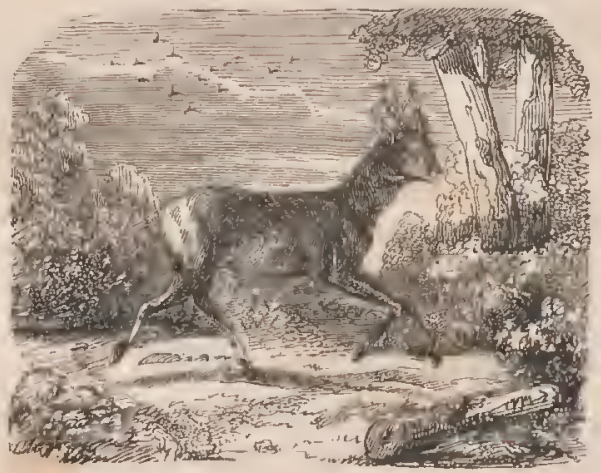




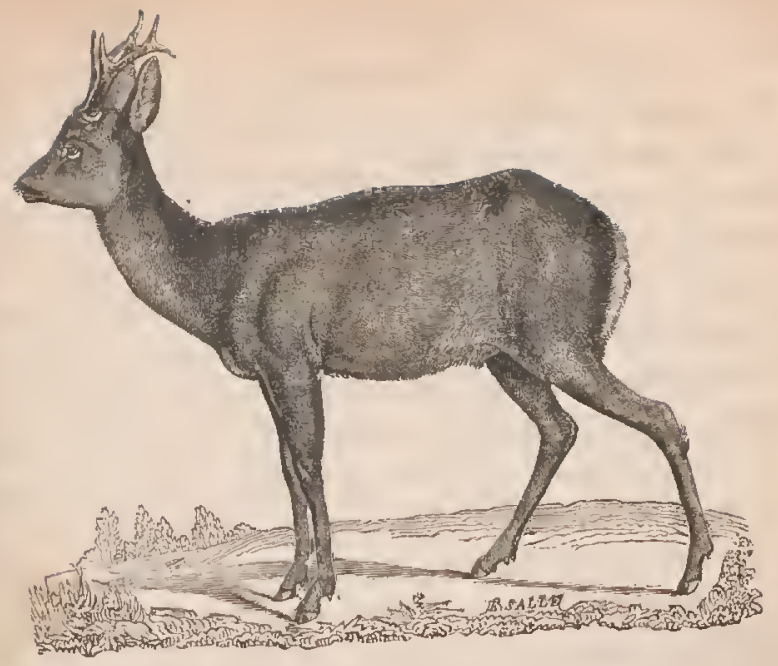

\section{LE CHEVREUIL.}

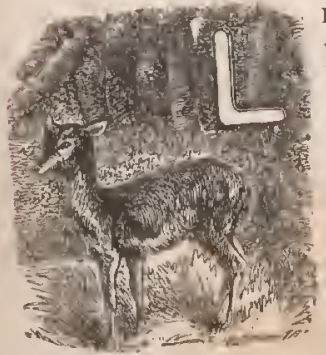

E cerf, comme le plus noble des habitants des bois, occupe dans les forêts les lieux onbrigés par' les cimes élevées des plus hautes futaies: le chevreuil, comme étant d'une espèce inférieure, se contente d'habiter sous des lambris jlus bas, el se lient ordinairement dans le feuillage épais des plus jeunes taillis ; mais s'il a moins de noblesse, moins de force, et beaucoup moins de hauteur de taille, il a plus de grâce, plus de vivacité, et même plus de courage que le cerf; il est plus gai, plus leste, plus éveillé; sa forme est plus arronclio, plus élé- 
gante, et sa figure plus agréable; ses yeux surtout sont plus beaux, plus brillants, ct paraissent animós d'um sentiment plus vif; ses nembres sont plus souples, ses mouvements plus prestes, ct il bondit, sans effort, avce autaut de foree que de légèreté. Sa robe est toujours propre, son poil net et lustré; il ne se roule jamais dans la fango comme le cerf; il ne se plait que dans les pays les plus élevés, les plus sees, où l'air est le plus pur; il est eneore plus rusé, plus adroit à se dérober, plus difficile ì suivi’e; il a plus de finesse, plus de ressourees d'instinct. Car', quoiqu'il ait le désavantage mortel de laisser apròs lui des impressions plus fortes, et qui donnent aux chicns plus d'ardcur et plus de vóhémenee d'appétit que l'odeur du ecrf, il ne laisse pas de savoir se soustraire à leur poursuite par la rapidité de sa course et par ses détours multipliés ; il n'attend pas, pour employer la r'use, que la foree lui manque; dès qu'il sent, au contraire, que les premiers cfforts d'une fuitc lapide ont étẻ sans succès, il revient sur ses pas, retourne, revient encore, et lorsqu'il a eonfondu par ses mouvements opposés la direction de l'aller avec celle du retour, lorsqu'il a mêlé les émanations prósentes avee les émanations passées, il se sépare de la torre par un bond, et, se jctant ì côté, il se met ventre ì terre, et laisse, sans bouger, passer près de lui la troupe entière de ses ennemis ameutós.

Il diffère du cerf et du daim par le naturel, par le tempérament, par les mours, ct aussi par presque toutes les labitudes de la nature: au lieu de marcher par grandes troupes, il demeure en famille; le père, la mère et les petits vont onsonnble, et on ne les voit jamais s'associer aveo des étrangers; comme la chevrette produit ordinai- 
r'ement deux faons, l'un mâle et l'autre lentelle, ces jeunes animaux, élevés, nourris ensemble, prennent une si forte affection l'un pour l'auti'e qu'ils ne se quiltent jamais.

Les faons restent avec leur père et leur mère liuit ou neuf mois en tout ; et lorsqu'ils se sont séparés, c'est-àdire ver's la fin de la preinière annéc de leur âģe, leur première tête commence à paraître sous la formc de deux dagues beaucoup plus petites que celles du cerf; mais ce qui marque encore une grande différence entre ces animaux, c'est que le ccrf ne met bas sa têtc qu'au printemps, et ne la refait qu'en été, au lien que le chevrcuil la met las à la fin de l'automne, et la refail pendant l'hiver.

Lorsque le chevreuil a refuit sa tête, il touche au bois, comme le cerf, pour la dépouiller de la peau dont clle cst revêtue, et c'est ordinairement dans le mois de mar's, avant que les arbres commencent à pousser.

Comme la chevrette ne porte que cinq mois el demi, et que l'accroissement du jcune chevreuil est plus prompt que celui du cerf, la durée de sa vie est plus courle, et je ne crois pas qu'elle s'étende à plus de douze ou quinze ans tout au plus; ils sont très-délicats sur le choix de la nourriture; ils ont besoin de mouvcment, de beaucoup d'air, de bcalleoup d'espace, et c'est ce qui fait qu'ils ne résistent que pendant les premières années de lcur jeunesse aux inconvénients de la vic domestique. Il leur faut un parc de cent arpents, pour qu'ils soient à leur aise : on peut Jes apprivoiser", mais non pas les rendre obéissants, ni même familicrs; ils retiennent toujours quclque chose de leur naturel sauvaggc; ils s'ćpouvantent aisément, et ils se précipitcut contre les murailles avec tant de force, que souvent ils se cassent les jambes. 
Les jeunes chevreuils ont une petite voix courte et plaintive, mi....mi, par laquelle ils inarquent le besoin qu'ils ont de nourriture: ce son est aisé à imiter, et la mère, trompée par l'appeau, arrive jusque sous le fusil du chasseur.

En hiver, les chevreuils se tiennent dans les taillis les plus fourés, etil.s vivent de ronees, de genêt, de bruyère et de ehatons de coudrier, de marsaule, etc. Au printemps, ils vont dans les taillis les plus clair's, et broutent les boutons et les feuilles naissantes de presque tous les arbres: eette nourriture chaude fermente dans lenr estomae et les enivr'e de manière qu'il est alors très-aisé de les surprendre; ils ne savent où ils vont; ils sortent même assez souvent hors du bois, et quelquefois ils approchent des endroits liabités.

La chair de ees aninaux est, comme l'on sait, excellente à manger ; eependant il y a beaucoup de choix à faire; la qualité dépend prineipalement du pays qu'ils habitent.

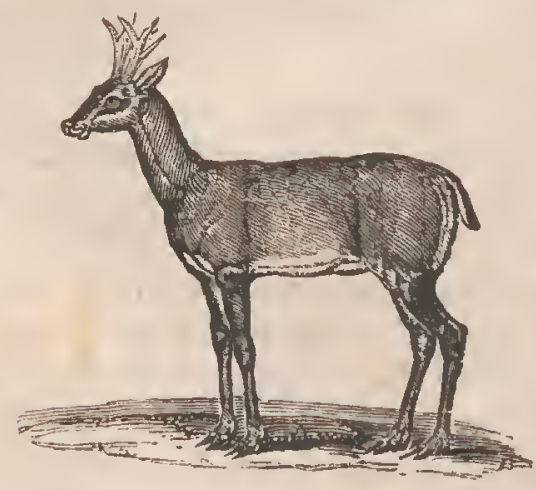




\section{L'ELAN ET LE RENNE.}

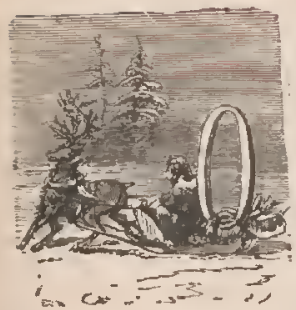

vorQue l'ćlan et le renne soient deux animaux d'espèces différentes, nous avons $c r^{\prime} u$ devoir les réunir, larce qu'il n'est guère possible de faire l'histoire de l'un sans emprunter beancoup de eelle de l'autre, la plupart des anciens auteurs, et même des moderues, les ayant eonfondus ou désignnćs par des dénominations équivoques qu'on pour’ait appliquer à tous doux.

On peut prendre des idées asscz justes de la forme de l'élan et de celle du renne, en les comparant tous deux avec le eerf. L'élan est plus grand, plus gros, plus élevé sur ses jambes; il a le eou plus eourt, le poil plus long, le bois beaucoup plus large et plus massif que le eerf. Le renne est plus bas, plus trapu; il a les jambes plus courtes, plus grosses, et les pieds bien plus larges, le poil tròsfourni, le bois beaucoup plus long et divisé en un grand nombre de rameaux, terminćs par des empaumures; au lieu que celui de l'élan n'est, pour ainsi dire, que découpé et chevillé sur la tranche. Tous dcux ont de longs poils sous le cou, et tous deux ont la quene courte et les oreilles beaucoup plus longues que le cerf; ils ne vont pas par bonds et par sauts, comme le chevrcuil ou le cerf ; lcur marche cst uno espèce de trol, mais si prompt et si aisce, yu'ils font dans le même temps presque autant de ehemin 
qu'eux, sans sc fatiguer antant; car ils peuvent trotler ainsi sans s'arrêter pendant un jour ou deux. Le renne se tient sur les montagnes; l'élan n'habile que les terres basses et les forêts humides : tous deux se metlent en 'roupes comme le cerf, et vont de compagnie; tous deux peuvent s'apprivoiser, mais le l'cnne bcaucoup plus que l'ćlan; cclui-ci, comme le cerf, n'a nulle part perdu sa liberté, au lieu que le renne est devenu domestique chez le dernier des peuples : les Lapons n'ont pas d'antre bétail.

En comparant les avantages quc les Lapons tirent du r’enne applivoisé avec ceux que nous tirons de nos animanx domestiques, on verra que cet animal en vaut seul deux ou trois; on s'en sert, comme du cheval, pour tirer des traîncaux, des voitures; il marche avec bien plus de diliggenec et de légèreté, fait aisément trente lieues par jour, et court avec autant d'assurance sur la neige gelie que sur une pelouse. La femelle donne du lait plus substantiel et plus nourrissant que celui de la vache; la chair de cet animal est très-bonnc à manger; son poil fait une excellente fourrure, ct la peau passée devient un cuir très-souple et très-durable: ainsi le renne donne seul tout ce que nous tirons du cheval, du bouf et de la brebis.

Il y a en Laponia des rennes sauvages et des rennes domestiques. Cornme les rennes sauvages sont plus robuctos et plus forts que los domestiques, on préfère ceux qui sont issus de ce mélange pour les atteler au traineau : ces rennes sont moins doux que les autres; car non-seulement ils refusent quelquefois d'obéir à celui qui les guide, mais ils se retournent brusquement contre lui, l'attaquent à coups de pied, en sorte qu'il n'a d'autre ressource que de se couvrir do son traineau jusqu'à cc que la colère de 


\section{ANHAUX SAUVAGES.}

sa bête soil apaisće. Le r'enne attelé n'a pour eollier qu'un moreeau de pean où le poil est resté, d'où deseend vers le poitrail un trait qui lui passe sous le ventre, entre les jambes, et va s'altacher à un trou qui est sur le devant dh traîneau; le Lapon n'a pour guides qu'une seule corde, attaehée à la raeine du bois de l'animal, qu'il jette diversement sur le dos de la bête, tantôt d'un côtć et tantôl de l'autre, sclon qu'il veut la diriger à droite ou à gauehe.

Les rennes ont à l'extéricur beaueoup de ehoses communes avee les ecrfs, et la conformation des parties inlérieures est, pour ainsi dire, la même: de eetle eonformité de nalure résultent des lıabiludes analogues et des effels semblables. Le renne jelte son bois tous les ans, eomnie le cerf, et se charge comme lui de venaison; les femelles, dans l'une et dans l'aulre espèce, portent huil mois el ne produisent qu'un petit; parmi los femcllos, eomme parmi les biehes, il s'en trouve quelques-unes qui ne produisent pas; chaque petit suit sa mère pendant deux ou trois ans, et ec n'est qu'à l'âge de quatre ans révolus que ees animaux ont aequis lcur plein aeeroisscment; c'est aussi à cet âge qu'on eommenee à les drosser' ct les cxcreer au truvail; parmi les rennes on ehoisil les plus vifs et les plus légers pour courir au traîncau, et les plus pesants jour voiturer à pas plus lents les provisions et les bagages. Ils sont, comme les ecrfs, sujels aux ver's dans la mauvaise saison; il s'en encendre sur la fin de l'hiver une si grande quantiló sous leur peau qu'elle en est alor's toulc eribléc; ees trous de vers sc referment en élé el arisși ee n'osl qu'en automne que l'on tue les rennes pour chl avoir la fourrure ou le curr.

Les troupcaux de cette ospèce demandent beaucoup 
de soin; les rennes sont sujets à s'écriter, et reprennent volonticrs leur libertó natur'clle; il faut les suivre et les veiller de pròs : on ne peut les mener paître yue dans des licux dćcouverts, et pour peu que le troupeau soit nombreux, on a besoin de plisieurs personnes pour les garm der, jour les contenir, pour les l'appeler, pour courir après ceux qui s'ćloignent; ils soni tous marqués, afin qu'on puisse les reconnaître, car il arrive souvent ol1 qu'ils s'ćgarent daus les bois, ou qu'ils passent à un autro troupcau; enfin les Lapons sont eontinucllenent occulés à ces snins: les rennes lont toutes leur's richesses, et ils savent en tirer toutes les eominolilés, ol1, pour unicux dire, les nécessités de la vie; ils se couviºnt depuis les picds jusqu'à la têto de cess l'onr'rures, qui sont impénétrables au froid et ¿̀ l'cau : e'est leur habit d'liver; l'ćté ils se servent cles peaux dont le poil esi tombé; ils mangent la chair du renne, en boivent lo Irit, et on lont des fromages très-gras.

L'élan et le renne sont tous deux du nombre des aniinatux ruminints. La duróo de la vie daus le renne domestique n'ost que de quinze d seizo nus; mads il est à prósumer que dans le renne sauvage elle est plus longue; cet animal, étant yualıe ans it croîtıo, doit vivie vingt-luuit ou trente ans, lorsqu'il est dans son état de nalure.

L'élin est un animal beaucoup plus granrl ot hien plus fort que le cerf et le renne; il a le poil si rude et le cuir si dur cue la balle du mousquet pent à peino y péuétrer; il a les janbes très-ferines, avec tant de mouvement it de force, surtout dans les pieds de devant, que d'uri seul coup il pout tuer un homne, un loup, ct nêne cisser 
un arbre. Cependant on le chasse ì peu près eomme nous chassons le eerf; on assure que, lorsqu'il est lancé ou poursuivi, il lui alrive souvent de tomber tout à coup, sans avoir élé ni tiré ni blessć. de lì on a présuné qu'il était sujet à l'épilepsie, et de eette présomption (qur n'est pas bien fondée, puisque la pour seule pourrait produire le même effet.) on a tiré cette conséquence absurde que la eorne de ses pieds devait gruérir de l'épilepsie, et même en préserver, et ee préjugć grrossicr a été si généralement répandu qu'on voit encor'e aujourd'hui quantité de gens du peiple porter des lragues, dont le ehaton renferme un potit moreeau de corrle d'élan.

Comme il y a tr'c̀s-peu d'hommes dans les parties septentrionales de l'Amérique, tous les animaux, et en partieulier les élans, y sont en phus grand nombre que dans le nord de l'Europe. Les sauvages n'ignorent pas l'art de les ehasser et de les prendre; ils les suivent à la piste, quelquefois pendant plusieurs jours de suite, et, à forec de constance et d'adresse, ils en viennent à jout. 


\section{LA GIRAFE.}

Thes a girafe est un des premers, des pilus beaux, des plus grands animaux, el qui, sans être nuisible, est cll mùme temps l'un des plus inutiles ; la disproxportion énorme de ses jambes, dont celles de devant sont une fois plus lonGuvis ylue culles de derrière, fait obstacle à l'exercicc do ses for'ces; son corps n'a pas d'assielte, sa démarche est vacillante, ses mouvements sont lents et contraints. L'espèce en est peu nombrcuse et a toujours été confinéc dans les déserts de l'Ethiopie et de quclqques autres provinces de l'Afrique.

La girafe peut atteindre avec sa tête à seize ou dixsept pieds de hauteur, étant dans sa situation naturellc, c'est-à-dire posće sur ses quatre pieds. Elle est d'un naturcl très-doux, et par cette qualité aussi bien que par toutes les autres habitudes physiques, et mène par lat forme du corps, elle approehe plus de la figure et de la nature du chameau que de celle d'aucun aulre aninal, elle est du nombre des ruminants, elle manque comme eux de dents incisives à la inâchoire supéricure.

La girafe est d'une espèce unique et très-différente de toute autre; mais si on voulait la rapprocher de quelyue autre animal, ee serait plutôt du chaneau que du eerf ou du boeuf.

Les femelles onl des cornes conme les mâles, mais tu 


\section{ANIMUUX SAUVAGES.}

leu plus pelites : si la gurafe était du genre des eer[s, l'analogie se démentirait encore ici, car de tous les animaux de ee genre, il n'y a que la femelle du renne qui ait un bois, toutes les autres femelles en sont dénuées. La girafe, à eause de l'exeessive hauteur de ses jambes, ne peut paitre l'herbe qu'avec peine et diffieulté ; aussi clle se nourrit prineipalement et presque uniquement de feuilles et de boutons d'arbres.

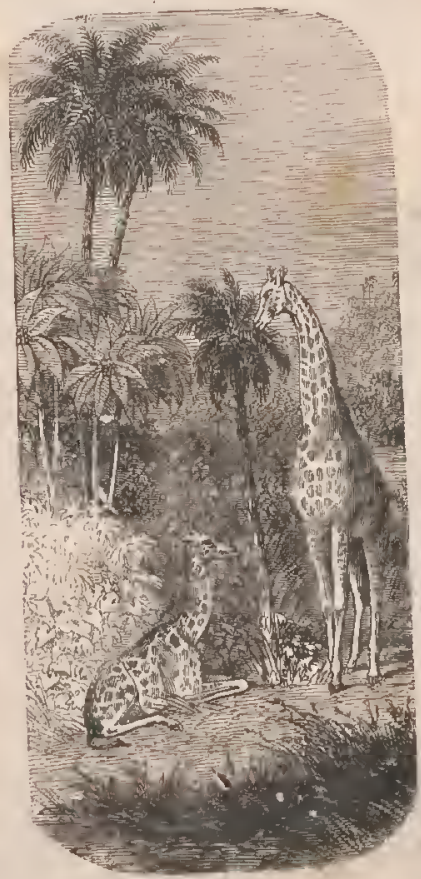




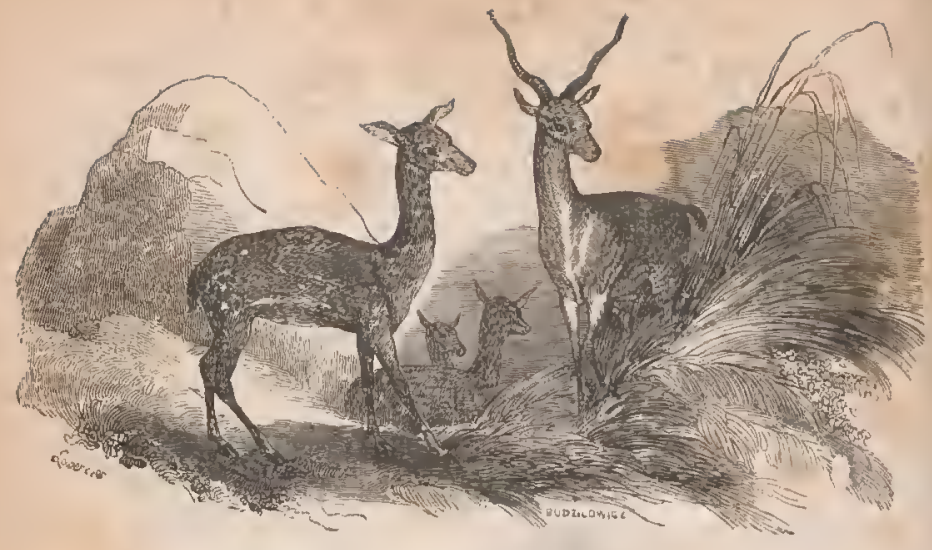

LES GAZELLES.

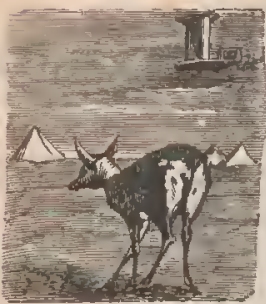

Es gazelles ressemblent beaucoup au chevreuil par la forme du corps, par la légrècté des mouvements, la grrandeur et la vivacité des yeux, etc.; inais olles en diffirent par la nature des cornes : collos du clicvreuil sont une espoce de bois solide qui lombe et se renouvello tous los ans comme celui du corl'; les cornes des gazclles, au contraire, sont creuses et permanentes comme celles de lu clic̀vre. Les gazelles ont, comme le chevieuil, des larmicrs ou enfoncoments audevant de chacue aril. Elles lui ressemblent encore jur la yualité du poil, par les brosses yu'elles ont sur les jalumbes; mais ces brosses dans le chevreuil sont sur les jambes de derrière, nu licu que dins les gazelles elles sont sur les jumles de rlevant: les grazelles paraissent 
done être des animaux mi-partis, intermédiaires entre le elıcrreuil et la chèvie. Dans quelques endroits on prend les gazelles sauvages avec dos gazellos apprivoisées, aux cornes desquelles on attache un piége de cordes.

Les antilopes, surtout les grindes, sont benucoup plus communes en Afrique qu'aux Indes; elles sont plus fortes et plus farouches que los autres gazellos. Les antilopes moyennes sont de la grandeur et de la couleur du dilim, on les trouve en grand nombre dans les contrées du Tremeecn, du Dugucla, du Tell et du Zaara. Elles sont propres et ne se couchent que rlans des endroits secs et nets; elles sont aussi très-lógères à la conrse, hès-altentives au danger, très-vigilantes; en sorte quc dans les lieux découverts elles regardent longtermps de tous côtés, et dìs qu'clles apercoivent un lomme, un chion ou quelque autre ennemi, elles fuient de toutes lours forces. Cependant elles ont, avec cette timidité naturellc, une espèco do courage, car lorsqu'elles sont surprises, clles s'arrêtent tout court, et font face à coux qui les altaquent.

En général, les gazelles ont les yeux noirs, grands et rifs; elles ont pour la plupart les jambes plus fines et llus déliées que le ehcvreuil, le poil aussi court, plus doux et plus lustré; leur's janbes de devant sont moins longues que celles de derrière, ce qui leur donne, comme au lièvre, plus do facilité pour courir en montant qu'en descendant; Ieur légèreté est au moins égale ì celle du ulievreuil, mais celui-ci bondit et saute plutôt qu'il ne "ourt, au lien que les gazelies courent uniformément plulôt qu'elles ne bondissent. 


\section{LE BUFFLE.}

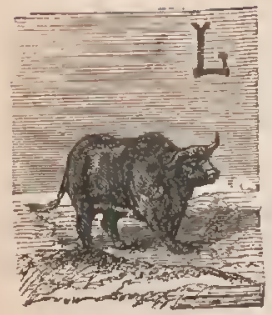

A taille et la grosseur du buffle indiqueraient seules qu'il est originaire des climats les plus chauds. Les plus grands, les plus gros quadrupèdes appartiennent tous à la zone torride dans l'ancien continent, et le buffle, dans l'ordre de grandeur ou plutôt de masse et d'épaisseur, doit être placé apı'ès l'ćléphant, lc rhinocćros et l'hippopotame. Gependant les buffles vivent et produisent en Italie, en France et dans les autres provinces tcmpérées. La femelle ne fait qu'un petit et le porte environ douze mois, ce qui prouve cncore la différence de cette espèce ì celle de la vache, quı nc porte que neuf mois. Il paraît aussi que ces animaux sont plus doux et moins brutaux dans leur pays natal, et que plus le climat est chaud plus ils sont d'un naturcl docile.

Il y a une grande quantité de buffles sauvages dans les contrées de l'Afrique et des Indes, qui sont arrosées de rivières ct où il sc trouve de grandes prairies; ces buffles sauvages vont en troupcaux et font de grands dégâts dans les terres cultivées, mais ils n'attaquent jamais les hommes et ne courent dessus que quand on vicnt de les blesser : alors ils sont très-dangercux, car ils vont droit à l'cnnemi, le renversent et le tuent cn le foulant aux pieds ; cepcndant ils craignent beaucoup l'aspect du feu, la couleur rouge leur déplaît. 
Le buffle, eomme tous les autres grands animaux des climats méridionaux, aime benueoup à se vautrer et même à séjourner dans l'eau; il nage très-bien et traverse hardiment les fleuves les plus rapides : eomme il a les jambes plus hautes que le bœuf, il court aussi plus légèrennent sur terre. Les Nègres en Guinée et les Indiens au Malabar, où les buffles sauvages sont en grand nombre, s'exereent souvent à les ohasser. Ils ne les poursuivent ni ne les attaquent de face; ils les attendent, grimpés sur des arbres ou cachés dans l'épaisseur de la forêt, que les buffles ont de la peine à pénétrer à eause de la grosseur de leur corps et de l'embarras de leurs cornes : ces peuples trouvent la chair des bufiles bonne, et tirent un grand profit de leurs peaux et de leurs eornes, qui sont plus dures of meilleures que colles du boeuf.

\section{LE MOUFLON ET LES AUTRES BREBIS.}

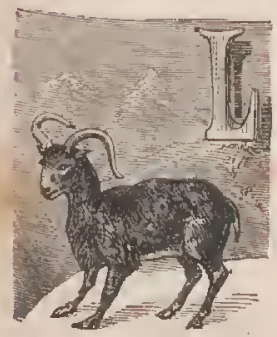

E mouflon parait être la souehe primitive de toutes les brebis; il existe dans l'état de nature, il subsiste of se multiplie sans le secours de l'homme; il ressemble plus qu'aueun autre animal sauvage à toutes les brebis domestiques; il est phis vif, plus fort et plus léģer qu'aucune d'entre elles; il a la tête, le front, les yeux et toute la face dı bélicr; 
il lui ressemble anssi par la forme des eornes et par l'habitude entiòre du eorps ; enfin il produit avec la brebis domestique, ee qui seul suffirait pour démontrer qu'il est de la même espèee et qu'il en est la souehe. La seule diseonvenanee qu'il y ait entre le moufton et nos brebis, e'est qu'il est eouvert de poil et non de laine; nais dans les brebis domestiques la laine n'est pas un earactère essentiel, e'est une production du climat tempéré, puisque dans les pays chauds ces mêmes brebis n'ont point de laine et sont toutes couvertes de poil, et dans les pays très-froids lcur laine est eneore aussi grossière, aussi rude que du poil : dès lors il n'est pas étonnant que la brebis originaire, la brebis primitive et sauvage, qui a dû souffrir le froid et le ehaud, vivre et se multiplier sans abri dans les bois, ne soit pas eouverte d'une laine qu'elle aurait bientôt perdue dans les broussailles.

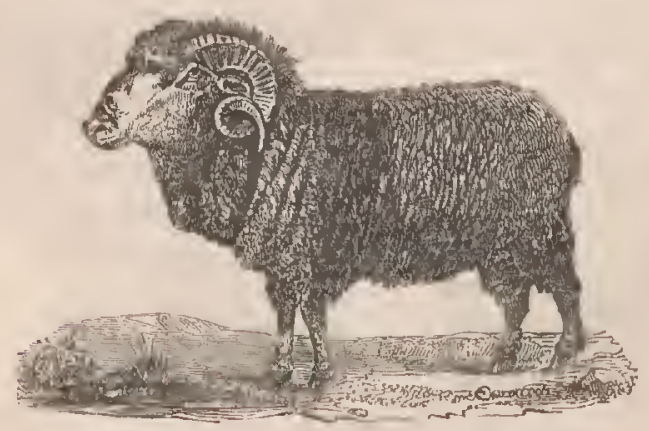




\section{LE BOUQUETIN ET LE CHAMOIS.}

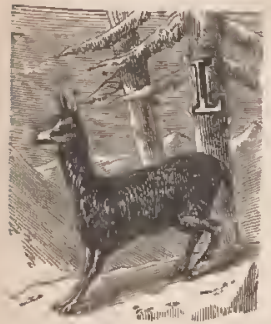

E bouquetin mâle diffère du chamois par la longueur, la grosseur et la forme des eornes ; il est aussi beaueoup plus grand de eorps, et il est plus vigourenx et plus fort; eependant le bouquetin femelle a les eornes différentes de eelles du mâle, beaueoup plus peliles et assez ressemblantes à celles du chamois ; d'ailleurs ees animaux ont tous deux les mêmes habitudes, les mêmes mocur's et la même patrie; seulement le bouquetin, eomme plus agile et plus fort, s'élève jusqu'au sommet des plus hautes montagnes, au lieu que le chamois n'en habite que le second étage ; mais ni i'un ni l'autre ne se frouvent dans les plaines : tous deux se frayent des chemins dans les neiges, tous deux franehissent des précipiees en bondissant de roehers en roeher's, tous deux sont couverts d'une peau ferme et solide, et vêtus en hiver d'une double fourrure, d'un poil extérieur assez rule et d'un poil intérieur plus fin et plus fourni; tous deux ont une raie noire sur le dos; ils ont aussi la quene à peu près de la même grandeur. Les bouquetins, aussi bien que les elıamois, lorsqu'on les prend jeunes el qu'on les élève avee les chìvres domesliques, s'apprivoisent aisément, s'accoutument à la domesticité, prennent les mêmes mœur's, vont comme elles en troupeaux, et reviennent de même ì l'étable. 


\title{
DES OISEAUX.
}

\section{LES OISEAUX DE PROIE.}

\author{
RAPACES.
}

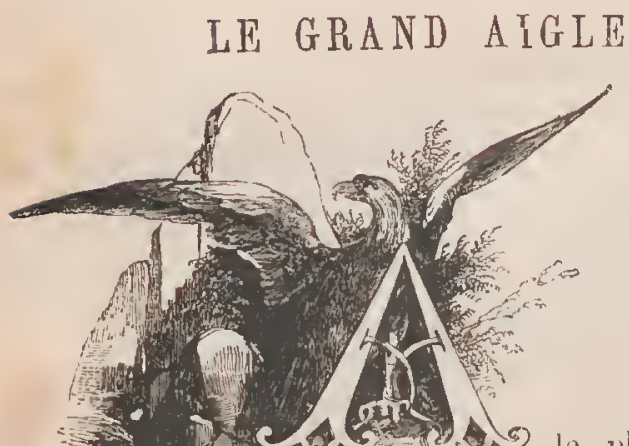

THÉNÉE ainsi que Belon ont nommé le grand aiçle l'aigle royal ou le roi des oiseaux; c'est plus grand de tous los aigles: la femelle a jusqu'a trois pieds et demi de longueur depuis le bout du bec jusqu'à l'extrémité des pieiłs, et plus de lıuit pieds et demi de vol ou d'envergure; le mâle est plus 
petil. Tous deux ont le bec très-fort et les ongles noirs ot pointus; les yeux sont grands, mais paraisscrit enfoncés dans une cavité profonde. Cet oiseau est gras, surtout en hiver; sa graisse est blanche, et sa chair, quoique dure et fibreuse, ne sent pas le sauvage eomine celle des autres oiseaux de proie.

On trouve cette espèce en Grèce, en France, en Allcmagne dans les montagnes de Silćsie, dans les forìts cle

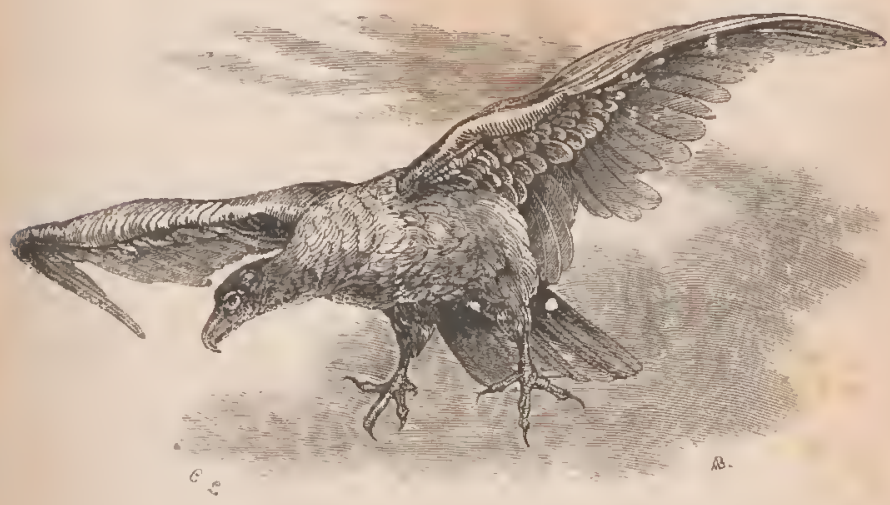

Dantzie et dans les monts Carpathiens, dans les Pyrénées et dans les montagnes d'Irlande. On la trouve aussi dans l'Asie Mineure et en Perse, en Arabie, en Maurilanie et dans plusieurs autres provinces de l'Afrique et de l'Asie jusqu'en Tartarie, mais point en Sibérie ni dans le reste du nord de l'Asie.

L'aigle a plusieurs convenances physirues et morales avec le lion : la force, et par conséquent l'empire sur les 
autres oiscanx, comme le lion sur les quadrupèdes ; li magnaniıniló : il dédaigne également los potits animaux et méprise leur's insultes; ee n'cst qu'après avoir' óté longteinps provoqué par les cris importuns de la colneille ou de la pie que l'aigle se détermine à les punir de mort; la tempérance : il ne mange presque jamais son gibier en entier, et il laisse, comme le lion, les débris et les restes aux autres animaux. Quelque aflamé qu'il soit, il no se jette jamais sur les cadavres. 11 est encore solitaile comme le lion. Il voit par excellence, mais il n'a que peu d'odorat en eomparaison du vautour; il ne chasse done ru'i vuc; et lor'syu'il a saisi sa proie il rabat sou vol eomme jour en éprouver le poids, et la pose à terre avant de l'cmporter dars son aire; c'est ainsi qu'on appelle son nid. On assure que le mêıne nid sert à l'aiglo jendant toute sa vie. La fornelle dépose ses oufs dans lo milieu de cotte aire; elle n'en pond que deux ou .trois qu'elle couve, dit-on, pendant trente jours; mais dans ces ooufs il s'en trouve souvent d'inféconds, et il est rare de trouver trois aiglons dans un nid: ordinairement il n'y ell a qu'un ou leux. Dès qu'ils deviennent un peu grands, la mèrc tuc le julus fajble ou le plus vorace de ses petits; ct, dès que les petits eommencent à être asse\% forts pour voler et se pourvoir d'eux-mênnes, le père et Ia mère les ehassent au loin sans leur permettre de jamais revenir.

On assure qu'ils vivent plus d'un sic̀cle. Inrsqu'ils no sont point apprivoisés, ils mordent eruellement les chats, los chiens, les hommes qui veulent los approeher. Ils jottent de temps en temps un cri aigu, sonore, pereant et lancutable, et d'un tou soutenu. L'aigle boit très-ra- 
rement et peut-être point du tout lorsqu'il est en liberté, parce quc lc sang de ses viclimes suffit à șa soif.

\section{L'A IGLE COMMUN.}

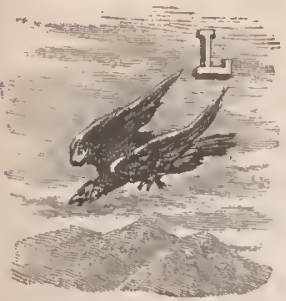

'AIGLE commun, noir ou brun, est toujours plus petit cue le grand aigle; celui-ci pousse fréqueınment un cli lamentable, au lieu que l'aigle commun, noil ou bl'un, ne crie que rarement. Il nouririt tous ses petits dans son nid, les élève ct les conduit ensuite dans leur jeunesse, au licu gue lo grand aigle les chasse lors du nid et les abandonne à eux-mômes dès qu'ils sont en état de voler.

L'espèce de l'aigle commun est plus nombreuse et plus répandue que colle du grand aigle : celui-ci ne se trouve que dans les pays chauds et tempérés de l'ancien continent; l'aigle commun, au contraire, prófère les pays froids, et se trouve également dans les deux continents. On le voit en France, en Savoie, en Suissc, en Allemafine, en Pologne et on Écosse; on lo retrouve en Anérique à la baic d'Hudson.

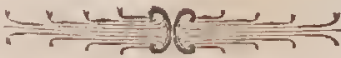




\section{LE PETIT AIGLE.}

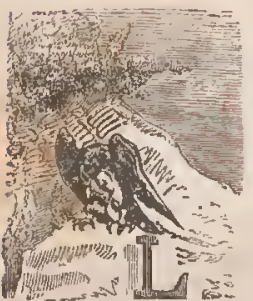

A troisic̀me espèce est l'aigle tacheté, appelé petit aigle. On l'a appelé aussi aigle plaintif, aigle criard, parce qu'il pousse continuellement des plaintes ou des cris lamentables. C'est de tous les aigles cclui qui s'apprivoise le plus nisément. Il est plas faible, moins fier et moins courageux que les autres. La gruc est sa plus forte proie, car il ne prend ordinairement que des canards, d'autres moindres oiseaux et des rats. L'espèce, quoique jeu nombreuse en chaque lieu, est répandue partout, tant en Europe qu'en Asie, en Afrique, où on la trouve jusqu'au cap de Bonne-Espérance, mais elle n'existe pas en Amérique. Si cc pctit aigle, qui est bealcoup plus docile et plus aisé à apprivoiser que les deux autres, se fût trouvé également couraggeux, on n'aurait pas manqué de s'cn servir pour la chasse; mais il ést aussi lûche que plaintif et criard. Un épervier bien dressé suffit pour lo vaincre el l'abattre.

La femclle qui, dans l'aigle, comme dans toutes les autres espèces d'oiseaux de proie, est plus grande que lc mâle, et semble être aussi, dans l'état de liberté, plus liardie, plus courageuse et plus fine, ne paraîl pas conserver ces dernières qualités dans l'élat de captivité.

Dans l'étal de nature, l'aiglc ne cliasse seul que dans le temps où la femelle ne peut quitter ses cufs ou ses petits; comme c'est la saison où le giluier commence d̀ 
devonil ahonclant par le retour des oiscaux, il pourvoit aisément à sa propro subsistance et à celle de sa femolle; mais dans tous les autres temps de l'année, le mâle et la femelle paraissent s'entendre pour la cliasse; on les voit presque toujours ensemble ou du unoins à pou de distanee l'un de l'autre.

\section{LE PYGARGUE.}

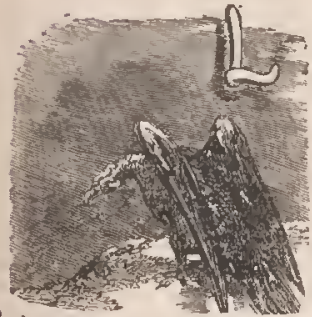

E pygargue aimo de préfúrence Ics climats froids; on le trourc dans toutes les provinces du nord de l'Europe. Le grand pysargue est à peu près de la même grosseur et do la môme foree, si l'aigle eommun; il est au moins plus earnassier, plus féroce et Inoins atlaché à sos petils; car il ne les nourrit pas lonģlemps; il les chasse hors du nid avant nême qu'ils soient en état de se pourvoir, et l'on prétend que, sans lo secours de l'orfraie, qui les prend alors sous sa protection, la plupart périraient : il produit ordinairement deux ou trois pelits et fail son nid sur de gr'os nrbres. Comme le grand aigle et le pygargue ne chassent ordinaircment que de gros animaux, ils se rassasient souvent sur le lieu, sans jouvoir les emporter; les pygargues, qui fréquentent de près les licux habités, no ehassent que pendant quelyues heures dans le milieu 
du jour, et ils se reposent le matin, lo soir et la nuit, au lieu que l'aigle commun est plus valeureux, plus diligent ct plus infatigable.

\section{LE BALBUZARD.}

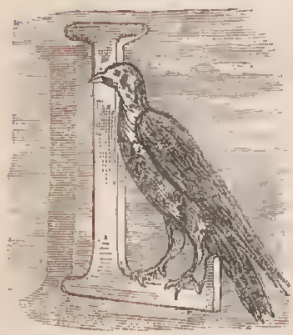

E balbuzard est l'oiscau qu'on appelle aigle de mer. Cet oiseau n'est pas un aigle, quoiqu'il ressemble plus aux aigles quaux autres oiseaux de proie. D'abord il est bien plus petit; il n'a ni le port, ni la figure, ni lo vol de l'aigle. Ses haljtudes naturelles sont aussi tròs-différentes, ainsi que ses appélits, car il ne vit guère que de poisson qu'il prend dans l'eau, même à quelques pieds de profondeur.

\section{L'ORFRAIE.}

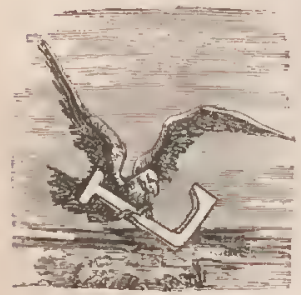

'OnFruse a été appelé lo grand angle de mer. Il est, cn effet, à peu prits. aussi grand que le grand aigle; il so tient volontiers près des borls de li mer et assez souvent dans le milicu des terres à portéc des lacs, 
des étangrs et des riviòres poissonneuses; il n'enlève que le plus gros poisson, mais cela n'empêche pas qu'il ne pronne aussi du gibier ; et, comme il est trèsgrand et très-fort, il ravit et emporle aisément les oies et les lì̀ves, ot même les agneaux et les chevreaux. L'orfraie femelle soigne ses petits avec la plus grande aflection.

Commo cet oiseau est des plus grands, que par celte rinison il produil peu, qu'il ne pond que deux œufs une fois par an, et que souvent il n'élève (qu'un pelit, l'espèce n'en est nombreuse nulle fart, mais elle est assez l'épandue: on la houve presque partout en Europe, et il parnît même qu'elle est commune aux denx continents, et que ces oisenux fréquentent les lacs de l'Anérique septentrionale.

\section{LES VAUTOURS.}

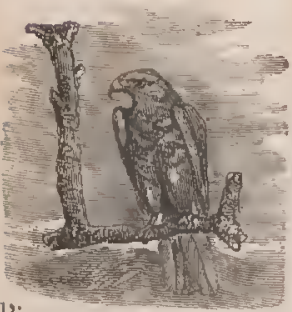

'on a donné aux aigles le premier rang parmi les oiseaux de proio, 11011 paree qu'ils solit plus forts et plus grands cue los vaulours, mais parec cu'ilis sont plus généreux, e'est-à-dirc moins basscment cruels : les vaulour's n'ont que l'instinct de la basse gourrmandise el de la voracité; ils ne combattent guère les vivants que quand ils ne penvent s'assouvir sur les morls. l'our' peu qu'ils prévoient tlo résistanee, ils se rémissent en troupres colnunc de 
làchos assassins et soul plutôt des volours que des gruclriers, des oisonux de carmage yquo des oiseaux do proic; car dans ce gomre il n'y a qu'eux qui so mollent cn nombre et plusicurs contro un, il n'y a qu'eux qui s'acharnent sur los cadavres an point de los céchiqucter jus fu'aux os; la corruption, l'infection les allire au lieu de les repoussor

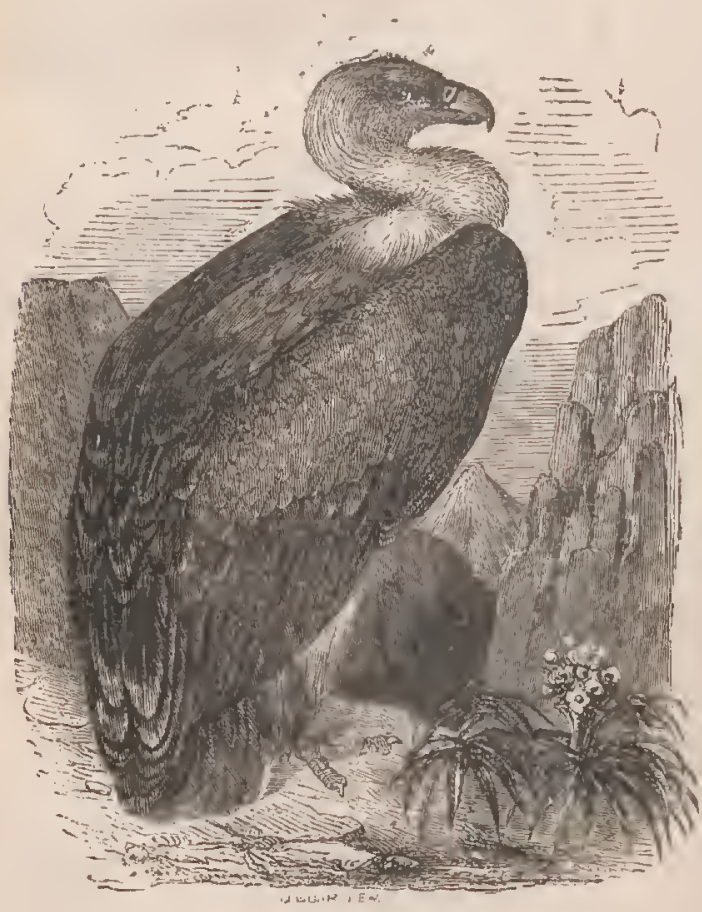




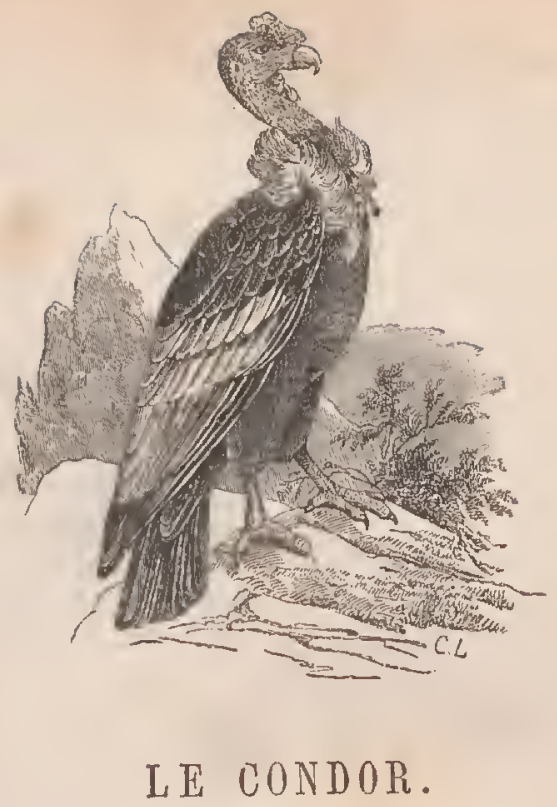

Le eondor possède ì un plus haut degré que l'aigle toutes les qualités, toules les puissanees que la nature a départies aux espèees les plus parfaites de celte classe d'êtres; il a jusqu'à dix-huil pieds de vol ou d'envergure, le eorps, le bee et les serres à proportion aussi grandes et aussi fortes, le eourage égal à la force.

Ces animaux gitent ordinairement sur les montagnes où ils trouvent de quoi se nourrir ; ils ne descendent sur le rivage que dans la saison des pluies; sensibles au froid, ils y viennent eherelıer la chaleur.

Le peu de nourriture qu'ils trouvent sur le bord de la mer, excepté lor'sque quclques tempêtes y jettent quelques gros poissons, les oblige à n'y pas faire de longs 
séjours; ils y viennent ordinairoment le soir, y passent toute la nuit et s'en retournent le matin.

On assure que le condor est deux fois plus grand que l'aigle, et qu'il est d'une telle foree qu'il ravit et dévore une brebis entière, qu'il n'éparñone pas même les eerfs, et qu'il renverse aisément un homme; heureusement il y a peu de condors, car s'ils étaient en grande quantité, ils détrun’aiont tout le bétail. Ils ont la vue perçante, le regar'd assuré et même cruęl ; ils ne fréquentent guère les forêts, il leur faut trop d'espace pour remuer leurs grandes ailes; mais on les trouve sur les lyords de la mer et des rivières, dans les savanes ou prairies naturelles.

\section{LE PETIT VAUTOUR.}

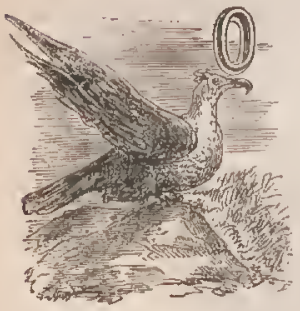

N compte trois petits vautours, savoil' : le vautour brun, le vautour d'Égypte et le vautour à têto blanehe. Cedernier se trouve communément en Arabie, en Egypte, en Gròce, en Allemagne et jusqu'en Nor'wége.

Des antres espèces de petits vautours indiqués sons les noms de vautour brun et de vantour d'Égyte, il paraît qu'il faut en retraneher ou plutôt séparer le seeond, c'est-à-dire le vautour d'Egypte, qui n'est point un vautour', mais un oiseau d'un autre genre. Quant au vautoul 
lırun, son existenee n'est nullement prouvée; aueun des naluralistes ne l'a vu.

\section{LE MILAN ET LES BUSES.}

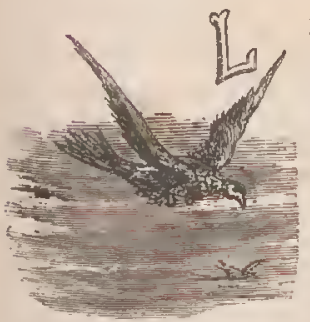

ES milans et les buses, oiseaux ignobles, immondes et lâehes, doivent suivie les vaulour's, auxquels ils ressemblent par le naturel et les mœurs. Les milans et los louses sont partout beaueoup plus eommuns, plus incommorles que les vautours; ils fréquentent plus souvent ot de phis près les lieux lıabités; ils font leur nid dans des endroits plus aceessibles; ils restent rarement dans les déserts; ils prófèrent les plaines et les collines ferliles aux montagnes stériles. Comme toute proie leur est bonne, que toute nourriture leur convient, et que plus la terre produit de végétaux, plus elle est en même temps peuplée d'insectes, de reptiles, d'oiseaux ot de petits animaux, ils établissent ordinairement leur domieile au pied des montagnes, dans les terres les plus vivantes, les plus ałondantes en gibier, en volaille, en poisson. Sans être eourageux ils ne sont pas timides, ils ont une sorte de stupidité féroee qui leur donne l'air de l'audace tranquille, et semble leur ôter la connaissanee du danger. On les approclie, on les tue bien plus aisément que les aigles ou les vautours : détenus en eaptivitć, ils sont cneore moins susceptibles d'éducation. 
Le milan est aisé ì distingucr, non-soulement des buses, mais de tous les autres oiscaux de proie, par 1 m seul caractc̀re facile à saisir : il a la queue fourohue; il a aussi lcs ailes proportionnollement plus longues que les buses, et le vol bien plus aisó : aussi passe-t-il sa vie dans l'air ; il ne se reposo presquo jamais, et parcour't chaque jour des espaces immonses. Il semble que le rol soit son état naturel, sa situation favorite; l'on ne pout s'ompêchor d'admircor la manièro dont il l'exécuto : scs ailes longues et étroites paraissent immobiles; c'est li queue qui semble diriger toules ses évolutions, et elle agit sans cesse. Il s'élève sans effort, il s'abaisse commo s'il glissait sur un plan incliné; il semble plutôt naģભ que voler; il précipite sa course, il la ralentit, s'arrête ct resto commo suspendu ou fixé à la môme place pendant des houres ontieres, sans qu'on puisso s'aperoevoir d'aulcun mouvement dans ses ailos.

Il n'y a, dans notro climat, yu'une seule espèce de milan qu'on a appelé milan royal, parce qu'il servait aux plaisirs des princes, qui hui faisaient donner la chasse ct livrer combat par' le faucon ou l'épervier.

Les milans ne sont pas des oiseaux de passage, car ils font lour nid dans des creux de roclier's. lls nichent en lirance et en Angleterre, et ils y restent pendant toute l'année; la femclle pond deux ou trois oufs qui, comme ceux do tous les oiseaux carnassiers, sont plus ronds quo les aufs de poule; ceux du milan sont blanchâtres, avec des taclses d'un jaune sale. Quelyues auteurs ont dit nussi qu'il faisait son nid dans les forêts, sur do vioux chênes on le vieux sapins.

L'espìce parait être répandue, dans tout l'ancien con 
tinent, dopuis la Suc̀de jusqu'au Sénégal, mais elle ne se trouve pas lans lo nouvoau continent.

\section{LA BUSE.}

Cet oiscru demeure pendant toute l'rnnée dans nos forêts; il parait assez stupide, soit dans l'état de domesticité, soit dans celui de libertẻ; il est assez sédentaire et même paresseux; il reste souvent plusieurs lieures de suite porché sur le même arłsre. Son nid est construit avco de petites branches, et garni en dedans de laine ou d'autres petits matóriaux liggers ou mollets : la buse pond deux ou trois oufs đqui sont blanchâtres, tachelés de jaune; elle élève et soiģno ses pelits plus longtemps que les autres oiseaux de proie, qui presque tous les chassent du nid avant qu'ils soient en état de se pourvoir aisément; on assure même que le mâle de la buse nourrit et soigne ses petits lorsup'on a tuć la mère.

Cet oiseau de rapine ne saisit pas sa proie au vol; il reste sur un arbre, un buisson ou une motte de terre, ot de lì se jette sur tout le petit gibier qui passe à sa portée; il prend les levrauts et les jeunes lapins aussi bien que les pordrix et les cailles; il dévaste les nids de la plupart des oiseaus; il se nourrit aussi de grenouilles, de lézards, de scrpents, de sauterelles, elc., lersque le gibier lui manque. 


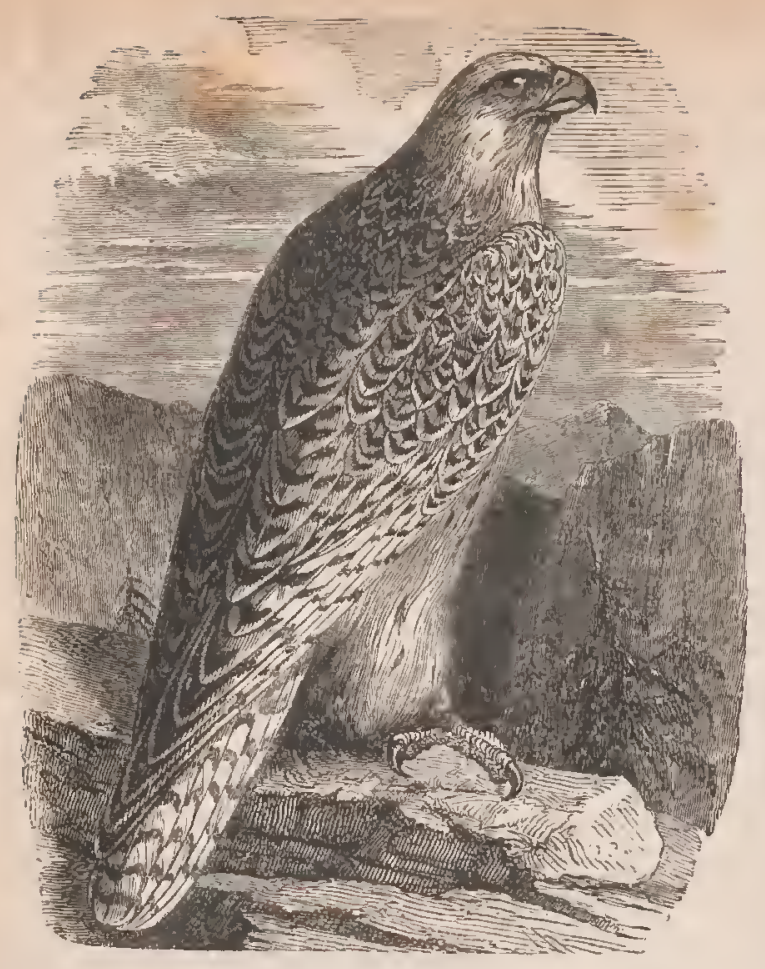

\section{LE FAUCON.}

Le faucon est pent-être l'oiseau dont le courage ost le plus franc, le plus grand, rolativement à ses lorees; il fond sans détour et perpendiculairement sur sa proie; on le voit fréquemment attarquer le milan, soit pour exercer son courage, soil pour lui enlever une proio; mais il hui fail plutôt la honte que lin gucrre; il le traite commo un làche, lo chasse, le frapre avec dédain, ch ne 
le mot point à mort, parce que le milan so dófend mal, et que probablement sa chair répugne au faucon encore plus çue sa lâcheté ne lui déplaît.

Commo ces oiseaux cherchent pariout les rochers los plus hauts, ot que la plupart dos îles ne sont que des groupes ct des pointes de montagnes, il y en a beaucoup à Rhodes, en Chypre, à Malte ct dans les autres îles de la Méditcrranée, aussi bien qu'aux Orcades et on Islandc.

11 n'y a de différence essentiello entre los faucons de difiérents pays que par leur grosscur ; ceux qui vionnent du Nord sont ordinaircment plus grands que ceux des montagnes, des Alpes et des Pyrénées : ccux-ci so mennent, mais dans lours nids; les autres se pronnent au passage dans tous los pays; ils passent en octobre et en noveml.re, et ropassent en février et en mars.

\section{LE GERFAUT.}

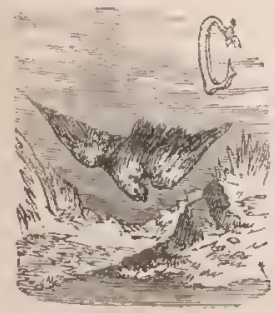
turel du gerfaut est si sanguinaire, que quand on le laisse en liberté avec plusieur's faucons, il les égorge tous les uns aprìs les autres : copendant il semble man- 
ger de préférence les souris, les mulots et les polits oiseaux. Il se jette avidemment sur la chair saignante, et refuse assez constamment la viande cuite; nais en lc faisant jeûner, on peut le forcer de s'en nour'rir; il plume les oiseaux fort proprement, et ensuite les dépèce avant de les manger, au lieu qu'il avale les souris tout enticres. Son cri est fortrauque, et finit toujours par des sons aigus, d'autant plus désagrénbles qu'il les répète plus souvent; il marque aussi une inquiétude mortelle dès qu'on l'approclic, et semble s'effaroucher de tout. On transporte les gerfauts d'Islande of de Russie en France, en Italic et jusqu'en Perse et en Turquic, ct il ne paraît pas que la clıaleur plus griande de ces climats leur ôte lien de leur force et de leur vivacité; ils attaquent les plus grands oiscaux, ct font aisément leur proic de la cigogne, du héron el de la grue; lá fomelle est, comme dans les autres oiseaux de proie, beaucoup plus grande et plus forte que le mâle.

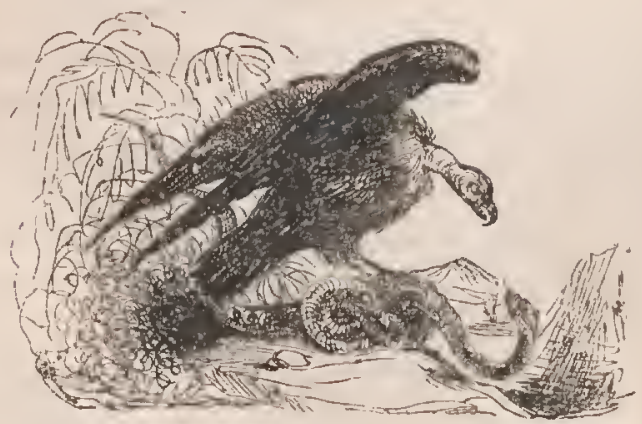




\section{L'ÉMERILLON .}

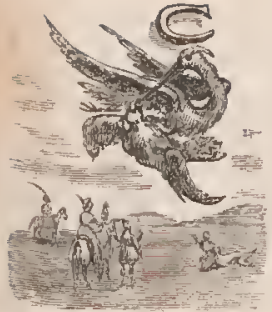

ET orscau est le pliss potit de tous les oiseaux de proie, ear il n'a que la grandeur d'une grosse mrive; néanmoins on doit le regarder comme un oiseau noble.

Le mâlc ct la femclle sont daus l'ćmerillon de la mềne grandeur.

I'émerillon vole bas quoique vite et trc̀s-lćgèrement; il fréquente les bois et les buissons pour y saisir les pctits oiseaux, et chasse seul sans chtre accompagné de sa femelle; clle niche dans les forcts et les montagnes, et produit einq ou six petits.

\section{L'AUTOUR.}

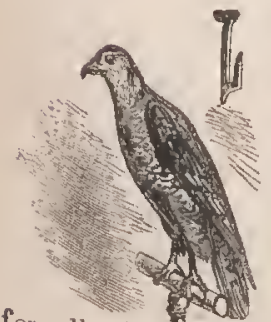

'autour est un bel oiscau beaucoup plus grand que l'épervier'; il a les jambes plus longues que les antres oiscaux qu'on pourrait lui comparer' et prendro pour lui; lo mâle autour est, comme la plupart des oiseaux de proie, beaucoup plus petit que la fernelle. Ils ont plusicurs habitudes communes avec l'ćpervier; jamais ils ne tombent à plomb sur leur proic; ils la prennent de côté. 
L'autour se trouve dans les montagnes de FrancheComlé, du Daupliné, du Bugcy, et même dans les forêts de la province de Bourgogne et aux environs de Paris; mais il est encore plus commun en Allemagne qu'en France, et l'espèce paraît s'c̀tre répandue dans les pays du Nord, jusqu'en Suède, ct dans ceux de l'Orient ct du Midi, jusqu'en P'erse et on Barbaric.

On a remarqué que, quoique le mâle fùl beancoup plus petit que la fomelle, il était plus féroce et plus méchant; ils sont tous deux difficiles ì priver.

\section{LE BUSARD.}

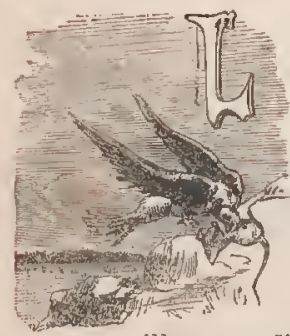

E busard chasse de préférence los poules d'cau, les plongeons, les canards et autres oiscaux d'cau; il prend les poissons vivants et les enlève dans ses serres : au défaut de gibier ou de poisson, il se nourrit de reptiles, de crapauds, de grenouilles et d'insectes nquatiques. Quoiqu'il soit plus petit que la buse, il lui faut une plus ample pâture, et c'est vraisemblablement parce qu’il est plus vil et qu'il se donne plus de mouvement qu'il a plus d'appétil; il est aussi bien plus vaillant. On a úlevé des busards à chasser ot prendre des lapins, des perdrix et des cailles. Les lobereaux of les cresserelles le redoutent, évitont sa rencontre, et même fuient lorsqu'il les approche. 


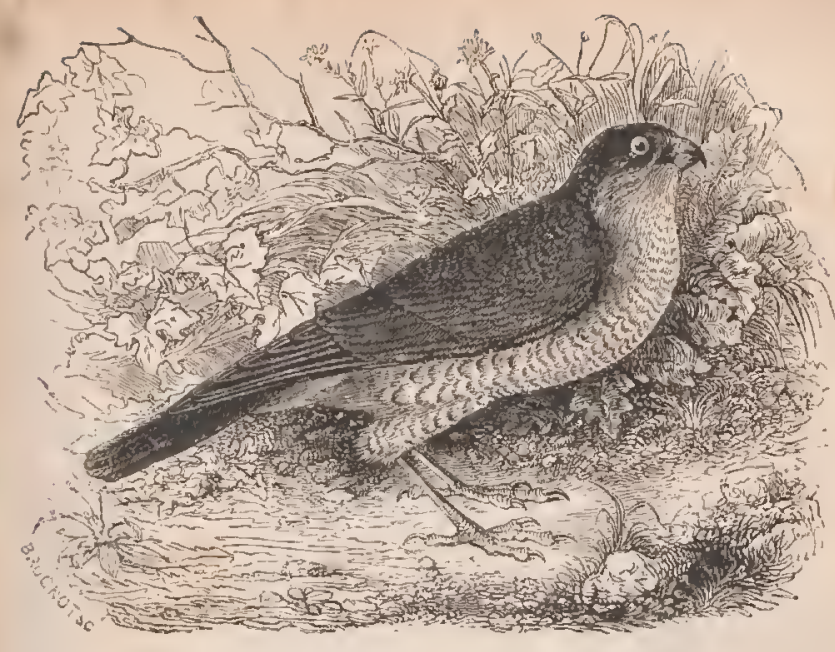

\section{L'ÉPERVIER.}

L'épervier reste toute l'annéc dans nolre pays : l'ospice on est assez nombrouse. La fomolle est beaucomp plus grosse que lo mâle; olle fait son nid sur les arbres les plus élevés des forêts; elle pond ordinairement quatro ou cinq oeufs. L'épervier, tant mâle quo femelle, est assez docilo : on l'apprivoise aisémont, et l'on peut le dresser pour la chasse des perdreaux et des caillos; il prend des pigeons séparés de leur compagnie, et fait une prodigicuse destruction des pinsons et dos autres petits oiseaux qui se mettent en troupe pendant l'hiver. L'ospèco de l'épervior' se trouve répandue dans l'ancien continont, depuis la Suède jusqu'nu cap de Bonne-Espérance. 


\section{LES OISEAUX DA PROIE NOCTURNES}

\section{LE DUC OU GRAND DUC.}

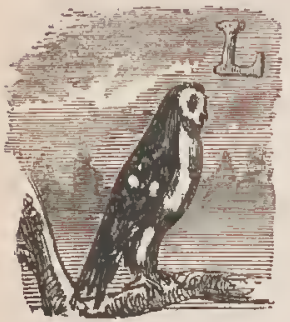

E due est l'aigle de la nuit; on lo distingue aisément à sa grossc figure, ì son énorme tête, aux larges et profondes cavernes de ses oreilles, aux deux aigrettes qui surmontent sa tête et qui sont ćlevées de plus de deux pouces ot duni; à son cri effrayant huihou, houhou, bouhou, pouhou, qu'il fait retentir dans le silence de la nuit, lorsque tous les autres animaux se taisent; ot c'est alors qu'il les éveille, les inquiète, les poursuit et les enlève ou los met å mort pour los dépecer et los emporter dans les cavernes qui lui servent de retraite. Aussi n'habitet-il que les rochers ou les vicilles tours abandonnées; il deseend rarement dans les plaines, et ne se perche pas volontiers sur les arbres, mais sur les églises écartécs et sur les vieux châteaux.

Comme cet oiseau craint peu le chaud et ne craint pas le froid, on le trouve également dans les deux continents, au nord et au midi. 


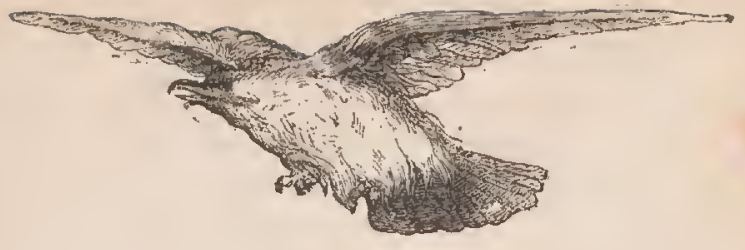

\section{LE HIBOU OU MOYEN DUC.}

Le hibou, ou moyen duc, a, comme le grand due, les orcilles fort ouvertes, et surmontées d'une aigrette composće de six plumes tournées en avant; mais ces aigrettes sunt plus courtes que colles du grand due, et n'ont guère plus d'un pouce de longueur; elles paraissent proportionnées à sa trille, car il ne pèse rqu'environ dix onces, et n'est pas plus gros qu'une corneille. Son espèce est commune et beaucoup plus nombreuse dans nos elimats que celle du grand due ; le moyen due y reste toute l'année, et se trouve même plus aisćment en hiver qu'en été. Il habite ordinairement dans les ancions bâtiments ruinés, dans les cavernes des rochers, dans lo creux des vieux arbres, dans les forêts en montagne, et ne descend guère dans les plaines. Lor'sque d'autres oiseaux l'attaquent il se sert très-bien et des grifles et du bee; il se retomne aussi sur le dos pour se défendre quand il est assailli par un ennemi trop fort.

Le hibou, qui est commun dans nos provinces d'Europe, so trouve aussi en Asie.

Ces oiseaux se donnent rarement la peine de faire un nid, ou se l'épargnent en entier; ils pondent ordinairement quatre ou einq $œ u f s$, et leurs petits, qui sont blane 
en naissant, prennent des couleurs au bout de quinze jours.

On se sert du hibou pour attirer les oiseaux à la pipée, et l'on a remarqué que les gros oiseaux viennent plus volontiers que les pelits ì la voix du libou, qui est une espèce de cri plaintif ou de gémissement grave et allongé, clow, cloud, qn'il ne cesse de répéter pendant la nuit.

\section{LE SCOPS OU PETIT DUG.}

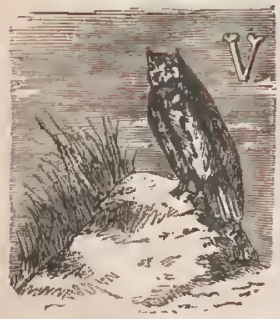

olcr la troisième et dernière espèce du genre des hiboux : elle est aisée à distinguer des deux autres, d'abor'd par la petitesse même du corps de l'oiseau, qui n'est pas plus gros qu'un merle. Tout son corps est très-joliment varié do gris, de roux, de brun et de noir, et ses jambes sont couvertes jusqu't̀ l'origine des ongles de plumes d'un gris roussâtre mêlé de taches brunes. Il se réunit en troupe on aulomne et au printemps pour passer dans d'autres olimats; il n'en reste que très-peu ou point du tout en hiver dans nos provinees, et on les voit partir après les hirondelles ot arriver à peu près en même temps. Quoiqu'ils habitent de préférence les terrains ćlevés, ils se rassemblent volontiers dans ceux où les mulots sc sont lo plus multipliés, ot y font un grand bien par la destruction de ces animaux. Quoique le petit due 
voyage par troupes nombreuses, il est assez rare partont ot difficile à prendre. La couleur de ces oiscaux varic beaucoup suivant l'âģe et le climat, et peut-être le sexe: ils sont tous grris dans le premicr âge; il y en a de plus bruns les uns que les autres quand ils sont adultes.

\section{LA HULOTTE.}

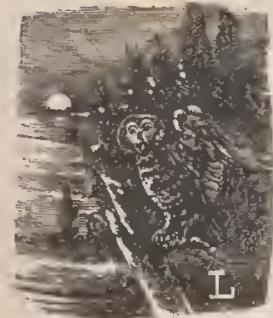

A hulotte, qu'on peut appeler aussi la chouette noire, est la plus grande de toutes les chouettes. Elle a la tête très-grosse et bien arrondie; olle vole légèrement et sans faire do bruit avec ses ailes, et toujours de côté comme toutes los autres choucttes; son cri hoû oû oû ổ ou ou ou ressemble assez au hurlement du loup.

La hulotte se tient pendant l'été dans les bois, toujours dans des arbres creux; quelquefois ello s'approche on hiver de nos habilations, elle chasse et prend les petits oiseaux, et plus encore les mulots et les campagnols. Lorsque la chasse de la campagne ne lui produit rien, elle vient dans les granges pour y chercher des souris et des rats; elle retourne au bois de grand matin à l'heure de la rentrée des lièvres, ot elle se fourre dans les taillis les plus épais ou sur los arbres les plus feuillés, ot y passe tout le jour sans changer de lieu. Dans la mauvaise saison, elle demeure dans les arbres creux pendant le jour 
et n'en sort qu'à la nuit. Elle pond ses neufs dans des nids ótr.ungers, surtout dans ceux des buses, des cresserelles, des corneilles et des pies; elle fait ordinairement quatre oufs à peu près aussi gros que ceux d'une petite poule.

\section{LE CHAT-HUANT.}

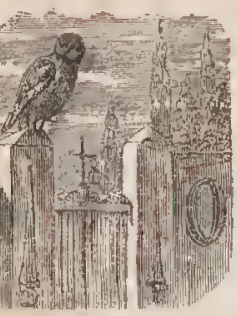

N reconnaît le ehat-huant d'abord à ses yeux bleuâtres, et ensuite ì la heauté et à la variété de son plumage ; et enfin à son cri hohô hohô, hohohoho, par lequel il semble huer, Iıôler ou appeler à la voix.

On ne trouve guère les chatshuants ailleurs que dans les bois: ils se tiennent dans dans des arbres creux.

Comme le chat-huant se trouve en Suc̀de et dans les anlres terres du Nord, il a pu passer d'un continent à l'autre: aussi le retrouve-t-on en Amérique jusque dans les pays chauds.

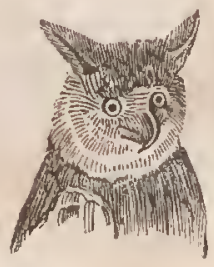




\section{IA CIOURTTE OU LA GRANDE CHEVECHE.}

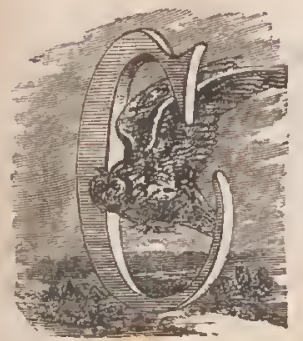

ETTE ospòce, qui estla chouctto proprement dite ct qu'on peut appeler la chouelle des rochors ou la grande cheviche, est assez commune, mais clle n'ilproche pas aussi souvent de nos liabitations uque d'autres espèces; cllc se tiont plus volonticrs dans les carrières, dans les rocher's, dans les bâtiments ruinés ot éloignés des lieux labités. Il semble qu'elle préfòre les lays de montagnes et qu'clle cherche les précijices escarpés et les endroils solitaires; eependant on ne la trouve pas dans les bois el clle ne se loge pas dans des arbres ereux.

Les labourcurs font grand cas de cet oiscau, en ce qu'il létruit quantilé de mulots; dans le mois d'avril on l'entend crier jour et nuit gont, mais d'un ton assez doux, "t (tund il doit plcuvoir, il ehange de eri et scmble dirc yoyon. La eltouctte ne fait point de nid, ne pond que trois weul's tout blanes, parfaiteinent ronds et gros comine cux d'un pigeon ramier.

Il parnit que la grando chevèche, qui est assez com1ume en Europe, surtont dans les pays de montagnes, se retrouve en Amćriqne, dans celles du Chili. 


\section{LA CHEVECHE OU PETITE CHOUETTE.}

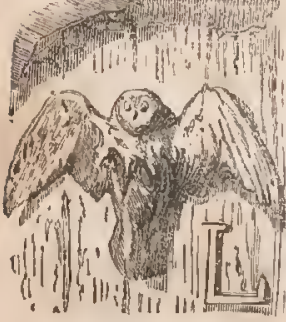

A ehevèche et le scops ou petit duc sont à peu près de la même grandeur : ee sont los plus petits oiseaux du genre des liboux ct des choucttes; ils ne sont que de la grosseur d'un merle. La ehovìche a un cri ordinaire poupou poupon qu'elle pousse el répète en volant, et un autre cri qu'elle fait entendic quand ellc est posée, qui resscmble beaueoup à la voix d'un jeune homme qui s'écrierait aỉme, hìme, ćsme plısicur's fois de suite. Elle se lient raremont dans les bois; son domieile ordinaire est dans les masures écartées des lieux pouplés, dans les carrières, dans les ruines des arlciens édifices abandonnés. Elle n'est pas absolument oiseau de nuit, elle voit pendant le jour beaneoup mieux que les autres oiscaux noeturnes, et souvent elle s'exeree à la chasse des hirondelles et dos autres petits oiseaux, quoique assez infruetueusoment, ear il est rare qu'elle en prenne; elle réussit mieux avee les souris et les petits mulots qu'elle ne peut avaler onticrs et qu'elle déchire avee le bee et les ongles ; ello plume aussi trèsproprement los oiscaux avant do les mangel. Eilo pond cinç oufs, qui sont tachetés de blane et de jaunâtre, et fail son nid presque à cru dans des trous de rochers ou de vieilles murailles. 


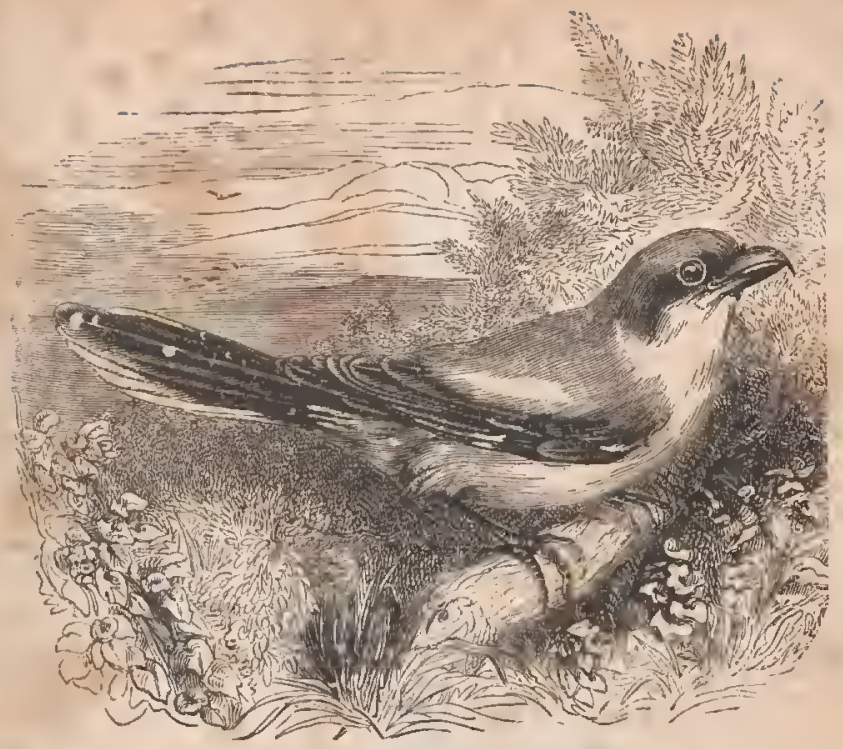

\section{LES PASSEREAUX.}

\section{LES PIES-GRIECHES.}

Ces oiscaux, quoique pelits, quoique délicats, doivent néannuins par leur courage, par leur large bec fort et crochu, et jur leur appélit pour la chair, ctre mis au rang des oiscaux de proie, même des plus fiers el des phus sanguinaires. On est toujours étonné de voir l'intrépidité avee laquelle une petite pie-grièche combat contre les pies, les corneilles, les cresserelles, tous oiseaux beaucoup plus grands et plus forts qu'olle; non-seulement olle 
combat pour se dófoncle, mais souvent clle attarue, et toujours avec avantage, surlout lorsque lo couple se rénit pour éloigrner do lours petits les oiseaux de rapino. Elles n'attendent pas qu'ils approchent, il suffit qu'ils passcnt à leur portéc pour qu'clles aillent au devant; clles les attaquent à grands oris, leur font des blessures cruclles, et les elassent avoc tant de furour qu'ils fuient souvent sams oser l'evenir. Et dans ce combat inégral contre d'aussi giands ennemis, il est rate de les voü succomber sous la force, ou se laisser emporter: il arrive soulcment qu'clles tombent quelquefois avee l'oiscau contre lequel olles se sont acelochées avee tant d'achalnement, que le combat ne finit quo par la chute ct la nort de tous deux : aussi les oiscaux de proie les plus braves les respectent-ils; les milans, les buses, les corhoaux, paraissent les eraindre et les fuir plutòt que les chereher. Ricn dans la nature ne peint mieux la puissance et les droits du courage que de voir ce petit oiscau, ¿qui n'est gucre plus gros qu'une allouctte, voler de pail avec les cyerviers, les fiucons et tous les autres tyrans do l'air', silns les redouter.

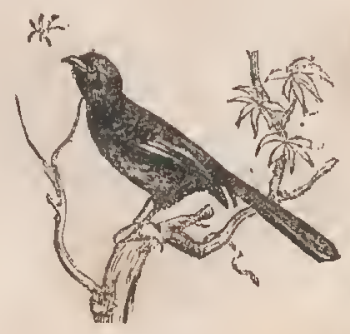




\section{LA PIE-GRIECIIE GRISE.}

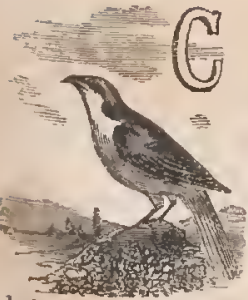

втте pie-grrièche grrise est très-coninune dans nos provinces de France, et parait être naturelle ì notre climat, car' ellc y passe l'hiver et ne le quitte en aucun temps; elle habite les bois et les montagnes cu ćté, et vient dans les plaines et près des habitations en liver. Elle fuit son nid sur les arlures les plus élevés des bois ou des terres en montagnes : ce nid est composé au dehors de mousse blanche entrelacée d'herbes longues, et au dedans il est bien doublé et tapissé de laine; ordinairement il est apluyyé sur une branche à double et triple fourche. La femelle, qui ne diffère jas du mâle par la grosseur, mais sculement par la teinte des couleurs, plus claires quo celles du mâle, pond ordinairement cinq ou six ct qucl(luefois scpt, ou même huit oufs gros comme ceux d'unc Brive; ello nourrit ses petits de chenilles et d'aulies insectes dans les premiers jours, ct bientòt elle leur fait manger de petils morecaux de viande que leur pòre lour apporte avec un soin et une diligence admirables. Bien différente des autres oiseaux de proie qui chassent leurs petits avant qu'ils soient en étal de se pourvoir d'cux-mêmes, la pie-grièche garde et soigne les sicns tout le temps du premier âge, et quand ils sont adultes elle's les soigne cncore; la fimille ne se séprare pas. On lus voil volur ensemble ponclant l'iutomne entier, et en- 
core en hiver, sans qu'ils se réunissent en grandes troupos : chaque famille fait une petite bande à part, ordinairement composée du père, de la mère et de cinq ou six petits, qui tous prennent un intérêt commun à ce qui lcur arrive, vivent en paix ot chassent de concer't la fitmille ne se sćpare quo pour on former de nouvelles.

Il est aisé de reconnaitre de loin les pies-gric̀ches, nonseulement à cause de cette petite troupe qu'elles forment après le temps des nichćes, mais oncore à leur vol, qui n'est ni rirect, ni oblique à la mêne liautcur, et qui se fait toujour's de bas en haut, et de haut en bas, alterintivenent et précipitamment. On peut aussi les reconnaitre, sans les voir, à lcur cri aigu, lrouí, trouî, yu'on entend de fort loin, et qu'elles ne ecssent de répéter' lor'squ'clles sont perchíes au sommet des ar'ures.

Il y a dans cette jromière espòce, varićté pour la grandcur, et variété pour la couleur.

\section{LA PIE-GRIECHE ROUSSE.}

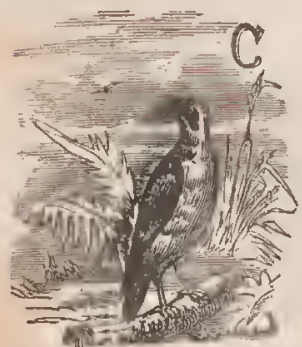

ETTE pie-Öric̀che rousse est un pou plus petite que la grise, et trèsaisée à r'econnaîtro par le roux qu'elle a sur la tôte, qui est quelquefois rouge et ordinairement d'un roux vif ; on pent aussi remarquel cu'elle at les yeux d'un gris blanchâtre ou jaunâtre, au lieu (que la pie-griciche grise les a bruns ; ello a aussi le bec et les jambes plus noires. 
Lo naturel de cette pie-gric̀eho rousse est à trìs-peu près le même que celui de la pic-grièehe grise; toutes deux sont aussi hardies, aussi méeliantes l'une que l'autre; mais ee qui prouve que ee sont néanmoins deux espèees différentes, c'est que la premičrc reste au pays toute l'année, au lieu que eelle-ei le quitte en automne et ne revient qu'au printemps. La famille qui ne se sépare pas à la sortie du nid, et qui demeure toujours rassemblée, part vers le eommeneemont de septembre, sans se réunir avec d'autres familles et sans faire de longs vols. Ces oiseaux ne vont que d'arbre en arbre et ne volent pas de suite, même dans le temps do leur départ; ils restent pendant l'été dans nos eampagnes et font leur nid sur quelque arbre touffu, au lieu que la pie-gric̀che grise habite les bois dans celte même saison et ne vient guère dans nos plainos que quand la pie-grièche rousse est partie. On prétend aussi que de toutes les pies-grièehes eclle-ci est la meilloure, ou, si l'on veut, la seule qui soit bonne à manger.

Le mâle et la femelle sont à très-peu pròs de la même grosseur; mais ils diffèrent par les eouleurs assez pour paraître des oiscaux de différente espèce. Ils proluisent ordinairement einq ou six cufs. Ces oiseaux font leur nid avee beaucoup d'art et de propreté, à peu près avec les mêmes matériaux qu'emploic la pie-grièche grise.

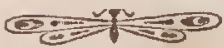




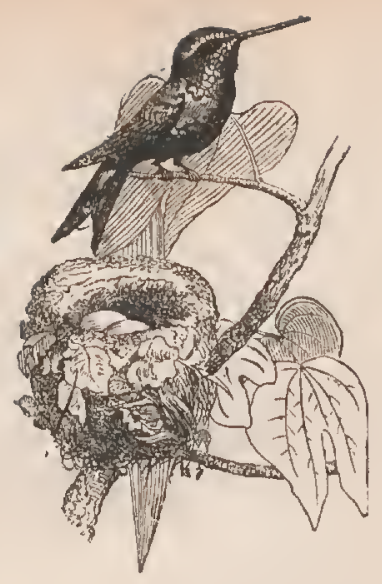

\section{LES GOBE-MOUCHES, MOUCHEROLLES} ET TYRANS.

Au dessous du dernier ordre de la grande elasse des oiseaux earnassiers, la nature a établi un petit genre d'oiseaux chasseurs plus innocents et plus utiles. Ce sont tous ees oiseaux qui ne vivent pas de ehair, mais qui se nourrissent de mouehes, de moueherons et d'autres inseetes volants sans toueher ni aux fruits ni aux graines.

On les a nommés gobe-mouehes, moueherolles et tyrans: e'est un des genres d'oiseaux les plus nombreux en espèees. Les unes sont plus petites que le rossignol, et les plus grandes approchent de la pie-grièehe ou l'égalent. Les terres du Midi, où jamais les inseetes ne eessent d'éelore et de voler, sont la véritable patrie de ees oiseaux; aussi contre deux espèees de gobe-mouehes qu'on trouve en Europe, en eompte-t-on plus de huil dans l'Afrique et dans les régions ehaudes de l'Asic, ct près de trente en Amérique. 


\section{LES GOBE-HOUCHES.}

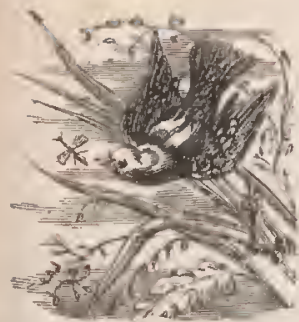

es gobc-mouches arrivent on avril et partent en septembre. Ils so tiennent eommunément dans les forêts, où ils eherchent la solitude et les lieux couverts et fourrés; on en rencontre aussi quelquefois dans les vergers épais. Ils ont l'air triste, le naturel sauvage, peu animé et même assez stupide. Ils placent leur nid tout à découvert, soit sur les arbres, soit sur les buissons; ancun oiseau faible ne se cache aussi mal, aucun n'a l'instinct si peu décidé. 11 pond trois ou quatre œufs et quelquefois cinq.

Ces oiseaux prennent le plus sonvent leur nourriture on volant, ct ne se posent que rarement et par instants ì torre, sur laquelle ils ne courent pas. Le mâle ne diffère de la fomelle qu'en ee qu'il a le front plus varié de brun, et le ventre moins blanc. Ils arrivent en France au printemps, mais les froids qui survicnnent quelqucfois vers le milieu de cette saison leur sont funestes. Tout degré de froid qui abat los inscetes volants dont cet oiseau fait son unique nourriture devicnt mortel pour lui : aussi abandome-t-il nos eontrées avant les premiers froids de l'automne, et on n'en voit guère plus dès la fin de septembre. 


\section{LE GOBE-NIOUCIES NOIR A COLLIER}

OU GOBE-MOUCHES DE LORRAINE.

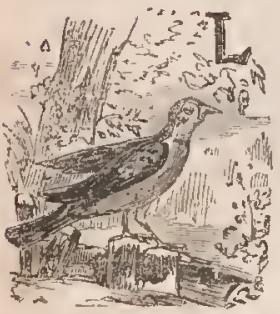

E gobe-mouches noil ì collicr est la sceonde des deux espèces de gobe-mouches d'Europe. Il est un peu moins grand que le précédent, n'ayant guc̀re que einq pouces de longuour : il n'a d'autres couleurs que du blane et du noir par plaques et taches bion marquées; car, suivant les différentes saisons, le mâle paraît porter quatre habits différents.

Cet oiseau arrive en Lorraine vers le milien d'avril. II se tient dans les forêts, surtout dans colles de hante futaic; il y niche dans des trous d'arbre, quelquefois assez profonds, et à une distance de terre asscz considérable; son nid est composé de petits brins d'herlje et d'un peu de ınousse qui couvre le fond du trou où il s'est étalsli : il pond jusqu'ì six oufs. Lorsquelespetits sont éclos, le père et la mère ne cossent d'entrer' et sortir pour leur porter à manger, et par cette sollicitude ils décèlent eux-mêmes leur nichée, que sans cela il ne serait pas facile de découvrir?.

Ils ne se nourrissent que de mouches et autres insectes volants; on ne les voit pas à terre, et presque toujours ils so tiennent fort élevés, voltigeant d'arbre en arbre. Leur voir n'est pas un claant, mais un accent plaintif très-aigu, roulant sır une consonne aigre, crrî, crri. 

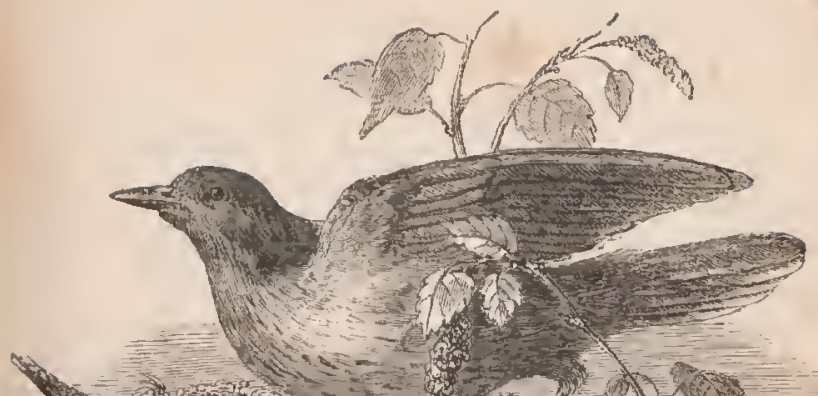

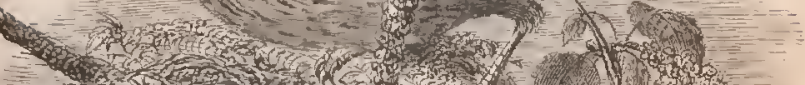

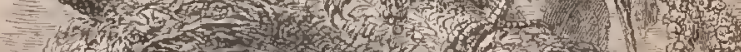

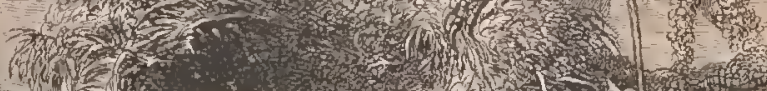

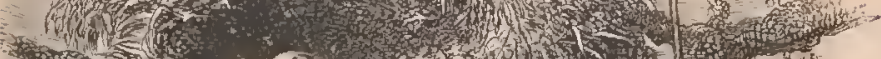

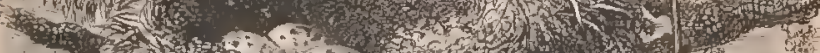

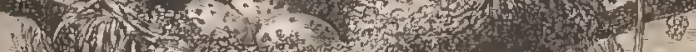

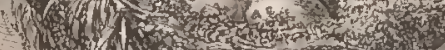

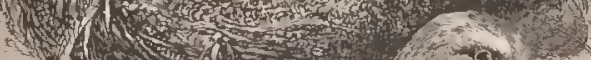

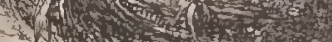

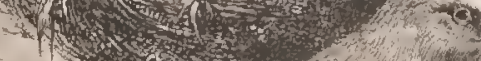

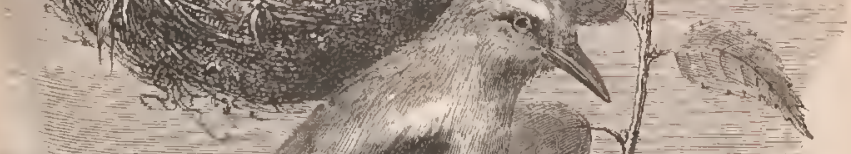

-

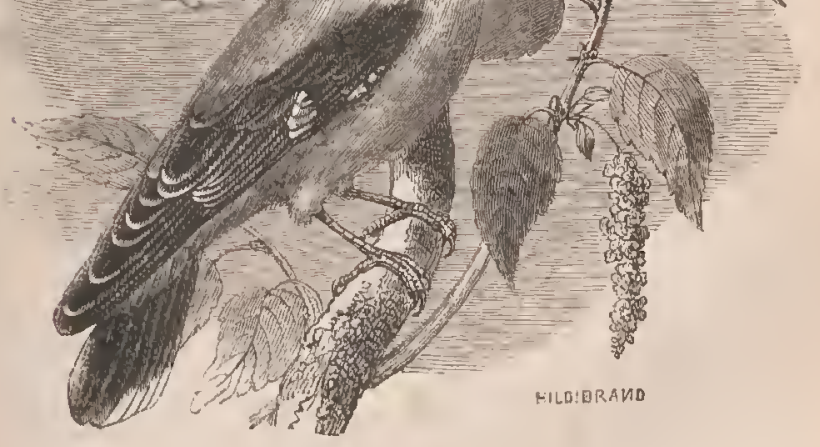



Ils paraissent sombres et fristes, mais l'amour de leur's pelits leur donne de l'activilé et même du courage.

$\mathrm{C}_{c}$ pelit oiscau, triste et sauvage, mène pourtant une vie tranquillc, sans danger, sans combats, prolégée par la solitude : jl n'arrive qu'à la fin du printemps, lorsque les inscetes dont il fait sa proie ont pris lcurs ailes, et lrapt dans l'arrièro-saison pour retrouver aux contrées du Iidi sa pâture et sa solitude.

Il pénètre assez avant dans le Nord puisqu'on le trouve 'n Sucde; mais il parait s'être porté beoucoup plus loin vers le Midi, qui est véritablement son elinat natal.

\section{LE LORIOT.}

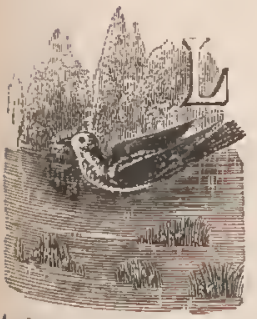

onsoue le nid du loriot a ólé tròs-artistement juréparé, la femelle y dépose quatre ou cinq oufs, qu'clle couve avec assiduité l'ospace d'environ trois semaines; et Iorsque les pelits sont éclos, non-seulement elle leur continue ses soins affectionnós pendant très-longicmps, mais elle les défond contre len's ennemis, et mòme contre l'homme, avee plus d'intrépidité qu'on n'en attendrait d'un si petit oiscau. On a vu Ic père et la mère s'élaneer courageuscment sur ceux cui leur enlevaiont leur couvéc, et, ce qui est encore plus rare, on a vu la mère, prise avec le nid, continuer de couver en cage et mourir sur ses ouls. 
Dès que les petits sont élevés, la famille so met en marche pour voyager; e'est ordinairement vers la fin d'août ou le commencement do septembre; ils ne se réunissent jamais en troupes nombrouses. Ils ne restent pas mêmo assemblés en famillo, car on n'en trouve gruère plus de doux ou trois onsemble. Quoiqu'ils volent peu légèroment et en battant des ailes, il est probable qu'ils vont passer leur quartier d'hiver on Afrique.

Lorsqu'ils reviennent au printemps, ils font la guerre aux insectes ct vivent de scarabées, de chenilles, de ver"misseaux, en un mot de ce qu'ils peuvent attraper; mais leur nourriture de choix, celle dont ils sont le plus avides, sont les cerises, les figues, les baies de sorbier et les pois.

Les loriots ne sont faciles ni à élever ni à apprivoiser.

\section{L $\Lambda$ GRIVE.}

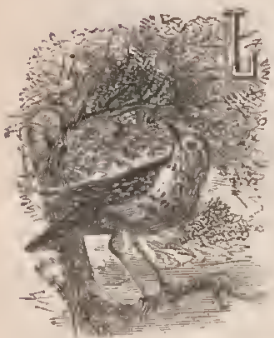

A grive scmble êtro attirée en France par la maturité des raisins; elle nous arrive, chaque annće, au temps des vondanges, et c'est pour cela, sans doute, qu'on lui a donné le nom de grive de vigne; elle disparaît aux gelées ot se remontro au mois de mars ou d'avril, pour disparaître encore au mois de mai. Chemin faisant, la troupe perd toujours quelqques traîneurs, qui ne peuvent suivre, ou qui plus pressés que les autres jar les 
louces influenees du printomps, s'arêtent dans les forits qui se trouvent sur leur passage pour y faire leur Donte. C'est par eotte raison qu'il reste toujours quelques frives dans nos bois, où elles font leur nid sur les pominicrs ot les poiriers sauvagos, et même sur los genéiriers et dans les buissons. Quelquefois elles l'attachent contre le tronc d'un gros arbre, ì dix ou douze pieds de ${ }_{1}$ auteur, ot dans sa construction elles emploient par jrófirence le bois pourri el vermoulu.

Elles ont eoutume de fairc deux pontes par an, et quelquefois une troisième, lorsque les premières ne sont pas venues à bien. La premic̀re ponte est de einq ou six Oufs, ot dans les pontes suivantes le nombre des oufs va toujour's en diminuant. La grive oliante, dit-on, les trois quarts de l'année : olle a coutume pour chanter de se mettre tout on liaut des grands arbres, ot olle s'y tient les hicures entières; soll ramage, eomposé de plusieurs couplets différents, est agréable et varié, eo qui lui a liait, clonner en plusieurs pay̧s la dénomination de grive clianleuse.

Chaque couvée va séparćment sous la conduite du bère et de la nùre. Comme quelquefois plusieur's couvées se rencontrent dans les bois, on pourrait penser, à les voir ainsi rassemblées, qu'elles vont par troupes nombreuses; mais leur's réunions sont fortuites, momentanées; bientôt on les voit se diviser en autant do petits pelotons qu'il y avait de fanilles réunies, et même se disperser absolument lorsque les petits sont assez lurts jour aller sculs.

Ces oiseaux se trouvent ou plutôt voyagent en Italie, (n Frine, en Lorraine, en Allomague, en Angleterre, 
en Ǵoosse, en Suède, où ils sc tiennent dans les bois qui aboudent en ćrables.

Les grives sont des oisenux tristes, mélancoliques, ct, comme e'est l'ordinaire, d'autant plus amoureux de leur' liberté. On ne les voit guère so jouer ni même se battro enscmble, encore moins se plier à la donesticité. Mais, s'ils ont un grand anour pour leur liberté, il s'en faut bicn qu'ils aicnt aulant de ressources pour la conscrver et pour se conserver cux-mêmes : l'inégalité d'un vol oblique ct tortueux est presque le seul moyen qu'ils aicnt porr échapper au jlomb du chasseur et à la serre de l'oiscau carnassier: s'ils peuvent gagncr un arbre touffu, ils s'y tiennent immobiles de pour, et on ne les fait par'tir que diffieilement.

\section{LE MERLE。}

Les merles ne s'éloignent pas seulcinent du geire des grives par la couleur du plumage, et par la différentc livrée du mâle ob de la femelle, mais eneore par leur cri que tout le monde connaîl, et par quelques-unes de le ur's habitudes. 1ls ne voyagent ni ne vont en troupes comill' les grives, et núanmoins, quoique plus sauvages entre eux, ils le sont moins à l'égard de l'homme; ear nous le:apprivoisons plus aisément que les grives, et ils ne se tiement pas si loin dos lieux habités. Au reste, ils passant communément pour ôtre trìs-lins, parec cue, aviant la vuo perçante, ils découvrent les eliasscur's de lort loin 
et se laissent approeher difficilement ; mais ils sont plus inquiets que rusés, plus peureux que défiants, puisqu'ils se laissent prendre à toutes sortes de piéges, pourvu que la main qui les a tendus saehe se rendre invisible.

Lorsqu'ils sont enfermés avee d'autres oiseaux plus faibles, leur inquiétude naturelle se ehange en pétulance;

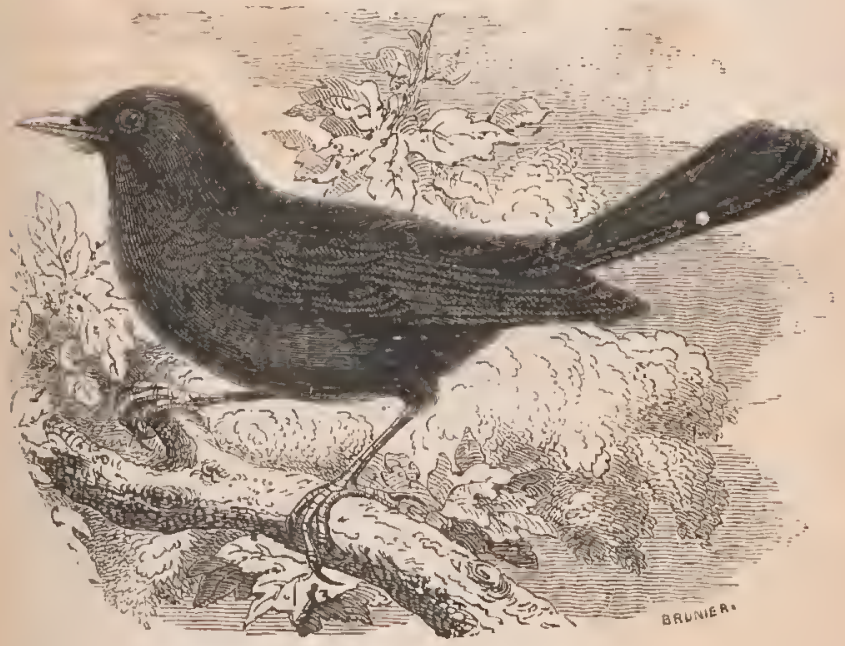

ils poursuivent, ils tourmentent eontinuellement leurs compagnons d'esclavage.

On peut en élever ù part à eause de leur chant; nor bis de leur ehant naturel, qui n'est guère supportable 'qu'en pleine campagne, mais à eause de la facilité qu'ils ont de le perfectionner, de retenir les air's qu'on leur appręd, d'imiter différents bruits, différents sons d'instruments, el même de contrefaire la voix humaine. 
Ces oiseaux font lour première ponte sur la fin de I'hiver'; elle est de einq ou six œuf's. Il cst rare que eette première ponte réussisse, à eause de l'intempérie de la saison; mais la seconde va mieux, et n'est que de quatre ou einq œufs. Le nid des merles est construit à peu près eomme celui des grives, exeepté qu'il est matelassé en dedans. Ils le font ordinairement dans les buissons ou sur des arbres de hautcur médiocre; il semble même qu'ils soient portés maturellement à le placer près de terre, et que ee n'est que par l'expérienee des ineonvénients qu'ils apprennent à le mettre plus haut.

I. nid achevé, la fernclle se met à pondre, et ensuite à couver ses œufs; elle les eouve seule, et le mâle ne prend part à cette opération qu'en pourvoyant à la subsistance de la eouveuse.

Cés oiseaux ne changent point de contréc pendant l'hiver, mais ils choisissent dans la contrée qu'ils habitent l'asile qui leur eonvient le mieux pendant cette saison rigoureuse.

11 n'est guère de pays où ect oiseau ne se trouve, atl nord et au midi, dans le vieux et dans le nouveau continent.

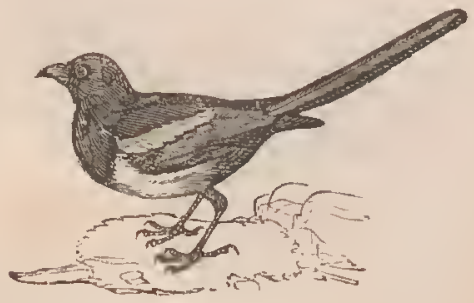




\section{LES FOURMILIERS.}

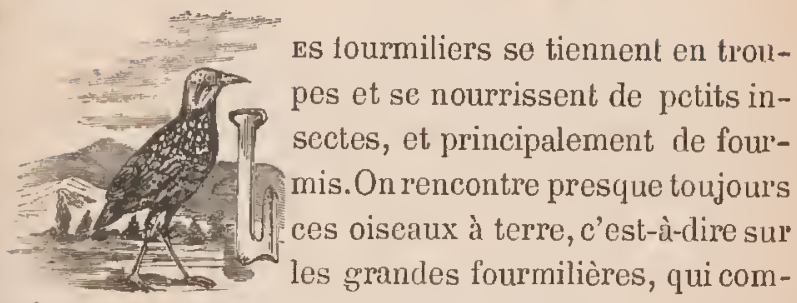
Munément, dans l'intérieur de la Guyane, ont plus de vingt pieds de diamètre; ces insectes, par leur multitude presque infinie, sont très-nuisibles aux progrès de la culture, et même ì la conscrvation des denrécs dans cette partie de l'Anérique méridionale.

L'on distingue plusieurs espèces dans ces orseaux mangeurs de fourmis; et, quoique différentes entre elles, on les trouve assez souvent réunies dans le même lieu.

Tous ees oiscaux ont les ailes et la queue fort courtes, ce qui les rend peu propres pour le vol; elles ne leur servent que pour courir et sauter légèrement sur quelques branches peu élevées : on ne les voit jamais voler en plein air.

Les environs des lieux habités ne leur conviennent pas; les insectes dont ils font leur principale nourriture, détruits ou éloignés par les soins de l'homme, s'y trouvent avec moins d'abondance : aussi ces oiseaux se tiennent-ils dans les bois épais et éloignés, ct jamais dans les savanes ni dans les autres lieux découverts, et encore moins dans ceux qui sont voisins des habitations. Ils 
construisent avec des herbes seches, assez grossièrement entrelacées, des nids qu'ils attachent ou suspendent, pal' les deux côtés, sur des arbrisseaux à deux ou trois pieds au-dessus de terre : les femelles y déposent trois à quatre cuf's presque ronds.

La voix des fourmilier's est très-singulière.

La chair de la plupart de ces oiseaux n'est pas bonne à manger; clle a un goût bilieux et désagréable.

\section{GROS - BECS.}

\section{LORTOLAN.}

Ne 'ortolar est un oiseau de passage; It chante peridant la nuit; lorsqu'il D. est gras, c'est un morceau trè-fir. zin très-recherché. A la vérité, ccs

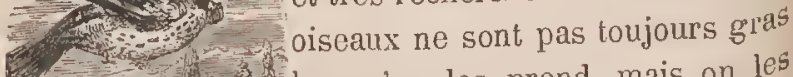

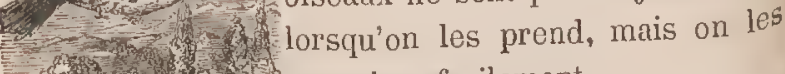

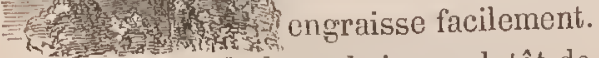

La délicatesse de leur ehair, ou plutôt de lour graisse, a plus contribué à leur célćbrité que la beauté de leur ramage : cependant lor'squ'on les tient en cage ils chan' tent au printemps, la nuit comme le jour. Dans les pay oùily a beaucoup de ces oiseaux, et où par conséquent ils 
sont bien connus, comme en Lombardie, non-sculement on les engraisse pour la table, mais on les cleve aussi pour le chant, car on trouve que leur voix a do Ia donceur.

Ces oiscaux arrivent ordinairement avee les hirondelles ou peu après, et ils aecompagnent les eailles ou les précèdent de fort peu de temps. Ils viennent de ln basse Provenee et remontent jusqu'en Bourgogne, sur-' tout dans les cantons les plus ehauds oi il y a des vignes: ils ne touehent eependant pas aux raisins, mais ils mangent les inseetes qui eourent sur les pampres et sur les tiges de la vigno. Ils font leur's nids sur los eeps ot les eonstruisent assez négligemment. I a femello y dépose quatre ou einc oufs, et fait ordinairement deux pontes par an. Dans d'autres pays, teis que la Lorraine, ils font leurs nids à terre, et par préférenee dans les l)lés.

La jeune famille eommenee à prendre le ehemin des provinees méridionales dès les premiers jours d'août; les vieux ne partent qu'en soptembre et même sur la fin.

Quelques personnes regardent ces oiseaux eomme étant originaires d'Ilalie, d'où ils se sont répandus en Allemagne et ailleurs. Il n'est pas rare de les voir', lor's'qu'i]s trouvent sur leur route un pays qui lour convient, s'y fixer ct l'adopter pour leur patrie.

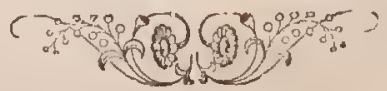




\section{LE BENGALI.}

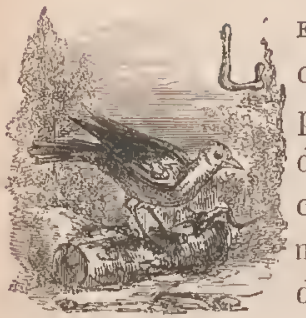

Es mœurs et les habitudes de tonte cettc famillo d'oiseaux ćtant ì trèspeu près les mêmes, il suffira d'indiquer ce que chacun a de particulicr. Lorsqu'on a à faire connaître des oiseaux tcls que ceux-ci, dont le principal méritc consiste dans les couleur's du plumage et ses variations, il faudrait quitter la plume pour prendre le pinceau.

Lc bengali a de chaque côté de la tête unc espèce de croissant couleur de pourpre qui accompagne le las des yeux, et donne du caractère à la physionounie de ce pelit oiseau.

La gorge est d'un bleu clair. Cette même coulcur domine sur toute la partıe inférieure du corps jusqu'au bout de la qucue, et même sur ses couvertures supérieures. Tout le dessus du corps, compris les ailes, est d'un beau gris.

Le mâle a un joli ramage ; on n'a point remarqué celui de la femellc.

Dans le bengali brun, le brun est, en effel, la couleur dominante de l'oiscau; mais il est plus foncé sous le ventre, et mêlé à l'endroit de la poitrine de blanchâtre dans quelques individus, ct le rougoeâtre dans d'autres. Tous les mâles ont quelques-unes des couvertures supéricures des ailes terminées par un point blanc, ce qui produit une moucheture fort apparente; mais elle est 
propre au mâle, car la femelle est d'un brun uniformo et sans taches : tous deux ont le bce rougeâtre el les pieds d'un jaune clair.

Un brun mộlé d'un rouge sombre règne sur toule la partic supéricure du $\operatorname{col}^{\prime}$ ps du bengali piquelé ; un rougo moins sombre règne sur tout le resle de la partie inféricurc du corps et sur les côtés do la tête. Le bec est aussi d'un rouge obscur, et les pieds d'un jaune clair.

La femelle n'est jamais piquetéc : elle diffère oneore du mâle en ce qu'elle a le cou, la poitrine ot le ventre d'un jaune pâle, et la gorgo blanche. Le bengali piquelé est d'une grosseur moyenne entre le bengali ordinaire ct le bengali brun.

Deux couleurs principales dominent dans le plumage du sénégrali, le rouge vinenx sur la têlo, la gorge, tout le dessous du corps jusqu'aux jambes; le brun verdâtre Sur lo bas ventre et sur le dos; mais à l'endroit du dos il a une légère teinte de rougo. Les ailes sont brunes, la queue noirâtre, les pieds gris, le bee rougeâtre. Cel oiseau est un peu moins gros que le bengali piqueté.

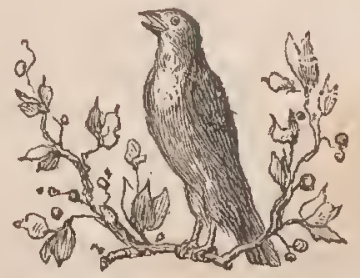




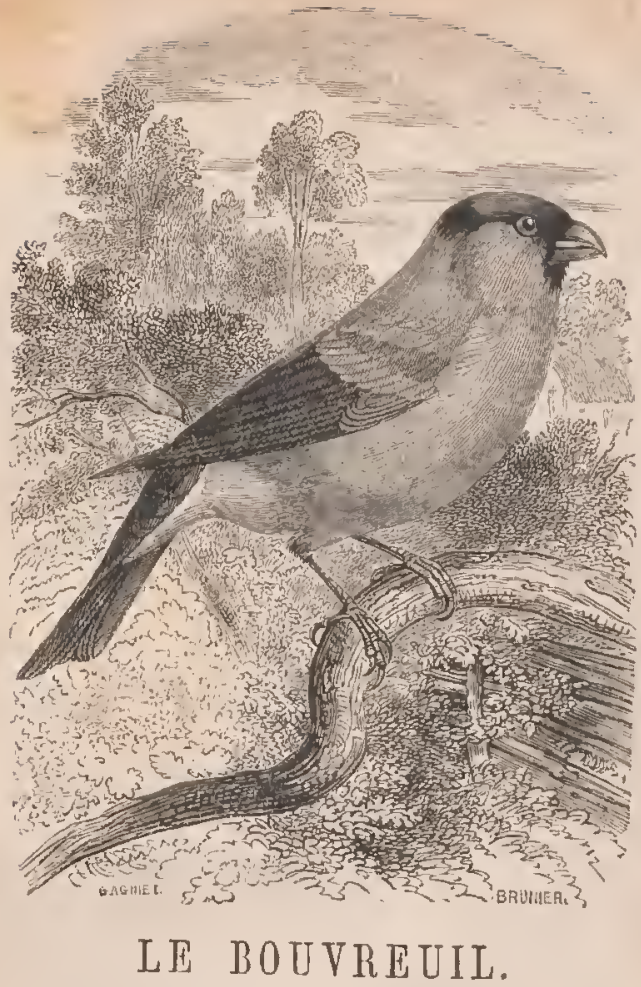

La nature a donné à cet oiseau un beau plumage et une belle voix : mais la voix a besoin des secours do l'art pour acquérir sa perfection. Un bouvreuil qui n'a point eu de leçons n'a que trois cris, tous fort pou agréables. le premicr est une espèce de coup de sifflet; le son de ce sifflet est pur, et quand l'oisenu s'anime, il semble articuler celte syllabe répétée $l u i, t u i, t u i$, et ces sons ont plus de force. Ensuite il fait entendre un ramnge plus 
suivi, mais rilus gr:ive. Enfin dans les intersilles il a un pelit eri intérieur, sec et coupé, fort aigu, mais en même tomps fort doux, et si doux qu'à peine on l'entend. Il exécute ce son fort ressemblant à cclui d'un ventriloque, sans aueun mouvement apparent. Tel est lo chant du bouvreuil de la nature, c'est-ì-dire du bouvreuil sauvage abandonné ì lui-même; mais, lorsque l'homme se charge de son éducation, l'oiseau docile, soit mâle, soit femelle, non-sculoment imite les sons avec justesse, mais quelquefois les perfectionne et surpasse son maitre, sans oublier pour cela son ramage naturel. 11 apprent aussi ì parler sans beaucoup de peinc. Il est très-capable d'altachement personnel, et même d'un attachement trèsfort et très-durable.

Les bouvreuils passent la belle saison tans les bois ou sur les montagnes : ils y font leur nid sur les buissons, à cinq ou six piods de laaut, et quelquefois plus bas.

La femelle y pond de quatre à six œufs, et le mâle a grand soin de sa femelle. On dit qu'il tient quelquefois fort longtemps une araignée dans son bec pour la clonner à sa compagne. Les petits ne commeneent à siffler que lorsqu'ils peuvent manger seuls. Les bonvreuils se nourrissent en été de toutes sortes de graines, de baics d'insectes, et l'liver de grains de geniòve, des boul'. greons dı tremble, de l'aune, du chêne, des arbres fruitiers : on les entend pendant cette saison siffler, se rípondro et égayer par lenr chant, quoique un pou triste, le silence encore plus triste qui règne alors dans la nature.

Ces oiseaux passent auprès de quelques personnes 
pour être attentifs et réfléchis; du moins ils ont l'ail' pesant, et à juger par la facilitć qu'ils onl d'apprendıe, on ne peut nier qu'ils ne soient capables d'attention jusqu'à un certain point. Ils vivent cinq à six ans.

\section{LE PINSON.}

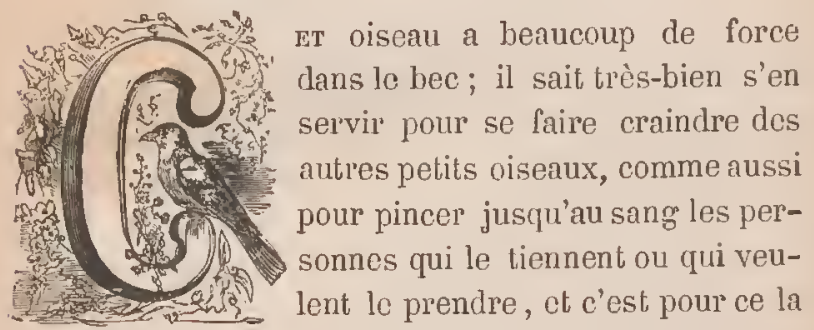
que, suivant plusieurs auteur's, il a recu le nom de pinson.

Les pinsons ne s'en vont pas tous en automne, il y en a toujours un assez bon nombre qui restent l'hiver avec nous; la plupart s'approchent alor's des lieux habités ct viennent jusque dans nos basses-cours où ils trouvent une subsistance plus facile. Jamais on ne les entend chanter dans cette saison, à moins qu'il n'y ait de beaux jour's; le reste du temps ils se cachent dans des laaies fourrées, sur des arbres toujour's verts, quelquefois même dans des trous de rocher's où ils meurent lorsque la saison est trop rude; ceux qui passent en d'autres climats se réunissent assez souvent en troupes innombrables.

Une singularité très-remarquable dans la migration des pinsons, c'est que sont les femelles qui voyagent et que les mâles restent l'hiver dans le pays. Ces oiseaux 
sont généralement répandus dans toute l'Emrope depuis la mer Baltique et la Suède, où ils sont fort communs et où ils nichent, jusqu'au détroit de Gibraltar, et même jusque sur les côtes d'Afrique.

Le pinson est un oiseau très-vif : on le voit toujours en mouvement, et cela joint à la gaietó de son chant, a donné lieu sans doute à la façon de parler proverbiale, gai comme pinson. Il commence à chanter de fort honne heure au printemps et plusieurs jour's avant le rossignol ; il finit vers le solstice d'été.

Les pinsons, outre leur ramage ordinaire, ont encorc un autre cri peu agréablequi, dit-on, annonce ln pluic.

Ces oiseaux font un nid bion rond et solidement tissu : il semble qu'ils n'aient pas moins d'adresse que de forco dans le bec; ils posent ce nid sur les arbres ou les arbustes les plus touffus; ils le font quelquefois jusque dans nos jardins, sur les arbres fruitiers, mais ils 10 cachent avec tant de soin cue souvent on a de la peine à l'apercevoir, quoiqu'on en soit fort pròs : ils le construisent de mousse blanche et de petites racines en dohors, de laine, de crins, de fils d'araignées et de pll1mes en dedans. La femelle pond cinq ou six ceufs; le lo mâle ne la quitte point tandis qu'cllo couve, surtout la nuit; il se ticnt toujours fort pròs du nill, et le jour, s'il s'éloigne un peu, c'est pour aller à la provision. Le pòre et la mère nourrissent leurs pelits de chenilles et d'inscetes; ils en mangent eux-mêmes; mais ils vivent plus communément de petites graines; ils se nourrissent aussi de lılé, et même d'avoine dont ils savent fort bien casser les grains pour en tircr la substance larineuse. 


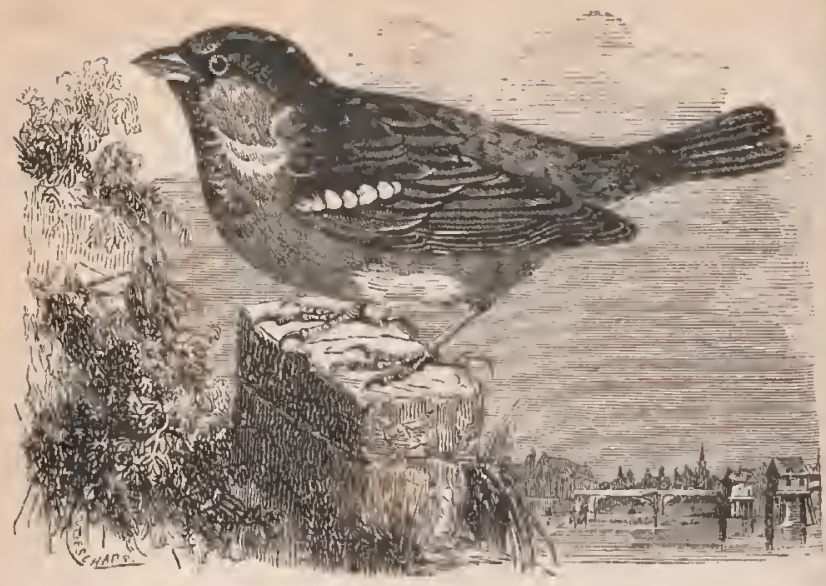

\section{LE MOINEAU.}

Dans quelque eontrée qu'habite lo moineau, on ne le trouve jamais dans les lieux déserts ni même dans ceux qui sont éloignés du séjour de l'homme; les moineaux sont, commo les rats, attachés à nos habitations; ils $1: 0$ se plaisent ni dans les bois ni dans les vastes campagues : on a même remarqué qu'il y en a plus dans les villes que dans les villages, et qu'on n'en voit point daus les hameaux et dans les fermes qui sont au milieu des forêts. Ils suivent la soeiété pour vivre à scs dépens : comme ils sont paresseux et gourmands, e'est sur les provisions toutes faites, c'est-ii-dire sur le bien d'autrui qu'ils prennent leur subsistance; comme ils sont aussi voraces que nombreux, ils ne laissent pas de faire plus de tort que leur espèce ne vaut.

Et ce qui les rendra éternellement incommodes, c'est 
non-seulément leur tres-nombreuse multupliontion, mais encore leur défiance, leur fincsse, leur's ruses et leur opiniâtreté à no pas désemparer des licux qui leur convionnent. Quoiqu'ils nourrissent leurs pelits d'insectes dans’le promier âgo, et qu'ils en mangent eux-mêmes en assez grande quantité, leur principale nouriture est notre meilleur grain.

Comme ces oiseaux sont robustes, on les élève facilement dans des cagos ; ils vivent plusiours annćes. Lorsqu'ils sont pris jeunes, ils ont assoz de docilité pour obéir d̀ la voix, s'instruire et retenir quelgue chose du chant des oiscaux auprès desquels on les net; naturellement fimiliors, ils lo deviennent encore davantago dans la caplivité : copendant co naturol si familier ne les porte pas à vivro ensemble dans l'état de liberté; ils sont assez solitaires, ct c'est peut-être lì l'origine de leur nom. Ils nichent ordinairement sous les tuiles, dans les clićneaux, dans les trous de muraille ou dans les pots qu'on leur offre, et souvent aussi dans les puits et sur les taljlettes des fenchtres dont les vitrages sont défendus par cles persiennes à clairo-voie : néanmoins il y en a quelques-uns qui font leur nid sur les arbres. Il se trouvo des moineaux plus paresscux, mais en même temps plus lardis que les autres, qui ne se donnent pas la peine de construire un nid, ot qui chassent du leur les hirondelles; quelquefois ils battent les pigcons, les font sortir de leur boulin et s'y établissent à leur place. 


\section{LE SERIN DES CANARIES.}

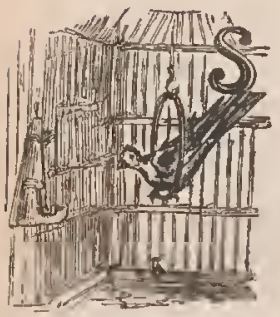

I le rossignol est le chantre des bois, le serin est le musicien de la chambre; le premier tient tout de la nature, le second participe à nos arts. Avec moins de force d'organe, moins d'étendue dans la voix, moins de variété dans les sons, le serin a plus d'oreille, plus de facilité d'imitation, plus de mémoire; ct conme il a l'ouïe plus attentive, plus susceptible de recevoir et de conserver les impressions étrangères, il devicnt aussi plus social, plus doux, plus familier; il est capablc de connaissance et même d'attachcment; ses caresses sont aimables, ses petits dépits innocents, et sa colc̀re ne blesse ni n'offense. Ses habitudes naturelles le rapprochent encore do nous, il se nourrit de graines comme nos autres oiseaux domestiques; on l'instruit avec succès; il apprend à parler et ì sifller. Il y a vingt-neuf espèces de serins des Canaries.

Les serins sont bien différents les uns des autres par leurs inclinations; il y a des mâles d'un tempérament toıtjour's triste, rêveurs, pour ainsi dire, et presque toujou's bouffis, chantant rarement, et ne chantant que d'un ton lugubre, qui sont des temps infinis à apprendre, ct ne savent jamais que très-imparfaitement ce qu'on leur a montré, et le peu qu'ils savent ils l'oublient aisément. Ces mêmes serins sont toujours d'un nalurel si malpropre 
qu'ils ont toujours les pattes et la queue sales. Il y a d'autres scrins qui sont si mauvais qu'ils tuent la fomelle qu'on leur donne, et qu'il n'y a d'autre moyen de les dompter qu'en leur en donnant deux; clles se r'ćuniront pour leur défense commune. Il y en a d'autres d'une inclination si barbarc qu'ils cassent et mangent les oufs lorsque la femelle les a pondus, ou si ce père dénaturé les laisse couVer, à peine les petits sont-ils éclos qu'il les saisit avec le bec, les traîne dans la cabane et les tue. D'autres, qui Sont sauvages, farouches, indépendants, qui ne veulent être ni touchés, ni caressés. Il y en a d'autres enfin qui sont tròs-paresseux : par exemple, les gris ne font presque jamais de nid. Tous ces caractères sont, comme l'0n voil, très-distinc ts entre eux et très-différents de cclili de nos serins favoris, toujour's gais, toujours chantants, si familiers, si aimables, sibons maris, si bons pères, et en tout d'un caractère si doux, d'un naturol si heureux, Gu'ils sont susceptibles de toutes les bonnes impressions et doués des meilloures inclinations. Ils récréent sans cesse leur femelle par leur chant; ils la soulagent dans la pénible assiduité de couver ; ils l'invitent à changer de situalion, à leur céder la place, et couvent eux-mômes tous les joul's pendant quelques heur'es; ils nourrissent aussi leurs petits, et enfin ils apprennent tout ce qu'on peut leur inontrer. C'est par' ceux-ci seuls qu'on doit juger l'espèce.

Dans ces oiseaux captifs la production n'est pas aussi Constante, mits paraît néanmoins plus nombreuse qu'elle ne l. Serait probablement dans leur état de liberté ; car il $\checkmark$ aquelques fomellos qui font quatre et même cinq pontes par an, cliacune de quatre, cinq, six et quelyuefois sept Gufs: communement elles font trois pontes. Dans leur 
pays natal, les serins se tiennent sur les, bords des petit ruisseaux on des ravines lumides ; il ne faut done jamais les laisser manquer d'cau tant pour boire que pour se baigner. Comme ils sont originaires d'un climat très-douxi, il faut les methe à l'abri de la rigueur de l'hiver.

Il cst rarc que les serins élevés en chambro tombent malades avant la ponte; si la femelle devient malade pen. dant la eouvée, il faut lui ôter ses œufs et les donner à unc autre, ear, fuland même elle se rétablirait promptement. olle no les eouverait julus. Le prenier synptôme de li maladie, surtout dans le mâle, est la tristesse; dès qu1"m! ne lui voit pas sa gaielé ordinaire, il faut le mettre senl dans une cage et lo plaeer au soleil dans la ehambre nil réside sa femelle. S'il devient bouffi, on rogardera s'il n'it pas un bouton au dessus do la qreue; lor'sque ee bouton est mûl' et blanc, l'oiscau le perec sotvent lui-même avec le hec, mais si la suppuration tarde trop, on pourra ouvrir le bouton avee une grosso aiguille, et onsuite ćtuver li: plaie avec de la salive sans y mêler de sel, ec qui la rent drait trop cuisante sur la plaic. Si la tristesse ct le déco ilt continuent après ces petits remèles, on ne pout grui: cspérer sauver l'oisean.

La cause la plus ordinaire des maladies est la trol? abondante ou la trop bonne nourriture: lorsqu'on fait nicher ees oiseaux en eage ou en cabane, souvent ils mangent trop ou prounent de préfírence les aliments succulents destinés aux petits, et la plupart tombent mat lades de réplétion ou d'inflammalion. En les tenant e!l chambre, on prévient on grande partie cet ineonvéniont. parce qu'élant en nombre ils s'empêehent réciproqui?" ment de s'excéder. Un mâle qui unang'e longtemps est sût' 
d'être battu par les autres mâles ; il en est de même des femelles; ces débats leur donnent du mouvement, des distrnctions ef de la tempérance par nécessité.

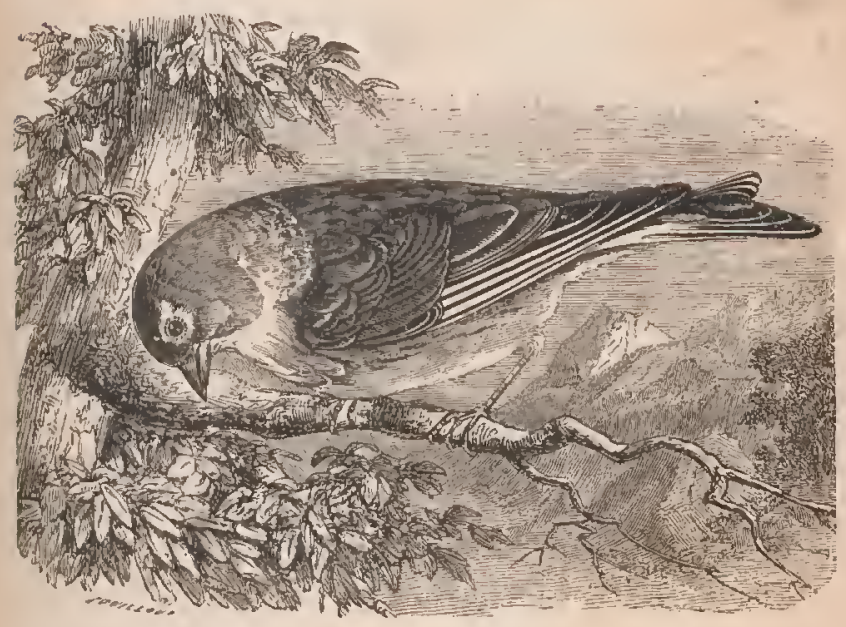

\section{LA LINOTTE.}

Il est peu d'oiserux aussi communs que la linotte, mais il en est peut-être encore moins qui réunissent autant do qualités : ramaģe agréable, couleurs distinguées, naturel docile et susceptible d'attachement, tout lui a étó donné, tout ce qui peut attirer l'attention de l'homme et contribuer à ses plaisirs. La belle couleur rouge dont la nature a dícoré la têle et la poitrine de la linotle, et qui, tans 
l'état de libcrté, brille d'un éclat durable, s'efface par degrés et s'éteint bientôt dans nos cages et nos volières.

A l'égrrrd de son chant, nons le dénaturons, nous substituons aux modulations libres et variées que lui inspire le printemps, les plırases contraintes d'un chant apprêté qu'elle ne répète qu'imparfaitement, et où l'on ne retrouve ni les agréments de l'art ni le charme de la natıre.

La linotte fait souvent son nid dans les vignes: de li lui est venu le nom de linotle des vignes. Quelquefois clle le pose à terre, mais plus fréquemment elle l'attache entre deux perches ou au cep même; elle le frit aussi sur les genćvricrs, les groseilliers, les noisetiers et dans les jeunes taillis. Les linottes ne font ordinairement que deux pontes, ̀̀ moins qu'on ne leur enlève leurs œufs; dans ce cas elles font jusqu'à quatre pontes.

Lorsque les couvées sont finies et la famille élevée, les linottes vont par troupes nombreuses. Hlles conlinuent do vivre ainsi en société pendant tout l'hiver; elles volent très-serrées, s'abattent et se lèvent toutes ensemble, se posent sur les mêmes arbres, et vers lc commencement du printemps on les entend chanter toutes à la fois : leur asile pour la muit, ce sont des chênos, des charmes, dont les feuilles, quoique sèches, ne sont point encore tombées. On les a vues sur des tilleuls, des peupliers, dont elles piquaient les boutons; elles vivent encore do toutes sortes de petites grairues, notamment de celle de chardon, etc. : aussi les trouve-t-on indifféremment dans les terres en friche et dans les champs cultivés. Elles marehent en sautillant ; mais leur vol est suivi et ne va point par élans répétćs comme celui du moineau.

Le chant de la linotte s'annonce par une espèce do 
prélude. Ori croit communément en Franee que le raInage de la linotte rouge est meilleur que celui do la linotle grise. Les fomelles ne eliantent ni n'apprennent ì chanter.

Le nom seul de ees oiseaux indique assez la nourriture qui leuj convient; on les a nommés linottes parce qu'ils aiment la graine du lin ou celle de la linaire; on y ajoute ${ }^{l}$ panis, la navette, le ehènevis, le millet, ete. Ils cassent les petites graines dans leur bee et rejettent les envelonpes; il leur faut très-peu de chènevis, paree qu'il les engraisse trop, et que cette graissc exeessive les fait 'nourir, ou tout au moins les empêche de ehanter. Avec beaucoup de propreté, beaueoup de soins, on peut les fajre vivre en eaptivité cinq ou six ans, suivant les uns, et beaucoup plus selon d'autres. Ils reconnaissent les personnes qui les soignent, ils s'y attachent, viennent se loser sur elles par' préférence, et les regardent avec l'air de l'affeetion.

\section{LE CHARDONNERET.}

Beauté du plumage, doueeur do la voix, finesse de l'instinct, adresse singulière, docilité à l'épreuve, ce charmant petit oiseau réunit tout, et il ne lui manque que d'être rare et de venir d'un pays éloigné pour être estimé ce qu'il vaut.

I es mâles ont un ramage très-agr'éable et très-connu; ils commencent à le faire entendre vers les premiers 
jours du mois de mars, of ils continuent pendant la belle saison; ils le conservent même l'hiver dans les poêles, où ils trouvent la température du printemps.

Ces oiseaux sont, avec les pinsons, ceux qui savent te mieux construire leur nid, en rendre le tissu plus solide, lui donner une forme plus arrondie et plus élégante. Ils

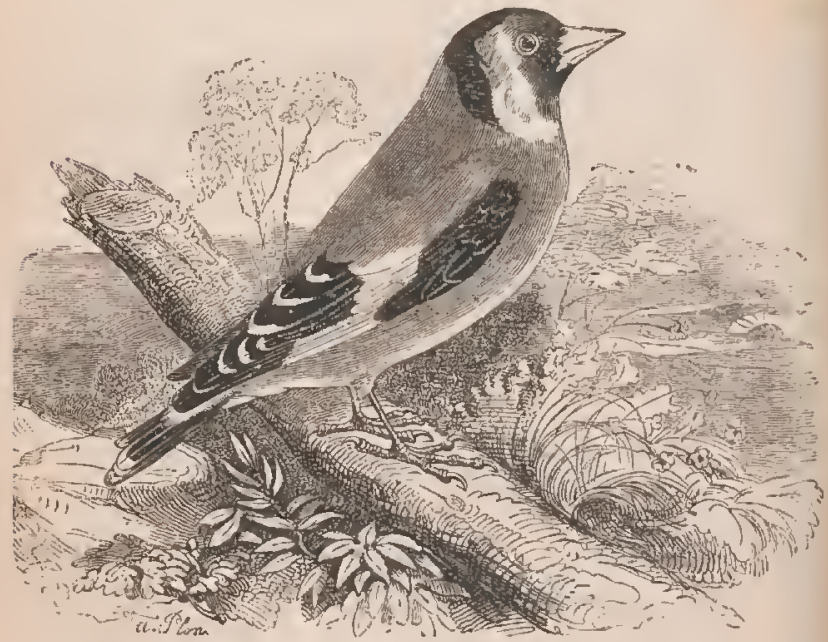

le posent sur les arbres, ot par préférence sur les prit niors et les noyers; quelquefois ils nichent dans les taillis. d'autıes fois dans des buissons épinoux. La femelle com menee à pondre ver's le milieu du printernps; cette pré mic̀re ponte est de cinc cufs. Lorsqu'ils ne viennent pas ì bien, elle fait une seconde ponte, ot mème unte troisièmo lorsque la seconde ne réussit jas; mais 10 
nombre des œufs va toujours en diminuant à chaque ponte.

Ces oiseaux ont beaucoup d'attachement pour leur's petits; il les nourrissent avec des chenilles et d'autres insectes, et si on les prend tous à la fois et qu'on les renferme dans la même cage, ils continueront d'en avoir soin.

La docilité du ehardonneret est connue : on lui apprend, sans beaucoup de peine, à exécuter divers mouvements avec précision, à faire le mort, ù metlre le feu à un pétard, à tirer de petits seaux qui contiennent son boire el son manger. On a vu des chardonnercts vivre seize à dixhuit ans.

\section{LE TARIN.}

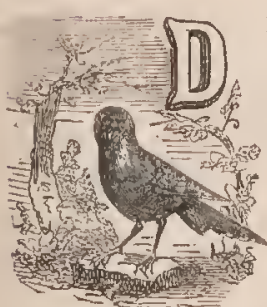

⿷ tous les granivores, le chardonneret est celui qui passe pour avoir le plus de rapport au tarin. Celui-ci est plus pelit que le chardonnerct ; il a lc bec un peu plus court à proportion, et son plumage est tout différent: il n'a point de rouge sur la tête, mais du noir.

Le tarin a un chant qui lui est particulier, et qui ne vaut pas eelui du chardonneret; il recherche beaucoup la graine de l'aune, à laquelle le chardonneret no touche point, et il ne lui dispute guère celle du chardon; il 
grimpe lo long des branchos et se suspend à leur extrémité comme la mésange ; il est oiseau de passage, et dans ses migrations il a le vol fort élevé; on l'entend encore plutôt qu'on ne l'aperçoit.

Il n'a pas moins de docilité que le chardonneret; et, quoique moins agissant, il est plus vif à certains égards, et vif par gaieté: toujours éveillé le premier dans la volière, il est le premicr à gazouillor et à mettre les autres en train. On l'apprivoise plus facilement qu'aucun autre oiseau pris dans l'âg'e adulte ; il ne faut pour cela que lui préscnter habituellenent dans la main une nourritı1'e inieux choisic que celle qu'il a à sa disposition, ct bientôt il sera aussi apprivoisé que le scrin le plus faunilier. Quoiqu'il semble choisir avec soin sa nourriture, it ne laisse pas de manger beaucoup; il boit autant qu'il nange, ou du moins il boit très-souvent, mais il se baigne peu: on a observé qu'il entree rarement dans l'cau, mais qu'il se met sur le bord de la baignoire, et qu'il y plonge seulcment le bec et la poitrine sans faire beaucoup de inouvements, excepté peut-être dans los grandes chaleur's.

Le ramage du tarin n'est point désagréable, quoique fort inférieur ì celui du chardonneret, qu'il s'approprie. dil-on, assez facilement.

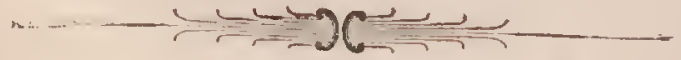




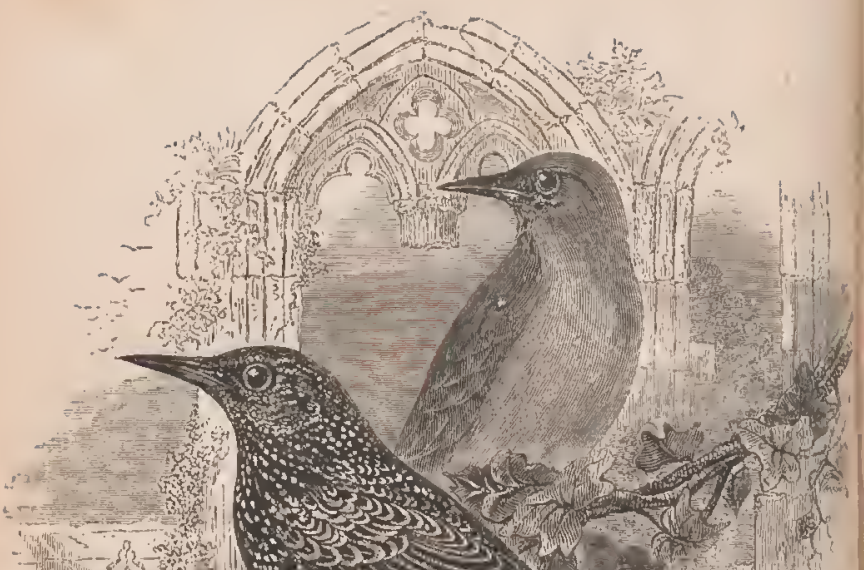

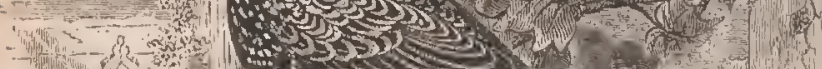

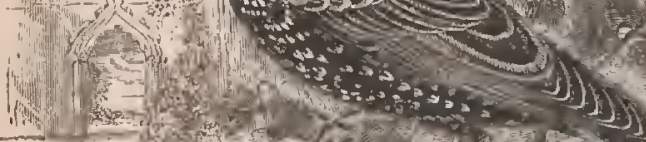

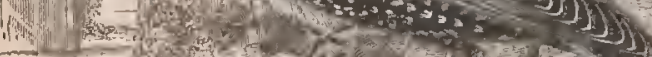

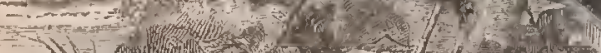

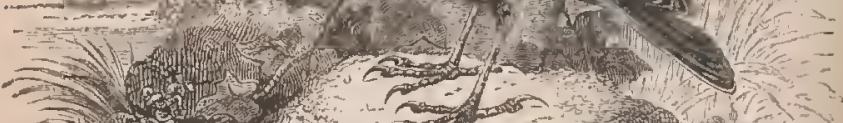

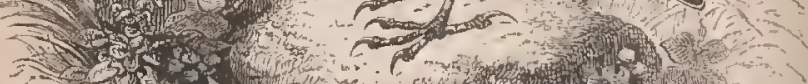

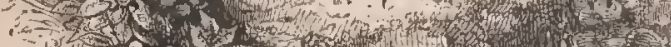

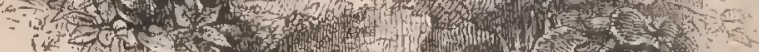

in w

\&

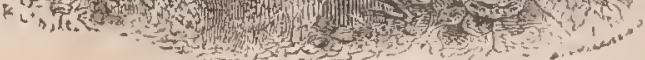




\section{L'ETOURNE AU.}

Il est peu d'oisenux aussi généralement commus que eclui-ci, surtout dans nos climats tempérés; car, outre qu'il passe toute l'année dans le canton qui l'a vu naitre Sans jamais voyager au loin, la facilité qu'on trouve à l'apprivoiser et à lui donner une sorle d'ćducation fait qu'on en nourrit beaucoup en cagre.

En liberté, e'est surtout le soir que les étourneaux sc réunissent on grand nombre, comme pour' se mettre en foree et se garantir des dangers de la nuit : ils la passent ordinairement tout entière, ainsi rassemulés, dans les roseaux où ils se jettent vers la fin du jour avee gr'and fracas. Ils jasent beaucoup le soir et lo matin avant de se séparcr, mais beaueoup moins le reste de la journée, et point du tout pendant la nuit.

L ses étourneaux sont tellement nés pour la soeiété qu'ils he vont pas seulement do eompagnie avec ceux de leur 'spèee, mais avec des espèces diflérentes. Quelquerois au printemps et en automne, c'est-ì-dire avant ef après la saison des couvées, on les voit so mêler el vivre avec les corneilles el même avec les pigeons.

Ils no prennent pas beaucoup de peino pour leur nid, Cal' souvent ils s'emparent de celui du pivert, comme lo pivert s'empare quolquefois du leur. Lor'squ'ils veulent le construire eux-mêmes, toute la façon eonsiste à amasser quelques feuilles sèches, quelques brins d'herbe et de mousse au fond d'un trou d'arbre ou de muraille : c'est sur ce matclas fuit sans art que la l'cinclle dépose cinq ou 
six oufs qu'elle couve l'espace de dix-huit à vingtjou's. Quelpuefois elle fait sa ponte dans les colombier's, audessus des entablements des maisons, et même dans leł trous de rochers sur les côtes de la mer.

Les étourneaux vivent de limaces, de vermisseaux, de scarabées; ils se nourrissent aussi de blé, de sarrasin, de mil, de chènevis, de graine de sureau, d'olives, de cerises, de raisins.

Ils suivent volontiers les boculs et autre gros bétail, paissant dans les prairies, attirés, dit-on, par les insectes qui voltigent autour d'eux. On les accuse encore de se nourril de la chair des cadavres exposés sur les fourches patibulaires; mais ils n'y vont apparemment que paree qu'ils y trouvent des insectes. Ces oiseaux vivent sept ou luit ans, et même plus, dans l'état de domesticité.

Un étourneau peut apprendre à parler indiffóremment français, allemand, latin, gree, etc.; et à prononcèr do suite des phrases un peu longues : son gosier souple se prête à toutes les inflexions, à tous les accents. Il articulo lianchement la lettre $k$, et soutient très-bien son non do sansonuet ou plutôt de chansonnet, par la douceur deson ramage acquis, beaucoup plus agréable que son ramage naturel.

Cet oiseau est fort répandu dans l'ancien continent : on le trouve en Suc̀de, en Allemaģne, en France, cıs Italie, daus l'île de Malte, au cap de Bonne-Lispérance.

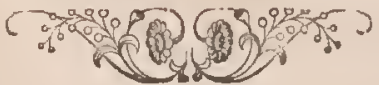




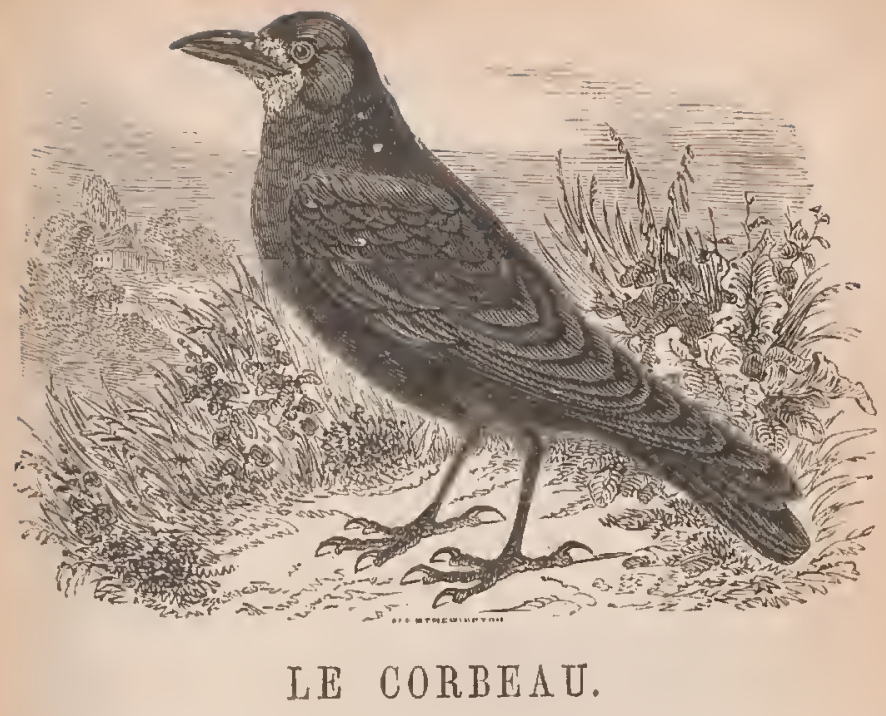

Cet oiseau a été fameux dans tous les temps; mais sa réputation cst encore plus mauvaise qu'ellc n'est étendue. On l'a toujours regardé comme le dernier des oiscaux de proic et comme l'un des plus lêches et des plus dégoûtants. Les voiries infectes, les charognes pourries Sont, dit-on, lc fond de sa nourriture; s'il s'assouvit d'ure chair vivante, c'est de colle des animaux faibles ou uliles, comme agncaux, levrauts, cte. On prólend même qu'il atlaque quelquefois les grands animaux avcc avantage, et que, suppléant à la force qui lui manque par la muse ct l'agilité, il se cramponne sur le dos dcs buffles, les ronge tout vif́s et en délail après leur avoir crevé les veux; t ce qui renclrait celte férocilé plus odieuse, c'cst qu'elle serait en lui l'cfret, non de la nécessité, mais d'un 
appétit de préférence pour la chair ct lc sang, d'autant cqu'il peut vivre de tous les fruits, de toutes les graines, de tous les insectes et môme des poissons morts, et qu'aucun autre animal ne mérite mieux la dénomination d'omnivore.

" Cette violence ct cette universalité d'appétit, ou plutôt cette vol'acité, tantôt l'a fait proscrire comme un animal nuisible et destrücteur, et tantôt lui a valu la protection des lois, comme à um animal utile et bienfaisant.

Si aux traits sous lesquels nous venons de représenter lc corheau on ajoute son plumage lugubre, son cri plus lugubre encore, quoique très-faiblc à proportion de si grosscur, son port ignoble, son regard farouche, on no sera pas surpris que, dans presque tous les temps, il ait ćlć regardé comme un objet de dlégoût et d'horreur. Partout on lc mot au nombre des oiscaux sinistres, qui n'ont le pressentiment de l'avenir que pour annoneer des malheurs.

Non-seulement lc corbeau a un grand nombre d'inflexions de voix répondant à ses différentes affections intérieures, il a cncore le talent d'imiter le cri des autres animaux, et même la parole de l'homme. Il devicnt fainilier dans la maison; il s'apprivoise, quoique vieux, ct paraît mêne capable d'un attachement personnel et durable.

Par une suite de cette souplesse de naturel, il apprend aussi, non pas à dépouiller sa voracité, mais à la régler et à l'employer au service de l'homme. Il semble qu'on lui ait appris quelquefois à défendre son maitrto et à l'aider contre ses ennemis avec une sortc d'il' telligence. 
Ajoutons à tout ecla que le eorbeau parait avoir une Erande sagaeité d'odorat pour évonter de loin les cadavres.

Les eorbcaux, les vrais corbeaux de montagne, ne sont point oiseaux de passage. Ils semblent particulièrement attachés au roeher qui les a vus naître; ils y restent toute l'annéc en nombre à peu pròs égal, et ils ne l'abandonnent jamais entièrement; s'ils deseendent dans la plaine, c'est poul clereher leur subsistance; mais ils y descendent plus rarement l'été que l'hiver, parec qu'ils évitent les grandes chaleurs, et e'est la seule inflnence quo la différente température des saisons paraisse avoir sur leurs habitudes. Ils ne passent point la nuit dans los bois, ils savent se ehoisir dans leurs montagnes une r'ctraite à l'abri du nord, sous des voûtes naturelles, formées par des avances ou des enfoncements de rochers; c'est là qu'ils sé retirent pendant la nuit au nombre de quinze ou vingt. Ils dorment perehés sur les arbrissenux 'ui croissent entre les voehors; ils font leurs nids dans les erevasses de ees mêmes roehers ou dans des trous de inurailles, au haut des vieilles tour's abandonnées, et qnelquefois sur les hautes branchos des grands arbies isolés.

$\mathrm{L}_{\perp \mathrm{a}}$ fernelle se distingue du mâle cn ee qu'elle est d'ua noip moins décidé et qu'clle a to bee plus faible. Elle pond vors le mois de mars, jusqu'à cinq ou six coufs. Elle les eouve pendant environ vingt jour's, et pendant ce temps le mâle a soin de pourvoir à sa nourriture; il y pourvoit même largement, car les gocns de la eampagne trouvent quclquefois dans los nids des corbeaux, ou aux cnvirons, des amas assez considérables de grains, do 
noix et d'autres finits. Cette habitude de faire ainsi des provisions et de cacher ec 'ju'ils peuvent attraper no se borne pas aux comestibles, ni même aux clioses qui peuvent leur être utiles; elle s'étend encor'e à tout ce qui se trouve à leur biensérnce, ct il paraît qu'ils préfèrent les pièces de métal et tout ee qui brille aux yeux. On en a vu un à Erfordd qui eut la patienee de porter une à une et de caeher sous une pierre dans un jardin une quantitó do petites monnaies, jusqu'à coneur'ence de einq ou six florins; et il n'y a guère de paya qui n'ait son histoire do pareils vols domestiques.

Quand les pelits viennent d'éclore, il s'en faut biell qu'ils soiont de la coulenr du père et de lá mère; ils sont plutòt blanes que noirs. Dans les premiers jours, la mère semble un peu négliger ses petits; cllo ne leur donne it manger que lor'suju'ils commenecnt à avoir des plumes, ct l'on n'a pas manqué de dire qu'ello ne commençait que cle ce moment à les reconnaître à leur plumaģe naissant, et à les traiter véritablement comme sions. La mère, aplè̀: ees premier's temps, nourrit ses petits avec des aliments convenables.

Le mâle ne so eontente pas de pourvoir à la subsistance de la famille, il veille aussi pour sa défenso; ${ }^{t}$ s'il s'aperçoil qu'un milan on tout autre oisean de prọ s'approchı du nid, le péril de ce qu'il aime le rend col* rageux : il prenil son essor, gagne le clessus, et, se rabattint sur l'ennemi, il le frappo violemment de sou bec. Si l'oisenu de proie finit des efforts pour reprendre te dessus, le corbeau on fait autant pour conservor son avantago, et ils s'élèvent quclquefois si haut qu'on les perd absolument de vue jusqu'ì ce que, excétés te fali- 
guc, l'un on l'antre, ou tous les doux, se laisscnt lomber du haut des airs.

Il paraît assez avérć quo le eorbeau vit quolque$f_{0 i s}$ un sic̀clc ct davantage : on en a vu dans plusicur's villes de France qui avaient attcint cet âge, et dans tous les pays et tous les temps il a passé pour un oiscau trẻsvivace.

\section{LES CHOUCAS.}

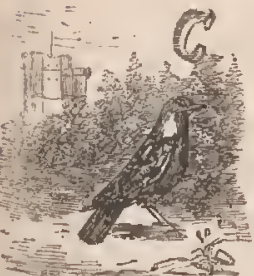

ES oiseaux ont avec les corneilles plus de traits de conformité que de traits de dissemblance.

Ils sont plus petits que les cornoilles; leur cri est plus aigre, plus la plupart des noms qu'on leur a donnćs en diffćrentes langues.

Comme les corneilles, ils vivent d'insectes, de grains, do fruits ct même de chair, quoique très-rarcment; mais ils n'ont pas l'habitude de se tonir sur les côtes pour se rassasier de poissons morts ct autros cadavres rejetés par la mer.

Ils volent en grandes troupes; ils forment des espèces do peuplades composćes d'une multilude de nids placés les uns près des autres el comme entassés, ou sur un grand arbre, ou dans un clocher, ou dans le comble d'un vicux château ábandonné. Le mâle et la femelle restent longtemps attachís l'un à l'autre. La fomelle pond cinq 
ou six oufs, ot lon'sfue ses pelits sont ćclos, olle les soigne, les nourrit, les élc̀ve avec une affection que le mâle s'emprosse de partager.

Les ohoucas sont oiseanx de passage; cependant les tour's de Vincennes en sont pouplées en tout temps, ainsi que tous les vieux édifices qui leur offrent la même sı̂reté et les inêmes commodités; mais on en voit loujours moins l'été que l'hiver.

On les apprivoise facilement, on lour apprond ' parlel sans peine.

\section{A PIE。}

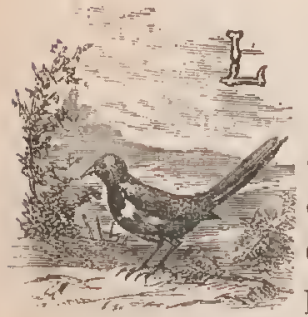

a pie passe ordinairement la belle saison avec son inâle, et occupée do la ponte et de ses suites. L'hivel olle vole par troupes, et s'approche d'autant plus des lieux habités, qu'elle y trouve plus de ressources pour vivre, et que la rigueur de la saison lui rond ces ressomrces plus nécessairos. Elle s'accoutume aisément à la vue de l'homme; elle devient bientôt familière dans la maison.

Elle jase à peu près comme la corneille, of apprend aussi à controfaire la voix des autres animaux et la parole de l'homme. On en cite une qui imitait parfaitement les cris du veau, du chevrear, de la brebis, et même lo flageolet du bergor; une autro qui répélait on entior une fanfare de trompetles. Margot est le noin quiou a cou- 
tume de lui donner, parce que e'est colui qu'elle prononce le plus volonticr's ou le plus facilement.

On prend la pic dans les piéges et de la même manière que la corneille, ot l'on a reconnu on ello lesmêmes mauvaises habitudes, celles de voler et de faire des provisions. On croit aussi qu'clle annonce la pluie lorsqu'elle jase plus qu'à l'ordinairc.

Elle montre plus d'inquiélude et d'activité quo les corneilles, plus de malice et de penchant à une sorte de moquerie. Elle met aussi plus de combinaisons et plus

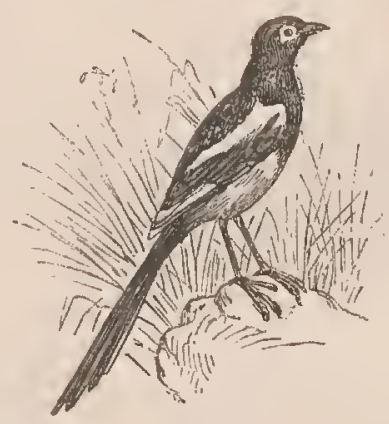

d'art dans la construction de son nid, soit qu'elle se montre très-tendre pour ses petits, soit qu'elle sache que plusieurs oiscaux de rapine sont fort avides de ses œufs et de ses petits.

Ello pond sept à huit œufs à chaque couvée, et ne fail qu'une seule couvée par an, à moins qu'on ne détruise ou qu'on né dérange son nid, auquel cas elle en enlreprend tout de suite un autre, et le couple y travaille avec tant d'ardeur, qu'il est achevé on moins d'un jour; aprìs quoi clle fait une seconde ponte de quatre on cinq $œ u$ fs ; 
el si clle est mocore troublée, elle fera un troisième nid semblable aux doux premiers, et une troisième ponte, mais toujour's moins abondante.

1 Les piats, ou les petits de la pie, sont aveugles et à poine ébauchés en naissant: co n'est qu'avec le temps, et par degrés, que le développoment s'achèvo et que leur' forme se décide. La mère, non-sculoment les élève avec sollicitude, mais leur continue ses soins longtemps après qu’ils sont ćlevés.

Quant à la duréc de la vie de la pie, on en a nour'li uno qui a vécu plus de vingt ans, mais qui, à cet âge, ćtait tout à fait aveugle de vieillessc.

Cet oiseau est très-commun en France, cn Angleterıe, en Allcmagne, en Suède et dans toute l'Europe, excepté cn Laponie et dans les pays de montagnes, où elle est rare; d'où l'on peub conclure qu'elle craint le grand floid.

\section{LE GEAI.}

Les geais sont fort pétulants de leur nature; ils ont les sensations vives, les mouvements brusques, et dans leur's fréquents accès de colère ils s'emportent et oublient te soin de leur propre conservation au poinl de se prendre quelquefois la tête entro doux branches, et ils mourent ainsi suspendus en l'air. Lour agitation porpétucllo prend encorc un nouveau degró do violonce lorsqu'ils se sentent gênés, et c'est la raison pourquoi ils deviennent tout à fait méconnaissables en cage, ne pouvant y conserver li 
beauté de leur's plumes, qui sont bientôt casseees, usées, déchirées, flétries par un frottement continucl.

Leur cri ordinaire est très-désagréable, ct ils le font entendre souvent; ils ont aussi de la disposition à con-

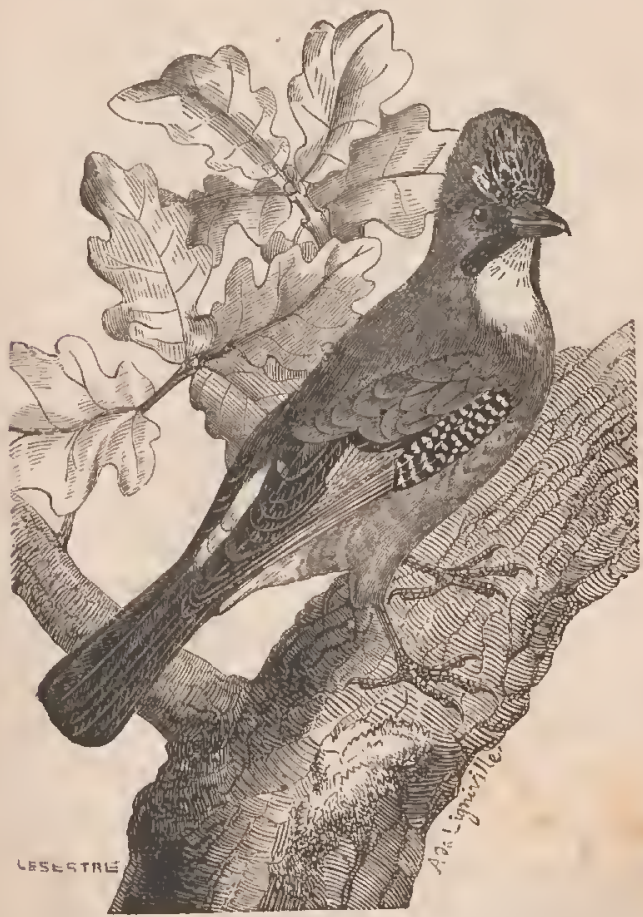

trefaire celui de plusieurs onseaux qui ne chantent pas mieux, tels que la cresserelle, le chat-huant, etc. S'ils apercoivent dans le bois un renard ou quelque autre animal de rapiuc, ils jettent un certain cri très-perģa.t, 
comme pour' s'appeler les uns les autres, et on les voit en jeu de temps rassemblés en foree et se eroyant en ćtał d'imposer par le nombre ou du moins par le bruit. lls ont comme la pie, les choucas, les corneilles et les cor" beaux, l'habitude d'enfouil leurs provisions superflues et celle de dérolor tout ce qu'ils peuvent emporter; ınais ils ne se souvienment pas toujour's de l'endroit où ils ont enter'ré leur trésor, ou bien, selon l'instinct commun i tous les avares, ils sentent plus la crainte de le dinimuel que le désir d'en fairc usago.

Les geais nichent dans les bois et loin des lieux habi tés, prélérant les elıùnes les plus toulfus et eeux dont lo tronc cst entouré de lierre; mais ils ne construisent pas leur's nids avec autant de précaution que la pie. Ils polrdent quatre ou cinq oul's; d'aulies discnt cinq ou six.

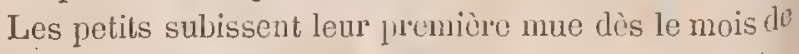
juillet; ils suivent leur père et leur mère jusqu'au pritrtemps de l'année suivante, temps oủ ils les quittent poul' se réunir deux à deux et former do nouvelles familles.

Dans l'état de domesticití, aupuel ils se facomnent asément, ils s'aecoutument ì toutes sortes de nourritur't et vivent ainsi luuit à dix ans : dans l'état sauvage, ils s0 nourrissent non-seulement de glands et de noiseties, mais de ehâtaignes, de pois, de fòves, de sorbes, de grtor seilles, de cerises, de flamboises, etc. Ils dévorent aus les pelits des autres oiseaux, quand ils peuvent les sul" prenria dans le nid.

On trouve le geai en Suc̀de, on Écosse, en Anglelerre, en Allemagne, en Italie, et il n' est étranger à auculo contrée de l'Europe, ni niême à aucune des contrées col'espondantes de l'Asic. 


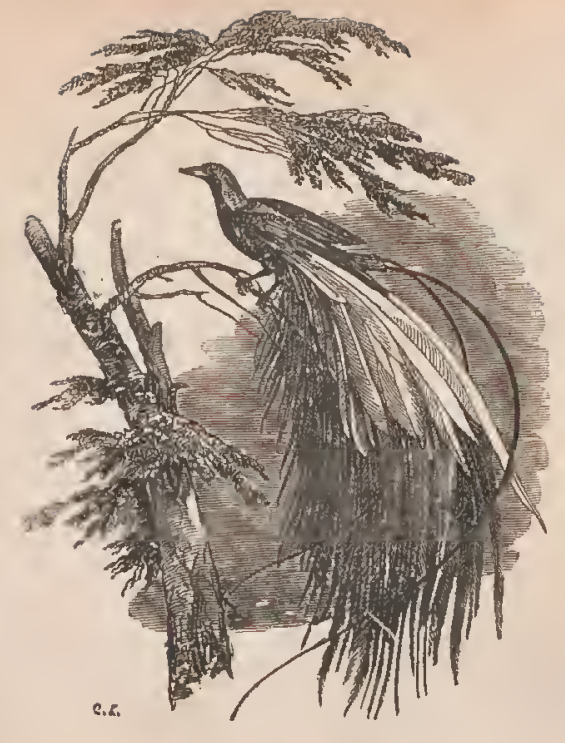

\section{L'OISEAU DE PARADIS.}

Le nom d'orseau de Paradis fait nâtre encore dans la Plupart des têtes l'idćc d'un oiseau qui n'a point de pieds, 'ui vole toujours, même en dormant, ou se suspend tou.t auplus pour quelques instants aux branches des arbres, Dar le moyen des longs filets de sa queue; qu ne vit que de vapeur's et de rosée; en un mol, qui n'a d'autre existence que le mouvement, d'sutre élćment que l'air, qui s'y souticnt toujours tant qu'il respire, comme les poisSons se soutiennent dans l'eau, et qui ne touche la terre 'u'après sa mort.

Ce tissu d'erreurs grossic̀res n'est qu'une chaine de conséquences assez bien tirées do la prenière erreur, 
qui suppose que l'oiseat de Paradis n'a point de pieds, quoicqu'il en ait d'assez gros.

Si qucliue chose pouvait donner unc apparence de probabilité à la fable clu vol perpótucl de l'oiseau do Paradis, c'est la grande lígìreté, produile par la quantité ct l'étendue considérable do ses plumes. On a remarqué que les oiscaux de Paradis cherchent à se mettre à l'abrí rles grands vents, el hoisissent pour leur sćjour ordinaire les contrées qui y sorit le moins exposées.

Ce bel oiscau n'est pas fort répandu : on ne le trouve guère que dans une partio de l'Asie cl dans la Nouvello* Guinée.

L'attachemont exchisil de l'oiscau de Paradis pour les contrées où croissent les épicerius donne lieu de croire ¿qu'il rencontre sur ces arbres aromatiques la nourriture (qui lui convient le micnx; flu moins est-il certain qu'il ne vit pas uniqucment de la rosée.

\section{¿'OISEAU-MOUCHE.}

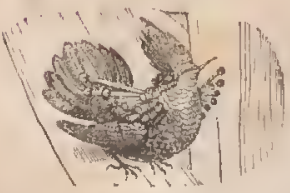

De tous les êlres animés, voici lo plus ćlégant pour la forme ct to phiss brillant pour les couleur's. $L^{b}$ bijon, le chef-d'œuvre de la natur est le potit oiseau-mouehe; elle l'a comblé de tous $\mathrm{J}^{5}$ dons qu'elle n'a fait que partager aux autres oiseaus: légèreté, rajuidilé, preslesse, grâce et riche parure, tor ${ }^{1^{\text {th }}}$ appartient à ce pelit favor'i. L'éncraude, le rubis, lit 
topaze, brillent sur ses habits; il ne les souille jamais de la poussière de la terre, ét, dans sa vie tont aéricnne, oule voit à peine touclier le gazon par instints; il est toujours en l'air, volant de fleurs en flcurs; il a lcur fraicheur comme il a leur ćclat; il vit de lenr neclar, ct n'labite que les climats où sans cesse clles se renourvellent.

C'est dans les contrées les plus chaudes du NouveauNonde que se trouvent toutes les espèces d'oiscaixmonelies.

Leur bee est uno aiguille fine, et leur lingue un fil délie; lcurs petits yeux noirs ne paraissont que deux Joints brillants; les plumes de lenr's ailes sort si déliciltes qu'eltes cu semblent transparentes; at peine aperfoit-on lems pieds, tant ils sont conts of menus; ils on font peu d'usage, ils ne se posent que pour passer la nuit, et se laissent, pendant lo jour, emporter dans los airs; Lur vol est continu, Jjourdornant ot rapide. Leur baltcthent est si vil (que l'oiscau, s'arrêtant dans les airs, Jatrait non-seulenent inmobile, mais toul à fait sans aclion; on le voit s'arrêter ainsi quelıues instants devaut thic fleur et parti. comne um trail pour alles à unc nu$t_{r e}$; il les risite loutes, plongeant sa petite languce thins leur sein, les flattant do ses ailes, sans jamais s'y fier, mais aussi sans les (puitter jamais, sans jamais les "lélrir'; il ne fait que pornper leur micl, et c'est ì cot usigge rque sa langue paraît uniquement destinée.

Pien n’égale la vivacité de ces petits oiseanx, si ce l'est leur courago on plutôt leur audace. On les voit polu'suive avee furie dos oiseaux vingt fois.plus gros Yu'u'ux, s'attacher à lcur corps, et, se laissant cmportcr 
par leur vol, les becqueter à coups redoublés jusqu'à co qu'ils aicnt assouvi leur pelite colèrc. Quclquefois même ils se livient entre cux de trìs-vifs combats; l'impatience paraît être leur âme. Ils n'ont point d'autre voix qu'un petit cri, screp, screp, fréquent et répété ; ils le font entcndre clans les bois dès l'aurore, jusqu'à ce qu'aux premiers rayons du soleil tous prennent l'essor et so dispersent dans les campagnes.

Ils sont solitaires, et il serait difficile qu'étant sins cesse cmportés dans les airs, ils pussent se roconnailro et se joindre. On voit les oiserux-mouches deux ì dous dans le temps des nieliées; le nid qu'ils eonstruisent répond à la délicatosse de leur corps; il est fait d'ur coton fin ou d'une bourre soyeuse leencillie sur des flcur's; la femelle sc cliar'ge de l'ouvrage et leisse au mâle le soin d'apporter les matériaux. On la voit cmpressée à ce travail chéri, ì ce doux berceau de sa progéniture. $\mathrm{Ce}$ nid n'est pas plus gros que la inoitié d'un abricot et fail de même en demi-coupe; on y trouve denx weufs toult blanes et pas plus gros (pue des pelits pois. Le mâle et la femolle les couvent tour à tour pendaut douze jours; les petils ćclosent au treizième joul', et ne sont alor's 1as plus gros que des mouches.

Avec lo lustre ef le velouté des lleur's, on a voulu cncore en trouver le parfum ì ces jolis oisceux. Plusicur's auleurs ont éerit qu'ils sentrient lo musc; c'est unc elreur. Ce n'est pas la scule petito merveille que l'imitgination ait voulu ajouter à leur listoire: on a dit qu'ils étaient moitié oiseaux et moitié mouches. On a dit qu'ils mouraient avec les flcurs pour r'enaitre avec elles; q qu'ils passaient dans un sommeil et un engourdissement total 
toute la mauvaise saison, suspendus par lo bec à l'éeol'ee d'm arlıe; mais ees fictions ont été rejetcees par les naturalistes sensés.

\section{LE COLIBRI.}

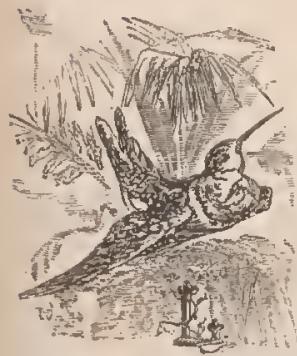

A nature, en prodiguant tant de beautés à l'oiseau - mouehe, n'a pas oublié le colibri; elle l'a produit dans le même elimat et formé sur le même modèle : aussi brillant, aussi léger que l'oiseaumouche, et vivant comme lui sur les fleurs, le eolibri est paré de mêne de tout ee çue les plus rielıes eouleur's ont d'éelatant, de moelleux, de suave, et ee que l'on a dit de la beauté de l'oiseau-mouche, de sa vivaeilé, de son vol bourdonnant et rapide, de sa constanee à visiter les fleurs, de sa manière de nieher et de vivre, doit s'appliquer également au coliłri. Un même instinet aniıne ees deux eharmants oiscaux, et eomme ils se ressemblent presque en tout, souvent on les a confondus sous un même nom; celui de colibri est pris de la langue des Caraïbes.

Tous les naturalistes attriluent avee raison aux eolibris ef aux oiseaux-mouehes la mêno manière de vivre.

Il n'est pas plus facile d'élever les petits du eolibri que ceux de l'oiseau-mouehe : aussi délicats, ils périssent de même en eaptivité; ou a vu le père et la mère, par au- 
dace de tendrosse, venir jusque daus les mains du ravisscur porter de la nourriture il leurs petits.

Un auteur, qui ne séparc pas les colibris des oiseauxmouches, ne donne à tous qu'un même petit cri, el nul des voyageurs n'attribue de clant à ces oiseaux.

Il ne paraît jas que les colibris s'avancent aussi loin dans l'Amérique sejtentrionale que les oiseaux-mouches. C'est done à vinģt ou vingt et un degrés de température qu'ils se plaisent; c'est lù que, dans une suite non interromjuc de jouissances et de délices, ils volent de la fleur' épanouie à la fleur naissaute, et que l'annće, composcie rl'nn cercle entier de heaux jours, ne fait pour eux qu'une seule saison constante de plaisirs les plus variés.

\section{LE MARTIN-PÉCHEUR OU L'ALCYON.}

Le nom de martin-pćchcur vient de marlinct pêcheur, qui était l'ancienne dénomination française de cet oiseau, dont lo vol ressemble à celui de l'hirondelle-martinet, lorsqu'clle file près de terre ou sur les eaux. Son nom ancien, alcyon, était bien plus noble, et on aurait dû le lui conserver.

C'est le plus bel oiseau de nos climats, et il n'y en it aucun en Euroje qu'on puisse comparer an martin-piccheur pour la netteté, la richesse et l'éclat des couleur's: elles ont les nuances de l'are-en-ciel, le brillant de l'émail, le lustre de la soie; tout le milieu du dos, avec le dessus de la quoue, est d'un bleu cluir et brillant, qui, 
alx rayons du soleil, a le jeu du saplin' et l'ocil de la turquoise; le vert se môlo au bleu sur les ailes, et la Hupart des plumes y sont terminúes et ponchuées jar une leinle d'aigntu-marine; la têle et lo dessus du cou sont jointillés de même de taches plus rlaties sur un fond d'azul'.

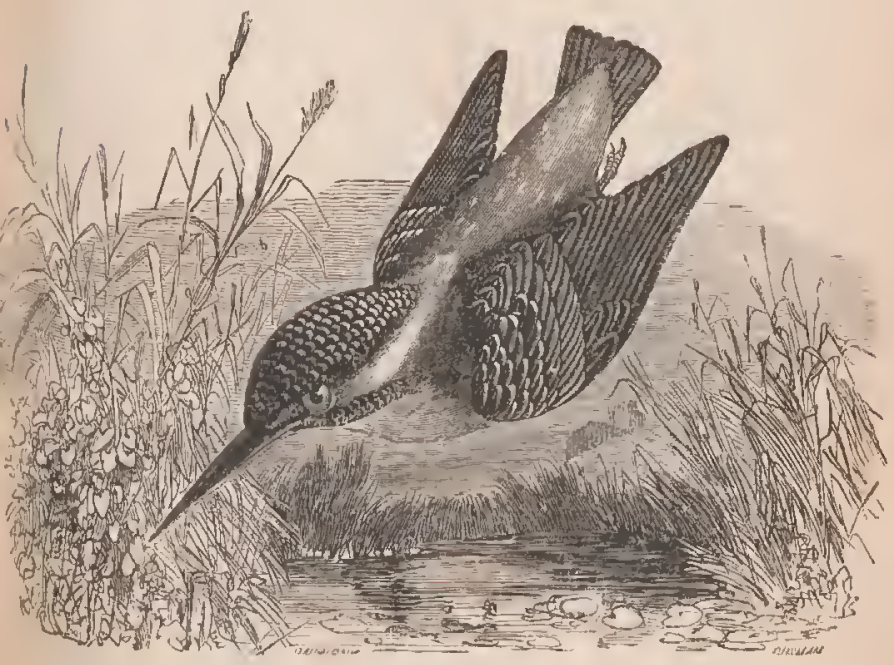

Il somble que le martin-pêcheur se soit éclıappé de ces climats où le solcil verse, avec les flots d'une lumìre Whs pure, tous los trésors des plus riches couleurs. Cet oiseau, quoique originaire de climats plus chauds, s'est labilué à la température et même au froid du notre: on le voil, en hiver, le long des ruisscaux plonfur sous la glace, ot cn sortir en rapjorlant sa proie. 
Son vol est rapide et flé; il suit ordinairement les contours des ruisseaux en msant la surface de l'eau; il crie, en volant, $k i, k i, k i, k i$, d'une voix perçante et yui fait retentir les rivages. 11 est très-sauvage et part lo loin; il se tient sur une branclıe avancée au dessus de l'cau pour pêcher; il y reste immobile, et épic sourent deux heuros entières le moment du passage d'un pelil poisson. Il fond sur cette proic en se laissant tomber dans l'eau, où il reste plusieurs secondes; il en sort avec le poisson au bec, qu'il porte ensuite sur la terre, contre laquelle il le bat pour le tuer avant de l'avaler.

Il niehe au bord des rivières et des ruisseaux, dans des trous creusés par les rats d'eau ou par les écrevisses. Dès le mois de mar's il commence à frécquenter son troll.

L'cspèco de notre martin-pôcheur n'est pas nombrouse, quoique ces oiseaux produisent six, sept et jusqu'à neul" petits ; mais le genre de vie auquel ils sont assujeltis les fait souvent péril', ct ce n'est pas toujours impunément qu'ils bravent la rigueur de nos hivers : on en tronte de morts sur la glace. Le inartin-pĉcheur ne peut s'aj ${ }^{\text {- }}$ privoiser, et il reste toujour's sauvage.

\section{LES MESSNGES.}

Tous les oiseaux de celte famille sont faibles en appac rence, parce qu'ils sont très-pelits; mais ils sont en même temps vifs, agissants el eourageux. On les voit sans cosse en mouvement; sans cesse ils voltigent d'arbre en arbre, ils sautent de branche en branche, ils grimpent sul l'ó 
corce, ils gravissent contre les murailles; ils s'accrochent, se suspendent de toutes les manières, souvent même la tête en bas, afin de pouvoir foullier dans toutes les petites fentes et y chcrchor les vers, les insectes ou leurs

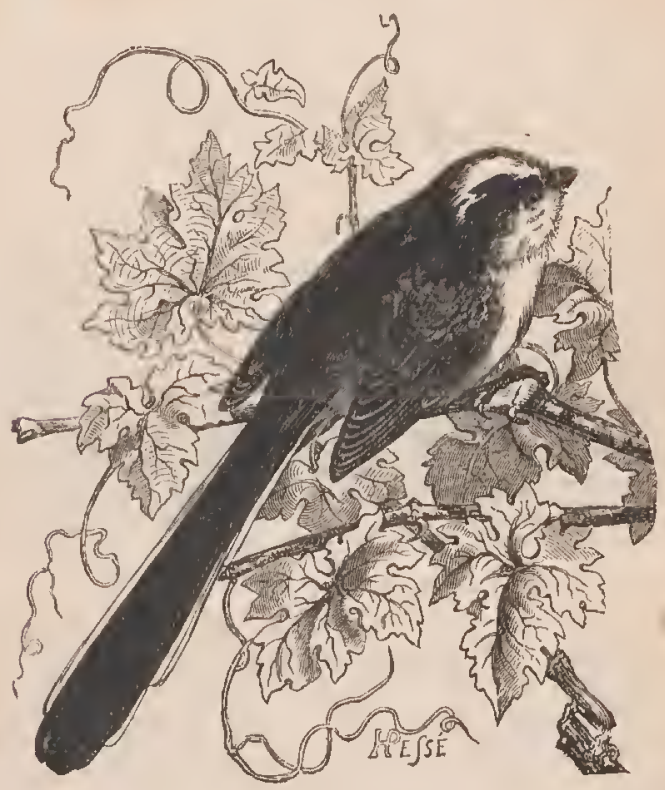

œufs. Ils vivent aussi de graines. Si on leur suspend une noix au bout d'un fil, ils s'accrocheront à cetle noix et en suiviont les oscillations ou bulancements sans làcher jrise, sans cesser de la becqueter.

La pluparl des mésanges d'Europe se trouvent dans nos elimals en toute saison, mais jamais en aussi grand 
nombre que sur la fin de l'automne, temps oì colles qui se tiennent l'élé dans les bois ou sur les montagnes, cn sont cliassécs par le froid, les neiges, et sont forcées de venir chercher leur subsistance dans les plaines cultivées, et à jorlée des lieux lıabités.

En général, toutes les mésangres, quoique un peu féroces, aiment la société deleurs semblables, ct vont par troupes plus ou inoins nombreuses : lorsqu'elles ont élú séparées paı quelque aecident, clles se rapjellent nutuellement et sont bientôt réunies; cependant elles semblent eraindre de s'approcher de trop près.

Elles sont plus fócondes qu'aucun aulre grenre d'oiseaux, et plus qu'en raison de leur petite taille. Elles ont beaucoup d'activité, de force et de courage. Aucun oiscau n'attaque ln chouette plus hardiment; clles s'elancent toujour's los premières et cherchent à lui erever les youx. Lorsqu'elles se sentent prises elles mordent vivement les doigts de l'oiseleur, les frippert à eoups de ljec redoublés, el rappellent à grands cris les oiseaux de leur espèce.

Elles pondent jusqu'à dix-huit ou vinğ oeufs; il semble qu'elles aiont compté leurs oufs avant de les pondre; il semble aussi qu'clles aiont une tendresse anticipće pour' les pofits qui en doivent éclore. Cela paraît aux précantions affectionnées qu'elles prennent dans la construction du nid, et à l'atlention prévoyante qu'ont certaines espèces de le suspendre au bout d'une branclıe; elles viennent à bout de procurer la subsistance d̀ leur nonbueuse famille; souvent on les voit revenir au nicl ayant des chenilles dans le lyec. Si d'autres oiscaux altaquent leur progéniture, elles la défendunt avce inlı́́pidité, 
fondent sur l'ennemi, et, à force de courage, font respecter la faiblesse.

Cies oiseaux sontrépandus tans toul l'ancien continent, depuis le Danemark et la Suède jusqu'au cap de BonneEsjérance.

\section{LE ROSSIGNOL.}

aty nuits de printemps, où, le ciel étant serein, l'air calme, toute la nature en silence, et, pour ainsi dire, attenwivi tive, on a écouté avec ravissementle ramage de ce chantre des forêts. Il

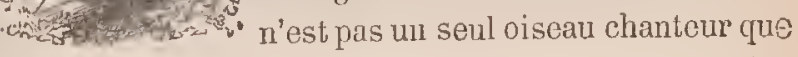
le rossignol n'eface par la réunion complc̀te de tous les talcnts diver's, et par la prodigieuse variété de son riérnage; en sorte que la chanson de chacun de ces oiseaux, prise daus toute son étendue, n'est qu'un couplet do celle du rossignol. Le rossignol charme toujour's et no se répète janais; il réussit dans tous les genres; il rend toutes les expressions, il saisit tous les caractères, ef de plus il sail en augmenter l'effet par les contrastes.

Une des raisons pour lesquelles le chant du rossignol est plus remarqué et produit plus d'effet, c'est parce que chantant la nuit, qui est le tcmps lc plus favorable, of chintant seul, sa voix a tout son éclat, et n'est offusquje par aucune autre voix. 
Il est étonnant qu'un si petit oiseau, qui ne pèse pas une demi-once, ait taut de forco dans les organes de la voix. Le chant du mâlo et colui do la femelle, qui chante rarement, ne se l'essemblent point.

On prćtend que le clıant du rossignnol dure dans toute sa for'ce quinze jour's et quinze nuits, sans interruption, dans le temps où les arbres se couvrent de vordure, ce qui doil ne s'entendre que dos rossignols sauvages; passé ce temps ils ne cliantent plus avec autant d'ardeur ni aussi constanment; ils commencent d'ordinaire au mois d'avril, of no finissent tout à fait qu'au mois do juin; mais la véritable époque où leur chant diminue beaucoup, c'est celle où lours petits viennent à éclore, parce qu'ils s'occupent alors du soin de les nourrir. Les rossignols captifs continuont de chanter pendant neuf ou dix mois, et leur cliant est non-sculement plus longtemps soutonu, mais encoro plus parfait et mieux formé. Il s'en faut bien cepeudant qu'ils soient insensibles à la perte dc leur libertó, surtout dans los commencemonts; ils sc laisseraiont mourir de faim los sept ou huit premiors jours, si on ne leur donnait la becquéo; et ils se casseraient la tète contre le plafond de lour cage, si on ne lcur attachait les ailes; mais, à la longuc, la passion de chanter l'emporte.

Tous les rossignols no chantent paś ćgaloment bien: il y en a dont le ramage cst si médiocre, que les amateur's ne reulent point les garder.

Passć le mois do juin, le rossignol ne chante plus.

Si l'on veut faire chanter le rossignol captif, il faut le bien traiter dans sa prison, il faut en peindre les murs de la couleur de ses bosquets, l'chivironner', l'ombrager' 
de feuillage, étendre de la nousse sous ses pieds, le garantil du froid, lui donner une nourriture abondante et 'ui lui plaise; en un mot, il faut lui fairo illusion sur sa captivité, et tìcher de la lui rendre aussi douce que la libẻrté, s'il était possible.

On ne se douterait pas qu'un chant aussi varié que celui du rossignol est renfermé dans les bornes étroites d'une seule octave.

Cet oiseau est capable î la longue do s'attacher ì la personne qui a soin de lui; lorsqu'une fois la connaissance est faite, il distingue son pas avant de la voir, il la salue d'avance par un eri do joie; lorsqu'il perd sa bienfaitrice, il mourt quclquefois de rogret : s'il survit, il lui faut longtemps pour s'accoutumer' à une autre; il s'attache fortement parce qu'il s'attache difficilement, comme font tous les caractères timides ct sauvages; il est aussi très-solitaire. Les rossignols voyarent seuls, arrivent sculs au nois d'avril et de mai, s'en retournent seuls au mois do septembre.

Chaque couple commence à fairc son nid vers la fin d'avril et au commencement de mai ; ils le posent ou sur les branches les plus lasses des arbustes, ou sur une touffe d'herbe, ct même à terre, au pied de ces arbustes; c'est ce qui fait que leurs cufs ou lcurs petits, et quelquefois la mère, sont la proie des chiens de chasse, des renards, des fouincs, des bclettes, des couleuvres, etc.

Dans notre climat, la femelle pond ordinairement cinq Curs qu'elle couve seule; elle no quitte son poste que pour chercher à nanger", et elle ne le quitte que sur le soir, et lorsqu'elle est pressée par la faim: pendant son absence le mâle semble avoir l'œil sur le nid. Au bout 
de dix-lunit on vingt jours, les petits eommeneent ì éelore; le nombre des mâles est eommunément plus quo double de eclui des femelles.

Au mois d'août, les vieux et les jeunes quittent lus bois pour se rapproeher des buissons, des haies vives, des terres nouvellement labourées, où ils trouvent plus de vers et d'inseetes : peut-être aussi ce mouvement général a-t-il queligue rapport à leur proehain dépari. Il n'en reste point en Franee pendant l'hiver, non plus qu'en Angleterre, en Allemagne, en Italie, en Grèee; et eomine on assure qu'il n'y en a point en Afrique, on peut juger qu'ils se retirent en Asic. Ils sont généralement répandus dans toute l'Europe, jusqu'en Suède et en Sibúrie, où ils chantent très-agréabilemenl; mais en Europe eomme en Asie, il y a des contr'ées qui ne leur conviennent poinl, et où ils ne s'arrêtent jamais. Cet oiseau apparlient à l'aneien eontinent.

\section{LA FAUVETTE.}

Des hôles des bois les fauvettes sont les plus nontbreuses cornme les plus aimables : vives, agiles, légères et sans eesse remuées, tous leurs mouvements onl l'ail' du sentiment, et tous leurs accents le ton de la joic. Cer jolis oiseaux arrivent au monnent où les arbres développent leur's feuilles et commencent à laisser épanouil' leurs fleurs; ils se dispersent dans toute l'étendue de nos campagnes; les uns viennent habiler nos jardins, d'attres préfèrent les avenues el les bosquels, plusicur's es- 
pèces s'enfoncent dans les grands bois, et quelques-unes se cachent au milieu des roseaux. Ainsi los fauvetlos remplissent tous les lieux de la terre el les animent par les unouvements et les accents de leur tondre gaieló.

La f'auvelle proprenent dite est de la grandeur du rossignol ; c'est la plus grande de toutes.

Elle habite, avec d'autres espèces de filuveltes plus pelites, dans los jardins, les bocages et les elımps somés de légumes, comme fùves ou pois. Toutes se posent Sur la ramée qui soutient ees légunes; elles s'y jouent, y jacent lcur nid, sortent et rentrent sans cesse jusqu'ì ce que le temp's de la récolte, voisin de celui de leur déparl, vienne les chasser de cet asile.

C'est un petit speclacle de les voir s'égayer, s'agacer el se poursuivre; leurs atlaques sont légères, et ees combals innocents se torminent toujours par quelques chlansons. Le mâle de la fauvelte prodigue à sa femello mille petits soins pendant qu'elle couve; il partage sa sollieitude pour les petits qui viennont d'éclore, et ne la quittc pas même après l'ćducation de la farnille.

Le nid est eomposé d'horbes sèches, de brins de clıan'r'e el d'un peu cle crin. on dedans; il eonticnl ordinairement cinq oufs que la mère abandonne lorsqu'on les a touchés, tant eelte apjuroche d'un ennemi lui paraît d'un mauvais augure pour' sa future famille. Il n'est pas possible non plus de lui faire adopter des oufs d'un autre oiscau : elle les recomnail, sail s'en défaire et les rejeter. Lá fauvette est d'un earactère crainlif; elle fuit devant des oiseaux tont aussi faibles qu'elle, et fuit encore plus vile et avec plus de raison devant la pie-grièche, sa redoutable cnnemie; nais l'instant du péril passé loul est 
oublié, et, le moment d'après, la fauvette reprend sa gaielé, ses mouvements et son ehant. C'est des raneaus les plus touffus qu'elle lo fait entendre; elle s'y tient ol* dinairement couvcrte, ne se montre que prar instants all bord des buissons, et rentre vite à l'intérieur, surtout pendant la chaleur du jour. Lc matin on la voit recucillir la rosée, el après ces courtes pluies qui tombent dans les jour's d'été, courir sur les feuilles mouillées et so baigner dans les gouttes qu'elle sccoue du fouillage.

Prosque toutes les fauvettes partent en même temps, au milicu de l'automne, et ì peine en voit-on encol'c quelques-unes en oclobre.

\section{LE BECFIGUE.}

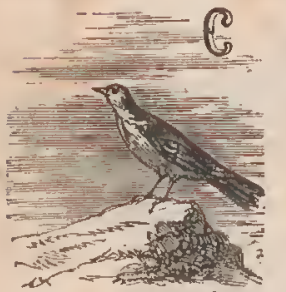

Es orseaux, dont le véritable clinat est celui du Midi, semblent ne venil' dans le nôtre que pour attendre lin malurité des fruits sueculents dont ils portent le nom; ils arrivent au plus tard au printemps, et ils partentavalt les premicrs froids d'automne. On lcs trouve en Angleterpe, en Allemagne, en Pologne, et jusçu'en Suède; il reviennent dans l'automne en Italie et en Grèce, ot pro' $\mathrm{r}^{\circ}$ hablement vont passer l'hiver dans des contrées encort plus chaudes. Ils semblent changer de mueurs en chatt geant de climal, car ils arrivent en troupes aux contrées méridionales, et sont au contraire toujour's dispersés 
pendant leur sćjour dans nos climats tempérés ; ils y linbitent les bois, se nourrissent d'insectes, et vivent daus la solitude. Lcurs nids sont si bien cachés qu'on a beaucoup de peine à les découvirir ; le mâle se tient souvent au sommet de quclque grand arbre, d'où il fait cntendre un petit gazouillement peu agréuble.

\section{LE ROUGE-GORGE.}

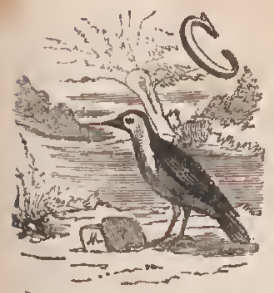

E petit orseau passe tout l'été dans nos bois, et ne vient à l'entour des habilations qu'à son départ en automne et ì son retour au rrintemps; mais dans ce dernier passage il ne fait que paraître, et sc hâte d'entrer dans les forêts pour y retrouver sa solitude, sous le feuillage qui vient de naître. Il place son nid près de terre sur les racines des jeunes arbres, ou sur des herbes assez fortes pour le souteni1; on trouve ordinairement dans ce nid einq et jusqu'il sept œufs.

Le rouge-gorge cherche l'ombrage épais et les endloits lumides; il se nourrit dans le printemps de vermisseaux ct d'insectes, qu'il chasse avec adresse et légèreté. Dans l'automne il mange anssi des fruits de ronces, ct des raisins à son passage dans les vignes; il va souvent aux fontaines, soit pour s'y baigner, soit pour boire.

Il n'est pas d'oiseau plus matinal que celui-ci. Le 
rougc-gorge est le premier éveillé dans les bois, et se filit entendre dès l'aubc du jour"; il est aussi le demier" qu'on y cutende et qu'on y voie voltigor le soir.

\section{LE ROITELET.}

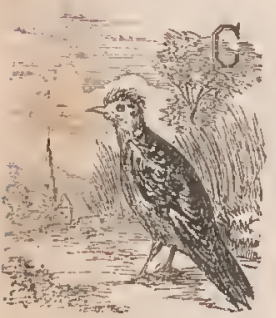

ET oiscan est si petit qu'il passe à traver's les mailles des filets ordinairos, qu'il s'échappe facilemont de loutes les carros, et que, lorsqu'on le iâche dans une chambro que l'or: croil bien fermćc, il disparait au bout d'un certain temps et se ford en quelque sorte sans qu'on en puisse retronver la trace: il ne faul, pour le laisser passer, qu'une issue presque invisible. Lorsqu'il vient dans nos jardins, il so glisse sulutilement dans les charmilles, et comment ne le perdrait-on pas biontôl de rue? la plus pelite feuillo suffit pour le cacher; comme il cst très-vif, il est déjà loin qu'on croit le tenir encore; son cri aigu ct perçant est cclui de la sautorelle, qu'il ne surpasse pas de beaucoup en grosseur. Ia femelle pond six on sept cufs, qui ne sont guère plus gros que des pois, dans un pelil nid fait en boule creuse, qu'elle élajlit le plus souvent dans los forêts, el quelqucfois dans les ifs et les charmilles de nos jardins, ou sur des pins à portée de nos maisons.

Les plus petits inscetes sont-la nourriture ordinaire die ces très-pelits oiseaux: l'élé ils les attrapont lestement 
en volant, l'hiver ils les cherchent dans leurs retraites, où ils sont engourdis, demi-morts, et quelquefois morts lout à fait.

Les roitelets se plaisent sur les cliênes, les ormes, les pins élevés, los sapins, les genévrier's, etc. On les voit En Silésie l'été conme l'hiver, et toujour's dans les bois; en Angleterre, dans les bois qui couvrent les monlaflhes ; en Bavière, en Autriche, ils viennent l'hiver nus Cnvirons des villes, où ils trouvent des ressources contre la rigueur de la saison. Ils ont beaucoup d'activité et d'agilité : ils sont dans un mouvement presque continuel, Voltigeant sans cesse de branche en branche, grumpant sur les arßres, se tenant indifféremment dans toutes los siluations, et souvent les pieds en haul, furetant dills toules les gercures de l'écorce, on tirant le petit gibicr 'Tui leur convient ou le guctaul à la sortie. Pendant les firoids, ils se tiennent volontier's sur les arjures toujour's Verts, dont ils mangent la graine.

$l_{\lrcorner} e_{S}$ roitelets sont répandus non-seulement en Europe, "drisuis la Suède jusqu'en Itrlie, et probablement jus'u'en Espagne, mais encore en Asie, jusqu'au Bengale, et niême en Amérique.

\section{LES BERGERONNETTES OU BERGERETTES.}

L'espèce d'affection que los bergeronnettes marquent pour les troupeaux, leur habitude à les suivre dans la Prairie, leur manière rle voltiger, de se promener au milieu du bétail paissant, de s'y mêler sans crainte jusqu'à 
se poser ruelquefois sur le rlos des vaches et des moutons, lour air do lamiliarilé avec le berger qu'elles pricèdent, qu'elles accompagnnent sans défiance et sans dan' ger', qu'elles avertissent même de l'approclie du loup ou' de l'oiseau de proie, leur ont fait donner un $110 \mathrm{~m}$ approprić, pour ainsı dire, à celte vie pastorale. Compagne

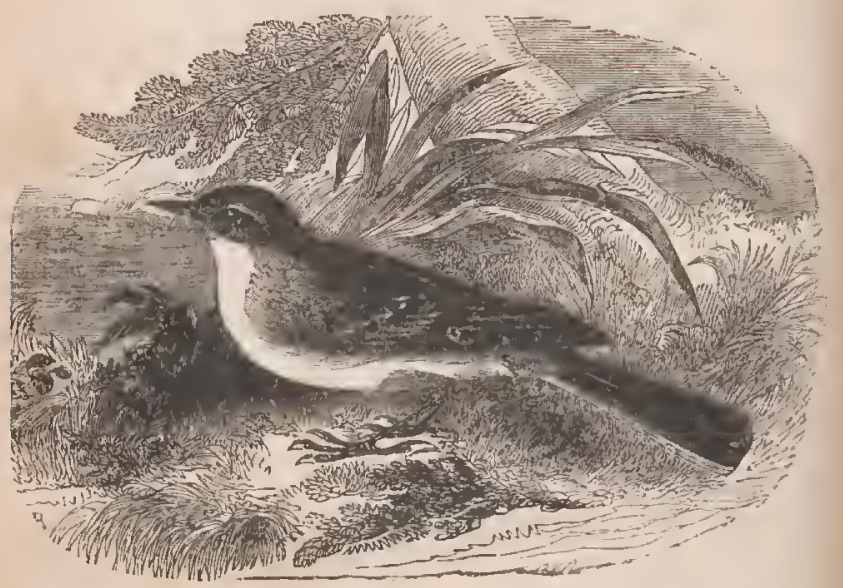

d'hommes innocents et paisibles, la bergeronnette semble avoir pour notre espèce ce penchant qu rapproclıe rait de nous la plupart des animaux, s'ils n'étaient $\mathrm{l}^{\mathrm{e}}$ poussés par notre barbaric, et ćcartés par la crainte do devenir nos viclimes. Dans la bergeronnette, l'affectiol est plus forte que la peur'; il n'cst point d'oiseau libre dans les champs qui se montre aussi privé.

Les mouches sont sa pîture pendant la belle saison; 
mais quand les frimas ont abattu les inseetes volants et renfermé les troupeaux dans l'étable, elle se retire sur les ruisseaux et $\mathrm{y}$ passe presque toute la mauvaise saison.

Elle fait son nid vers la fin d'avril, communément sur un osier près de terre, à l'ałri de la pluic; elle pond et couve ordinairement deux fois jar au.

La bergeronnette, si volontier's amie de l'homme, ne se plie point à devenir son eselave; elle meurt dans la Wrison de la eage. Elle aime la soeiété ct eraint l'étroite captivité; mais, laissée libre dans un appartement en hiver, elle y vit, donnant la ehasse aux mouches et ramassant les mics de pain qu'on lui jette.

\section{L'ALOUETTE.}

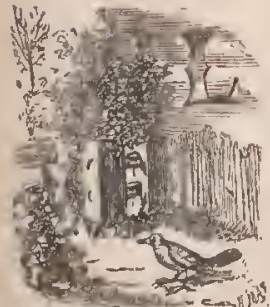

onsque l'aloutte est libre, elle commenec à ehanter dès los premiers jours du printemps, et elle continue pendant toute la belle saison; le matin et le soir sont le temps de la est milieu du jour eclui où on l'entend le moins. Elle plus elle s'élève, plus elle force la voix, et souvent elle la foree à un tel point que, quoiqu'elle se soutienne atı haut des airs et it perte de vue, on l'entend encore dislinctement, soit que ce ehant ne soit qu'un simple accent 
de gaieté, soit que ces petils oiseaux ne chantent ainsi en volant que par' une sorte d'émulation et pour se rap. peler entre cux. L'alouette chante rarement à terre, où neanmoins elle se tient toujour's lor's yu'elle ne vole point; car elle ne se perehe jamais sur les arbres.

La femelle fait promptement son nid ; elle le place entre deux mottes de terre, elle le garnit intérieurement d'herbes, de petites racines sèclics, et prend beaueoul' plus de soin pour le cacher que pour le eonstruire. Chaque femelle pond quatre ou cinq petits ours; clle we les couve que pendant quinze jours au plus, et elle emploie encore moins de temps à conduire el à élever ses pelils.

íes petits se tiennent un peu sćpurés les uns des autres, car la mère ne les rassemble pas toujours sous ses ailes, mais elle voltige souvent au-dessus de la eouvéc, la suivant de l'oil avec une sollicitude vraiment maternelle, dirigeant tous ses mouvements, pourvoyant à tous ses besoins, veillant à tous ses dangers.

On trouve l'alonelte dans presefue tons les pays halutés lles deux eontinents, ot jus(fu'an eaj) de BomeEspérance.

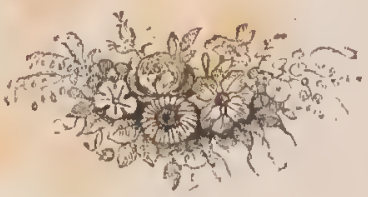




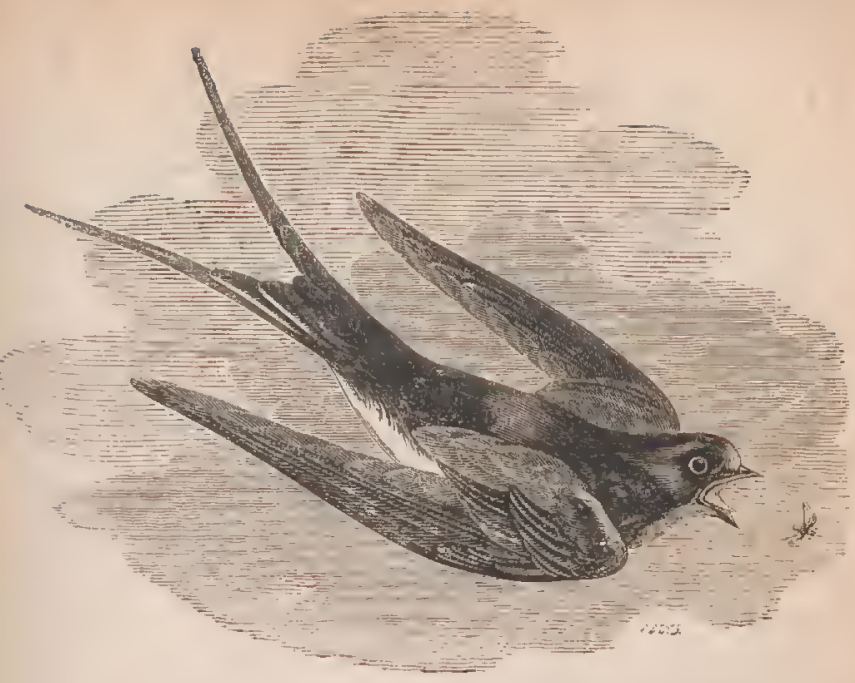

\section{LES HIRONDELLES.}

\section{LHIRONDELLE DE CHEMINEE}

OU L'HIRONDELLE DOMESTIQUE.

Elle est, cn effet, domestipue par instinet; elle recherche la société de l'homme par choix; clle la préfòre à toute autre sociétó; olle niche dans nos cheminées et Jusque dans l'intérieur de nos maisons, surtout de celles Où il y a peu de mouvement et de Jiruit. Lorsque les maisons sont trop bien closes et quo les cheminóes sont fi: r'm mécs par lc haut, cllc change de logement sans changel' d'inclination; elle se rélugic sous los avant-toits et $\mathrm{y}$ consiruit son nid, mais janais elle ne l'élablit volontai- 
rement loin de l'homme, et toutes les fois qu'un voyatgeur égaré aperçoit dans l'air quelqu'un de ces oiseaux, il peut les regrerder comme des oiseaux de bon augure et qui lui annoncent infailliblement quelque habitation proclaine.

L'hirondelle de cheminée est la preniùre qui paraisse dans nos climats : e'est ordinairement peu après l'équrnoxe du printempss; elle arvive plus tôt dans les contrécs méridionales, el plus tard dans les pays du Nord.

Les mêmes hirondelles reviennent aux mêmes endroits; elles n'arrivent que pour faire leur ponte et se mettent tout de suite ì l'ouvrage; clles construisent chrque annćc un nouveau nid et l'établissent au-dessus de celui de l'année prócédente, si le local le permet.

'Tandis que la femcllc couve, le mâle passe la nuit sul' le bord du nid; il dort peu, car on l'entend babiller dès l'aube du jour, ct il voltige presque jusqu'à la nuit close; lorsque les petits sont ćclos, le père et la mère leur portcnt sins cesse à manger et ont grand soin d'entretenir la projretó dans le nid jusqu'à ce ‘ue leurs petits, devenus plus forts, saclient s'ul'anger de manière à leur épargnor celte peine. Mais ce qui est plus intéressant, c'est de voir les vicux donner aux jeunes les premic̀res leçons de voler en les animant de la voix, leur prisentant d'ut jeu loin lat nour'riture, et s'éloignant encore à mesure "fu'ils s'avanecut pour la rocevoil'; les poussant douce. ment, et non sans quelque inquićtude, hors du nid; joutant devant eux et avec cux dans l'air, comme potl' leur offrir un sceours toujours présent, et accompagnant leur action d'un gazouillement si cxpressif qu'on croirait en entendre Io scus. Si l'on joint è celi ce qu'un a dit 
d'un de ces oiseaux qui, étant allé à la provision et trouvant à son retour la maison où était son nid embraSée, se jeta au traver's dos flammes pour porter nourriture ct sccour's à ses pctits, on jugera avce quelle passion les hirondelles aiment leur progéniture.

On a prótcndu que, lor'sque leurs petits avaient les Yeux crevés, même arrachés, elles los guérissaicnt et lour rendaient la vue avec une certaine herbe qui a été appelée chélidoine, c'est-à-dire lıcrbe aux hirondelles; mais des expériences nous ont appris qu'il n'est besoin d'alucunc herbe pour cola, et que, lorsque les yeux d'un joune oiseau sont, non pas arracliés tout à fait, mais seulement crevés ou même flétris, ils sc rétablissent trèsmomptement et sans aucun remède.

Les hirondelles vivent d'insectes ailés qu'elles happent th volant; mais comme ces insectes ont le vol plus ou moins élevé, selon qu'il fait plus ou moins chaud, il al-Vive que, lorsque le froid ou la pluie les rabat près do torre et les empêche même de faire usage de leurs ailes, ${ }^{r}$ os oiseaux rasent la terre et cherehont ces insccles sur les tiges des plantes, sur l'herbe des prairies et jusque Sur le pavé de nos l'ues; ils ladscnt aussi los caux et s'y jongent quelqucfois à demi en poursuivant les insectes "quatiques, ol dans les grandes disettes ils vont disputer 'Ux al'aignćes leur proie jusqu'au milieu de leur toile, ct frissent par les dévorer elles-mêmes. Quoique les hirondelles de cheminée passent la plus grrande partic de leur Vie dans l'air, elles se posent assez souvent sur les toils, les clicminces, les barres de fer, et même ì terre et sur tes arbres. Dans notre climat, elles passent souvent los luits, vors la fin de l'été, pcrchécs sur des aunes, au 
nord des rivières; elles choisissent les branches les plus basses qui se trouvent au-dessous des berges et bien à l'abri du vent; on a remarqué que les branches qu'clles adoptent pour y passer ainsi la nuit meurent et se rlessichent.

C'est encole sur un arbre, mais un tris-grand arbile qu'elles ont coutune de s'assembler pour le départ. Ellé s'en vont de ce pays-ci ver's le commencement d'octobre; elles partent ordinairement la muit comme pour dérobel' leur marche aux oisentux de jroie, qui ne manquent guc̀ te de les harceler dans leur 1'oute. On en a vu (juelquefois lartir en plein jour. Elles dirigrent leur route du côté d"t Midi, on s'aidant d'un vent favorable aulant qu'il est possible; et lorsqu'elles n'éuromvent point de contré temps, elles arrivent en Africuc dans la première lıul' taine d'octobre.

Quoique en général ces lin'ondelle's soient des oisenu' de passage, on peut bien s'imagriner qu'il en reste quel ques-unes penrlant l'hivel, surtout dans les pays ten' lér'ós. Il y a encoro l'hirondelle de fenêtro, l'hirondelle' de rivage et l'hirondello griso de roeher. 


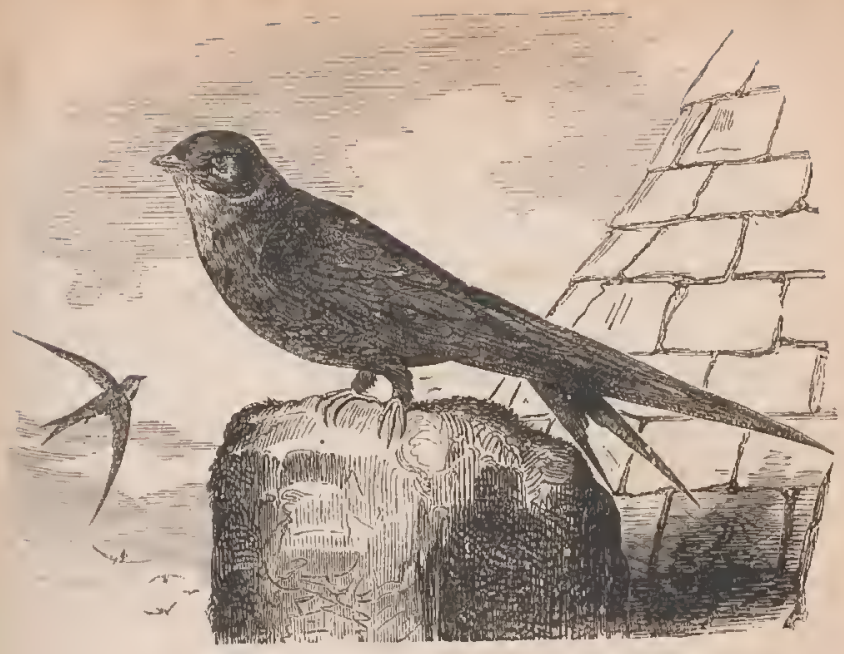

\section{LE MARTINET NOIR.}

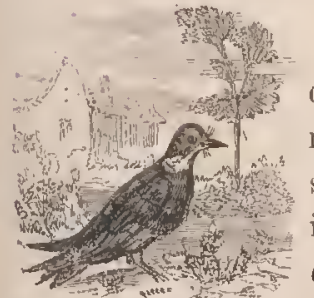

Las martinets sont de tous les oiseaux de passage cenx qui, clans notre pays, arrivent les derniers et s'en vont les premiers ; d'ordinaire ils commeneent à paraître sur la fin d'avril ou au commeneenent de mai, et ils nous quittent avant la fin de juillet.

Ces oiseaux, pendant leur eourt séjour dans notre pays, n'ont que lo temps de faire une seule ponte; elle est communément de cinq oufs. Lorsque les petits ont percé la coque, bien différents des petits des autres hil'ondelles, ils sont presque muets et ne demandent rien; heureusement leur père el leur mère entendontle eri de 
la nature et leur donnent tout ce qu'il leur faut; ils ne leur portent à manger que deux ou trois fois par jour, mais à chacque fois ils reviennent au nid avec une ample provision.

Vers le milieu de juin, les petits commencent à voler et quittent bientôt le nid, après quoi le père et la mère ne paraissent plus s'occuper d'eux.

Les martinets craignent la chaleur, et c'est par cette raison qu'ils passent le milieu du jour dans leur nid, dans les fentes de murailles ou de rochers. Le caractère de cet oiseau est un mélange assez naturel de défianee el d'étourderie : sa défiance se marque par toutes les précautions qu'il prend pour cacher sa retraite, dans liquelle il entre furtivement, où il reste longtemps, d'où il sort à l'improviste, où il élève ses petits dans le silence; mais lorsque, ayant pris son essor, il a le sentiment actuel de sa force ou plutôt de sa vitesse, la colscience de sa supériorité sur les autres habitants de l'air, c'est alors qu'il devient étourdi, téméraire; il ne craint plus lien, parce qu'il se croit en état d'échapper à tous les dangers.

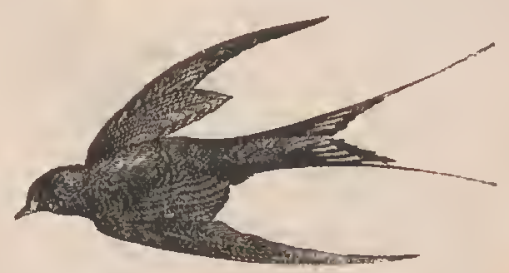




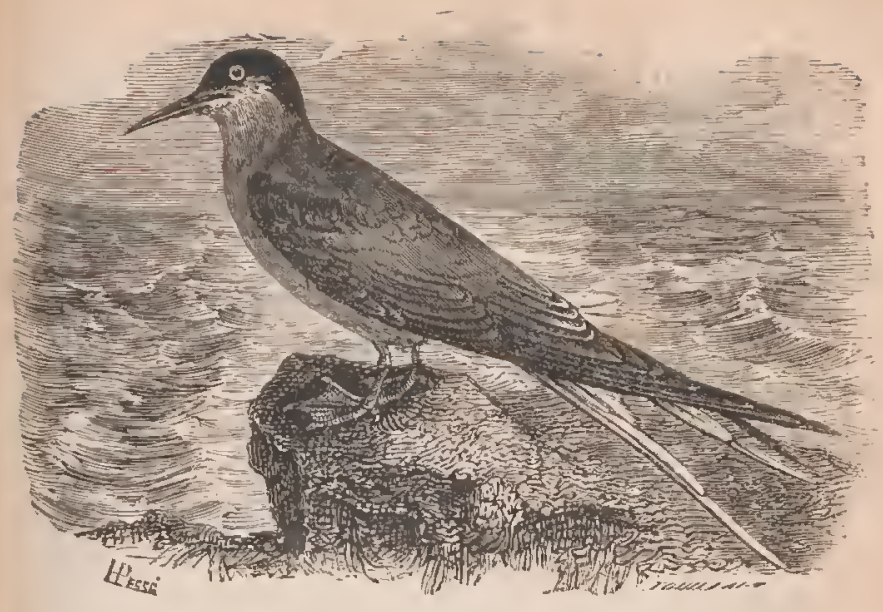

\section{LES IIRONDELLES DE MER.}

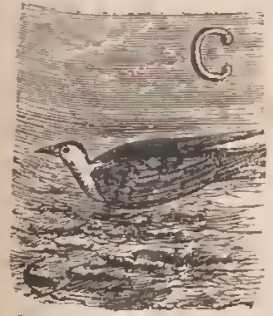

ETTE pelile famille d'oiseaux pêcheurs qui ressemblent à nos liirondelles par leurs longues ailes et leur queue fourchue, et qui par leur vol constant ì la' surfice des eaux, repl'ésentent assez bien sur la plaine liquide les allures des hirondelles de terre dans nos campagnes et autoul de nos labitations; les hirondelles de mer, en un mot, non moins agiles et aussi vagabondes, rasent les eaux d'une aile rapide et enlèvent en volint les petits poissons qui sont à la surface de l'eau, comme nos hirondelles y Saisissent les insectes. Les pieds des hirondelles de mer sont garnis de pelites membranes retirées entre les doigts, ot ne leur servent pas pour nager. Les hiron- 
delles de mer jettent en volant de grands cris aigus et perçants. Elles arrivent par troupcs sur nos côtes de l'Ocćan au commencement de mai; la plupart y demeurent et n'cn quittent pas les bords; d'autres voyagent plus loin et vont chercher les lacs, les grands étangs, en suivant les rivières: partout elles vivent de petite pêclıe, et nême quelques-unes gobent en l'air les insectes volints; le bruit des armes à feu ne les effraye pas : ce signal de danger, loin de les écarter, semble les attirer.

Cette famille des hirondelles de mer est composée de plusicurs espèces, dont la plupart ont franchi les océans et peuplé leu's rivages; on les trouve depuis les mers, les lacs el les rivières du Nord, jusque dans les vastes plages de l'Océan austral.

\section{LES PICS.}

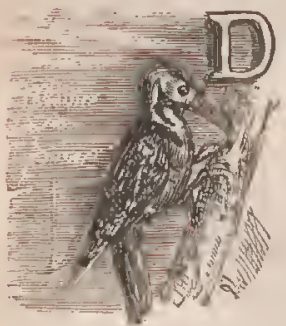

E tous les oiseaux que la natıre force à vivre de la grande ou de la pelite chasse, il n'en est aucun dont elle ail rendu la vie plus laborieuse, plus dure que celle du pic. En effet, assujctti à une tâche pénible, il $11^{\ell}$ peut trouver sa nourriture c qu' perçant les écorces el lia fible rlure des arbres qui la l'er cèlent: occupé sans relûche à ce travail do nćcessité, if ne connaît ni dúlassement ni repos; sonvent, même il dort et passe la nuit dans l'attilude contrainte de la be- 
sogne du jour; il ne partagre pas los doux ébats dos autres habilants de l'air; il n'entre point dans leurs concerts, et n'a que des cris sauvages, dont l'accent plaintif, en troublant le silence des bois, semble exprimer ses eflorts et la peine. Ses mouvements sont brusques; il a l'air inquiel, les traits et la physionomie rudes, le naturel sauvago et farouche; il fuit toute la société, même celle de son semblable.

Il a reçu de la nature des organes et des instruments ipproprićs à celte destinée, ou plutôt il tient celtc destinèe des organes avec lesquels il est né. Quatre doights ¿jonis, nervenx, tournés deux en avant, doux en arrière; tous armés de gros onģles arqués, implantés sur un pied très-court et puissamment musclé, lui servent à grimper en tous sens autour du tronc des arbres; son bec tranchant, droit, en forme de coin, et taillé verticalement à sa pointe comme un ciseau, est l'instrument avec lequel il perce l'écorce of entame profondément lo bois des arlues. Do forts muscles dans un cou raccourci, portent et dirigent les coups léitérés que ìe pic frappe incessamment pour percer lc bois et s'ouvrir un accòs jusqu'au ccur des arhres: il y darde une longue langue effilće, arpondic, scmblable à un verre de terre, arméc d'uno pointe dure, osseuse, comme d'un aiguillon. Il niche dans les cavités qu'il a en partic creusées lui-même.

Lo genre du pic est très-nombreux en espèces qui varient pour les couleurs et different par la grandeur : les phus grands pics sont de la taille de la corneille, et les plus pelits de celle de la mésange. La nalure a placé des pics dans toules les contrées où elle a produil des arbres, et en plus grande quantití dans los climats plus chauds. 
On on connaît douze espèces en Europe et vingt-sept daus les régions chaudes de l'Amérique, de l'Afrique ot de l'Asic.

\section{LE PIC VERT.}

Le pie vert est le plus connu des pies, et le plus conl" mun dans nos bois; il arrive au printemps et fait retentit les forèts de cris aigus el durs, liacacan, liacacan, que l'on entend de loin, et qu'il jetle sirtout en volant $p^{\text {at }}$ élans et par bonds. Quoiqu'il ne s'élève qu'à une petilu lauteur, il franchit d'assez grands intervalles de terres découvertes pour passer d'une forêt à l'autle.

L.e pie vert se tient à terre plus souvent que les autres pies, surtout près des fourmilic̀res; il attend les fourmi in $^{\text {the }}$ au passage, couchant sa longue langue dans le petit sentier qu'elles ont coutume de tracer ct de suivre à ta file ; et lorsqu'il sent sa lanģue couverte de ces insecteś il la relire pour les avaler.

Il grimpe aussi contre les arbores, qu'il attaque et qu'il frappe à coups de bee rcdoublés; travaillant avec la plus grando activité, il dépouille souvent les arbres secs do toute leur éeoree; on entend de loin ses coups de bec el l'on peut les compter.

G'est au cœur d'un arbore vermoulu qu'il place son nid, à quinze ou vingt pieds au-dessus de terre, et le $p^{\text {lltis }}$ souvent dans les arbres de bois tendre. Le mûle et la for melle travaillent incessamment et tour' à tour ì percer lis 
partıe vive de l'arbre, jusqu'ì ee qu'ils rencontrent le centre carié. Là ils nourrissent leurs petits. La ponte est

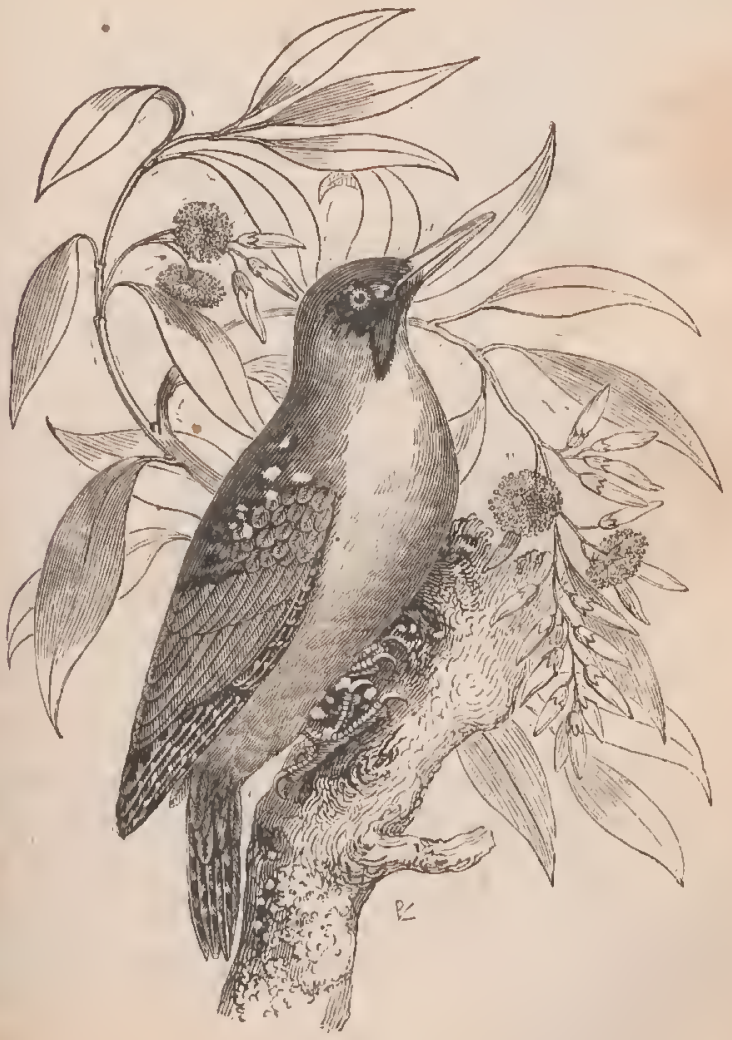

ordinairement de cinq œuls. Les jeunes pies commencent à grimper lout petits et avant de pouvoil voler. Le mâle et la femelle no se quittent guère, se couchent de bonne 
heure, avant les aultres oiseaux, et restent dans le trou jusqu'au jour.

On appolle le pic vert l'oiseau de la pluie, qu'il annonce par un cri plaintif. Son espèce se trouve dans les deux continents, où, quoique peu nonbreuse, tllo est fort ?épandue.

\section{LE COUCOU.}

On a fait du coucou lo type de l'ingratitnde. Que d'ab surdilés dans tous ces contes!

Bien loin d'être ingral, le coucou parait conserver le souvenir des bienfaits et n'y être pas insensible. On préc tond qu'en arrivant de son quartier d'hiver" il se rend

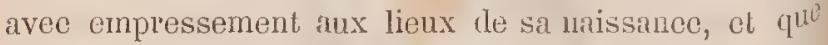
lor'squ'il y retrouve sa nourrice ou ses frères nour'tciers, tous éprouvent une joie réciproque qu'ils exprir ment chacun à leur manière. Ce sont ecs cris, ces jeuś, qu'on aura pris pour une guerre que les petits oiseaul faisaient au coucou; il se peut néanmoins qu'on ait v $\mathbf{1}^{1}$ entre eux de véritables combats : par exemple, lorsqu'tul' coucou ćtranger, cédant à son instinct, aura voulu dér truire leurs œufs pour placer le sien dans leur nid, el qu'ils l'auront pris sur le fait. C'est cette habitude biell constatée qu'il a de pondre dans le nid d'autrui, qui ejt la principale singularité de son histoire.

Une autre singularité de son histoire, e'est qu'il ne pond qu'un œuf, du moins qu'un œuf dans chaque nidi car il est possible qu'il en ponde doux. 


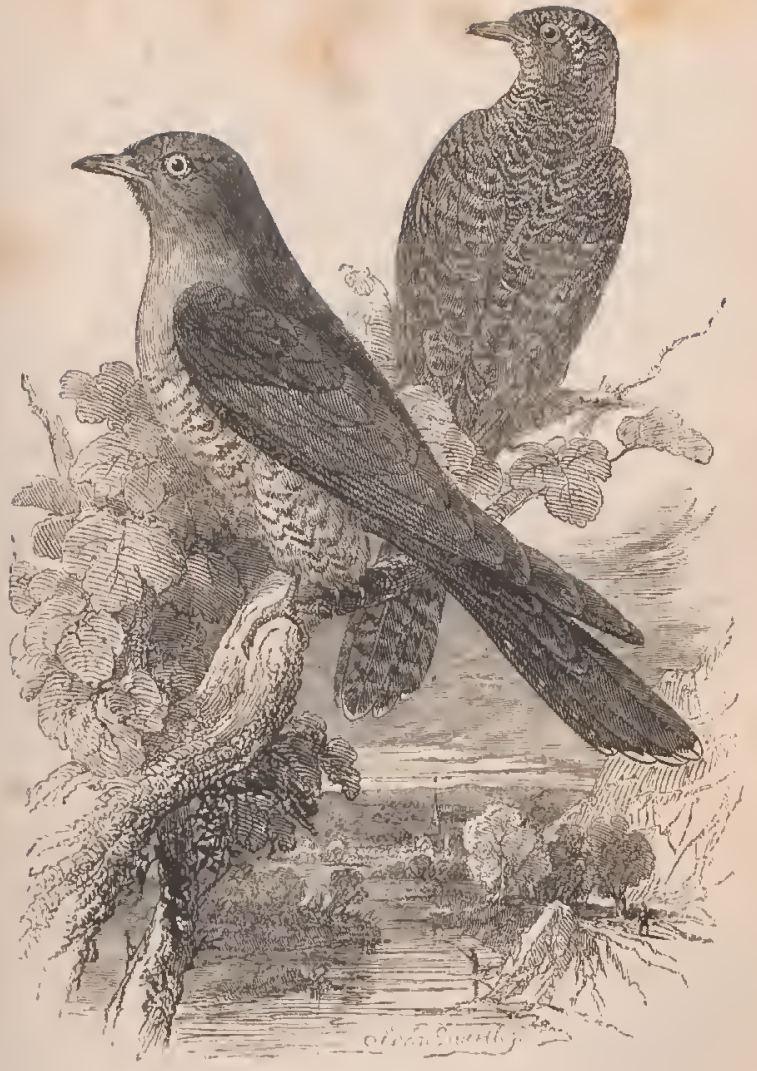



Cos deux singularités scmblent tenir à une troisième et pouvoir s'expliquer par elle: c'est que lour muc est et jlus tardive et plus complète que cclle de la plupart des oiscaux; on rencontre quelquefois l'liver, dans le creux des arbres, un ou deux coucous entièrement nus, nus au point qu'on les prendrait au premier coul' d'œil pour de Véritables crapauds. Comme les coucous mâles ont l'instinct de manger les $œ u f s$ des oiscaux, la femelle doit cacher soigncusernent le sien; elle ne doit pas retourner à l'endroit où elle l'a déposé, de peur de l'indiquer à son mâle; elle doit done choisir le nid le mieux caché, le plus éloigné des endroits qu'il fréquente; elle doit même, si elle a des oufs, les distribuer en différents nicls; elle doit les confier à des nourrices étrangères et Se reposer sur ces nourrices de tous les soins nécessaires ù leur entier déve?oppement: c'est aussi ce qu'elle fait, en prenant toutes les précautions qui lui sont inspirées Dar la tendresse pour sa progéniture, et sachant résister ì cette tendresse mêne pour qu'elle ne se trahisse point Dar indiscrétion. Considérés sous ce point de vue, les Drocédés du coucou rentreraient dans la r’ègle générale, et supposeraient l'anour de la mère pour ses petits, et rêtine un amour bien entendu.

Ce qui me semble avoir le plus étonné, e'est la conWaisance dénaturéc de la nourrice du coucou, laquelle oublie si facilement ses propres oufs pour donner tous ${ }^{80} \mathrm{~S}$ soins à celui d'un oiseau étranger, et même d'un oiseau destructeur de sa propre famille.

Tous les liabitants des bois assurent que, lol'squ'une fois la mère coucou a dćposé son ouf dans le nid qu'elle 'choisi, elle s'éloigne, semble oublier sa progéniturc ct 
la perdre entièrement de vuc, et qu'à plus forte raison le mâle ne s'en occupe point du tout; cependant on a obscrvé, non que le père el la mère donnent des soins à leurs petils, mais qu'ils s'en approehrent ì une certaine distanee en chantant, que de jart et d'autre ils semblent s'éeouter, se répondre, el se prêter mutuellement alten* tion.

Tout le monde connât le chant du coucou, du moins son chant le plus ordinaire: il est si bien articulé et rée pété si souvent, que, dans presque toutes les langues, il a influé sur la dénomination de l'oisenu : ce chant appar" tient exclusivement au mâle, et c'est au printemps quo ce mâle lc fait cntondre, tantôt perché sur une branche sèche, et tantôt en volant. Les mâles sont beaucoup plit's nombreux que les femelles.

Les jeunes coucous ne chantent point la première an née, et les vieux eessent de chanter' assidûment, ver's $l^{a}$ fin de juin; mais ce silence n'annonce point lour départ' on en trouve même dans los plaines jusqu'ì la fin do septembre et encore plus tard: ce sont sans doute les premier's froids et la disette d'insectes qui les déterninent à passer dans des climats plus chauds; ils vont ${ }^{10}$ plupart en Afrique.

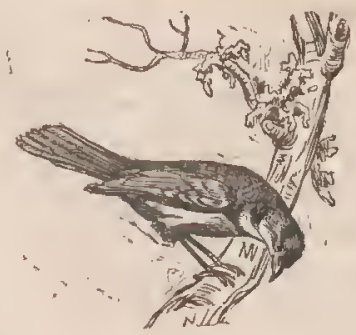




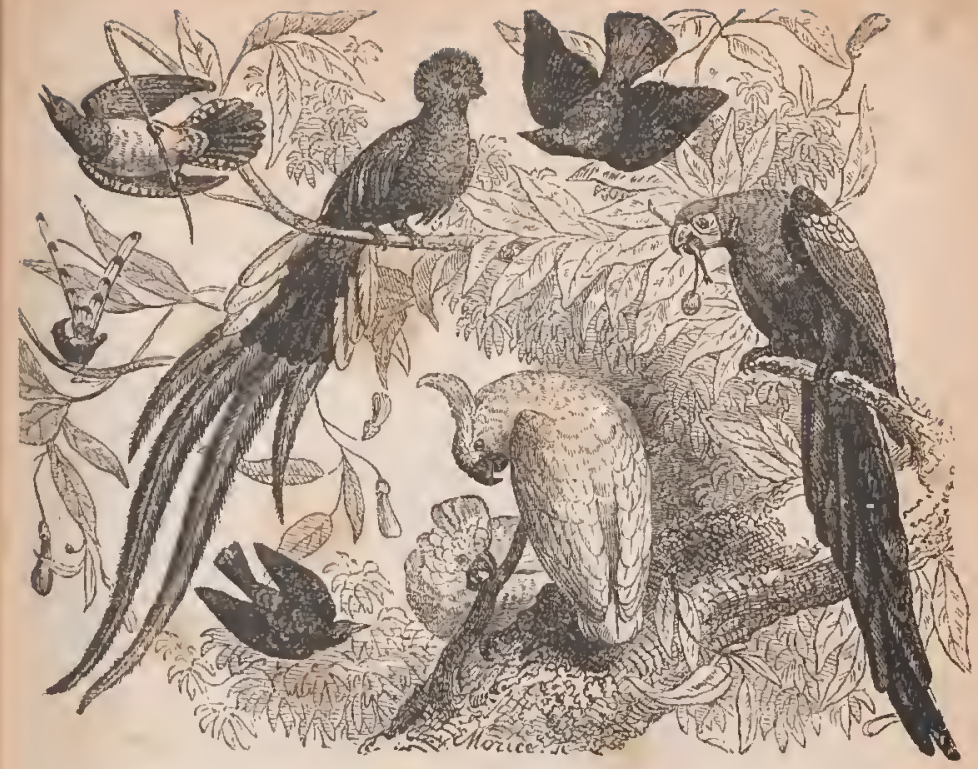

PSITTACÉS.

\section{LE PERROQUET.}

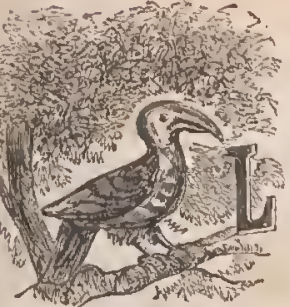

médiaircs entre l'homme el la lrule.
Es animaux que l'homme a le plus admirés sont ceux qui lui ont paru participer ì sa nature; le singe par la ressemblance des formes extérieures, et le perroquet, par l'imitation de la parole, lui ont semblé des ĉtres privilégićs, inter- 
Les l'ortugais, qui, les jromier's, ont doublé le cap de Bonne-Espúrance et reconnu les côles de l'Afrique, trouvìrent les terres de Guinée ol toutes les îles de l'océan Indien peuplées, commo le conlinent, de divorses espècos do perroquets, toutes inconnuos à l'Europe, et en si grand nombre qu'à Calicul, à Bengale et sur les côtes d'Afriçue, les Indiens ot les Nègres étaiont obligús de so tenir dans leurs champs de maïs et de riz vers le tomps de la inaturité pour en éloigner ces oiseaux qui viennent les dévaster.

Cette grande inultitude de perroquets dans toutes leg rúgions qu'ils habitent scinble prouver qu'ils réitèrent leurs jontes, puisque chacune est assez peu nombreuse; mais rien n'égale la variété d'espèces d'oiscaux do ce genre qui s'oll'rirent aux navigateurs sur toutes les plages inćridionales du Nouveau-Monde, Iorsqu'ils on fircut la découverte. Plusieurs îles reçurent le nom d'îles des Perroquets. Ce furent los sculs animaux que Colomb trouva dans la première où il aborda, et ces oiscaux servirent d'objels d'éclıange dans lo premier coinuncroe qu'curent les Europécns avee les Américains.

Daus l'ancien continent il y a cinq grandes famillos de perroquets, savoir: les kakatoës, les porroquels proprement dits, les loris, les perruches à longue queue et los perruches à queuc courto; et dans lo nouveau continent il y a six autres familles, savoir: les ar'as, les anazones, les oriks, les papogais, les perrichos à queuo longue, et enfin les porrichos à queue courto. Chacune de ces onze tribus ou familles est désignéc par des caractères dislinctifs, ou du moins chacune porte queli plo $^{\mathrm{t}}$ livrće particulic̀re qui les roud reconnaissables. 


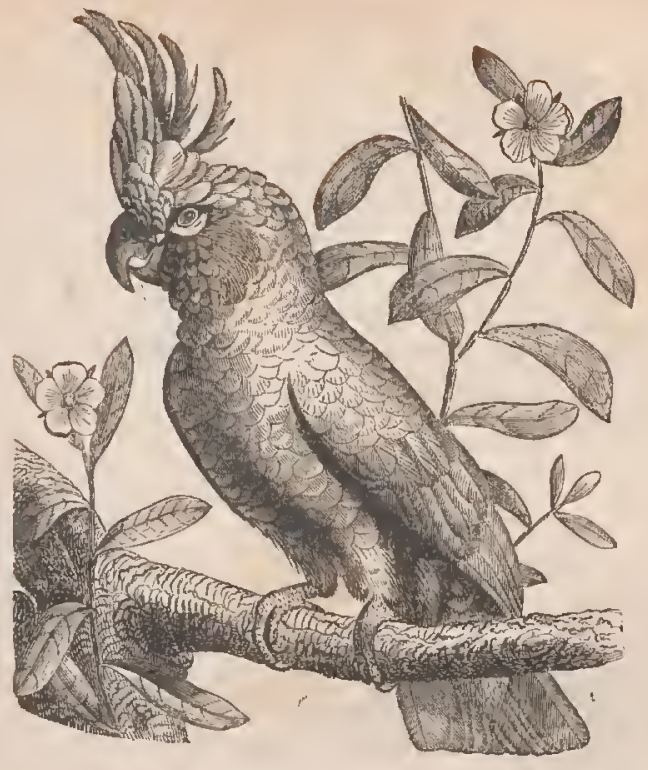

\section{LE KAKATOES.}

Les plus grands perroquets de l'ancion continent sont les kakatoës; ils en sont tous originaires et paraissent êtro naturels aux climats de l'Asic méridionale, mais il est sûr qu'il ne s'en trouve point en Amérique : ils paraisscnt répandus dans les régions des Indes méridionales el dans toutes les îles de l'ocćan Indien. Leur nom de kakatoës vient de la ressemblance do ce mot à leur cri. On les distingue aisément des autres perroquets par leur plumage blane el par leur bec plus crochu et plus arrondi, et particulic̀rement par une huppe de longues 
plumes dont lour tête est ornéc, et qu'ils élèvent et abaissent à volonté.

Ces perroquets kakatoës apprennent dilfieilement à parler, il y a même des espècos qui ne parlent jamais; mais on en est dédommagé par la facilité de leur édueation: on les apprivoise tous aisément. Ils ont dans tous leurs mouvements unc douceur et une grrûce qui ajoutent encore à leur beauté.

\section{LE JACO OU PERROQUET CENDRE.}

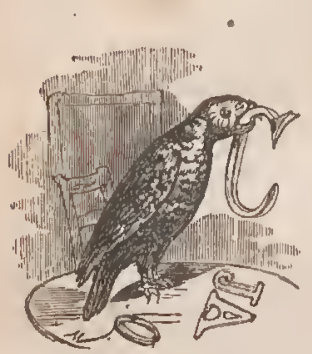

'EST l'espèce du perroquet propre" mont dit que l'on apporte le plus communément en Europe aujour" d'hui, et qui s'y fait le plus aime!' tant par la douceur de ses moeurs, que par son talent et sa doeilité, en quoi il égale au'moins le perroquet vert, sans avoir ses cris désagreabbles. Le mot jaco, qu'il paraît se plaire à prononcer, est le nom qu'ordinairement on lui donne; tout son corps est d'un bealu gris de perle et d'ardoise, blanchissant au ventre; une queue d'un rouge de vermillon tormine et relève ee plu* magee lustré, moiré, el comme poudré d'une blaneheul' qui le rend toujour's frais; l'œil est plaeé dans une peatl blanche, nue et farineuse, qui couvre la joue; le bee $e^{\text {t }}$. noir, les pieds sont gris, l'iris de l'wil est couleur d'or'; la longueur totale de l'oiseau est d'un pied. 
La phupart de ces perroquets nous sont apportés ile la Guinće; ils viennent de l'intérieur des terres de eelle partic de l'Afrique; on les trouvo aussi à Congo et sul' la eôte d'Angole ; on leur apprend fort aisément ì parler, et ils semblent initer de préférenee la voix des enfants et reecvoir d'eux plus facilement leur édueation à cet égard.

Non-seulement cel oiseau a la facilité d'imiter la voix de l'lomme: il semble eneore en avoir le désir'; il le manifeste par son allention ì éeouter, par l'effor'l qu'il fait pour répéter. Souvent on est étonné de lui entendre répéter des mots ou des sons que l'on n'avail pas pris la peine de lui apprendre, et qu'on no le soupconnait pas mêne d'avoir ćcoutés; il semble se faire des tûches et cherche à retenir sil lecon chaque jour ; il en est oecupé jusque dans le sommeil. C'est surtout dans ses premières années qu'il montre cette faeilité, qu'il a plus de múmoire, el qu'on le trouve plus intelligent et plus doeile; quelquefois eelte faeulté de mémoire, eullivée de bonne lieure, devient útomnante, mais plus îgé le perroquet se montre rebelle et n'apprend que diffieilement.

Il est naturel de eroire que le perrnquet ne s'entend pas parler, mais qu'il croit cependant que quelqu'un lui parle: on l'a sonvent entendu se demander ì lui-mêne la patte; el il ne manque jamais de répondre ì sa propre question en tendant effeetivement la pattc. Les talents des perroquels do cette espuce ne se bornent pas it l'imitation de la parole; ils apprennent aussi ì eontrefaire certains gestes, certains mouvements, eertaines danses.

Les naturalistes ont tous remarciué la forme particu- 
lic̀re du bec, de la langue ot do la tête du jaco. Son bec arrondi en dehors, creusć et concave en dedans, offre cn. quelque manière la capacité d'une bouche dans laquelle la langue se meut libroment. Cette langue est rondo et épaisse, plus grrossc même dans le perroquet à proportion que dans l'homme.

Le bec est très-fort : le jaco casse aisément les noyaux des fruits rouges; il rongo le bois, et même il fausse avec son bec et écarte les barreaux de sa cage; il s'en sert plus quo de ses pattes pour se suspendre et s'aider' en montant.

Quelquefois on voit ce perroquet devonir, après une mue, jaspé de blanc et de couleur de rose, soit que ce changement ait pour cause quelque maladic, ou los proğrès de l'âğo. Le perroquet cendré est, comme plusicurs autros espècos de ce gonre, sujet à l'ćpilepsie et à la goutte; néanmoins il est très-viģourcux et vit longtomps. On assure on avoir vu un à Orléans âgé de plus de soixante ans, et cncore vif et gai.

Il est assez raro de voir des perroqucts produire dans nos contrées tempérécs, copendant on a quelques exemples do perroquets nés en France.

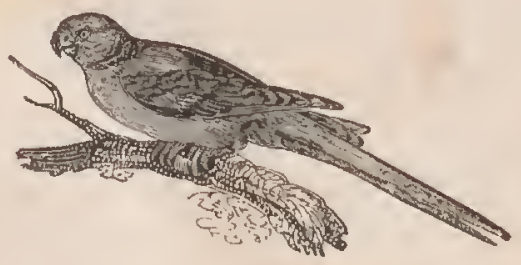




\section{LES $\triangle R A S$.}

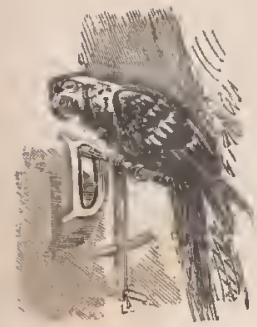

E tous les perroquets, l'ara est le plus grand et le plus magnifiquement paré ; le pourpre, l'or et l'azur' brillent sur son plumage ; il a l'œil assurć, la contenance ferme, la démarche grive et même l'air désagr'éablement déđaigneux, comme s'il sentait son prix et connaissait trop sa beauté. Néanmoins son naturel paisible le rend aisćment familier et môme susceptible de quelque attachement; on peut le rendro domestique sans en fairc un esclave, il n'abuse pas de la liberté qu'on lui donne; la douce liabitude le rappello auprès de ceux qui le nourrissent, et il revient assez eonstamment au domicile qu'on lui fait adopter.

Tous les aras sont naturels aux climats du NouveauMonde situés entre les deux tropiques, mais aueun ne se trouve ni en Afrique ni dans les Grandes-Indes. On les rencontre jusque dans les îles désertes, et partout ils font le plus bel ornement de ees sombres forêts qui couvrent la tcrre abandonnée à la seulo nature.

Nous eonnaissons quatre espèces d'aras, savoir: le rouge, le bleu, le vert ot le noir.

Les earactères qui distinguent les aras des autres porroquets du Nouvoau-Monde sont la grandeur et la grosSour du corps, la longueur do la queue, la peau nue et d'un blane salc, qui couvie les deux côtés de la tête. C'est mềne cette peau nuc, au milieu de laquelle sont situés 
les yeux, qui donne ì ces oiseaux une physionomie désagrréable. Leur voix l'est aussi, et n'est qu'un eri qui semble articuler, ara, d'un ton rauque, grasseyant, et si fort qu'il offense l'oreille.

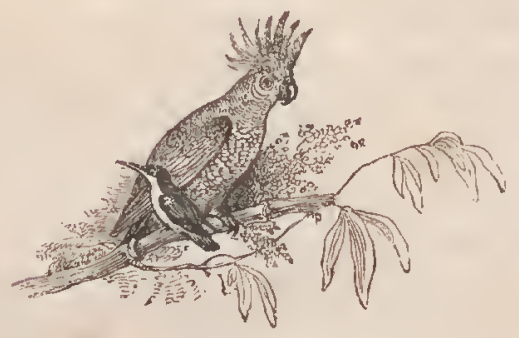




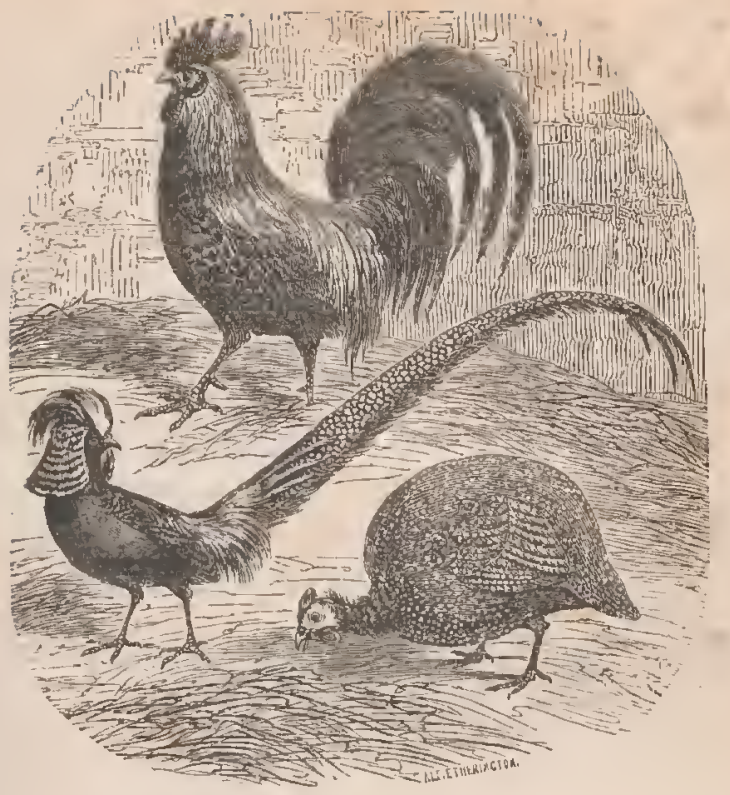

GALLINACE்S.

\section{LE PIGEON:}

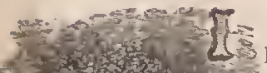

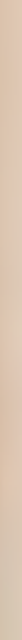
Y - vés, laits exprìs, bien enduits en C. Idolors et garnis en dedans de nomCS lıcuses cellules, pour attirer, retenir el. loger los pigeons : ils ne sont récllement ni domestiques comme les chiens ct les chcraux, ni prisonniers comme les poules; 
co sont plutôt des captifs volontaires, dos lootes fugitifs, qui no se tiennent dous Ic logement qu'on leur offro qu'autant qu'ils s'y plaiscnt, autant qu'ils y trouvent la nourriturc abondante, Io gîto agrćable et toutes les commodités, toulos los aisances nécessaires à la vie. Poür pou que quelque chose leur manque ou leur dóplaise, ils quittont et se dispersent pour aller aillours: il y en a môme qui prófèrent constamment les trous poudreux des murailles aux boulins los plus propres de nos colombier's; d'autres qui so gîtont dans des fentes ot des croux d'al'bres; d'autres qui scmblent fuir nos haljitations et que rien ne pout y attiror, tandis qu'on en voit, au contrair'c, qui n'osent les quitter et qu'il faut nourrir autour rle lour volic̀re qu'ils n'abandoment, jamais. Ces habitudes opposéos, cos différences de mœur's sembleraiont indiquel qu'on comprend sous le nom de pigeons un grand nombre d'espèces diverses dont chacuno aurait son naturel proprc et différent de celui des autres ; car on compte, indépendamment d'un grand nombro do variétés, cinq ospècos do pigeons, sans y comprendre ni les ramicrs, ni les tourterolles.

Cos cinq ospèces de pigeons sont : $1^{0}$ le pigeon domostique ; $2^{\circ}$ le pigeon romain, sous l'espc̀ce duquel on com prond soizo variétés; $3^{\circ}$ lo pigcon biset; $4^{\circ}$ lo pigcon do roche avec une varićté; 5o lc pigeon sauvage.

Tous ces pigcons ont de cortaines qualités qui lour sont communos: l'amour de la socićté, l'attachoment à lour's semblables, la douccur' de mocurs, ln propreté, le soin dé soi-même, les mouvements doux; nulle lrumeur', nu's dégoût, nulle quorolle; toutes les fonctions pénibles également répartios ; lc mâle aimant assez pour partagor locs 
soins maternols of même s'en charger, couvant régulièrcment à s.m tour et les coufs el les potits pour on Épar'nner la peirıc à sa compagno, pour mettro entre elle ot lui cette égalitć dont dópend le bonheur de toutc union durable: quols modèles pour l'homme, s'il pouvait ou savait les imiter!

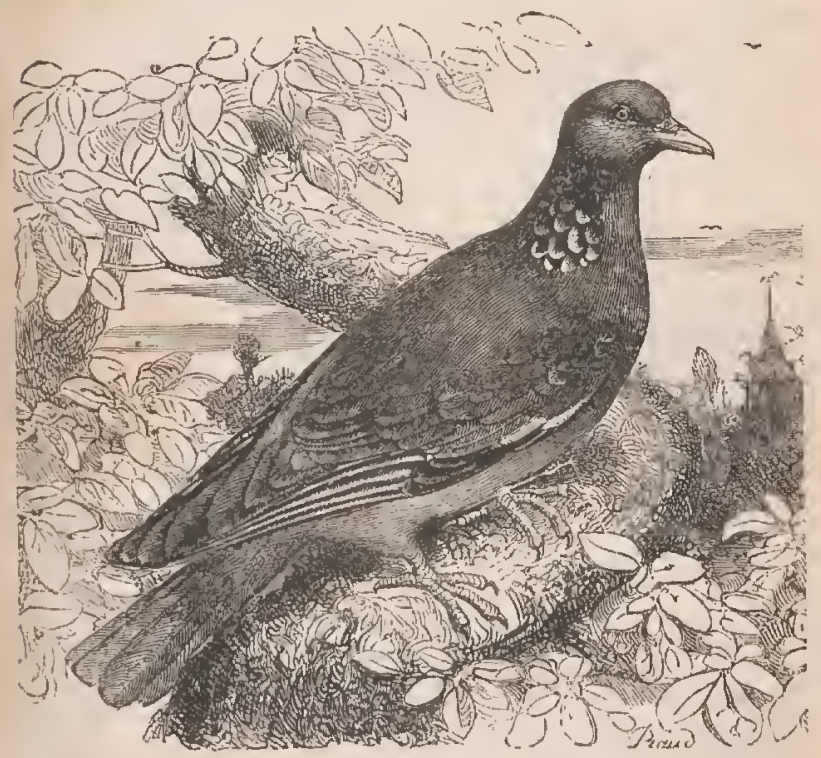

\section{LE RAMIER.}

Comme cet oiseau est beaucoup plus gros quc le bisct, cl quo tous deux ticnnent de très près au piģcon domestique, on pourrait croire que les petites races do nos pigeons de volic̀ro sont issues des biscts, ot quo les plus 
grandes viennent des ramiers; cependant le biset et lo ramier ne se mêlent pas dans los bois.

| Les ramiers arrivent en France au printemps, un pou plus tôt que les biscts, et partent en automne un peu plus trrd. Il reste des ramiers pendant l'hiver dans la plupart de nos provinces. Comme il y a constance et fidélité dans I'union du mâlc et de la femelle, cela suppose que lo sentiment d'affection et le soin des petits dure toute l'annćc.

Ils ont un roucoulernent plus fort que celui des pigeons, mais qui ne se fait entendre que dans les jour's sereins; car, dès qu'il pleut, ces oiscaux se taisent, ot on ne les entend que très-rarement en hiver. Ils se nourrissent de fruits sanvages, de glands, de faînes, de fraises, dontils sont très-avides, et aussi de fùves et de grains de toule espèce. Ils font un grand dógàt dans los blés lorscu'ils sont versés, et quand ces aliments lour manquent, ils mangent de l'herbe. Ils boivont à la manière des pigeons, c'est-à-dire de suitc et sans relever la têle qu'apròs avoir' avalé toute l'eau dont ils ont besoin. Comme leur ehair, et surtout celle des jeunes est excellente à manger, on recherche soignousoment leurs nids, et on on détruit ainsi une grande quantité. On en prend beaucoup avec des filets dans les lieux de leur passagc.

Il paraît que, quoique le ramicr préfère les climats chauds et tempérós, il habite quelquefois dans les pays's septentrionaux, et il paraît aussi qu'il a passé d'un continent à l'autre.

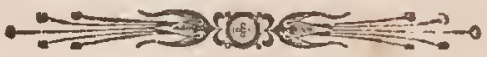




\section{LA TOURTERELLE.}

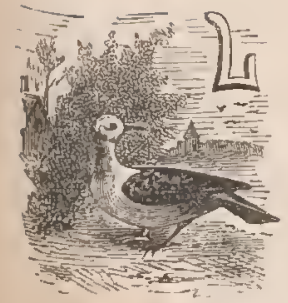

A tourterelle aime, peut-ĉtre plus qu'aucun autre oiseau, la fraîcheur en été et la chaleur en hiver : elle arrive dans notre climat fort tard au printemps, et le quitte dòs la fin du mois d'août. Toutes les tourterclles, sans en excepter une, se r'éunissent en troupe, arrivent, partent et voyagent ensemble; elles ne séjournent ici que quatre ou cinq mois : pendant ce court espace do temps elles nichent, pondent et élèvent leurs petits au point de pouvoir les emmener avec clles. Ge sont les bois les plus sombres et les plus frais qu'elles préfèrent pour s'y établir; elles placent leur nid, qui est presque tout plat, sur les plus hauts arbres, dans les lieux les plus éloignés de nos habitalions. En Suède, on Allemagne, en France, en Italie, en Grèce, et peut-être encore dans des pays plus froids et plus chauds, elles ne séjournent que pendant l'été, et quittent également avant l'automne; elles cherchent les elimats très-chauds pour y passer l'hiver. On les trouve presque partout dans l'ancien continent; on les retrouve dans le nouveau et jusque dans les îles de la mel du Sud: elles sont, comme les pigeons, sujetles à varier, et, quoique naturellcment plus sauvages, on peut néanmoins les élever de môme, et les faire multiplier dans des volières.

Nous connaissons dans l'espèce de la tourterelle deux races ou varićtés constantes: la première est la tourte- 
relle commune : la seeonde s'appolle tourtcrelle à collicr, parco qu'ollo porte sur lo cou une sorte de collier noir. Toutes deux se trouvent dans notre climat. La tourtcrolle à collier est un peu pliss grosse que la tourtorelle " eommune, et ne diffòre on rien pour lo naturel et los mœurs; on pout mêmo dire qu'on génèral les pig̣eons, les ramiers ot les tourterolles se ressemblent encore pluf par l'instinct et los habitudes naturelles quo par la figure: ils mangent et boivent de même sans relever la tôto qu'après avoir avalé toute l'eau qui leur est nócessaire; ils volont do même en troupos; dans tous, la voix ost plutôt un gros murmure ou un gómissement plaintif qu'u» chant articulé; tous ne produisont quo deux ocufs, quelquefois trois, et tous pouvont produire plusiours fois l'année dans des pays ehauds ou dans des volièros.

\section{LE COQ ET LA POULE.}

Le coq est un oiseau pesant, dont la démarehe est grave et lente, ot qui ayant les ailes fort courtes, ne vole que raremont, ct quelquefois avoc des eris qui expriment l'effort ; il ehante indifféremment la nuit et lo jour, mais non pas réģulièroment à certainos heures, et son chant est fort différent do oelui de la poule, quoiqu'il y ait aussi quelques poules qui ont lo mêmo cri du eoq, c'est-à-dire qui font lo même effort du gosior avec un moindro effct; car leur voix n'est pas si forto et leur cri n'ost pas sibion artieuló. Il gratte la torro pour cherehor sa nourriture; 
il avale autant de petits cailloux que de grains, et n'on digère que mieux; il boil en prenant de l'eau dans son hee el levant la tête à chaque fois pour l'avalor; il dort le plus souvent un pied en l'air et en cachant sa tête sous l'aile du môme côté.

Il a beaucoup de soin, et môme d'inquićtude et de souci pour ses poules; il ne les perd guère de vue, il les

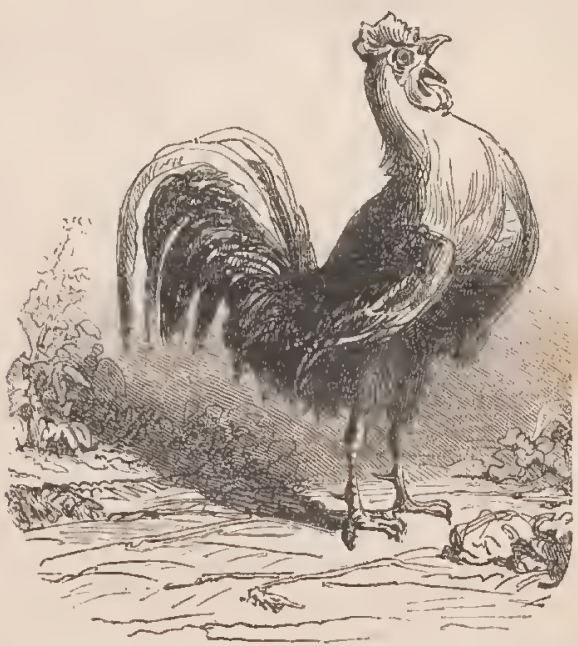

conduit, les défend, les menace, va ehorchor celles qui s'écartont, les ramòne, et ne se livre au plaisir de manger que lorsqu'il les voit toutes manger autour de lui : à juger par les différentes inflexions de sa voix et par los différentes expressions de sa mine, on no peut guère douter qu'il ne leur parle différents langages. Quand il les perd, il donne des signes de regrets. Il n'en maltraite 
aucune. S'il se présente un autre coq, il aecourt l'œil en feu, los plumes hórissées, se jette sur son rival, ot lui livre un combat opiniâtre jusqu'ì ce que l'un ou l'autro succombe, ou que le nouveau venu lui cède le clıamp do bataille; il a une poule favorite qu'il cherche de prófé'rence, et à laquelle il revient presque aussi souvent qu'il va vers les autres.

Les hommes, qui tirent parti de tout pour leur amuscment, ont bion su mettre en cuvre cette antipathie invineible que la nalme a établie entre un coq et un coq; ils ont cultivé avee tant d'art eette haine innée, quo les combats de deux oiseaux de basse-cour sont devenus des spectaeles dignes (l'intércsser la curiosité des peưples, même des peuples polis.

La poule, qui couve ses œufs avce tant de soin et d'assiduité, ne se relroidit pas lorsque ses poussins sont éclos; son attachement, fortifié par la vue de ces petits êtres qui lui doivont la naissance, s'accioìt encoro tous les jours par les nouveaux soins qu'exige leur faiblesse. Sans cosse occupéc d'cux, clle no clicrelıe de la nourriture que pour cux; si clle n'en trouve point, elle gratte la terre avec ses ongles pour lui arracher los aliments qu'elle recèle dans son sein, et elle s'en prive on leur faveur. Elle les rappelle lorsqu'ils s'égarent, los met sous ses ailes à l'abri des intempéries et les couve unc seconde fois; elle se livie à cos tendres soins avec tant d'ardeur et de souci que sa constitution en est sensiblement altérće, et qu'il est facile de distinguer de toute autre poule une mère qui mòne ses petits, soit à ses plumes hérissées et ì ses ailes traînantes, soit au soll enroué de sa voix et à ses différentes inflexions toutes 
expressives, et ayant toutes une forte empreinto de sollicitude et d'affcclion maternelle.

Mais si elle s'oublie elle-même pour conserver scs petits, elle s'expose à tout pour les ủéfendre : paraît-il un épervier dans l'air, cette mùre si faible, si timide, et qui, en toute autre circonstance, chercherait son salut dans la fuite, devient intrépide par tendresse; elle s'élance au devant de la serre redoutable, et, par ses cris redoublés, ses battements d'aile et son audace, elle impose souvent à l'oiseau carnassier, qui, rebuté d'une résistance imprévue, s'éloigne et va chereher une proie plus facile. Elle parait avoir toutes les qualités du bon coeur, mais, ce qui ne fait pas autant d'honneur au surplus de son instinct, c'est que, si par liasard on lui a donnć cle couver des oufs de camne ou de tout autre oiseau de rivière, son affection n'est pas moindre pour ces étrangrers qu'elle le serait pour ses propres poussins; elle ne voit pas qu'elle n'est que leur nourrice et non pas leur mère, et lorsqu'ils vont, guidés par la nature, s'ébattre ou se plonger dans la rivière roisine, c'est un spectacle sinģulier de voir la surprise, les inquiétudes, les transes de celte pauvre nourrice qui se croit encore mère, et qui, pressée du désir de les suivre au milieu des eaux, mais retenue par une répugnance invincible pour cet élément, s’agite incertaine sur le rivage, tromble el se clésole, voyant toute sa couvée dans un péril évident, sans oser lui donner de secour's. 


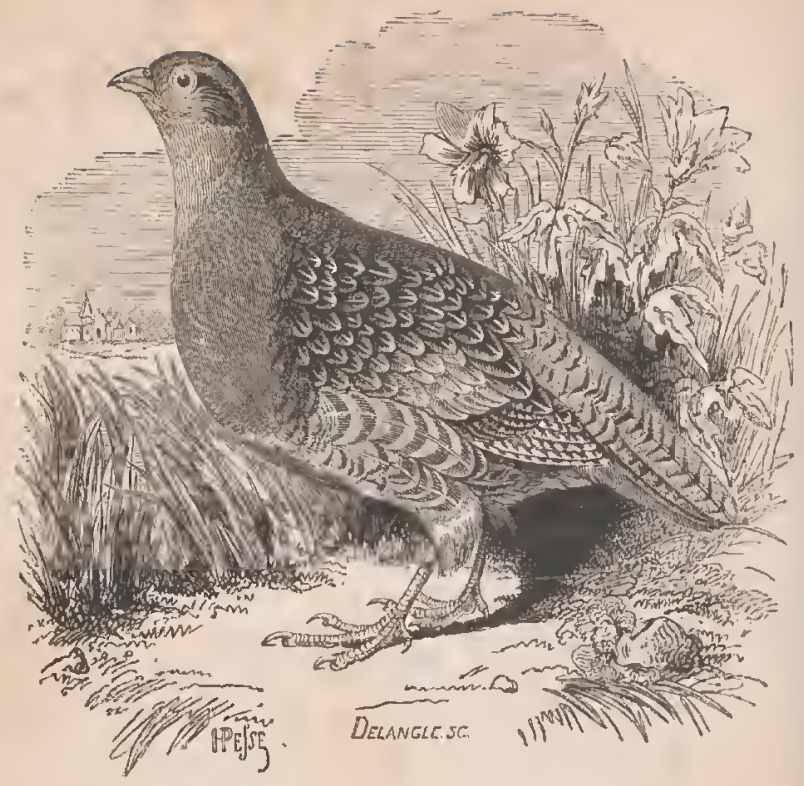

\section{LA PERDRIX GRISE.}

Quoiqu'on ait dit que les perdrix grises sont communes partout, il est certain néanmoins qu'il n'y en a point dans l'île de Gròte; elles ne sont pas même égalemont. communes dans toutes les partios de l'Europe; et il paraît, en général, qqu'elles fuient la grande chaleur comme le grand froid, car on n'en voit point on Afrique, ni $\mathrm{cn}$ Laponie; et les provinces les plus tempérćes de la Franco et de l'Allomagne sont celles où olles abondent le plus. La perdrix grise est assez rópandue en Suc̀de, où elle passe l'hiver sous la neige dans des espèces de clapier's qui ont deux ouvertures. 
La perdrix grise diffère beaucoup de la rouģe; quoique l'une et l'autre se tiennent quelquefois dans les mêmes endroits, elles ne se mêlent point ensemble.

Ces oiseaux se plaisent dans les pays à blé et surtout dans ceux où les terres sont bien cultivées, sans doute paree qu'ils y trouvent une nourriture plus abondante soit en grains, soit en insectes. Les perdrix grises aiment la pleine campagne et ne se réfugient dans les taillis et les vignes que lorsqu'elles sont poursuivies par le ehasseur ou par l'oiseau de proie; mais jamais elles ne s'enfoncent dans les forêts, et l'on dit même assez communément qu'elles ne passent jamais la nuit dans les buissons ni dans les vignes: cependant on a trouvé un nid de perdrix dans un buisson, au pied d'une vigne.

Les perdrix gyrises sont des oiseaux sédentaires, qui non-seulement restent dans lo même jays, mais ‘ui s'écartent le moins qu'ils peuvent du eanton où ils ont passé leur jeunesse, et qui y revionnent toujour's. Elles craifrnent beaueoup l'oiseau de proie; lorsqu'elles l'ont aperçu, elles se mettent en tas les unes contre les autres et tiennent ferme, quoique l'oiseau, qui les voit aussı lort bien, les approche de très-près en rasant la terre, lour tâcher d'en faire partir quelqu'une et de la prendre atu vol. Au milieu de tant d'ennemis et de dangers, on sent bien qu'il y on a peu qui vivent âgo de perdrix : quelques-uns fixent la duréc do leur vie à sept années, d'autres à douze ou quinze. 


\section{LA PERDRIX ROUGE D'EUROPE.}

Cette perdrix tient le milieu pour la grosseur entre la bartavelle et la perdrix grise : elle n'est pas aussi répandue que ectte dernière, et tout climat ne lui est pas bon. On la trouve dans la plupart des pays montagneux et tompérés de l'Europe, de l'Asie et de l'Afrique, mais olle est rare dans les Pays-Bas, dans plusieurs parties de l'Allernagne et de la Bohême; on n'en voit point du tout en Angleterre.

Les perdrix rouges se tiennent sur les montagnes quí produisent beaueoup de bruyères et de broussailles, mais dans les parties moins élevées, ct par conséquent moins froides et moins sauvages. Pendant l'hiver, elles se re." cèlent sous des abris de rochers bien exposés et se ró pandent peu; le reste de l'annće elles se tiennent dans les broussailles, elles résistent souvent mieux que les grises aux riguour's de l'hiver, et, bien qu'elles soient plus aisćes ì prendre dans les diffẻrents piẻges quo los grises, il s'en trouve toujour's à peu près le même nombro au printemps dans les endroits qui leur conviennent. Elles vivent de grains, d'herbes, de limaces, de chenilles, 'd'oufs de fourmis et d'autres insectes; mais leur' chair' se sent quelquefois des alinents dont elles vivent.

Elles volent pesamment et avec effort, comme les grises ; lorsqu'elles sont suivies de prè̀s et poussées vivoment, clles se réfugrient dans les bois, se perclıent mûme sur les arbres, et se terrent quclquelois, ee que ne font point les perdrix grises: 


\section{LES OISEAUX.}

Lies perdrix rouges diffèrent encore des grises par le naturel et les mocurs; elles sont moins sociables.

Par une suite de leur naturcl sauvage, les perdrix rouges, que l'on élère à peu près comme les faisans, sont encore plus difficiles à élever, exigent plus de soins et de précautions pour les accoutuner à la captivité, ou, pour mieux dire, elles ne s'y accoutument janais, et meuront bientôt d'ennui ou d'une maladie qui en est la suite, si on ne les lâche dans le temps où elles commencont à avoir la tête garnie de plumes.

\section{LA CAILLT.}

La femelle diffère du mâle en ce qu'elle est un peu plus grosse ; d'autres la font égale, ot d'autres plus petite.

Le mâle et la femolle ont chacun deux cris, l'un plus éclalant ct plus fort, l'autre plus faible: le mâle fait ouan, ouan, ouan, ouan; il ne donne sa voix sonore que lorsqu'il est éloigné des femclles, et il ne la fait jamais entendre en cage, pour peu qu'il ait une compagne avec lui; la femelle a un cri que tout le monde connaît.

Ia caille ne produit que lorsqu'clle est en liberté : on a beau fournir à celles qui sont prisonnic̀res dans des Cages tous les matériaux qu'elles emploient dans la construetion de leurs nids, elles ne nichent jamais et ne prennont aucun soin des oufs qui leur échappent, et qu'elles semblent pondre malgré clles.

Ijes cailles so nourrissent de blé, de millet 
vis, d'herbe verte, d'insectes, de toutes sortes de graines, même de eelle d'ellébor'e.

Il semble que le boire ne leur est pas absolument nćcessaire, quoiqu'elles boivent assez fréquemment lol'squ'elles en ont la eommodité.

On a eru remarquer qu'elles troublaient l'eau avant de boire. Elles se tiennent dans les ehamps, les prés, les vignes, mais tròs-rarement dans les bois, et elles ne se perehent jamais sur les arbres. Quoi qu'il en soit, elles prennent beaueoup plus de graisse que les perdrix par l'habitude où elles sont de passer la plus grande partio

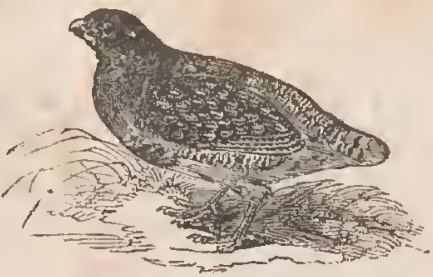

du jour sans mouvernent; elles se eaehent alor's dans I'herbe la plus serrée; et on les voit quelquefois demeurer quatre heures de suite dans la même place, couchées sur lo eôté et les jambes étendues.

On dit qu'elles ne vivent guère au delà de quatre ou einq ans; et l'on regarde la brièveté de leur vie eomme une suite de leur disposition à s'engraisser; d'autres l'atribuent à leur earaetère triste et querelleur; et tel est, en effet, leur earaetère; aussi n'a-t-on pas manqué de les faire battre en public pour amuser la multitude. 
On juge bien qu'avee l'habitude de ehanger de clinat et de s'aider du vent pour faire ses grandes traversées, la caille doit être un oiseau fort répandu, et, en effet, on lo trouve au eap de Bonne-Espéranee et dans toute l'Afrique liabitable, en Espagne, en Italie, en France, en Suisse, dans les Pays-Bas et en Allemagne, en Angloterre, ete.; il est même très-probable qu'elle a pu passer' en Amórique. La eaille se trouve done partout, et partout on la regarde comme un fort bon gibier dont la chair est de bon goût, et aussi saine que peut l'čtre une chair aussi grrasso.

On se sert aussi do la femelle, ou d'un appeau qui imile son eri, pour attirer les mâles dans le piége ; on dit même qu'il no faut que lour présenter un miroir avec un filet au-devant, où ils se prennent, en accourant à lour image, qu'ils prennent pour un autre oiseau de leur' espèce. Les variétés de l'espèce sont le chrokiel ou frande eaille de Pologne; la caille blanche; la eaille des îlos Malouines; la fraise ou eaille de la Cline; le turnix ou eaille de Madagasear, et le réveille-matin ou la eaille de Java.

\section{LE PAON.}

Si l'empire appartenait à lą bcauté et non à la force, le paon serait, sans contredit, le roi des oiseaux; il n'en est point sur qui la nature ait versé ses trésors avec plus de profusion: la taille grande, le port imposant, la dèmarelıe fic̀re, la figure noble, los proportions du corps 
élégantes et sveltes, tout ce qui annonce un ôtrc de distinction lui a été donné. Unc aigrette mobile et légère, peinte des plus riches couleurs, orne sa tête ct l'ćlève sans la charger; son incomparahle plumage semble rćunir tout ce qui flatte nos yeux dans le coloris tcndre et frais des plus bclles fleurs, tout cc qui les éblouit dans les reflcls pétillanls des picrrcries, tout ce qui les étonne dans l'ćclat majestueux de l'arc-en-ciel. La nature a réuni sur le plumage du paon toutes los

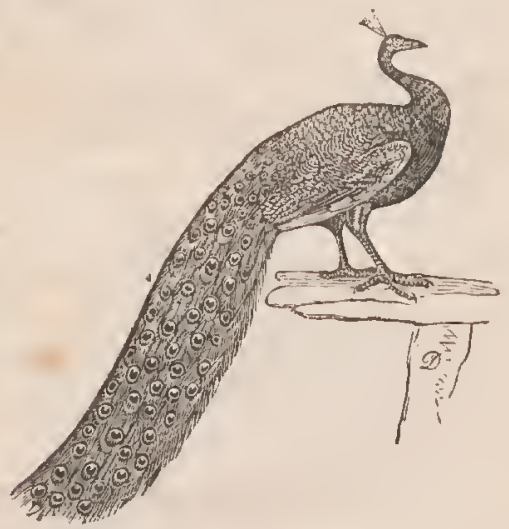

couleurs du ciel et de la terre pour en faire le chefd'ouvre de sa magnificence.

Mais ces plumes brillantes, qui surpassent cn éclat les plus belles fleurs, sc flétrissent aussi comme olles, et tombent chaque année; le paon, comme s'il sentait la honte de sa perte, craint de sc faire voir dans cet étal humiliant, et cherche les retraites les plus sombres poul' s'y cacher à tous les yeux, jusqu'ì ce qu'un nouvcau printemps, lui rendant sa parure accoutumćc, le ramènc sur 
la scène pour jouir des lommages dus à sa beauté : ear on prétend qu'il en jouit on effet, qu'il est sensible à l'arlmiration, que le vrai moyon de l'cngager à étaler ses belles plumes, c'est de lui donner des regards d'attention et des louanges; ct qu'au contraire, lorsqu'on paraît le regarder froidement et sans beaucoup d'intérêt, il replic tous ses trésors et les cache à qui ne sait point les admirer.

Quoique le paon soit depuis longlemps comme naturalisé en Europe, eependant, il n'en est pas originaire : ce sont les Indes oriontales, e'est le climat qui produit le saplin, le rubis, la topaze, qui doit être regardé comme son pays natal.

La paonne ne fait jamais éclore tous ses œufs à la fois; mais dès qu'clle voit quelques poussins éclos, elle quitto tout pour les conduire.

On a observé quo les premicrs jours la mòre ne revenait jamais coueher avee sa couvíe dans le nid ordinaire, ni même deux fois dans un même endroit.

Les paonneaux, jusqu'ì ee qu'ils soient un peu for'ts, purtent mal leurs ailes, les ont trainantes, et ne savent pas encore s'en servir : dans ces commencoments, la mère les prend tous les soirs sur son dos et les porte l'un après l'autre sur' la brancho où ils doivent passer la nuit; le lendemain matin elle saute devant eux du haut de l'arbre en bas, et les aeeoutume à en faire autant pour' la suivre, et à faire usage de leurs ailes.

A mesure que les jeunes pronneaux se fortifient, ils commencent à se battre, surtout dans les pays chauds. Les paons aiment heaucoup la propreté.

Quoiqu'ils ne puissent pas voler beaucoup, ils aiment à 
grimper, ils passent ordinairement la nuit sur les combles des maisons, où ils causent, beaucoup de dommage, et sur les arbres les plus élevés : c'est de là qu'ils cont souvent entendre leur voix, qu'on s'accorde à trouver' désagréable, peut-ôtre parce qu'elle trouble le sommeil, et d'après laquclle on prétend que s'est formé leur noln dans presque toutes les langues.

On assure que la femelle n'a qu'un seul cri, qu'elle ne fait guère entendre qu'au printcmps, mais que le mâle ent a trois.

Les uns ont dit que leurs cris, souvent répétés, sont un présage de"pluie; d'autres, qu'ils l'annoncent aussi lorsqu'ils grimpent plus haut que de eoutume ; d'autres, quc ces mêmes cris pronostiquaient la mort à quelque voisin; d'autres, enfin, que ces oiseaux portaient toujours sous l'aile un moreeau de racine de lin comme un amulette naturel pour se préserver des fascinations, tant il est vrai que toute chose dont on a beaueoup parlé a fait dire bcaucoup d'ineptics!

Outre ces différents eris, lo mâle et la femelle pro* duisent encore un certain bruit sourd, un eraquenent étouffé, une voix intérieure et renfermée qu’ils répìtclt souvent et quand ils sont inquiets, et quand ils paraissent tranquilles ou même eontents.

La durée de la vie du paon est de vingt-eing ans, el non de eent ans, ainsi qu'on a voulu le dire.

Comme les paons vivent aux Indes dans l'ćtat de sat" vages, e'est aussi dans ee pays qu'on a inventé l'art do lcur donner la chasse; on ne peut guère les approchel' de jour, quoiqu'ils se répandent dans les claamps pal' troupes assez nombreuses, paree que, dès qu'ils dícou'- 



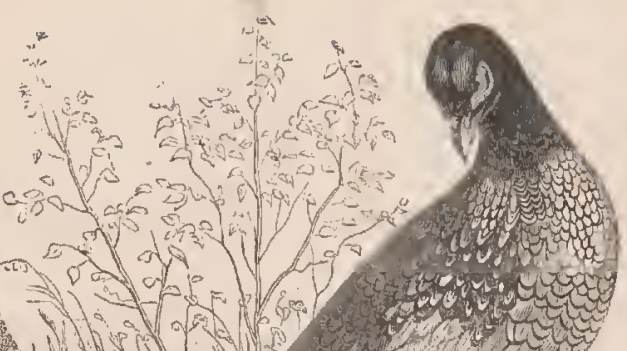

WW $(2)=2$

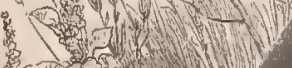

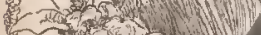

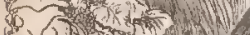

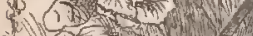

a.

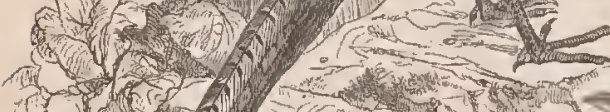

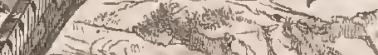

j.

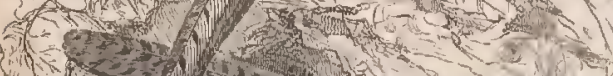

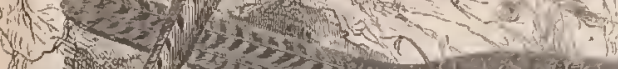

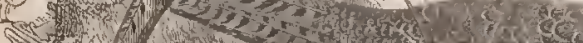

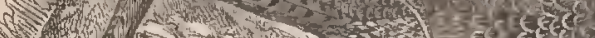

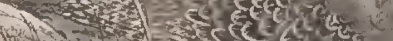

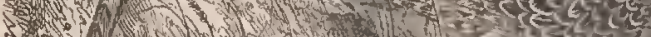

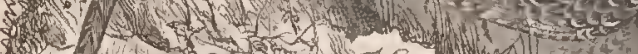

3.

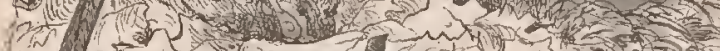

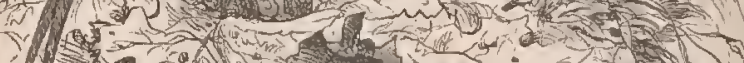

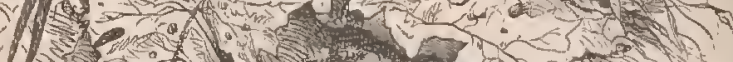

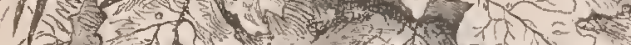

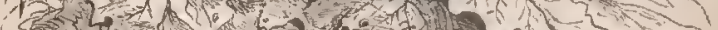

1 दुरा

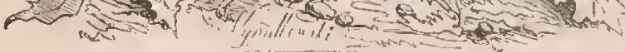


vrent le classeur, ils fuient devant lui plus vite que la perdrix, et s'enfoncent dans les broussailles où il n'est guèro possible de les suivre; ce n'est done que la nuit qu'on parvient à les prendre. On compte parmi les variétés de l'espèce le pron blanc, ot le paon panachić.

\section{LE FAISAN.}

Le faisan se plait dans les licux marécageux; on on prend quelquefois dans les marais; ils s'óloignent le Dlus qu'il est possible de toute habitation lumaine, car ce sont des oisenux trc̀s-saurages, et qu'il est extrêmement difficile d'apprivoiscr. On prétend néanmoins qu'on les accoutume à revenir au coup de sifflet, c'est-à-dire 'qu'ils s'accontument ì venir prondre la nourrilure que ce coup de sifflet leur annonce toujours; mais dès que leur besoin est satisfait, ils reviennent à leur naturel; ils ne connaissent aucun bien qui puisse entrer en comparaison avec la liberté, ils cherchent continuellement à la rocouvrer, et ils n'en manquent jamais l'occasion.

Ils se plaisent encore dans les bois en plaine; pendant la nuit ils se perchent au haut des arbres, où ils dorment la tête sous l'aile : leur cri, c'est-à-dire le cri du mâle, car la femelle n'en a presque point, ost entre celui du paon et celui de la pintade, mais plus pròs de celui-ci, ct par conséquent très-peu agrćable.

Leur naturel est si farouche, que non-seulement ils évitent l'homme, mais qu'ils s'évitent les uns les autres. La faisane fuit son nid à clle seulc: cllo choisit poü 
ecla le recoin lo plus ohscur de son habitation; elle $y$ emploie la paille, les feuillos et autres choses semblables, ct, quoiqu'tlle le fasse fort grossic̀rement en apparence. clle lo préfc̀re, ainsi fait, à tout autre micux construit, mais qui ne le scrait point par clle-même. Elle ne fait qu'une ponte chaque année, du moins dans nos climats; celte ponte est de douze œufs. Elle pond ordinairement de deux ou trois jours l'un : ses œufs sont beaucoup moins gros que ceux de poule, et la eoquille en est plus minec que coux même de pigeon.

Ces animanx vivent de toutes sortes de grains et d'her' bages, de lèves, de earottes, de pommo do terre, d'oignons, de laitues el de panais, surtout de ces deux dernières plantes, dont ils sont très-friands. On dit qu'ils aiment aussi bearcoup le gland, les baies d'aubépine et la graine d'absinthe; mais le froment est la moilleuro nourriture qu'on puisse leur donner, en y joignant des coufs de fourmis.

On dit quo le faisan est un oiseau stupide, qui se croit bien en sûrcté lorsque sa tête est cachée, comme on l'a dit de tant d'autres, ot qui se laisse prendre à tous les piégos.

Un faisandeau bien gras est un morccau exquis, of cn môme temps une nourriture très-saine : aussi ce mets a-t-il ćtć de tout tomps réservé pour la tablo des riches.

Cet oisenu vit eomme les poules communes, enviroll six ì sept ans; et c'est sans aucun fondement qu'on a prétendu connaître son âge par lo nombre des bandes transversales de sa queue.

Il y a encore le faisan blanc, lo faisan varié et lo cocruar. 


\section{LE FAISAN DORE}

\section{OU LE TRIGOLOR HUPPÉ DE LA CHINE.}

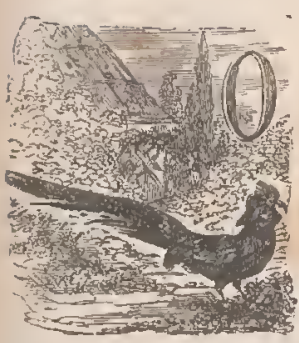

N peut regarder ce faisan comme une varićlé du faisan ordinaire, qui s'cst embelli sous un ciel plus beau : ce sont deux branches d'unc môme famille qui se sont séparécs depuis longtemps, qui même ont formó deux races distinctes, et qui cependant se reconnaissent encore ; car elles s'allient, se mêlent ot produisent ensemble.

Le tricolor huppé de la Chine est plus petit que notre faisan : la beauté frappante de cet oiseau lui a valu d'être cultivé et multiplić dans nos faisanderies, où il est assez commun aujourd'hui; son nom de tricolor huppé indique le rouge, le jaune doré et le bleu qui dominent dans son Dlumage, et les longues et belles plumes qu'il a sur la lête, ot qu'il relòve quand il veut on manière de huppe; il a l'iris, le bec, les pieds et les ongles jaunes, la queuo plus longue à proportion que notre faisan, plus émaillée, et, en général, le plumage plus brillant; au-dessus des plumes de la queue sortent d'autres plumes longues et étroites, de coulcur ćcarlate, dont la tige ost jaune; il n'a point les ycux cntourés d'une peau rouge commc lo faisan d'Europe.

La femelle du faisan doré est un pou plus petite que le mâle; elle a la quouc moins longue; les couleurs de son 
plumago sont fort ordinaires, et eneore moins agréahles que celles de notre faisane; mais quelquefois elle devient aveo le temps aussi belle que le mâle.

Les wufs de la f'úsane dorée ressemblent heaueoup ì ceux de la pintade, et sont plus petits ì proporlion quo ceux de la poule domestique, et plus rougeîlres que ceus de nos faisans.

\section{LE DINDON.}

Il y a des dindons hlanes, d'autres variés de noir et de blane, d'autres de blane el d'un jaune roussître, et d'autres d'un gris uniforme, qui sont les plus rares do tous ; mais le plus grand nombre a le plumage tirant sıll' le noir. Bien des gens croient que les dindons blancs sont les plus robustes, et c'est par cette raison quo dans quelques provinces on les ćlc̀ve de préfúrence.

La poulo d'Inde differe du coq en ee cqu'clle n'a pas d'éperons aux pieds; elle en diffèro encore en ce qu'elle est plus petite, qu'elle a moins de earactère dans la phý sionomie, moins de ressort à l'inléricur', moins d'aotioll au dehors; son eri n'est qu'un aecent plainlif, elle n'a de mouvement que pour eliercher sa nourriture ou pour' fuir le danger.

Ce sont les poules de l'année prćeédente qui, d'ordinaire, sont les meilleures eouveuses; elles se dévouent à eetle oeeupation avee tant d'ardeur et d'assiduité, qu'elles mourraient d'inanition sur leur's oufs, si l'orl n'avait le soin de les lever une fois tous les jour's pour' 
leur donner à boire el à manger. Cette passion de couver est si forte et si durable, qu'elles font quelquefois deux couvées de suite ot sans auoune interuplion; inais, dans ce cas, il faut les soutenir par une meilleme nourriture. Le mâle a un instinet bien oontraire; car, s'il aperçoit sa femelle couvant, il casse ses ocufs, et e'est peut-ĉtre la raison pourquoi la femelle se eache alors avec tant de soin.

Le temps est venu où ces ceufs doivent éclore, les dindonneaux percent avec leur bee la eorpille de l'œul' qui les renferme; mais cette coquille est quelquefois si dure, ou les dindonnenux si faibles, qu'ils périraient s1 on ne les aidait à la briser.

Dans les premiers temps il faut tenir les jeunes dindons dans un lieu ehaud et sec où l'on aura ótendu une litic̀re de fumior long, bien Jattue; ct lol'sque dans la suite on voudra les faire sortir on plein air, ce ne sera que par degrés el cn ehoisissant les plus beaux jours.

I_instinct des jeunes dindonneaux est d'aimer mieux à prendre leur nourriture dans la main que de toute aus tre manière : on juge qu'ils ont besoin d'en prendre lorsqu'on les entend piauler, el cela arrive fréquemment; il faut leur donner à manger quatro ou cinq fois par jour. Quelquefois ils paraissent engourdis et sans mouvement, lorsqu'ils onl été surpris par une pluie froide, et ils thourraient certrinement, si on n'avait le soin de les onvelopper de linges chands, et de leur souffler à plusieurs leprisos un air chaud par le bec.

La mère les mène avec la même sollicitude que la poule mène ses poussins; elle los réchaufre sous ses ailles avec la mîme affection, elle les défend nvee le même 
courage, il semble que sa tondresso pour sos petits rendo sa vue plus percante; ollo dócouvre l'oiseau de proic d'une distance prodigieuse, et lorsqu'il est cneore invisible à lous les autres youx: dès qu'olle l'a apercu, ollo

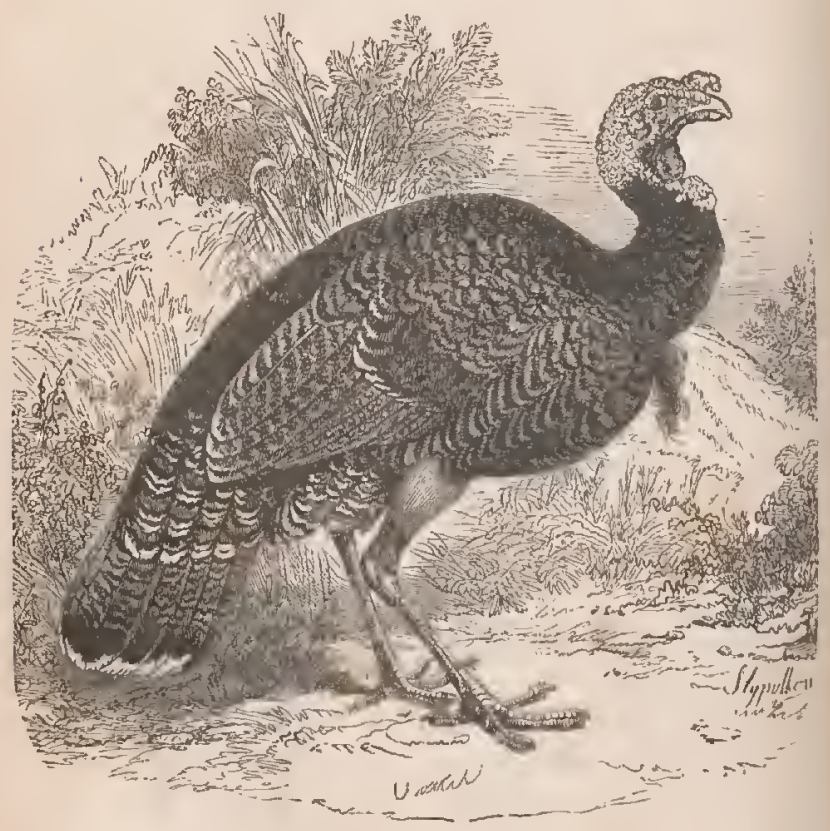

jette un eri d'effroi qui répand la consternation dans toute la couvée; chaque dindonneau se réfugie dans los buissons ou se tapit dans l'herbe, et la mère les y letient en répétani le mêmu eri d'effroi autant de temps que l'onnemi est à portée; mais: lo voil-cllo prendre soll 
vol d'un autre eòté, elle les on avertit aussitôt par un autre eri bien différent du promier, et qui est pour tous le signal de sortir du licu où ils se sont eachés, et de se rassembler autour d'elle.

Lorsqu'ils sont devenus forts ils quittent leur mèrc ou ils en sont abandonnés. Plus les dindonneaux étaient faibles el délieats dans le premier âge, plus ils deviennent avec le temps robustes et eapables de soutenil. toutes les injures du temps: ils aiment à se percher on plein air, et passent ainsi les nuits les plus froides de l'hiver, tantôt se soutenant sur un seul pied, et retirant l'autre dans les plumes de leur ventre eomme pour le réchauffer, tantôt au eontraire, s'aceroupissant sur leur bâton et s'y tenant en équilibre: ils se mettent la tête sous l'aile pour dormir, et pendant leur sommeil ils ont le mouvernent de la respiration sensible et très-marqué. Tout eoneourt à prouver que l'Amérique est le payss hatal des dindons; et eomme ees sortes d'oiseaux sont pesants, qu'ils n'ont pas le vol élevé et qu'ils ne nagent point, ils n'ont pu en aucune manière traverser l'espace qui sépare les deux continents pour aborder en Afrique, On Europe ou en Asie.

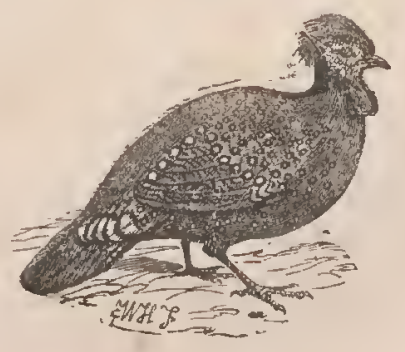




\section{LA PINTADE.}

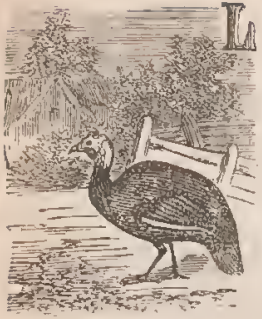

A pintade est un oiseau vif, inquieb et turbulent, qui n'aime point à se tcnir en plaee, et qui sait se rendre maitre de la basse-eour; il se fait craindı'e des dindons même, et quoique beaueoup plus petit, il leur inpose par sa pétulanee.

La pintade est au nombre des oiseaux pulvérateur's qui cherchent dans la poussière où ils sc vautrent uth remide contre l'ineommodité des inseetes; elle gratte aussi la terre comme nos poules communes, et va pal' troupes nombreuses : on en voit à l'île de May des vor lées de deux ou trois eents. Comme elles ont les aile fort eourtes, elles volent pesamment ; mais elles courent très-vite : elles se perehent la nuit pour dormir, el quelquefois la journée, sur les mur's de elôture, sur les haiés' et même sur les toits des maisons et sur les arbres.

La poule pintade pond et eouve à peu près comme lit poule commune; mais il parait que sa fécondité n'e $e^{\text {st }}$ pas la même en différents climats, ou du moins qu'elle est beaucoup plus grande dans l'état de domestieité, oil elle regorge de nourriture, que dans l'état sauvage.

Ses ceufs sont plus petits à proportion que ceux de lit poule ordinaire, et ils ont aussi la coquille beaucoul plus dure.

Les pintadeaux de basses-eours sont d'un forl boll goùt, et nullement inférieurs aux perdreaux; mais les 
Sauvages ou marrons de Saint-Domingue sont un mets "xquis au-dessus du faisan.

Les œufs de pintade sont aussi fort bons à manger.

\section{L'OUTARDE.}

L'outarde est un oiseau granivore : elle vit d'herbes, de grains et de toutes sortes de semenees; de feuilles de choux, de dent-de-lion, de navets, de myosotis ou oreille de souris, de vesee, d'aehe, de foin, et de ces gros vers de terre que pendant l'été on voit fourmiller. Sur les dunes tous les matins avant le lever du soleil. Dans le fort de l'liver', et par les temps de neige, olle mange l'éeoree des arbres; en tout temps elle avale de petites pierres, mème des pièees de inétal, comme l'iutruche, et quelquefois en plus grande quantité.

On a trouvé dans l'estomae de ees oiseaux, au temps de la moisson, trois ou cuatre grains d'orge, avee une frande quantité de graine de eiguë, ee qui indique un appétit de próférenee pour celte graine, el par conséquent le meilleur' appât pour attirer l'outarde dans les piéges.

Cet oiseau ne eonstruit point de nid, nais il ereuse seulement un trou en grattant la terre, el y déposes ses deux ceufs qu'il eouve pendant trente jour's. Lor'sque la mère inquiète se défle des ehasseur's, ot qu'elle eraint Gli'on n'en veuille à ses ocufs, elle les jrend sous ses ailes et les transporte en lieu sûr. Elle s'établit ordinai- 
rement dans les blés qui approchent de la maturité pour y faire sa ponte, suivant en cela l'instinct commun à tous les animaux de mettre leurs petits à portće de trouver' en naissant une nourriture convenable.

L'outarde se trouve dans la Lybie, aux environs d'Alexandrie, dans la Syrie, dans la Grèce, en Espagne, en France, dans les contrćes ouvertes de l'est et du sud de la Grande-Bretagnc, dans les Pays-Bas, en Allemagne, en 'Ukraine et en Pologne, où elle passe quelquefois l'hiver au milieu des neiges.

L'outarde ne se trouve que rarement dans les contríes montagneuses ou bion peuplées comme la Suisse, le Tyrol, l'ltalie.

Elle ne vole guère que lorsqu'elle est poursuivie, et elle ne vole jamais bien loin; d'ailleurs elle évite surtout les eaux, d'où il suit qu'elle n'a pas dù se hasarder d̀ franchir de grandes étendues de mel ${ }^{*}$

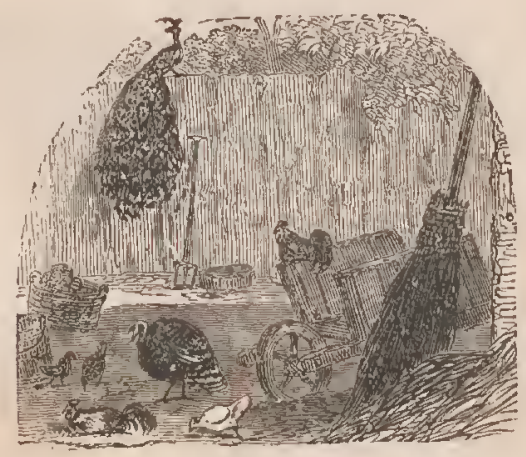




\section{STRUTHIONS.}

\section{L'A UTRUCHE.}

L'autruche passe pour être le plus gr'and des oiseaux; mais, par sa grandeur même, elle est privée de la prineijale prérogative des oiseaux, c'est-à-clire de la puissanee de voler. Elle est très-féconde ct produit beaucoup; ses oufs sont très-dur's, très-pesants et très-gros. Aussitôt que les jeunes autruches sont éeloses, elles sont en état de mareher, ct même de courir el de elrercher leur nourriture.

Les autruclıes vivent principalement de matières vćgétales; mais elles avalent tout ce qu'elles trouvent, du fer, du euivre, des pierres, du vorre et du bois.

L'autruehe est un oiseau parliculier à l'Afrique, aux îles voisines de ce eontinent et à la partie de l'Asie qui confine à l'Afrique; on n'en trouve pas en Amćrique. Elle fuit l'hornme, mais l'homme, qui sait le profit qu'il en peut tirer, va la ehereher dans les retraites les plus sauvages.

Quoique les autruehes courent plus vite que lo cheval, e'est cependant avee le eheval qu'on lcs eourt et qu'on les prend. On dit que, lorsqu'elles se sentent hol's d'état d'échapper' aux chasseurs, elles cachent leur tête, comme pour mettre en sûreté la partic qui est à la fois la plus importante el la plus faible. 
On s'est encore servi de chiens et de filets pour la cliasse à l'autruche, mais il parait qu'on la fait plus communément à cheval; et cela seul suffit pour cxpliquer l'antipathie qu'on a. cru remarquer entre le cheval et l'autruche.

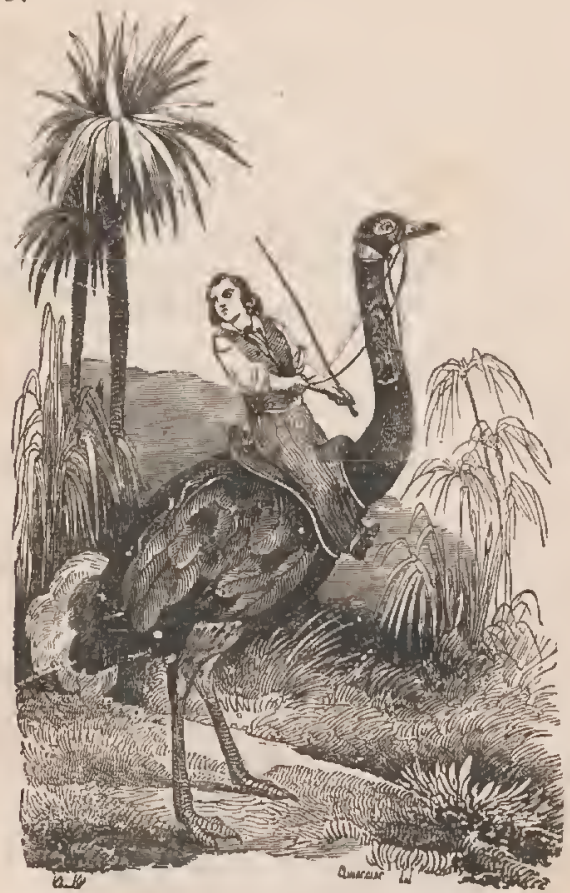

On a dit que l'autruche était privée du sens de l'ouie, mais il est probable ou qu'elle n'nst sourde qu'en certaines circonstances, ou qu'on a imputé quelquefois ì surdité ce qui n'était que l'effet de la stupidité.

Elle fait rarement entendre sa voix; car très-peu de 
personnes en ont parlé : les écrivains sacrós comparent son cri ̀̀ un gémissement ; un auteur dit que ce cri ressemble à la voix d'un enfant enroué, et qui est plus triste encore.

Les autruches, quoique habitantes du désert, ne sont pas aussi sauvages qu'on l'imaginerait : tous les voyageurs s'accordent à dire qu'elles s'apprivoisent facilement, surtout lorsqu'elles sont jeunes. Les habitants de Dara, ceux de Libye, etc., en nourrissent des troupeaux, dont ils tirent sans doute ces plumes de première qualilé, qui ne se prennent que sur les autruches vivantes. Elles s'apprivoisent même sans qu'on y mette de soin, et par la seule habitude de voir des hommes et d'en recevoir la nourriture et de bons traitements. Un voyageur, en ayant acheté deux à Serinpate, sur la côte d'Afrique, les trouva tout apprivoisées lorsqu'il arriva au fort Saint-Louis.

On fait plus que les apprivoiser ; on en a domplé quelques-unes au point de les monter comme on monte un cheval.

\section{LE CASOAR.}

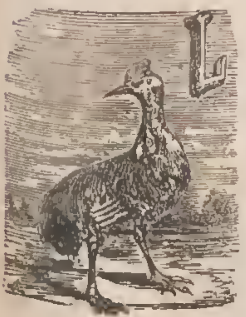

E casoar, sans être ni aussi grand $\mathrm{nl}$ même aussi gros que l'autruche, paraît plus massif aux yeux, par'ce qu'avec un corps d'un volume presque égai, il a le cou et les pieds moins longs et beaucoup plus gros à proportion.

Il est remarquable que le casoar, 
l'autruche et le touyou, les trois plus gros oiseaux que l'on eonnaisse, sont tous trois attaelıés au elimat de la zone torride, qu'ils semblent s'être partag'ée entre eus; et où ils se maintiennent ehacun dans leur terrain, sans se mêler ; tous trois véritablement terıestres, incapables de voler, mais courant d'une très-grande vitesse; tous trois avalant à peu près tout ee qu'on leur jette, grains, herbes, ehairs, os, pierres, eailloux, fer, glaçons.

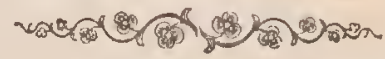

\section{LES OISEAUX AQUATIQUES.}

ËCHASSIERS.

\section{LES PLUVIERS.}

Ces oiseaux d'eau jaraissent en troupes nombleuses lans nos provinees de Franee, pendant les pluies d'aulomne, et c'est de leur arrivée dans la saison des pluies qu'on les a nommés pluviers; ils fréquentent, eomme les vanneaux, les fonds hurnides et les terres limoneuses oil ils eherehent des vers et des inseetes; ils vont à l'eau le matin pour se laver le lee et les pieds qu'ils se sont remplis de terre en la fouillant, pour en faire sortir les vers. Quoique les pluviers soient ordinairement fort 
gras, on leur trouve les intestins si vides, qu'un a imigin's qu'ils pouvaient vivre d'air ; d'aillcur's ils paraissent caprables de supporter un longr jeûne.

Rarement ils se tiennent plus de vingl-qualre heures dans le mème lieu; en volant, ils suivent le vent, et l'ordre de leur marche est assez singulier; ils forment dans

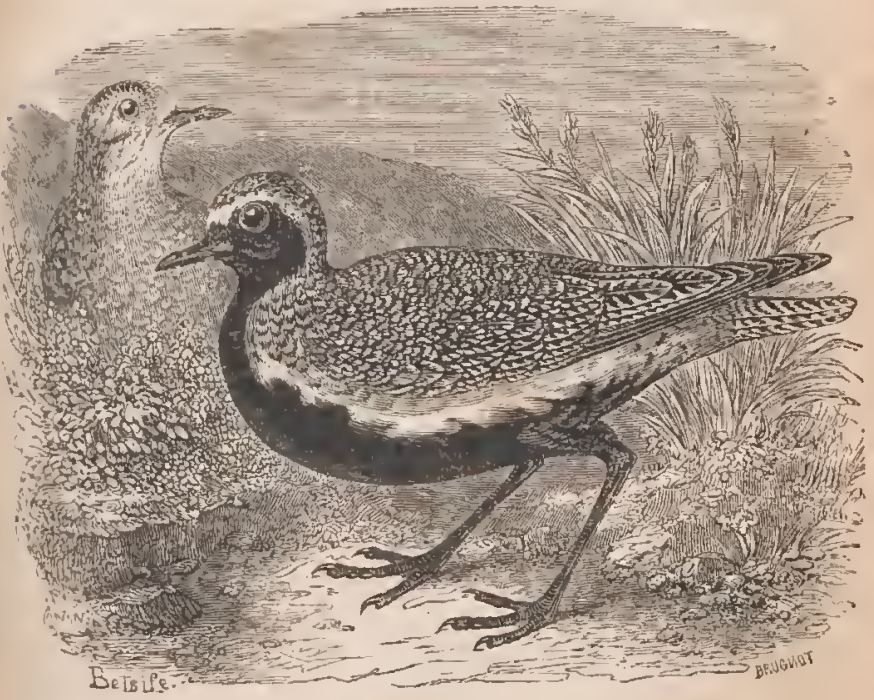

l'air des zones transversales forl élroites et d'une trisgrarde longueur. A terre, ils eourent beaucoup et tròsvite; ils demeurent attroupés tout le jour, et ne se séphrent que pour passer la nuit, pendant laquelle ehacun gîte à part ; mais, dès le point du jour, le preniicr éveilló jette lo cri de réelume, hui, hui, hui, et dans l'instant 
tous les autres so rassemblent à cet appel. C'est lc moment qu'on choisit pour en faire la chasse ; on en prend des quantités dans les plaines de Beauce et de Champagne. Quoique fort communs dans la saison, ils ne laissent pas d'être estimés comme un bon gibier. Hôtes passagers plutôt qu'habitants de nos campagnes, ils disparaissent à la chute des neiges, et ne font que repasser' au printemps; ils vont faire leur couvée dans les contrées septentrionales. Cetle famille d'viseaux, qui a beaucoup d'espèces, est commune aux deux continents.

\section{LE GRAND PLUVIER}

VULGAIREMENT APPELÉ GOURLIS DE TERRE.

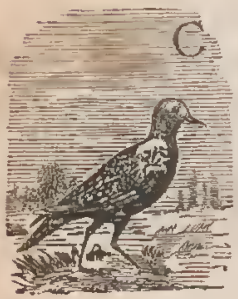

ET oiseau est beaucoup plus grand que le pluvier doré, il est même plus gros que la bécasse ; ses jambes épaisses ont un renflement marqué au-dessous du genou; il n'a, comme le pluvier, que trois doigts fort courts; ses jambes et ses pieds sont jaunes; son bec est jaunâtre jusque vers le milieu, et noirâtre jusqu'à son extrémité. Tout le plumage, sur un fond gris blanc et gris roussâtre, est moucheté par pinceaux de brun et de noirâtre, dont les traits sont assez distincts sur le cou et la poitrine, et plus confus sur le dos et sur les ailes.

Le temps de son départ et la saison de son séjour ne 
sont pas les mîmes que pour les pluviers ; il part on novembre, pendant les dernières nuits d'automne; mais avant d'cntreprendro le voyage, ces oiseaux se rćunissent en troupes do trois ou quatre cents, à la voix d'un seul qui les appelle, et leur départ se fait pendant la nuit. On les revoit de bonne houre au printemps, et dès la fin de mars ils sont de retour on Beauee, en Sologne, en Berry et dans quelques antres provinces de la France. La femelle ne pond que deux ou quelquefois trois oufs sur la terre nue, cntre des pierres ou dans un potil creux qu'clle forme sur le sable des landes et des dunes. Le mâlc ne la quilte pas; il l'aidc à conduirc ses petits, à les promener et à leur apprendre à distinguer leur nourriture. Cette éducation est même longue; car, quoique les petits marehent et suivent leur père et leur mère peu de temps après qu'ils sont nés, ils ne premnent que taı assez de forees dans l'aile pour pouvoir voler.

\section{LE VANNEAU.}

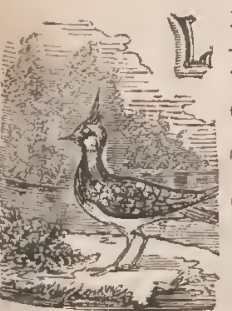

E vanneau paraîl avoir tiré son nom du bruit que font ses ailes en volant, qui cst assez semblable au bruit d'un van qu'on agite pour purger le blé. Il donne en partant un ou deux coups de voix, et se fait aussi entcndre par reprises dans son vol, mème durant la nuit; il a les ailus tris-lurtes, et il s'en sert beaucoup, vole longtemps 
de suite et s'élève très-haut; posé à terre, il s'élanee, bondit et parcourt le terrain par petits vols eoupés.

Cet oiseau est fort gai ; il est sans eosse ell mouvement, folâtre, et so joue de mille façons en l'air.

Les vanneaux arrivent dans nos prairies en grandes troupes au eommeneement de mars ou nême dès la fin de février, après le dernier dégel, et par le vent du sud. On les voit alors se jeter dans les blés verts, et couvinir le matin les prairies marécageuses pour y ehereher les ver's qu'ils ont l'adresse de faire sortir de terre. Le soil' venu, ees oiseaux courent dans l'herbe et sentent sous leurs pieds les vers qui sortent à la fraîcheur; ils en font ainsi une ample pâture, et vont ensuite se laver le bee et les pieds dans les petites mares ou dans les ruisseaux.

Ils se laissent difficilement approcher : on peut les joindre de plus près lorsqu'il fail un grand vent, ear alor's ils ont peine à prendre leur essor.

Ces oiseaux semblent être inconstants, et, en effet, ils no se tiennent guère plus de vingt-quatre heures dans le nême canton; mais cette inconstance est fondée sul 111 besoin réel: un canton épuisé de vers on un jour, la lendemain la troupe est forece de se transporter ailleurs. L'espècé lu vamieau est très-répandue en Europe et on Asie.

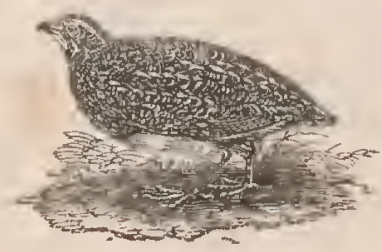




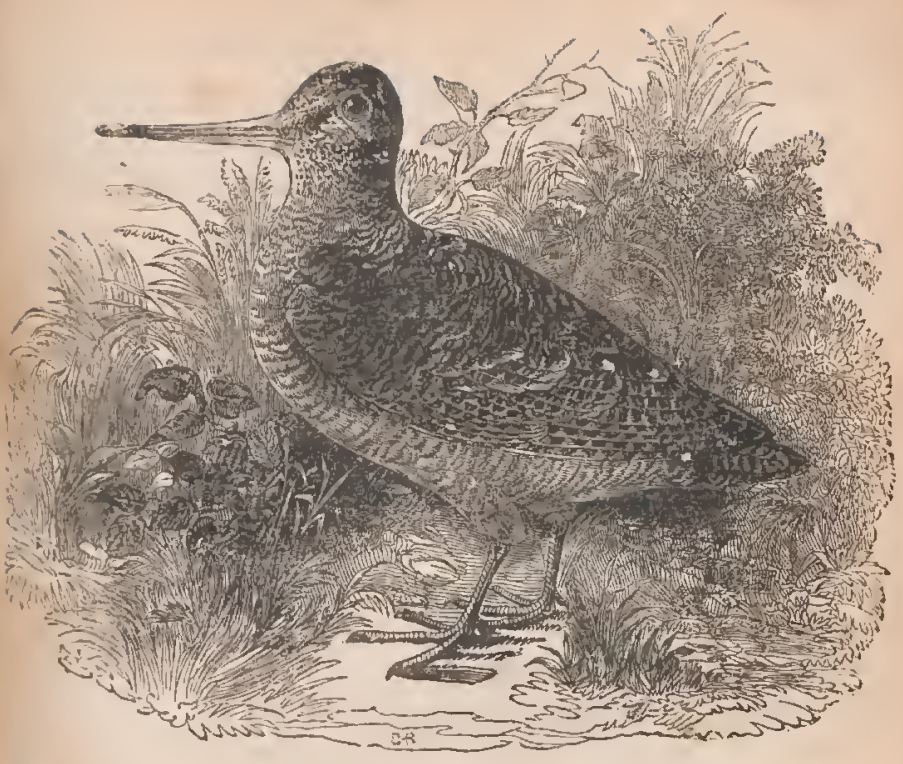

\section{LA BECASSE.}

Ce bon oiseau stupide arrive dans nos bois vers le milier d'octobre en inème temps que les grives. La bícasse descend alors des hautes montagnes où elle halite pendant l'ćlé, et d'où les premiers frimas déterminenl son depart et nous l'amènent: c'est des sommets des Pyrénées et des Alpes, où elle passe l'été, qu'elle descend aux premic̀res neiges qui tombent sur ces hauteurs dès le commencement d'octobre, pour venir dans les bois des collines inféricures et jusque dans nos plaines.

Les bécasses arrivent la nuit et quelquefois le jour, par un temps sombre, loujour's une à une ou deux en- 
semble, et jamais en troupes; elles s'abattent dans les grandes haies, dans les taillis, dans les futaies, et préfèrent les bois où il y a beaucoup de terreau ct de feuilios tombées; elles s'y tiennent retirées et tapies tout le jour'; elles quiltent ces endroits fourrés à l'entrée de la nuit, pour se répandre dans les clairiìres, en suivant les sentiers; elles cherchent les terres molles et les petites mares, où elles vont pour se laver le bec et les pieds qu'elles se sont remplis de terre en cherchant leur nourriture.

La bécasse bat des ailes avec bruit en partant ; son vol, quoique rapide, n'est ni élevé ni longtemps soutenu; elle s'abat avectant de promptitude, ru'elle semble tomber comme une masse abandonnée à toute sa pesanteur; peu d'instants après sa chute elle court avec vitesse, mais bientôt elle s'arrête, élève sa tête, regarde de tous côtús pour se rassurer avant d'enfoncer son bec dans la terre.

Il parait que cet oiseau, avec de grands yeux, ne voit bien qu'au crépuscule, et qu'il est offusqué d'une lumière plus forte: c'est ce que semblent prouver ses allures et ses mouvements, qui ne sont jamais si vifs qu'à la nuit tombante et à l'aube du jour.

C'est à la fin de l'hiver, c'est-à-dire au mois de mars, que presque toutes les bécasses quittent nos plaines pour retourner sur leurs montagnes; au printemps, elles volent sans s'arrêter, pendant la nuit; mais le matiı elles se cachent dans les bois pour y passer la journée, et en partent le soir pour continuer lour route; tout l'été elles se tiennent dans les lieux les plus solitaires et les plus élevés des montagnes où elles nichent.

Elles font leur nid par terre, comme tous les oiseanx qui ne se perchent pas. On trouve dans ce nid quatre ou 
cincl œufs. Lorsque les petits sont éclos, ils quittent le nid et courent quoique eneore eouverts de poil follet; ils commeneent même à voler avant d'avoir d'autres plumes que eelles des ailes; ils fuient ainsi voletant et courant quant ils sont déeouverts; on a vu la mère et le père prendre sous leur gorge un des petits, le plus faible, sans doute, et l'emporter ainsi à plus de mille pas; le mâle ne quitte pas la femelle tant que les petits ont besoin de leur seeours; il ne fait entendre sa voix que dans le temps de leur édueation; ear, pendant le reste de l'année, il est muet ainsi que sa femelle. L'espèee de la béeasse est universellement répandue.

\section{LA BÉCASSINE.}

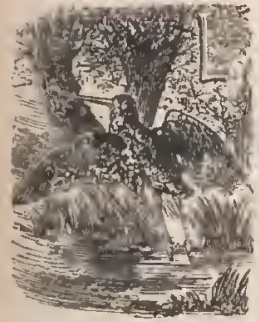

A béeassine a, eomme la béeasse, le bec très-long et la tête earrée; le plumage madré de même, exeepté que le roux s'y mêle moins, et que le gris blane et le noir y dominent; mais la bécassine a des habitudes tout opposées à celles de la bécasse; elle ne fréquente pas les bois; elle se tient dans les endroits marécageux des prairies, dans les herbages et les osiers qui bordent les rivières; elle s'élève si haut en volant, qu'on l'entend eneore lorsqu'on l'a perdue de vue; elle jette, en prenant son essor, un petit cri court et siffle; elle n'habite les montagnes en aucune saison. 
En Franee, les béeassines paraissent en automne : oll en voit quelquefois trois ou quatre ensemble, mais 10 plus souvent on les rencontre seules. Il on reste tout l'hiver dans nos contrées autour des fontaines chaudes et des petits marais voisins de ces fontaines; au printemps elles repassent en grand nombre, et il parait quo cette saison ost celle de leur arrivée en plusieurs pays où elles niclıent, comme en Allemagnne, en Silésie, en Suisse ; on trouve leur nid en juin : il est placé à terro, sous quelque grosse racine d'aulne ou de saule. Les petits quittent le nid en sortant de la coque: ils paraissent laids et informes; la mère ne les en aime pas moins; clle en a soin jusqu'à ce que leur grand bec, trop inou, soit devenu plus forme, et ne les quitte que quand ils peuvont aisément se pourvoir d'eux-inêmos.

La bćoassine pique continuelloment la terre, sans qu'on puisse bien bien dire ce qu'elle mange; elle est ordinairement fort grasse.

Quoiqu'on ne manque grière de trouver en automno des bécassines dans nos marais, l'espèce n'en est pas aussi nombreuse aujourd'hui qu'clle l'était ci-devant; mais elle est répanduc encore plus universellement que celle de la bécnsse, car on la rencontre dans loutes los parties du monde.

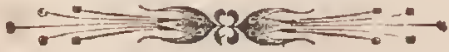




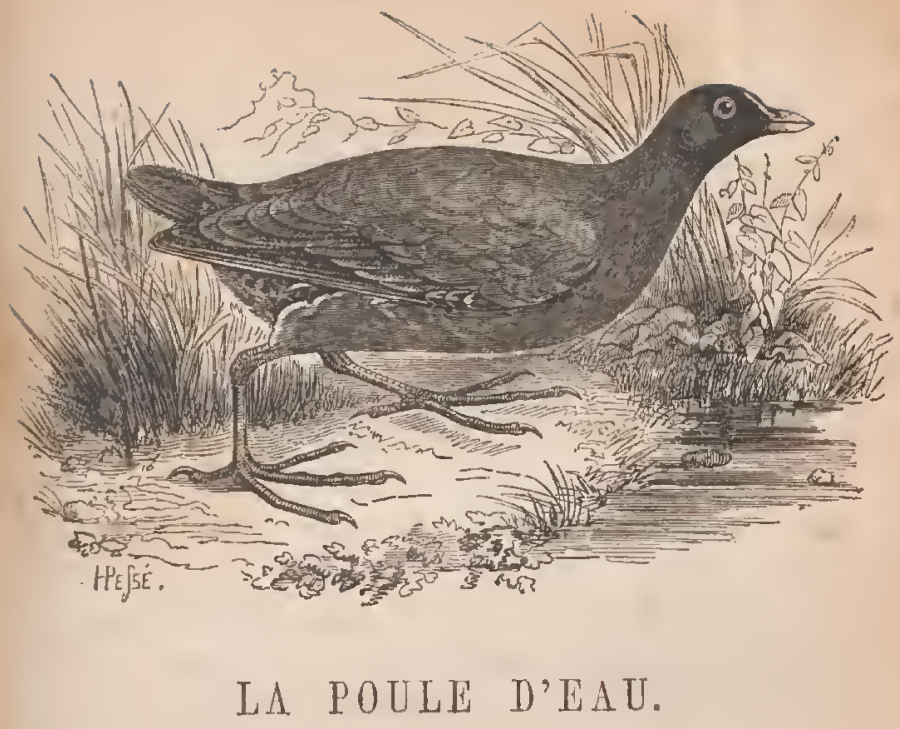

Les habitudes de lá poule d'eau répondent à sa conformation ; elle va à l'eau, sans eependant y nager beaucoup, si ce n'est pour traver'ser' d'un bord à l'autre ; cachée durant la plus grande partie du jour dans les roseaux ou sous les racines des aulnes, des saules et des osiers, ce n'est que sur le soir qu'elle se promòne su' l'eau; elle fréquente inoins les marécagres et les ınarais que les rivières et les étangs. Son nid, posé tout au bord de l'eau, est construit d'un assez gros amas de débris de roseaux et de joncs entrelacés; la ınère quitte son nid tous les soirs, et eouvre ses ceufs auparavant avec des llins de jones et d'herbes. Dès que les petits sont éclos, lls courent et suivent leur mère qui les mène ì l'ean: clle cache si bien sa pelite famille, qu'il est très-diffieile 
de la lui enlever, pendant lc très-petit temps qu'elle la soigne; car bientôt ces jeunes oiseaux sont devenus assez forts pour se pourvoir par eux-mêmes. Les poules d'eau quittent en octobre les pays froids et les montagnes, et passent l'hiver dans les climals tempérés.

\section{LE COURLIS.}

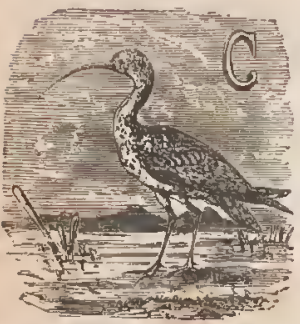

ET oiseau a le bec très-long, rclativement à la grandeur de son corps; ce bec est assez grêle, sillonné de rainures, également courbé darił toute sa longucur et terminé en pointe mousse; il est faible et d'une substance tendre, et ne paraît propre qu'à tirer les vers de la terre molle.

Le courlis se nourrit de vers de terre, d'insectes, de menus coquillages, qu'il ramasse sur les sables et les vases de la mer, ou sur les marais et dans les prairies humides.

Ces oiseaux courent très-vite et volent en troupes; ils sont de passage en France, et s'arrêtent à peine dans nos provinces intérieures ; mais ils séjournent dans nos contrées maritimes, comme en Poitou, en Aunis et en Bretagne, le long de la Loire, où ils nichent. On assure qu'en Angleterre ils n'habitent les bords de la mer qu'en hiver, et qu'en été ils vont nicher dans l'intérieur dı pays vers les montagnes; on cn voit dans l'automne ell 
Silésie, et ils se portent en été jusqu'à la mer Ballique at au golfe de Bothnie; on les trouve également en Italie et en Grèce, et il paraît que leurs migrations s'étendent au delà de la $\mathrm{mcr}^{r}$ Méditerranée, car ils passent à Malte deux fois l'année, au printemps et en automne; du reste, on rencontre des courlis dans presque toutes les parties du inonde.

\section{LA GRUE.}

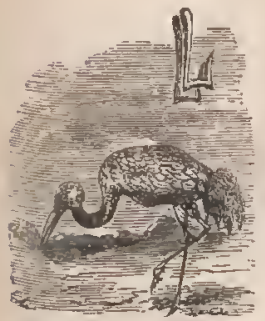

Es grues portent leur vol très-haut, et se mettent en ordre pour voyager; elles forment un triangle à peu pròs isocèle, comme pour fendre l'air plus aisément. Quand le vent se renforce et menace de les rompre, elles se resaussi quand l'aigle les attaque; leur passage s'opèrc le plus souvent dans la nuit.

Le vol de la grue est toujours soutenu, quoique marqué par diverses inflexions; ses vols différents ont été observés comme des présag̣es des changements du ciel et de la teinpérature. Les cris des grues dans le jour indiquent la pluie ; les clameurs plus bruyantes et comme tumultueuses annoncent la tempête. Si le matin ou le soir on les voit s'élever et voler paisiblement en troupe, c'est un indice de sérénité; au contraire, si elles pressentent l'orage, elles baissent leur vol et s'abattent sur terre. 
A terre, les grues rassemblées chablissont une garde pendant la nuit, et la circonspection de ces oiseaux a été regardćc comme le symbole de la vigilance : la troupe dort la tête cachéc sous l'aile, mais le chel' veille la tête haute, ot si quelque objet le frappe, il en averit par un cri.

Les premiers froids de l'automne avertissent les grrues de la r'évolution de la saison; clles partent alors pour' changer cle ciel. Cel'es du Danube et de l'Allemagne passent sur l'Italie. Dans nos provinecs de France, elles paraissent au mois de septemabio et d'octobre, et jus(qu'en novembre, lorsque le temps de l'arrière-automne est doux; mais la jlupart ne font que passor rapidement et ne s'arrêtent point : elles reviennent au promier printemps, en mar's ct avril. C'est dans les terres du Nord, autour des marais, que la plupart des grues vont posel' lcurs nids; d'autre còté, on assure que les grues no nichont que dans les régions de l'Inde, co qui prouverait qu'elles font deux nichées et dans les doux climats opposés. Les grues ne pondent que deux ceufs; les petils sont à pcine élevés qu'arrive le temps du départ, et leư's premières forces sont employées à suivre et accanpagner lcur pòre et leur mère dans leurs royages.

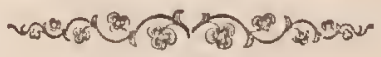




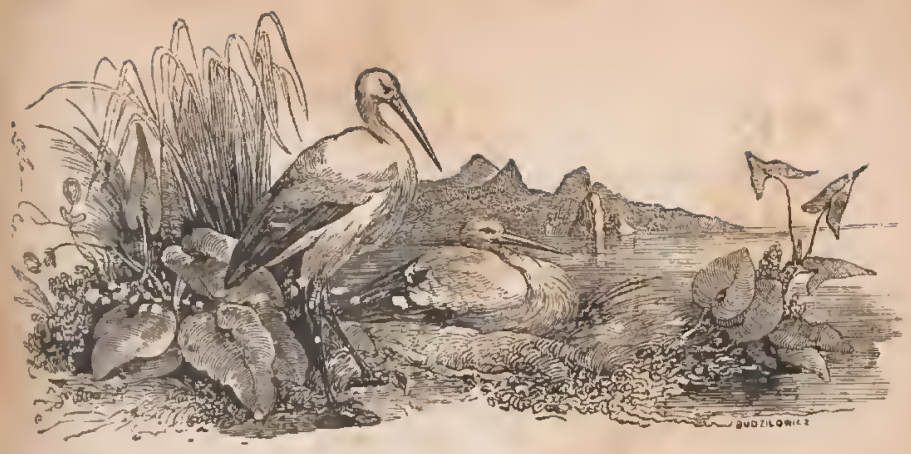

\section{LA CIGOGNE.}

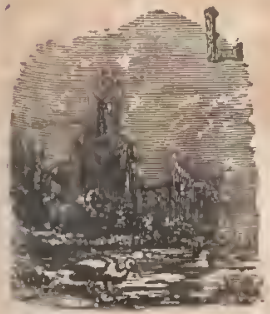

A cigogne blanche a le vol puissant et soutenu, comme tous les oiseaux yui ont des ailes très-amples et la queue courte; elle porte en volant la tête roide en avant et les pattes ótendues en arric̀re comme pour lui servir de gouvernail ; elle s'ćlève fort haut et fait le très-longs voyages, même dans les saisons orageuses. On voit les cigognes arriver en Allemagne ver's le 8 ou le 10 de mai; elles devancent oc temps dans nos provincos. Leur retour est partout d'un agrćablo angure, et leur apparition annonce lo printemps. Elles reviennont constamment aux mêmos lieux, et si leur ancien nid est détruit, elles le reconstruisent de nouveau. C'est ordinirement sur les combles élevés, sur les créneaux des tours, et quelquelois sur les grands arbres, au bord des eaux ou ì la pointe d'un rocher oscarpé, qu'ellos le posent. 
Dans l'attitude du repos, la eigogne se tient sul' un pied, le cou replié, la têtc en arrière et couchée sur l'élraule; elle guette les mouvements de quelques reptiles (qu'elle fixe d'un œil perçant : les grenouilles, les lézards, les eouleuvres et les petits poissons sont la proie qu'elle va cherehant dans les marais, ou sur les bords des eaux et dans les vallées humides.

Elle ne pond pas au delà de (quatie oufs, et souvent pas plus de deux. Le mâle les eouve dans le temps que la femelle va ehercher sa pâture; les œufs éelosent au bout d'un mois ; le père et la mère redoublent alors d'activité pour porter la nourriture à leurs petits, qui la reçoivent en se dressant et rendant une espèce de sifflement. Au reste, le père et la mère ne s'éloignent jamais du nid tous deux ensemblc; et tandis que l'un est à la ehasse, on voit l'autre se tenir aux environs, debout sur une jambe, et l'œil toujour's à ses petits.

Lorsqu'elles sont assemblées pour le départ, il se fait alor's un grand snouvement dans la troupe : toutes semblent se chercher, se rcconnaitre et se donner l'avis du départ général, dont le signal, dans nos contrées, est le vent du nord. Elles s'élèvent toutes ensemble, et dans quelques instants se perdent au haut des airs. La eigogne est d'un naturel assez doux; elle n'est ni défiante ni sauvage, et elle peut s'apprivoiser aisément; elle a presque toujours l'air triste et la contenanec morne, quoiru'elle donne quelquefois des signes de craieté; elle est d'une propreté remar'quable; elle vit longrtemps.

L'on attribue à cet oiseau des vertus morales dont l'imaçe est toujours respectałle : la tempéranee, la pióté filiale et paternelle. 


\section{LE KAMICHI.}

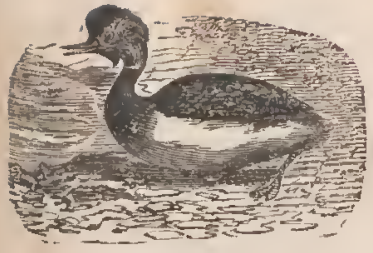

Au milieu des sons discordants d'oiseaux criards et de reptiles croassants, s'élòve par intervalles une grande voix qui leur impose à tous, et dont les eaux retentissent au loin : e'est la voix du kamichi, grand oiseau noir trèsremarquable par la force de son ori et par colle de ses armes; mais, malgré des armes très-offensives ct qui le rendraient formidable au eombat, le kamichi n'attalue point les autres oiseaux, et ne fait la guerre qu'aux reptiles; il a môme les mours douces et le naturel profondément sensible, car lo mâle et la fomelle so tiennent tonjour's enscmble, et à la mort de l'un d'eux, celui qui reste erre sans cesse en gémissant, et se consume près des lieux où il a perdu ce qu'il aime.

Ces affections touchantes forment dans eet oiseau, avec sa vie de proie, un singulier eontraste. On a romarqué avec raison que l'espèce du kamichi est seule clans son genro; sa forme est, en effet, composée de parlies disparates, et la nature lui a donné des attributs cxtraordinaires; c'est done sans aucun fondement qu'on en a fail un aignle, puisqu'il n'en a ni le bee, ni la tête, ni les pieds. Le kamichi est un oiseau demi-rquatique; il construit son nid en forme de four au pied d'un al'hre, il marche le cou droit, la tète haute, el il hante 
les forêts. Cependant plusieurs voỳageurs ont assuré qu'on le trouve encore plus souvent dans les savanes.

\section{LE HERON COMMUN.}

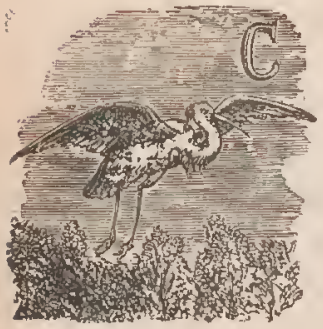

ET oiscau nous offre l'image d'une vie de souffrance, d'anxièté, d'indigence: n'ayant ưue l'embuscade pour tout moyen d'industrie, le héron passe des heures, dos jour's enticrs à la même place, immobile au point de laisser douter si c'est un être animé. Réduit à attendre que sa proie vicrne s'offrir à lui, et n'ayant qu'un instant pour la saisir, il doit subir de lonģs jeûnes et quelquefois périr d'inanition: car il n'a pas l'instinct, lorsque l'eau est couverte do glace, d'aller chercher à vivre dans des climats plus tempérós; il supporte la faim et la soif; il ne résisto ot ne vit qu'à force de patienco et de sobriété.

Lor'squ'on prend un héron, on peut le garder quinze jours sans lui vorr chercher ni prendre aucune nourriture : il rejette môme celle qu'on tente de lui faire avaler ; sa mélancolie naturelle, augmentée sans doute par la captivité, l'emporte sur l'instinct de sa conscrvation; l'ąpathique héron semble se consumer sans languir" it pórit sans se plaindre et sans apparence de remret; mais, s'il est pris jeune, il s'apprivoise, se nourrit of s'engraisse. 
Triste et solitaire hors le temps des nichées, il ne parait connaître aucun plaisir, ni même les moyens d'éviter la peine. Dans les plus mauvais temps il se tient isolé, découvert, posé sur un pieu ou sur une pierre, au bord d'un ruisseau, sur une butte, au milieu d'une prairie inondée; il reste ainsi exposé à toutes les injurcs de l'air et à la plus grande rigucur des frimas. Ses longues jambes ne sont que des échasses inutiles à la course; il reste debout et au repos absolu pendant la plus grande partie du jour, ct ce repos lui tient lieu de sormmeil, car il prend quelque essor pendant la nuit. On l'entend alors crier en l'air à toute heure et dans toutes les saisons; sa voix est un son unique, sec, aigre et plaintif; ce cri se répète de moment en moment, et se prolonge sur un ton plus perçant et très-désagréablc lorsque l'oiseau ressent de la douleur.

Le héron ajoute encore aux malheurs de sa chétive vie le mal de la crainte et de la défiance; il parait s'inquiéter et s'alarmer de tout.

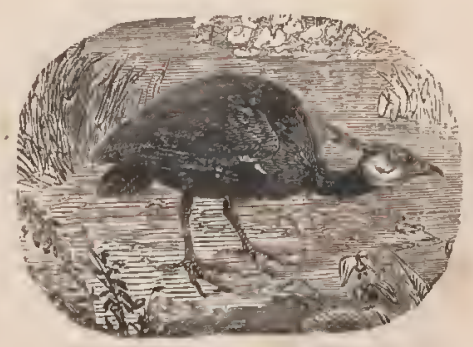




\section{LE BUTOR.}

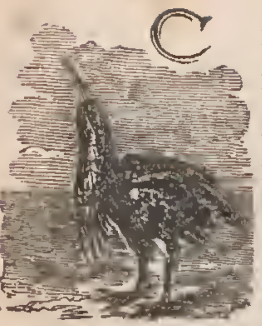

ET oiseau est toujours si eaché qu'on ne peut le trouver ni le voir de près. A toutes ces précautions pour se rendre invisible et inabordable, le butor semble ajouter une ruse de défiance: il tient sa tête élevće, et comme il a plus de deux pieds et demi de hautcur, il voit par-dessus les roseaux sans être luimême apcrçu; il ne ehange de licu qu'ì l'approche de la nuit dans la saison d'automne, et il passe le reste de sa vie dans une inaction qui lui a fait donner le surnom de paresseux ; tout son mouvement se réduit, en effet, à se jeter" sur une grenouille ou un petit poisson qui vient so livreı lui-même à ee pêcheur indolent.

Il fait son nid presque sur l'eau, au milieu des roseaux, dans le mois d'avril ; les jeunes naissent presque nus of sont d'une figure hideuse : ils semblent n'ôtre que eou et jambes; ils ne sortent du nid que plus de vingt jours après leur naissance ; le père et la mère les nourrissent dans les premiers temps de sangsues, de lézards, de grenouilles et de petites anguilles. Les busards, qui dévastent les nids de tous les autres oiseanx do marais, touchent rarement à celui du butor ; le père ef la mère y voillent sans eesse et le dófendent; les enfants n'osent on approchel, ils risqueraient de se faire crever les yeux. 


\section{LE RALE DE TERRE OU DE GENET}

VULGAIREMENT ROI DES CAILLES.

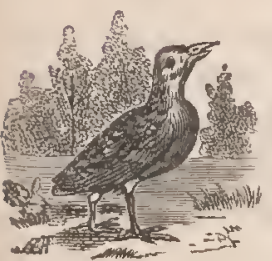

Dans les prairies humides, dès que l'herbe est haute et juscu'au temps de la récolte, il sort des endroits les plus touffus de l'herbage une voix rauque, ou plutôt un cri bref, aigre etsec, crék crék crék, assez semblable au bruit que l'on exciterait en passant et appuyant fortement le doigt sur les dents d'un gros peigne; et lor'squ'on s'avance vor's cette voix, elle s'éloignc et on l'entend venir de cinquante pas plus loin: c'est le râle de terre qui jette ce cr'i, qu'on prendrait pour le croassement d'un reptilc. Cet oiseau fuit rarement au vol, mais presque loujour's on marchant avec vitesse et passant à traver's le plus touffu des herbes, il y laisse une trace remarquable. On commence à l'entendre vers le 10 ou le 12 do mai, dans le même tcmps que les cailles, qu'il semble accompagner en tout temps, car il arrive et repart avec elles; cette circonstance, jointe à ce que le râle et les cailles habitent également les prairies, qu'il y vit scul, et qu'il est beaucoup moins commun et un peu plus gros que la caille, a fait imaginer qu'il se mettait à la tête de leurs bandes comme chef ou conducteur de lcur voyage, et c'est ce qui lui a fait donner le nom de roi des cailles; mais il diffère de ces oiseaux par les caractères de conformation. 


\section{LE RALE D'EAU.}

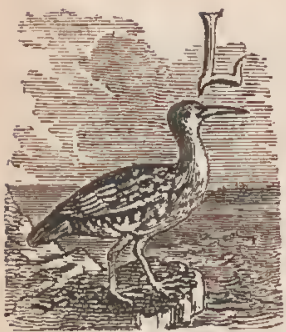

E râle d'eau court le long dcs eaux stagnantes aussi vitc que le râle de terre dans les champs; il se ticnt de même toujours caché dans les grandes hcrbes et les joncs ; il n'en sort que pour traverser les eaux à la nage et même à la course, car on le voit souvent courir légèrement sur les larges feuilles du nénuphar, qui couvrent les eaux dormantes. Il se fait de petites routes à travers les grandes herbes; on y tend dcs lacets, et on le prend d'autant plus aisément, qu'il revient constamment à son gîte, et par le même chemin.

\section{PALMIPÈDES.}

\section{LE CYGNE.}

Roi paisible des oiscaux aquatiques, il brave les tyrans de l'air; il attend l'aigle sans le provoquer, sans le craindre; il repousse ses assauts, en opposant à ses armes la résistance de ses plumes, et les coups précipités 
d'une aile vigoureuse qui lui sert d'égide, el souvent la victoire couronne ses efforts. Au reste, il n'a que ce fier ennemi, tous les autres oiseaux de guerre le respectent, et il est en paix avec toute la nature.

Les grâces de la figure, la beauté de la forme répondent, dans le cygue, à la douceur du naturel; il plaît à

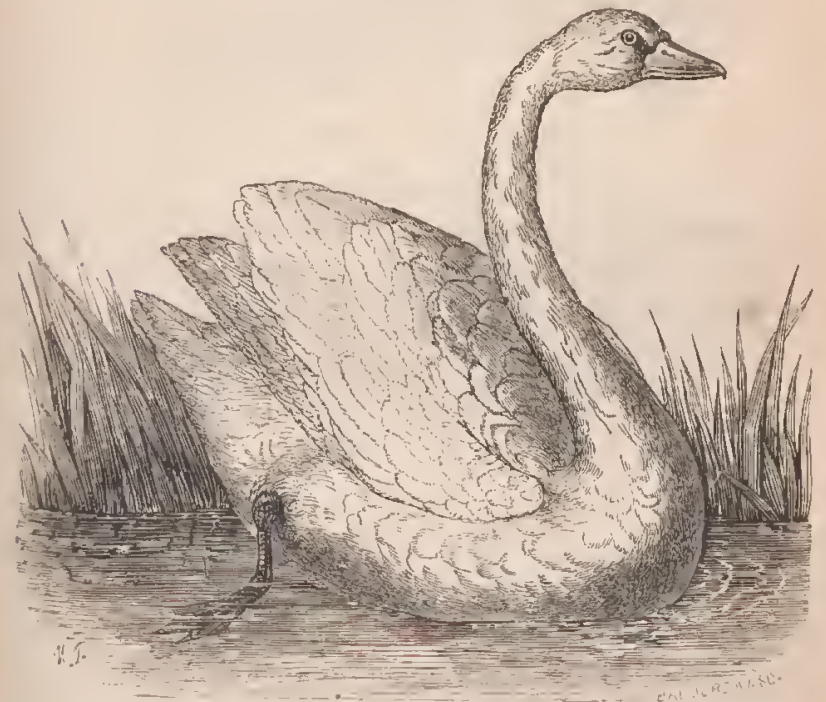

tous les yeux, il décore, embellit tous les lieux qu'il Tréquente; on l'aime, on l'applaudit, on l'admire.

Il nage si vite, qu'un homme, marchant rapidement au rivage, a grand'peinc à le suivr'e. Il vit tròs-longtemps, jusqu'à trois cents ans, a-t-on dit, mais sans doute avec exagcération. Ia mère recueille nuit et jour ses petits 
sous ses ailes, ct le père se présente arec intrépidité pour les défendre avec courage, avec fureur contre tout assaillant. Les petits naissent fort laids et seulement couverts d'un duvet gris ou jaunâtre, comme les oisons; leur's plumes ne poussent que quelques semaines après, et sont encore de la même couleur; ; ce vilain plumagge change à la première mue, au mois de septembre; ils prennent alors beaucoup de plumes blanches, d'auties plus blondes que grises, surtout à la poitrine et sur le dos; ce plumage chamarı́c tombe à la seconde mue, et ce n'est qu'à dix-huit mois et même deux ans d'âğe que ees oiseaux ont pris leur belle robe d'un blanc pu' et sans taclie.

I.es anciens ne s'étaient pas contentés de faile du cygne un chantre merveilleux: seul entre tous les êtres qui frémissent à l'aspect de leur destruction, il chantait eneore au moment de son agonie, et préludait par des sons harmonieux à son dernier soupir. Nulle fiction ell histoire naturelle, nulle fable chez les anciens, 17'a été plus célébrée, plus répétée, plus accréditéc. Les eygnes, sans doute, ne cliantent point leur mort; mais toujours, en parlant du dernier essor et des derniers élans d'un heau génie près de s'éteindre, on rappeller avee sentiment cette expression touchante: C'est le chant du cygne!

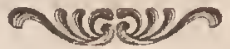




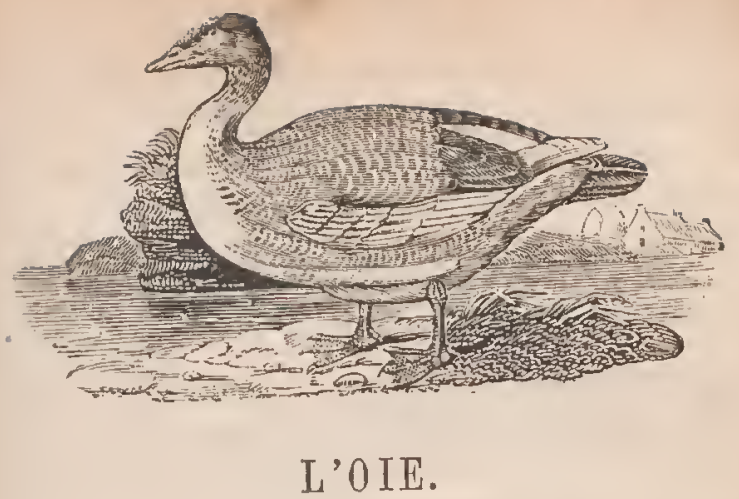

L'oie est, dans le peuple de la basse-cour, un habitant de distinction ; sa corpulence, son port droit, sa démarche grave, son plurnage net et lustré, et son naturel social qui la rend susceptible d'un fort attachement et d'une longue reconnaissance; enfin sa vigilance, trèsanciennement célébrée, tout concourt à nous présenter l'oie comme l'un des plus intéressants et même des plus utiles de nos oiseaux domestiques; car indépendamment de la bonne qualité de sa chair et de sa graisse, dont aucun autre oiseau n'est plus abondamment pourvu, l'oie nous fournit cette plume délicate sur laquelle la mollesse se plaît à reposer, et cette autre plume, instrument de nos pensées, et avec laquelle nous écrivons ici son éloge. La domesticité de l'oie est moins ancienne et moins complète que celle de la poule: celle-ci pond en toul temps, plus en été, moins en hiver; mais les oies ne produisent rien en hiver, et ce n'est communément qu'au mois de mars qu'elles commencent à pondre. Mais, si la domesticité de l'oie est plus moderne que 
celle de la poule, clle parait être plus ancienne que celle du canard, dout les traits oliginaires ont moins changé, en sorte qu'il y a plus de distance apparente entre l'oio sauvage et l'oic privée, qu'entre les canards.

La femelle couve constamment et si assidùnent, cqu'elle en oublie le boirc el le manger, si l'on ne place tout près du nirl sa nourrituıe. Quoique la marche de l'oie paraísse lente, oblique el pesante, on ne laisse pas d'en conduire des troupeaux fort loin à pctiles journées. Le plus léger bruit les évcille, et toutos ensemble crient; clles jettent aussi de grands cris lor'squ'on leur présente de la noul'riture, au lieu qu'on rend le chien muet en lui offrant cet appât, ce qui a fait dire que les oies étaicnt les meitleures et les plus sûres gardiennes de la ferme, et la pius vigilante sentinelle que l'on puisse poser dans une vilie assiégée. Tout le monde sait qu'au Capitole elles avedtirent les Romains de l'assaut que tentaient les Gaulois, ct que ce fut le salut de Rome.

On donne assez volontiers le nom de l'oie aux gens sots et niais; mais, indépendamment des marques de selltiment, des signes d'intelligence qu'on lui rcconnail, le conragre avce lequel elle défend sa couvée et se défelld ellc-même contrc l'oiseau de proie, et certains traits d'attachement, de r'econnaissance, même très-singuliel's, démontrent que ce mépris serait très-nal fondé. Outre l'oie domestique, il y a encore l'oie sauvage, qui ne dilfùre de la première que parce qu'elle a pu échapper is l'homme ct conserver sa liberté.

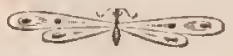




\section{LE CANARD.}

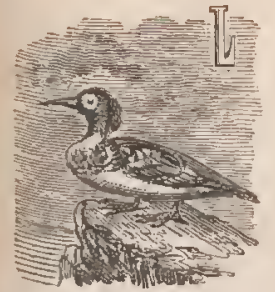

'espìce du canard est partagée en deux grandes tribus ou races distinctes dont l'une, depuis longtemps privée, se propage dans nos bassescours en y formant une des plus utiles et des plus nombreuses familles de nos volailles, ot l'autre, sans doute encore plus étendue, nous fuit constamment, se tient sur les eaux, ne fait, pour ainsi dire, que passer et repasser en liver dans nos contrées, et s'enfonce au printemps dans les régions du Nord pour y nicher sur les terres les plus úloignées de l'empire de l'lomme.

C'est vers le 15 d'octobre que paraissenten France les Jrcmier's canards ; leurs bandes, d'abord petites et peu fréquentes, sont suivies en novembre par d'autres plus nombreuses.

Ces oiseaux sont très-défiants; jamais ils ne se posent qu'aprìs avoir fait plusieurs circonvolutions sur le lieu où ils voudraient s'abattre, comme pour l'examiner, le reconnaitre et s'assurer s'il ne recèle aucun ennemi; et lon'squue enfin ils s'abaissent, c'est toujours avee précaulion. Les allures du canard sauvage sont plus de nuit que de jour; ils paissent, voyagent, arrivent et partent principalement sur le soir et même la nuit.

Tant que la saison ne devient pas rigoureuse, les insectes aquatiques et les petits poissons, les graines du jone, la lentille d'eau et quelques autres plantes maréca- 
geuses, fournissent ahondamment à la pûture des canards; mais vers, la fin de décembre ou au commencement de janvier, ils se portent sur les rivières encorte coulantes, et vont ensuite à la rive des bois ramasser le glands. Dans la saison d'été ils couvrent, pour ainsi dire, tous les lacs et toutes les rivières de Sibérie et de Lapo* nie. Quoique la cane sauvage place de préférence $5^{\mathfrak{l}}$ nichće près des eaux, on ne laisse pas d'en trouver quelques nids dans les bruyères assez éloignées. Il y a ordle nairement dans chaque nid dix à quinze et quelqucfois jusqu'à dix-huil oul's.

Le mâle ne paraîl pas remplacer la femelle dans le soitl de la couvée : seulement il se tient à peu de distance, ${ }^{j}$ l'accompagne lorsqu'elle va chercher sa nourriture. Toll" les petits naisscnt dans la même journée, et dès le lêl" demain la inèrc descend du nid et les appelle à l'cart timides ou frileux, ils hésitent et même quelques-uns $\mathrm{s}^{\text {b }}$ retirent, néammoins le plus hardi s'élance après la mèrê el bientôt les autres lc suivent. Une fois sortis du nid, il n'y r'entrent plus; tout le jour ils guettent, à la surfacte de l'eau et sur les herbes, les moucherons et autres mé nus insectes qui font leur première nourriture; on ler voit plonger, nager et faire mille évolutions sur l'eal avec autant de vilesse que de facilité.

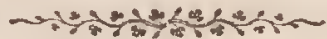




\section{LES SARCELLES.}

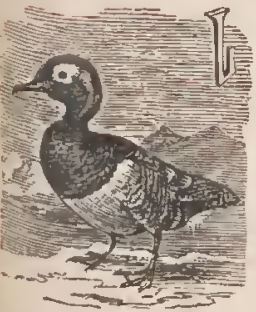

A forme que la nature a le plus nuaneée, variée, multiplicee dans les oiseaux, est eelle du canard. Mais il se présente un genre subalterne, presque aussi nombreux que celui des eanards; les sareelles sont de véritables canards bien plus petits que les autres. Il y en a plusieurs espèees; mais aueune n'est aujourd'hui, eomme autrefois, destinée à la domesticité.

La figure de la sarcelle eommune est celle d'un petit canard, et sa grosseur eelle d'une perdrix. Le plumage du mâle, avec des couleurs moins brillantes que eelui du canard, n'en est pas moins riehe en reflets agréables; le devant du eorps présente un beau plastron tissu de noir slur gris; les eôtés du cou et les joues, jusque sous les Yux, sont ouvragés de petits traits de blane sur un fond roux; des plumes longues et taillées en pointe eouvrent les épaules et retombent sur l'aile en rubans blancs et "airs; les eouvertures qui tapissent les ailes sont ornées d'un petit iniroir vert.

La parure de la femelle est bien plus simple; vêtue Partout de gris et de gris brun, à peine remarque-t-on quelques ombres d'ondes ou de festons sur sa robe."

A eertaines époques, le mâle fait entendre un eri semblable ì eelui du râle; la femelle ne fait guère son nid dins nos provinces, et presque lous ces oiseaux nous 
quittent avant le 15 ou 20 d'avril; ils volent par bandes dans leurs voyages, mais sans garder d'ordre régulier'; ils ne se plongent pas souvent, et trouvent à la surface de l'eau el ver's ses bords la nourriture qui leur convient; les mouches et les graines des plantes aquatiques sont leurs aliments de préférenee.

\section{LE PÉLICAN.}

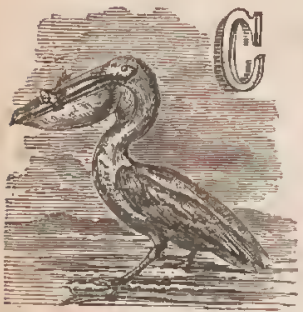

ET oiseau, par la largeur de ses ailes, dont l'envergure est de onze ou douze pieds, se soutient trèsaisément et très-longtemps dans l'air.

Les pélicans prennent, pour pê cher, les heures du matin et du soir où le poisson est le plus en mouvement, et choisissent les lieux où il est le plus abondant.

Ce gros oiseau paraît susceptible de quelque édueation et même d'une certaine gaieté, malgré sa pesanteur' : il n'a rien de farouche, et s'habitue volontiers avec l'homme. Il y a l'histoire fameuse de ee pélican qui suivait l'empereur Maximilien, volant sur l'arméc quand elle élait en marche, et s'élevant quelquefois si haut, qu'il ne paraissait plus que comme une hirondelle, quoiqu'il eût quinze pieds d'un bout des ailes à l'aútre.

Le pélican vit très-longtemps, et même en captivité il prolonge sa vie beaueoup plus que la plupart des autres 
oiseaux. Il est très-vorace, très-grand mangeur et engloutit en une seule pêche autant de poisson qu'il en faudrait pour le repas de six hommes; il avale aisément un poisson de sept ou huit livres. Il se trouve dans les deux continents.

\section{LE CORMORAN.}

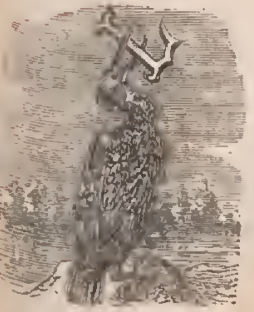

v cormoran est d'une telle adresse à pêcher et d'unesi grande voracité que, quand il se jelte sur un étang, il y fait seul plus de dégâl qu'une troupe entière d'autres oiseaux pêcheur's. Cornme il peut rester longlemps plongé, el qu'il nage sous l'eau avec la rapidité d'un trait, sa proie ne lui échappe guère, et il revient presque loujours sur l'eau avec un poisson en travers de son bec. Pour l'avaler il fait un singulier Manége; il jette en l'air son poisson, et il a l'adresse de le recevoir la tête la première, de façon que les nageoires se couchent au passage du gosicr, tandis que la peau inembraneuse qui garnit le dessous du bec, prête et s'étend comme il est nécessaire pour admettre et laisser passer le corps entier du poisson, qui est souvent fort Gros en comparaison du cou de l'oiseau.

La faim seule donne de l'activité au cormoran, il devient paresseux et lourd dès qu'il est rassasié.

Ce qu'il y a de fort singulier dâns la nature du cor-. 
moran, c'est qu'il supporte égalcment les ehaleurs du Sćnćgral et les frimas de Sibérie.

\section{LES GOËLANDS ET LES MOUETTES.}

Les goëlands et les inouelles sont ćgalement voraces et eriards; on peut dire que ee sont les vautours de la iner; ils la nettoient des eadavres de toute espèee qui llollent à sa surface ou qui sont rejetés sur les rivagoes , aussi lâehes que gourmands, ils n'attaquent que les, antmaux faibles, ot ne s'aeliarnent que sur les eorps morts. Leur port ignoble, leurs eris importuns, leur bec tranchant et crochu, présentent les images désagréables d'oiseaux sanguinaires et bassement cruels. Le poisson frais ou gâté, la chuir sanglante, réccntc ou eorrompue, les ćcailles, les os même, tout se digère et sc eonsume dars leur' estomae; ils avalent l'amoree et l'hameçon.

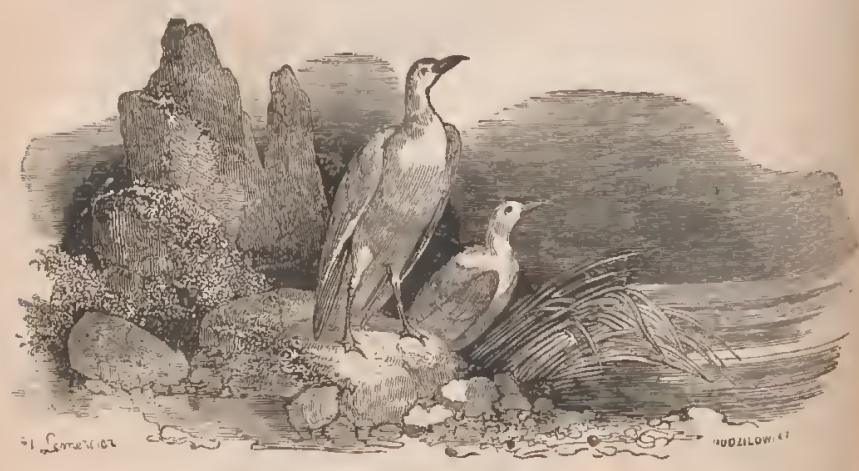




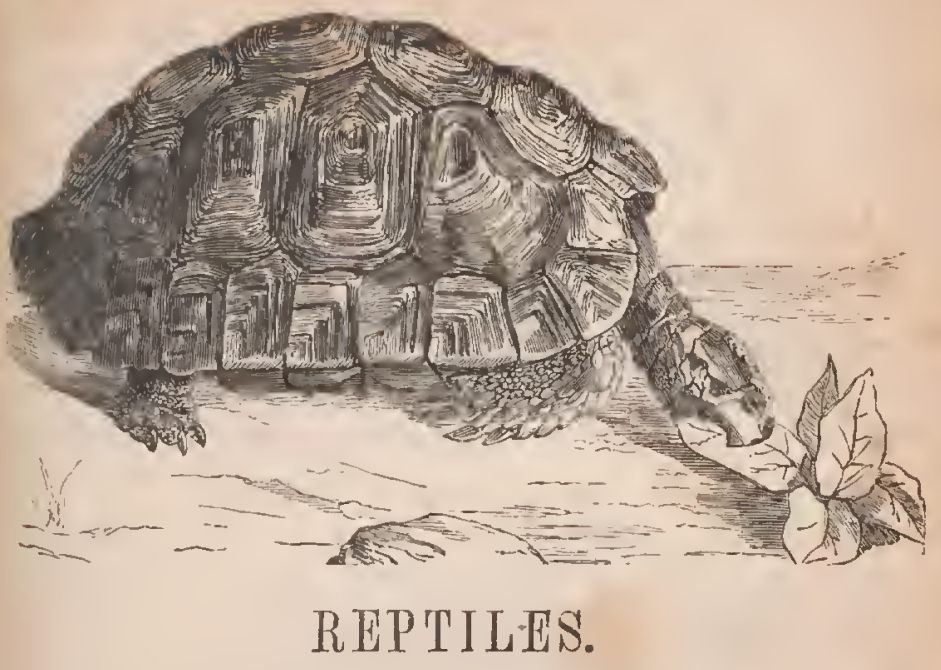

\section{LES TORTUES}

Les tortues ont reçu en naissant une sorte de domicile durable : elles portent partout avec elles l'abri que la nature leur a donné; et c'est avec toute vérité qu'on a dit qu'elles traînent leur maison, sous laquelle elles sont d'autant plus à couvert, (qu'elle ne peut pas être détruite par les efforts de leurs ennemis.

La plupart des tortues retirent quand elles veulent

1. Ici commence une serie d'animaux dont l'histoire et la description sont extraites dos đuvres do Lacépèdo. 
leur' tête, leur's pattes et leur queue sous l'envoloppe dure et osseuse qui les revêt par-dessus ot par-dessous, et dont les ouvertures sont assez étroites pour que les serres des oiseaux voraces ou les dents des quadrupèdes carnassiers n'y pénètrent que difficilement. Ce bouclier impénétrable qui les garantit est composć de deux espèces de tables osseuses, plus ou moins arrondies et plus ou moins convexes. L'une est placée au-rlessus ot l'autre au-dessous du corpps. La supérieure s'appelle carapace; et l'inféricure se nomme plastron. Ces deux couvertures ne se touclient ot ne sont attachées ensemble que par les côtćs; clles laissent dleux ouvertures, l'une devant, et l'autre derrière : la premièro donne passage ì la tête et aux deux pattes de devant; la secondo aux deux pattes do derrière et à la queue. Lorsque les tortues veulent ou marcher ou nagor', elles sont obliggées d'étendre leur' tête, lour cou et leurs pattes, qui paraissent alors à l'cxtérieur. Lour tôle est garnie de petites écailles comme celle des lézards, des serpents et des poissons, avec lesquels olle donne aux tortues un trait de ressenJlance.

Le plastron est presque toujours plus court que lit carapace, qui le déborde et le rocouvre par devant, et surlout par derrière; il est aussi moins dur, et souvent presque plat. Ces deux houcliers sont composés de plusicur's pièces osseuses, dont les bords sont comme dentelés, et qui s'engrènent les unes dans les autres d'une manic̀re plus ou moins sensible.

Les tortues présentent, dans certaines espèces, des couleurs assez belles pour être recherchées et servir ì des objets de luxe; et ce qui les rend d'autant plus propres 
à être employées dans les arts, e'est qu'elles se ramollissent et se fondent à un feu assez doux, de manière à ètre réunies, moulées, et à prendre toutes sortes de figures.

Nous connaissons vingt-quatre espèees de ces animaux; elles different toutes les unes des autres par leur grandeur, et aussi par leurs habitudes : les unes vivent presque toujours dans la mer; les autres, au eontraire, préfèrent le séjour des eaux douees ou des terrains secs et élevés.

\section{LES LEZARDS.}

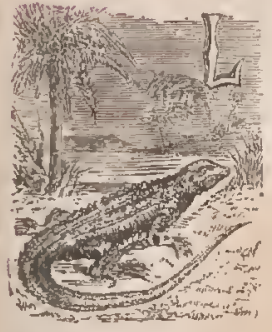

E genre des lézards est le plus nombreux de eeux qui forment l'ordre des quadrupèdes ovipares.

On peut distinguer facilement les lézards des autres quadrupèdes ovipares, paree qu'ils ne sont pas couverts d'une earapace eomme les tortues, et paree qu'ils ont une queue, tandis que les grenouilles et les erapauds n'en ont point. Leur eorps est revêtu d'éeailles plus ou moins fortes. Leur grandeur varie depuis la longueur de deux ou trois pouees jusqu'à celle de vingt-six ou même trente pieds. La forme et la proportion de leur queue varient aussi : dans les uns, elle est aplatie; dans les autres, elle est ronde. Dans quel- 
qucs espèces, sa longueur ógale trois fois celle du corps: dans quelques autres, elle est très-courte; dans toutes, elle s'étend horizontalement, et est presque aussi grosse à son origine que l'extrémité du corps à lacquelle elle cst attachée.

Les habitudes de ces animaux sont aussi diversifices que leur conformation extérieure : les uns passent leur' vie dans l'eau ou sur les bords déserts des grands fleuves et des marais : d'autres, bien loin de fuir les endroits habités, les choisissent de préf́crence pour leur demeure ; ceux-ci vivent au milieu des bois, et y courent avec vitesse sur les rameaux les plus élcvés.

\section{LE LEZARD VERT.}

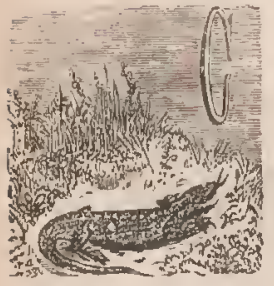

'EST dans les premiers jour's du printemps que le lézard vert brille de. tout son éclat, lorsque ayant quitté sit vieille peau, il expose au soleil son corps émaillé des plus vives couleurs. Los rayons qui rejaillissent de dessus ses écailles les dorent par reflets ondoyants : elles étincellent du feu de l'émeraude. C'est principalement dans les climats chauds qu'il se montre avec l'éclat de l'or et des pierreries; c'est là qu'une lumière plus vive anime ses coulours et les multiplie.

Plus fort que le lézard gris, le vert se bat contre les serpents : il est rarement vainqueur. L'on a dit yu'il 
avertissait l'homme de la présence des serpents qui pouvaient lui nuiro. Il recherche les vers et les insectes. Il se nourrit aussi d'œufs de petils oiseaux, qu'il va chercher au haut des arbres, où il grimpe avec assez de vitesse.

Quoique plus bas sur ses pattes que le lézard gris, il court cependant avec agilité et part avec assez do jromptitude pour donner un premier mouvement de

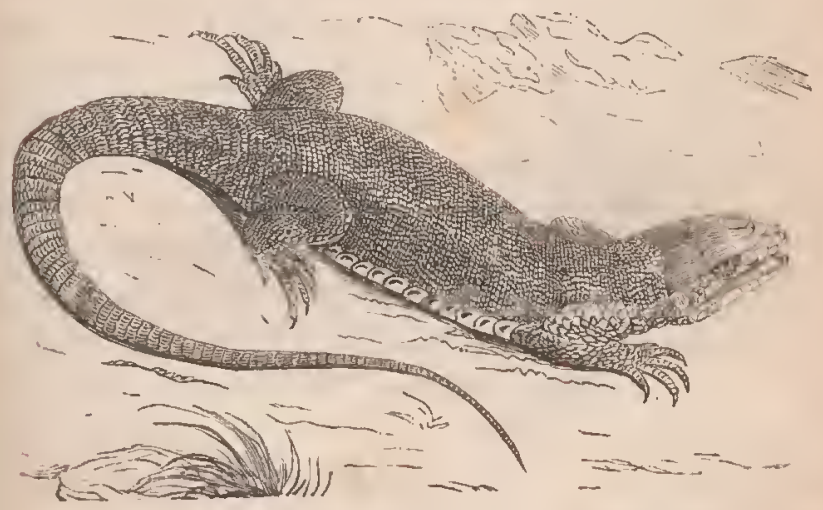

surprise et d'effroi, lorsqu'il s'élance au milieu dos broussailles ou des feuilles sèches. Il saute très-haut; et comme il est très-fort, il est aussi plus hardi que lo lézard gris : il se défend contre les chiens qui l'attaquent.

Ses habitudes sont d'ailleurs assez semblables à celles du lézard grris, et ses œufs sont ordinairement plus gros que ceux de ce dernier.

Ce n'est pas seulement dans les pays cliauds des deux 
continents qu'on trouvo ces lézards; ils habitent aussi des contrées très-tempérées, et même un peu septentrionales, quoiqu'ils y soient moins nombreux et moins grands.

\section{LE LEZZARD GRIS.}

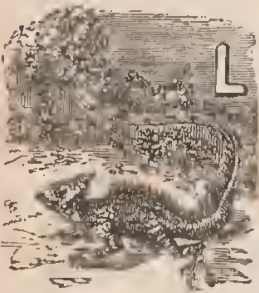

E lćzard gris paraît être le plus doux, le plus innocent, et l'un des plus utiles des lézards. Ce joli petit animal, si commun en France, n'a pas reçu de la nature un vêtement aussi éclatant que plusieurs autres quadrupèdes ovipares; mais elle lui a donné une parure élégante : sa petite taille est svelte; son mouvement agile ; sa course si prompte, qu'il échappe à l'œeil aussi rapidement que l'oiseau qui vole. Il aime à recevoir la chaleur du solcil; ayant besoin d'une température doucc, il cherche les abris; et, lorsque dans un beau jour de printemps, une lumière pure éclaire vivement un gazon en pente, ou une muraille qui augmente la chaleur en la réfléchissant, on le voit s'étendre sur ce mur ou sur l'herbe nouvelle, avec une espèce de volupté. Il se pénètre avec délices de cette chaleur bienfaisante; il marque son plaisir par de molles ondulations de sa queue déliée; il fait briller ses yeux vifs et animés; il se précipite comme un trait pour saisir une petite proie, ou pour trouver un abri plus commode. Bien loin de s'enfuir à 
l'approche de l'homme, il paraît le regarder avec comjlaisance: mais au moindıe bruit qui l'effraye, à la cliute scule d'une feuille, il se roulc, tombe et demeure pendant quelques instants comme étourdi par sa chute.

La couleur grise que présente le dessus de son corps est variée par un grand nombrc de taches bleutitres, et par trois bandes presque noires qui parcourent la longueur du dos; colle du milieu est plus étroite que les cleux autres. Son ventre est peint do vert changeant en lileu; il n'est aucune de ses écailles dlont lo reflet ne soit agríable; et pour ajouter à cette simple mais riante parure, le dessous du cou est grarni d'un collier composé d'écailles, ordinairement au nombre de sept, un peu plus grandes que les voisines, et qui réunissent l'éclat et la couleur do l'or.

Il a ordinairement cinq à six pouces de long, et un demi-pouce de large. On ne craint point ce lézard doux et paisible; on l'observe de près. Il échappe communément avec rapidité, lorsqu'on veut le saisir; mais lorsqu'on l'a pris, on le manie sans qu'il cherche à mordre; les enfants en font un jouct, ct, par suite de la granle douceur de son caractère, il devicnt familier avec cux. Les ancicns l'ont appelé l'ami de l'homme; il aurait fallu l'appeler l'ami de l'enfance.

Sa queue, qui va toujours en diminuant de grosscur, et qui se tcrmine en pointe, est à peu près dcrix fois aussi longue que le corps. Lorsqu'ello a été briséc par quelque accident, ellc repousse quelquefois. 


\section{LE CROCODILE.}

Cet animal énorme, vivant sur les confins de la terre et des eaux, ótend sa puissance sur les habitants des mers et sur ceux que la terre nourrit.

Il surpasse, par la longuour de son corps, et l'aigle et lo lion, ces fiers rois de l'air et de la terre.

Il ne lo cède en grandour qu'ù un petit nombre des animaux qui habitent les mêmos pays que lui. Il n'a pas l'instinct inné de la férocité. S'il se nourrit de proir, s'il dérore les autres animaux, s'il attarue même quelquefois l'homme, ce n'est pas pour assouvir un appétit cruel, mais uniquemenl pour satisfaire des besoins d'autant p'lus impérieux qu'il doit entretenir une masse plus considórable.

La forme générale dı crocodile est assez semblable, en grand, à celle des autres lézards. Nais sa tête est allongée, aplatie et fortemont ridée, le museau gros et un peu arrondi.

Les dents sont quelquefois au nomlire de trente-six dans la mâchoire supćrieure, et de trente dans la mîchoire inférieure; mais ce nombre doit souvent varier. Ellos sont fortes, un peu oreuses, pointues, inćrgales en longueur, altachées par de grosses l'acines placées de cliaque côté sur un seul ranģ, et un peu eourbéos en arrière, principalement celles qui sont vers le bout du museau. Leur disposition est telle, que, quand la gueule est ferméc, elles passent les unes entre les autres. 


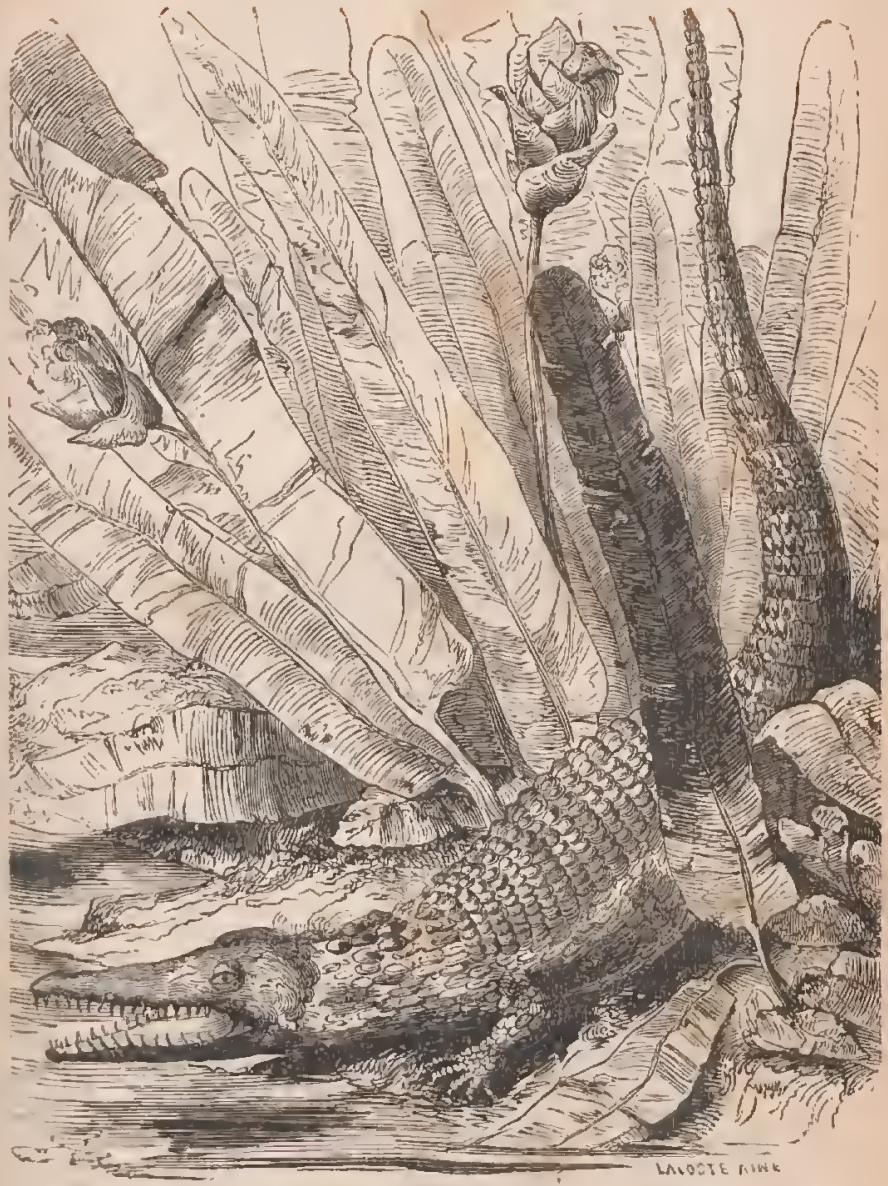


La mâchoirc inférienre est la senle mobile dans le crocodile; ainsi que dans les autres quadrupèdes.

On a pensé que le crocodilc n'avait pas de languc; il en a une cependant fort large, mais qu'il ne pcut ui allonger ni darder' à l'extéricur, parce qu'elle cst attachée aux cleux bor‘ls de la mâchoire infórieure par une membrane qui la couvre.

La nature a pourvu à la sûreté des crocodiles en les rcvêtant d'une armure presque impćnétrable. Tout leur' corps est couvert d'ćcailles, excepté le sommet de lit tête.

Ces écailles carrécs ont une très-grande dureté, et une flexibilité qui les empêche d'ètre cassantes: le milieu de $\cos$ lames présente une sorte de crêtc dure, qui ajoute à leur solidité, et, le plus souvent, elles sont à l'épreuve de la balle. C'est par les parties plus faibles que les cétacés et les poissons voraces attaquent le crocodile; c'est par' là que le dauphin lui donne la mort, et lorsque le chion de mer, connu sous le nom de poisson-scic, lui livie un combat, qu'ils soutiennent tous deux avec furie, le poissoll-scie, ne pouvant percer les écailles tuberculcuses qui revêtent le dessus du corps de son ennemi, plonge et lo frappe au ventre.

La couleur des crocodiles tire sur le jaune verdâtre, plus au moins nuancé d'un vert faible, par taches et par bandes; ce qui repr'isente assez bien la couleur du bronze un peu rouillé.

La taille des crocodiles varie suivant la températuro des diverses contrées dans lesquelles on les trouve. La longueur des plus grands ne passe guère vingt-cinq ou vingt-six pieds; dans certaines contrées, leur longueur 
ordinaire ne s'étend pas nu delà de treize ou quatorze pieds.

On n'a point recucilli assez d'observations sur les crocodiles pour savoir précisément quelle est la durće do leur vie; mais on peut croire qu'olle est très-longue.

Le crocodile fréquente de préfórence les rives des grands fleuves, dont les eaux surmontent souvont leul's bords, et qui, couvertes d'une vase limoneuse, ofrent en plus grande abondance les testacés, les vers, les grenouilles, les lézards dont il se nourrit. Il se pliît surtout dans l'Amérique mćridionale, au milieu des laes narécageux et des savanes noyúcs.

Quclque redoutable que paraisse le crocodile, les Nègres des environs du Sénćgal oscnt l'attaquer pendant qu'il est endormi, et tâchınt de lo surprendre dans des cndroits où il n'a pas assez d'eau pour nager'; ils vont ì lui audacicusement, le bras gauche enveloppé dans tun cuir ; ils l'attaquent à coups de lance ou de zagaie; ils le pereent do plusieurs coups au gosier et dans les yeux; ils lui ouvrent la gueule, la ticnnent sous l'cau et l'enpêchent de se fermer, en plaçant lour zagaie entre lut mîchoires, jusqu'à ce que le crocodile soit suffoqué pat' l'eau qu'il avale en trop grande quantité.

I.es sauvages de la Floride ont une autre manière do le prendre; ils se réunissent au nombre de dix ou douze; ils s'avancent au devant du crocodilc qui clierche une proie sur le rivage; ils portent un arbre qu'ils ont coupé par le picd; lo crocodile va ì eux la gueule béante; mais en enfonçant leur arbre dans cette large gueule, ils ont bientòt renviersé et mis à nnort le crocodile.

On dit aussi qu'il y a des gens assez hardis pour aller, 
en nageant, jusque sous le erocodile, lui pereer la peau du ventre, qui est presque le seul endroit où le fer puisse pénétrer.

Mais l'homme n'est pas le seul ennemi que le crocodile ait à eraindre; les tigres en font leur proie; l'hippopotame le poursuit, et il est pour lui d'autant plus dangereux, qu'il peut le suivre avee acharnement jusqu'au fond de la mer. Les eouguars, quoique plus faibles que les tigres, détruisent aussi un grand nombre de croeodifes. Ils attaquent les jeunes eaïmans; ils les attendent cn embuscade sur le bord des grands fleuvos, les saisissent au moment où ils montrent la tête hors de l'eau, et les dévorent. Mais lorsqu'ils en rencontrent de gros et de forls, ils sont attaqués ì leur tour; en vain ils enfoncent leurs griffes dans les yeux du crocodile; cet énorine lézard, plus vigoureux qu'eux, les entraino au fond de l'eau.

\section{LE CAMELÉON.}

On a dit que le eaméléon ehangeait souvent de forme, (qu'il n'avait point de couleur en propre, cu'il prenait eelle de tous les objets dont il approchait, qu'il en était par là une sorto de miroir ficlèle; qu'il ne se nourrissait que d'air. Mais le eaméléon des poëtes n'a jamais existé pour la nature.

Lorsque cependant nous aurons éearté les qualités faJuleuses attribuées au caméléon, et lorsque nous l'aurons peint tel qu'il est, on devia le r'egarder encore comme un 
des animaux les plus intéressants aux yeux des naturalistes, prar la singulière conformation de ses dirorses partios, par les habiturles remarquablos qui en dépendcut, et même par des propriétés qui ne sont pas très-différentes de colles qu'on lui a faussement attribuéos.

On trouve des onméléons de plusieurs tailles assez différentes les unes des autres.

La peau du caméléon est parsemée de petites ćminences comme le chagrin : elles sont très-lisses, plus marquées sur la tête, et environnées de grains presquc imperceptibles.

Non-seulement le caméléon a les yeux enveloppés d'une manière qui lui est particuliòre, mais ils sont mobiles indépendamment l'un de l'autre : quelcuefois il los tourne de manière que l'un regarde en arricire, et l'autre en avant; ou bien de l'un il voit les objets placés audessus de lıi, tandis que de l'autro il apercoit eeux qui sont situés au-dessous.

Sa langue, dont on a comparé la forme à um vor de torre, est longue et ronde communément de einq on six pouces, terminée par' une espèce de gr'os noud, ereuse, et enduite d'une sorte de vernis visqueux qui sert au caméléon à retenir les mouches, les scarabćes, les sauterelles, les fourmis et les autres insectes dont il se nourrit, et qui ne peuvent lui ćchapper, tant il la darde et la retire avec vitesse !

Le eaméléon est plus élevé sur ses jaunbes que le plus grand nombre des lózards; il a moins l'air de rampel' lor'squ’il marche. Il habite de préféronce sur les arbres, où il a d'autant plus de facilité à grimper et à se tenir, que sa queue est longue ot douée d'une assez grande 
force. C'est toujours avec lenteur qu'il va d'un rameau à un autre, et il esl plutôt dans les bois en embuscade sous les feuilles pour retenir Ies insectes ailés qui peuvent tomber sur sa langue giluante, qu'en mouvement de chasse pour aller les surprondre.

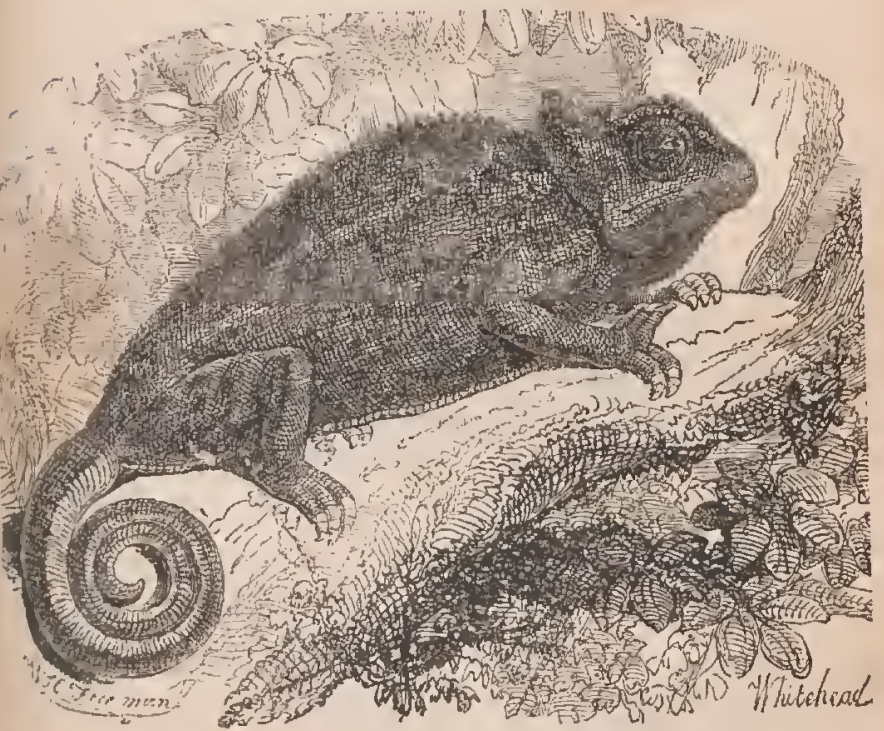

Il est si doux qu'on peut lui mettre le doigt dans la bouche, et l'enfoncer très-avant, sans qu'il cherche ì mordre.

Soit qu'il grimpe le long des arbres, soit que, caclıé sous les fenilles, il $y$ attende paisiblement les insectes doni il se nourrit, soit enfin qu'il marche sur la terre, il 
paraît toujonrs assez laid; mais la faculté qu'il a de présenter, suivant ses différents états, des couleurs plus ou moins variécs, a toujour's atliré sur lui l'attention.

Ces diverses teiutes changent, cn effet, avec autant de fréquence que de rapidité; elles paraissent d'ailleur's dépendre du climat, de l'âge ou du scxe. Il est donc assez difficile d'assigner quelle est la couleur naturelle du caméléon. Il parait cependant qu'en général ce lézard est d'un gris plus ou moins foncé, ou plus ou moins livide.

Il n'a reçu presque aucune arme pour se défendre : ne marchant quc très-lentement, ne pouvant point éclıapper par la fuite à la poursuite de ses ennemis, il est la proic de presque tous les animaux qui cherchent à lo dévorer.

Cet animal peut vive pris d'un an sans manger, et c'est vraisemblablement ce qui a fait dire qu'il ne se nom'rissait que d'air.

On trouve le camćlćon dans tous les climats clauds, tant de l'ancien que du nouveau continent.

\section{LA GRENOUILLE COMHUNE.}

Les grenouilles communes sont en apparence si contormes aux crapauds, qu'on ne peut aisćment se reprćscnter les unes sans penscr aux autres. S'il n'avait point cxisté de crapauds, si l'on n'avait jamais eu devant les yeux ce vilain objet de comparaison, qui enlaidit par sa ressemblance autant qu'il salit par son approche, la gre- 
nouille nons paraitrait aussi agréahle par sa conformation que distinguée par ses qualités, ct intéressante par les phénomènes qu'elle présente dans les diverses époques de sa vie.

Les grenouilles communes varient par la grandeur, suivant les pays qu'elles habitent, la nourriture qu'elles trouvent, la chaleur qu'elles éprouvent, etc. Dans les zones tempérées, la longueur ordinaire de ces animaux

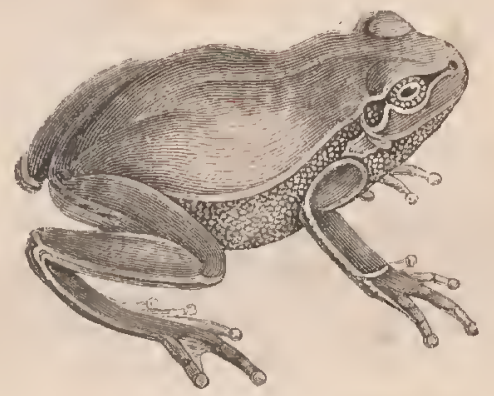

est rle deux à trois pouces. La gr'enouille est un des quadrupèdes ovipares les mieux partagés pour les sens extérieurs. Ses yeux sont, en effet, gros et saillants; sa peau molle, qui n'est recouverte ni d'écailles ni d'envcloppes osseuses, est sans cesse abreuvée et maintenuc dans sa souplesse par une humeur visqueuse qui suinle au travers de ses pores : elle doit donc avoir la vue trèsbonne et le toucher très-délicat; et si ses oreilles sont recouvertes par une membrane, elle n'en a pas moins 'ouie fine.

Cette supériorilé dans la sensibilité des grenouilles les 
rend plus difficiles sur la nature de leur nourriture; elles rejeltent tout ce qui pourrait présenter un commencement de décomposition. Si elles se nourrissent de vers, de sangsues, de petits limacons, de scarabées et d'autres insectes tant ailés que non ailés, elles n'en prennent aucun 'ju'elles ne l'aient vu renuer, comme si elles voulaient s'assurer qu'il vit encore.

La grenouille commune sort souvent de l'eau, nonseulcment pour chercher sa nourriture, mais encore pour s'imprégner des rayons du soleil. On l'entend de très-loin, dès que la belle saison est arrivée et qu'ellc est pénétrée de la chaleur du printemps, jeter un cri qu'elle répète pendant asscz longtemps, surtout lorsqu'il est nuit.

Le coassement des grenouilles, qui n'est composé que de sons rauques, de tons discordants et peu distincts Ins uns dles autres, serait très-desagrćable par lui-mòme, el quand on n'entendrait qu'une seule grenouille à la fois : mais c'est toujours en grand nombre qu'elles coasscnt; et c'cst toujours de trop près qu'on entend ces sons confus, dont la monotonie fatigante est réunie à une rudesse propre à blesser' l'oreille la moins délicate.

Elles sont dévorées par les serpents d'eau, les anguilles, les brochets, les taupes, les putois, les loups, les oiseaux d'eau et de rivage, etc. Comme elles fournissent un aliment utile, et que même certaines parties de leur corps forment un mets très-agréable, on les recherclie avec soin. On a plusieurs manières de les pêcher; on les prend avec des filets à la clarté des flambeanx, qui les effrayent et les rendent souvent comme imnobiles; ou bien on les pêclıe d̀ la ligne avec des lamecons quion 
Garnit de vers, d'insectes ou simplement d'un morceau d'étolfe r'ouge ou couleur de clrair' : ear les grenouilles sont goulues; elles saisissent avidement et retiennent ¿ivec obstination tout ce qu'on leur présente.

La grenouille commune habite presque tous les pay's.

\section{LE CRAPAUD COMIUN.}

Depuis longtemps l'opinion a flétri cet animal dégoìtant, dont l'approche révolte tous les sens. L'espèce d'hor'reur avec laqquelle on le découvre est produite même par l'image que le souvenir en retrace : beaucoup de gens ne se le représentent qu'en éjrouvant une sorte de frémissement, et les personnes qui ont le tempérament faible et les nerfs délicats, ne peuvent en fixer l'idée sans croire sentir dans leurs veines le froid glacial que l'on a dit accompagner l'attouchement du crapaud; tout en est vilain, jusqu'ì son nour, qui est devenu le siģne d'une basse difformité.

Non-seulcment le crapaud ne peut point marcher, mais il ne saute qu'à une tròs-petite hauteur; lor'squ'il se sent pressć, il lance contre ceux qui le poursuivent les sues létides dont il est imbu; il fait jaillir une liqueur limpide qui, dans certaines circonstances, est plus ou moins nuisible. Il transpire de tout son corps une humeur laiteuse, et il découle de sa bouche une bave qui peut infecter les herbes et les firuits sur lesquels il passe, de manière à incommoder ceux qui en nangunt sans les laver. Cette bave 
et cetle humeur laiteuse peuvent être un venin plus ou moins actif, ou un corrosif plus ou moins fort, suirant lat température, la stison, et la nourriture des clapauds, l'espèce de l'animal sur lequel il agit, et la nature de la par.

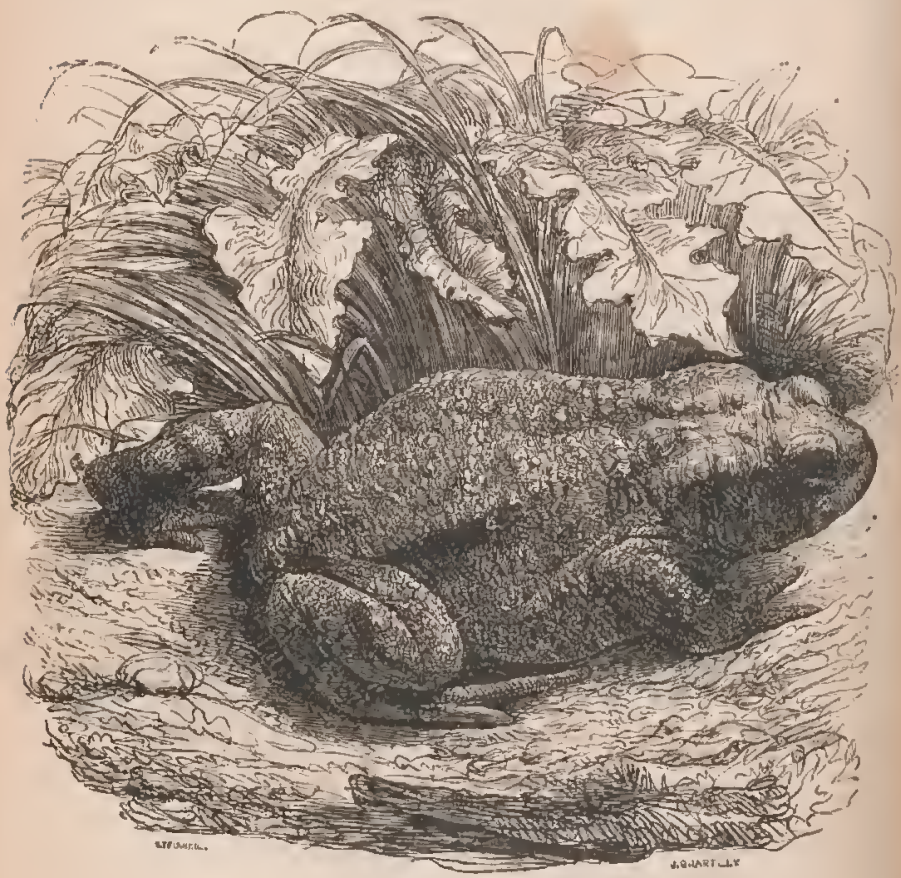

tie qu'il attaque. La traee du crapraud peut donc êtı'c, dans certaines circonstances, aussi funeste que son aspect est dégoûtant.

Le crapaud habite pour l'ordinaire dans les fossés, sul'tout dans ceux où une eatu fétide croupil depuis longr- 
temps; on le trouve dans les furnier's, dans les caves, dans les antres profonds, dans les forêts où il peul se dérober Aisément à la clarté qui le blesse en choisissant de préférence les endroits ombragés, sombres, solitaires, en s'enfonçant sous les décombres et sous les tas de pierre.

C'est dans ees diver's asiles obscurs qu'il se tient renfermé pendant tout le jour, à moins que la pluic ne l'oblige à en sortir.

\section{LES SERPENTS.}

Les espèces des scrpents sont en grand nombre; on en compte plus de cent quarante : quelques-unes parvienment à une grandeur trìs-considérable; elles ont plus de trente pieds, et souvent mìne plus de quarante pieds de longueur. 'Toutes sont eouvertes d'écailles ou de tubercules écailleux qu'elles licnt les uns avec les autres; mais ces écailles varient beaucoup par leur forme et par leur grandeur.

Entre les limites assignnées par la nature à la longueur des serpents, c'est-ì-dire dejuis celle de quarante ou nême cinquante pieds jusqu'à celle de quelques pouces, on trouve presque tous les degr'és intermádiaires occupés par quelque espèce ou quelque variété de ces reptiles : si l'on ajoute à la variété des longueur's des serpents celle des couleurs éclatantes dont ils sont peints, depuis le blaric et le rouge le plus vif jusqu'au violet le plus foncé, et niême jusqu'au noir; si l'on réunit encore à toutes 
ces différences celles que l'on doit tirer de la position, de la grandeur et de la forme des écailles, ne verrit-t-on pas que l'ordre des serpents est un des plus varićs de ceux qui peuplent et embellissent la surface du globe?

Toutes les espèces de ces animaux habitent de préférence les contrées chaudes ou tempérées; on en trouv" dans les deux mondes, où ils paraissent ì peu près également répandus en raison de la chaleur, de l'humidité et de l'espace libre. Plusieurs de ces espèces sont communes aux deux continents ; mais il paraît qu'en général ce sont les plus grandes qui a ppartiennent à un plus grand nombre de contrées différentes.

Tous lcs serpents viennent d'un ucuf; mais, dans certaines espèces de ces reptiles, Ies oeufs éclosent dans le ventre de la mòre.

Les femolles ne courent point leurs oufs; elles les abondonnent après la ponte.

Lorsque les petits serpents sorit éclos, ils trainent seuls leur frèle existence; ils n'apprennent de leur mère, dont ils sont sćparćs, ni à distinguer leur proie, ni à trouver un abri ; ils-sont réduits à leur scul instinct; aussi doit-il en périr beaucoup avant qu'ils soient assez développés et «qu'ils aicnt acquis assez d'expérience pour se trarantir des dangers. Le sens de l'ouïe doit être très-obtus dans ces animaux. Lcur odorat ne doit pas être très-lin, mais leurs yeux sont ordinaircment brillants et aninés, trèsmobiles, très-saillants, placés de inanière à recevoil l'image d'un cspace étendu. Leur vue doit donc être, el est, en effct, très-perçante. Leur goût peut être assez actif. Leur toucher même doit être assez fort. Plusieur's espìces de serpents vivent tranquillement aupròs des 
habitations de l'hommc, entrent filmiliuremont dans ses rlcmeures, s'y ćtablisscnt même quelquofois et les délivrent d'animaux nuisibles, et particulic̀rcment d'insectes malfaisants; on a vu des serpents réduils à une vraie domesticité, donner ì leurs maittres des sig̣nes d'atla-

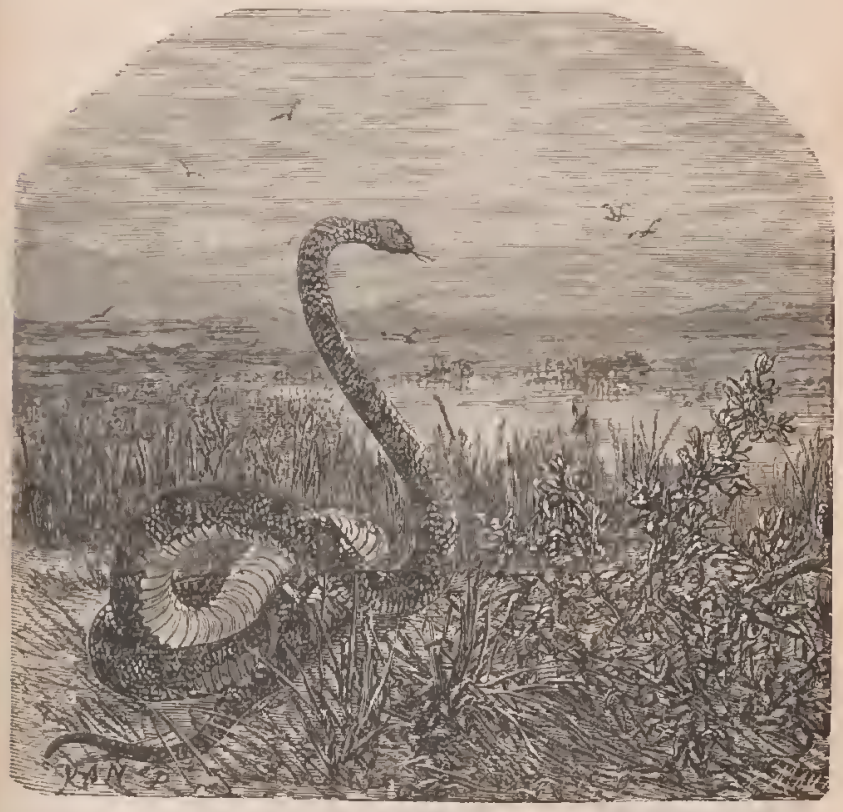

chloment supćrieurs à lous ceux qu'on a remarqués dans [Nusieurs espèces d'oiscaux et mềne de quadrupèdes.

Il en est des serpents comme de plusieurs autres ordres d'animaux: eeux qui sont très-orrands sont rarement Musieurs enscmble. Il leur faut trop de place pour se Inouvoir, trop d'cspace pour chasser'; doués de plus de 
force et d'armes pllus puissantes, ils doivent s'inspirer' mutuellement plus de crainte. Mais ecux qui ne parviennent pas à une longueur trùs-eonsidérable, et qui n'exeèdent pas sept ou liuit pieds de long, lrabitent souvent en très-grand nombre, non-seulement sur le même rivage ou dans la même forêt, suivant qu'ils se nourrissent d'animaux aquatiques ou de ceux des bois, mais dans le même asile souterrain; e'est dans des eavernes profondes qu'on les reneontre entassés, pour ainsi dire, les uns contre les autres, repliés et entrelaeés de telle sorte qu'on eroirait voir des serpents à plusieurs têtes.

Les petites espèces éprouvent, pendant l'hiver, un engourdissement plus ou moins profond et plus ou moins long, suivant la rigueur et la durée du froid.

Elles sortent de Iour sommeil anmuel lorsque les premiers jours clıuds du printemps se font ressentir.

On ignore quelle est la longucur de la vie des serpents. On doit eroire qu'elle varie suivant les espuces, et pu'elle est d'autant plus considúrable qu'elles pirvienment à de plus grandes dinensions. Los très-grandes espèces doivent vivre u'ès-longtemps.

Lorsque los très-grands serpents sont encore éloignés de leur eourte vieillesse, lorsqu'ils jouissent de toute leur aetivité et de toutes leurs forces, ils doivent Ies cntretenir par' une grande quantité de nourriture substantielle; aussi ne se contentent-ils pas de brouter l'herbe ou de manger des graines et des fruits, ils dévorent les animaux qu'ils peuvent saisir ; et eomme, dans la plupart des serpents, la digestion est très-Iongue, et que leurs aliments demeurent très-longlemps dans leur corps, les substanees animales qu'ils avalent, et qui sont très-sus- 
reptibles de putréfaction, s'y décomposent et s'y corrompent au point de rúpandre l'odeur la plus fétide.

La masse des aliments qu'ils avalent est quelquefois si grosse relativement à l'ouverture de leur gosier', que,

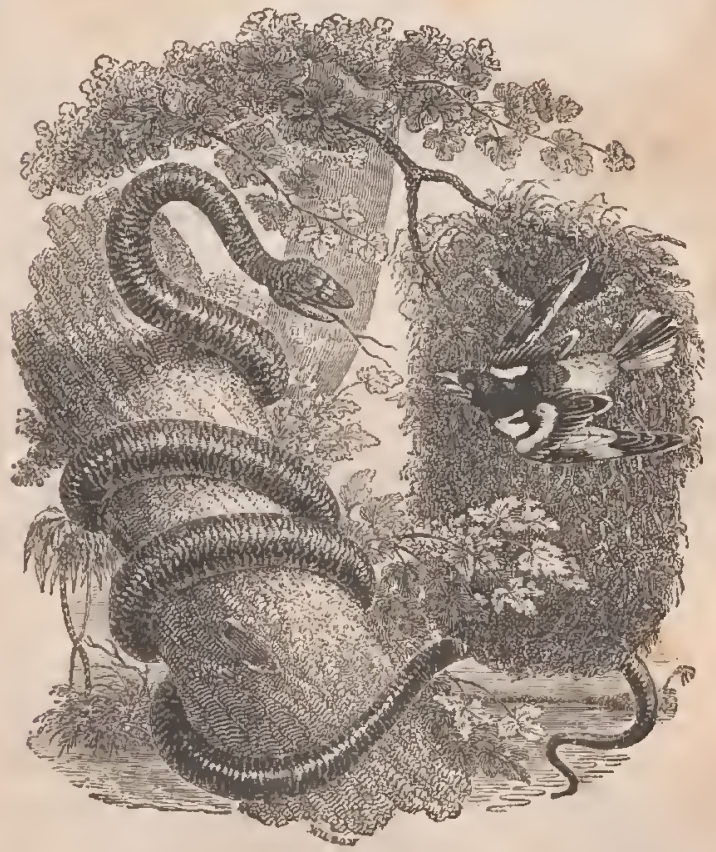

malgré tous leur's elforts, l'écartement de leurs mâchoires et l'extension de leur peau, leur proie ne peut entrer qu'ì demi dans leur estomac. Étendus alors dans leur retraite, ils sont obligés d'attendre que la partie qu'ils ont déjà avalée soit digćrée, et qu'ils puisscnt de nouveau ćcraser, broyer, cnduire et fréparer les portions trop grosses. 
Lorsque leur digestion est achevée, ils reprennent une aetivité d'autant plus grande que leurs forees ontété jlus renouvelées ; ct pour peu surtout qu'ils ressentent alor's de nouveau l'aiguillon de la faim, ils redeviennent trèsdangereux pour les animaux plus faibles qu'eux ou moins bien armés. Ils préludent presque toujours aux eombats qu'ils livrent par des sifflements plus ou moins forts.

Si les sifflements des très-grands serpents étaient entendus de loin eomme les cris des tigres, des aigles, des vautours, ete., ils serviraient à garantir de l'approche dangereuse de ces énormes reptiles; mais ils sont bien moins forts que les rugisscments des grands quadrupèdes earnassiers et des oisenux de proie. La masse seule de ees grands serpents les tralit et les empêehe de eaeher' leur' pour'suite; on s'apercoit facilement de leur approehe, dans les endroits qui ne sonl pas eouverts de bois, par le mouvement des hautes herbes qui s'agilent et se coulbent sous leur poids.

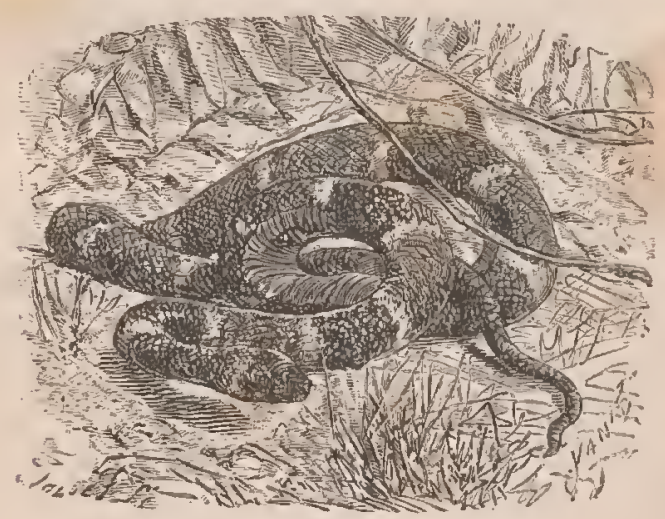




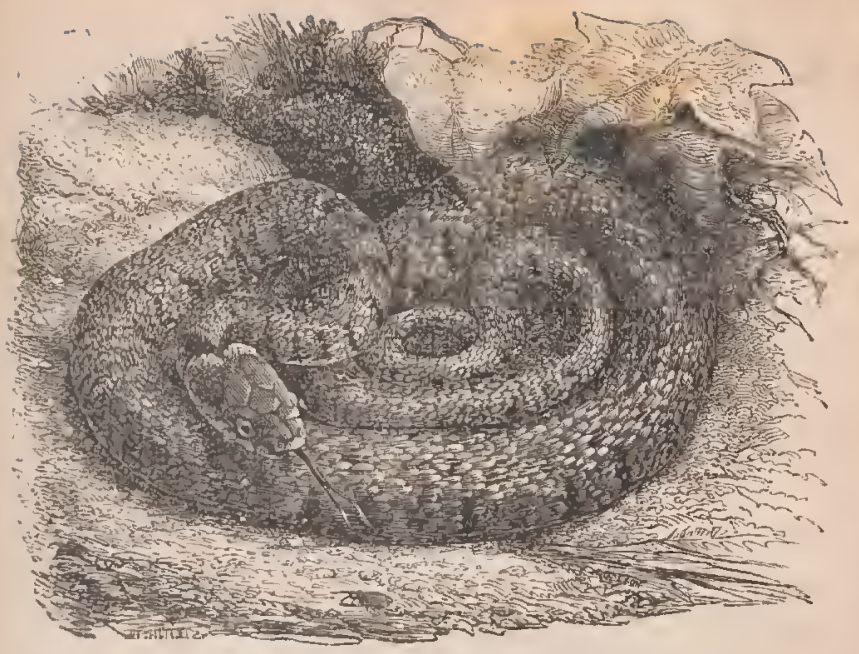

\section{COULEUVRES ET VIPËRES.}

\section{LA VIPLRE COMMUNE.}

Parmi les espèces de serpents dont le venin est plus ou moins funeste, une des plus anciennement et des Inieux connues est la vipère commune. Elle est, en effet, très-multipliée en Europe; elle habite autour de nous; elle infeste nos bois et nos demeures ; elle est aussi petite, áussi faible, aussi innocente en apparence, que son venin est dangereux; elle serait presque ignorée sans le poison funeste qu'elle distille. Sa longueur totale est communément de deur pieds. Sa couleur est d'un gris condré, et le long de son dos, depuis la tête jusqu'à l'extrémité de la 
queue, s'étend unc sortc de chainc composée de taches noirâtres de forme irrégulière, et qui, en se réunissant cı plusieurs endroils les unes aux autres, r'cprésentent fort bien une bande dentelće et située en zigzzag.

La tête va en diminuant de largeur du côté du museau, où elle se termine en s'arrondissant.

Le nombre des dents varic suivant les individus; il est souvent de vingt-huit dans la mâchoire supérieure, ct de vingt-quatre dans l'inférieure: mais toutes les vipères ont, de chaque côté de la mâchoirc supérieure, me ou deux, quelquefois trois ou quatre dents, longues d'environ trois lignes, blanches, diaphanes, crochues et très-aiguës ; on les a appelées les dents canines do la vipirr. Ges dents longues et crochues sont très-mobiles et creuses; elles renferment une double cavité et sont elles-mêmes renfermées, jusqu'aux deux ticrs de leur longueur, dans une espèce de gaine composée de fibres très-fortes et d'un tissu cellulaire. Cotte gaine ou tunique est toujours ouverto vers la pointe de la dent.

Le poison de la vipère est contenu dans une vésicule placée dẻ chaque côté de la tête, au-dessous du muscle de la mâchoire supérieure: le mouvement du muscle pressant cette vésicule en fait sortir le venin, qui arrive par un conduit à la base de la dent, traverse la gaine qui l'enveloppe, entre dans la cavité de cettc dent par le trou situé près de la base, en sort par celui qui est auprès de la pointe, et pénètre dans la blessure. Ce poison est la seule humeur malfaisante que renferme la vipèrc.

La vipère a les yeux très-vifs et garnis du paupières, et, comme si elle sentait la puissance redoutable du venil qu'elle recèle, son regard parait liardi; ses yeux brillent, 
surtout lorsru'on l'irute; et alors non-sculement elle les anime, mais ouvrant sa gueule elle darde sa langue, qui est communément grise, fendue en deux ; l'animal l'agite avec tant de vitesse, qu'clle étincelle, pour ainsi dire, et que la lumière qu'elle réfléchit la fait paraître comme unc sorte de petit phosphore.

Elle peut passer un très-long temps sans manger, ct l'on a même éerit qu'elle pouvait vivre un an et plus sans rien prendre. Ce fait est peut-être exagéré; mais du moins il est sûr qu'elle vit plusieurs mois privée de toute nourriture.

L'on ignore quelle est la durée exaete de la vie des vipères.

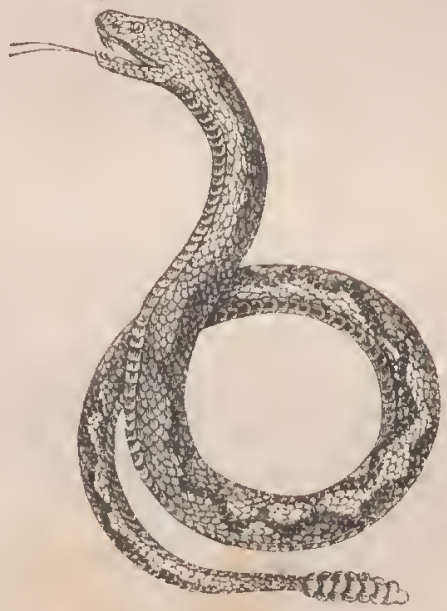




\section{LA COULEUVRE VERTE ET JAUNE.}

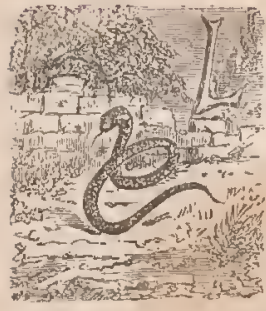

A couleuvre est nussi innocente que la vipère cst dangereuse: parée de coulcur's plus vives que ce reptile funestc, douée d'une grandeur plus considérable, plus svelte dans ses proportions, plus agile dans ses mouvements, plus douce dans ses hahitudes, n'ayant aucun vcnin à répandre, elle devrail être vue avec autant de plaisir que la vipère avec effroi.

Cependant cet animal, aussi doux qu'agréable à la vue, peut être aisément distingué de tous les autres serpents, et particulièrement des dangereuses vipères, par les belles couleurs dont il est revêtu.

Elle se tient presque toujours cachée, comme si les mauvais traitements qu'elle a si souvent reçus l'avaient rendue timide; elle cherche à fuir lorsqu'on la dècouvre. Elle devient docile lorsqu'elle est prise; clle subit une sorte de domesticité ; elle obéit aux divers mouvements qu'on veut lui faire suivre.

Il y a cependant certains moments, et même certaines saisons de l'année, où la couleuvre verte et jaune, sans être dangereuse, montre ce désir de se défendre ou de sauver ce qui lui est cher, si naturel à tous les animaux.

Dans tous les endroits où le froid est rigoureux, la couleuvre commune s'enfoncc, dès la fin de l'automne, dans des trous souterrains ou dans d'autres creux, où elle s'engourdit plus ou moins complétement pendant l'hiver. 
Lorsque les benux jour's du printemps paraissent, ce reptile sort de sa torpcur et se dépouille comme les autres serpents.

\section{LA COULEUVRE A COLLIER.}

C'est encore dans nos contrées que se trouve en trèsgrand nombre ceserpent, allssi doux, aussi innocent, áussi familier que la eonleuvre verte ct jaune. Ses habitudes ne diffèrent pas, à beaucoup d'égards, de eelles de eette couleuvre. Il parait cependant (qu'il se plaît davantage dans des lieux humides, ainsi qu'au milieu des eaux; et c'est ee qui lui a fait donner par plusieurs naturalistes le nom de serpent d'cau, de scrpent nageur, d'anguille do haie. Il parvient quelquefois à la longueur de trois ou quatre pieds.

In couleuvre à collier ne renfermant ancun venin, on la manie sans danger ; clle ne lait aucun effort pour mordre; elle se défend seulement en agitant rapidement sa queue, et clle ne refuse pas plus que la couleurre eommune de jouer avec les enfunts. On la nourrit dans les maisons, où elle s'accoutume si bien à ceux qui la soiGnent, qu'au moindre signe clle s'entortille autour de leurs doights, de leurs bras, de leur cou, et les presse comme pour leur témoigner une sorte de tendresse et de reconnaissanee. La couleuvre à collier se trouve dans presque tontes les contrées de l'Europe, et il paraît qu'elle peut supporter les climats très-froids, puisqu'elle vit en Écosse et en Suède.

On a employé sa chair en médecine. 


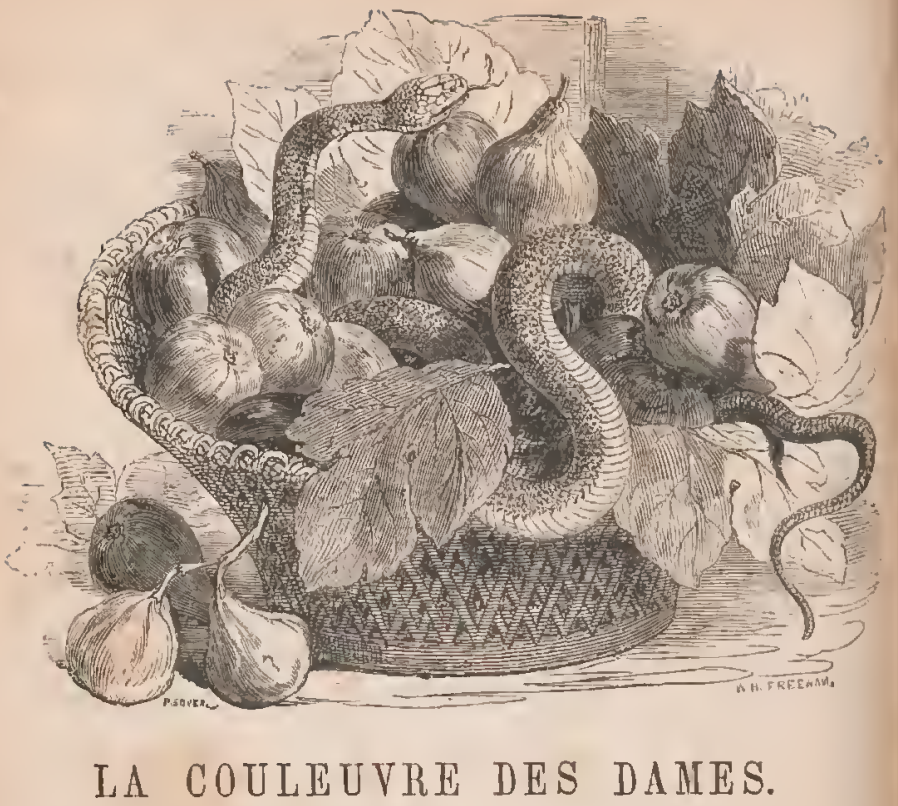

Voici un des plus jolis et des plus doux serpents. Sa petitesse, ses proportions, plus sveltes encore que celles de la plupart des autres espèces, ses mouvements agiles, quoique modérés, ajoutcnt au plaisir avec lequel on considère le mélange de ses belles tcintes. Il ne présente cepcndant que deux couleurs, un beau noir et un blanc assez pur; mais elles sont si agréablement contrastéos ou réunics, et si animées par le luisant des écailles, que celte parure élégante el simple attirc l'oeil et charne d'autant plus les regards, qu'elle n'éblouit pas commc des couleurs plus richcs el plus éclatantes.

Comme plusieurs autres serpents, cclui des darnes est 
. 


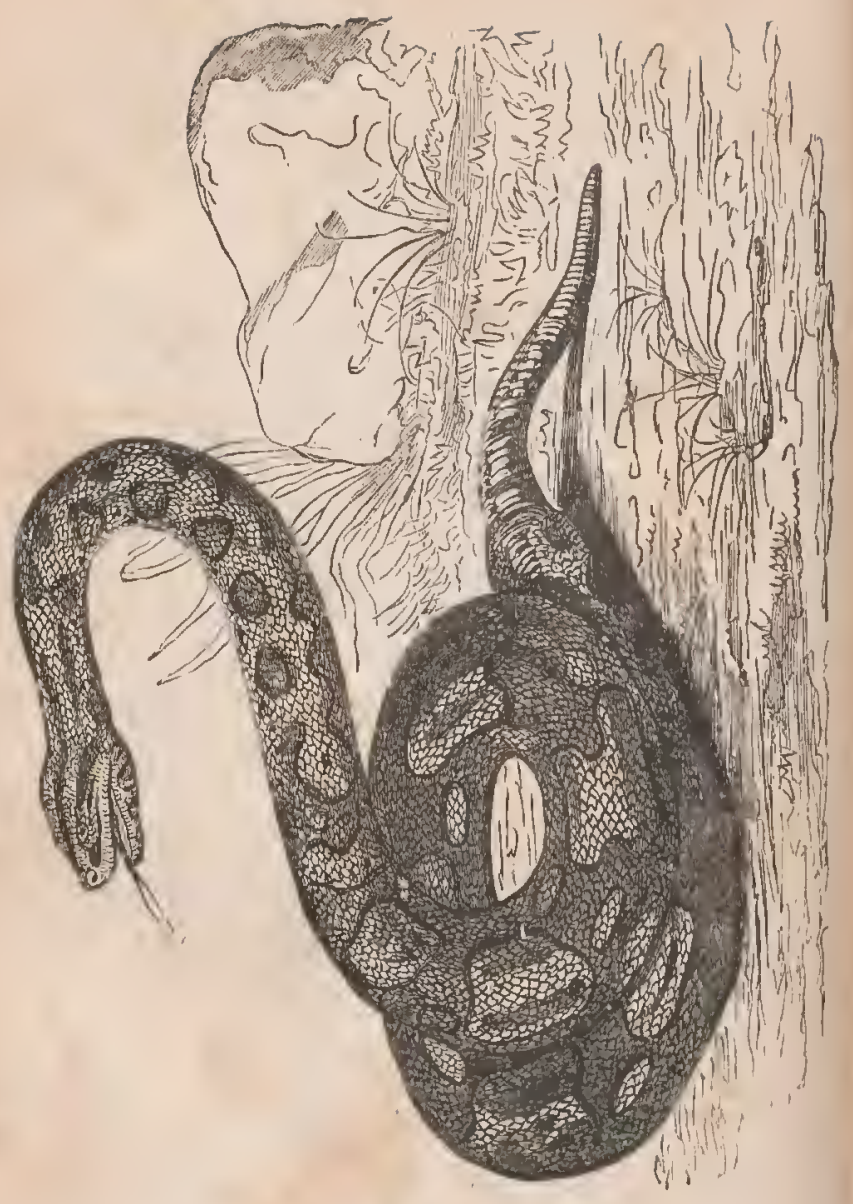


très-familier; il ne s'enfuit pas, et mêmc il n'éprouve aucune crainte lorsqu'on l'approche : bien plus, il semble que, très-sensiblc à la fraîcheur plus ou moins grande qu'il ćprouve quelquefois, quoiqu'il labite des climats tròs-chauds, il recherche des secours qui l'en garantissent, et sa petitesse, son peu de force, l'agrément de ses couleurs, la douceur de ses mouvements, l'innocence de ses habitudes, inspiront aux Indieus un tel intérêt pour ce délicat animal, que le sexe le plus timirle, bien loin d'en avoir peur, le prend dans ses mains, le soigne, le caresse.

\section{LE BOA OU DEVIN.}

Le devin est jarıni les serpents comme l'éléphant ou le lion parmi les quadrupèdes; il surpasse les animaux de son ordre par sa grandeur comme le premicr, et par sa force comme le second. Il parvient communćment à la longueur de plus de vingt pieds, èt il paraît que c'est à cette espc̀ce qu'il faut rapporter les individus de quarante ou cinquante picds de long qui habitent les déscr'ts brûlants où l'homme uc pénètre qu'avec peine.

Le devin est romarquable par la forme de sa tête, qui annonce, pour ainsi dire, Ia supćriorité de sa force. Le sornnet en est élargi, le front ćlevé el divisć par un sillon longitudinal; les orbites sont saillantes, et les ycux très-gros ; le muscau est allongé et tcrminć par une grande écaille blanchâtre, tachetée de jaune, placée presque verticalement, et échancréc par le bas pour laisser passer la 
langue; l'ouverture de liı guculo est très-m̧rande. Les dents sont tris-longues; mais le devin n'a point de oroclıets mobiles. La queue est trìs-courte en proportion du corps, qui est ordinairement neuf fois aussi long que cette partie; mais ollo est très-dure et très-forto.

Ce scrpent ćnormo cst d'ailleurs aussi distingué par la lreauté des ćcailles quil le couvrent et la viracité des couleur's dont il ost peint, que par sa longueur prodigicuse.

Lorsque l'on considère la taille démesuréc de ce scrpent, l'on ne doil pas ètre étonné de sa forec prodigieuse. Indépondamment le la roideur do ses muscles, il est aisé de concevoil' comment un animal qui a quolquefois trente picds de lonrog peut, avec facilité, éloufler et écrascr de très-gros anirnıux dans les replis multipliés do son corps, dont tous les points agissent, et dont lous les contours saisissent la proie.

Il habite presque tous les pays oì il a trouvé asscz de clialeur pour ne rion pordro de son activité, assez de proic pour se nourrir, et assez d'espaco pour n'ètre pas trop souvent tourmenté par ses emremis; il vit dans les Indes oriontales et dans les grandes îles de l'Asic, ainsi que dans les parlies do l'Anérique voisines des deux tropiques.

Mais c'est surtout dans les déserts brûlanis de l'Afrique, qu'cxcrçant une dominalion moins troublée, il parvient à une longueur plus considérable. On fiémit lorsqu'on lit, dans les relations des vorageurs qui ont pénétré dans l'intérieur de celte partic du monde, la nıanicre dont l'énorme serpent devin s'arance au milien des herbes hautes et des broussailles, ayant quelquefois plus de dix-lıuit pouces de dianc̀tre, et semblable à une 
longue poutre qu'on remuernit avec vitesse. On aperçoit de loin, par le mouvement des plantes qui s'inclinent sous son passage, l'espèce de sillon que tracent les diverses ondulations de son corps; on voit fuir devant lui les troupeaux de gazelles et d"autres animaux dont il fait sa proie; et le seul parti qui reste à prendre dans ces solitudes immenses, pour se garantir de sa dent meurtrière et de sa force funoste, est de mettre le feu aux horbes dójà à demi brûlées par l'ardour du soleil. Le fer ne suffit pas contre ce dangereux serpent, lorsqu'il est parvenú à toute sa longueur, et surtout lorsqu'il est irrité par' la faim. L'on ne peut éviter la mort qu'en couvrant un pays immense de flammes qui so propagent avec vitosse au milicu de végélaux presque cntièrement desséchés, cn cxcitant ainsi un vaste incendic, et en élevant, pour ainsi dire, un rempart de feu contro la poursuile de cet ćnorme animal.

Il se retire aussi quelquefois dans les cavernes des montagnes, et dans d'autros antres profonds où il a moins à craindre les altaques de ses ennemis, et où il cherche un asile contre les tempéralures froides, les pluies trop abondantos, et los aulres accidents de l'atmosphère qui lui sont contraires.

\section{LE SERPENT A SONNETTE OU LE BOIQUTRA.}

Ce terrible reptile renferme un poison mortel; et il n'est pout-être aucune espèce de serpent qui contionne un renin plus aclit. 
Le boiquira parvient quelquefois à la longueur de six pieds, et sa circonfércnce est alors de dix-huit pouces.

Sa tête aplatie est couverte, auprès du museau, de six écailles plus grandes que leurs voisines.

Les ycux paraissent étincelants, et luisent même dans les ténèbres, comme ceux de jlusieurs autres reptiles, en laissant échapper la lumic̀re dont ils ont été pénétrés pendant le jour ; et ils sont garnis d'une membrane clignotante.

La couleur du dos est d'un gris mêlé de jaunâtre, et sur ce fond on voit s'étendre une rangée de taches noircs borilées de blanc.

La queue est terminée par un assemblago d'écailles sonores qui s'emboîtent les unes dans les autres, et qui forment la sonnette.

Toutes les parties des sonnetles ćtant très-sèches, posées les unes au-dessus des autres, et ayant assez do jou pour se frotter mutuollement lorsqu'clles sont secouées, il n'est pas surprenant qu'elles produisent un bruit assoz sensiblo; ce bruit, qui resscmble à celui du parchemin qu'on froisse, peut être entendu à plus de soixamte pieds de distance. Il serait bien à désirer qu'on pût l'entendre do plus loin encorc, afin que l'approche du boiquira, étant moins imprévue, fut aussi moins dangereuse. Ce serpent est, en effet, d'autant plus à craindrc, que ses mouvements sont sourent très-rapides; en un clin d'ocil il se replie en cercle, s'appuie sur sa qucue, se précipite comme un ressort qui se débande, tombe sur sa proie, la blesse et sc retire pour échapper ì la vengcance de son ennemi : aussi les Mexicains le désignent-ils par un nom qui signifie le vent. 
Ce funeste reptile habite presque toutes les eontrées du Nouveau-Monde. Il se nourrit de vers, de grenouilles ct même de lièvres : il fait aussi sa proie d'oisenux et d'éeureuils, ear il monte avec facilité sur les arbres, et s'y élanee avee vivacité de branehe en branche, ainsi que sur les pointes de roehers qu'il habite, et ee n'est que dans la plaine qu'il court avee diffieulté, et qu'il est plus aisé d'éviter sa poursuite.

Son haleine empestée, qui trouble quelquefois les petits animaux dont il veut se saisir, peut aussi empêcher qu'ils ne lui échappent. Les Indiens raeontent qu'on voit souvent le serpent à sonnette entortillé à l'entour d'un arbre, lançant des regards tcribles eontre un écureuil, qui, après avoir manifesté sa frayeur par ses cris et son agitation, tombe au pied de l'arb)re, où il cst dévoré.

Lor'sque le printemps est arrivć dans les pays habités par les boiquiras, que les neiges sont fonducs et que l'air ost réehauffé, ils sortent pendant le jour de lcurs retraites, pour aller s'exposer aux rayons du soleil. Ils rentrent pendant la nuit dans leurs asiles, et ce n'est que lor'sque les gelćes ont entièrement eessé qu'ils abandonnent leurs eavernes, se répandent dans les eampagnes, et pénètrent quelquefois dans les maisons.

Le boiquira naģe avee la plus grande aģilité; il sillonne la surface des eaux avec la vitessc d'unc flèche. Mallıeur à eeux qui navigntent sur de petits bâtiments auprès des plages qu'il firćcuente!

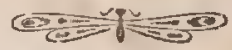




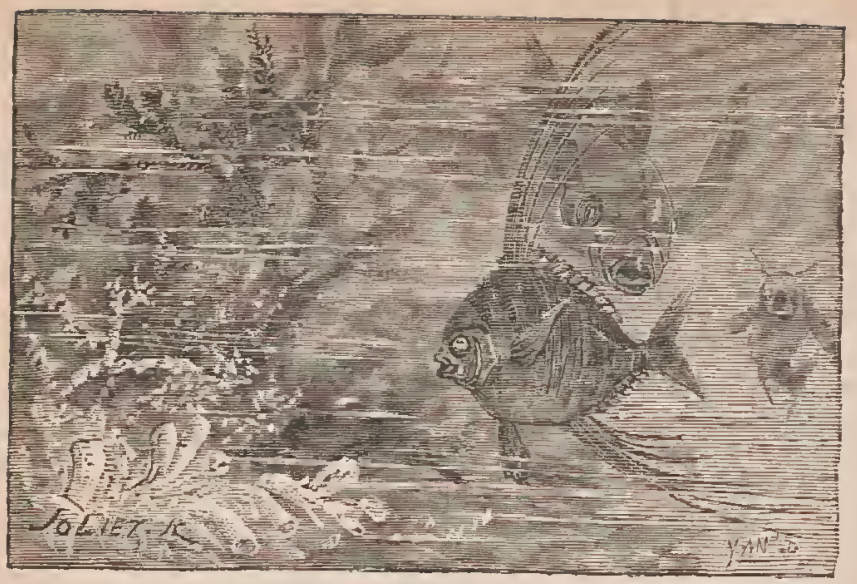

\section{POISSONS.}

POISSONS CARTILAGINEUX.

\section{LA RAIE BATIS.}

C'est toujours au milieu des mers que les raies font leur séjour; mais, suivant les différentes époquos de l'année, elles changent d'habitation au milieu des flots de l'Ocćan.

L'ensemble du corps de la raic batis présente un peu la forme d'un losange. La pointe du inuseau est placée à l'angle antérieur'; les rayons les plus longs de chaque nageoire pectorale occupent les deux angles latéraux, 
et l'origine de la queue se trouve au sommet de l'angle de dorric̀re.

L'ouverture de la bouche, placée dans la partic inférieure de la tête, et même à une distance assez grande de l'extrómité du museau, est allongée et transversale, et ses bords sont eartilagineux et garnis de plusieurs

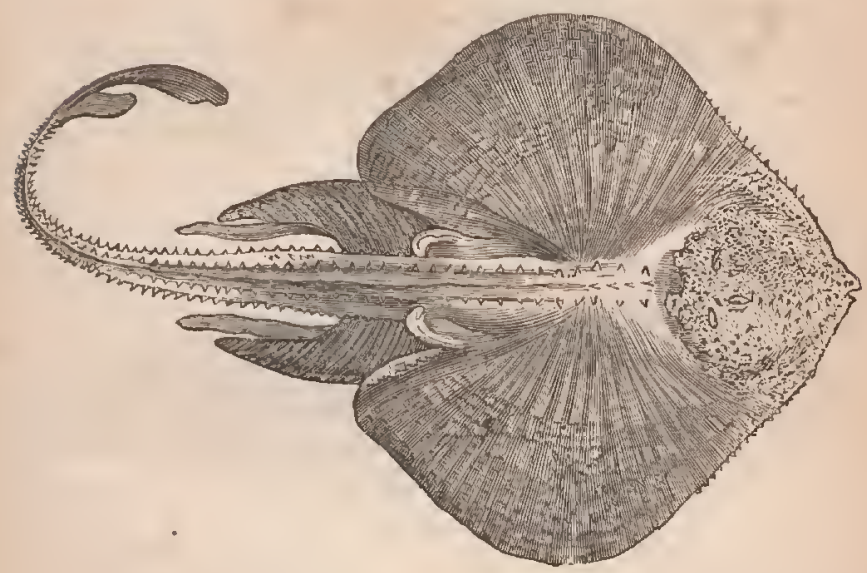

rangs de denls très-aiguës ol crochues. La langue esı triscourte, large, et sans aspérités.

Les narines, placées au-dovant do la bouche, sont situées également sur la partio infóricure do la tèle. L'ouverture de eet orgganc peut ôtro élargie ou rétrécic à la volonté de l'animal, qui d'aillours, après avoir diminuó le diamètre de cette ouverlure, peut la fermer en totalité par une membrane particulière attaclice alu 
côté de l'orifice le plus voisin du milieu du mmsenn, et | laquelle, s'étendant aveo facilité jussu'au bord opposé, et s'y collant, pour ainsi dire, peut fairc l'office d'une sortc de soupape, et empêcher que l'eau chargée des ćmanations odorantes ne parvienne jusqu'à un organe trèsdélicat, dans les moments où la batis n'a pas besoin d'être avertie de la présonee des objets extérieurs, et dans ceux où son système nerveux serait douloureusement affecté par une action trop vive et trop constante.

Les youx sont situés sur la partie supérieure de la tête, et à peu près à la même distance du inuseau que l'ouverture de la bouche.

Elle a dcux nageoires ventrales placées à la suite des nagcoires pectorales, que deux antres nageoires touclent de plus près, et entourent, pour ainsi dire.

Elle remuc avec force ct avec vitosse sa queue lon gue, souple et menue qui pout sc flćchir et se contourner on différents sens. Elle l'agite comme une sorte de fouct, non-seulement lorsqu'elle se défend contre ses ennemis, mais oncore lorsqu'elle attaque sa proie. Elle s'en sert particulièrement lorsqu'on embuscade dans le fond de la mer, cachée presque entièrement dans le limon, elle voit passer autour d'elle les animaux dont elie cher'che à se nour'rir; elle emploie alors sa queue, et, la fléchissant avee prompiitude, elle atteint sa vietime et la frappe souvent à mort.

La peau rui revêt et la tôte, et le eorps, et la queue, est forte, tenaee ot enduite d'une humeur gluante qui en entretiont la souplesse, et la rend plus propre à rósistar sans altération aux attaques des ennemis des raies, et aux effels du fluide au milieu duquel vivent les batis. 
On pêche un très-grand nombre de batis sur plısieurs côtes, et il est même des riviıges où on en prend ıne si grande quantité, qu'on les y prépare pour les envoyer au loin, comme la morue et d'autres poissons sont préparés à Terre-Neuve ou dans d'autres endroits.

\section{LA TORPILLE.}

La torpille possède la puissance remarquable et redoutable de lancer, pour ainsi dire, la foudre; elle aceumule dans son corps et en fait jaillir le fluirle ćlcotrique aveo la rapidité de l'éclair; elle imprime une commotion soudaine ot paralysante au bras le plus roluste qui s'avance pour la saisir, à l'animal le plus terrible qui veut la dévorer; clle engourdit pour des instants assez longs les poissons les plus agiles dont elle cherche à se nourrir; clle frappe quelquefois ses coups invisibles à une distance assez grande.

Un naturaliste voulut éprouver la vertu d'une torpille que l'on venait de pêcher. "A peine l'avais-jo touchéc et serrée avec la main, dit-il, que j'éprouvai darıs eette partie un picotement qui se communiqua dans le bras ot dans toute l'épaule, et qui fut suivi d'un tremblement désigrićable et d'une douleur acoablante et aiguë dans lo coude, en sorte que je fus obligé de retirer aussitôt li main. ¿ Cet engourdissement a été aussi décrit par Róaumur, qui a fait plusieurs observations sur la raic torpille. a Il est très-différent des engourdissements 
ordinuires, a écrit ce savant naturaliste ; on rossent dans toute l'étendue du bras une espèce d'étonnement qu'il n'est pas possible de bien peindre, mais lequel a quelque rapport avec la sensation douloureuse que l'on éprouve dans le bras lorsqu'on s'est frappé rudernent le coude contre quelque corps dur. "

\section{LE REQUIN.}

Le requin est le tigre de la mer. Rechercliant sans crainte tout ennemi, poursuivant aveo plus d'obstination, attacuant avec plus de rage, combattant avec plus d'acharnement que les autres habitants des eaux; plus dangereux que plusieurs cétacés, qui presque toujours sont moins puissants' que lui ; inspirant même plus d'effroi que les baleines, rapide dans sa course, répandu sous tous les climats, ayant envahi, pour ainsi dire, toutes les mers; paraissant souvent au milieu des tempêtes; aperçu facilement par l'éclit phosphorique dont il brille parmi les ombres des nuits les plus orageuses; menaçant de sa gueule énorme et dévorante les infortunćs navigateur's exposés aux horreurs du naufrage, leur fermant toute voie de salut, leur montrant en quelque sorte leur tombe ouverte, et plaçant sous leurs yeux le signal de la destruction, il n'est pas surprenant qu'il ait reçu le nom qu'il porte, et qui, réveillant lant d'idées lugubres, rappelle surtout la mort, dont il est le ministre. Requin est en effet une corruption de requiem, qui dé- 
signe rlepuis longtemps, en Europe, la mort et le ropos éternel.

Le corps du requin est très-allongé, ct la peau qui le recouvre est garuie de petits tubcreules très-scrés lcs uns contrc les autres. Comme cetto peau tuberculéc ost très-dure, on l'emploie, dans les arts, ṫ polir différents ouvrages de bois et d'ivoire; on s'en sert aussi pour couvrir des étuis et d'autres meubles.

La eouleur de son dos et de ses côtós est d'un condré brun, ct celle du dessous do son eorps d'un blanc sale.

La tête est aplatie, et terminóo par un muscau un pen arrondi. Au-dossous de cette extrémité, on voit los narines qui, étant lo siége d'un odorat très-fin et très-lílicat, doment au requin la facilité de reconnaitre do loin sa proie, et de la distingucr au milieu des eaux los plus agitées par les vents, ou des ombres de la nuit la plus noire, ou de l'obscurité des abînes les plus profonds de l'Océan.

L'ouverture de la houche est en forme de demi-cercle, et placée transvorsalement au-dessous de in têtc et derrière les narines. Elle est très-grande; et l'on pourra juger facilement de ses dimonsions, on sachant que lo contour d'un côté de la mâchoire supéricure, mesuró depuis l'anglo des deux mâchoires jusqu'au sommet de la mâchoire d'en haut, égalle à pell près le onzic̀me de la longueur tolale de l'animal. Le contour de la mâchoire supérieure d'un requin de trente piods est done environ de six pieds de longueur.

Lorsque cctte gueule est onverte, on roit au deli des lèvres, qui sont étroites of de la consistance du eriir, des dents plates, triangulaires, dentelées sur leurs bor'us, et 
blinches comme de l'ivoire. Chacun des bords de cette partie émaillée, qui sort hor's des gencives, a communément près de deux pouces de longueur dans les requins de trente pieds. Le nombre des dents augmente avec l'àge de l'animal. Lorsque le requin est encore très-jeune, il n'en montre qu'un rang, dans lequel on n'aperçoit même quclquefois que de bien faibles dentelures : mais lor'squ'il est devenu adulte, sa gueule est armée, dans le liauk comnle dans le bas, de six rangs de ces dents fortes, dentelées et si propres à déchirer ses victimes.

Toute la partie antérieure du muscau est criblée, pardessus et par-dessous, d'une grande quantité de pores répandus sans ordre, très-visibles, et qui, lorsqu'on comprime fortement le devant de la tête, répandent une espèce de gelée épaisse, cristalline et phosphorique.

Les yeux sont petits et presque ronds; la cornée est très-dure; l'iris d'un vert foneé et doré; et la prunelle, qui est Hleue, consiste dans une fente transversale.

Toules les nageoires sont fermes, roides et cartilagineuses. Ies pectorales, triangulaires, et plus grandes que les autres, s'étendent au loin de clıaque côlé, et n'ajoutent pas peu à la rapidité avec laquelie nage le requin, et dont il doit la plus grande partic à la forec et à la mobilité de sa queue.

Lorsque lc requin est sorti de son ocuf, et qu'il a étendu librement tous ses membres, il n'a encore que quelques pouces de longueur; et l'on ignore quel nombre d'années doit s'écouler avant qu'il présento celle de plus de trente pieds. Mais à peine a-t-il atteint quelques degrés de cet innmense développoment, qu'il se montre avec toute sa voracité. 
Quelquefois lo défaut d'aliments plus substantiels l'oblige de se eontenter de sépies, de mollusques, ou d'autres vers marins : mais ee sont les plus grands animaux qu'il reeherche avee le plus d'ardeur; il est surtout trèsempressé de eourir partout où l'altirent des eorps morts de poissons ou de quadrupèdes, et des eadavres humains.

Il y a sur les côtes d'Afrique des nèmres assez hardis pour s'avaneer en nageant vers un requin, le liarceler, prendre le moment où l'animal se retourne, et lui fenclı̀e le ventre avee une arme tranehante. Ce n'est que diffieilement qu'on lui ôte la vie; il résiste sans périr à de larges blessures; et lorsqu'il a expiré, on voit eneore pendant longtemps les différentes parties de son corps donner tous les signes d'une grande irritabilité.

La elıair du requin est dure, coriace, de mauvais goût, et difficile à digóerer. Les Nègres de Guinée, et particulic̀rement eeux de la Gôte d'Or, s'en nourrissent eependant, et ôtent à cet animal presque toute sa dureté en le gardant très-longtemps. Les Islandais font un grand usage de la graisse du requin : ils s'en servent à la plaee du lard de eochon, ou la font bouillir pour en tirer l'huile.

Les requins sont très-répandus dans toutes les mers.

\section{L'ESTURGEON.}

Cet énorme paisson habite non-seulement dans l'Océan, mais encore dans la Méditerranée, dans la mer Rougre, dans le Pont-Luxin, dans la mer Caspienne. Mais au lieu 
de passer sa vie clans lesmers salées, comme les raies, les squales, les lophies, les balistes et les ehimères, il roeherehe les eaux douces comme le pétromyzon lamproie, lorsque lo printemps arrive, qu'une ehaleur nouvelle se fait sentir jusqu'au milieu des ondes, y ranime le sentiment le plus aetif, et que le besoin de pondre et de féeonder ses œufs le presse et l'aiguillone. Il s'engago alor's dans presque tous les grands fleuves.

Il grandit et engraisse dans les rivières fortes et rapides, suivant qu'il y reneontre la tranquillité, la tempćrature et les aliments qui lui conviennent le mieux; et il est de ees fleuves dans lesquels il est parvenu à un poids énorme, et jusqu'à celui de mille livres.

Lorsqu'il est eneore dans la mer, ou près de l'embouehure des grandes rivières, il se nourrit de harengs ou de maquereaux et de gades; et lorsqu'il est engagé dans les fleuves, il attaque les saumons, qui les remontent à peu près dans le même temps que lui, et qui ne peuvent lui opposel qu'une faible résistanee. Comme il paraît semblable à un géant au milieu de ces légions nombreuses, on l'a comparé à un ehef, et on l'a nommé le conducteur des saumons.

Il dépose dans les fleuves une immense quantité d'œufs, et sa ehair y présente un degré de délicatesse très-rare, surtout dans les poissons eartilagineux. Aussi eetle chair a-t-elle été prise très-souvent pour eelle d'un jeune veau, et l'esturgeon a-t-il été de tous les temps très-reeherehé. Non-seulement on le mange frais, mais, dans tous les pays où l'on en prend en grand nombre, on emploie plusicurs sortes de préparations pour le eonserver of pouvoir l'envoyer au loin 


\section{POISSONS OSSEUX.}

\section{L'ANGUILLE.}

Los nageoires pectorales de l'anguille sont assez pctites, et ses autres nageoires assez étroiles pour qu'on puisse la confondre de loin avee un véritable sorpent: 'elle a do même lo corps très-allongé et prosque eylindrique. Sa têtc est menue, lo museau un peu pointu, ct la mâehoire inférieure plus avaneće que la supérieure.

Les couleur's que l'anguille présente sont toujours agréables, mais elles varient assez fréquemment; et il parait que leurs nuances dépendent beaucoup de l'animal, et de la qualité de l'eau au milieu de laquelle il vit.

Los anguillos se nourrissont d'insectes, de vers, d'œufs et de petitos espèees de poissons. Elles attaquent quelquefois des animaux un peu plus gros. Dans eertaines cireonstanees, elles se contentent do la ehair de presque lous les animaux morts qu'elles reneontrent au milieu 'les eaux; mais elles causent souvent de grands ravages dans les rivières. Dans la basse Seine elles détruisent beaueoup d'éperlans, de elupécs feintes et de brènes.

Ce n'est pas eependant sans danger qu'elles recherchent l'alimont qui lour eonvient le micux : malgré leur souplesse, leur vivaeilé, la vitesse de leur fuito, elles ont des ennomis auxquels il leur est très-diflicile d'échapper. 
Les loutres, plusieurs oiscaux d'eau et les grands oiseaus de rivage, tels que les grues, les hérons et les cigognes, les pêchent avee habileté et les retiennent avec adresse; $l^{e}$ brochet, l'esturgeon en fout aussi leur proie.

Pendant le jour, la murène anguille, moins occupce do se procurer l'aliment qu'elle désire, se tient presque toujours dans un repos réparateur, et dérobée aux yeus de ses ennemis par un asile qu'elle préjare avec soin. Elle se creuse avee son museau une retraite plus ou moins grande dans la terre molle du fond des lacs et des rivières; et par une altention yarticulic̀re, cette espèce de terrier a deux onvertures, de telle sorte que, si elle est attaquéc d'un eôté, elle peut s'échapper de l'autre.

Lor'squ'il fait très-chaud, l'anģuille quitte cependant quelquefois, même vers le milieu du jour, cet asile qu'elle sait se donner. On la voit très-souvent alors s'approcher de la surface de l'eau, se placer au-dessous d'un amas do

- mousse flotlante ou de plantes aquatiques, y domeurer' immobile, et paraître se plaire dans cette sorle d'inaction et sous cet abri passager.

Lorsque les maladies ne dérangent pas l'organisation intérieure de l'anguille, lorsque sa vie n'est attaquée qul par des blessures, elle la perd assez difficilement; lo principe vital paraît disséminé d'une manièreassez in dépendanto dans los diverses parties de cette murène, pour qu'il ne puisse être éteint que lor'squ'on cherche ì l'anéantir dans plusieurs points à la fois; et de mênc que dans plusieurs serpents, et particulièrement dans la vipère, une lıeure après la séparation du trono et do ${ }^{13}$ tête, l'une et l'autre de ces portions peuvent donner en" core des signes d'une grande irritabilité. 
Cette vitalité tenace est une des causes de la longue vic que l'on croit devoir attribuer aux anguilles, ainsi qu'ì la pluparl des autres poissons.

Tous les climats peurent convenir à l'anguille.

\section{LA MORUE.}

Dans toutcs les contrées de l'Europe, et dans presque toutes celles de l'Amérique, il est bien peu de persolnnes qui ne connaissent le nom de la morue, lá bonté de son goût, et les qualités qui distinguent sa chair.

Le corps de la morue est allongé, légèrement comprimé et revêtu d'écailles plus grandes que cellos des autres gades.

L'espèce ordinaire est d'un gris condré, tacheté de jaunâtre sur le dos. La partie inférieure du corps est blanche, et quelquefois rougeâtre, avec dos taches de couleur d'or dans les jeunes individus. Les nageoires pectorales sont jaunâtres; une teinte grise distingue les jugulaires. Toutes les autres nageoires présentent des taclies jaunes.

La morue est si goulue, qu'elle avale souvent des morceaux de bois ou d'autrcs substances qui ne peuvent pas servir à sa nourriture : mais olle jouit de la faculté qu'ont reçue les squales et les oiseaux de proie, elle peut rejcter facilement les corps qui l'incommodent.

L'eau douce ne parait pas lui convenir'; on ne la voit jamais dans les fleuves ou les rivières; elle ne s'approche 
môme des rivages que dans le temps du frai; pendant le leste de l'année, clle se tient dans les profondeurs des mers. Elle Labite partieulièrement l'océan Septenuiontl.

Depuis plusieurs sic̀cles, les peuples industrieux et marius de l'Europe out senti l'importance de la pêehe des :arorues, et s'y sont livrés avee ardeur.

\section{LE MERLAN.}

Tout le monde sait que le eorps du merlan est allongé, et revêtu d'ćcailles petites, minces el arrondies; que ses nageoires dorsales sont au nombre de trois ; qu'il n'a pas de barbillons; que sa mâchoire supérieure est plus avaneée que l'inférieure; que eette mâehoire d'en haut est armée de plusieurs rangs de dents, dont les antérieures sont les plus longues; qu'on n'en voit qu'une rangéc à la mâchoire d'en bas.

Le merlan habite dans l'océan qui baignne les eôtos europćennes. Il se nourrit de vers, de mollusques, de crabes, de jeunes poissons. Il s'approehe souvent des rivages, et voilà pourquoi on le prend pendant presque toute l'année; mais il abandonne partieulièrement la haute mer, non-seulement lorsqu'il va se débarrasser du poids de ses œufs ou les féeonder, mais eneore lorsgu'il est attiré vers la terre par une nourriture plus agréablo et plus abondante, et lorscu'il y eherehe un asile contro les gros animaux marins qui en font leur proie. 


\section{LA LOTE.}

La lote a le corps très-allongé et serpentiforme. On voit sur son dos deux nageoires dorsales, mais très-basses et très-longues. Ses écailles sont très-minces, molles, trc̀spetites, el quelquefois sćpiarées les unes des autres; ct la peau à laquclle elles sout altachécs est enduite d'une liumeur visqueuse très-abondante, comme celle de l'unguille : aussi échappe-t-elle facilement, de même que ce dernier poisson, à la main de ceux qui la serrent avec trop de force et veulent la retenir avec irop peu cl'adresse; elle glisse entrc leurs doigts, parce qu'ello est perriétucllement arrosée d'une liqucur gluante, et elle sc dérobe encore à ses enncmis, parce que son corps, trèsallongé et très-mobile, se contourne avec promptitude en différents sens, et imite parfaitement toutes les positions et tcus les mouvements d'un reptile.

La lote est, de plus, d'une couleur assez semblable à celle dc plusieurs murènes, ou de quelques murénophis. Elle est variée, dans sa partie supérieure, de jaune et de brun; et le blanc rògne dans sa partie inférieurc.

Au lieu d'habiter dans les profondeurs de l'Océan ou près des rivages de la mer, clle passe sa vie dans les lacs, dans les rivic̀res, au milicu de l'eau douce, à de trèsgrandes distances de l'Ocćan.

On la trouve dans un tr'c̀-grand nombre de contrées, non-seulement en Europe, mais encore dans l'Asie et dans les Indes, 
La lote croit beaucoup plus vite que plusieurs autres osseux; elle farviont jusqu'ì la longueur d'un mòtre.

Sa chair ost blanche, agréable au goût, facile ì cuire ; son foie, qui est très-volmmineux, ost rogardé comme un mets délicat. Ses œufs sont presque toujours difficiles à digërer.

\section{LE THON.}

Cos poissons ont besoin d'une asso7. grande quantité de nour'riture, parce qu'ils présentent communément des dimensions considurables. Les observateurs modernes ont mesuré et pesé des thons de trois cent vingth-ciny centimètres, et du poids do cinquante-cinc ou soixante lilogrammes, et cependant ces poissons, ainsi que tous ceux qui n'éclosent pas dans le ventre de lemr mùre, proviennent d'œufs très-pelits : on a comparó la grosseur de ceux du thon à collo des graines de pavot.

Le corps de ce scombre est très-allongé, et semblable à une sorte de fuseau tròs-étendu. La tête est petite, l'œil 'gros, l'ouverture de la bouche très-large; la mûchoire inférieure plus avancée que la supérieure, ot garnie, comme cotte dernière, de donts aiguës; la langue courto et lisse. Les coulcur's qui le distinguent ne sont pas trisvarićes, mais agréables ot brillantes.

On s'occupe de la pêche de ces animaux sur plusicur's rivages de la France et de l'Espagne, depuis les premiers jour's d'avril jusqu'con septembro; et l'on assure que l'ar" 
rivée des maquereaux annonce cclle des thons, qui los poursuivent poù les dévorer.

\section{LE IIAQUEREAU.}

La grande vitcsse avec laquelle les marquereaux se transportent d'une plage ver's une autre n'a pas peu contribué à l'opinion adoptée presque universellement jusqu'à nos jours, au sujet de leurs changements périodiques d'habitalion. On a cru que le maquereau était soumis à des migrations régulières, et que les individus de cette espèce qui passaient l'hiver dans un asile plus ou moins sûr auprès des glaces polaires, voyageaient pendant le printemps ou l'été jusque dans la Méditerranće. Mais on sait aujourd'hui que les maquereaux passent l'hiver dans les fonds de la iner plus ou moins éloignés des côtes dont ils s'approchent vers le printempls; qu'au commencement de la belle saison, ils s'avancent vers le rivage qui leur convient le mieux, se montrent souvent à la surface de la mer, parcourent des chemins plus ou moins directs, ou plus ou moins sinucux, mais ne suivent point le cercle périodique auquel on a voulu les attacher et n'obéissent pas à cet ordre de lieux et de temps auque on les a dits assujettis.

Dans les régions polairos, ils rostent une partie de l'année enfouis au fond de la mer, dans un ctat d'engourdissement complet. Ce n'est que vers la fin de juin qu'ils reprennent une partie de leur activité, sortent de leur's 
trous, s'élaneent dans les flots, et pareourent les grands rivages. Il semble même que la stupeur ou l'engourdissement dans lequel ils doivent avoir été plongés pendant les très-grands froids, ne se dissipe que par degrós: leurs sens paraissent très-alfaiblis pendant une vingtaine de jours: leur rue est alor's si débile, qu'on les eroit aveugles, et qu'on les jrend faeilement au filct. Après co temps de faiblesse, on est souvent foreé de renoncer à ectte maniòre de les pêeher ; les inaquercaux, reeouvrant entièrenent l'usage de leurs yeux, ne peuvent plus en quclque sorte être puis à l'hameçon; mais eornme ils sont eneore très-maigres, et qu'ils se ressentent beaucoup de la longue diète qu'ils ont éprouvée, ils sont très-avides d'appâts, et on en fait une pêehe trìs-abondante.

Comme les appélits des maquereaux sont très-violents, et que leur nonbre leur inspire peut-être une sorte de confianee, ils sont voraees et même liardis : ilsattaquent souvent des poissons plus gros et plus forts qu'eux; et on les a même vus quelquefois se jeter avee une audace aveugle sur des pêelıeurs qui voulaient les saisir, ou qui se baignaient dans les eaux de la mer. Mrais s'ils oherchent à faire beaucoup de vietimes, ils sont perpétuellement entourés de nombreux ennemis. Les grands habitants des mers les dévorent; et dles poissons en apparenee assez faibles, tels que les murènes el les murénophis, les eombattent avec avantage. 


\section{LE ROUGET.}

Avoc quelle magnificenee la nature n'a-t-elle pas décoré ee poisson! Quels sourenirs ne réveille pas ee mulle dont le nom se trouve dans les éorits de tant d'autcurs faneux de la Grìce et de Rome! G'est à sa brillante parure qu'il a dû sa eélébrité. Et, on effot, non-seulement un rouge éclatant le colore en se mêlant à des tointes argentines sur ses eôtés et sur son ventre; nonseulement ses nageoires resplendissent des divers reflets de l'or"; mais enoore le rougre clont il est point, appartenant au eorys proprement dit du poissoll, ot paraissant au travers des écailles très-transparentes qui revêtent l'animal, reçoil par sa transmission et le passage que lui livre une substance diaphane, polie ot luisante, toule la vivacité que l'art peut donner' aux nuanees qu'il emploie, par lo moyen d'un vernis habilement préparé. Voilà pour'puoi le rouget montre encore la tointe qui le dislingue lorsqu'il ost dépouillé de ses écailles; et voilà pourquoi eneore les Romains gardaient les rougets dans leurs viviers, comme un ornement qui devint bientôt si lecherché, que Ciećron reproche à ses compatriotes l'orgucil insconsé auquel ils se livraient, lorsqu'ils pouvaient montrer de beaux mulles dans les caux de leu's habitations favorites.

Lo devant de la tôte du rouģet paraît comme tronqué, 011, pour micux dire, lo sommet de la tête de ee poisson est très-élevé. Les deux mâchoires, égalemen tavancécs, sont, de plus, garnies d'une grande quantité de petites dents. 
Los écaillos qui rocouvrent la tête, le corps et la queue, se détacient facilement.

Le rouget vit souvent de crustacés. Il n'entre que rarement dans les rivières, et il est des contrées où on le prend dans toutes les saisons. On le pêclıe non-seulement à la ligne, mais cncore au filet.

On le trouve dans plusicur's ners, auprès des côtes du Portugal, de l'Esjagne, de la France, et particulièrement à une petite distance de l'embouchure de la Gironde, dans la Méditerranéc, aux environs de la Sardaigne, de Malte, du Tibre et de l'Hellespont, et dans les eaux qui baignent le rivage des îles Moluques.

\section{LA PERCHE.}

La porche habite parmi nous; clle peuple nos lacs et nos rivières; elle est servie sur toutes nos tables. Elle attire les regards par la nalure et par la disposition de ses couleurs, surtout lorsqu'clle vit au milicu d'une onde pure.

On en a jêché en Angleterre du poirls de quatre ou einq kilogrammes. On en trouve, en Sibérie et dans la Laponie, d'une grandeur telle, que plusieurs écrivains les ont nommées monstrueuses.

Elles se plaisent beaucoup dans les laes; elles les quittent néanmoins pour remonter dans les rivières et dans les ruisscaux, lorscu'clles doivent frayer. On ne les. voit guère que dans les eaux douces. 
La perche habite dans presque toute l'Europe, et si elle est asscz rare vel's l'embouchuro des rivières, elle ost comıruno auprès de lcur's sources, dans los lacs d'où elle tiro son origine.

Ce poisson vit de proie. Il ne peut attaquer avec avantago quo de petits animaux; mais il so jetto avec aviditć non-soulement sur des poissons très-jeunes ou très-faibles, mais oncore sur des campagnols aquatiques, des salamandros, des grenouilles, des couleuvres encoro peu développées. Il se nourrit aussi quelquofois d'insectes; et lorsqu'il fait très-chaud, on le voit s'ćlever à la surface des lacs ou des rivières, et s'ćlaneer avec agilité pour saisir les cousins qui se pressent par milliors audossus de ces rivières ou de ees laes.

La perehe ost nồme si vorace ru’ello se précipite fréquomment ot sans précaution sur des ennemis dangereux pour clle par lcurs armes, s'ils ne lo sont pas par lour forco. Elle veut souvent dévolor des épinoches; mais ces derniers poissons, s'agitant avec vitesse, font pénólrer lours piquants dans le palais de la perche, qui dès lors no pouvant ni les avaler, ni les rejeter, ni fermer sa bouche, est contrainte de mourir de faim.

Lorsqu'clle peut se proeurer faciloment la nourriture qui lui cst nécessairc, et qu'clle vit dans les eaux qui lui sont lo plus favorables, clle est d'un goût exquis. Sa chair est d'ailleurs blanche, forme et très-salubre.

Les perches du Rhin sont particulièrement trèsestimées. 


\section{LA LIMANDE}

Ce poisson, très-eommun sur nos tables, se trouve nonseulement daris l'oeéan Allantique, mais encore dans la Baltique et dans la Méditerranée. Le temps de l'année où il est le plus agréable an groût, au moins dans les eontrées du nord de l'Europe, est la fin de l'hiver ou le eommeneement du printemps.

La limande vit de vers ou d'inseetes marins, et trèssouvent de petits erabes.

\section{LA SOLT.}

Ge poisson est reeherehé, même pour les tables les plus somptueuses. Sa chair est si tendre, si délicate et si agréable au goût, qu'on l'a surnommé la perdrix de mer. On le trouve non-seulement dans la Baltique et dans l'océan Atlanlique boréal, mais encore dans les environs de Surinam ot dans la mer Méditerranće, où l'on en fait parlieulièrement une pêehe abondante. 11 paraît que sa grandeur varie suivant les eôtes qu'il fréquente, et vraisemblablement suivant la nourriture qu'il peut avoir à sa portée. On en prend quelquefois, auprès de l'embouehure de la Seine, qui ont cinq, six et sept déeimètres de longueur. Il se nourıit d'œufs, ou de très-petits individus de quelques espèces de poissons; mais lorsqu'il est cncore très-jeune, il est la proie des grands crabes, qui 
le déchirent, le dépèeent et le dévorent. On le voit quelquefois cntrer dans les rivières. Pendant l'hiver, il se tient dans les profondeurs de l'Oeéan. Il quitte le fond de la mer lorsque la belle saison arrive. Il va ehercher alors les endroits voisins des rivares ou des embouchures des fleuves, où les rayons du soleil peuvent parvenir assez faeilement pour faeiliter l'aeeroissement des œufs.

On a d'autant plus do motifs de pêeher la sole, qu'une saveur exquise n'est pas la seule qualité précicuse de la chair de ce poisson. Cette même chair présente aussi la propriété de pouvoir ĉtre gardée pendant plusieurs jours sans se corrompre.

\section{LE TURBOT.}

Ce poisson est très-recherché ct doit l'être. En offet, il réunit la grandeur ì un goùt exquis, ainsi qu'à une ehair ferme; ot voilà pourquoi on l'a nommé faisan d'eau, ou faisan de mer. Le turbot habite non-seulement dans la mer du Nord et dans la Baltique, mais eneore dans la Méditerranée. On en prend quelquefois sur les eôtes de Flanee et d'Angleterre, qui pèsent de dix à quinze liilogrammes.

Le turbot est très-goulu; sa voracité le porte souvent à se tenir auprès de l'embouchure des fleuves, ou de l'entrée des étangs qui eommuniquent avec la mer, pour trouver un plus graul nombre de jeunes poissons dont il se nourrit, et pour les saisir' avec plus de facilité lorsqu'ils pénètrent dans ces étangrs et dans ces fleuves, ou 
lorsqu'ils en sortent pour revenir dins la mer. Quoique très-grand, il ne se eontente pas d'employer la force contre sa proie: il a reeours à la ruse. Il se préeipite au fond de l'Océan ou des méditerranées, applique son large corps sur le sable, se eouvre en partie de limon, tronble l'eau autour de lui, et se tenant en embuseade au milieu

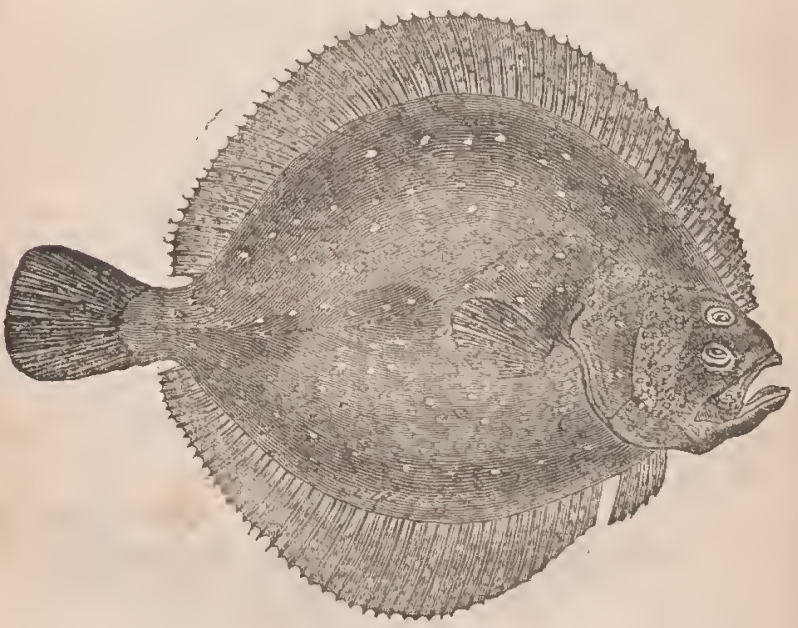

de cette enu agiliée, vascuse et peu transparente, il trompe ses vietimes, et les dévore.

Au reste, les turbots sont très-diffleiles dans le ehoix de leur nourriture ; ils ne touchent guère qu'à des poissons vivants ou très-frais. Ils sont très-abondants sur los côtes de Suède, d'Angloterre et de France. On en trouve notamment un très-grand nombre entro Honfleur et l'embouchure de l'Orie. 
La forme générale du turbot est un losanģe; et e'est de eette figure qu'est venu le nom de rhombe, que tant d'auteur's anciens et modernes lui ont donné. La mâehoire inférieure, plus avaneéc que la supérieure, est garnie, comme eette dernière, de plusieurs rangées de petites dents. Les nageoires sont jaunâtres avee des taches et des points bruns; le eôté gauehe est marbré de brun et de jaune; le côté droit, qui est l'inférieur, est blane avec des taches brunes.

\section{LE CARRELET.}

Le carrelet est très-commun. On le trouve dans l'oeéan Atlantique borćal, ainsi que dans la Méditerranéc. Il se plâit particulièrement dans eette dernière mer, auprès des côtes de la Sardaigne. Il pénètre quelıuefois dans les fleuves; il entre notamment dans l'Elbe.

Le carrelet et le turbot sont les pleuronectes qui présentent le plus de largeur ou plutôt de hauteur.

On doit remarquer chez le earrelet sa mâchoire inférieure, un peu plus avancée que la supćricure, les différentes rangées de dents petites, inégales cl pointues, qui arment les deux mâehoires, et la couleur blanche du côté droit de l'animal. 


\section{LA LOCHE.}

La loche est très-petite; elle ne parvient guère qu'à la longueur de dix ou douze centimètres; mais le goût do sa chair est très-agréable, et dans plusieurs contrées do l'Europe on a donné beaucoup d'attention et des soins très-multiplićs ì ce poisson. On le trouve le plus souvel. dans les ıuisscaux et dans los petites riviòres qui coulent sur un fond de picrres ou de cailloux, et particulièrement dans coux qui arrosent les pays montagnoux. Il vit de vors et d'insectes aquatiques. Il se plaît dans l'eau courante, ot paraît éviter colle qui est tranquille ; il préfère les eaux profondes, et même quelquefois les eaux dormantes, à colles qui sont très-agitées et très-battues. Il change rarement de place dans cos portions de rivière dont le courant est moins fort; il s'y tient comme collé contre le sable et le gravier, et scmble s'y nourrir de ce que l'eau y dépose.

La loche est la victime d'un très-grand nombre de poissons contre lesquels sa petitesse ne lui permet pas de sc défendre, et, malgré cette mêne potitesse, ello est la proie dos pêcheurs. On la recherche surtout vers la fin do l'automne, et pendant le printemps, qui ost la saison de sa ponte. A ces deux époques, sa chair est si délicate, qu'on la préfère à celle de presque tous los autres habitants des eaux, surtout lorsqu'elle a expiré dans du vin ou dans du lait. Elle meurt très-vite dès qu'clle est sortic de l'eau, et même dès qu'on l'a placéc dans quelque vase dont l'eau est dans un repos absolu. On la conserve, 
au eontraire, pendant longtemps en vie, en la renfermant dans une sorte de huche trouée que l'on met au milieu du eourant d'une rivière.

\section{LE SAUMON.}

Le saumon se plaît dans presque toutes les mers. Il préfère pourtant le voisinage des grands fleuves et des rivières, dont les eaux douces et rapides lui servent d'habitation pendant une très-grande partie de l'année. Il n'est point étranger aux lacs immenses ou aux mers intérieures qui ne paraissent avoir aucune eommunication avee l'Océan.

Il tient le milieu entre les poissons marins et ceux des rivières. S'il eroît dans la mer, il naît dans l'eau douce ; si pendant l'hiver il se réfugie dans l'Océan, il passe la belle saison dans les fleuves. Il en rechcrehe les eaux les plus pures; il ne supporte qu'avec peine ce yui peut en troubler la limpidité.

Il parcourt avee faeilité toute la longueur des plus grands fleuves. Il parvient jusqu'en Bohême par l'Elbe, en Suisse par le Rhin, et auprès des hautes Cordillières de l'Amérique méridionale, par l'immense Maragnon, dont le cours est de quatrc eents myriamètres.

Dans les contrées tempérées, les saumons quittcnt la mer vers le eommencement du printemps. Si les ehaleurs de l'été deviennent trop fortes, ils se réfugient dans les endroits les plus profonds, où ils peuvent jouir de la frấcheur qu'lls reeherehent. 
Ils redescendent dans la mer vers la fin de l'automne, pour remonter de nouveau dans les lleuves à l'approche du printemps. Ils s'úloignent de la mer cul troupes nombreuses, et prósentent souvent dans l'arrangement de colles qu'ils forment aulant de régularitć qu'cn offrent les ćpoques de leurs grands voyages. Le plus mros de ces poissons, qui est ordinairement uno femelle, s'avance le premicr; à sa suitc vicnnent les autres fomelles, deux à deux, et chacune à la distance d'un ou deux mèti'es de eclles qui la précède ; les mâles les plus grands paraissent ensuite, observent le même ordro que les femelles, et sont suivis des plus jeunos.

S'ils donnent contre un filet, ils lo déchirent, ou cherchent à s'ćchapper par-dessous ou jar los côtés de cet obstaclo : et ḋ̀s qu'un de ces poissons a trouvé une issue, les autros le suivent, et lour promier ordre se rétablit.

Lorsqu’ils nagent, ils se ticnnent au milicu du fleuve et près de la surface de l'cau; et comme ils sont souvent trèsnombreux, qu'ils agitent l'cau violcminent, et qu'ils font beaucoup de bruit, on les entend de loin comme le murmure sourd d'un ornge lointain. Lorsque la tempête monaee, que le soleil lance des rayons très-ardents, ot que l'atmosphèrc est très-ćchaulfćc, ils romontont les fleuves sans s'éloigner du fond de la rivière.

Si la température de la rivic̀re, la nature de la lumière du soleil, la vitesse et les qualités de l'cau leur conviennent, ils voyagent lentement; ils jouent à la surface du fleuvo; ils s'écartent do leur route. Mais s'ils veulent se dérober à quelque sensation incommode, éviter un danger, échapper à un piége, ils s'úlancent avec tant de rapidité, que l'ocil a de la peine à los suivre. 
Ils ont dans leur queue une rame tròs-puissante. Les museles de cette partie de leur eorps jouissent même d'une si grande éncrgie, que des cataractes élevées ne sont pas pour ees poissons un obstacle insurmontable.

Indépendamment de leur queue longue, agile et vigoureuse, ils ont, pour attaquer ou pour se défondre, des dents nombreuses et très-pointues qui garnissent les deux mâehoires et le palais, sur ehacun des eôtés duquel elles forment une ou deux rançées.

Les jeunes saumons qui ont atteint une longucur de quatre ou einq décimètres quittent la mer pour remonter dans les rivières ; mais ils partent le plus souvent beaucoup plus tard que les gros saumons; ils attendent communément le eommencement de l'été.

On les suppose âgés de deux ans lorsıu'ils pèsent de trois à quatre kilogrammes. A l'âge de cinq ou six ans, ils pèsent de cinq à six kilogrammes, et parviennent bientôt à un développement très-considérable.

Les saumons vivent d'insectes, de ver's, de jeunes poissons. Ils saisissent leur proie avee beaueoup d'agilité; et, par exemple, on les voit s'ćlancer avec la rapidité de l'éelair sur les mouehorons, les papillons, les sauterelles, et les autres inseetes que les courants cliarrient, ou qui voltigent à quelques eentinètres au-dessus de la surface des eaux.

Mais s'ils sont à eraindre pour un grand nombre de petits animaux, ils ont à redouter des ennemis bien puissants et bien nombreux. Ils sont poursuivis par les grands habitants des mers et de lcurs rivages, par les squales, par les phoques, par les marsouins. Les gros oiseaux d'eau 
los attaruent nussi; et les pêcheurs leur font surtout une guerro eruelle.

Leur chair, surtout colle des mâles, ost, à la vérité, un peu difficile à digérer, mais grasse, nourrissante, ct trèsagréable au goût. Ellə plaît d'ailleurs à l'œil par sa bollo couleur rougeâtre. Ses nuances ct sa délicatesse ne sont cependant pas les mômes dans toutes les eaux.

Les saumons meurent bientôt, non-sculement lorsqu'on les tient hor's de l'eau, mais encore lor'squ'on les mot dans uno huche qui n'ost pas placóe au milieu d'une rivière. Des pêoheurs prétendent (que, pour empêchor oos poissons de portre lour goût, il faut se presser de los tuer dìs le noment où on les tire de l'cau.

\section{LA TRUITE.}

La truite n'ost pas seulement un des poissons les plus aģréables au goûl, elle est oncoro un des plus beaux.

On trouve la truite dans presque toutes les contrées clu globe, et particuliòrement dans presque tous les lacs élovés, tels que ceux du Léman, de Joux, de Neufchâtel.

- Elle a ordinairement trois ou quatre décimètres de longueur, et pèse alors deux ou trois hectogrammes. On en pêche cependant, dans quelques rivières, du poids de deux ou trois kilogrammes; on a parlé d'une truite qui pesait quatre kilogrrammes, et qu'on avait prise en Saxe.

Le salmone truite aime une eau claire, froide, qui des- 
cende de montagnes élevćes, qui s'échappe avec rapidití, et qui eoule sur un fond pierreux.

Les grandes chaleurs peuvent incommoder la truite au point de la faire périr. Aussi la voit-on vers le solslice d'été, lorsque les nuits sont très-courtes et qu'un solcil ardent rend los eaux presque tic̀les, quilter les bassins pour aller habiter au milieu d'un courant, ou cliercher pròs du rivage l'eau fraiche rl'un r'uisseau ou celle d'une fontaine.

Elle peut d'autant plus aisément choisir entre ces divers asiles, qu'elle nage eontre la direetion dos caux les plus rapides avee une vitesse qui étonne l'observateur, et qu'elle s'élance au-lessus de digues ou de cascades de plus de deux mètres de haut.

Elle se nourrit de petits poissons très-jeunes, de pelits animaux à coquille, de ver's, d'insectes, ct particuliùrement d'éphémères, qu'elle saisit avec adrosse Iorsqu'ellos voltigent auprès de la surface de l'eau.

On marine la truile comme le saunon, et on la sale eomme le hareng. Mais c'est surtout lor'squ'elle est frâche que son goût est lrès-agréable. Sa chair est tendre, particulièrement pendant l'hiver; les personnes même dont l'estomac est faible la digèrent facilement.

Comme on ne voit guère la truite séjourner naturcllement que dans les lacs ćlevćs et dans les rivieres ou ruisseaux des montagnes, elle est trìs-chère dans un grand nombre d'endroits. 


\section{LA TRUITE SAUMONEE.}

Sa forme, ses couleurs, scs habitudes, la rapprochent bcaucoup du saumon et de la truite.

Elle habite dans un très-grand nombre de contrées; mais on la trouve principalement dans les laes des hautes montagnes et dans les rivières froides qui en sortent ou qui s'y jettent. Elle sc nourrit de vers, d'insectes aquatifues, et de très-petits poissons. Les caux vives el courantes sont cclles qui lui plaisent; elle aime les fonds de sable ou de cailloux. Cc n'est ordinairemen que vers le milieu du printemps qu'elle quitte la mel pour aller dans les fleuves, les rivières, les lacs et les ruisseaux, choisir l'endroit commode et abrité où elle dépose scs œufs.

Elle parvient à une grandcur considérable. Quelques individus de cette cspèce pèsent quatre ou cinq kilogrammes ; et ceux même qui n'en pèsent encore quc trois ont déjà plus de six décimètres de longueur.

La bonté de la chair de la truite saumonéc dépend trìs-souvent de la qualité des eaux où clle a séjourné; mais en général, ot surtout un peu avant le frai, celte chair est toujours tendre et facile à digérer.

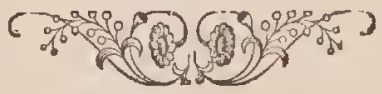




\section{LE BROCIIET.}

Le brochet est le requin des eaux douces; il y règno en tyran dévastaleur, comme le requin au milicu des mers. S'il a moins de puissanec, il ne renoontre pas de rivaux aussi redoutables; si son empire est moins étenılu, il amoins d'espace à parčourir pour assouvir sa voracité; si sa proie est moins variée, clle est souvent plus abondlante; et il n'est point obligé, comme le requin, de traverser d'immenses profondeurs pour l'arracher à ses asiles. Insé tiable dans ses appétits, il ravage avec une promptitude effrayante les viviors et les étangs.

Lo sens di: l'ouie du brochet est plus parfait que eelui de pres.jue tous les autres poissons osseux. Sous Charles IX, rıi de France, des individus de cette espèce, réunis dans un bassin du Louvre, venaient, Iorsqu'on les appelait, recevoir la nourriture qu'on leur avait préparée.

C'est dans les rivières, Ies fleuves, les lacs et 'es étangs, qu'il se plaît à séjourner. On ne le voit dans la mor que lol'squ'il y est entrainé par des accidents passagers, et retellu par les causes extraordinaires qui ne l'empêchent pas d'y dépérir'; nais on l'a observé dans presque toutes los eaux douces de l'Europe.

Il parvient jusqu'à la longueur de deux ou trois mètres, et jusqu'au poids de quarante ou cinquante kiogrammes.

Le brochet n'est pas seulement dangereux par la grandeur de ses dimensions, la force de ses uuuscles, lo nom- 
lıe de ses armes; il l'est eneore par les finesses de la ruse et les ressour'ces de l'instinct.

Lorsqu'il s'est élancé sur de gros poissons, sur des serpents, des grerouilles, des oiseaux d'eau, des rats, de jemes ehats, ou même de petits ehiens tombés ou jetés dans l'eau, et que l'animal qu'il veut dévorer lui oppose un trop grand volume, il le saisit pal' la tête, le retient avee ses dents nombreuses et recourbées, jusqu'à ce que la portion antérieure de sa proie soit ramoliie dans son large gosicr; il en aspire ensuite le reste, et l'engloutit.

On prend les broehets de diverses manières : en hiver, sous les glaees ; en été, pendant les orages, qui, en éloignant d'eux leurs vietimes ordinaires, les portent davantage ver's les appâts; dans toutes les saisons, au elair de la lune; dans les nuits sombres, au feu des bois résineux. Leur ehair est agréable au goût.

\section{LE HARENG.}

Ces poissons ne forment pour tant de peuples une branche immense de commerce, que depuis le temps où l'on a employé, pour les préserver de la eorruption, les différentes préparations que l'on a suceessivement inventées et perfeetionnées. Avant la fin du quatorzième siècle, époque à laquelle Guillaume Deukclzoon, pêeheur célèbre de Flandre, trouva l'art de saler les harengs, ces animaux devaicnt être et élaient, en offet, moins reeherelıés; mais, dès le commeneenent du quinzième 
siècle, les Hol'andus cmployèrent à la pêche de ces clupées de grands rilets et des bâtiments considćrables et allongés, auxquels ils donnont le nom de buys : et depuis ce même sic̀clo il y a eu des années où ils ont mis en mor trois mille raisseaux et occupé quatre cent cinquante mille hommes pour la pêclıe de ces poissons.

Les filets dont ces mêmes Hollandais se servent pour prendre les harengs out de mille à douze cents mètres de longueur; ils sont composés de cinquante à soixante nappes, ou parties distinctes. On les fabrique avec une grosse soic que l'on fait venir de Perse, et qui (lure deux ou trois fois plus que le chanvre. On les noircit à la fuméc, pour que leur couleur n'effraye pas les harengs. La partic supérieure de ces instruments est soutenue par des tonnes vides ou par des morceaux de liége; et leur prartie infćrieure est maintenue par des pierres ou par d'autres corps pesants, à la profondeur' convenable.

On jette ces filets dans les endroits où une grande abondance de liarengs est indiquée par la présence des oiseaux d'eau, des squales, et des autres ennemis de ces poissons, ainsi que par une quantité plus ou moins considérable dc substance huileuse ou visqueuse que l'on nomme graissin dans plusicur's pays, qui s'étend sur la surface de l'eau au-dessus des grandes troupes de ces clupécs, etque l'on reconnaît facilement lorscjue le temps est calme. Les liarengs, comme plusieur's autres poissons, se précipitent vers lus feux qu'on leur présente; et on les attirc dans les filets en les trompant par le moyen de lumières que l'on place de la manière la plus convenable dans différents endroits des vaisseaux, ou qu'on élève sur des rivages voisins. 
On prépare les harengs de difrérentes manières, dont les détails varient un peu, suivant les contrées où on les cmploie, et dont les résultats sont plus ou moins agréables au goût et avantageux au commorce.

On sale en pleine mer les harengs que l'on trouve los plus gras et que l'on croit les plus succulents.

La préparation qui proeure particulièrement au eommerce d'immenses bénéfices est cclle qui fait donnor le nom de harengs blancs aux clupées harengs pour lesquels on l'a employée.

Dès que les harengs dont on veut faire des harengs blinces sonthor's de la mer, on les ouvre, on cn ôte les intestins, on les met dans une saumure as sez chargéc pour que ces poissons y surilagent; on les en tire au bout de cuinze ou dix-huil heures; on les net dans des tonnes; on les transporte à terre; on les y encaque de nouveau; on les place par lits dans les caques ou tonnes qui doivent les conserver, et on sépare ees lits par des couchos de sel.

On a soin de choisir du bois de chêno pour les tonnes ou caques, ol de bion en réunir toutes les prarties, de peur que la saumure ne se perde et que les harengs ne se gititent.

\section{LA SARDINE.}

La sardine se trouve non-seulement dans l'océan Atlantique boréal et dans la Baltique, mais encore dans la Méditerrancée, ot particulièrement aux environs de la 
Sardaigne, dont clle tire son mon. Elle s'y tient dans les endroits très-profonds; mais, pendant l'automne, elle s'ipproche des côtes pour frayer.

Les individus de cette espèce s'avancent alor's vers les rivages en troupes si nombreuses, que la pêche cn est très-abondante. On les mange frais, ou salés, ou fumés. La branche de commeree qu'ils forment est importante dans plusieurs contrées de l'Europe.

\section{L'A LOSE。}

Les aloses balitent non-senlement dams l'ocóan Atlanlipue septentrional, mais eneore dans la Míditcrance ct dans la mer Caspienne.

Elles forment des troupesnombreuses, que les pêclıcurs 'de la plupart des rivières où elles s'engagent voient arriver avec une granle satisfaction. Le nombre de ces elnfúcs cependant varic beaucoup d'une année à l'autre. Dans la Seine inférieure, par exemple, on prend treize ou quatorze mille aloses rims certaincs années, et, dans d'autres, on n'en prend que quinze cents on deux mille.

Elles sont le plus souvent maigres et de mauvais goût en sortant de la mer; mais le séjour dans l'oan donce les engraisse. Elle parviennent à la longueur d'un mìtre. 


\section{I.'A NCII OIS.}

Il n'est guc̀re de poisson plus connu que l'anchois, de tous ceux yui aiment la bonne chìre. Ce n'est pas pour son volume qu'il est rechcrché, ear il n'a souvent qu'un décimètre ou moins de longueur'; il ne l'est pas non plus pour la saveur particulière qu'il présente lorsqu'il est frais ; mais on consommo une énorme quantité d'individus de cotte espèce, lor'sque après avoir ćté salés ils sont devenus un assaisonnement des plus agréables et des plus propres à ranimer l'appétit. On les prépare en leur ôtant la tête et les cntrailles; on les pénètre de sel ; on les renforme daus des barils avee les précautions particulières; on los envoie à de très-grandes distances sans qu'ils puissent se gâter. Ils sont employés, surles tables modestes comme dans les festins somptreux, à relever la saveur des végétaux, et ì donner arx sauces un piquant de très-bon goût. Les Grecs et les Romains, dans le temps où ils attachaient le plus d'importance à l'art de préparer les aliments, faisaiont avec ces chupées une liqueur que l'on nommait gar'um, et qu'ils regardaient comme une des plus précieuses.

\section{LA CARPE.}

Les carpes sc plaisent dans les ćtangs, dans les lacs, dans les rivières qui coulent doucement. Il y a mône 
dans les qualités des eaux des différences qui sont si sensibles pour ces cyprins, qu'ils abondent quelquelois dans une partie d'un lac ou d'un fleuve, et sont très-rares dans une autre partie peu éloignée eependant de la première.

Ces poissons frayent en mai et même en avril, quand le printemps est chaud. Ils cherchent alor's les places couvertes de verdure pour y déposer ou leur laite ou leurs œufs.

A cette même époque, les carpes qui liabilent dans les fleuves ou dans les rivières s'empressent de r fuilter leur's asiles pour remonter ver's les eaux plus trancuilles. Si, dans cette sorte de voyage annuel, elles rencontrent une barrière, elles s'efforeent de la franchir. Elles peuvoul, pour la surmonter, s'élancer à une hauteur de deux mètres.

Leur conformation et la force de leurs muscles lemr donuent une grande facilité pour celto manouvre. Leur's proportions indiquent, en effel, la vigueur et la légèreté.

Leur tête est grosse; leurs lèvres sont épaisses, leur front est large; leurs quatre barbillons sont attachés à leur mâchoire supérieure; leur's écaillos sont grandes ct striées.

Quand elles sont bien nourries, elles croissent vite, et parviennent à une grosseur considérable.

On en pêehe dans plusieurs laes de l'Allemagne sep-tentrionale qui pèsent plus de quinze kilogrammes. On cn a pris une du poids de plus de dix-neuf kilogrammes à Dertz, dans la nouvelle Marche de Brandebourg sur los frontières de la Poméranic.

On assure qu'on en a pris du poids de quarante-cinq 
kilogrammes dans le lac de Kug, en Suisse; et enfin il en lıabile dans le Dniester de si grosses que leurs arêtes peuvent servir à faire des manches de couteau.

Ces poissons deviennent très-ricux. Ils se multiplient avec une facilité extraordinairc.

Tous les fleuves et toutesles rivières ne communiquent pas les mêmes qualités à la clıair des carpes. Il est des rivières dont les eaux donnent à ceux de ces eyprins qu'elles nourrissent une saveur bien supérieure à celle des autres carpes; et parmi les rivic̀res de Franee on peut citer particulièrement cclle du Lot.

\section{LE BARBEAU.}

Co poisson a quelques rapports extérieurs avec le lrochel, à causo de l'allo:igement de sa tête, de son corps et de sa queue.

Le barbcau se plaît dans les eaux rapides qui coulent sur un fond de cailloux; il aine à se eacher parmi les pierres et sous les rives avancécs. Il se nourrit de plantes aquatiques, de limacons, de ver's et de jetits poissons; on l'a vu même reehereher des cadavres. Il parvient au poids de neuf ou dix kilogrammes. On le pêche dans les grands fleuves de l'Europe, et particulièrement dans ceux de l'Europe méridionale.

Les barbeaux se réunissent en troupes de douze, de quinze et quelquefois de cent individus. Ils se renferment dans une grotte communc, à laquelle lcur association doit le nom de nichée que leur donnent les pêclienrs. 


\section{LE GOUJON ET LA TANCHE.}

Le goujon se trouve dans los eaux de l'Europe dont le sel n'altère pas la purcté, ct particulièrcment dans celles qui reposent ou conlent nollement el sans mélange sur un fond sablonneux. Il prófère les lacs que la tempête n'agile pas. Il y passe l'hiver, ol lorsque lo printemps est arrivé, il remonte dans les livières, où il dépose sur les 1,icrressa laitc ou ses ceufs, dout la couleur est lileuâtro a le volume très-petit. Les fenclles de l'espèce du goujon sont eing ou six fois plus nombreuses que les mâles.

Vers l'aulomno les gonjons reviennont dans les lacs. On les prend de plusieurs inanières; on los pêclie avec des filcts el avec l'hameçon. Ils sont d'ailleurs la proie des oiscaux d'eau, ainsi que des grands poissons, et cepentant ils sout tris-multiplićs, $i$ is vivent de plantes, do petits ouls, de débris de eorps organisés. Ils paraissent se plaire plusicurs ensemble; on les rencontro presque tonjour's réunis en troupes nombreuses. Ils perdent diffieilcment la vic. A peine parviennent-ils it la longucur d'un ou deux décimètres.

Leurs couleurs varient avee leur âge, leur nourrilure, pt la nature de l'eau dans laquelle ils sont plongés; mais le plus souvent un bleu noirâtre rigne sur leur dos; lenrs côlés sont blcus dans leur partie supérieure; le bas de ces mèmes côtés et le dessous dı corps offrent des teintes mêlécs de blnno el te janne; tes taehes blenes sont plaećes sur la lignc latéralc; et l'on voit des taches 
noires sur la eaudale et sur la dorsale, qui sont jaunâtres ou rougeâtres, comme les autres nageoires.

Les tanehes sont aussi sujettes que les goujons à varier dans leur nuances, suivant l'âge, le sexe, le climat, les aliments et les qualités de l'eau. Communément on remarque du jaune verdâtre sur leurs joues, du blanc sur leur gorge, du vert foncé sur leur front et sur leur dos, du vert clair sur la partie supérieure de leurs côtés, du jaune sur la partie inférieure de ces dernières portions, du blanehâtre sur le ventre, du violet sur les nageoires. Dans lesfemelles eomine dans les mâles la tête est grosse, le front large, l'œil petit, la lèvre épaisse, le dos un peu arqué.

On trouve des tanehes dans presque toutes les parties du globe. Elles habitent dans les laes ou dans les marais; les eaux stagnantes et vaseuses sont celles qu'elles reeherehent. Elles ne eraignent pas les rigueurs de l'hiver.

On peutmettre des tanches dans des viviers, dans des mares, même dans de simples abreuvoirs; elles se contentent de peu d'espace.

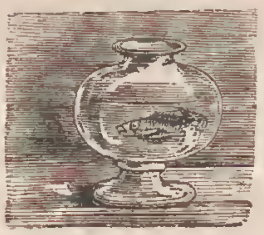





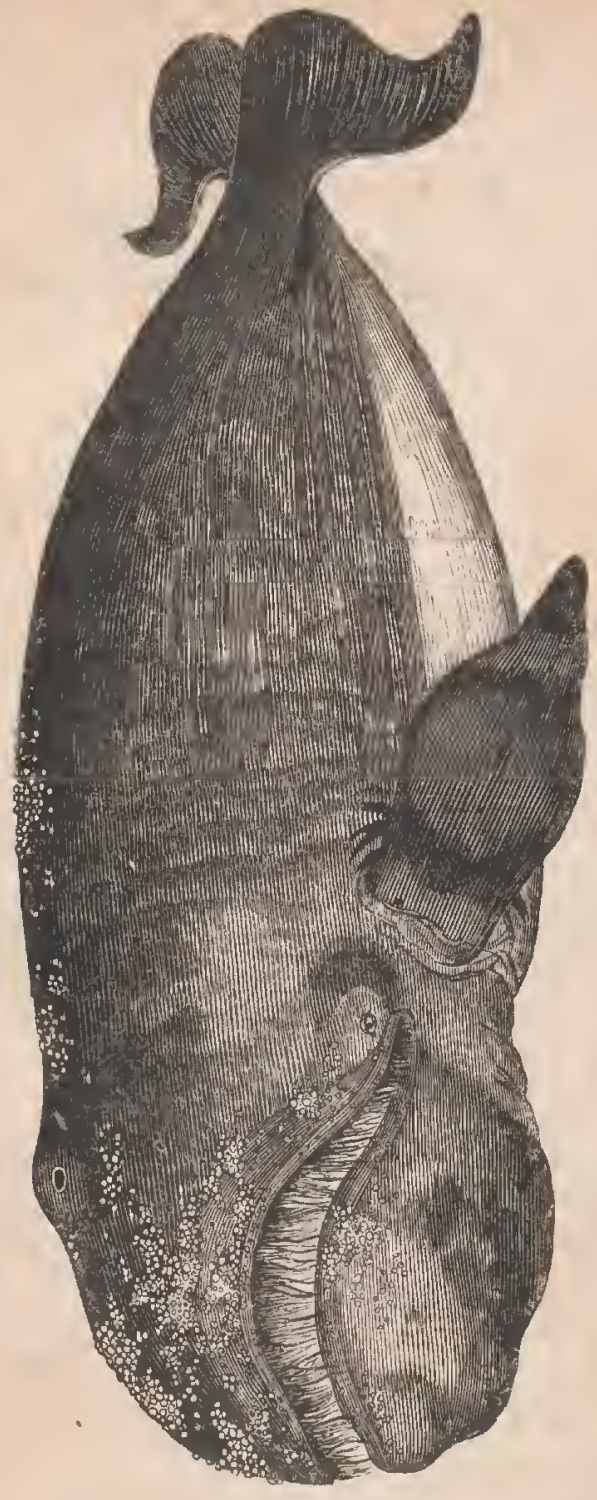




\section{GËTAGÉS.}

\section{LA BALEINE FRANCIIE.}

L.es individus de cette espice, fue l'on rencontre à une assez prrande distance du pôle aretique, ont depuis vingt jusqu'à quarante mòtres de longrueur. Jeur circonférence n'est pas toujour's dans la mème proportion avec leur longueur totale. La plus grande circonférence surpassiut, en effet, la moitié de la longueur dans un individn de seize milres de long ; elle n'égalait pas colto même longueur totale dnns d'autres individus lonğs de plus de trento mètres. Le poids total de ces derniers individus surpassail cent cinquante lilogrammes.

En s'approchant néanmoins de cette masse, on la vo.t en quolque sorte se changer en un tout micux ordonné. On peut comparer ce gi zantesque enscmble à une espèce re oylindro inmense ot irrógulier.

La tête forme la partie antérieure de ce cylindre démesuré ; son volume égale lo quart et quelquofois le tier's du volume total de la baleine. Elle est convexe, pardessus, de manière à roprésenter uno portion d'une largo splic̀re. Vers le milicu de cette grande voûte et un $\mu c u$ 
sur Ie derriìre, s'élève une bosse, sur laqnelle sont placés Ics orifices des deux évents.

On donne ce nom d'ćvents aux deux canaux qui partent du fond de la bouchc, parcourent obliquemcnt, et en se courbant, l'intérieur de la têtc, et aboutissent vers lc milieu de sa partic supérieure.

Ils servent à rejetcr l'eau qui pénètre dans l'intérieul' de la gueule de la baleine franche, ou à introduire jusqu' $i$ son larynx, et par conséquent jusqu'à ses poumons, l'air' nécessaire à la respiration de ce cétacé.

La baleine fait soltir par ces évents un assez grand volume d'eau pour qu'un canot puisse en être bicntòt rempli. Elle lance ce fluide avec tant de rapidité, particulic̀rement quand elle est animée par des affections vives, tourmentée par des blcssures et irrilćc par la doulem', que le bruit de l'eau qui s'élc̀ve et retombe en colonnes, ou se disperse en gouttes, cffraye presque tous ceux qui l'entendent pour la premicre fois, et peut retentir fort loin, si la mer est très-calme. On a comparé cc bruit, ainsi que celui que produit l'aspiration de la baleine, au bruissement sourd et terrible d'un orage éloigné.

Elle n'a pas de dents ; mais tout le dessous de la mâchoire inférieurc, ou, pour micux dirc, tonte la vonte dı palais est garnie de lames que l'on désigne sous le nom de fanons.

La quene de la baleine a la figure d'un cône, dont la base s'applique au corps proprement dit. Les muscles qui la composent sont très-vigoureux. Une saillie longitudinale s'étend dans sa partie supérieurc, depuis le milieu de sa longueur jusqu'à son extrémité. Elle est terminée par une grande nageoire, dont la position cst 
remarquable. Celte nageoire est horizontale, an lieu d'être verticale comme la nageoire de la queue des poissons.

Ce grand instrument de natation est le plus puissant de ceux que la baleine a reçus; mais il n'est pas le seul. Ses deux bras peuvent être comparés aux deux nageoires pectorales des poissons: au lieu d'être composés, ainsi que ces nageoires, de rayons soutenus el liés par une membrane, ils sont formés d'os, de muscles, et de chair tendineuse, recouverts par une peau épaisse ; mais l'ensemble que chacun de ces bras présente consiste dans une sorte de sac aplati, arrondi dans la plus grande partie de sa circonférence, terminé en pointe, ayant une surface assez étendue, réunissant enfin tous les caractòres d'une rame agile et forte.

La peau de la baleine est très-forte, quoique percée rle grands pores. Son épaisseur surpasse deux décımètres. Elle n'est pas garnie de poils, comme celle de la plupart des mammilères.

La chair qui est au-dessous de l'épiderme et de la peau est rougeâtre, grossière, dure et sèche, excepté celle de la quene, qui est moins corince et jlus succulente, quoique peu agréable ì un goût délicat, surtout dans certaines circonstances où elle répand une odeur rebutante.

Entre cette chair et la peau est un lard épais, dont une partie de la graisse est si liquide, qu'elle s'écoule et forme une huile, même snus être exprimée.

Le baleineau tette au moins pendant un an.

Il est, pendant le temps qui suil immédiatement sa naissance, l'objel d'une grande tendresse, et d'une sollicilude qu'aucun obstacle ne lasse, qu'nncun clanger n'in- 
timide. La mire le soigne même quelquefois pendant trois ou quatre ans. Elle ne le perd pas un instaut de vue.

La baleine franche n'a vraiscmblablement pour aliments que des crabes et des mollusques. Ces animaux dont elle fait sa proie sont lien petits; mais leur nombre compense le peu de substance que présente chacun de ces mollusques ou insectes. Ils sont si multiplies dans les mers fréquentées par la baleine franche, que ce cétacé n'a souvent qu’à ouvrir la gueule pour en jrendre plusieur's milliers à la fois.

A quelque distance que la baleine franclie doive aller chercher l'aliment qui lui convient, elle pout la franchir avec une grande facilité : sa vitesse est si grande, que cr cétacé laisse derrière lui une voie large el frofonde comme celle d'un vaisseau qui vogue ì pleines roiles. Elle pareourt onze mètres par seconde.

Une baleine franche peut peser plus de cent einquante mille kilogrammes. Sa unasse est doncégale à celle to cent linocéros, on de cent hippopotames, ou de cent dlépliants.

Voici trois ennemis de la baleine, remarquables par leur grandeur, leur agilité, leur force el leurs armes. IIs la suivent avec acharnement, ils ln combattent arec fureur. Ces trois emnemis sont: la scie, le dauphin ghladiateur et le requin.

I a scie l'encontre-t-elle une baleine franche dont l'âge soit encore trùs-peu avancé et la figure peu développée, elle ose, si la fain la dóvore, se jeter sur ce cétacé. I a joune baleine, pour la reponsser, cnfonce sa tête dins l'ean, relève sa qucue, l'agite, et frappe des denx côtés. 
Si elle attcint son ennemi, elle l'accable, le tue, l'écrase d'un scul coup. Mais le squale se précipite on arrière, l'évile, bondit, tourne el retournc autour de son adversaire, change à chaque instant son altaque, saisil le moment favorable, s'élanee sur' la baleine, enfonee dans son dos ln lame longue, osseuse et donlelée, dont son musean est garni, la retire avec violence, blesse profondénent le jeune cétacé, le déchire, le suit dans les profondeurs re l'Océan, lo force à romonter vers la surfizce de la mor, rocommenee un combat terrible, et, s'il ne pout lui donner la mort, expire en frémissant.

Les dauphins gladiatour's se réunissent, forment une grande troupe, s'arancent tous ensemble vers la baleine franclie, l'atlaquent de toutos parts, la mordent, la hareèlent, la fatiguent, la eontraighnent ì ouvrir la gueule, ct, se jetant sur sa langue, dont on dil qu'ils sont trisaviles, la mettant en pièces, et l'arraehant par lambcaux, causent des douleurs insupporta]Jles au célacé vaincu par le nombre, en l'ensanglantant par des blessürs mortelles.

Les énormes requins du Nurl, que quelques navisateur's ont nommé our's do mer à eause de leur voracité, combattent la baleine sous l'eau; ils ne cherchent pas ì se jeter sur sa langue, mais ils parviennent à enfonecr dans son ventre les quintuples rangs de leurs dents pointues et dentclées, et lui enlèvent d'énormes morceaux de téguments et de muscles.

Un mugissement sourd exprime, a-t-on dil, et les tourments et la rage de la baleine. Une sueur abondante manifeste l'execis de sa lassitude el le commencement de son épuisement. Blessée, privéc de presque tout son 
sang, harassée, excédće, accablée par ses proprres efforts, elle n'a plus qu'un faible reste de sa vigueur et de sa puissance. L'onts blanc ou plutôt l'ours maritime, ce vorace et redoutable animal que la faim rend si souvent plus terrible encore, quitte alors les bancs de glaces ou les lives gelées sur lesuquels il se tient en embuscade, se jette à la nage, arrive jusqu'ì ee cétacé, ose l'attaquer. Nais la baleine, quoique expirante, inontre encore qu'elle est le plus grand des animaux; ellc ranime ses forces défaillantes; et peu d'instants même avant sa mort, un coup de sa queue immole l'ennemi trop audacieux qui a cru ne trouver en elle cu'une victime sans défense.

Le cadavre de la baleine flotte sur la mer. L'our's marilime, les squales, les oiseaux de mer, se précipitent alors sur cette proie facile, la déchirent et la dévorent.

La baleine franche liabite tous les climats ; elle apparticnt aux deux hénisphères, ou plutôt les mers australes et boréales lui appartiennent.

En considérant les résultats et les bénéfices si importants que procure la pêche de la baleine, pourrait-on être étonné de l'attention, des soins, des précautions multipliées par lesquels on tâche d'assurer ou d'accroître les suceès de cette pêche ? Tous les procédés qu'on emploie pour cette pêehe sont eurieux; mais le détail nous mènerait trop loin.

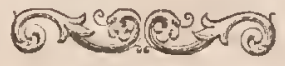




\section{LE CACHALOT MACROCEPIIALE.}

Moins fort que le premier des cétacés, il a reçu des armes formidaljles, que la nature n'a pas données ì la baleine. Des dents terribles par leur force et par leur nombre garnissent les deux côtés cle la mâchoire inférieure. Son organisation intérieure, un peu différente de cellc de la baleine, lui impose d'aillcur's le besoin d'une nourriture plus substantielle. Aussi ne règne-t-il pas sur les ondes cn vainqueur pacifique comme la balcine; il $\mathrm{y}$ excrce un cmpire redouté : il ne se contente pas de repousser l'cnneni qui l'attaque, de briser l'obstacle qui l'arrête, d'immoler l'audacieux rui le blesse; il cherche sa proie, il poursuit ses victimes, il provoque au combat.

Sa tète cst une des plus volunineuses, si elle n'est pas la plus grande de toutes celles que l'on connait. Sa longueur surpasse presque toujours le tiers de la longueur totale du célacé. Elle paraît comme une grosse massc tronquéc par devant, presque cubique, et terminée par eonséquent à l'extrémité du museau par une surface trèsétendue, mresque car'ŕe, et presque verticale. C'est dans la surface inféricure de ce cube innnense, mais imparfait, que l'on voit l'ouverture de la bouche, étroite, longue, un peu plus reculée que le bout du musear, et fermée à la volonté du cachalot par la mâchoire d'en bas, comme par un vaste couvercle renversé.

Cette mâchoire l'en bas est donc évidemment plus courte que cello d'en haut. Chaque branche de la mâchoire d'en bas a quelquefois, eependant, un mitre 
d'épaissenr. La chair des gencives est ordinairement très-blanchc, dure comme de la corne, revêtue d'une sorte d'écorce profondément ridée.

Le nombro des derits qui grarnissent de chaque côtéla mâchorre d'en bas est de vingtt-trois. Ces dents sont fortes, coniques, un peu recoubcées ver's l'intérieur de la ggueule. Les deux premières et les quatre dernières de chacque rangée sont quclquefois moins grosses et plus pointues que les autres. Elles ont à l'cxtérieur" la couleur et la duretó de l'ivoire; mais elles sont, à l'intérieur, plus tendres et plus grisos.

La langue est charnue, un peu mobile, d'un rouge livide, et remplit presque tout le fond de la gueulc.

L'oil est silué plus haut que dans plusicurs grands cétacés. Il est noirâtre, entouré de poils très-ras et trèsdilliciles à découvrir. Cet organe n'a d'ailleurs qu'un urès-petit diamètre.

I a Méditerranée n'est pas la seule mer intérieure dans laquelle pénètre le macrocéplıale; il apparticnt même à presque toutes les mers. Il ne se nourrit pas selllement de mollusques; il est aussi tres-avide de poissons. On en a trouvé de deux mètres de longueur dans son estomac. Jl poursuit les phoques, les baleinoptires, les dauphins vulgaires. 11 chasse les roquins arec acharnement ; et ces squales, si dangereux pour tant d'autres animaux, sont saisis d'me telle fraycul' à la vue du terrible macrocéplıale, qu'ils s'empressent de sc cacher sous le sable ou sous la vase, qu'ils se précipitent au travers des écueils, qu'ils se jettent contro les rochers avec assez de violence pour so donner la mort, et qu'ils n'osent pas même approcher de son catavro, malģré l'aridité avec 
laquelle ils dévorent les r'cstes des autres cétacés. Le macrocéphale est assez vorace pour saisir un bateau pêcheur, le briser dans sa gueule, et engloutir les hommes qui le montent; aussi les pêcheurs islandais redoutent-ils son approche.

La mère a pour son petit une affection plus grandc cneore que dans presque toutes les autres espèces de cétacés. Ce sentiment de la mère pour le jeune cétacé auquel elle a donné le jour se retrouve même dans presque tous les macrocéphalcs pour los cachalots avee lesquels ils ont l'habitude de vivre. Lorsqu'on attaque une troupe de maerocéplaales, ceux qui sont déjà pris sont bien moins à craindre pour les pêcheurs que leur's compagnons encore libres, lesquels, au lieu de plonger dans la mer, on de prendre la fuite, vont arec audacc couper les cordes qui retiennent les premiers, repousser ou immoler leurs vainqueurs, et rendre la liberté aux captifs.

Les macrocéplıales résistent plus longtemps que beaucoup d'autres cétaeés aux blessures que leur font la lanco ct le harpon des pêeheurs. On ne leur arrache que difficilement la vie, et l'on assure que l'on a vu de ces cachalots respirer encore, quoique privés de parties considérables de leur corps, que le for avail désorganisées au point de les faire tomber en putréfaction. 


\section{IL DAUPHIN VULGAIRE.}

L'homme trouve le dauplin sur la surfaee de toutes Ios mers; il le rencontre et dans les climats heureux des zones tempérées, et sous le ciel brûlant des mers équatoriales. Partout il le voit, léger dans ses mouvements, r'apide dans sa natation, élonnant dans ses ljonds, sc plaire autour de lui, disparaître comme l'éclair, s'éclıậper comme l'oiseau qui fend l'air, reparaître, s'enfuir et se montrer de nouvean.

Les formes générales du dauphin vulgaire sont plus agréables à la vue que celles de presque tous les autres cćtacés; ses proportions sont moins ćloignées de celles (que nous regardons comme le type de la beauté. Sa tîte, par exemple, montre, avec les autres parties de ce cćtacé, des rapports de dimension beaucoup plus analogues it ccux qui nous ont charmés dans les animaux que nous croyons les plus favorisés par la nature. Son ensemble est comme composé de deux côncs allongós presque égaux, et dont les bases sont appliquées l'une contre l'autre. La tête forme l'extrémité du cône antérieur'; aucun cnlonc'ement ne la sćpare du corps proprement dit, et ne sert à la faire reconnaitre; mais elle se termine par un museau très-distinct du crûne, très-avancé, très-aplati clo liaut en bas, arrondi dans soil contour, de maniòre à prósentcr l'image d'une portion d'ovale, et comparé part plusieur's autcurs à un énorme bec d'oic ou de cygne, dont ils lui ont clonné le nom.

Lorsqu'ils nagent en troupe nombreuse, les daupl:ins 
présentcut souvent une sorte d'ordre: ils for'ment des l'angs réguliers; ils s'avancent quelquefois sur une ligne, comme disposés en ordre de bataille; et si quelqu'un d'eux l'emporte sur les autres par sa force ou par soll audace, il précède ses compagnons, parce qu'il nage avec moins de précaution et plus de vitesse; il parait comme leur chef ou leur conducteur.

Mais les animaux de leur. espèce ne sont pas les sculs êtres sensibles pour lesquels ils paraissent concevoir de l'affection; ils se familiarisent dı moins avec l'homme. Ils se rassemblent autour des bâtiments, et arcc tous les siones de la confiance et d'une sorte de satisfaction, ils s'agitent, se courlent, se replient, s'élancent au-dessus de l'cau, pirouettent, r'ctombent, bondissent, et s'élancent de nouveau pour pirouetter, tomber', bondir et s'élever' encore.

Ils se nourrissent de substances animales : ils reelicrchont particulièrement les poissons; iis préfèrent les n11rues, les églefins, les persèques, les pleuronectes; ils joursuivent les troupes nombreuses de mugres jusqu'auprès des filets des pêcheurs; et à cause de cette sorto de familiarité hardie, ils ont été considérés comme les auxiliaires de ces marins, dont ils ne voulaient cependant qu'enlever ou partager la proie:

On les a vus non-seulement dans l'ucéan Atlantique septentrional, mais encore dans le grand Océan équinoxial, auprès des côtes de la Cline, près des rivages de l'Amérique méridionale, dans les mers qui baignent l'Alique, dans toutes les grandes méditerranées, dans cello 1'trticulièrement qui ar'rose et l'Afrique et l'Asie ot l'iurupe. 
Les dauphins n'ayant pas besoin d'cau pour respirer, et nc pouvant même respirer que dans l'air, il n'cst pas surprenant qu'on puisse les conscrver trc̀s-longtemps hol's de l'eau sans lcur f'airc pordre la vic.

On a dislingué les dauphins d'un brun livide; ceux qui ont le dos noirûtre, avec les côtés et le ventre d'un gris de perle mouchcté de noir ; ceux dont la couleur est d'un gris plus ou moins foncé; et enfin ceux dont toute la surface est d'un blanc éclalant comme celui de la neigge.

\section{LE DAUPHIN MARSOUIN.}

Le inarsouin ressemble beaucoup au dauphin vulgaire ; il présente les mêmes traits; il est doué des mêmes qualitćs; il of rro les mêmes at tributs; il éprouve les inèmes affections: et ccpendant, quellc différencc dans leur fortune! le dauphin a été divinisé, et le marsouin porte le nom de pourcean do lit mer.

L'enscmblo formé par le corps et la queue du marsouin rẹprésen te un cônc très-allongé. Ver's les deux tier's de la longueur du dos, s'élève une nagcoirc assez peu échanerće par derric̀re, et assez pcu courbée dans le haut, pour paraître de loin former un triangle rectangle. La têtc, un pcu renflée au-dessus dcs yeux ressemble d'ailleurs à un cône très-court, ì sommét obtus, et dont la base serait opposćc à eellc du cône allongé que forment le corps of la queue.

Les deux mâchoires, presque aussi avancées l'une que 
l'autre, sont dénuées de lèves proprenent dites, et garnies chacune do dents petites, un peu aplaties, trancliantes, et dont le nombre varie depuis quarantc jusqu'ì cinquante.

Les yeux sont petits ct silnćs à la même hauteur que les lèves. Une huncur muqueuse onduit la surface intérieure des paupic̀res, qui sont trìs-peu mobiles. L'iris est jaunâtre et la prunclle paraît souvent triangulaire.

Un bleu très-foncé ou un noir luisant règne sur la partie supérieure dı marsouin, et une teinte blanchâtre str' sa partie infóriente.

Un épiderme trìs-doux an toncher, mais qui se détache facilement, et une pcau très-lisse, recourrent une coucle assez épaisse d'une graisse très-blanche.

La longueur totale du marsouin peut aller à plus de trois mètres, et son poids à plus de dix myriagrammes.

La distance qui sépare l'orifice des évents de l'cxtr'ćmité du museau, est ordinairenent égalc aux trois vingtsixièmes de la longueur de l'animal; la longucur do la nageoire pectorale éģale cette distance; et la largुeur le la nageoire de la queue atteint presque le quart do la Inngucur totale du cétacé.

Celte grande largeur de la caudale, cetle étendue de la lune principale du marsouin, ne contribuent pas peu it c'lle ritesse ćlonnante que les navigatcurs ont remarquée dans la natation de ce dauplin, el à cetto vivacité de llouvements qu'aucune fatigue ne parait suspendre, et que l'œil a de la pcine à suivre.

Le marsouin, devant lequel les llots s'ouvrent, pour atinsi dire, aroce tant de docilité, paraît se plaire à surlinonter l'action des courants et la violence des vagues 
que les grandes marées pousscnt vers les côtes ou ramc̀nent vers la liaute mer.

Lorsque la tempête bouleverse l'Océan, il en parcourt la surface avec facilité, non-seulement parce que la puissance électrique qui, pendant les orages, règne sur la mer comme dans l'atmosphère, le maîtrise, l'anime, l'agitc ; mais encore parce que la force de ses muscles pcut aisément contre-balancer la résistance des ondes soulevées. Il joue avec la mer furieuse.

Les marsouins vont presque toujours en troupes.

La portée n'est le plus souvent que d'un petit, qui est déjà parvenu à unc grosseur considérable lorsqu'il voit la luinière. Le marsouin nouveau-né ne ccsse d'être auprès de sa mère pendant tout le temps où il a besoin dc teter, el cc temps est d'une année. Il se nourrit ensuite, comme son père et sa mère, de poissons qu'il saisit avec autant d'adresse qu'il les poursuit avec rapidité.

On trouve les marsouins dans la Baltique, près des côtes du Groënland et du Labrador, dans le golfe SaintLaurent, dans presque tout l'océan Atlantique, dans lc grand Océan, auprés du golfo de Panama; ils apjarltiennent à presque toutes les mers. Ces cétacés paraissent plus fréquemment en hiver qu'en été dans certains parages; et dans d'autres, au contraire, ils se montrent pendant l'étć plus que pendant l'hircr.

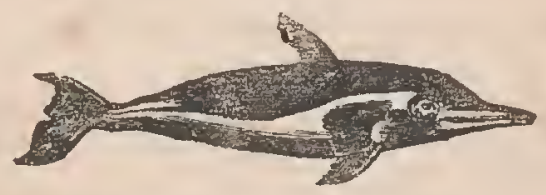




\section{TABLE}

PAR ORDRE DE MATIETES ET PAR ORDRE ALPHABÉTIQUZ

\section{L'IIOHME.}

Sa supériorité sur les Animaux..................

\section{ANIMUUX DOMESTIQUES.}

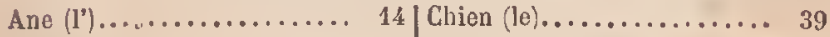

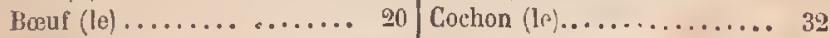

Brebis (la)............. 24 Cochon (le) de Stan...... 32

Chat (le)............. 48 Mulet (le)............ 13

Cheval $\langle$ le $) .. \ldots \ldots \ldots \ldots \ldots . \quad 8$ Sanglier $(10) \ldots \ldots \ldots \ldots \ldots .32$

Chèrre (la)............ 29

\section{ANIMAUX SAUVAGES.}

Adive (l) ............ $106 \mid$ Bonquetin (le $\ldots \ldots \ldots \ldots \ldots .96$ Ai $\left(l^{\prime}\right) \ldots \ldots \ldots \ldots \ldots \ldots \ldots 173$ Buffle $(10) \ldots \ldots \ldots \ldots \ldots .244$ Anta (l') ............... 200 Campagnol (le).......... 149

Babouin (le) proprement dit. 56 CARNASSIERS. ......... 66 Belette (la)............. 90 Castor (le) ............ 150 Blaireau (le)............ $80 \mid$ Cerf $(l e) \ldots \ldots . \ldots . . . .294$ 
Chacal (le).

Chameau (le).

Chamois (le)

Chaure-Souris (1t) $\ldots \ldots . . .60$

Chevreuil (le)...

Civelte (la)...

Coclion (le) d'Inde.

Daim (1c)

Dromadaire (le)

ficureuil (I')

Elan (I")

Éléphass (l').

Fouine (la)

Fourmilier (le

Furet (le).

Gazclles (les)...

Genette (la)

Gibbon (le).

Girale (la).

Guenons (les)

Hérisson (le) ...........

Ilermine $\left(\mathrm{l}^{\prime}\right) \ldots . . \ldots \ldots \ldots$.

Hippopotame $\left(\mathbf{l}^{3}\right) \ldots . \ldots . \ldots .207$

IIyène $(1 ') \ldots \ldots \ldots \ldots \ldots$. 11 k

Jaguar (le)............. 131

Lama (le).............. 218

Lamantin $(l e) . . \ldots \ldots \ldots \ldots \ldots$

Lapin (le).............. 167

Léoparıl (le). .......... 1 $1 \pm$

Lièvro (le) ............. 163

Lion $(\mathrm{le}) . . . \ldots \ldots \ldots \ldots \ldots . .117$

Loir (le) .............. 1351

Loup (la) ..............

Loup Cervier (le)......... 131

Loris $(10) . . . \ldots \ldots \ldots . . \ldots$. 63

Loutre (la) ...................

Lynx (le).............. 131

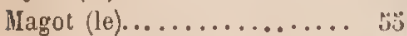

Makis (les)............... 63

Marmotte (la) ............. 139

MARSUPIAUX.
Marte (la).............. 8

Mouflon (le) et les atitres

Brebis............... 24:

Mulot (le) .............. 148

Musaraigne $(1 a) \ldots \ldots \ldots \ldots$. 71

Musaraigne (la) ilea

Musc (le)..............

Once $(\mathrm{l}) \ldots \ldots \ldots \ldots \ldots \ldots . \ldots 196$

Opossum $\left(l^{\prime}\right) \ldots \ldots \ldots \ldots \ldots$. 178

Orang-0ulang (l') Pours,.... \$3

Ours $(1) \ldots \ldots \ldots \ldots \ldots \ldots$. 76

Ours blane (l') .......... 79

PACHYDERMES ......... 18.

Paco (le) .............. 218

Pantlière (la).......... Ig6

Papion (le) on habuin projrc-

ment dit............. 56

Pekan (le)............. 93

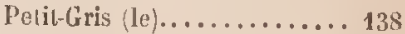

Pithèquo (le)............ 54

Porc-Epic (le)............. 169

Putois (le).............. \&6

QUADRUMANES........ \$4

liat (le........... .149

Rat d'eau (le)............ 15i

fienard (ln).............. 103

Renne (le) ............. 233

Rlinocéros (1e) .......... $20 z$

RONGEURS ........... 133

Roselet tiri............ 91

RUMINANTS. . ......... 211

Sagonius (les) ............ :8

Sapajous (les) .......... is

Sarigue (le)............. 178

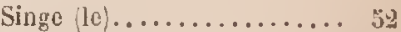

Souris (la)............ 146

Tamandua (le) .......... 174

Tamanoir (le)............ 174

Tapir (le).............. 900

Taupe (la)............ 73

178 Tigre (le $\ldots . . . \ldots \ldots \ldots . .124$ 
Unau (1')............. 173| Zibeline (la).......... 93

Vison (le).............. 93 Zibet (le)............. 103

Zèbre (lo $. . . \ldots . . . . . .209$

\section{OISE $\perp$ UX.}

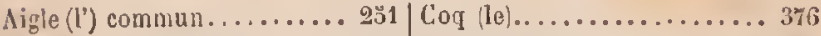

Aigle (le grand)......... 2 is Corbeau (t)............ 31:

Aigle (le petit)......... . 252 Cormoran $(1, \ldots \ldots \ldots \ldots .433$

Aleyrion $\left(l^{\prime}\right) \ldots \ldots \ldots \ldots \ldots .3 \pm 0$ Coucou $(\mathrm{lc}) \ldots \ldots \ldots \ldots \ldots 338$

Alouetle $\left(l^{n}\right) \ldots \ldots \ldots \ldots \ldots$. 313 . Courlis (le) ........... 114

Aras (les) ............. 369 Courlis (le) de 1 rre....... 406

sutour (1')........... $26:$ Cygne (le)...........424

Autruche $(l) \ldots \ldots \ldots \ldots$. 101 Dindon (le) ............ 394

Balbuzard (l.)........... 25i Duc (le) ou grand linc..... 968

Bècasse (la)........... 409 ÉCHASSIERS......... 40

Bécassine (la)........... 411 Emprillun (l').... ...... 26:

Becfigue (le)............ 340 Épervier (l')............ 267

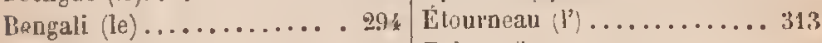

Bergerettes (les) ......... 333 Faisan (le)............ 391

Bergeronnelles (les) ....... 343 Faisan (le) dori......... 393

Bouvreuil (le)........... 296 Faucon (le) ............ 262

Busard (le)............. 266 Fauvette (la)............ 338

Buse (la).............. 261 Fonrmiliers (les).......... 291

Buses $($ l +5$) \ldots \ldots \ldots \ldots \ldots .259$ GALLINAGÉS........... 3T

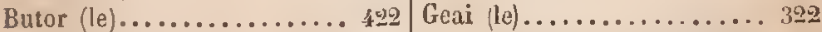

Caille (la)............. 383 Gerfaut (le) ............ 263

Canard (le)............. $\$ 29$ GOBE-MOUCHES, MOUCHE-

Casoar (le $\ldots . . \ldots \ldots \ldots . .403$ ROLLES ET TYRANS.... 280

Chardonneret (le)........ 307 Gobe-Monches ........... 281

Chat-IInant (I0)......... 272 Gobe-Nouches noir i co!-

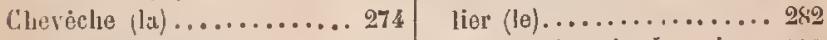

Chevèche (la grande)....... 273 Gobe-llouclies de Lortaine. 182

Choucas (les)........... 319 Goëlands (les) .......... 434

Chouette (la)........... 273 Grive (la)............. 286

Chouette (la petite)....... 274 GROS-BECS ........... 292

Cigogne (la)............ 417 Grue (la).............4.

Colibri (le $\ldots . \ldots \ldots \ldots \ldots \ldots 329$ Hẻron (le) commun....... 420

Condor (le) ............. 257 Hibou (le) ou moyen 1ne... 269 
HIRONDELLES

Hirondelle (l') de elıeminée... 34 Ilirondelle (l') domestique ... 347 Hirondelies (les) de mer..... 333 Hulotte (la)............ 271 Jaeo $\left(l^{b}\right) \ldots \ldots \ldots \ldots \ldots \ldots . \ldots 36$ Kakatoës (le)............ 363

Kamichi (le) ............ $\$ 19$ Linotte (la) ............. 30s Loriot (le) ............. 89 Nartinet (le) noir......... 351 MLartin-Pécheur (Ic) ....... 330 Merle (le)............... 288 Mlésanges (les)............ 332 Milan (le).............. 259 Moineau (le) ............ 300 Mouettes (les) ........... 434 Oie (l') ..............4 427 OISEAUX-AQUATIQUES... . 404 Oiseau-Muuelıe $\left(l^{\prime}\right) \ldots \ldots \ldots \ldots 396$ Oisean (l') de Pararlis....... 39: OISEAUX DE PROIE...... 248 OISEAUX DE PROIE NOGTURNES

Orfraie (l).............. 254

Ortalan (l') ............ 292

Outarde (l') ............ 399

PALMIPĖDES

Paou (le).

PASSEREAUX

Péliean (le)

Perdrix (la) grise.

Perdrix (la) rouge d'Eurone. Perroquet (le).
Perroquet (le) eendré...... 366 Pics (les) ............. 35 k Pie vert (le)............. 3550 Pie (la)................ 320 Pies-Grièches (les)......... 973 Pie-Griciehe (la) grise ...... 277 Pie-Grièche (la) rousso..... 978 Pigeon (le)............. 371 Pinson (le).............. 298 Pintade (la).............. 398 Pluviers (les)............ 401 Plavier (le grand)......... 406 Punle (1a).............. 376 Puale (la) d'cau .......... 413 PSITTACÉS ............ 363 Pygargue (le)............ 283 Rảle (le) d'eau ........... 424 Râle (le) de terre ou de genét. 423 Ramier (Ie).............. 373 RAPACES ............ 248 Roi des Cailles...........423 Roitelet (le)............ 349 Rossignol (le) ............ 333 Ronge-Gorge (le) ......... 341 Sarcelles (les).......... 431 Scops (le) ou petit Duc..... 270 Serin (le) des Canaries..... 302 STRUTHIONS .......... 401 Tarin (le) .............. 309 Tourterelle (la)........... 375 Tricolor (le) liuppé de la Chine 393 Vanuean (le)............. 407 Vautours (les)........... 255 Vautour (le petit).......... 98

\section{REPTILES ET POISSONS.}

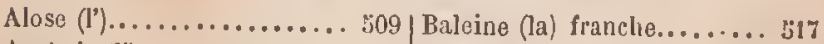
Anehois $\left(l^{\prime}\right) \ldots \ldots \ldots \ldots \ldots . .510$ Barbeau $(l e) \ldots . . . \ldots . . .519$ Anguille $\left(l^{\prime}\right) \ldots \ldots \ldots \ldots \ldots$............ 483 
Bolquira (1e) ...........471 | Loche (1a)............ 498

Brochet (le)........... 508 Lote (la $\ldots \ldots \ldots \ldots \ldots \ldots \ldots .487$

Cachalot (le) macrocéphale.. 523 Maquerean (le)............ 489

Caméléon (le $\ldots \ldots \ldots \ldots \ldots$.47 Mlerlan (le $\ldots \ldots \ldots \ldots \ldots \ldots .486$

Carpe (1a)............. \$10 Morue (la) ............ 48

Carrelet (le)........... 497 Perche (la)............. 492

CÉTACÉS.............. 517

COULEUVRES ET VIPERES.

POISSONS CARTILA -

GINEUX............. 47k

POISSONS OSSEUX....... 483

Couleurre (la) a collier...... 465

Couleurre (la) des dames ... 466

Coulenvre (la) verte el jaune, 464

Crapaud (le) commun....... 453

Crocodile (le) proprement dit 442

Dauphiu (le) marsouin ...... 528

Dauphin (le) vulgaire....... 326

Devin (le) ou Boa.......... 469

Esturgeon (I')...........481

Govjon (le).............

Grenouille (la) commun. ... 450

Hareng (le) ............ 506

LEZZARDS

437

Lézard (le) gris .......... 140

Lezzard (le) ver $\ldots \ldots \ldots \ldots \ldots, 438$

Limande (la)............49.4

Raie (la) batis........... 474

liequin (le)............. 478

Riouget (le)............. 491

Sardine (1a)............. 508

Saumon (le)............. 499

SERPENTS ............ 43̈:

Serpent (le) à Sonnctto..... 471

Sole (la) ............... 494

Tanche (la) ............ 513

Thon (10) ............ 488

Torpille (la)............477

TORTUES ............ 335

Truite (la) ............ 502

Truite (la) saumone....... 504

Turbot (le)............. 495

Vipère (la) conunnue...... 461

IN DE LA TABLE.

Clichy. - Imp. Fiul bupont, rue du Bac-d'Asnléres, 12. 
$\sqrt{1}$

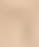

? 142

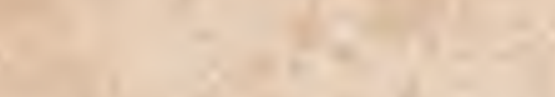

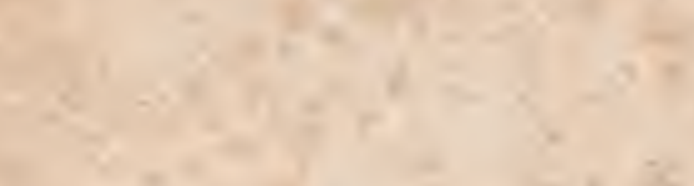

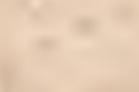

=

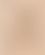

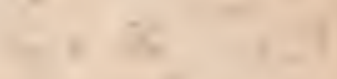

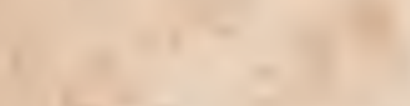

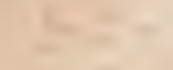

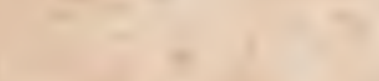

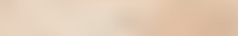

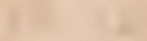

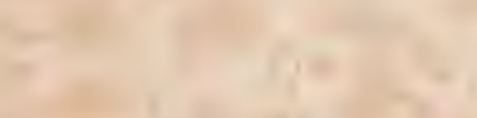

$x^{2}$

$\sqrt{2}+x^{2}$

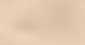

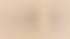

$=$

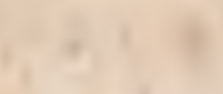

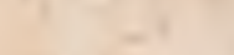

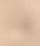

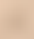

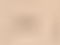

$$
+
$$

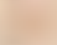

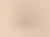

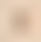

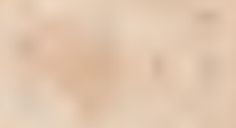

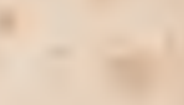

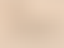

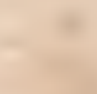
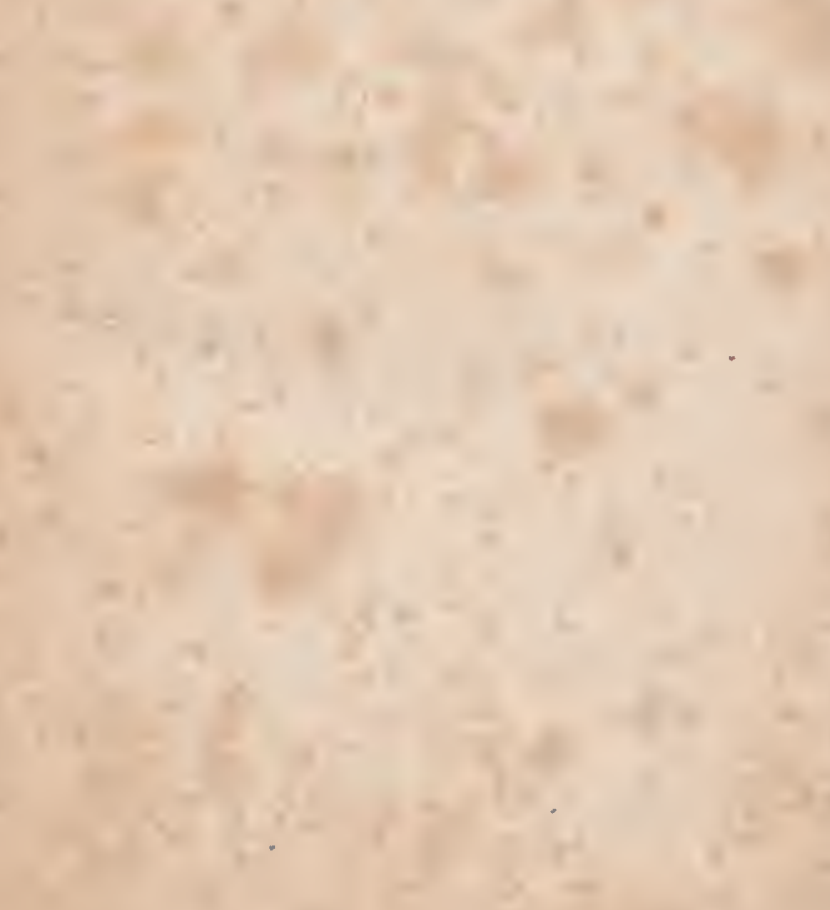

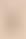
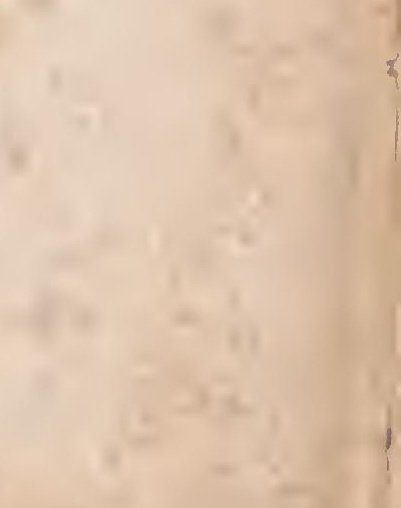



